INSTITUTO DE PESQUISAS ENERGÉTICAS E NUCLEARES

Autarquia Associada à Universidade de São Paulo

\title{
AVALIAÇÃO DA CONCENTRAÇÃO DE METAIS E OUTROS ELEMENTOS DE INTERESSE EM AMOSTRAS DE SEDIMENTOS DOS ESTUÁRIOS DE SANTOS/ SÃO VICENTE E CANANÉIA, ESTADO DE SÃO PAULO, BRASIL
}

Eduardo Paulo de Amorim

Tese apresentada como parte dos requisitos para obtenção do grau de Doutor em Ciências na área de Tecnologia Nuclear - Aplicações

Orientadora:

Profa. Dra. Déborah Inês Teixeira Fávaro

São Paulo 
"Cada dia da vida humana contém alegria e cólera, dor e prazer, trevas e luz, crescimento e decadência. Cada momento é gravado com o grande desígnio da natureza - não tentes negar nem te oponhas a ordem cósmica das coisas"

Morihei Ueshiba

"Nunca perca a fé na humanidade, pois ela é como um oceano. Só porque existem algumas gotas de água suja nele, não quer dizer que ele esteja sujo por completo."

Mahatma Gandhi 


\section{AGRADECIMENTOS}

Em primeiro lugar, agradeço a Deus por tudo que Ele me deu, sendo que meus primeiros e mais preciosos presentes foram meus pais Elisiário (in memorian) e Arlinda, aos quais sou eternamente grato por tudo que aprendi e ao apoio incondicional de ambos para o meu desenvolvimento humano, através de seus conselhos, dedicação, carinho e paciência, tanto nos momentos felizes, quanto nos momentos difíceis da vida.

À Dra. Déborah Ines Teixeira Fávaro, que desde meus tempos de aluno na iniciação científica, me apoiou, incentivou, compartilhou seus conhecimentos, que com certeza contribuíram de forma altamente significativa para o meu desenvolvimento profissional e também pelo total apoio para a conclusão deste trabalho.

À minha esposa Juliana, pela ajuda e compreensão durante o período de realização deste trabalho, e ao amigo Raphael pela "consultoria" prestada durante a elaboração do presente trabalho.

A Comissão Nacional de Energia Nuclear (CNEN) e ao Instituto de Pesquisas Energéticas e Nucleares (IPEN) pela oportunidade de realizar esse trabalho.

Aos colegas alunos e pesquisadores do Centro do Reator de Pesquisa do IPEN /CNEN-SP, pelo companheirismo durante a realização deste trabalho.

A todos os amigos que contribuíram com os momentos de descontração e as muitas risadas que demos juntos e que também estiveram presentes nos momentos difíceis da vida, os quais não irei citar nomes, pelo receio da memória falhar e injustamente esquecer de alguém, pois são muitos e todos são igualmente especiais para mim.

A todos, deixo aqui registrado o meu muito obrigado. 


\section{AVALIAÇÃO DA CONCENTRAÇÃO DE METAIS E OUTROS ELEMENTOS DE INTERESSE EM AMOSTRAS DE SEDIMENTOS DOS ESTUÁRIOS DE SANTOS/ SÃO VICENTE E CANANÉIA, ESTADO DE SÃO PAULO, BRASIL}

\section{Eduardo Paulo de Amorim \\ Resumo}

No presente trabalho foram avaliados os teores de alguns metais tóxicos como $\mathrm{Cd}, \mathrm{Hg}$ e $\mathrm{Pb}$, outros elementos maiores e traço em amostras de sedimentos superficiais, provenientes de dois sistemas sob diferentes graus de ação antrópica, o sistema estuarino de Santos/São Vicente e na porção sul do sistema estuarino lagunar de Cananéia, ambos no litoral do Estado de São Paulo. Foram coletados sedimentos em 16 estações no estuário de Santos/São Vicente e 13 estações no estuário de Cananéia, durante o verão e inverno de 2005 e 2006, em ambos os estuários. Foram utilizadas 3 técnicas analíticas: NAA, AAS e ICP OES. Pela técnica de ativação neutrônica (NAA) foram determinados os teores dos elementos maiores ( $\mathrm{Ca}, \mathrm{Fe} \mathrm{e} \mathrm{Na}$ ), elementos traço (As, Ba, Br, Cd, Co, Cu, Cr, Cs, Hf, Rb, Sb, Sc, Ta, Th, U, Zn e terras raras $\mathrm{La}$, $\mathrm{Ce}, \mathrm{Eu}, \mathrm{Nd}, \mathrm{Sm}, \mathrm{Lu}, \mathrm{Tb}, \mathrm{Yb})$. Pela técnica de espectrometria de emissão ótica com plasma indutivamente acoplado (ICP OES), foram avaliados os teores de $\mathrm{Al}, \mathrm{Ba}, \mathrm{Be}, \mathrm{Bi}, \mathrm{Co}, \mathrm{Cu}, \mathrm{Cr}, \mathrm{Fe}, \mathrm{Li}, \mathrm{Mn}, \mathrm{Mo}, \mathrm{Ni}, \mathrm{Sr}$ e $\mathrm{Zn}$. Pela técnica de espectrometria de absorção atômica atômica (AAS), foram determinados por forno de grafite (GF AAS) $\mathrm{Cd}$ e $\mathrm{Pb}$, e pela técnica de geração de vapor frio (CV AAS), o $\mathrm{Hg}$. As metodologias analíticas foram validadas quanto à precisão e exatidão, por meio da análise de materiais de referência certificados. Foram calculados os limites de detecção e quantificação, para cada elemento analisado, para as diferentes técnicas analíticas. Foram avaliadas também as variações espaciais, sazonais (inverno e verão) e temporais (2005 e 2006) dos metais e elementos traço nos sedimentos. No estuário de Santos/São Vicente, em geral, as concentrações de metais e elementos traço, teores de matéria orgânica e \% da fração pelítica encontrados no canal de Santos (área 1), foram maiores do que na baía de Santos (área 2) e no canal de São Vicente (área 3). A área 1 sofre grande impacto das atividades industriais da região de Cubatão e do porto de Santos. Os sedimentos da estação 14 (área 3, Canal de São 
Vicente) apresentaram comportamento semelhante aos da área 1, sofrendo influência do polo industrial e por estar localizado em uma área de mangue. $\mathrm{Na}$ comparação com os valores orientadores TEL e PEL adotados pela CETESB para os metais tóxicos em sedimentos, verificou-se que a área 1 ultrapassou os limites TEL para alguns dos metais, principalmente para $\mathrm{Hg}$. Os sedimentos da área 2 e da área 3 (exceto estação 14), não ultrapassaram os valores limites para a maioria dos metais analisados. Apesar dos sedimentos do estuário de Cananéia serem compostos principalmente por frações de areia, em algumas estações a fração pelítica foi bastante significativa. A partir dos resultados obtidos na região de Cananéia, observou-se que as concentrações potencialmente disponíveis dos metais $\mathrm{Cd}, \mathrm{Pb}, \mathrm{Hg}, \mathrm{Cr}, \mathrm{Cu}, \mathrm{Ni}$ e $\mathrm{Zn}$ se encontraram abaixo dos limites estabelecidos pela legislação CONAMA 344/2004 para sedimentos e dos limites TEL e PEL, para as 3 áreas avaliadas: área 1 (Mar de Cananéia), área 2 (Baia de Trapandé) e área 3 (Mar de Cubatão). Fator de Enriquecimento (FE) e índice de geoacumulação (Igeo), ferramentas geoquímicas para avaliação da contaminação de metais e elementos traço, foram usadas para avaliar os níveis de contaminação em ambos os estuários. Aos resultados obtidos foi aplicada análise estatística multivariada e por último, os resultados foram comparados com outros dados publicados na literatura para as regiões em estudo (Santos/São Vicente e Cananéia). 


\title{
METAL AND TRACE ELEMENT SEDIMENT ASSESSMENT FROM TWO ESTUARINE SYSTEMS: SANTOS/SAO VICENTE AND CANANEIA, STATE OF SAO PAULO, BRAZIL
}

\section{Eduardo Paulo de Amorim}

\begin{abstract}
This study evaluated some toxic metals such as $\mathrm{Cd}, \mathrm{Hg}$ and $\mathrm{Pb}$ and some other major and trace elements in surface sediment samples, from two different systems under different degrees of anthropogenic actions: the estuarine system of Santos/São Vicente and the southern part of the Cananéia estuary, both on the São Paulo state coast. Sediment samples were collected in 16 stations in the Santos/São Vicente estuary and 13 stations in the Cananéia estuary, during summer and winter of 2005 and 2006, in both estuaries. Three analytical techniques were used: NAA, AAS and ICP OES. NAA was used for the quantification of major element concentration levels $(\mathrm{Ca}, \mathrm{Fe}$ and $\mathrm{Na}$ ), trace elements (As, Ba, Br, Cd, Co, Cu, Cr, Cs, Hf, Rb, Sb, Sc, Se, Ta, Th, U, and Zn and rare earths elements $\mathrm{La}, \mathrm{Ce}, \mathrm{Eu}, \mathrm{Nd}, \mathrm{Sm}, \mathrm{Lu}, \mathrm{Tb}, \mathrm{Yb}$ ). ICP OES was used for determination of the concentration levels of $\mathrm{Al}, \mathrm{Ba}, \mathrm{Be}, \mathrm{Bi}, \mathrm{B}, \mathrm{Cd}, \mathrm{Co}, \mathrm{Pb}$, $\mathrm{Cu}, \mathrm{Cr}, \mathrm{Sn}, \mathrm{Sr}, \mathrm{Fe}, \mathrm{Li}, \mathrm{Mn}, \mathrm{Mo}, \mathrm{Ni}, \mathrm{Tl}, \mathrm{Ti}, \mathrm{V}$ and $\mathrm{Zn}$. AAS for $\mathrm{Cd}$ and $\mathrm{Pb}$ quantification through graphite furnace (GF AAS) and $\mathrm{Hg}$ through cold vapor generation ( $C V$ AAS). Methodology validation according to precision and accuracy was performed by reference material analyses for the three analytical techniques used. Detection and quantification limits were calculated for each element evaluated. Seasonal variations (summer and winter), spatial and temporal (2005 e 2006) variations of metals and trace elements were also evaluated. In the Santos estuary, in general, metal and trace element concentrations, organic matter content and \% of pellitic fraction found in the Santos channel (area 1) were higher than those of the Santos Bay (area 2) and São Vicente channel (area 3). Area 1 suffers high impact from industrial activities from the Cubatão region and Santos port. The sediments from station 14 (area 3, São Vicente channel), showed the same behavior of those from area 1, suffering influence from the industrial pole and located in a mangrove area. In comparison with TEL and PEL oriented values adopted by CETESB for
\end{abstract}


toxic metals content in sediments, area 1 surpassed the TEL limits for some metals, mainly for $\mathrm{Hg}$. Sediments from area 2 and 3 (except station 14), did not exceed the limits for most of the metals analyzed. Although the sediments from Cananéia region were composed mainly of sandy fractions, in some stations the pellitic fraction was greatly significant. From the results obtained in the region, the concentration levels of metals potentially available such as $\mathrm{Cd}, \mathrm{Cr}, \mathrm{Cu}, \mathrm{Hg}$, $\mathrm{Ni}, \mathrm{Pb}$ and $\mathrm{Zn}$ were below the limits TEL and PEL oriented values and CONAMA 344/2004 resolution for the 3 areas assessed: area 1 (Cananéia sea), area 2 (Trapandé Bay) and area 3 (Cubatão sea). Enrichment Factor (EF) and Geoaccumulation index (Igeo), geochemical tools used for contamination assessment were used to evaluate the contamination level in both estuaries. Multivariate statistical analysis was applied to the results which were then compared to the results of other published studies in these regions (Santos/São Vicente and Cananéia). 


\section{SUMÁRIO}

Página

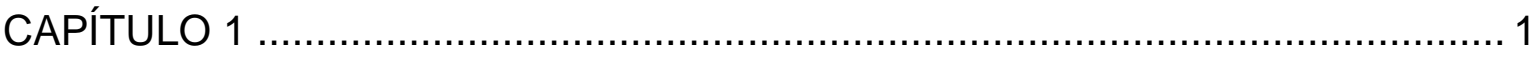

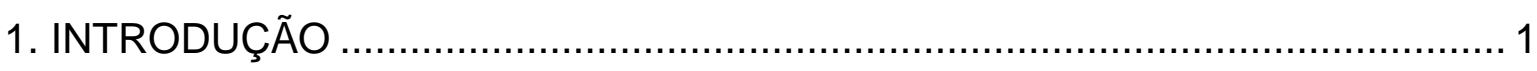

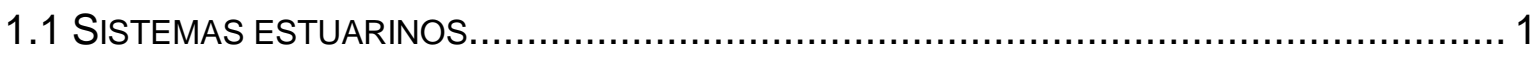

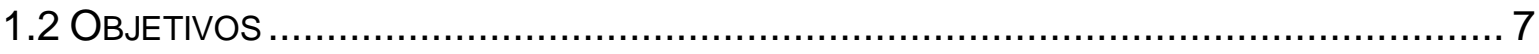

1.2.1 Objetivos do presente estudo...................................................................... 7

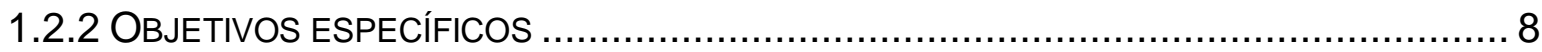

1.2.3 CONTRIBUIÇÃO ORIGINAL DO PRESENTE ESTUDO $\ldots \ldots \ldots \ldots \ldots \ldots \ldots \ldots \ldots \ldots \ldots \ldots \ldots$

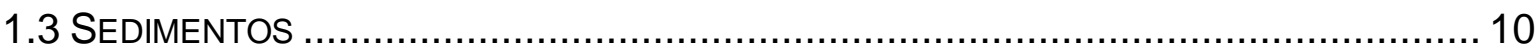

1.3.1 VALORES ORIENTADORES DE QUALIDADE DE SEDIMENTOS ............................ 11

1.3.2 TÉCNICAS ANALÍTICAS USADAS NA ANÁLISE DE SEDIMENTOS .......................... 17

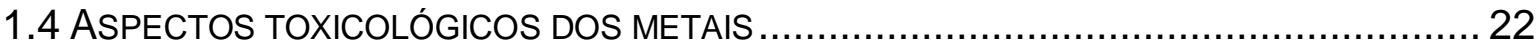

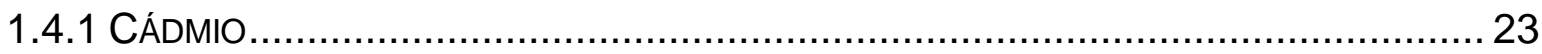

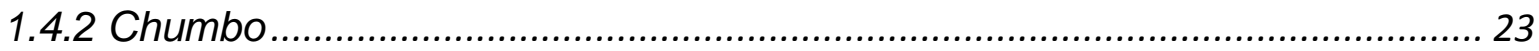

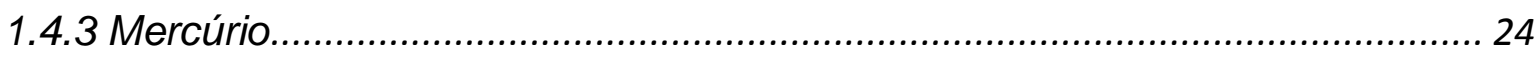

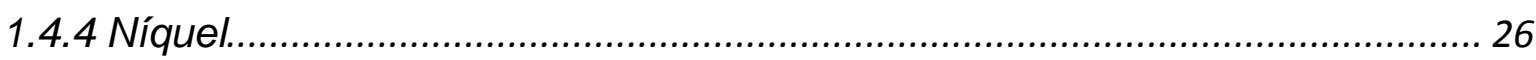

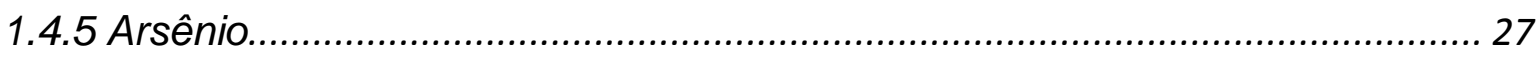

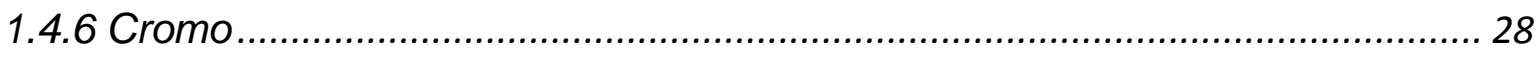

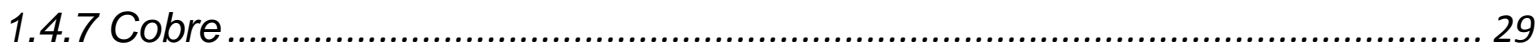

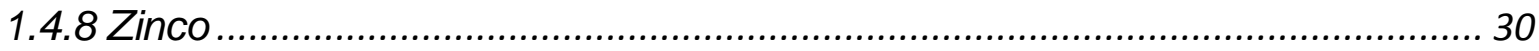

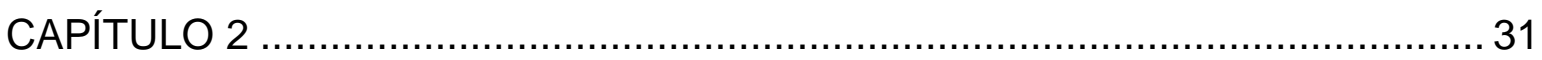

2. LOCAIS DE ESTUDO - REVISÃO DA LITERATURA ............................... 31

2.1 Sistema estuarino Santos/ São Vicente .............................................................. 31

2.2 Sistema estuarino-lagunar de Cananéia Iguape ......................................... 41

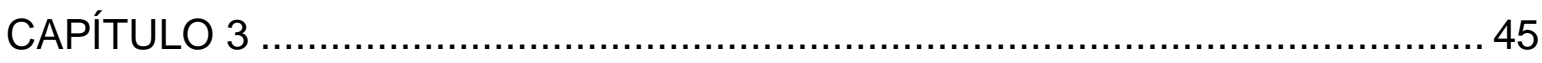

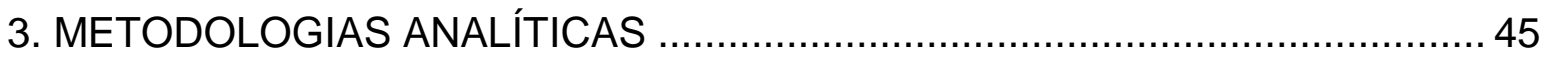

3.1 Espectrometria de Absorção Atômica ............................................................ 45

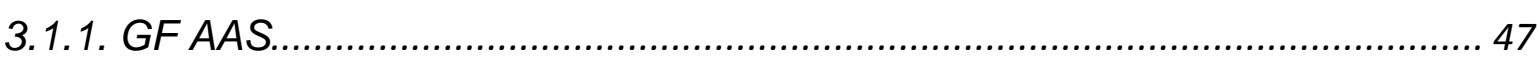

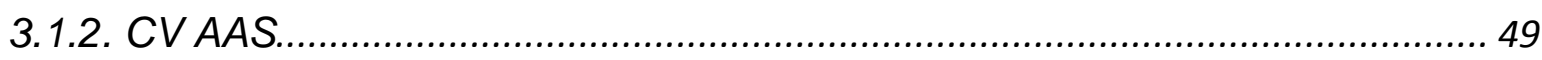

3.2. Espectrometria de Emissão Atômica com Plasma Indutivamente Acoplado

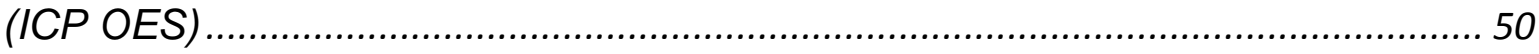




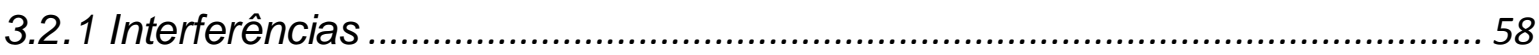

3.3. Análise por Ativação Neutrônica (NAA)....................................................... 59

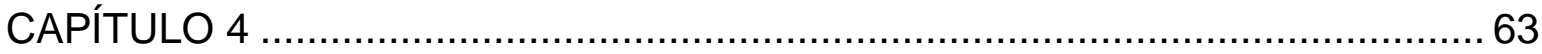

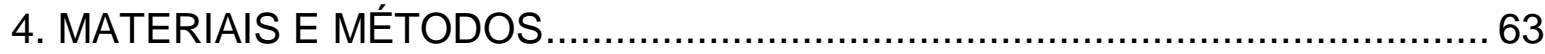

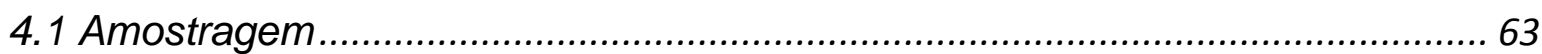

4.2.1 Estuário de Santos/ São Vicente e baía de Santos ....................................... 63

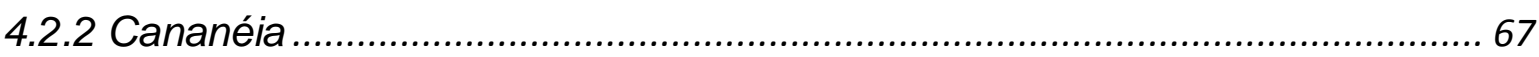

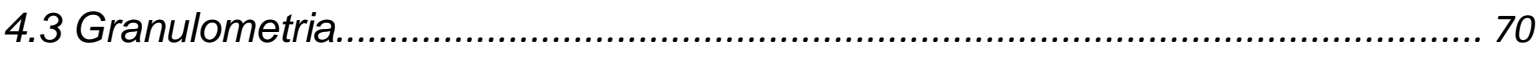

4.4 Determinação dos teores de carbonatos ...................................................... 70

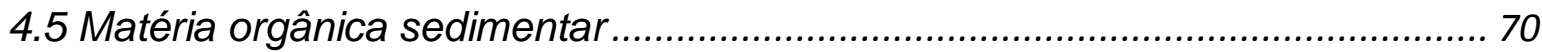

4.6 Fósforo Orgânico ( $\left.P_{\text {org}}\right)$, Fósforo Inorgânico $\left(P_{\text {inorg }}\right)$ e Fósforo Total $\left(P_{\text {total }}\right)$... 71

4.7 Preparo das amostras de sedimentos para análises químicas....................... 72

4.8 Digestão das amostras de sedimentos, assistida por microondas................... 72

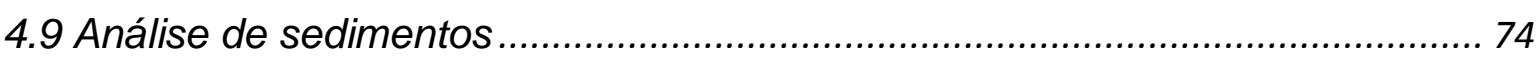

4.9.1 Espectrometria de Absorção Atômica com forno de grafite (GF AAS) .......... 74

4.9.1.1 Calibração do equipamento de GF AAS e leitura das amostras ................ 79

4.9.2. Espectrometria de Absorção Atômica com geração de vapor frio (CV AAS)80

4.9.2.1 Preparação e leitura de $\mathrm{Hg}$ total nas amostras ........................................... 80

4.9.2.2 Calibração do equipamento de CVAAS e leitura das amostras ................. 81

4.9.3 Espectrometria de emissão atômica com fonte de plasma indutivamente

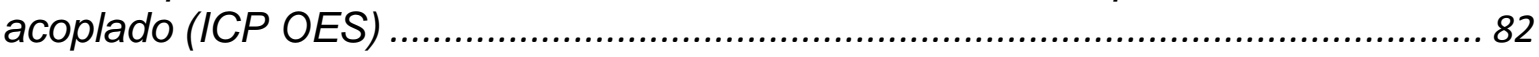

4.9.3.1 Verificação e calibração do equipamento de ICP OES ............................... 84

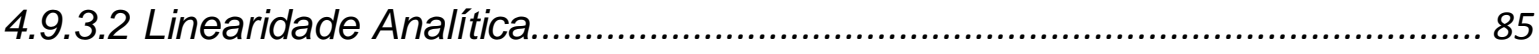

4.9.4 Analise por Ativação Neutrônica (NAA) …........................................................ 86

4.9.4.1 Preparação dos padrões sintéticos ............................................................ 86

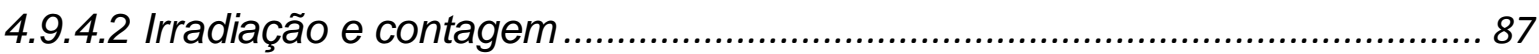

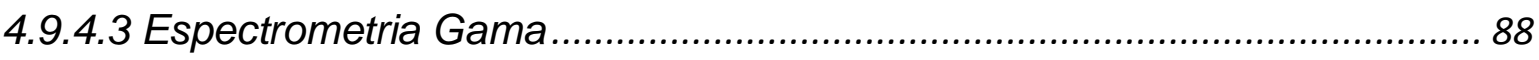

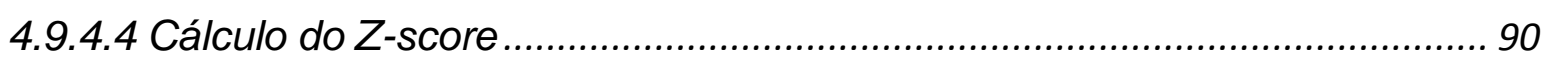

4.10 Limites de detecção e de quantificação ......................................................... 90

4.10.1 Limites de detecção e de quantificação: AAS e ICP OES ............................ 90

4.10.2 Limites de detecção e de quantificação: NAA .............................................. 93

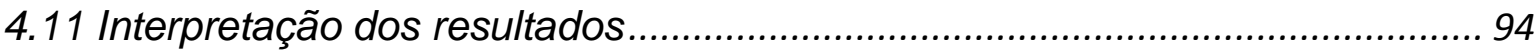

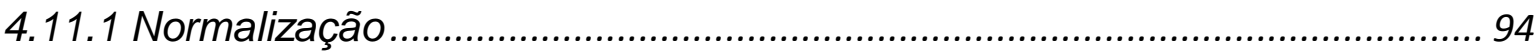

4.11.2 Cálculo do Fator de Enriquecimento (FE) ............................................ 96 
4.11.3 Índice de Geoacumulação (Igeo)............................................................ 97

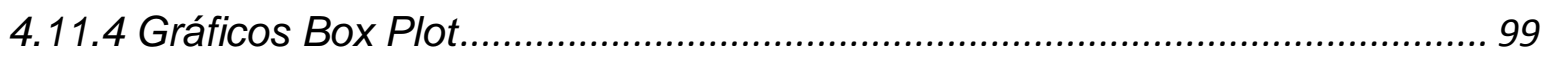

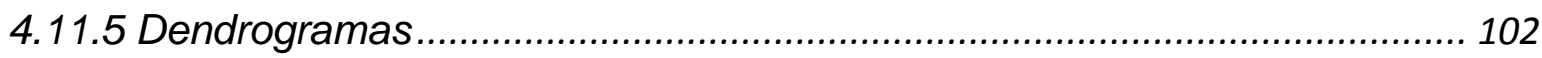

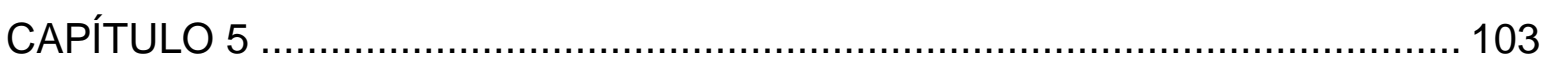

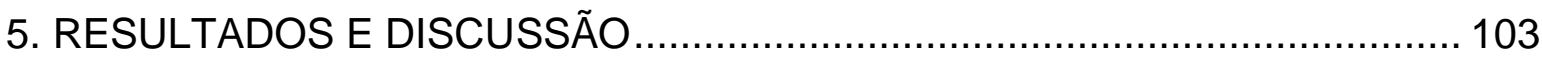

5.1 Resultados das análises dos materiais de referência.................................... 104

5.1.1 Resultados das análises dos materiais de referência pela técnica ICP OES104

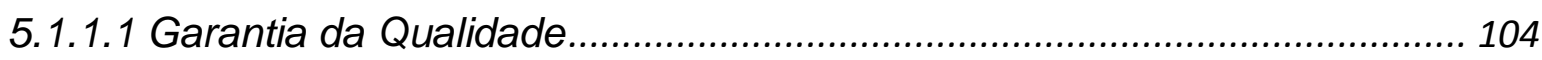

5.1.2 Resultados das análises dos materiais de referência pela técnica AAS: GF

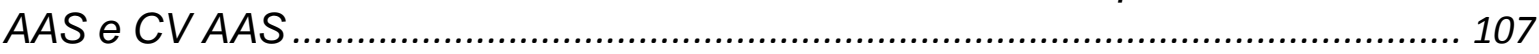

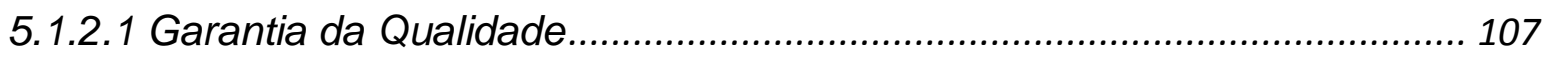

5.1.3 Resultados das análises dos materiais de referência pela técnica de

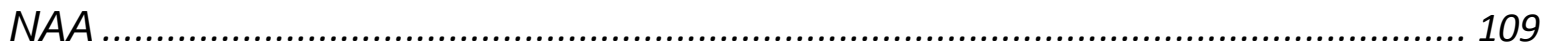

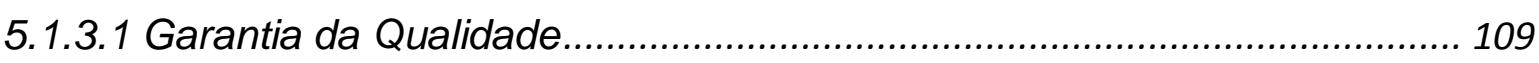

5.2 RESULTADOS DAS ANÁLISES DAS AMOSTRAS DE SEDIMENTOS ....... 111

5.2.1 SISTEMA ESTUARINO DE SANTOS E SÃO VICENTE ........................... 111

5.2.1.1 Resultados de $\mathrm{MO}$, silte, argila e areia, $\mathrm{CaCO}_{3}, P$ inorg, org e total......... 112

5.2.1.2 Resultados de concentração para os elementos determinados por ICP OES, GF AAS e CV AAS nos sedimentos..................................................... 113

5.2.1.3 Estudo da variação sazonal - Gráficos Box Plot ...................................... 124

5.2.1.4 Estudo de Normalização................................................................... 134

5.2.1.5 Análise de Agrupamento (Cluster Analysis) ........................................... 143

5.2.1.6 Fator de Enriquecimento e Índice de Geoacumulação .............................. 153

5.2.1.7 Resultados de concentração para os elementos determinados por NAA

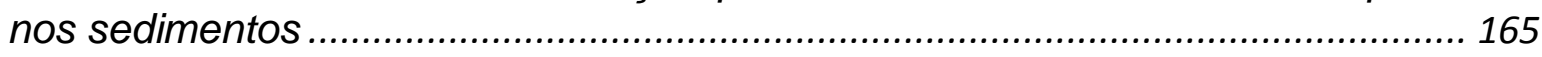

5.2.1.7.1 Fator de enriquecimento (FE) para os elementos determinados por NAA

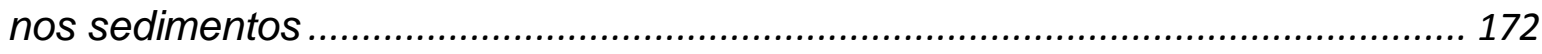

5.2.1.7.2 Comparação de valores de concentração obtidos por meio de diferentes

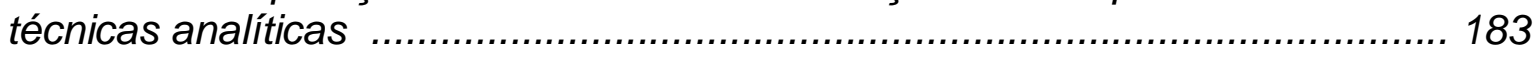

5.2.1.7.3 Análise de Agrupamento - Considerações Finais................................ 189

5.2.2 SISTEMA ESTUARINO LAGUNAR DE CANANÉIA .................................. 194

5.2.2.1 Resultados de $\mathrm{MO}$, silte, argila e areia, $\mathrm{CaCO}_{3}, P$ inorg e org.................. 194

5.2.2.2 Resultados de concentração para os elementos determinados por ICP OES e AAS (GF AAS e CV AAS) nos sedimentos de Cananéia .......................... 197

5.2.2.3 Estudo da variação sazonal - Gráficos Box Plot ........................................ 201

5.2.2.4 Estudo de Normalização........................................................................ 211 
5.2.2.5 Análise de Clusters

5.2.2.6 Fator de Enriquecimento e Índice de Geoacumulação .............................. 224

5.2.2.7 Resultados obtidos para os elementos traço e alguns metais por NAA Cananéia.

5.2.2.8 Fator de Enriquecimento (FE) para os elementos determinados por NAA nos sedimentos coletados em Cananéia.

5.2.2.9 Comparação de valores de concentração obtidos por meio de diferentes técnicas analíticas.

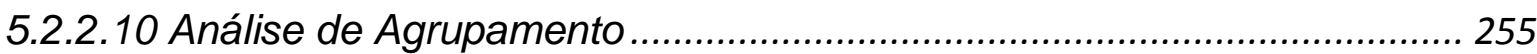

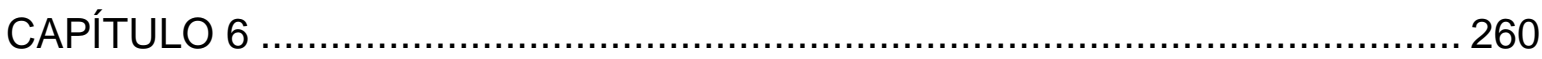

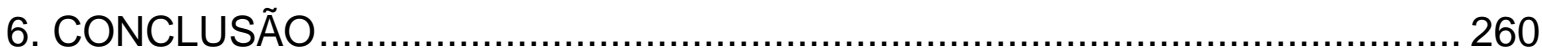

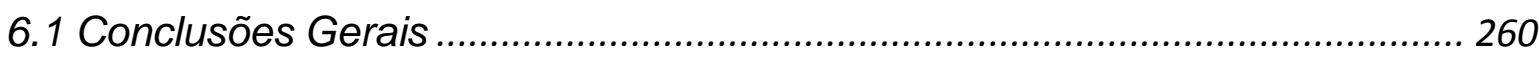

6.2 Conclusões- Sistema Estuarino de Santos e São Vicente............................... 263

6.3 Conclusões- Sistema Estuarino de Cananéia ................................................. 267

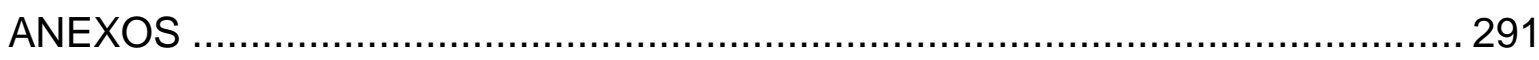




\section{LISTA DE ABREVIATURAS}

AAS - Atomic Absorption Spectroscopy

APA - Área de Proteção Ambiental

BEDS - Biological Effects Database for Sediments

CCD - charge-coupled device

CCME - Canadian Council of Ministers of The Environemt

CETESB - Companhia Ambiental do Estado de São Paulo

CNEN - Comissão Nacional de Energia Nuclear

CONAMA - Conselho Nacional do Meio Ambiente

COT - Carbono Orgânico Total

CVAAS - Cold Vapor Atomic Absorption Spectrometry

DPR - Desvio Padrão Relativo

EDL - Electrodeless discharge lamps

EPA- Environmental Protection Agency

ER - Erro Relativo

ETR - Elementos Terras Raras

FAAS - Flame Atomic Absorption Spectrometry

FAPESP - Fundação de Amparo à pesquisa do Estado de São Paulo

FE - Fator de Enriquecimento

FIMS - Flow Injection Mercury System

GF AAS - Graphite Furnace Atomic Absorption Spectrometry

HG AAS - Hydride generation Atomic Absorption Spectrometry

HG AFS - Hydride generation atomic fluorescence spectroscopy

HPGe - Hig Purity Germanium 
IAEA - International Atomic Energy Agency

IBA - Ion Beam Analysis

ICP MS - Inductively Coupled Plasma Mass Spectrometry

ICP OES - Inductively Coupled Plasma Optical Emission Spectrometry

Igeo - Índice de Geoacumulação

INAA - Instrumental Neutron Activation Analysis

INMETRO - Instituto Nacional de Metrologia, Normalização e Qualidade Industrial IO-USP - Instituto Oceanográfico da Universidade de São Paulo

IPEN - Instituto de Pesquisas Energéticas e Nucleares

ISQG - Interim Sediment Quality Guidelines

IUPAC - International Union of Pure and Applied Chemistry

LAN- Laboratório de Ativação Neutrônica

LD - Limite de Detecção

LQ - Limite de Quantificação

MO - Matéria Orgânica

MR - Material de Referência

MRC - Material de Referência Certificado

NAA - Neutron Activation Analysis

NASC - North American Shale Composite

NIST - National Institute of Standards and Technology

NSTP - National Status and Trends Program

OMS - Organização Mundial da Saúde

PAH - polycyclic aromatic hydrocarbons

PCB - Polychlorinated biphenyl

PEL - Probable Effect Level

PIXE - Particle Induced X-Ray Emission

RBS - Rutherford Backscattering Spectrometry

REE - Rare Earth Element 
SSTT - Spiked-sediment toxicity test

STPF - Stabilized Temperature Platform Furnace

TEL - Thereshold Effect Level

UCC - Upper Continental Crust

UNESCO - United Nations Educational, Scientific and Cultural Organization USEPA - United States Environmental Protection Agency

XRF - X-Ray Fluorescence 


\section{CAPÍTULO 1}

\section{INTRODUÇÃO}

\subsection{Sistemas estuarinos}

A definição mais largamente citada para estuário na literatura científica foi dada por Cameron \& Pritchard em 1963, como estuário sendo um corpo de água semi-fechado que tem uma livre conecção com o mar aberto e dentro a água marinha sofre diluição pelo aporte de água continental (DAY Jr et al., 1989 e ELLIOT \& McLUSKY, 2002). Portanto a característica mais fundamental de um estuário é a interação que ocorre em seu interior entre a água salgada e doce, e por isso é muito comum a classificação pela salinidade, relatando graus de mistura entre essas duas massas de água (FALCÃO, 2005).

Os estuários são locais com variações espaciais e temporais contínuas (ELLIOT \& McLUSKY, 2002). Diversas variáveis ambientais, além da salinidade, apresentam mudanças gradativas desde o mar até o interior do estuário, tais como: a turbidez da água, composição química da coluna d'agua incluindo a mudança na quantidade e tipos de nutrientes dissolvidos, na quantidade de oxigênio e outros gases dissolvidos, no pH e na composição dos sedimentos (FALCÃO, 2005).

Os sistemas estuarinos, de uma maneira geral, apresentam inúmeras funções vitais, como ecossistemas complexos, sendo o habitat.natural de aves, mamíferos e peixes, além de serem rotas migratórias propícias a diversos peixes com valores comerciais. (DAMATTO, 2010)

O aumento populacional intenso a partir do século $X X$ influenciou na ocupação das regiões costeiras, impactando de forma negativa os ecossistemas que ali se encontravam. 
Com o advento da revolução industrial, as indústrias que utilizavam uma imensa quantidade de água, como as indústrias metalúrgicas, químicas, têxteis ou provenientes do setor agrícola, nos últimos 50 anos tendiam cada vez mais a lançar seus resíduos e efluentes no ambiente aquático, juntamente com uma série de substâncias tóxicas (CARRASCO et al, 2003).

Os sistemas estuarinos estão propensos a receber substâncias naturais e produtos provenientes de atividades humanas, como herbicidas e pesticidas da agricultura, organismos patogênicos de despejos municipais, metais, óleos e substancias químicas de indústrias, portos, marinas e navegação o que pode ocasionar a degradação da qualidade da água.

Segundo Damatto (2010), um estuário é caracterizado pelo encontro dos rios com o mar, sendo um ambiente de transição entre o oceano e o continente, o que acarreta na diluição da água salgada. Os sistemas estuarinos apresentam altas concentrações de nutrientes orgânicos e inorgânicos devido à descarga de água doce na parte interna e a entrada de água do mar, além do transporte de sedimentos em suspensão, o que ocasiona em uma condição mais favorável para o desenvolvimento biológico do que os rios e oceanos.

Os estuários são ecossistemas dinâmicos que tem como particularidade uma grande variedade biológica e alta produção primária devido à grande disponibilidade natural em nutrientes nestes sistemas. Os estuários não só provém recursos naturais diretos em termos comerciais como peixes e outros organismos do próprio local como também servem de alojamento na fase juvenil de muitas espécies adultas oriundas da plataforma continental, economicamente importantes (BERBEL, 2008).

As análises de metais e suas distribuições nos sedimentos estuarinos são normalmente empregadas para entender os processos biogeoquímicos nos ecossistemas identificando as possíveis mudanças devido às atividades antrópicas e, deste modo, são de fundamental importância para o entendimento dos impactos causados pela ação humana. 
Os sedimentos desempenham um papel importante no ciclo elementar no ambiente aquático, pois são responsáveis pelo transporte de uma proporção significativa de muitos nutrientes e contaminantes. Eles também podem mediar a captação, armazenamento, liberação e transferência entre compartimentos ambientais. A maioria dos sedimentos nas águas de superfície deriva da erosão da superfície e inclui um componente mineral, resultante da erosão de rochas, e por componentes orgânicos que surjam durante os processos de formação do solo (incluindo a produção biológica, microbiológica e decomposição). Um componente orgânico adicional pode ser devido às atividades biológicas no interior do corpo d'água (BARTRAM, 1996).

Processos naturais responsáveis pela formação dos sedimentos podem ser alterados por atividades antrópicas. As análises de sedimentos fornecem informações significativas sobre o meio ambiente. Sua caracterização química é necessária para o entendimento dos processos naturais e também da influência antrópica, nesses processos (IAEA, 2003).

O transporte de sedimentos em rios é associado com uma grande variedade de questões ambientais e de engenharia. $O$ estudo dos sedimentos em suspensão é cada vez mais importante, devido à necessidade de avaliar os fluxos de nutrientes e contaminantes em lagos e oceanos. Um dos problemas ambientais mais graves são a erosão e a conseqüente perda de solo. Embora a erosão seja um fenômeno natural, a taxa de perda de solo é muito maior por más práticas agrícolas que resultam, por sua vez, em maior carga de sedimentos em suspensão nas águas doces (BARTRAM, 1996).

Os sedimentos de granulometria fina (silte + argila) são responsáveis por uma proporção significativa no que diz respeito ao transporte de metais, fósforo, pesticidas clorados e muitos compostos industriais, tais como hidrocarbonetos aromáticos polinucleares, bifenilas policloradas, dioxinas e furanos (BARTRAM, 1996).

O estudo das fontes, reações, transporte, efeitos e destinos das espécies químicas na água, solo, sedimento, ar e os efeitos causados pela tecnologia é denominada como Química Ambiental (MANAHAN, 1999). 
Tradicionalmente, a ciência ambiental tem sido dividida entre o estudo da atmosfera, a hidrosfera, a geosfera e a biosfera. A atmosfera é a fina camada de gases que cobrem a superfície da Terra. Além de seu papel como um reservatório de gases, a atmosfera modera a temperatura da Terra, absorve a energia e a radiação ultravioleta prejudicial do sol e também transporta energia para regiões mais frias (MANAHAN, 1999).

A hidrosfera contém a água da Terra e mais de $97 \%$ dessa água se encontra nos oceanos e a maioria do restante da água doce, está na forma de gelo. Por isso, apenas uma percentagem relativamente pequena do total de água na Terra é realmente envolvida com os processos terrestres, atmosféricos e biológicos. A água circula através de processos ambientais e dos ciclos na atmosfera, no subsolo (águas subterrâneas) e águas de superfície como em riachos, rios, lagos, lagoas e reservatórios. A geosfera é constituída pela terra sólida, incluindo solo, que sustenta a vida para a maioria das plantas. A parte da geosfera que é diretamente envolvida com os processos ambientais através do contato com a atmosfera, a hidrosfera e seres vivos é a litosfera. A litosfera varia de 50 a $100 \mathrm{~km}$ de espessura. A crosta terrestre é composta por grande parte dos minerais mais leves à base de silicatos e todas as entidades vivas na Terra compõem a biosfera (MANAHAN, 1999).

Nas últimas duas décadas, houve no Brasil uma crescente conscientização por parte dos cidadãos e empresas sobre os danos causados ao meio ambiente, devido às atividades humanas, tanto na questão doméstica quanto em atividades industriais. Uma grande parte destas atividades gera resíduos e efluentes que, de uma maneira geral, são destinados à atmosfera, solos, corpos d'água naturais e artificiais, continentais, costeiros ou nos oceanos. Estes efluentes e resíduos são basicamente constituídos de Carbono, Nitrogênio e Fósforo, provenientes de nutrientes, além dos contaminantes orgânicos e inorgânicos, que são os grandes responsáveis pela deterioração que nossos ecossistemas vêm sofrendo (MOZETO, 2002).

As regiões costeiras, de uma maneira geral, tendem a apresentar intensa ocupação humana, ocasionando forte pressão sobre os frágeis ecossistemas que aí se encontram. Os sistemas estuarinos de Santos e São 
Vicente, inseridos na Região Metropolitana da Baixada Santista, SP, representam um dos mais importantes exemplos brasileiros de degradação ambiental por poluição hídrica e atmosférica de origem industrial em ambientes costeiros. A região abriga também, o maior porto da América Latina (o porto de Santos) e o maior polo industrial do país, situado em Cubatão (CETESB, 2001).

Em estudos realizados em 1979 e 1981 (CETESB, 1979, 1981), avaliando os impactos da poluição em águas, sedimentos e organismos aquáticos, verificou-se o comprometimento do ambiente aquático em todos os locais estudados. Foram apontadas como causas de degradação, a poluição de origem doméstica e industrial, responsáveis pela contaminação química e microbiológica, e as alterações físicas dos habitats resultantes de processos de erosão, assoreamento, aterros de canais e manguezais e intervenções no sistema de drenagem (CETESB, 2001).

O Sistema Estuarino de Santos-São Vicente está susceptível a introdução de terras raras em seu ecossistema, devido ao polo petroquímico, ou através de indústrias de fertilizantes, via fosfogesso. O fosfogesso, em alguns casos, é armazenado a céu aberto nas proximidades do estuário, além das atividades agrícolas, industriais e domésticas que fornecem ao sistema o excesso de nutrientes como o nitrogênio e fósforo, o que intensifica o processo de eutrofização, acarretando no aumento de algas e dinoflagelados produtores de toxinas, afetando seriamente a qualidade das águas (BERBEL, 2008).

Ao contrário do estuário de Santos e São Vicente, o complexo estuarino lagunar de Cananéia-Iguape é considerado Área de Proteção Ambiental (APA) (Bernardes, 2001) e, em 1999, recebeu o título de Patrimônio da Humanidade pela UNESCO. Poucos estudos têm sido desenvolvidos nessa área não somente pela CETESB como também por pesquisadores brasileiros.

Devido a diversos fatores geológicos, geográficos e hidrodinâmicos, a região da llha Comprida possui uma extrema fragilidade natural. A composição arenosa e a natureza inconsolidada tornam grande parte da ilha sujeita à erosão e à sedimentação aceleradas, em especial na desembocadura lagunar de Icapara, ao norte de Iguape e na desembocadura lagunar de 
Cananéia. A ilha está com o lado sudeste exposto às ondas do Oceano Atlântico, que exibem maior energia durante as incursões de frentes frias, 0 que acarreta um intenso transporte de sedimentos por correntes paralelas à costa, portanto qualquer interferência antrópica terá reflexos imediatos, acelerando os processos de erosão e sedimentação. Além disso, as cotas muito baixas da ilha dificultam a implantação de sistemas eficientes de saneamento (BECEGATO, 2007). 


\subsection{Objetivos}

\subsubsection{Objetivos do presente estudo}

O presente estudo, teve como objetivo a caracterização química de sedimentos superficiais coletados em diferentes pontos do estuário de Santos/São Vicente, baía de Santos e porção sul do sistema de Cananéia, utilizando as técnicas analíticas de ativação neutrônica (NAA), espectrometria de absorção atômica (AAS) e espectrometria de emissão ótica com plasma indutivamente acoplado (ICP OES). A região de Santos está sujeita a alterações em suas características naturais devido a diversas fontes de poluição, desde atividades domésticas e industriais, até a presença do maior porto da América Latina, o Porto de Santos. Já a região de Cananéia, não possui um volume de dados significativo disponível na literatura, e o presente trabalho contribuiu de forma significativa para o melhor entendimento das características químicas dos elementos encontrados nas regiões, assim como a comparação dos teores de Matéria Orgânica e granulometria com os resultados obtidos nas análises de metais em sedimentos. O presente trabalho estudou as áreas de Santos/São Vicente e Cananéia, locais com formação geológica e hidrodinâmica diferentes e com variações quanto ao impacto ambiental, ressaltando que não é de interesse comparar as duas áreas, mas sim, avaliar cada impacto individualmente, pois apresentam características diferentes.

Esse estudo fez parte do projeto de pesquisa "MATÉRIA ORGÂNICA NA AVALIAÇÃO DE IMPACTO AMBIENTAL NO MEIO MARINHO: BIOQUÍMICA, BIOGEOQUÍMICA, BIOACUMULAÇÃO E BIOTOXINAS (MOBIO), coordenado pela Dra. Elisabete Braga (IO-USP) e financiado pela FAPESP (processo $n^{0}$ 2005/50769-2). 


\subsubsection{Objetivos específicos}

- Utilização da técnica de Análise por Ativação Neutrônica Instrumental (NAA), para a quantificação de alguns elementos maiores ( $\mathrm{Ca}, \mathrm{Fe}$ e $\mathrm{Na}$ ), elementos traço (As, Ba, $\mathrm{Br}, \mathrm{Co}, \mathrm{Cu}, \mathrm{Cr}, \mathrm{Cs}, \mathrm{Hf}, \mathrm{Rb}, \mathrm{Sb}, \mathrm{Sc}, \mathrm{Ta}, \mathrm{Th}, \mathrm{U}$, e $\mathrm{Zn}$ e terras raras $\mathrm{La}, \mathrm{Ce}, \mathrm{Eu}, \mathrm{Nd}, \mathrm{Sm}, \mathrm{Lu}, \mathrm{Tb}, \mathrm{Yb}$ ) nos sedimentos;

- Utilização da técnica de Espectrometria de Absorção Atômica com forno de grafite (GF AAS) para a determinação de $\mathrm{Cd}$ e $\mathrm{Pb}$ e com geração de vapor frio (CV AAS), para determinação de $\mathrm{Hg}$;

- Utilização da técnica de ICP OES (espectrometria de emissão ótica com plasma indutivamente acoplado) para a determinação dos elementos: Al, Ba, Co, Cr, Cu,Fe, Li, Mn, Ni, Sr e Zn;

- Avaliar o conteúdo dos metais e demais elementos nos sedimentos à luz dos índices propostos por legislações ambientais nacionais e internacionais;

- Avaliar o conteúdo em Fósforo Orgânico, Fósforo Inorgânico e total nos sedimentos.

- Caracterizar os sedimentos das duas regiões quanto às características geoquímicas identificando os locais onde a presença da fração fina e do teor de matéria orgânica é mais acentuada, revelando maior propensão à acumulação de metais;

- Calcular os fatores de enriquecimento (FE) para os elementos analisados, utilizando-se o Sc como elemento normalizador

- Calcular o lgeo (índice de geoacumulação) para verificação da contaminação por metais em sedimentos

- Comparar os valores de concentração de metais com os valores orientadores da CETESB e com outros trabalhos desenvolvidos na região. 


\subsubsection{Contribuição original do presente estudo}

Esse estudo contribuiu com dados de concentração de metais e elementos traço de interesse ambiental com valores controlados pelo órgão ambiental do estado de São Paulo (CETESB) em amostras de sedimentos superficiais de dois estuários, Santos/São Vicente e Cananéia (porção sul). Para a região de Cananéia existem poucos trabalhos publicados na literatura contemplando esses dados, conforme descrito anteriormente. Para o estuário de Santos/São Vicente, devido a sua importância ambiental, vários trabalhos já foram publicados, mas nenhum que contemple dados de concentração para todos os metais e elementos traço analisados no presente estudo, obtidos por três técnicas analíticas diferentes, em diversos pontos de amostragem, em duas estações climáticas, inverno e verão, em dois anos consecutivos. $O$ volume de dados gerados com o presente estudo contribuiu, de forma significativa, para o entendimento da variação sazonal, hidrodinâmica e de processos biogeoquímicos que ocorrem em ambos os estuários em estudo. Nenhum estudo anterior contemplou todos os parâmetros estudados no presente trabalho. 


\subsection{Sedimentos}

Sedimentos são as camadas de partículas finamente divididas, que cobrem o fundo de rios, córregos, lagos, represas, baías, estuários e oceanos. Consiste, basicamente, na mistura de diferentes formas granulométricas que podem ser finos, médios e de textura granulada, nos quais se incluem argila, silte e areia, misturado com matéria orgânica. Podem variar na composição de uma matéria mineral pura à matéria predominantemente orgânica e são repositórios de uma variedade de produtos químicos, biológicos e detritos poluentes nos corpos d'água. Uma preocupação particular é a grande probabilidade da transferência de espécies químicas ligadas aos sedimentos para as cadeias alimentares dos organismos aquáticos (camarões, lagostas, caranguejos, moluscos, vermes, insetos, anfípodes, bivalves e outros organismos menores) que passam parte significativa de seus ciclos de vida em contato com os sedimentos (MANAHAN, 1999).

Nos sedimentos também ocorre intensa atividade biológica, sendo considerados grandes depósitos de material tóxico e de bactérias que atuam nos processos de bioacumulação e biomagnificação. Neste caso, a biometilação dos metais é favorecida em diversos tipos de sedimentos. Por isso, a proteção da qualidade dos sedimentos é um componente do gerenciamento global da água (BAIRD, 2002).

Muitos compostos orgânicos sintéticos e metais tendem a adsorver as partículas que, eventualmente, acabam como depósitos de fundo. Uma vez lá, eles podem se tornar indisponíveis para o ecossistema sobrejacente e podem ser transformados em formas mais ou menos tóxicas, ou podem migrar dos sedimentos para organismos bentônicos (como macroalgas, microalgas e ervas marinha) ou em águas sobrejacentes. Em última análise, podem ser retomadas na cadeia alimentar, contaminando peixes, animais selvagens e seres humanos.

Entretanto, se os contaminantes irão permanecer no local ou contaminar o ecossistema como um todo é difícil de saber. Nenhuma resposta simples será suficiente para todos os locais de amostragem. 
Uma série de métodos promissores tem sido desenvolvida nos últimos anos para avaliar a extensão e gravidade da contaminação dos sedimentos. Como os sedimentos e suas interações com os processos do ecossistema são igualmente complexos, a avaliação do seu papel será sempre um desafio. Apesar dessa complexidade, existem ferramentas eficazes para avaliar o problema (BURTON, 1992).

Adams et al (1992), forneceram informações básicas sobre o status da avaliação de sedimentos nos Estados Unidos, a partir da revisão dos métodos existentes disponíveis para avaliação da qualidade do sedimento, além da análise de complexidade e incertezas dessas metodologias e uma proposta que utiliza os atributos únicos de muitos destes métodos, em uma estratégia de avaliação em camadas de sedimentos. Os autores concluíram que a avaliação da qualidade dos sedimentos é mais complexa que a avaliação da qualidade da água devido a muitos parâmetros específicos que não tem tanta influencia sobre a água. Dentre estes fatores incluem a biodisponibilidade e as características dos sedimentos tais como assoreamento, erosão e compactação, além das diferenças espaciais e temporais.

A fração silto-argilosa de sedimentos superficiais, dada a sua composição química e mineralógica e sua superfície específica, é a fração que contém os principais carreadores geoquímicos tanto de origem natural, quanto antrópica e, consequentemente, apresenta as maiores concentrações de metais (FORSTNER, 1990).

\subsubsection{Valores orientadores de qualidade de sedimentos}

Diversos produtos ou substâncias químicas são liberados no ambiente diariamente por processos naturais ou por atividades humanas, e podem ser inseridos nos ecossistemas aquáticos na forma particulada. Estas partículas podem ser depositadas nas camadas superficiais dos sedimentos, onde os contaminantes podem se acumular ao longo do tempo. Os sedimentos 
funcionam como reservatórios de produtos químicos para o meio aquático e para os organismos vivos ou que tenham contato direto com os sedimentos.

Devido ao fato de que os sedimentos compreendem um componente importante dos ecossistemas aquáticos, fornecendo habitat para uma vasta gama de organismos bentônicos e epibentônicos, a exposição a determinadas substâncias nos sedimentos representa um perigo potencial significativo para a saúde dos organismos. A avaliação eficaz deste risco requer o entendimento das relações entre as concentrações dos produtos químicos associados a sedimentos e a ocorrência de efeitos biológicos adversos. Diretrizes sobre a qualidade dos sedimentos são os instrumentos científicos que sintetizam as informações sobre as relações entre as concentrações dos contaminantes encontrados nos sedimentos e os efeitos adversos biológicos resultantes da exposição a esses produtos químicos (CCME, 1999).

As diretrizes de qualidade dos sedimentos estabelecem padrões de referência científica, para a avaliação dos efeitos biológicos adversos em sistemas aquáticos. As orientações são derivadas das informações toxicológicas de acordo com o protocolo formal estabelecido pelo Conselho Canadense de Ministros do Meio Ambiente (CCME, 1999).

Para estabelecer estes limites, são coletados diversos dados de contaminantes e os dados de caráter biológicos (ou dados de coocorrência) são avaliados a partir de numerosos estudos individuais para estabelecer uma associação entre a concentração de cada substância química medida no sedimento e quaisquer efeitos adversos biológicos observados. Os dados de coocorrência são compilados em um banco de dados denominado BEDS (Biological Effects Database for Sediments), a fim de calcular dois valores de avaliação. $O$ valor inferior, referido como o nível de efeito limiar ou TEL (Thereshold effect level), representa a concentração abaixo da qual os efeitos biológicos adversos não são esperados (CCME, 1999). O valor superior, conhecido como o nível de efeito provável ou PEL (Probable effect level), define o nível acima do qual os efeitos adversos são esperados ocorrer com frequência. Ao derivatizar os limites TEL e PEL, segundo uma fórmula padrão, três faixas de concentrações químicas são definidas: (1) o intervalo de um 
efeito mínimo no qual os efeitos adversos ocorrem raramente (ou seja, menos de $25 \%$ de ocorrência de efeitos adversos abaixo do limite TEL); (2) a faixa em que os efeitos adversos ocorrem ocasionalmente (isto é, o intervalo entre TEL e PEL) e (3) o intervalo de prováveis efeitos adversos (mais de $50 \%$ de efeitos deletérios acima do valor de PEL). As definições destes intervalos baseiam-se no pressuposto de que o potencial para a observação de toxicidade resultantes da exposição a uma substância química aumenta com o aumento da concentração da substância no sedimento (LONG et al. 1995).

A abordagem SSTT (spiked-sediment toxicity test) envolve uma avaliação independente das informações a partir de testes de ecotoxicidade em sedimentos fortificados sinteticamente, para estimar a concentração de uma substância química abaixo da qual os efeitos adversos provavelmente não irão ocorrer. Nesta abordagem, um valor SSTT é derivado usando dados de testes laboratoriais controlados nos quais os organismos são expostos a sedimentos fortificados com concentrações conhecidas de uma substância química ou mistura de substâncias químicas específicas. Tais estudos fornecem relações quantificáveis de causa e efeito entre a concentração de uma substância química em sedimentos e da resposta observada no meio biológico (por exemplo, sobrevivência, sucesso reprodutivo, ou de crescimento). Os testes de toxicidade de sedimentos fortificados também podem ser usados para determinar a biodisponibilidade de uma substância química e, finalmente, a resposta dos organismos expostos aos sedimentos contaminados (CCME, 1999).

As diretrizes provisórias da qualidade dos sedimentos (ISQG's ou Interim sediment quality guidelines) são recomendadas para a concentração total de substâncias químicas em água doce e sedimentos superficiais marinhos (ou seja, nos $5 \mathrm{~cm}$ superiores), quantificados por protocolos padronizados para cada substância química. Para a quantificação analítica de metais em sedimentos, a escolha do método de digestão depende do uso pretendido dos resultados (por exemplo, para a quantificação da fração biodisponível, ou para a avaliação geoquímica). 
Como os ISQGs destinam-se a avaliação da possibilidade de efeitos biológicos, os métodos de extração de metais traços removem a fração potencialmente disponível dos metais e os metais residuais (ou seja, os metais totais). Para determinar as concentrações de metais totais dos sedimentos, são recomendados os métodos de extração utilizando ácido fluorídrico, pois seria possível eliminar simultaneamente as frações biodisponíveis e residuais dos metais no sedimento. Entretanto, a concentração de metais totais pode se referir como a concentração de metais recuperados usando uma digestão quase total (digestão leve, por exemplo, água régia, ácido nítrico ou ácido clorídrico). Até o momento, dados sobre a toxicidade de sedimentos contaminados são limitados ou mesmo inexistentes, portanto, os ISQGs, que são calculados com base apenas na versão modificada da NSTP (National Status and Trends Program) (por exemplo, o TEL), são reconhecidos como os valores que refletem a qualidade dos sedimentos. Atualmente, ISQGs e PEL são recomendados para 31 substâncias ou produtos químicos (7 metais, 13 PAH's, e 11 compostos organoclorados) (CCME, 1999).

O grau de contaminação química do sedimento, com vistas à proteção da vida aquática, é classificado segundo os valores guias estabelecido pelo "Canadian Council of Ministers of the Environment" (EC, 1999) para arsênio, metais tóxicos e compostos orgânicos, conforme demonstra a Tabela 1.1.

A adoção dos valores TEL e PEL tem caráter meramente orientador na busca de evidências da presença de contaminantes em concentrações capazes de causar efeitos deletérios, sobretudo com relação à toxicidade para a biota. Os valores ISQG's destinam-se ao uso em conjunto com outras informações complementares, que incluem concentrações basais de determinados locais, concentrações de outras substâncias de ocorrência natural, avaliação biológica, valores orientadores de qualidade ambiental de outros componentes (água, tecidos biológicos e solo). Os valores ISQG's são desenvolvidos unicamente para fins científicos. (CCME, 1999) 
Tabela 1.1 Valores guias ( $\mathrm{mg} \mathrm{kg}^{-1}$ ) estabelecidos pelo "Canadian Council of Ministers of the Environment" (EC, 1999)

\begin{tabular}{c|c|c|c|c}
\hline \multirow{2}{*}{ Elementos } & \multicolumn{4}{|c}{ Environmental Canada } \\
\cline { 2 - 5 } & \multicolumn{4}{|c}{ Sedimentos } \\
\cline { 2 - 5 } & \multicolumn{2}{|c}{ Água doce } & \multicolumn{2}{c}{ Água Salobra } \\
\cline { 2 - 5 } & TEL & PEL & TEL & PEL \\
\hline $\mathbf{A s}$ & 5,9 & 17 & 7,24 & 41,6 \\
\hline $\mathbf{C d}$ & 0,6 & 3,5 & 0,7 & 4,21 \\
\hline $\mathbf{P b}$ & 35 & 91,3 & 30,2 & 112 \\
\hline $\mathbf{C u}$ & 35,7 & 197 & 18,7 & 108 \\
\hline $\mathbf{C r}$ & 37,3 & 90 & 52,3 & 160 \\
\hline $\mathbf{H g}$ & 0,17 & 0,486 & 0,13 & 0,696 \\
\hline $\mathbf{N i}$ & 18 & 35,9 & 15,9 & 42,8 \\
\hline $\mathbf{Z n}$ & 123 & 315 & 124 & 271 \\
\hline
\end{tabular}

TEL : "Threshold Effect Level", ou seja concentrações abaixo deste valor são raramente associadas a efeitos biológicos adversos

PEL : "Probable Effect Level", ou seja concentrações acima deste valor são freqüentemente associadas a efeitos biológicos adversos

Critério do Environment Canada (1995)

O Conselho Nacional do Meio Ambiente (CONAMA) (Resolução no 344) estabelece as diretrizes gerais e os procedimentos mínimos para a avaliação do material a ser dragado em águas jurisdicionais brasileiras, e dá outras providências. A Tabela 1.2 apresenta os níveis de classificação do material a ser dragado. (CONAMA, 2004) 
Tabela 1.2 Níveis de classificação do material a ser dragado (CONAMA, 2004)

\begin{tabular}{|c|c|c|c|}
\hline \multicolumn{2}{|c|}{ Poluentes } & \multicolumn{2}{|c|}{$\begin{array}{c}\text { Níveis de classificação do } \\
\text { material a ser dragado (em } \\
\text { unidade de material seco) }\end{array}$} \\
\hline & & Nível 1 & Nível 2 \\
\hline \multirow{8}{*}{$\begin{array}{l}\text { Metais tóxicos } \\
\text { e As } \\
\left(\mathrm{mg} \mathrm{kg}^{-1}\right)\end{array}$} & As & 8,2 & 70 \\
\hline & Cd & 1,2 & 9,6 \\
\hline & $\mathbf{P b}$ & 46,7 & 218 \\
\hline & $\mathrm{Cu}$ & 34 & 270 \\
\hline & $\mathrm{Cr}$ & 81 & 370 \\
\hline & $\mathrm{Hg}$ & 0,15 & 0,71 \\
\hline & $\mathbf{N i}$ & 20,9 & 51,6 \\
\hline & $\mathrm{Zn}$ & 150 & 410 \\
\hline
\end{tabular}

** Long, E.R., et al, (1995).

Segundo o Art. 3 da resolução CONAMA, "Para efeito de classificação do material a ser dragado, são definidos critérios de qualidade, a partir de dois níveis, conforme procedimentos estabelecidos".

"I - nível 1: limiar abaixo do qual se prevê baixa probabilidade de efeitos adversos à biota."

"Il - nível 2: limiar acima do qual se prevê um provável efeito adverso à biota."

A resolução CONAMA de 2004 utiliza ainda como valores de referência para materiais dragados de águas doces os valores estabelecidos pelo "Canadian Council of Ministers of the Environment", apresentados anteriormente, na Tabela 1.1. A nova resolução CONAMA 454 de novembro de 2012 (CONAMA, 2012), estabelece as diretrizes gerais atuais e os procedimentos referenciais para o gerenciamento do material a ser dragado em 
águas sob jurisdição nacional. Porém no presente estudo, todas as considerações foram feitas em cima dos valores da Resolução CONAMA de 2004, uma vez que a nova Resolução ainda não tinha sido publicada.

No Brasil, até o presente momento, ainda não estão definidos os critérios para classificação da qualidade de sedimentos em relação aos teores de metais e, por isso, a CETESB utiliza os critérios do Environment Canada (EC, 1999) para a classificação dos sedimentos coletados no estado de São Paulo.

\subsubsection{Técnicas analíticas usadas na análise de sedimentos}

A avaliação de sedimentos e sua correlação com o meio ambiente tornou-se importante e necessária nos últimos anos.

Técnicas analíticas nucleares e relacionadas são usadas para análise de sedimentos. A espectrometria de raios gama é usada para a determinação de radionuclídeos naturais e/ou artificiais, enquanto a análise por ativação neutrônica (NAA) e fluorescência de raios $X$ (XRF), são usadas para a caracterização multielementar. Outras técnicas não destrutivas utilizadas na análise de sedimentos são: Análise por feixe de íons (IBA) que inclui a técnica PIXE (Emissão de Partículas induzidas por raios $X$ ) e "Rutherford Backscattering Spectrometry" (RBS) (IAEA, 2003).

A análise por ativação com nêutrons foi descoberta em 1936, sendo bastante utilizada para análises multielementares (Ward Center Staff, 2000). GLASCOCK (2003) cita aplicações dessa técnica em diferentes áreas como: arqueologia, toxicologia, bioquímica, geologia e análises de solo em geral. É considerada uma técnica não destrutiva e fornece a concentração total dos elementos presentes na amostra.

A ativação neutrônica (NAA) vem sendo largamente utilizada em diversos países para a análise de solos e sedimentos (REZAEE et al, 2011; CRISTACHE et al, 2009; LLOYD et AL, 2005; AL-JUNDI \& RANDLE, 2001; 
DINESCU et al, 1998) e no Brasil, esta técnica está sendo utilizada em diferentes estudos e regiões de interesse, pelo grupo de pesquisadores do Laboratório de Análise por Ativação Neutrônica (LAN) do IPEN/CNEN - SP (AMORIM et al, 2007, 2008, 2009; FÁVARO et al, 2001; 2006; 2007; FIGUEIREDO et al, 2009; GUIMARÃES et al, 2012; FRANKLIN et al, 2012; LARIZZATTI et al, 2001).

A maioria das determinações de elementos maiores, menores e traço em sedimentos usando técnicas analíticas destrutivas, envolvem técnicas como a espectrometria de emissão ótica com plasma indutivamente acoplado (ICP OES) ou espectrometria de massa (ICP-MS) e técnicas monoelementares como espectrometria de absorção atômica. Alguns métodos eletroquímicos, espectrometria de massa por diluição isotópica, métodos fluorimétricos e espectrofotométricos são usados, mas as técnicas de preparação da amostra não são diferentes (IAEA, 2003).

Vallius \& Leivuori (1999) estudaram a distribuição de metais tóxicos em sedimentos do Golfo da Finlândia, empregando técnicas como ICP MS, CV AAS e GF AAS. As maiores concentrações dos metais analisados foram encontradas na parte leste do Golfo, provavelmente influenciado pelo afluente do rio Neva e o carregamento das cidades de São Petersburg, Baia Vyborg e o rio Kymi, também claramente afetado pelos sedimentos oriundos do alto mar.

Townsend et al (2001), demonstraram a aplicação das técnicas ICP MS, GF AAS e HG AFS (hydride generation atomic fluorescence spectroscopy) para a análise de águas e sedimentos estuarinos do rio Huon, na Tasmânia. Foram analisados elementos como Al, Sc, V, Cr, Mn, Fe, Co, Ni, Cu, Zn, As, Cd e $\mathrm{Pb}$.

Rose \& Yang (2005) apresentaram a distribuição espacial e temporal de alguns elementos traço em amostras de sedimentos de lagos no entorno da Inglaterra, que representavam um gradiente de deposição, além de discutir alguns fatores que afetavam a distribuição dos elementos encontrados nos sedimentos e a poluição histórica nos locais de amostragem. Foram avaliados $\mathrm{Pb}, \mathrm{Zn}, \mathrm{Cu}, \mathrm{Cd}, \mathrm{Cr}, \mathrm{Ni}, \mathrm{Sn}$, As e V, e os elementos majoritários Fe, Mn, Ti e Al 
em cinquenta amostras utilizando as técnicas de ICP-MS para a análise dos elementos traço e um espectrômetro de fluorescência de raios $X$, para a análise dos elementos majoritários. Os resultados demonstraram que os locais relativamente remotos tiveram maior deposição atmosférica de elementos traço proveniente há mais de 100 anos, o que pode indicar que a contaminação teve início antes do período da industrialização.

Kalantari \& Ebadi (2006) estudaram os níveis de alguns metais tóxicos presentes nos sedimentos do rio Neka, na província de Mazandaran, Irã, pelas técnicas de GF AAS e FAAS. Foram coletadas quatro amostras de sedimento ao longo do rio, e após tratamento as amostras foram digeridas em forno microondas, seguindo o procedimento da EPA 3051 (US EPA, 2007).

Harper \& Oliveira (2006) determinaram a concentração de elementos traço em amostras ambientais de solos e lodos de esgoto por ICP OES (axial), utilizando a decomposição assistida por microondas (EPA método 3051). Concluíram que o método utilizado para a determinação de elementos traço em solos e lodos no modo axial, forneceu os mais baixos limites de detecção possíveis para a aplicação, além de ser preciso e exato. Discutiram ainda que o método empregado era ideal para análises em rotina, devido ao acoplamento com a decomposição assistida por microondas.

Oliveira et al (2008) verificaram a mobilização de metais e elementos traço em ambientes aquáticos em zonas do semi-árido, aplicando a análise de componentes principais, com a finalidade de identificar os fluxos dos metais dos sedimentos para as colunas de água. A determinação de metais foi realizada por ICP OES e GF AAS. Concluíram que as relações entre a variação sazonal, pH e concentração das espécies químicas, de modo geral, demonstravam a influência do $\mathrm{pH}$ nas concentrações de $\mathrm{Ca}, \mathrm{Mg}, \mathrm{Zn}, \mathrm{Sr}, \mathrm{Fe}$, $\mathrm{Cd}, \mathrm{Pb}$ e $\mathrm{Mn}$ na interface coluna d'água/sedimento de fundo dos reservatórios, principalmente quando suas concentrações se aproximavam dos limites de saturação.

No presente estudo, foram também alvos de avaliação o desempenho em relação a parâmetros como custo, tempo de análise, 
facilidade de operação, limites de detecção, presença de interferentes entre outros fatores.

A técnica de ICP OES apresenta como principais características o baixo nível de radiação de fundo (background), bons limites de detecção para cerca de 70 elementos, ampla faixa de calibração além de ser uma técnica multielementar. Porém quando comparada à técnica de AAS, tem como desvantagens o custo operacional elevado, o equipamento é cerca de 3 vezes mais caro e requer maior expertise do analista (devido ao equipamento ser pouco robusto).

Quando se utiliza a técnica de absorção atômica com geração de vapor frio (CV AAS), normalmente obtém-se maior eficiência analítica devido à utilização de $100 \%$ da amostra, em comparação aos 5 a 10\% utilizados nos nebulizadores convencionais, como por exemplo, no ICP OES. Com isto observa-se uma melhora significativa no limite de detecção, entretanto a técnica é limitada apenas a analise de $\mathrm{Hg}$, podendo ser estendida aos elementos $\mathrm{As}$, Se, Bi, Sb, Te e Sn, no caso de utilizar-se absorção atômica com chama (FAAS) e geração de hidretos (técnica de HG AAS), além de requerer aparelhagem à parte.

A Figura 1.1 apresenta uma comparação entre os limites de detecção das técnicas FAAS, ICP OES (radial e axial), HG AAS, GF AAS e ICP MS: 


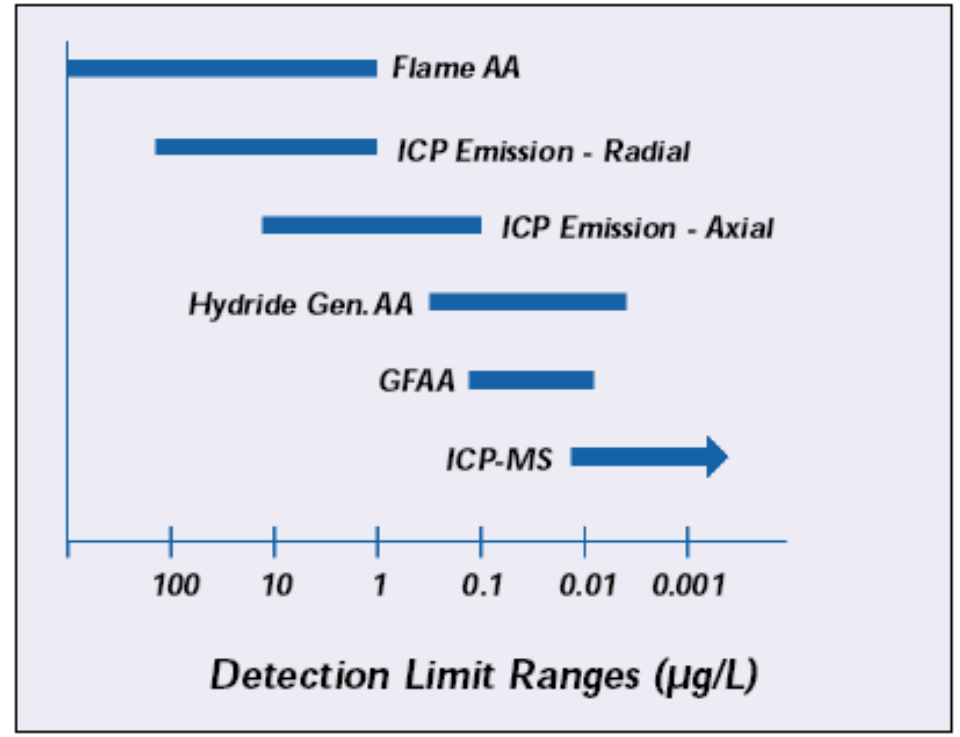

Figura 1.1 Faixas de limites de detecção para as técnicas de FAAS, ICP OES, HG AAS, GF AAS e ICP MS (Perkin Elmer,2000)

Devido ao fato do sistema de instrumentação dos equipamentos de Absorção Atômica para um único elemento (FAAS e GF AAS) serem menos complexos em relação às técnicas multielementares ICP OES e ICP-MS, existe uma variação considerável de custos devido, principalmente, à versatilidade e automação do equipamento. A Figura 1.2 apresenta uma comparação típica de custos das principais técnicas de espectroscopia atômica:

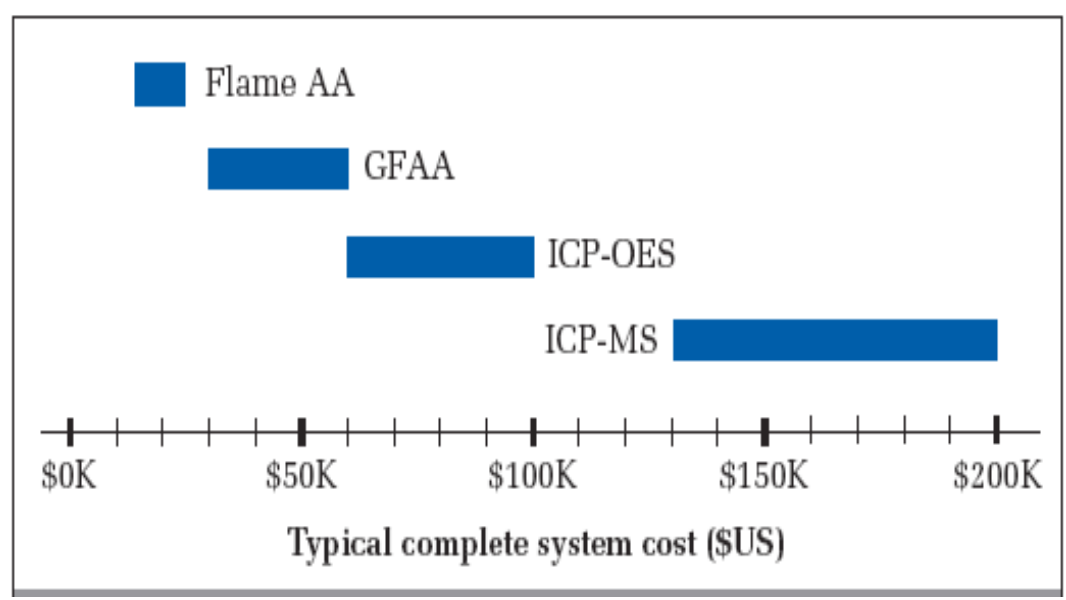

Figura 1.2 Comparação dos custos dos equipamentos de FAAS, ICP OES, GF AAS e ICP MS (Perkin Elmer, 2000) 


\subsection{Aspectos toxicológicos dos metais}

O significado literal do termo toxicologia é "o estudo de venenos". O início da história da toxicologia foi focado na compreensão e utilização de venenos diferentes e ainda hoje, a maioria das pessoas tende a pensar em venenos como uma poção mortal que quando ingerida causa danos quase imediatamente ou mesmo à morte (WILLIAMS et al, 2000).

O termo "tóxico" é tido como a característica de produzir um efeito de saúde indesejável ou adverso, enquanto que a "toxicidade" é definida como qualquer efeito adverso que um agente químico ou físico pode produzir em um organismo vivo (WILLIAMS et al, 2000).

É possível classificar as exposições a produtos tóxicos em quatro categorias gerais: exposição aguda e crônica, locais ou sistêmicas. A exposição aguda local ocorre durante um período de poucos segundos a poucas horas, e pode afetar o local exposto (pele, olhos ou membranas das mucosas). As mesmas partes do corpo podem ser afetadas pela exposição crônica local, para a qual o intervalo de tempo pode ser de até vários anos. A exposição aguda sistêmica é uma breve exposição e ocorre com substâncias tóxicas que podem entrar no corpo por inalação ou ingestão, e afetar órgãos como o fígado. A exposição crônica sistêmica ocorre durante um período de tempo prolongado (MANAHAN, 1999).

Em geral, alguns elementos são considerados essenciais em baixos níveis de concentração, mas quando estão em altos níveis, são considerados tóxicos.

A maioria dos metais tóxicos têm uma grande afinidade por enxofre e podem causar disfunções nas enzimas, através de reações com os compostos de enxofre presentes nas enzimas. Grupos como os ácidos carboxílicos $\left(-\mathrm{CO}_{2} \mathrm{H}\right)$ e amino $\left(-\mathrm{NH}_{2}\right)$ também podem fixar os metais tóxicos, devido à atração química. $\mathrm{Cd}, \mathrm{Cu}, \mathrm{Pb}$ e $\mathrm{Hg}$ podem ligar seus íons nas 
membranas celulares, dificultando os processos de transporte nas paredes celulares (MANAHAN, 1999).

Com base na resolução CONAMA 344/04 e nos valores orientadores adotados pela CETESB, serão discutidos alguns aspectos toxicológicos dos elementos $\mathrm{As}, \mathrm{Cd}, \mathrm{Pb}, \mathrm{Cu}, \mathrm{Cr}, \mathrm{Hg}$, $\mathrm{Ni}$ e $\mathrm{Zn}$.

\subsubsection{Cádmio}

A poluição causada por $\mathrm{Cd}$ em águas pode ser proveniente de inúmeros fatores, como intemperismo, erosão do solo, descargas industriais, vazamentos de aterros e locais contaminados e resíduos de mineração (AZEVEDO, et al, 2003).

Quimicamente, o Cd é muito semelhante ao $\mathrm{Zn}$, e estes dois metais frequentemente são encontrados juntos em processos geoquímicos. Ambos são encontrados na água no estado de oxidação +2. Os efeitos da intoxicação aguda pelo cádmio em seres humanos são muito graves. Entre eles, estão a hipertensão arterial, danos nos rins, destruição do tecido testicular e destruição das células vermelhas do sangue (MANAHAN, 1999).

\subsubsection{Chumbo}

$\mathrm{O} \mathrm{Pb}$ é reconhecido pela Organização Mundial da Saúde (OMS) como um dos elementos químicos mais perigosos à saúde humana, e destacam-se dois grupos tóxicos que apresentam diferentes toxidades que são representadas pelo $\mathrm{Pb}$ inorgânico e $0 \mathrm{~Pb}$ orgânico. $\mathrm{Na}$ exposição ao $\mathrm{Pb}$ inorgânico, a intoxicação ocorre principalmente através da via respiratória e digestiva, distribuindo-se inicialmente nos tecidos moles e posteriormente, apresentando uma redistribuição e deposição nos ossos, dentes e cabelos. Quase todo chumbo inorgânico circulante encontra-se associado aos eritrócitos (SCHIFER, 2005). 
O segundo grupo é o do $\mathrm{Pb}$ orgânico, que tem o chumbo tetraetila e tetrametila como suas principais fontes de intoxicação. Os principais sistemas prejudicados são: o gastrointestinal, neuromuscular, neurológico, hematológico e renal (SCHIFER, 2005).

O chumbo é depositado na água (lagos, rios e oceanos) proveniente da atmosfera ou da lixiviação do solo, de fontes naturais ou antropogênicas, sendo que o chumbo encontrado em águas superficiais pode estar complexado tanto com compostos orgânicos naturais (ácidos húmicos ou fúlvicos), como compostos de origem antropoênicas, por exemplo, através do complexo com ácido etilenodiaminotetracético (AZEVEDO, et al, 2003).

$\mathrm{O} \mathrm{Pb}$ no solo e em poeiras são as principais fontes de exposição em crianças, e quando são expostas em níveis relativamente baixos, pode causar efeitos neurológicos adversos em fetos e crianças. Efeitos neurocomportamentais também foram documentados em estudos com animais, bem como em humanos. $\mathrm{O} \mathrm{Pb}$ afeta o sistema hematopoiético, alterando a atividade de algumas enzimas, o que pode causar, posteriormente, a diminuição dos níveis de hemoglobina e anemia. $\mathrm{O} \mathrm{Pb}$ pode causar danos nos rins, como resultado de exposição aguda ou crônica. Dentre outras doenças, a exposição pode resultar em nefrite intersticial, fibrose e atrofia tubular, cólicas, náuseas, vômitos e anorexia (WILLAMS, 2000).

\subsubsection{Mercúrio}

Devido a sua toxicidade e mobilização para formas metiladas por bactérias anaeróbias e outros fatores poluidores, o $\mathrm{Hg}$ gera uma grande preocupação quando presente em locais poluídos. $\mathrm{O} \mathrm{Hg}$ é também encontrado em níveis de traço em muitos minerais, como rochas continentais, contendo uma media de $80 \mathrm{ppb}$ ou um pouco menos. Combustíveis fósseis de carvão contém mercúrio, muitas vezes em níveis de 100 ppb ou até mais, tornando-se uma preocupação com a crescente utilização desses combustíveis para recursos energéticos. $\mathrm{O} \mathrm{Hg}$ metálico foi utilizado como eletrodo na geração eletrolítica de cloro gasoso, em aparelhos de vácuo no laboratório e em outras 
aplicações. Quantidades significativas de $\mathrm{Hg}$ inorgânico $\left(\mathrm{Hg}^{+1}\right.$ e $\left.\mathrm{Hg}^{+2}\right)$ são utilizadas anualmente. Os compostos orgânicos de $\mathrm{Hg}$ são amplamente aplicados como pesticidas e fungicidas.

O Hg entra no ambiente de diversas formas, devido aos diversos usos e o mau gerenciamento dos resíduos gerados. Estes incluem descarte de produtos químicos de laboratórios, baterias, termômetros quebrados, restauração de amalgama dentário, mineração de $\mathrm{Au}$, entre outros. Tomados individualmente, cada uma destas fontes pode não contribuir muito à toxidez, mas o efeito total pode ser substancial. Em esgotos, não é difícil encontrar concentrações de até 10 vezes o nível de $\mathrm{Hg}$ encontrados em águas naturais (MANAHAN, 1999).

As concentrações elevadas de $\mathrm{Hg}$ encontradas nas águas e nos tecidos de peixe tem como resultado a formação do íon solúvel monometilmercúrio $\left(\mathrm{CH}_{3} \mathrm{Hg}^{+}\right)$e dimetil-mercúrio volátil $\left(\mathrm{CH}_{3} \mathrm{HgCH}_{3}\right)$, devido a ação das bactérias anaeróbias em sedimentos.

Entre os efeitos tóxicos do $\mathrm{Hg}$, são destacados os danos neurológicos, incluindo irritabilidade, paralisia, cegueira ou loucura. Os sintomas mais leves de intoxicação por Hg como depressão e irritabilidade têm um caráter psicopatológico e devido à semelhança destes sintomas ao comportamento humano comum, uma leve intoxicação por Hg pode não ser detectada facilmente (MANAHAN, 1999).

A Figura 1.3 apresenta o ciclo do $\mathrm{Hg}$ no ambiente aquático, com o $\mathrm{Hg}$ proveniente de fontes industriais ou mineração. 


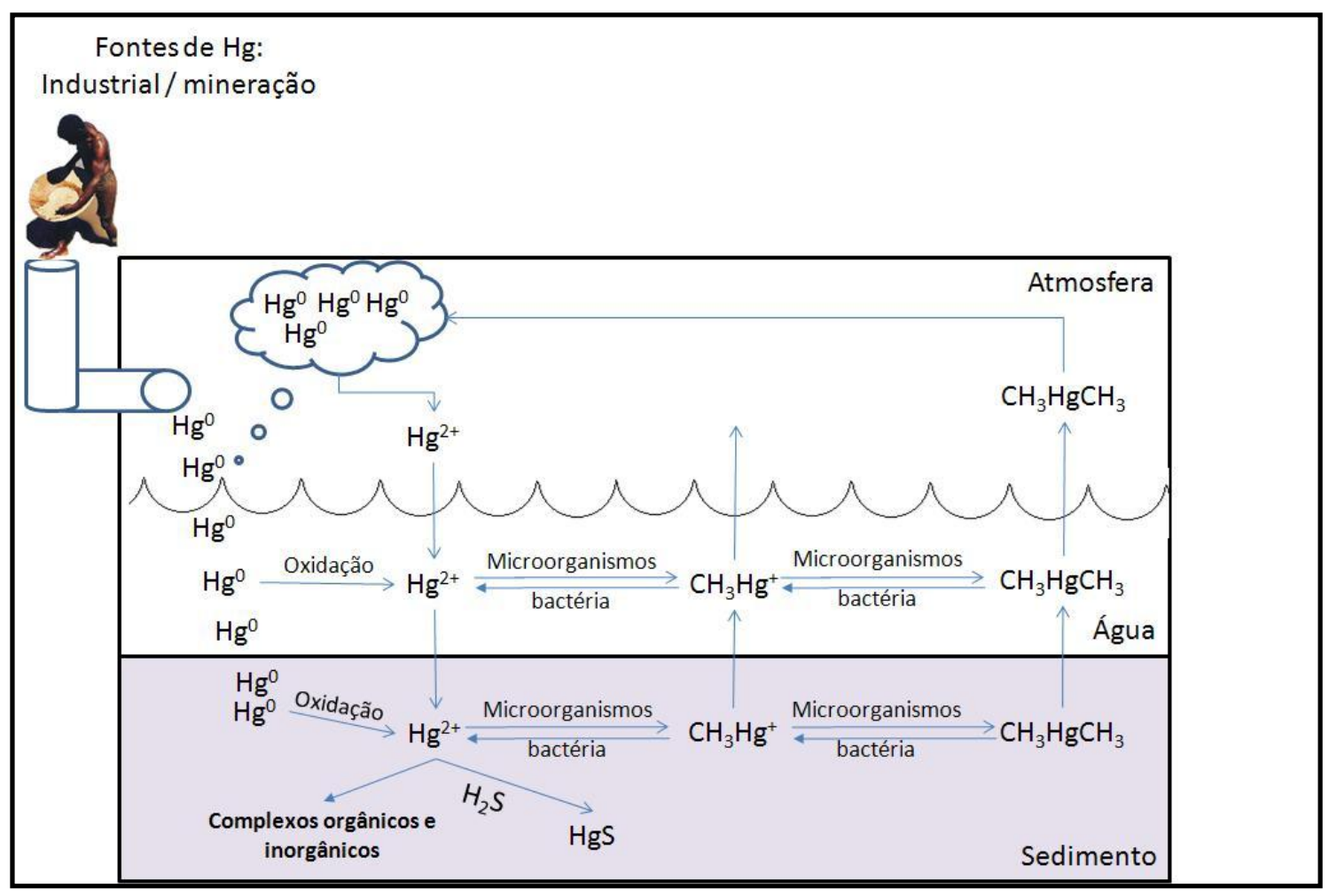

Figura 1.3 Fontes de $\mathrm{Hg}$ : Industrial/ Mineração

(Fonte: http://www.cq.ufam.edu.br/Artigos/mercurio/images/ciclo_Hg.jpg, acesso em 07/05/11)

Algumas formas de $\mathrm{Hg}$ são relativamente atóxicas e eram utilizadas como medicamentos, por exemplo, no tratamento de sífilis. Outras formas de $\mathrm{Hg}$, em particular os compostos orgânicos, são altamente tóxicas (MANAHAN, 1999).

\subsubsection{Níquel}

O Ni é um elemento metálico utilizado em ligas e chapas metálicas, devido a sua resistência à oxidação. $\mathrm{Na}$ crosta terrestre, ocorre naturalmente combinado com outros elementos. O Ni liberado para a atmosfera normalmente está na forma particulada ou adsorvido em partículas dispersas no ar. Quando liberado ao solo, o Ni pode ser absorvido em sua superfície, dependendo das condições do solo, e nos sistemas aquáticos, existe em forma de partículas que se instalam nas áreas de sedimentação ativa, entretanto pode existir na forma 
solúvel, quando em condições adequadas. Sais de Ni apresentam solubilidade significativa em água (WILLIAMS, 2000).

Normalmente o $\mathrm{Ni}$ ocorre naturalmente em água de consumo e não representa um problema de toxicidade após a ingestão. $O$ efeito mais comum de exposição ao Ni é a dermatite em indivíduos que possuem sensibilidade ao $\mathrm{Ni}$ nas áreas que ocorrem o contato ou neurodermatite. A sensibilidade ao $\mathrm{Ni}$, uma vez adquirida, pode ser persistente. A preocupação dos efeitos tóxicos aos trabalhadores expostos nas indústrias é tida em duas categorias de efeitos potenciais: 1) Dermatoses de contato e dermatite atópica e 2) Câncer no pulmão e seios nasais. Os efeitos não carcinógenos, como a bronquite e enfisema, também podem ocorrer em exposições ocupacionais. Atualmente, o Ni não é considerado como um carcinógeno pela via oral (WILLIAMS, 2000).

\subsubsection{Arsênio}

O As é um semi-metal de cor cinza encontrado no ambiente em compostos orgânicos e inorgânicos. O As inorgânico ocorre naturalmente em vários tipos de rocha. Baixos níveis de As estão presentes no solo, água, ar e alimentos. $O$ As também foi bastante utilizado em herbicidas e inseticidas (WILLIAMS, 2000).

O poluente mais importante da classe dos metalóides na água é o As, que pode causar intoxicação aguda pela ingestão de cerca de $100 \mathrm{mg}$ do elemento. A intoxicação crônica ocorre com a ingestão de pequenas quantidades de As por um longo período de tempo. Existem evidências que este elemento é cancerígeno (MANAHAN, 1999).

A introdução do As no ambiente é dada pela queima de combustíveis fósseis, especialmente carvão. O As é encontrado em minerais de fosfato e também pode entrar no ambiente juntamente com alguns compostos de fósforo. Alguns pesticidas utilizados no passado continham compostos de As altamente tóxicos como o arseniato de chumbo $\left[\mathrm{Pb}_{3}\left(\mathrm{AsO}_{4}\right)_{2}\right]$ 
e o arsenito de sódio $\left(\mathrm{Na}_{3} \mathrm{AsO}_{3}\right)$. Outra forma importante de As é derivada dos rejeitos de mineração.

$\mathrm{Na}$ exposição humana ao As, estão envolvidas a inalação de poeiras, ingestão do As em água ou alimentos, ou contato dérmico com poeiras, solos ou águas. Na rota de inalação, a preocupação é maior devido ao risco de câncer no pulmão, seguido de irritação respiratória, náuseas e efeitos na pele. Embora os dados em seres humanos sejam escassos existe suposição de que a inalação de As pode levar a danos neurológicos (WILLIAMS, 2000).

A exposição oral pode resultar em irritações gastrointestinais, neuropatia periférica, lesões vasculares, anemia e doenças de pele. Existem relatos de muitos casos de morte em pessoas devido à ingestão intencional ou acidental de doses elevadas de compostos de As. Em quase todos os casos, os efeitos imediatos são vômitos, diarréia e hemorragia gastrointestinal. Uma série de estudos em humanos indica que a ingestão de As pode levar a sérios efeitos cardiovasculares. Estudos epidemiológicos sugerem que a exposição por inalação de As inorgânico aumenta 0 risco de câncer de pulmão (WILLIAMS, 2000).

\subsubsection{Cromo}

O $\mathrm{Cr}$ é encontrado na natureza principalmente como Cromita, na forma de $\mathrm{Cr}^{3+}$. Este mineral é utilizado para a fabricação de pigmentos, cromatos, dicromatos, ácido crômico, bem como para o $\mathrm{Cr}$ metálico. Os produtos químicos derivados de $\mathrm{Cr}$ são de grande significância para a saúde dos trabalhadores. A adsorção de $\mathrm{Cr}$ através das vias aéreas e do trato digestivo é muito mais rápida no $\mathrm{Cr}^{+6}$ do que no estado de $\mathrm{Cr}^{+3}$. O $\mathrm{Cr}$ é encontrado em todos os órgãos humanos de adultos e recém-nascidos, e as maiores concentrações deste elemento são geralmente encontradas nos tecidos pulmonares, onde a concentração tende a aumentar com a idade, provavelmente resultado da inalação e retenção de compostos de $\mathrm{Cr}$ com baixa 
solubilidade em água. O $\mathrm{Cr}$ é excretado pela urina e das fezes, principalmente pela urina (NORDBERG, et al, 2005).

$\mathrm{O}_{\mathrm{Cr}^{3+}}$ representa um suplemento nutricional para humanos $\mathrm{e}$ animais, e pode desempenhar um papel importante no metabolismo da glicose, porém quando encontrado na forma de $\mathrm{Cr}^{6+}$, a exposição pode ocasionar efeitos indesejáveis no organismo, como por exemplo, reações alérgicas da pele. $\mathrm{O} \mathrm{Cr}^{6+}$ pode induzir a ulcerações da mucosa do septo nasal e úlceras de pele, além de alguns compostos fornecerem um risco elevado de câncer no aparelho respiratório. $\mathrm{O} \mathrm{Cr}^{6+}$ é um dos agentes cancerígenos mais potentes conhecidos (NORDBERG, et al, 2005).

\subsubsection{Cobre}

O Cobre é um metal avermelhado que ocorre naturalmente em rochas, solo, água, sedimentos, no ar e também é encontrado naturalmente em plantas e animais. É um elemento essencial para todos os organismos vivos, incluindo os seres humanos e outros animais em baixos níveis de ingestão. Em níveis mais elevados, os efeitos tóxicos podem ocorrer. (U.S. DEPARTMENT OF HEALTH AND HUMAN SERVICES, 2004)

Quando ocorre a exposição por inalação, podem ser observados efeitos nos sistemas gastrintestinal, hematológico, hepático, endócrino e ocular. Efeitos respiratórios podem ocorrer quando ocorre exposição via aerossóis de sulfato de cobre (U.S. DEPARTMENT OF HEALTH AND HUMAN SERVICES, 2004). Trabalhadores expostos a poeiras contendo Cobre, relatam uma série de sintomas que são sugestivos de irritação das vias respiratórias, incluindo tosse, espirros, dor torácica e corrimento nasal. Dentre os efeitos gastrintestinais, são relatadas anorexia, náusea e diarréia (U.S. DEPARTMENT OF HEALTH AND HUMAN SERVICES, 2004).

Existem relatos de diminuição da hemoglobina e dos níveis de hemácias em trabalhadores expostos a níveis de cobre no ar de 0,64-1,05 mg $\mathrm{m}^{-3}$ (U.S. DEPARTMENT OF HEALTH AND HUMAN SERVICES, 2004). 


\subsubsection{Zinco}

O Zn é um elemento relativamente abundante e não é tóxico, mas tal como acontece com outros metais, a mineração e processamento de zinco podem trazer grandes preocupações ambientais. O zinco ocorre como $\mathrm{ZnS}$ em um mineral chamado esfalerita. $\mathrm{O} Z \mathrm{Zn}$ é amplamente utilizado como metal e quantidades menores são usadas para fazer produtos químicos à base de zinco. Um dos maiores usos para o zinco é como revestimento resistente à corrosão do aço. Esta aplicação, confere um grau elevado de refinamento na indústria automobilística nos últimos anos, por prolongar significativamente o tempo de vida de corpos automotivos (MANAHAN, 1999).

Dois aspectos do $\mathrm{Zn}$ podem ser tratados com respeito à sua ecologia industrial. O primeiro deles é que, embora não seja muito tóxico para os animais, o $\mathrm{Zn}$ é fitotóxico (tóxico para plantas) e o solo pode ser "envenenado" pela exposição ao zinco oriundo de fundição de zinco ou pela aplicação de lodo rico em zinco. A segunda delas é que a reciclagem de zinco é complicada por sua dispersão como um revestimento de outros metais (MANAHAN, 1999). 


\section{CAPÍTULO 2}

\section{LOCAIS DE ESTUDO - REVISÃO DA LITERATURA}

\subsection{Sistema estuarino Santos/ São Vicente}

A região da Baixada Santista, SP, abriga uma estrutura complexa, na qual estão inseridos os sistemas estuarinos de Santos e São Vicente, além de possuir o maior porto da América Latina e o principal acesso portuário do Brasil (o Porto de Santos) e também o maior polo industrial do país, situado em Cubatão. Esta complexa estrutura em conjunto com a intensa ocupação urbana representa um dos mais importantes exemplos brasileiros de degradação ambiental por poluição hídrica e atmosférica de origem antrópica em ambientes costeiros. (CETESB, 2001).

O sitema estuarino de Santos, na Baixada Santista, compreende um complexo e terrenos sedimentares de idade Cenozóica, limitados no lado continental por rochas de idade Pré-Cambriana pertencentes ao cinturão dos dobramentos do Sudeste brasileiro (Fulfaro et al, 1983 apud Siqueira et al, 2004).

A hidrologia do sistema estuarino de Santos é caracterizada por dois canais de comunicação com o mar, a do canal de Paranapuã (São Vicente), e a do canal de Piaçaguera (Santos e Guarujá). Pelos estudos realizados sobre a circulação das águas nos estuários de Santos e São Vicente, verificou-se que existe um regime de circulação de águas que caracteriza os braços do porto dos canais de Santos e de São Vicente como parcialmente misturados (CETESB, 1981).

De acordo com Fulfaro \& Ponçano (1976), a baía de Santos dividese em duas áreas de sedimentação distintas: uma é consequência de um fluxo 
unidirecional que provém do estuário santista, saindo pelo canal do porto. A outra é do domínio das marés, oriundas da plataforma continental adjacente.

O Nucleo de Estudos Populacionais (NEPO) da UNICAMP, publicou recentemente, um estudo intitulado "Baixada Santista: uso, expansão e ocupação do solo, estrututação de rede urbana regional e metropolização" escrito pelo professor Carlos Zundt. Nesse texto pode-se encontrar uma visão geral do processo de metropolização da Baixada Santista desde o século 16 até a década de 2000 (NEPO, acesso em 12/2012)

Nas décadas de 70 e 80, estudos realizados por Tommasi (1979, 1983), verificaram-se que as águas da baía de Santos encontravam-se bastante contaminadas pelos diversos efluentes domésticos, rejeitos portuários e despejos de origem industrial que são lançados na região estuarina, e que provavelmente chegam até essa área pelos canais laterais dos setores de Santos e São Vicente.

A Companhia Ambiental do Estado de São Paulo - CETESB é a agência do Governo do Estado responsável pelo controle, fiscalização, monitoramento e licenciamento de atividades geradoras de poluição, com a preocupação fundamental de preservar e recuperar a qualidade das águas, do ar e do solo.

Entre os anos de 1979 e 1981 foram realizados estudos da região de Santos/SP (CETESB, 1979, 1981), para avaliar os impactos provocados pela ação antrópica na poluição das águas, sedimentos e organismos aquáticos, concluindo-se que o ambiente aquático de todos os locais estudados estava comprometido. As principais causas da degradação da região foram a poluição de origem doméstica e industrial, responsáveis pela contaminação química e microbiológica, e as alterações físicas dos habitats resultantes de processos de erosão, assoreamento, aterros de canais e manguezais e intervenções no sistema de drenagem (CETESB, 2001).

O Porto de Santos está sujeito a diversos processos para a garantia da segurança de navegação, dentre os quais são realizadas dragagens 
periódicas para aprofundamento do canal de Santos, de modo a permitir que os navios trafeguem sem riscos à segurança da navegação. Para este propósito, são realizadas as chamadas dragagens de manutenção, as quais mantêm os níveis de profundidades adequados para a navegação, eliminando os efeitos de redução da lâmina d'agua pelo assoreamento. O projeto de dragagem no Porto de Santos tem cotas variando de 13 a $14 \mathrm{~m}$. Um outro tipo de dragagem realizada na região é a dragagem de aprofundamento, que tem por finalidade aprofundar o canal existente visando receber navios com maiores calados. $O$ projeto da dragagem de aprofundamento, para o Porto de Santos, têm cotas que variam de 16 a $17 \mathrm{~m}$.

Para detectar possíveis efeitos deletérios sobre a biota e os processos ecológicos do local de disposição do sedimento dragado, são realizados monitoramentos periódicos pela Companhia Docas do estado de São Paulo (CODESP) desde 2005, a qual avalia dentre outros parâmetros, a qualidade dos sedimentos, comunidades bentônicas, qualidade da água de fundo e da coluna d'água.

Apenas a partir do ano de 1984, efetivamente deu-se início a um programa intensivo de controle da poluição do ar, das águas e do solo, no polo industrial em Cubatão, de modo a reverter a situação dos ecossistemas degradados, através da implementação de sistemas de tratamento de efluentes industriais em todas as indústrias da região, o que resultou em uma acentuada redução da carga de poluentes para o sistema hídrico (Tabela 2.1).

Apesar do grande esforço para o controle da poluição e melhoria da qualidade ambiental, um levantamento realizado em 1988, concluiu que a região continuava impactada por concentrações elevadas de metais tóxicos e compostos organoclorados na água, nos sedimentos e nos organismos aquáticos (CETESB, 1990, EYSINK et al, 1991, VARGAS-BOLDRINI et al., 1991). 
Tabela 2.1 Redução do lançamento de poluentes industriais de Cubatão nos rios e estuários, em toneladas por ano (CETESB, 2001)

\begin{tabular}{c|c|c|c}
\hline Poluentes & $\begin{array}{c}\mathbf{1 9 8 4} \\
\text { (ton/ano) }\end{array}$ & $\begin{array}{c}\mathbf{1 9 9 4} \\
\text { (ton/ano) }\end{array}$ & $\begin{array}{c}\text { Redução } \\
\text { (\%) }\end{array}$ \\
\hline Carga orgânica & 22.678 & 1.547 & 93 \\
\hline Metais tóxicos & 1.467 & 44 & 97 \\
\hline $\begin{array}{c}\text { Resíduos } \\
\text { sedimentáveis }\end{array}$ & 216 & 22 & 90 \\
\hline
\end{tabular}

Em 1999, a CETESB realizou um levantamento da contaminação ambiental do Sistema Estuarino de Santos e São Vicente analisando amostras de água, sedimentos e organismos aquáticos na região (CETESB, 2001). As áreas que apresentaram as maiores concentrações de contaminantes localizavam-se próximas às fontes de poluição. Os elementos $\mathrm{Cd}, \mathrm{Pb}, \mathrm{Cu}, \mathrm{Hg}$, $\mathrm{Ni}$ e $\mathrm{Zn}$ estiveram muitas vezes acima das concentrações que podem causar efeitos tóxicos aos organismos aquáticos, de acordo com os critérios do Environment Canada (1999). Segundo a CETESB (2001), as cargas poluidoras orgânicas de origem industrial excedem as cargas orgânicas de origem domésticas no sistema estuarino.

Nos últimos anos, muitos estudos sobre a qualidade dos sedimentos na região mostraram que os problemas de contaminação por metais tóxicos em matéria de poluição continuam a existir, impactando fortemente nas espécies ali presentes.

Braga et al (2000) verificaram o processo de eutrofização e a poluição por bactérias no sistema estuarino de Santos, com altas concentrações de nutrientes tais como nitrato $\left(>90 \mathrm{~mol} \mathrm{~L}^{-1} \mathrm{~N} \mathrm{NO}_{3}{ }^{-}\right)$e fosfato $\left(>24 \mathrm{~mol} \mathrm{~L}^{-1} \mathrm{PPO}_{4}^{-3}\right.$ ) perto do complexo industrial de Cubatão. Os autores verificaram um claro gradiente de diluição do interior do estuário até a entrada, mas não alcançando baixas concentrações para todos os elementos na baía de Santos. 
Em 2003, Siqueira realizou um estudo na área do estuário de Santos, São Vicente e baía de Santos, para determinar as concentrações (frações móvel e total) de diversos elementos (Al, $\mathrm{Ca}, \mathrm{Mg}, \mathrm{Na}, \mathrm{K}, \mathrm{Fe}, \mathrm{Mn}, \mathrm{Ti}$, $\mathrm{Hg}, \mathrm{As}, \mathrm{Ba}, \mathrm{Li}, \mathrm{V}, \mathrm{Ni}, \mathrm{Pb}, \mathrm{Cr}, \mathrm{Zn}, \mathrm{Co}, \mathrm{Cu}$ e $\mathrm{Sr}$ ) a partir das análises de amostras de sedimentos nas frações granulométricas menores que 0,063 mm (230 mesh). A partir dos resultados, foi possível observar que, em alguns pontos, ocorreu redução de concentração para os metais $\mathrm{Hg}$ e $\mathrm{Ni}$ e aumento para os elementos $\mathrm{Pb}, \mathrm{Cr}$, $\mathrm{Zn}$ e $\mathrm{Cu}$.

Siqueira et al (2004), realizaram um estudo no sistema estuarino de Santos, visando a evolução do impacto ambiental causado por matéria orgânica, $\mathrm{Hg}$ e As em sedimentos de fundo. Os resultados revelaram contaminação antrópica para alguns setores, sendo as fontes atribuídas ao parque industrial petroquímico-metalúrgico de Cubatão, aos efluentes da COSIPA e à descarga de efluentes lançados pelo emissário submarino na baía de Santos.

Siqueira et al (2005), publicaram um estudo específico sobre a distribuição do $\mathrm{Hg}$ nesses sedimentos e concluíram que essa distribuição parece ser influenciada pelos efluentes locais e pela circulação de água no sistema. Os teores mais elevados foram encontrados nas proximidades dos setores mais industrializados (estuário de Santos) e na saída do emissário submarino (baía de Santos), sinalizando possíveis ações antrópicas nesses sítios. Ainda no estuário de Santos, Siqueira et al (2006) avaliaram as distribuições espaciais de carbono orgânico, nitrogênio total e enxofre total para estabelecer as razões $\mathrm{C} / \mathrm{N}$ e C/S e determinar o conteúdo em matéria orgânica (MO) relacionado ao aporte ao ambiente sedimentar. Concluíram que os sedimentos estudados recebiam contribuição de $\mathrm{MO}$ tanto de origem continental quanto marinha.

Silva (2004), a partir das análises de amostras de sedimentos superficiais e testemunhos, estudou o impacto ocasionado na região pela analise das concentrações, utilizando diferentes técnicas analíticas, dos elementos pertencentes às séries radioativas naturais do $U$ e Th e dos elementos $\mathrm{Al}, \mathrm{As}, \mathrm{Ba}, \mathrm{Br}, \mathrm{Ca}, \mathrm{Cs}, \mathrm{Co}, \mathrm{Cr}, \mathrm{Cu}, \mathrm{Eu}, \mathrm{Fe}, \mathrm{Hf}, \mathrm{Hg}, \mathrm{K}, \mathrm{La}, \mathrm{Li}, \mathrm{Lu}, \mathrm{Mg}$, 
$\mathrm{Mn}, \mathrm{Na}, \mathrm{Nd}, \mathrm{Ni}, \mathrm{Pb}, \mathrm{Rb}, \mathrm{Sb}, \mathrm{Sc}$, Se, Sm, Ta, Tb, Yb, Zn e Zr. Foram determinadas também, a porcentagem de fração fina e a quantidade de matéria orgânica.

Hypolito et al (2005), avaliaram o comportamento das espécies de mercúrio no município de Cubatão, no sistema sedimento-água, onde relataram que a área de estudo encontrava-se degradada devido ao lançamento contínuo de efluentes na baía de Santos, Rios Cubatão, Mogi, etc com fontes difusas de emissão de mercúrio, além da ocupação urbana e industrial, muito próximas. $O$ mercúrio achava-se associado à matéria-orgânica nos sedimentos enquanto nos lodos era praticamente nula a influência em seu comportamento. Concluíram também, que os óxido-hidróxidos ( $\mathrm{Fe}$ e Al) pouco contribuíam para a fixação do mercúrio nos sedimentos, mas eram decisivos nos lodos. A força iônica tinha influência na mobilidade e com relação ao mercúrio, apenas nos locais sujeitos à variação da maré.

Hortellani et al (2005), avaliaram as concentrações de mercúrio nos sedimentos provenientes do sistema estuarino Santos - São Vicente, em 31 amostras de sedimentos com tamanhos de partículas inferiores a $0,05 \mathrm{~mm}$ e moídas na fração < 80 mesh. Foi observado que as concentrações variaram de 0,04 a $1,19 \mathrm{mg} \mathrm{kg}^{-1}$, de modo que $90 \%$ das amostras analisadas apresentaram concentrações acima do critério estabelecido pela legislação Canadense e adotado pela CETESB.

Abessa et al (2005) estudaram a influência do emissário submarino situado na baía de Santos. Verificaram que esse emissário era uma fonte potencial de contaminantes aos ecosistemas marinhos adjacentes. Verificaram que no local do emissário os sedimentos tendiam a ser mais finos, organicamente enriquecidos e exibiram altos teores de surfactantes e metais, excedendo os níveis de TEL.

Aguiar (2005), estudou a variabilidade sazonal e temporal de fósforo em um gradiente de salinidade no sistema estuarino de Santos/São Vicente. Constatou que esse sistema era extremamente degradado devido à descarga contínua de efluentes domésticos e industriais. Observou também que no 
Canal de Santos, a contaminação por formas inorgânicas de P predominavam, enquanto no Canal de São Vicente, predominava a forma orgânica. Concluiu que a remoção de $\mathrm{P}$ através da produção biológica era mínima, uma vez que a concentração de biomassa no sistema era muito pequena.

Luiz-Silva et al (2006) estudaram a variabilidade espacial e sazonal da concentração de elementos traço em sedimentos, do sistema estuarino de Santos-Cubatão. Verificaram uma maior concentração de $\mathrm{Hg}$ nos sedimentos do rio Cubatão e os demais elementos, nos sedimentos do rio Morrão. Os elementos com concentrações anômalas identificados neste trabalho $\mathrm{Cd}, \mathrm{Cr}$, $\mathrm{Cu}, \mathrm{Hg}, \mathrm{Mn}, \mathrm{Ni}, \mathrm{Pb}$ e $\mathrm{Zn}$ eram oriundos de várias fontes antrópicas.

Cesar et al (2006) avaliaram a qualidade de seis estações no sistema estuarino e portuário de Santos e São Vicente, usando testes de toxicidade aguda com anfípodos (Tiburonella viscana) em sedimentos e análises químicas de metais, PCB e PAH. Foram observados níveis de contaminação mais altos na porção interna do estuário onde se localiza o porto de Santos e a zona industrial. Os testes de toxicidade mostraram resultados adversos significantes para a maioria das amostras testadas e os sedimentos da porção interna do estuário, apresentaram toxicidade mais elevada. As análises de componentes principais indicaram uma relação forte entre contaminação do sedimento e toxicidade.

Quinaglia (2006) avaliou a concentração de metais nos sedimentos do sistema estuarino da Baixada Santista, de modo a estabelecer os níveis basais de diversos elementos, além de avaliar a distribuição das concentrações de metais em duas diferentes frações granulométricas $(<2,00 \mathrm{~mm}$ e $<63 \mu \mathrm{m})$. Observou-se que na maioria dos casos, a fração mais fina $(<63 \mu \mathrm{m})$ incorporou maior quantidade de metais que a fração total $(<2,00 \mathrm{~mm})$. Foram avaliadas diferentes metodologias para a determinação de metais por técnicas espectrométricas, a partir dos métodos de digestão EPA $3051^{\text {a }}$ (com $\mathrm{HNO}_{3}$ e $\left.\mathrm{HNO}_{3}+\mathrm{HCl}\right)$, EPA $3052\left(\mathrm{com} \mathrm{HNO}_{3}+\mathrm{HCl}+\mathrm{HF}\right)$.

Sousa et al (2007) avaliaram a qualidade dos sedimentos do Canal de Santos e das áreas de disposição atuais e antigas, utilizando testes de 
toxicidade integral nos sedimentos com anfípodos e de toxicidade de elutriatos com embriões de ouriço do mar. Realizaram também as análises do tamanho das partículas pelo método proposto por Suguio (1973). Carbono orgânico total (COT), nitrogênio total e compostos de enxofre foram determinados pelo analisador LECO CNS 2000. Os resultados obtidos mostraram que os sedimentos apresentavam evidências de degradação em sua qualidade, porém sugeriram que novos estudos deveriam ser conduzidos visando determinar as relações entre contaminação e toxicidade. Os resultados sugeriram ainda que a disposição dos sedimentos dragados deveria ser reavaliada.

Martins et al (2007) estudaram a correlação entre a presença de hidrocarbonetos antropogênicos e susceptibilidade magnética em testemunhos de sedimentos no estuário de Santos.

Fukumoto (2007) realizou o estudo do histórico da contaminação da região do Alto Estuário Santista por metais tóxicos e a avaliação da aplicabilidade da suscetibilidade magnética na detecção de anomalias geoquímicas, a partir das análises de três testemunhos coletados próximos a fontes de poluição. O teor de metais foi determinado pela técnica de ICP OES, onde foi evidenciado que os elementos $\mathrm{Pb}, \mathrm{Cu}, \mathrm{Cr}$ e $\mathrm{Zn}$ apresentaram uma tendência de aumento da concentração em direção ao topo dos testemunhos, porém os maiores teores não ocorreram na superfície, e sim a alguns centímetros de profundidade.

Oliveira et al (2007) documentaram a presença de elementos terras raras (ETR) como traçadores de contaminação por fosfogesso de sedimentos no estuário de Santos, devido as industrias de produção de fertilizantes em Cubatão. As amostras contaminadas apresentaram composição química afetada pela presença de fosfogesso com altas concentrações de ETR, Ba, Zr e Th e um grau de fracionamento de ETR mais acentuado. Os autores verificaram também que os sinais do fosfogesso diminuíam rapidamente com a corrente, indicando para uma área limitada de influencia das estacas de fosfogesso presentes a céu aberto nas proximidades das indústrias de fertilizantes. 
Machado et al (2008) também verificaram anomalias antropogênicas de radionuclídeos e elementos maiores, em um testemunho de sedimentos coletado no rio Morrão. Foram encontrados níveis de $\mathrm{P}(>3,4 \%)$, $\mathrm{Ca}(>6,1 \%)$, ${ }^{226} \mathrm{Ra}\left(>744 \mathrm{~Bq} \mathrm{~kg}^{-1}\right)$ e ${ }^{210} \mathrm{~Pb}\left(>1317 \mathrm{~Bq} \mathrm{~kg}^{-1}\right)$ com pelo menos uma ordem de magnitude acima dos níveis naturais.

Luiz-Silva et al (2008) estudaram o histórico da contaminação e as fontes de 38 elementos em sedimentos do sistema estuarino de SantosCubatão. A composição de um testemunho de $260 \mathrm{~cm}$ de profundidade do estuário do rio Morrão foi feita pela técnica de ICP-MS e a avaliação dos dados foi feita por meio de fatores de enriquecimento, análise de componentes principais, matrizes de correlação e assinaturas geoquímicas. Esse estudo contribuiu com dados de concentração de metais em sedimentos em níveis de base (background), ou seja, antes da contaminação do local por fontes antropogênicas.

Hortellani et al (2008), realizaram um estudo para avaliar a contaminação dos sedimentos aquáticos do estuário Santos e São Vicente por alguns elementos metálicos, utilizando-se da normalização com o teor de $\mathrm{Al} \mathrm{e}$ comparação com critérios indicativos da qualidade dos sedimentos descritos na literatura. Os elementos $\mathrm{Cd}, \mathrm{Co}, \mathrm{Hg}, \mathrm{Ni}, \mathrm{Pb}$ e $\mathrm{Zn}$ foram determinados utilizandose um espectrômetro de absorção atômica marca Varian (modelo- Spectra AA220-Fast Sequencial), após lixiviação dos sedimentos com uma mistura de ácidos grau p.a. e isentos em $\mathrm{Hg}$, sob refluxo, para se evitar perdas de elementos voláteis, como $\mathrm{Zn}$ e $\mathrm{Hg}$.

Nizoli et al (2009), investigaram o potencial de biodisponibilidade sazonal (inverno e verão) de seis metais $(\mathrm{Hg}, \mathrm{Cu}, \mathrm{Pb}, \mathrm{Cd}, \mathrm{Zn}$ e $\mathrm{Ni}$ ), considerando sedimentos em diferentes profundidades do estuário do Rio Morrão (sistema estuarino de Santos-Cubatão), pela técnica de ICP OES. Foi verificado o papel dos sulfetos volatilizados por acidificação (acid volatile sulfide - AVS) na imobilização destes metais, assim como a influência de outros parâmetros, como granulometria dos sedimentos, pH, Eh e matéria orgânica. Concluíram que se fossem considerados os monosulfetos como as principais 
fases controladoras do potencial de biodisponibilidade de metais em estuários, os sedimentos estudados apresentavam perigo à biota ali existente.

Gonçalves (2009), estudando a sazonalidade geoquímica em águas intersticiais, superficiais e sedimentos estuarinos de Cubatão, sugeriu que existem diferenças sazonais nas concentrações de metais e As para o estuário do rio Morrão, tanto em águas superficiais e intersticiais como em sedimentos. Dentre outras conclusões, foi observado que elementos que possuem alto potencial tóxico tiveram variações em suas concentrações no verão e no inverno e o As, apresentou concentrações inferiores no inverno em relação ao verão. Os elementos $\mathrm{Ni}$ e $\mathrm{Zn}$ apresentaram tendência de maior concentração (água e sedimento) durante o verão.

Damatto (2010) analisou diferentes perfis de sedimentos coletados no Estuário de Santos-Cubatão, estuário de São Vicente, canal de Bertioga e baía de Santos, para avaliar o impacto ambiental na região. Observou que o elemento As apresentou valores acima de TEL nos ecossistemas estudados; 0 elemento $\mathrm{Cr}$ apresentou valores maiores que TEL em todos os ecossistemas estudados, com exceção do perfil Largo da Pompeba do estuário de São Vicente; o elemento $\mathrm{Zn}$ ultrapassou o valor de TEL apenas em algumas fatias de cinco perfis analisados. As concentrações de As, Cr e Zn não ultrapassaram o valor de PEL em nenhum dos ecossistemas estudados.

Silva et al (2011), realizaram um estudo para determinar os níveis basais dos elementos $\mathrm{As}, \mathrm{Br}, \mathrm{Ce}, \mathrm{Cs}, \mathrm{Co}, \mathrm{Cr}$, Eu, Fe, Hf, La, Lu, Nd, Rb, Sb, Sc, Se, Sm, Ta, Tb, Yb e Zn na região da Baixada Santista, utilizando a técnica de NAA em amostras de testemunhos de sedimentos, com variação de profundidade de 50 a $100 \mathrm{~cm}$. Foi observado que a região contém indicadores de contribuição antrópica. A técnica de normalização dos dados geoquímicos e a realização da analise estatística multivariada foram utilizadas para determinar os valores de referência para os elementos analisados nos sedimentos da região estudada, considerando a fração total.

Bordon et al (2011) também determinaram a concentração de metais ( $\mathrm{Al}, \mathrm{Cd}, \mathrm{Cr}, \mathrm{Co}, \mathrm{Cu}, \mathrm{Fe}, \mathrm{Hg}, \mathrm{Mn}, \mathrm{Ni}, \mathrm{Pb}$ e $\mathrm{Zn}$ ) em amostras de sedimentos 
superficiais desse sistema estuarino e concluíram que a contaminação por metais ainda existe, e se constitui em um problema para o ecossistema desse estuário.

\subsection{Sistema estuarino-lagunar de Cananéia Iguape}

O complexo estuarino-lagunar de Cananéia-Iguape, com aproximadamente $75 \mathrm{~km}$ de extensão, é constituído por um sistema de quatro corpos d água em torno de 4 ilhas: Comprida, Cananéia, Cardoso e Iguape. Os corpos d'água que circundam as ilhas são: Mar de Cananéia, entre as ilhas de Cananéia e Comprida, Baía de Trapandé, entre as ilhas do Cardoso e Cananéia, Mar de Itapitangui e Cubatão, entre o continente e a ilha de Cananéia, e canal do Ararapira, entre a ilha do Cardoso e o continente (Aguiar, 2005).

A região de Cananéia-lguape é considerada um dos maiores berçários de vida marinha do mundo tendo importância singular, não só para a sobrevivência de diversas espécies, mas também como fonte de renda para inúmeras famílias que vivem no seu entorno. A porção mais preservada do sistema é a área situada entre Cananéia e Paranaguá. A região de CananéiaIguape é considerada Área de Proteção Ambiental (APA) (Bernardes, 2001) e, em 1999, recebeu o título de Patrimônio da Humanidade pela UNESCO. No entanto, a região do Vale do Ribeira, como um todo, foi palco de intensa atividade de mineração e o refino de metais, até 1996, quando a empresa Plumbum e as últimas minas de chumbo foram fechadas, deixando importante passivo ambiental. Essa região abrigou várias minas de chumbo, zinco e prata, que estiveram em atividade de 1945 a 1995. Vários estudos comprovaram que a bacia do Ribeira foi extremamente afetada pelas atividades de refino e mineração, pela contaminação de sedimentos fluviais por chumbo, zinco, cobre e arsênio e, mais esporadicamente, pelo registro de elevadas concentrações de metais na água. 
Saito et al (2001) avaliaram os níveis de $\mathrm{Pb}, \mathrm{Cu}$ e $\mathrm{Zn}$ em testemunhos de sedimentos coletados em 4 pontos do estuário de CananéiaIguape. Os intervalos de concentração para esses metais foram: 3 a $166 \mathrm{mg}$ $\mathrm{kg}^{-1}(\mathrm{~Pb}), 3$ a $44 \mathrm{mg} \mathrm{kg}^{-1}(\mathrm{Cu})$ e 8 a $133 \mathrm{mg} \mathrm{kg}^{-1}(\mathrm{Zn})$. O testemunho de sedimentos coletado no Valo Grande apresentou as maiores concentrações para esses metais mostrando a influência do rio Ribeira de lguape nesse sistema. As concentrações mais baixas foram obtidas para o testemunho coletado na Ponta do Frade. Os autores concluíram que, aparentemente, estava ocorrendo uma diminuição na concentração de $\mathrm{Pb}$ que se deposita nos sedimentos mais superficiais da área mais afetada.

Cunha (2003) estudando a região, concluiu que embora as atividades de mineração e metalurgia tenham cessado em 1996, as populações dessa região ainda convivem com várias fontes de contaminação ambiental, em especial o chumbo e o arsênio, tipicamente originados da atividade de extração, beneficiamento e refino mineral. As emissões de metais para a atmosfera, durante décadas de funcionamento da refinaria, e a subsequente deposição de particulados, foram responsáveis pela contaminação de solos e sedimentos nessa região.

Barcellos et al (2005) investigaram a distribuição e composição do fósforo sedimentar (total, inorgânico e orgânico) e sua relação com o carbono, através da razão $\mathrm{C} / \mathrm{P}$, no sistema estuarino-lagunar de Cananéia-Iguape. Foi possível observar que os maiores teores de fósforo apresentaram expressiva correlação com os sedimentos ricos em conteúdos de pelitos e eram compatíveis com os teores observados em outros ambientes estuarinos tropicais e subtropicais do globo terrestre.

Semensatto-Jr et al (2007) determinaram a concentração de metais e não-metais em sedimentos de um manguezal não-poluído, Ilha do Cardoso, Cananéia. Os autores analisaram a distribuição espacial, distribuição sazonal de metais e não-metais, e também as variáveis físico-químicas nesses sedimentos. Os elementos, determinados por ICP OES, foram os seguintes: Al, $\mathrm{Ba}, \mathrm{Ca}, \mathrm{Cd}, \mathrm{Co}, \mathrm{Cr}, \mathrm{Cu}, \mathrm{Fe}, \mathrm{K}, \mathrm{Mg}, \mathrm{Mn}, \mathrm{Na}, \mathrm{Ni}, \mathrm{P}, \mathrm{S}, \mathrm{V}$ e Zn. 
Maluf (2009) estudou as características hidrológicas e hidroquímicas das águas de superfície e fundo, do complexo estuarino lagunar de CananéiaIguape com coletas realizadas em dois períodos sazonais (outono e primavera). Foram avaliados os metais $\mathrm{Zn}, \mathrm{Cd}$ e $\mathrm{Pb}$, pela técnica de voltametria por redissolução anódica. Foi observado que as concentrações dos metais traço estiveram sempre abaixo dos limites propostos pela legislação ambiental brasileira (CONAMA) e norte-americana (EPA USA).

Mahiques et al (2009), determinaram as variações ambientais no sistema lagunar Cananéia-Iguape, causadas pela abertura do canal artificial, através da análise das camadas superiores da coluna sedimentar de um testemunho coletado no sistema. As concentrações de $\mathrm{Pb}$ no testemunho coletado indicaram valores duas vezes maiores do que os medidos em sedimentos contaminados do estuário de Santos, situado na zona costeira mais industrializada do Brasil. A análise do tamanho de partículas foi realizado a partir do uso do Malvern Mastersizer 2000 Laser Analyser. A matéria orgânica total foi determinada pela diferença de massa antes e após calcinação em mufla a $550^{\circ} \mathrm{C}$, por 2 horas. $\mathrm{O}$ carbonato foi determinado pela diferença de massa antes e após a acidificação de cada amostra com $\mathrm{HCl} 1,0 \mathrm{~N}$. As análises dos elementos $\mathrm{Al}, \mathrm{Sc}, \mathrm{Cu}, \mathrm{Pb}$, e $\mathrm{Zn}$ foram realizadas por ICP OES, seguindo os procedimentos descritos no método EPA 3050b. Dentre as conclusões, os autores destacaram o fato de que a entrada de metais tóxicos, especialmente $\mathrm{Pb}$, não terminou após o encerramento das atividades da empresa Plumbum S/A em 1996, e é possível que a entrada dos metais nos sedimentos do rio Ribeira ainda ocorrem devido ao desgaste das pilhas de escória que ainda estão presentes na bacia de drenagem.

Armelin \& Saiki (2009) determinaram os elementos Al, As, Ba, Br, $\mathrm{Cs}, \mathrm{Eu}, \mathrm{K}, \mathrm{La}, \mathrm{Mn}, \mathrm{Sb}, \mathrm{Sc}, \mathrm{Sm}, \mathrm{Th}, \mathrm{Ti}, \mathrm{U}$ e V em testemunho de sedimento de $200 \mathrm{~cm}$ coletado no litoral Sul do estado de São Paulo, que compreende a região de Cananéia. Destacaram que ocorreu um decréscimo abrupto na concentrações de todos os elementos na camada de profundidade 132 - 134 $\mathrm{cm}$, o que indica a presença de impacto devido à atividade antrópica. 
Figueira et al (2011) realizaram o estudo da disponibilidade dos metais em sedimentos do sistema estuarino-lagunar de Cananéia-Iguape, a partir das análises da fração solúvel em ácido, fração redutível, fração oxidável e a fração residual. Concluíram que a ordem de mobilidade dos elementos, ou seja, do mais para o menos disponível era $\mathrm{Pb}>\mathrm{Zn}>\mathrm{Cu}$. Ainda em relação ao $\mathrm{Pb}$, observaram que os teores eram mais elevados na fração redutível, onde estão associados a óxidos de Fe e Mn. 


\section{CAPÍTULO 3}

\section{METODOLOGIAS ANALÍTICAS}

Descrevem-se a seguir, considerações teóricas sobre as técnicas analíticas utilizadas no presente estudo: AAS (GF AAS e CV AAS), ICP OES e NAA.

\subsection{Espectrometria de Absorção Atômica}

Atualmente, a espectrometria de Absorção Atômica é uma técnica amplamente utilizada em laboratórios de pesquisa, de aplicações e de controle de qualidade para a determinação de diversos elementos em diferentes tipos de matrizes (CORREIA et al, 2003).

Dentre as principais aplicações da técnica, podemos destacar:

- Análises Clínicas: São realizadas análises em fluídos biológicos como urina e sangue (HALLS et al, 1981; HORNG et al, 1996; DUTRA et al, 2004; FABRINO, 2008; GUILHEN et al, 2010).

- Análises Ambientais - São realizadas pesquisas de vários elementos em amostras de águas de rios, água marinha, água potável, petróleo, sedimentos, solos, etc. (PINTO et al, 2009; ANJOS, 2006; HORTELLANI et al, 2008; FERREIRA, 2005).

- Análise de Fármacos - Em alguns processos de fabricação de produtos farmacêuticos, podem ser encontrados contaminantes metálicos e estes não devem estar presentes no produto final, sendo então necessária a sua identificação para as providencias cabíveis (MOREIRA, 2002). 
- Análise de Produtos Industrializados como alimentos e bebidas, pode ser afetada por alguns constituintes inorgânicos. Por exemplo, no processo de produção do vinho os elementos como $\mathrm{Ca}, \mathrm{K}, \mathrm{Al}, \mathrm{Cu}, \mathrm{Mg} \mathrm{e}$ $\mathrm{Na}$, influenciam a estabilidade, a cor e a limpidez do produto final. A monitoração dos teores de íons metálicos e seus compostos também são importantes, devido às suas características essenciais ou tóxicas aos organismos vivos (SPAZIANI et al, 2006; QUINAIA \& NOBREGA, 2000).

Além da vasta gama de aplicações, o espectrômetro de Absorção Atômica se destaca pela simplicidade de sua construção, conforme demonstrado na Figura 3.1. Os componentes principais do equipamento são a fonte de radiação $(A)$, a qual emite as linhas espectrais características do elemento de interesse; um atomizador (B), no qual ocorre a formação dos átomos da amostra a ser analisada, pela dissociação molecular térmica; um monocromador (C) para a dispersão da radiação em vários comprimentos de onda até $\mathrm{o}$ isolamento do comprimento de onda necessário na grade de difração (D); a fotomultiplicadora (E), que tem a função de converter os fótons em sinais elétricos (CORREIA et al, 2003).

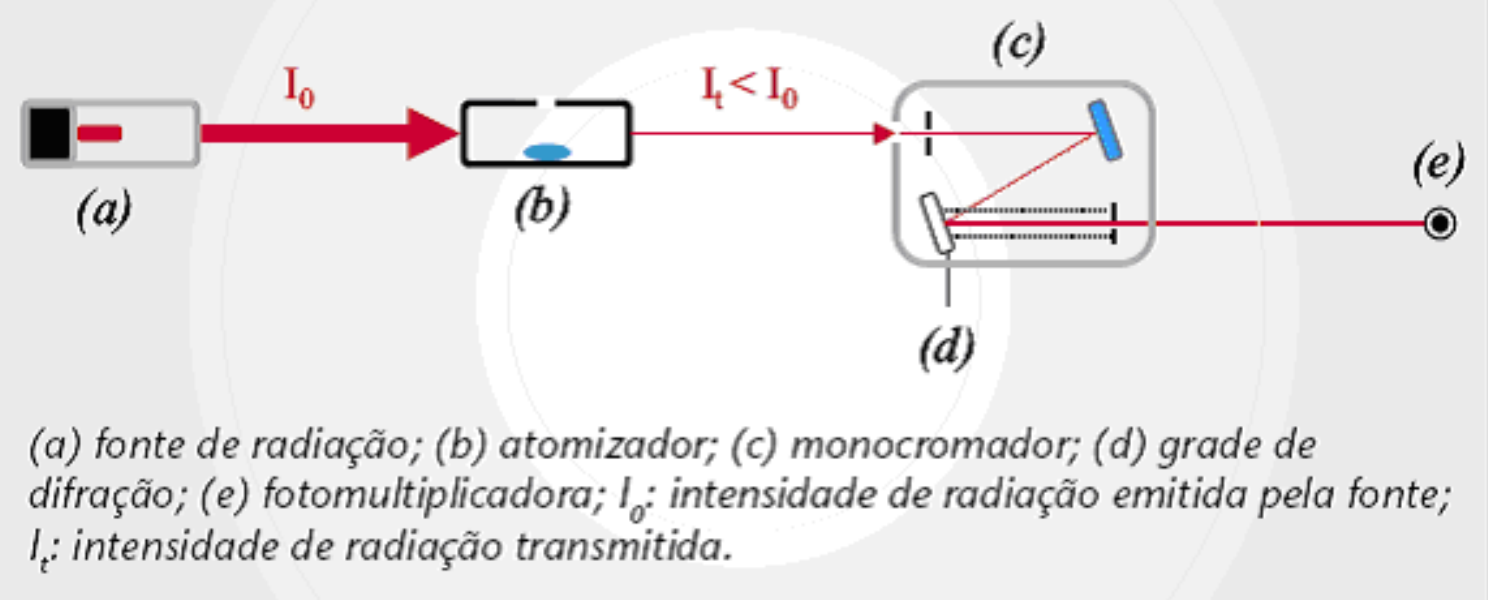

Figura 3.1- Configuração tradicional do espectrômetro de absorção atômica mono-elementar (Fonte: Correia et al, 2003) 
A técnica de Absorção Atômica pode ser dividida nas seguintes vertentes: Absorção Atômica com Chama (FAAS), Absorção Atômica com Forno de Grafite (GF AAS), Absorção Atômica com Geração de Hidretos (HG AAS) e a Absorção Atômica com Geração de Vapor Frio (CV AAS).

No presente estudo, foram utilizadas as técnicas GF AAS, para a determinação de $\mathrm{Cd}$ e $\mathrm{Pb}$ e a técnica CV AAS, para a determinação de $\mathrm{Hg}$.

\subsubsection{GF AAS}

A técnica de GF AAS é uma técnica extremamente poderosa no que diz respeito à sua elevada sensibilidade, seletividade, à pequena quantidade de amostra necessária para realizar a análise e a possibilidade de tratamento térmico da amostra durante o programa de aquecimento, tornando possível introduzir amostras na forma sólida ou de suspensões (CORREIA et al, 2003).

Atualmente, existem diversos métodos bem estabelecidos para diferentes tipos de matrizes. Entretanto, a característica de análise monoelementar, aliada a fatores como os tempos longos dos programas de aquecimento, custo dos tubos de grafite e reagentes de alta pureza, possam em alguns casos, inviabilizar o uso desta técnica, devido principalmente ao custo de operação, ou mesmo se a frequência analítica é um parâmetro a ser considerado (CORREIA et al, 2003).

Conceitualmente, a técnica GF AAS foi consolidada após algumas inovações instrumentais e experimentais, que resultaram no conceito STPF (Stabilized Temperature Platform Furnace), que na realidade é um conjunto de requisitos que asseguram uma condição adequada para a análise, minimizando efeitos de interferentes e alcançando uma maior sensibilidade analítica (CORREIA et al, 2003).

A Tabela 3.1, apresenta os requisitos instrumentais e operacionais necessários para atender as condições STPF. 
Tabela 3.1 Condições STPF (Stabilized Temperature Platform Furnace)

\begin{tabular}{|c|c|}
\hline Condições STPF & Resultado obtido \\
\hline Tubo de grafite com plataforma de L'vov & $\begin{array}{l}\text { Estabelecimento de um ambiente quase } \\
\text { isotérmico durante a atomização }\end{array}$ \\
\hline $\begin{array}{c}\text { Sinais de absorbância registrados em } \\
\text { área }\end{array}$ & $\begin{array}{l}\text { Minimização dos efeitos das variações } \\
\text { cinéticas do processo de atomização }\end{array}$ \\
\hline $\begin{array}{l}\text { Atomizador construído com grafite } \\
\text { pirolítico }\end{array}$ & $\begin{array}{l}\text { Redução de perdas por difusão através } \\
\text { da parede do atomizador }\end{array}$ \\
\hline $\begin{array}{l}\text { Aquecimento transversal do tubo de } \\
\text { grafite }\end{array}$ & $\begin{array}{l}\text { Estabelecimento de um ambiente } \\
\text { espacialmente isotérmico }\end{array}$ \\
\hline $\begin{array}{l}\text { Correção da radiação de fundo por efeito } \\
\text { Zeeman }\end{array}$ & Correção das interferências espectrais \\
\hline Utilização de modificador químico & $\begin{array}{l}\text { Aumento da eficiência do tratamento } \\
\text { térmico durante a pirólise }\end{array}$ \\
\hline $\begin{array}{l}\text { Interrupção do fluxo de gás durante a } \\
\text { atomização }\end{array}$ & $\begin{array}{l}\text { Aumento do tempo de residência da } \\
\text { nuvem atômica na zona de observação }\end{array}$ \\
\hline $\begin{array}{l}\text { Elevada taxa de aquecimento do tubo de } \\
\text { grafite }\end{array}$ & $\begin{array}{l}\text { Redução de interferência na fase vapor e } \\
\text { formação de uma densa nuvem atômica }\end{array}$ \\
\hline $\begin{array}{l}\text { Eletrônica adequada para permitir a } \\
\text { integração do sinal transiente }\end{array}$ & $\begin{array}{l}\text { Obtenção do registro dos sinais de } \\
\text { absorbância em tempo real }\end{array}$ \\
\hline
\end{tabular}

Fonte: Correia et al, 2003 


\subsubsection{AAS}

A técnica de Espectrometria de Absorção Atômica com Geração de Vapor Frio (CV AAS) é a metodologia mais popular para a determinação de mercúrio em vários tipos de amostras (IUPAC, 1998).

O Hg é o único entre os metais que possui uma alta pressão de vapor a temperaturas relativamente baixas, e devido a esta característica, o $\mathrm{Hg}$ pode ser introduzido quantitativamente para o espectrômetro em forma de vapor sem dificuldades. A absorção em 253,7 nm, na região do ultravioleta pode ser determinada com o uso de lâmpadas de cátodo oco como fonte de mercúrio (IUPAC, 1998).

O processo para liberar $\mathrm{o} \mathrm{Hg}$ de uma solução aquosa ou de amostras digeridas é a redução química, seguida pela volatilização e introdução do $\mathrm{Hg}$ no sistema analítico, utilizando argônio ou nitrogênio como gás de arraste, e cloreto estanoso como agente redutor (IUPAC, 1998). A equação 3.1 apresenta a reação química com a formação do Hg volátil:

$$
\mathrm{Hg}^{2+}+\mathrm{Sn}^{2+} \rightarrow \mathrm{Hg}^{0}+\mathrm{Sn}^{4+}
$$

(Equação 3.1)

Os átomos de mercúrio formados são introduzidos na cela de absorção, a qual é mantida no percurso ótico do espectrômetro de absorção atômica. A quantidade de energia absorvida é proporcional à quantidade do elemento de interesse na amostra. A quantificação do metal se dá, com a comparação do sinal analítico obtido na leitura da amostra, com uma curva analítica (BACCAN, 1994; PERKIN ELMER, 1996).

A grande vantagem desta técnica está na sensibilidade, em comparação com o método de atomização por chama, pois todo o mercúrio da solução é quimicamente atomizado e transportado para a cela. Em geral os níveis de detecção desta técnica, atingem concentrações inferiores a $0,1 \mu \mathrm{g} \mathrm{L}^{-1}$ (BACCAN, 1994). 
Mais recentemente, a EPA USA (US EPA, 2007) em seu método 7473 descreve uma metodologia para análises de $\mathrm{Hg}$ em amostras aquosas e sólidas de forma direta. A decomposição térmica da amostra e a detecção por absorção atômica reduz o tempo total de análise, para a maioria das amostras, para menos de 5 minutos.

O DMA-80 (Direct Mercury Analyser) é um equipamento de termodecomposição e deteç̧ão por espectrometria de absorção atômica específico para determinação de mercúrio. (DURÃO JUNIOR, 2010).

\subsection{Espectrometria de Emissão Atômica com Plasma Indutivamente Acoplado (ICP OES)}

A versatilidade da técnica de ICP OES provém uma grande variedade de aplicações, não somente devido ao grande número de elementos que podem ser determinados rapidamente em níveis traço, mas também devido à grande diversidade de matrizes que podem ser analisadas utilizando a técnica de ICP OES (BOSS \& FREDDEN, 1997).

Todas as matrizes, exceto amostras de águas subterrâneas filtradas, incluindo águas, amostras líquidas, extratos orgânicos, resíduos industriais, solos, lodos, sedimentos e outros resíduos sólidos, requerem um processo de digestão antes da análise (USEPA, 2007).

A técnica de ICP OES utiliza um plasma como fonte de atomização e excitação. O plasma é eletricamente neutro e é um gás altamente ionizado, que consiste de íons, elétrons e átomos. $O$ sol, raios e a aurora boreal são exemplos de plasmas encontrados na natureza. A energia que mantém um plasma analítico é derivada de um campo elétrico ou magnético, e não uma "chama". Vários plasmas operam com Argônio puro ou Hélio, nos quais uma combustão é impossível. Os plasmas são caracterizados por suas temperaturas, bem como suas densidades eletrônicas e iônicas. A temperatura 
usualmente encontrada em plasmas de instrumentos analíticos varia de 600 a $8.000 \mathrm{~K}$, podendo chegar a até $10.000 \mathrm{~K}$. Em comparação, a temperatura no interior do Sol é de milhões de graus, mas em sua superfície, a temperatura é de aproximadamente $10.000 \mathrm{~K}$ (MANNING \& GROW, 1997).

A Figura 3. apresenta as faixas de temperaturas típicas no plasma do ICP OES.

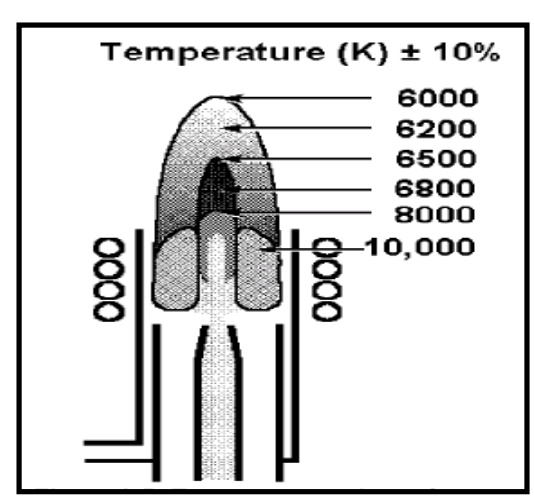

Figura 3.2 Distribuição da temperatura no plasma (Fonte: BOSS \& FREDDEN, 1997)

A fonte de emissão mais comum para medidas espectroscópicas é o Plasma Indutivamente Acoplado. A emissão decorre de uma mudança especifica de energia no sistema atômico. As regiões do espectro eletromagnético podem ser identificadas em termos de comprimento de onda $(\lambda)$ e freqüência (f). $O$ produto de ambos é igual à constante da velocidade da luz, conforme a equação 3.2 (relação entre comprimento de onda e frequência):

$$
c=f \lambda
$$

O comprimento de onda $(\lambda)$ normalmente é expresso em nanômetros $(n m)$ e a frequência $(f)$ em ciclos por segundo $\left(s^{-1}\right)$ ou hertz $(H z)$. A constante $\mathrm{c}$, da velocidade da luz é aproximadamente $3,00 \times 10^{8} \mathrm{~m} \mathrm{~s}^{-1}$.

A Figura 3. representa as regiões do espectro eletromagnético: 


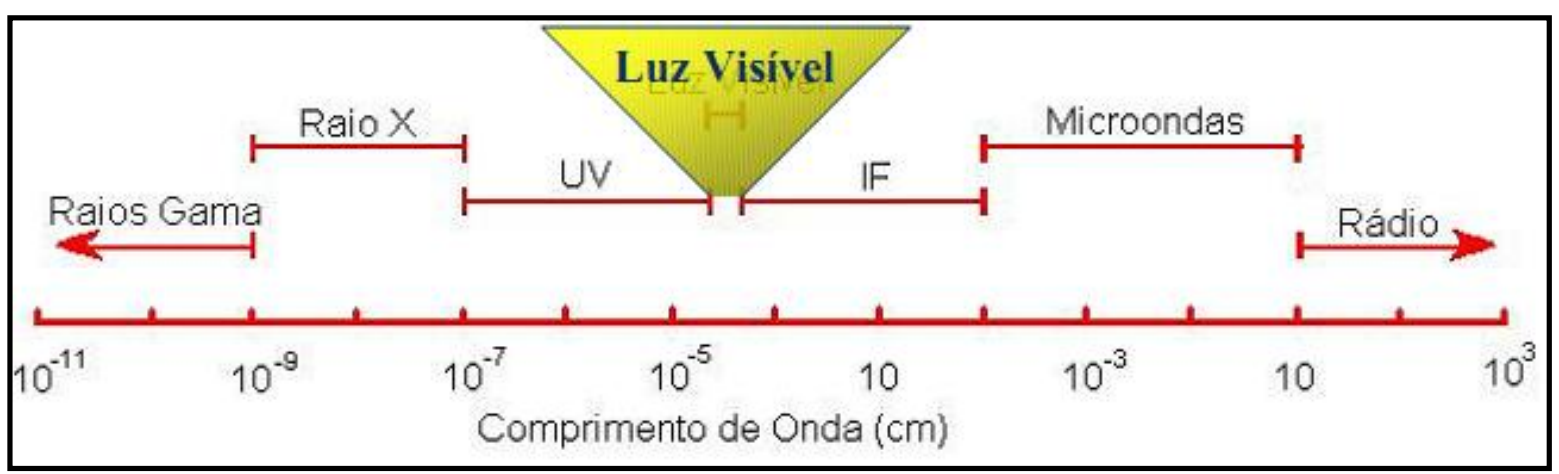

Figura 3.3 Regiões do espectro eletromagnético

Assim como a frequência e o comprimento de onda, a radiação eletromagnética também pode ser expressa em "pacotes" de energia (E), são os chamados fótons (DEAN, 2005). A energia de um fóton pode ser expressa em termos de frequência, como demonstra a equação 3.3:

$$
\mathbf{E}=\boldsymbol{h f} \quad \text { (Equação 3.3) }
$$

Onde h é a constante de Planck $\left(6,626 \times 10^{-34} \mathrm{~J} \mathrm{~s}\right)$. Pela substituição da equação 3.2 na equação 3.3 , é possível obter a equação relacionada diretamente ao comprimento de onda, como demonstrado na equação 3.4 :

$$
E=h c / \lambda
$$

(Equação 3.4)

A medida de absorção e emissão de uma radiação eletromagnética pode ser descrita de acordo com o modelo atômico de Bohr. O átomo é descrito como um núcleo rodeado por elétrons que viajam em torno deste núcleo em orbitais discretos. Cada um destes orbitais eletrônicos possui um nível de energia associado e, em geral, quanto mais distante do núcleo está o orbital, maior o nível de energia (BOSS \& FREDEEN, 1997).

Quando os elétrons de um átomo estão em orbitais próximos ao núcleo e menores energias envolvidas, o átomo está em seu estado estável, conhecido como estado fundamental. Quando são adicionadas energias ao átomo, como resultado de absorção de radiação eletromagnética ou uma colisão com outra partícula (elétron, átomo, íon ou molécula), um ou mais fenômenos possíveis irão ocorrer. Dois dos eventos mais prováveis são da 
energia ser utilizada para aumentar a energia cinética do átomo ou para o átomo absorver a energia e ser promovido ao estado excitado. A figura 3.4 apresenta o processo de excitação e decaimento no modelo atômico de Bohr. Como a energia é absorvida pelo átomo, um elétron é promovido a um orbital com maior nível energético. Quando ocorre o retorno ao estado de menor energia, o átomo libera um fóton, $h v$ (BOSS \& FREDEEN, 1997).

Quando um átomo se torna excitado, um elétron de um átomo no estado fundamental é promovido a um orbital com um maior nível de energia. Um átomo é menos estável em seu estado excitado, e tende a perder a energia através de uma colisão com outra partícula ou pela emissão de radiação eletromagnética, conhecida como fóton. Como resultado dessa perda de energia, o elétron retorna a um orbital mais próximo ao núcleo do átomo.

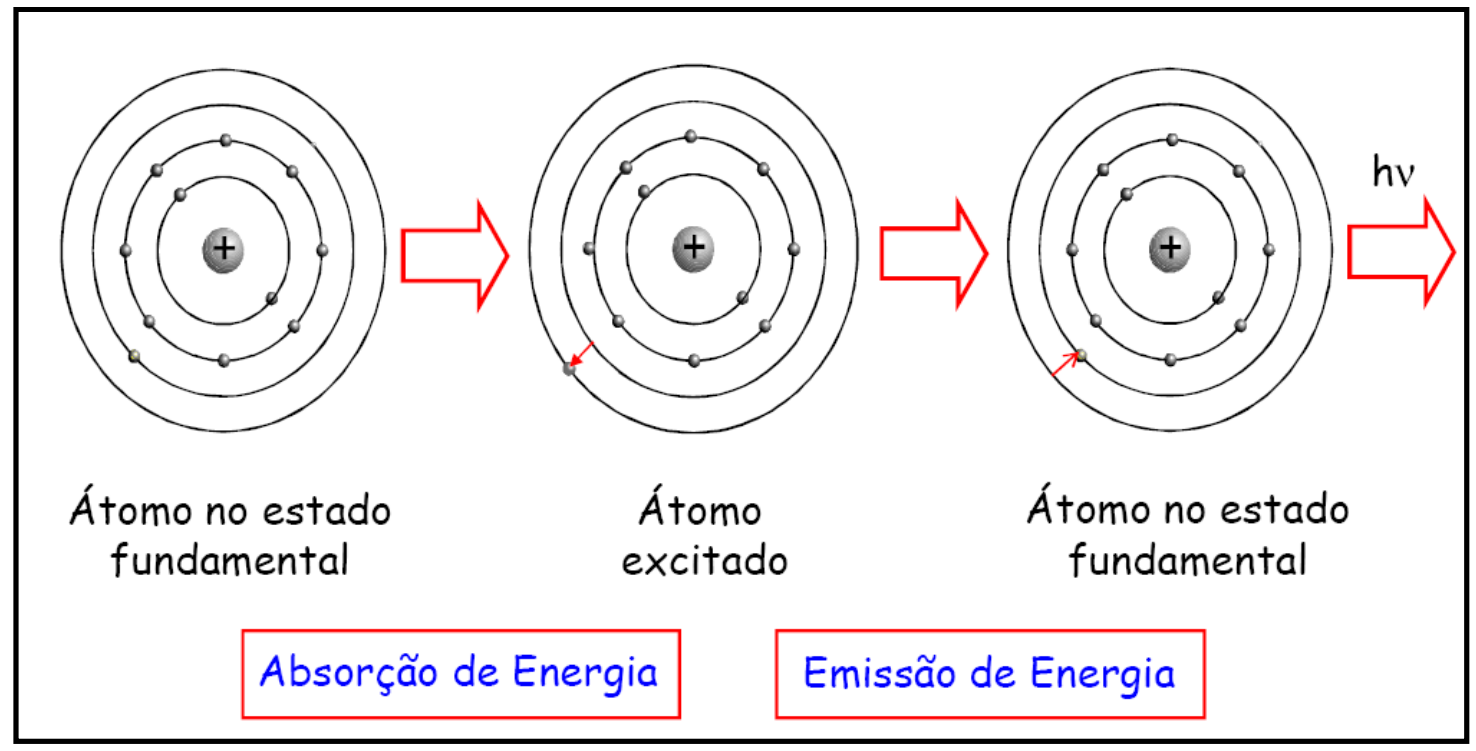

Figura 3.4 Modelo atômico de Bohr, com o fenômeno de absorção e emissão de energia.

Se a energia absorvida por um átomo é alta o suficiente, um elétron pode ser completamente dissociado do átomo, o que se torna um íon com carga positiva. A energia necessária para este processo, conhecida como ionização, é chamada de potencial de ionização e é diferente para cada 
elemento. Os íons também possuem estado fundamental e excitado, através do qual eles podem absorver e emitir energia pelos mesmos processos de excitação e de decomposição como um átomo (BOSS \& FREDEEN, 1997).

A figura 3.5 apresenta esquematicamente os processos de excitação, ionização e emissão. As linhas horizontais deste diagrama simplificado representam os níveis de energia de um átomo. As setas verticais representam as transições energéticas, ou mudanças na quantidade de energia de um elétron. As transições de energia em um átomo ou íon podem envolver absorção ou emissão de energia eletromagnética (radioativa), ou envolvendo transferência de energia através de colisões com outras partículas (térmica). A diferença entre os níveis superiores e inferiores de energia de uma transição radioativa definem o comprimento de onda da radiação envolvida na transição (BOSS \& FREDEEN, 1997).

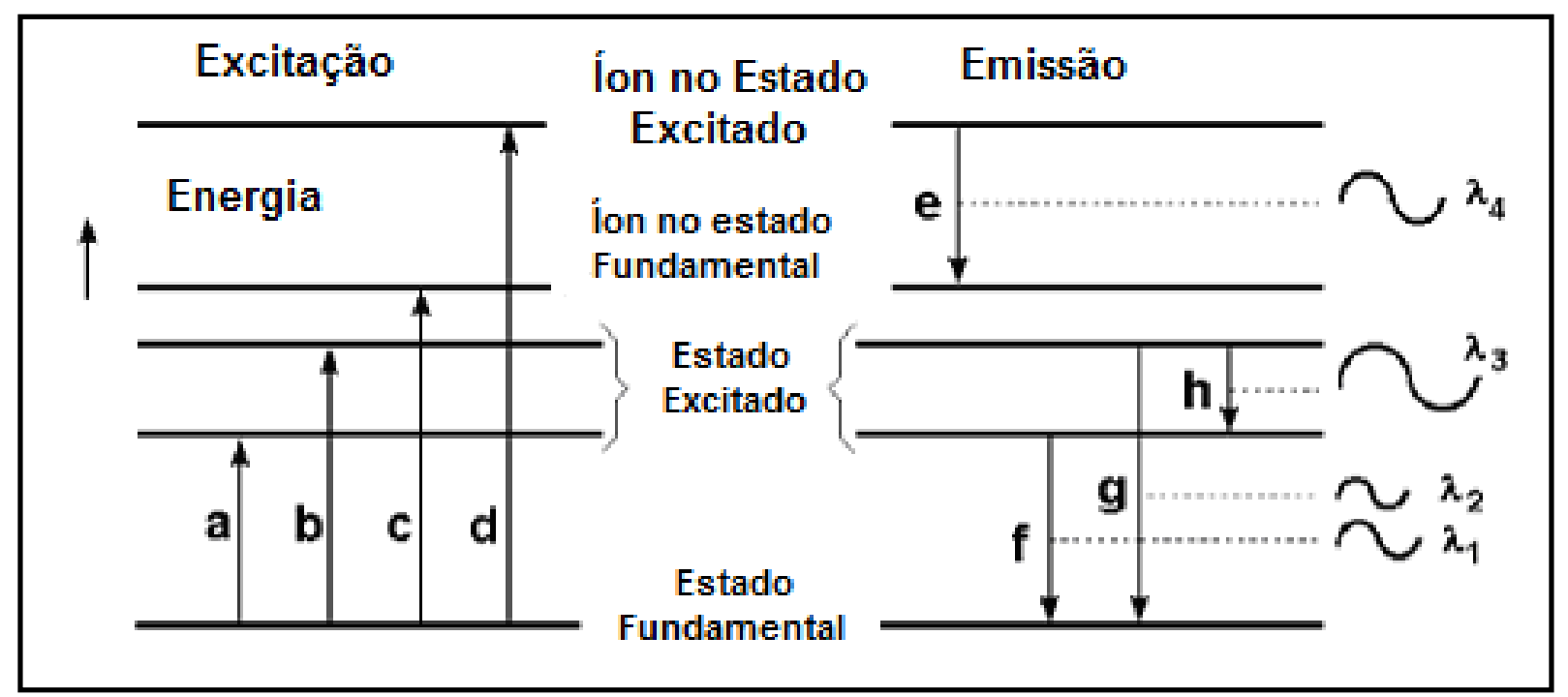

Figura 3.5 Diagrama de transições energéticas, onde "a" e "b" representam a excitação, "c" é a ionização, "d" é a ionização/excitação, "e" demonstra a emissão iônica, e "f", "g" e " $h$ " representam a emissão atômica

Na técnica de espectrometria de emissão ótica (OES), a amostra é submetida à alta temperatura que é suficiente para causar não só a 
dissociação dos átomos, mas para causar significativa quantidade de excitação por colisão (e ionização) dos átomos da amostra. Uma vez que os átomos ou íons estão em seus estados excitados, eles podem decair para estados mais baixos, através da radiação térmica ou transições de energia. A intensidade da luz emitida em comprimentos de onda específicos é utilizada para determinar as concentrações dos elementos de interesse (BOSS \& FREDEEN, 1997).

O funcionamento da descarga do plasma induzido indutivamente consiste no fluxo do gás Argônio, que é direcionado a uma tocha de quartzo com três tubos concêntricos, como demonstra a figura 3.6. Uma bobina de cobre envolve a parte final da tocha e é conectada ao gerador de radiofreqüência (BOSS \& FREDEEN, 1997).

Quando uma potência da radiofrequência (tipicamente entre 700 1500 watts) é aplicada à bobina de cobre, uma corrente alternativa gera uma alternância de movimentos dentro da bobina, a uma taxa correspondente a frequência do gerador. Na maioria dos instrumentos ICP, esta frequência é entre 27 a $40 \mathrm{MHz}$. Esta oscilação de corrente na radiofrequência faz com que sejam criados campos elétricos e magnéticos na parte superior da tocha. Com o gás argônio que está sendo inserido na tocha, uma faísca é aplicada ao gás, o que causa a liberação de alguns elétrons dos átomos de argônio. Estes elétrons são apanhados no campo magnético e então acelerados. A adição de energia para os elétrons através da utilização de uma bobina é conhecida como acoplamento indutivo (inductive coupling). Os elétrons de alta energia colidem com outros átomos de argônio, tirando ainda mais elétrons. Esta ionização colisional do gás argônio continua em uma reação em cadeia, o que irá decompor o gás em um plasma constituído por átomos de argônio, elétrons e íons de argônio, o que é conhecido como um plasma indutivamente acoplado.

A descarga é então sustentada dentro da tocha e da bobina, conforme a energia da radiofrequência é continuamente transferida através do processo de acoplamento indutivo (BOSS \& FREDEEN, 1997). 


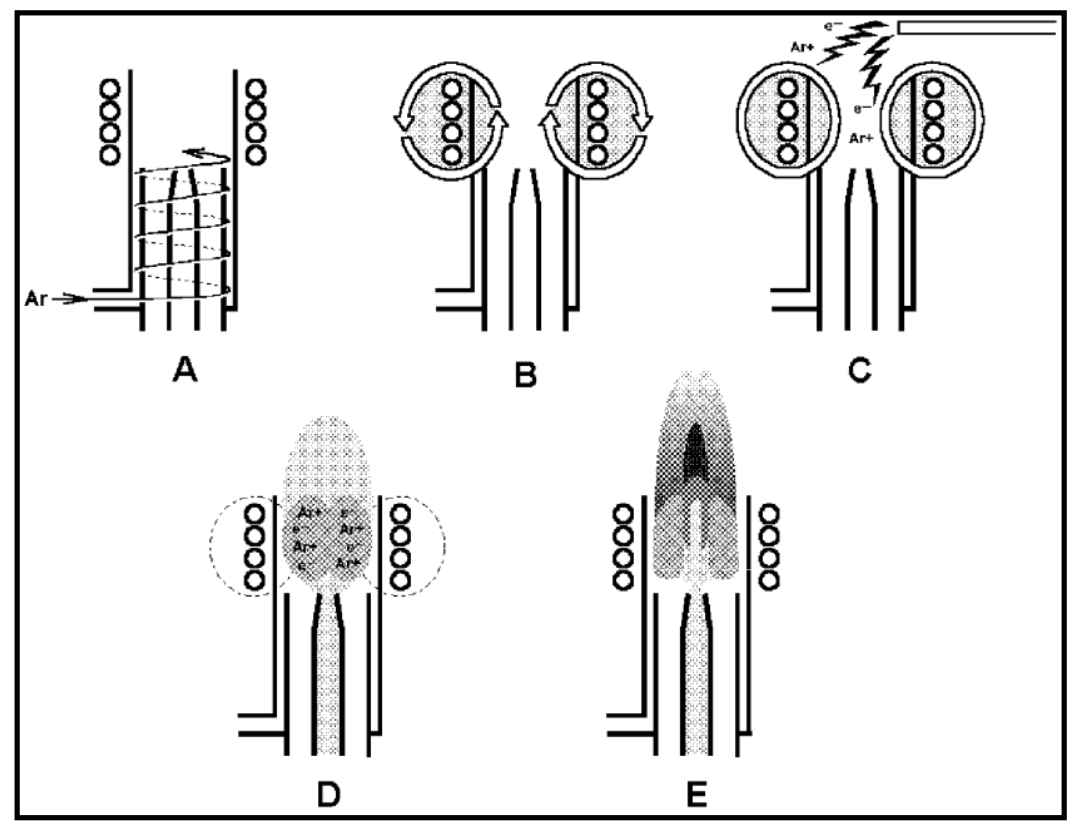

Figura 3.6 Seção transversal de uma tocha e uma bobina de ICP que descrevem uma seqüência de ignição. (Fonte: BOSS \& FREDEEN, 1997).

$\mathrm{Na}$ entrada "A", demonstrada na figura 3.6, o Argônio é inserido na tocha. Em "B", a potencia da Radiofrequência é aplicada a bobina de carga. "C" - uma faísca produz alguns elétrons livres no argônio. "D" - Os elétrons livres são acelerados por campos de Radiofrequência causado ionização e formando o plama. "E" - A amostra é inserida por um nebulizador até o plasma.

A maioria das amostras são nebulizadas em forma de aerossol, que consiste em uma névoa fina de gotículas da amostra, de modo a ser introduzida ao ICP. O aerossol da amostra é então levado ao centro do plasma, pelo fluxo de argônio (BOSS \& FREDEEN, 1997).

Resumidamente, as etapas básicas da análise por ICP OES consistem em:

1- Preparação das amostras: algumas amostras requerem etapas especiais de preparação, incluindo tratamento com ácidos, aquecimento e digestão por microondas.

2- Nebulização: o líquido é convertido em aerossol 
3- Dessolvatação/Volatilização: o solvente é seco, e as porções remanescentes de líquidos e sólidos são convertidas em gases.

4- Atomização: a fase gasosa é quebrada e ficam disponíveis apenas os átomos. A temperatura do plasma e o ambiente quimicamente inerte são fundamentais neste estágio.

5- Excitação/Emissão: os átomos ganham energia das colisões e emitem luz com comprimentos de onda característicos para cada elemento químico.

6- Separação/Detecção: a luz separada pela grade de difração é quantitativamente mensurada (MANNING et al, 1997).

No ICP OES, a luz emitida pelos átomos e íons excitados no plasma, é medida para obter informações sobre as amostras. Devido às espécies excitadas no plasma emitirem luz em diversos comprimentos de onda, a emissão do plasma é dita como policromática. Esta radiação policromática pode ser separada em comprimentos de onda individuais, para que a emissão de cada espécie excitada possa ser identificada e a intensidade possa ser medida sem interferências de emissões de outros comprimentos de onda. A separação da luz de acordo com cada comprimento de onda geralmente é feita utilizando um monocromador, que é utilizado para medir a radiação de cada elemento individualmente, um a um. No caso de realizar a medida de vários comprimentos de onda de elementos diferentes em uma única vez, é utilizado um policromador (BOSS \& FREDEEN, 1997).

Além de ser capaz de determinar um grande número de elementos em uma ampla faixa de concentrações, uma grande vantagem da técnica de ICP OES é que muitos elementos podem ser determinados facilmente em uma mesma corrida analítica. Esta capacidade multielementar decorre do fato de que todos os sinais de emissão necessários para obter informações qualitativas e quantitativas são emitidos a partir do plasma, ao mesmo tempo.

A precisão e exatidão das análises ICP OES são consideradas suficientes para análises elementares em níveis traço. Mesmo na presença de 
interferências, modernas técnicas de compensação de sinal são utilizadas para realizar análises com notável precisão (geralmente menor de 1\%) (BOSS \& FREDEEN, 1997).

A figura 3.7 apresenta um esquema típico da injeção de amostras até a obtenção dos dados analíticos:

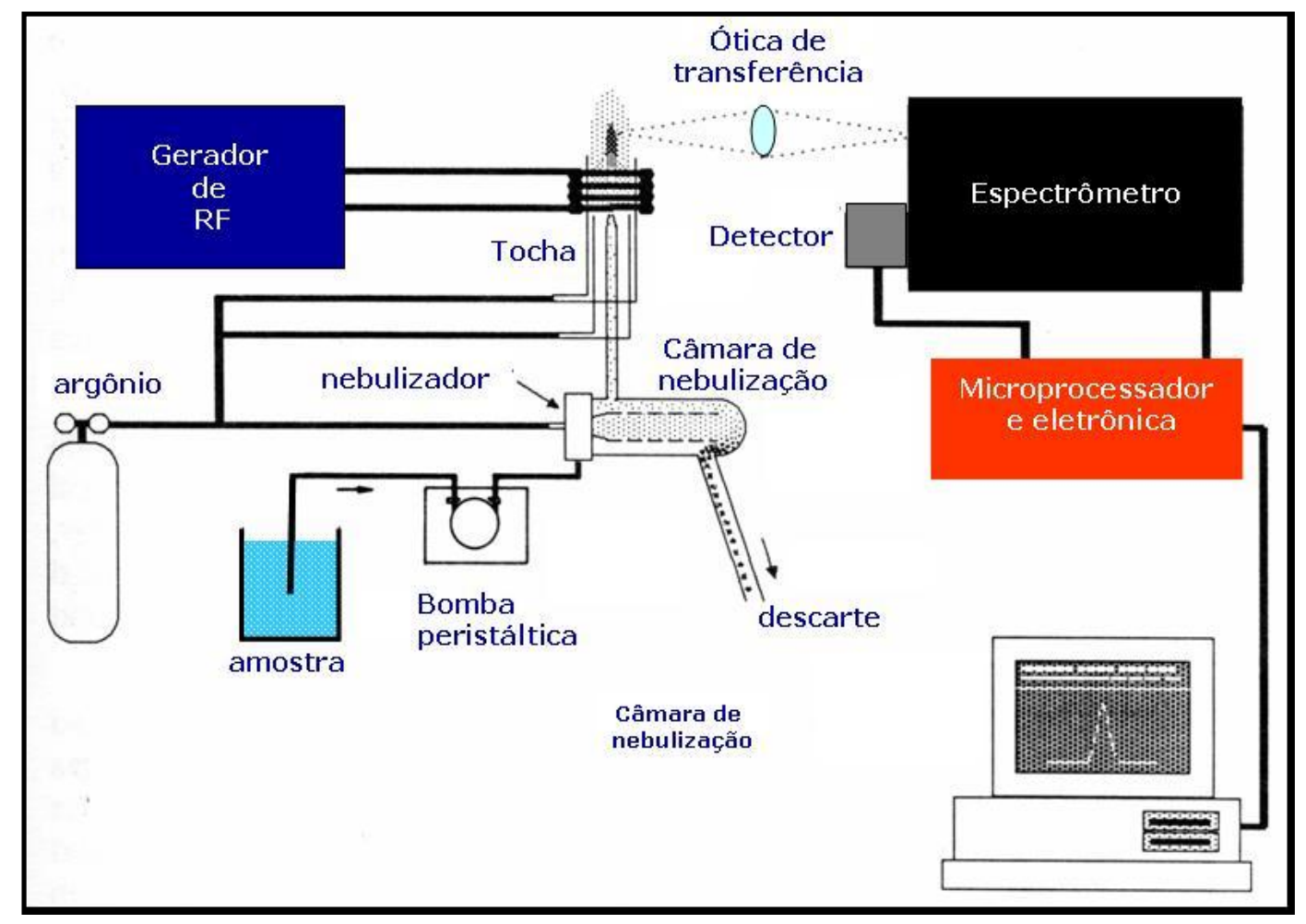

Figura 3.7. Esquema básico das etapas da técnica de ICP OES (Adaptado de BOSS \& FREDEEN, 1997).

\subsubsection{Interferências}

Qualquer processo químico ou físico que afete adversamente a medição da radiação de interesse pode ser classificado como uma interferência. As interferências no ICP OES podem começar na fase de preparação de amostra e abrangem as condições de funcionamento do plasma. 
O primeiro tipo de interferência comum envolve dois ou mais elementos na matriz emitindo radiação no mesmo comprimento de onda (por exemplo, Cu em 515,323 nm e 515,139 nm em Ar). Estas interferências espectrais podem ser minimizadas utilizando um sistema de alta resolução usando várias linhas de análise para a detecção de um único elemento. Um segundo tipo de interferência envolve a formação de espécies indesejáveis (por exemplo, íons e óxidos metálicos). Por exemplo, alguns metais são extremamente sensíveis a flutuações de plasma pequeno em termos de seu átomo neutro em relação à densidade de íons. É importante notar que um átomo de um elemento específico (por exemplo, Fe) tem um espectro de emissão diferente do que um de seus íons (por exemplo, $\mathrm{Fe}^{+3}, \mathrm{Fe}^{+2}$, etc.) (MANNING et al, 1997).

As interferências observadas na análise por ICP OES geralmente podem ser classificadas como espectrais ou não espectrais.

Dentre as interferências não espectrais, são destacados os fatores como o transporte da amostra, supressão do sinal analítico e efeitos de ionização.

Dentre as interferências espectrais normalmente encontradas destacam-se efeitos de background e sobreposição de linhas (especialmente para elementos em altas concentrações que possuem comprimentos de onda próximos a elementos traço).

\subsection{Análise por Ativação Neutrônica (NAA)}

A técnica de análise por Ativação Neutrônica é uma técnica baseada na medida de radiação característica de radionuclídeos formados diretamente ou indiretamente pela irradiação com nêutrons na amostra de interesse. Nas últimas décadas, a análise por ativação neutrônica tem sido utilizada amplamente na determinação de elementos em níveis menores e traço em vários tipos de matrizes. 
Dentre suas aplicações, estão as análises ambientais, alimentos, materiais geológicos e ciência dos materiais. A fonte de nêutrons para a NAA mais empregada é um reator de pesquisas (IAEA, 2001).

Dentre as características principais da técnica NAA, podemos destacar:

(1) Baixos limites de detecção para 30 - 40 elementos

(2) Pequena quantidade de amostra utilizada para análise

(3) Não é necessária a determinação de branco analítico

(4) Possibilidade de utilizar-se como técnica não destrutiva

(5) Efeito de matriz pouco pronunciado, se comparado às outras técnicas

(6) Análise multielementar

Dentre as desvantagens da utilização da NAA, são verificadas:

(1) Tempo de análise longo, se comparado a outras técnicas analíticas

(2) Manipulação de amostras irradiadas

(3) Geração de lixo radioativo

Em relação aos critérios de sensibilidade e exatidão, a NAA é extensivamente aplicada às ciências ambientais, estudos nutricionais, estudos relacionados à saúde, geologia e geoquímica, ciência dos materiais, estudos arqueológicos, forenses, etc.

Devido à necessidade de um reator nuclear de pesquisa, o método de NAA é menos utilizado que outras técnicas como AAS, ICP OES e Fluorescência de Raios X (IAEA, 2001), para analise de elementos. 
O método de análise por ativação com nêutrons consiste no bombardeamento com nêutrons de um dado material, o qual forma os radionuclídeos artificiais, a partir de elementos estáveis (figura 3.8).

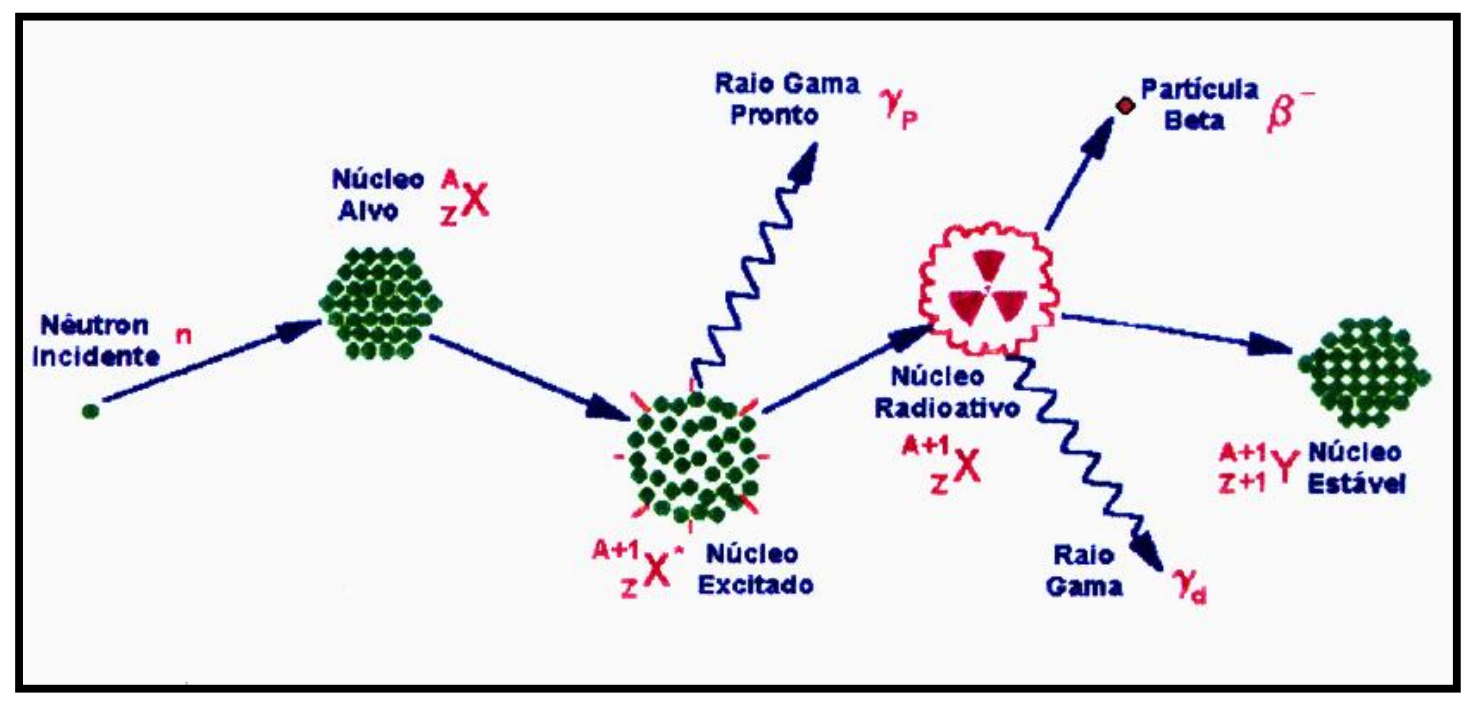

Figura 3.8 Representação esquemática da interação do nêutron com um núcleo alvo

No caso da NAA comparativa a amostra é irradiada juntamente com um padrão de composição o mais similar possível, nas mesmas condições. Após a irradiação, amostra e padrão são medidos no mesmo detector, o que permite que a concentração desconhecida possa ser diretamente calculada a partir das taxas de contagens da amostra e do padrão e conhecendo-se a massa do padrão e da amostra.

A concentração dos elementos presentes na amostra é obtida pela comparação de áreas de picos referentes a padrões que são ativados juntamente com as amostras, utilizando-se para o cálculo a seguinte expressão, demonstrada na equação 3.5 : 


$$
C_{a}^{i}=\frac{\left(\mathrm{Aa}^{\mathrm{i}} m_{p} C_{p}^{i}\right) \mathrm{e}^{\lambda\left(\mathrm{t}_{\mathrm{a}}-t_{p}\right)}}{A_{p}^{i} \mathrm{~m}_{\mathrm{a}}} \text { (Equação 3.5) }
$$

onde:

$\mathrm{C}_{\mathrm{a}}{ }^{\mathrm{i}}$ : Concentração do elemento i na amostra

$\mathrm{C}_{\mathrm{p}}{ }^{i}$ : Concentração do elemento i no padrão

$A_{a}{ }^{i}:$ Atividade do elemento i na amostra

$A_{p}^{i}$ : Atividade do elemento i no padrão

$m_{a}$ e $m_{p}$ : massas da amostra e padrão, respectivamente

$\lambda$ : constante de decaimento do radioisótopo

$t_{a}:$ tempo de resfriamento da amostra

$t_{p}:$ tempo de resfriamento do padrão

Recentemente, GREENBERG et al (2011) publicaram um artigo, afirmando que o método de NAA comparativo, apresentava todos os requisitos para ser considerado como método primário de análise conforme definição do "Comité Consultatif pour La Quantité de Matière - Metrologie en Chimie" (CCQM). A tese dos autores é evidenciada nesse artigo em 3 capítulos, aonde foram discutidos todos os requisitos para que um método fosse considerado primário. Os autores discutiram que a performance da NAA em exercícios de intercomparação do CCQM no período de 2000 a 2007, era semelhante ao do método de Espectrometria de Massa com Diluição Isotópica (ID-MS), já considerado como método primário de análise pelo CCQM. 


\section{CAPÍTULO 4}

\section{MATERIAIS E MÉTODOS}

\subsection{Amostragem}

Os sedimentos foram amostrados com pegador de fundo tipo "van Veen" em aço inox. Após coleta, o material foi manuseado com espátula em material inerte e armazenado em sacos plásticos pré-lavados com solução de ácido clorídrico e enxaguados com água destilada e deionizada. O material foi congelado $\left(-20^{\circ} \mathrm{C}\right)$, levado ao laboratório e, em seguida, liofilizado sendo a fração total $(<2 \mathrm{~mm})$, reservada para análise. Uma outra parte da amostra de sedimentos foi seca a $50^{\circ} \mathrm{C}$ em estufa ventilada, até peso constante.

\subsection{LOCAIS DE AMOSTRAGEM}

\subsubsection{Estuário de Santos/ São Vicente e baía de Santos}

As amostras coletadas no estuário de Santos contemplam as regiões de São Vicente, Santos, Cubatão e Vicente Carvalho. Foram coletadas amostras de sedimentos em duas estações, inverno e verão, nos anos de 2005 e 2006 nos pontos descritos na Figura 4.1. Cerca de 60 amostras de sedimentos foram coletadas no total.

No presente estudo, com a finalidade de facilitar o entendimento das regiões estudadas, as amostras foram divididas em áreas distintas, de acordo com as características geográficas dos pontos de amostragem, conforme indica a Tabela 4.1: 
Tabela 4.1 Localização dos pontos de amostragem divididos por áreas

\begin{tabular}{c|c|c}
\hline Localização & $\begin{array}{c}\text { Pontos de } \\
\text { amostragem }\end{array}$ & Área \\
\hline $\begin{array}{c}\text { Canal de } \\
\text { Santos }\end{array}$ & 01 a 06 & $\mathbf{0 1}$ \\
\hline $\begin{array}{c}\text { Baía de } \\
\text { Santos }\end{array}$ & $\begin{array}{c}07 \text { a } 10,15, \\
16\end{array}$ & $\mathbf{0 2}$ \\
\hline $\begin{array}{c}\text { Canal de } \\
\text { São Vicente }\end{array}$ & 11 a 14 & $\mathbf{0 3}$ \\
\hline
\end{tabular}

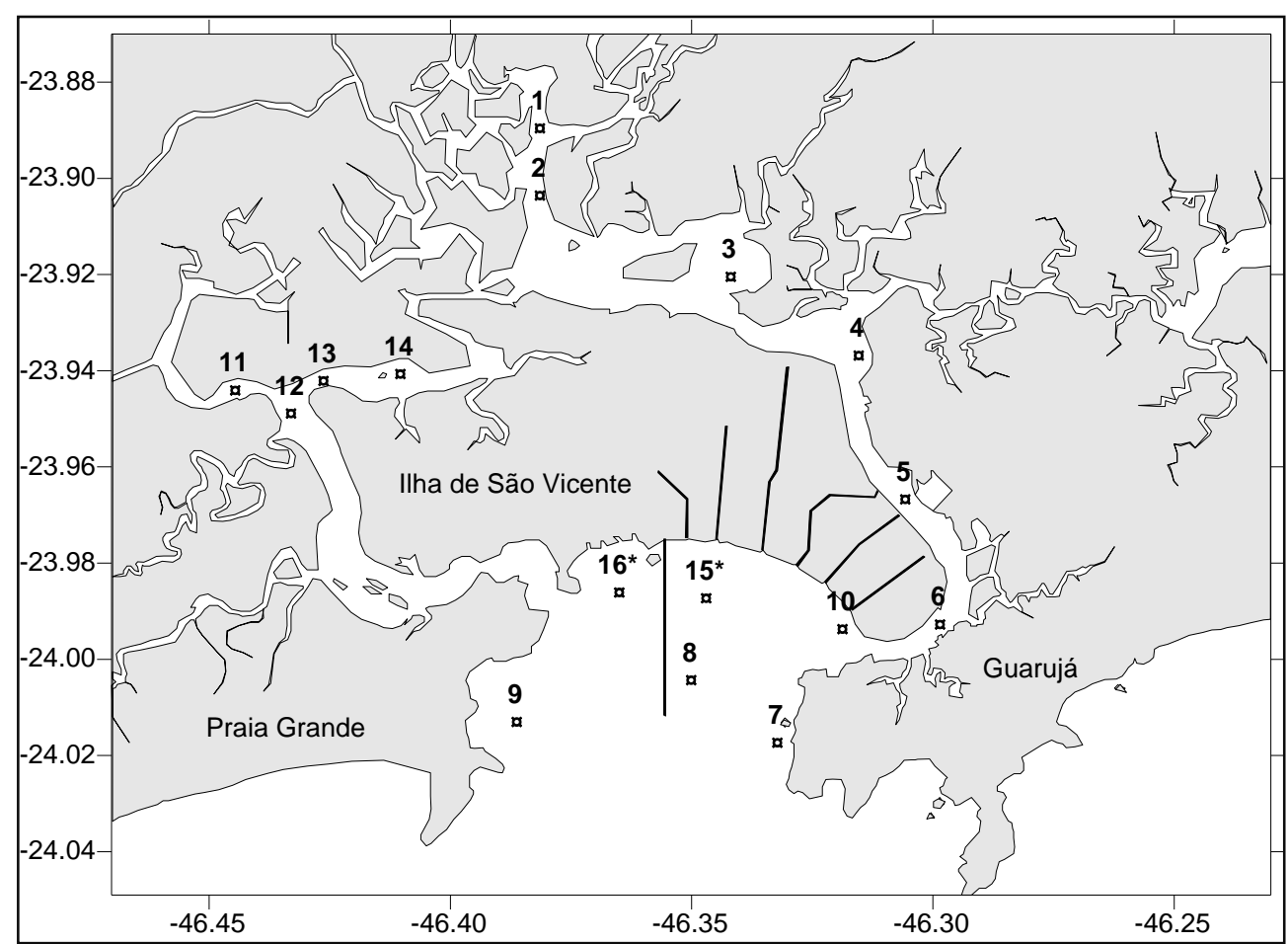

Figura 4. 1 Localização dos pontos de amostragem no estuário de Santos/São Vicente

A Tabela 4.2 apresenta as coordenadas geográficas dos pontos amostrados na região do estuário de Santos/São Vicente. 
Tabela 4.2 Coordenadas geográficas das estações de amostragem na região do estuário Santos/São Vicente

\begin{tabular}{|ccc|}
\hline Estações & Latitude & Longitude \\
\hline 1 & $-23^{\circ} 890$ & $-46^{\circ} 381$ \\
2 & $-23^{\circ} 904$ & $-46^{\circ} 381$ \\
3 & $-23^{\circ} 920$ & $-46^{\circ} 342$ \\
4 & $-23^{\circ} 937$ & $-46^{\circ} 315$ \\
5 & $-23^{\circ} 967$ & $-46^{\circ} 306$ \\
6 & $-23^{\circ} 993$ & $-46^{\circ} 299$ \\
7 & $-24^{\circ} 017$ & $-46^{\circ} 332$ \\
8 & $-24^{\circ} 004$ & $-46^{\circ} 350$ \\
9 & $-24^{\circ} 013$ & $-46^{\circ} 386$ \\
10 & $-24^{\circ} 994$ & $-46^{\circ} 319$ \\
11 & $-23^{\circ} 944$ & $-46^{\circ} 445$ \\
12 & $-23^{\circ} 949$ & $-46^{\circ} 433$ \\
13 & $-23^{\circ} 942$ & $-46^{\circ} 426$ \\
14 & $-23^{\circ} 941$ & $-46^{\circ} 410$ \\
15 & $-23^{\circ} 988$ & $-46^{\circ} 349$ \\
16 & $-23^{\circ} 987$ & $-46^{\circ} 363$ \\
\hline
\end{tabular}

A CETESB apresentou em 2001 em seu relatório o mapeamento das áreas que possuem impactos antrópicos por fontes industriais e fontes ligadas ao saneamento básico, conforme demonstram as Figuras 4.2 e 4.3, respectivamente (CETESB, 2001).

De acordo com o mapeamento de indústrias apresentado na Figura 4.2Erro! Fonte de referência não encontrada., observa-se uma grande quantidade de indústrias na região do polo industrial de Cubatão e na Figura 4.3, são identificados vários pontos de lançamento de águas de drenagem contaminadas por esgotos domésticos ao redor da ilha de São Vicente, os quais representam fortes pontos de poluição de origem antrópica. 


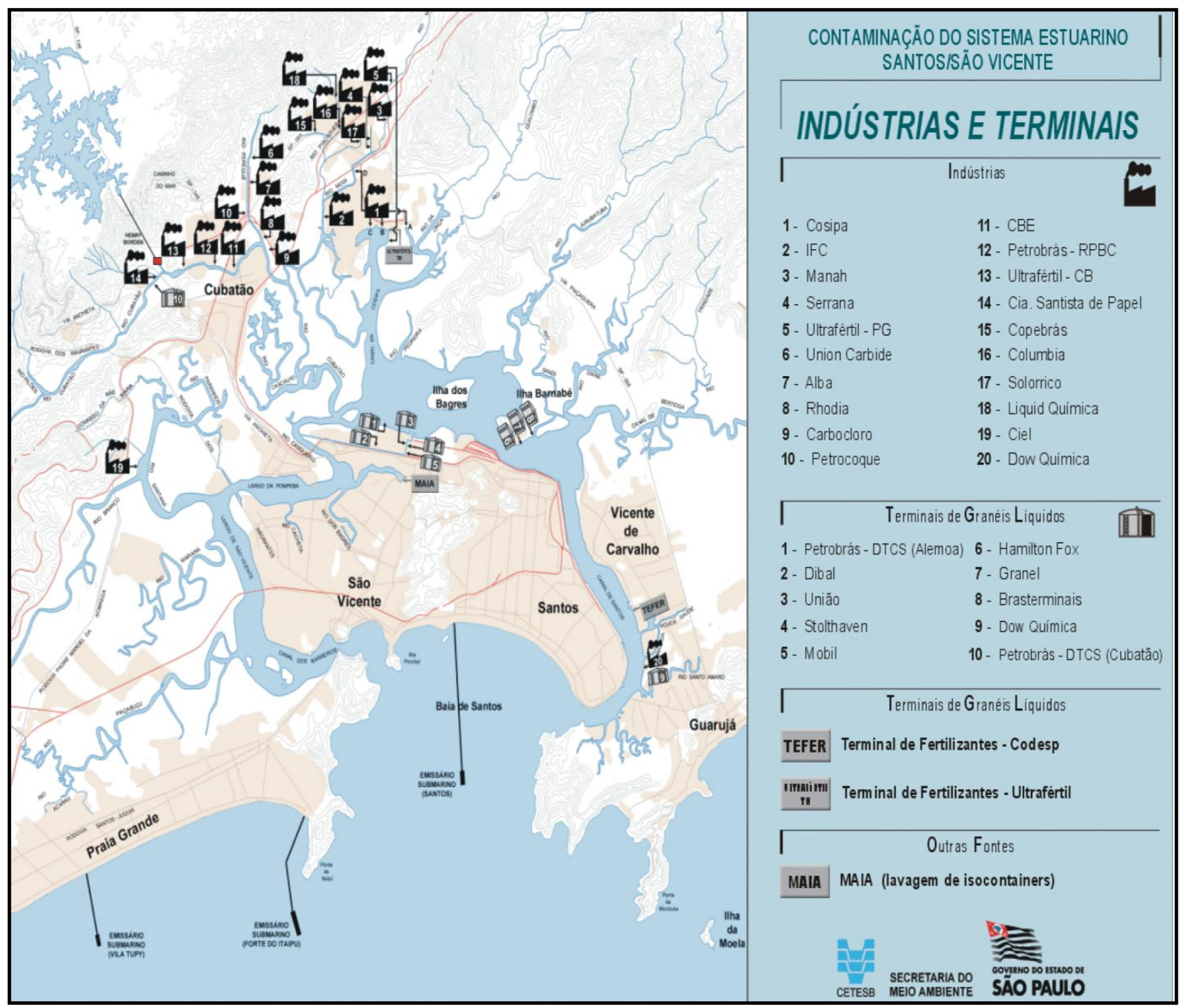

Figura 4. 2 Fontes industriais de Contaminação do Sistema Estuarino Santos/São Vicente. Fonte: CETESB, 2001 


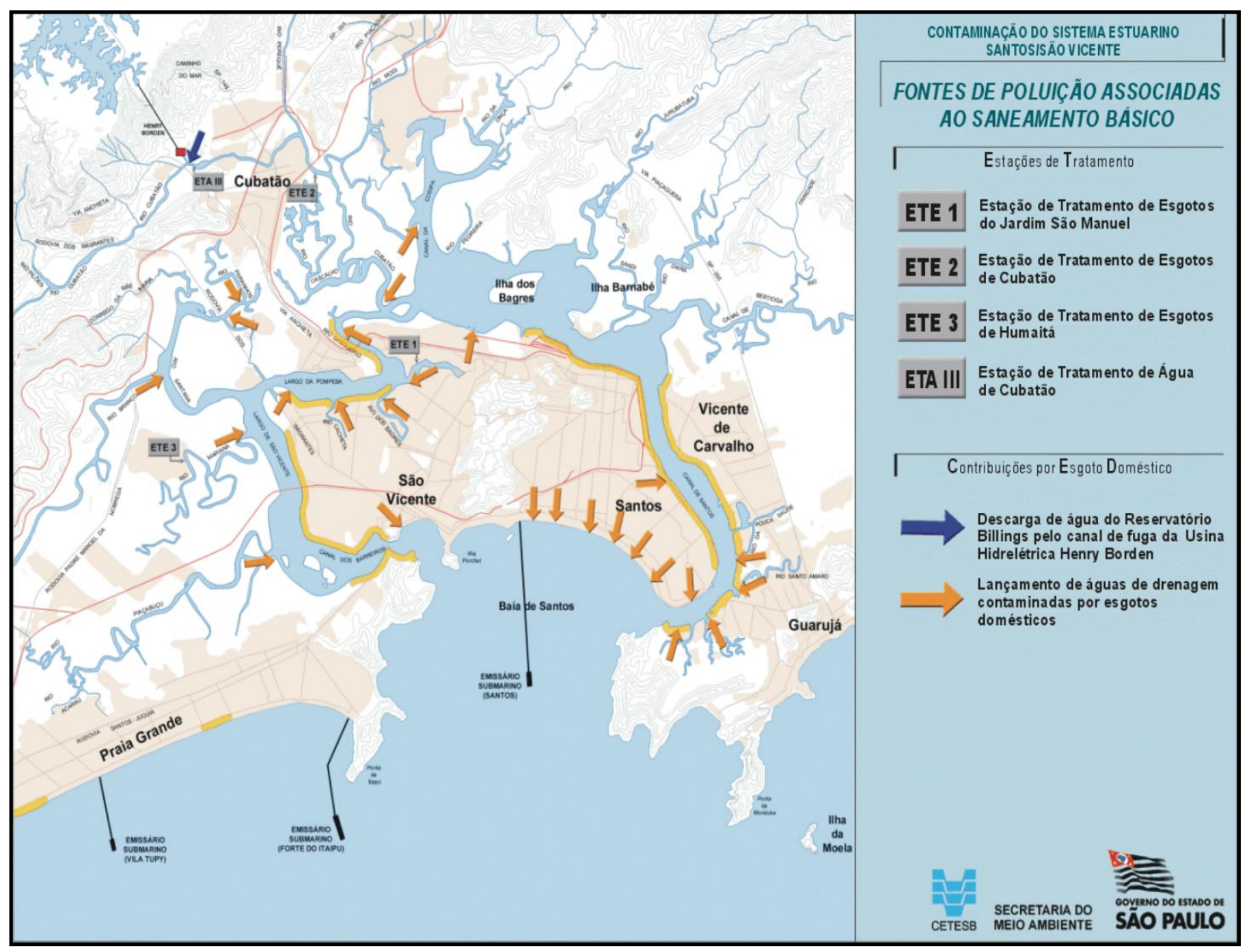

Figura 4. 3 Fontes de poluição associadas ao saneamento básico. Fonte: CETESB, 2001

\subsubsection{Cananéia}

O estuário de Cananéia foi amostrado em vários pontos contemplando dois mares internos (Mar de Cananéia e Mar de Cubatão) e a Baía de Trapandé. Estes pontos localizam-se na porção sul do Complexo Estuarino-Lagunar e apresentam hidrodinâmica diferenciada em relação à influência marinha (Figura 4.4). 


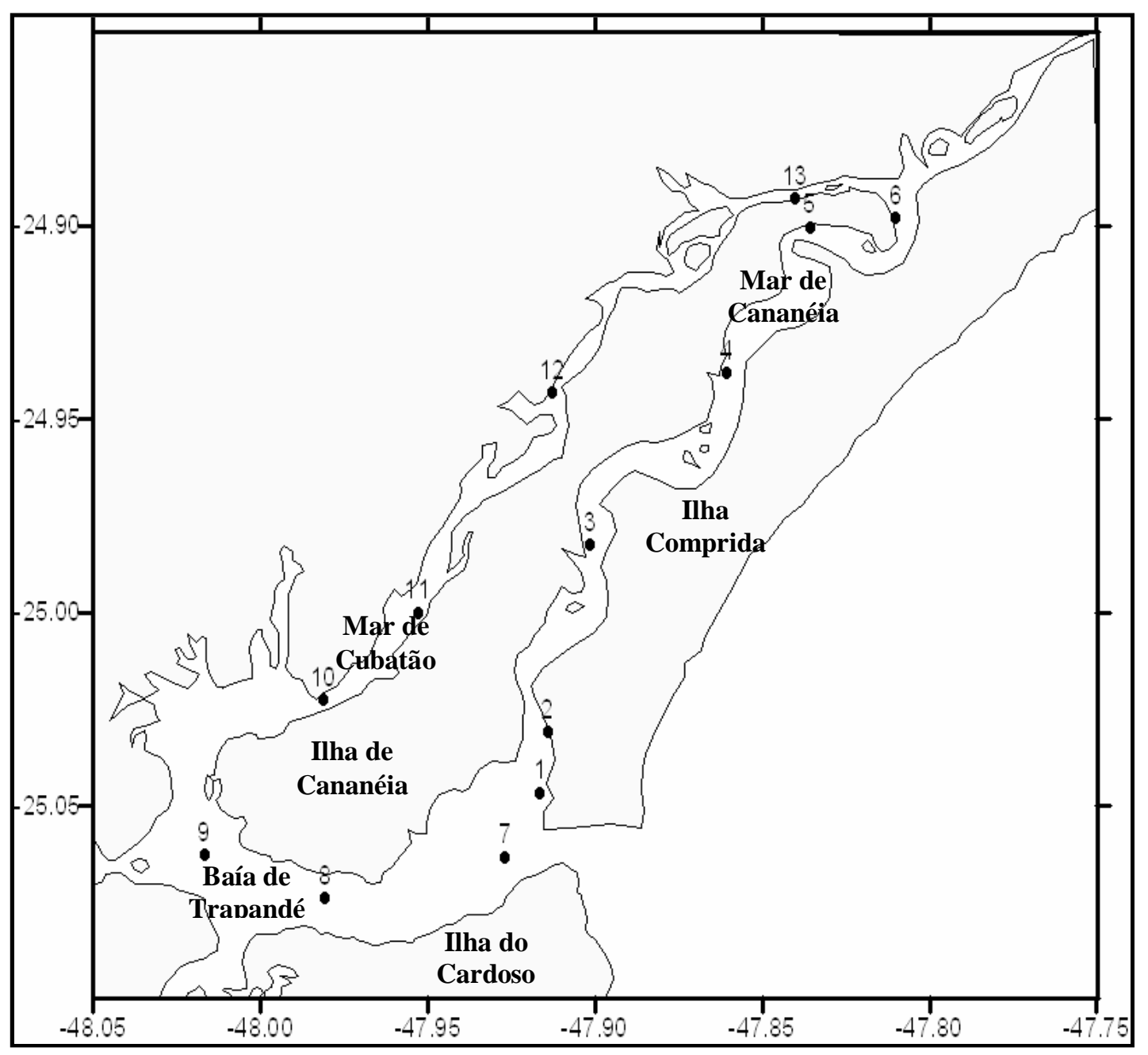

Figura 4. 4 Pontos de coleta no estuário em Cananéia

Foram coletadas amostras de sedimentos em duas estações, inverno e verão, nos anos de 2005 e 2006 nos pontos descritos na Figura 4.4.

No presente estudo, com a finalidade de facilitar o entendimento das regiões estudadas, as amostras foram agrupadas, de acordo com as características geográficas dos pontos de amostragem, conforme indicado na Tabela 4.3. 
Tabela 4.3 Localização dos pontos de amostragem em Cananéia, divididos por áreas

\begin{tabular}{c|c|c}
\hline Localização & $\begin{array}{c}\text { Pontos de } \\
\text { amostragem }\end{array}$ & Áreas \\
\hline Mar de Cananéia & 01 a 06 & $\mathbf{0 1}$ \\
\hline $\begin{array}{c}\text { Baia de } \\
\text { Trapandé }\end{array}$ & 07 a 09 & $\mathbf{0 2}$ \\
\hline Mar de Cubatão & 10 a 13 & $\mathbf{0 3}$ \\
\hline
\end{tabular}

A Tabela 4.4 apresenta as localizações geográficas das estações coletadas no estuário de Cananéia.

Tabela 4.4 Coordenadas geográficas das estações amostradas no estuário de Cananéia

\begin{tabular}{|ccc|}
\hline Estações & Latitude & Longitude \\
\hline 1 & $-25^{\circ} 047$ & $-47^{\circ} 917$ \\
2 & $-25^{\circ} 031$ & $-47^{\circ} 914$ \\
3 & $-24^{\circ} 983$ & $-47^{\circ} 902$ \\
4 & $-24^{\circ} 938$ & $-47^{\circ} 861$ \\
5 & $-24^{\circ} 900$ & $-47^{\circ} 836$ \\
6 & $-24^{\circ} 898$ & $-47^{\circ} 810$ \\
7 & $-25^{\circ} 063$ & $-47^{\circ} 927$ \\
8 & $-25^{\circ} 074$ & $-47^{\circ} 981$ \\
9 & $-25^{\circ} 063$ & $-48^{\circ} 017$ \\
10 & $-25^{\circ} 023$ & $-47^{\circ} 981$ \\
11 & $-25^{\circ} 000$ & $-47^{\circ} 953$ \\
12 & $-24^{\circ} 943$ & $-47^{\circ} 913$ \\
13 & $-24^{\circ} 833$ & $-47^{\circ} 840$ \\
\hline
\end{tabular}




\subsection{Granulometria}

As análises granulométricas foram processadas no Laboratório de Sedimentologia do Instituto Oceanográfico da Universidade de São Paulo. Para essa análise foi utilizado o método de Suguio (1973). O sedimento foi separado utilizando-se um jogo de peneiras da marca GRANULOTEST com malhas de 2 $\mathrm{mm}$ a $63 \mu \mathrm{m}$, com intervalos de 0,5 . Os dados de granulometria foram processados segundo o programa LABSE 2.0, que calcula os dados estatísticos dos sedimentos como diâmetro médio, grau de seleção, curtose e assimetria segundo Folk \& Ward (1957).

\subsection{Determinação dos teores de carbonatos}

A análise do carbonato biodetrítico foi feita pelo laboratório de Sedimentologia do Instituto Oceanográfico da USP. Pesou-se aproximadamente 5,0 gramas de sedimento em uma balança analítica. Submeteu-se a um ataque ácido com $\mathrm{HCl} 10 \%$ em massa durante 12 horas, lavando-se posteriormente com água deionizada. Secou-se então o sedimento e pesou-se novamente (Byers et al., 1978). O teor de carbonato biodetrítico foi calculado conforme a equação 4.1 , apresentada abaixo:

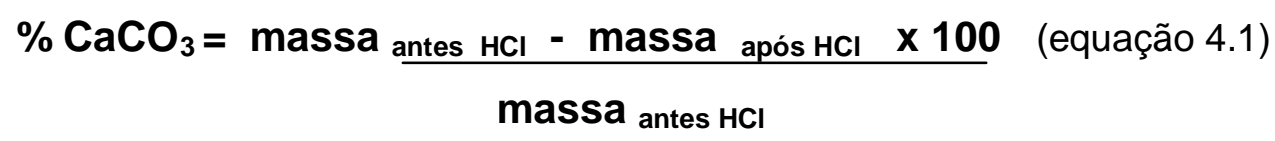

\subsection{Matéria orgânica sedimentar}

Após a liofilização das amostras de sedimentos em liofilizador, pesou-se aproximadamente 2 gramas, em balança analítica, marca BEL modelo $210 \mathrm{~A}$, com precisão $\pm 0,00005 \mathrm{~g}$ em um cadinho $\left(p_{1}\right)$. Posteriormente, 
calcinou-se a amostra a $450^{\circ} \mathrm{C}$ por $4 \mathrm{~h} 30 \mathrm{~min}$. Após esse tempo, o cadinho foi colocado num dessecador por 1 hora para resfriamento e efetuou-se uma nova pesagem $\left(p_{2}\right)$. O cálculo da porcentagem de matéria orgânica está representado pela equação 4.2 abaixo:

$$
\text { \% M.O. }=\left(\mathbf{p}_{1}-\mathbf{p}_{2}\right)^{*} \mathbf{1 0 0} / \mathbf{p}_{1} \quad \text { (equação 4.2) }
$$

\subsection{Fósforo Orgânico ( $\left.P_{\text {org }}\right)$, Fósforo Inorgânico $\left(P_{\text {inorg }}\right)$ e Fósforo Total ( $P$ total)}

O conteúdo em Fósforo orgânico, Fósforo inorgânico e Fósforo total foram determinados conforme descrito em Berbel (2008). Para a determinação de fósforo orgânico $\left(P_{\text {org }}\right)$, o sedimento final vai para uma mufla a $550^{\circ} \mathrm{C}$ (marca Pyrotec Schrack) por $1 \mathrm{~h} 30$ minutos e depois é tratado com $\mathrm{HCl} 1 \mathrm{M}$ por 16 horas.

O fósforo inorgânico total e fósforo total são determinados após a retirada de alíquota de aproximadamente $0,50 \mathrm{~g}$ de sedimento seco, o qual foi pesado numa balança analítica e posteriormente submetido a extração ácida com o uso do agitador mecânico orbital (Kline modelo 108 A). O sedimento recebeu uma alíquota de solução $\mathrm{HCl} 1 \mathrm{M}$ e foi submetido a uma agitação por 16 horas para a obtenção do fósforo inorgânico total $(P$ inorg $)$. Para o fósforo total, utilizou-se o mesmo procedimento acima, mas com uma calcinação prévia a $550^{\circ} \mathrm{C}$ por $1 \mathrm{~h} 30$ minutos. $O$ fósforo orgânico foi obtido pela diferença entre o fósforo total e fósforo inorgânico e a concentração dada em $\mu \mathrm{mol} \mathrm{g}{ }^{-1}$.

As análises de fósforo orgânico, inorgânico e total foram realizadas no laboratório LABNUT (Laboratório de Nutrientes do IO/USP) por Berbel (2008) e com o auxílio da Dra. Elisabete de Santis Braga. 


\subsection{Preparo das amostras de sedimentos para análises químicas}

As amostras de sedimentos foram secas a $50{ }^{\circ} \mathrm{C}$ em estufa ventilada, posteriormente passadas por uma peneira de $2 \mathrm{~mm}$ e então homogeneizadas. A fração total $(<2 \mathrm{~mm})$ foi analisada.

\subsection{Digestão das amostras de sedimentos, assistida por microondas}

A determinação da concentração de metais em amostras sólidas, pelas técnicas de GF AAS, CV AAS e ICP OES, necessitam de digestão prévia. Optou-se pela digestão assistida por microondas, por sua eficiência, rapidez e baixa contaminação. Esta técnica tem sido uma ferramenta analítica indispensável na preparação de amostras. A energia de microondas é transmitida através das paredes dos recipientes de Teflon®. São utilizados ácidos minerais como ácido nítrico, ácido sulfúrico, ácido clorídrico, entre outros. Para esse experimento utilizou-se o ácido nítrico, para dissolução dos metais presentes nas amostras, em frascos de Teflon $\AA^{\circledR}$, em sistema fechado, com monitoramento de pressão nos frascos. A grande redução de tempo de digestão vem da combinação da velocidade de aquecimento, com a possibilidade de trabalhar sob pressões mais altas.

O método selecionado para a digestão das amostras, assistida por microondas foi o método SW-846-3051 - USEPA (USEPA, 2007): a massa da amostra, cerca de $0,50 \mathrm{~g}$, após secagem, maceração e peneiramento, é transferida para vaso de digestão de Teflon ${ }^{\circledR}$. Adiciona-se $10 \mathrm{~mL}$ de ácido nítrico concentrado p.a.. Os vasos são fechados e levados à digestão assistida por microondas. Ao término da programação, após resfriamento, a solução de amostra digerida é transferida para balão volumétrico sob filtração e diluída a $50 \mathrm{~mL}$, aferindo-se o volume com água deionizada. Após esse procedimento as amostras e padrões estavam prontos para leitura pelas técnicas de GF AAS (Cd e $\mathrm{Pb}$ ) e ICP OES. A digestão das amostras foi realizada no LAN/CRPq, IPEN/CNEN-SP. 
O tratamento de amostras para a dissolução mediante 0 aquecimento com radiação microondas tem demonstrado ser um processo mais rápido, eficiente e seguro em comparação ao aquecimento convencional. Além disso, o uso de recipientes fechados durante o tratamento com microondas minimiza as possibilidades de contaminação das amostras e diminui o número de reagentes necessários para converter a amostra em uma solução, tornando-a adequada para a determinação dos analitos de interesse.

A possibilidade de redução de volumes de reagentes é atrativa devido à possibilidade de minimização da quantidade de resíduos gerados, redução nos custos, obtenção de menores valores de brancos analíticos e digeridos mais apropriados para a introdução por nebulizadores em equipamentos de análise. $O$ aumento de pressão dentro do frasco de reação promove a elevação do ponto de ebulição da mistura de digestão ácida e a elevação de seu potencial oxidante. Conseqüentemente, as reações de oxidação são favorecidas e mais rápidas nessas condições. Durante a oxidação dos compostos orgânicos da amostra pela ação do $\mathrm{HNO}_{3}$ ocorre a formação de $\mathrm{NO}$ gasoso. O NO é removido do meio reacional aquecido e reage com $\circ \mathrm{O}_{2}$ presente na fase gasosa do frasco de reação. A seguir, o $\mathrm{NO}_{2}$ é gerado e reabsorvido na solução, resultando na formação de $\mathrm{NO}_{3}{ }^{-}$e $\mathrm{NO}$, sendo que 0 ciclo de reação se repete, até que não haja a presença de $\mathrm{O}_{2}$ na fase gasosa do sistema.

$$
\begin{aligned}
& 2 \mathrm{NO}_{(\mathrm{g})}+\mathrm{O}_{2} \longrightarrow 2 \mathrm{NO}_{2}(\mathrm{~g}) \quad \text { (equação 4.3) } \\
& 2 \mathrm{NO}_{2(\mathrm{~g})}+\mathrm{H}_{2} \mathrm{O}_{(\mathrm{l})} \longrightarrow \mathrm{HNO}_{3}+\mathrm{HNO}_{2} \quad \text { (equação 4.4) } \\
& \mathrm{HNO}_{2} \longrightarrow \mathrm{H}_{2} \mathrm{O}+\mathrm{NO}_{2}+\mathrm{NO} \text { (equação 4.5) }
\end{aligned}
$$




\subsection{Análise de sedimentos}

\subsubsection{Espectrometria de Absorção Atômica com forno de grafite (GF AAS)}

Os metais determinados por GF AAS, foram $\mathrm{Cd}$ e $\mathrm{Pb}$, e para a realização das análises, utilizou-se um Espectrômetro de Absorção Atômica com Forno de Grafite, da PerkinElmer, AAnalyst 800, equipado com um amostrador automático, e com correção de fundo por Efeito Zeeman, localizado no LAN/CRPq do IPEN/CNEN-SP.

Para a avaliação do sinal analítico, optou-se pelo uso da área do pico das absorbâncias obtidas, e para a melhor performance das análises, foram utilizadas lâmpadas de descarga sem eletrodos "EDL", as quais foram operadas de acordo com a Tabela 4.5, que também apresenta os volumes de injeção de amostra e do modificador químico:

Tabela 4.5 Parâmetros de determinação de $\mathrm{Cd}$ e $\mathrm{Pb}$ ajustados para análise

\begin{tabular}{lcc}
\hline Parâmetros de determinação & $\mathbf{C d}$ & $\mathbf{P b}$ \\
\hline Lâmpada & EDL & EDL \\
Comprimento de onda & $228,8 \mathrm{~nm}$ & $283,3 \mathrm{~nm}$ \\
Fenda & $0,7 \mathrm{~nm}$ & $0,7 \mathrm{~nm}$ \\
Corrente da lâmpada & $230 \mathrm{~mA}$ & $440 \mathrm{~mA}$ \\
Volume de injeção de amostra & $20 \mu \mathrm{L}$ & $20 \mu \mathrm{L}$ \\
Volume de injeção de modificador & & \\
químico & $10 \mu \mathrm{L}$ & $10 \mu \mathrm{L}$ \\
\hline
\end{tabular}

Para a eliminação de efeitos de matriz, utilizou-se como modificador químico $\mathrm{Mg}$ e $\left(\mathrm{NH}_{4}\right)_{2} \mathrm{PO}_{4}$.

Todos os reagentes usados foram de alto grau analítico. A água foi destilada em um sistema Milli-Q (Millipore). O ácido nítrico utilizado para a preparação das soluções analíticas foi da marca Merck. O gás Argônio (99,9\%) 
da White Martins, foi utilizado como gás de purga no espectrômetro de absorção atômica com forno de grafite.

Para a otimização do método de análise, foram realizadas as curvas de atomização e pirólise, as quais definem as melhores condições de Temperatura nas etapas de trabalho, na técnica GF AAS. Também foi realizada uma análise crítica dos sinais de absorbância obtidos diretamente no software Winlab 32 for AAS versão 6.2.0.0079 (Perkin Elmer). Foi observado que, em alguns casos, embora o valor numérico de absorbância fosse superior, o espectro apresentava picos duplos, indefinição ou alto teor de background.

$\mathrm{Na}$ construção da curva de pirólise, fixou-se a temperatura de atomização em $1600^{\circ} \mathrm{C}$, e foram realizadas leituras do material de referência WQB-3 em diferentes temperaturas na etapa de pirólise, conforme demonstra a Tabela 4.6, seguida da representação da Figura 4.5, para o elemento $\mathrm{Pb}$ :

Tabela 4.6 Curva de pirólise do Pb (temperatura versus absorbância)

\begin{tabular}{cc}
\hline Temperatura de pirólise $(\stackrel{\circ}{ } \mathrm{C})$ & Absorbância \\
\hline 600 & 0,8156 \\
700 & 0,8144 \\
850 & 0,8504 \\
950 & 0,9093 \\
\hline
\end{tabular}

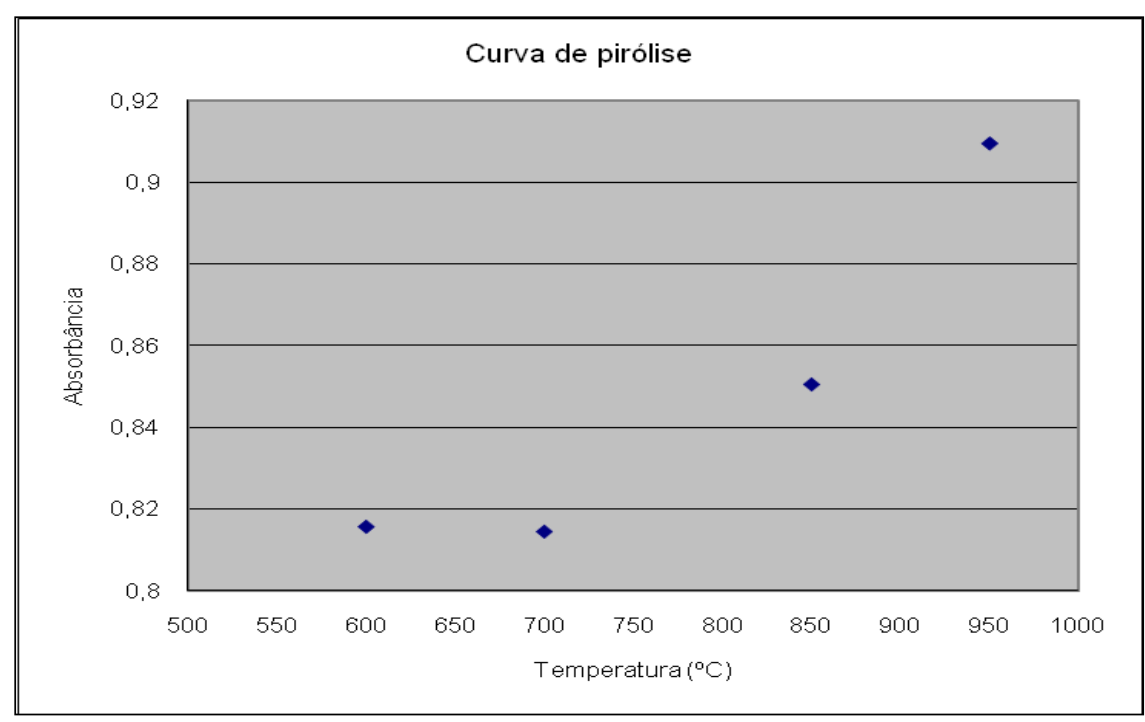

Figura 4. 5 Curva de pirólise para o $\mathrm{Pb}$ 
De acordo com a Figura 4.5, podemos verificar que aparentemente a temperatura de $950^{\circ} \mathrm{C}$ apresenta o melhor valor numérico de absorbância para - $\mathrm{Pb}$, entretanto, observou-se um maior valor de background nesta temperatura. Portanto, após esta análise crítica optou-se pela utilização da temperatura de $850^{\circ} \mathrm{C}$, na etapa de pirólise.

Para a obtenção da curva de atomização do $\mathrm{Pb}$, utilizou-se a temperatura de pirólise fixa em $850^{\circ} \mathrm{C}$, e diversas temperaturas diferentes na etapa de atomização, conforme apresentado na Tabela 4.7 e Figura 4.6:

Tabela 4.7 Temperaturas de atomização para o $\mathrm{Pb}$ (Temperatura versus Absorbância)

\begin{tabular}{cc}
\hline $\begin{array}{c}\text { Temperatura de atomização } \\
\left({ }^{\circ} \mathrm{C}\right)\end{array}$ & Absorbância \\
\hline 1500 & 0,9131 \\
1600 & 0,8504 \\
1700 & 0,8529 \\
1800 & 0,8403 \\
\hline
\end{tabular}

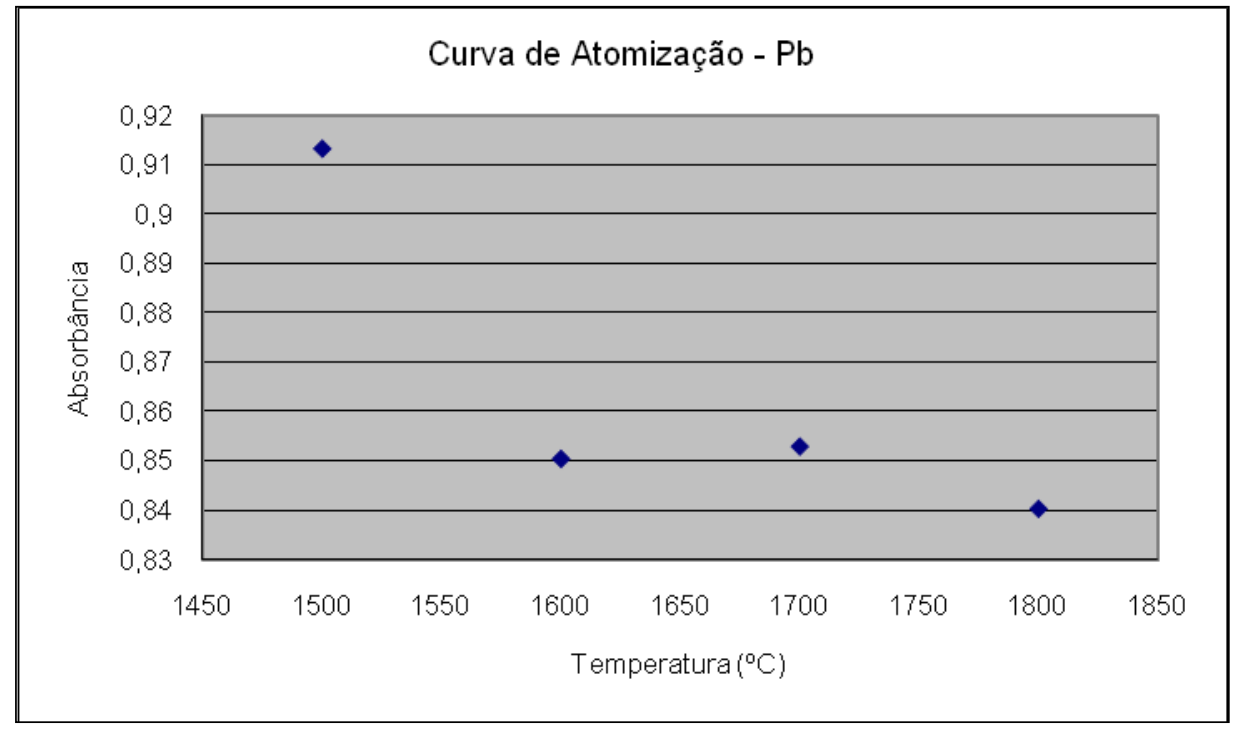

Figura 4. 6 Curva de atomização do $\mathrm{Pb}$ 
Após a análise crítica dos resultados, optou-se em utilizar a temperatura de atomização de $1600^{\circ} \mathrm{C}$ para a análise de $\mathrm{Pb}$, devido a temperatura de $1500^{\circ} \mathrm{C}$ apresentar a formação de picos analíticos menos definidos, o que poderia gerar uma incoerência nos resultados obtidos, devido ao elemento não estar totalmente atomizado.

Nas análises de $\mathrm{Cd}$, também foram realizadas as curvas de atomização e pirólise, conforme demonstrado nas Figuras 4.7 e 4.8:

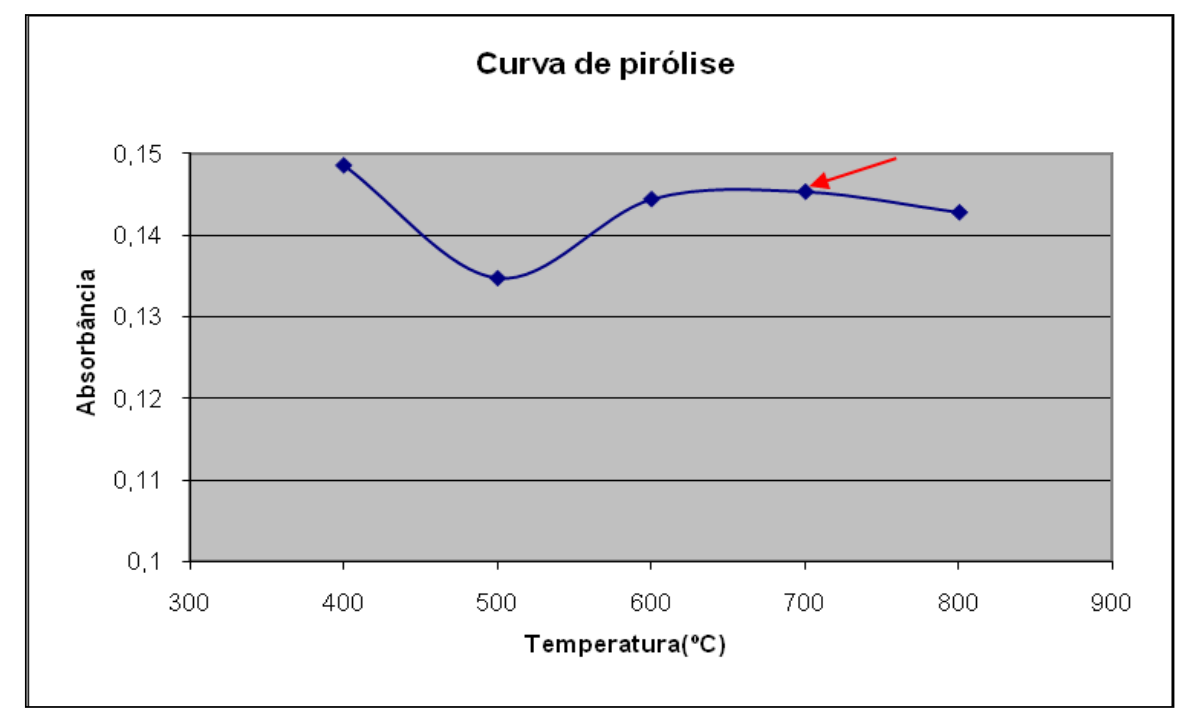

Figura 4. 7 Curva de pirólise - Cd

$\mathrm{Na}$ análise da curva de pirólise, é verificado que não há uma diferença significativa nas absorbâncias obtidas, porém na análise crítica dos espectros, verificou-se uma melhor definição do espectro na temperatura de $700^{\circ} \mathrm{C}$, a qual foi escolhida para a realização das análises. 


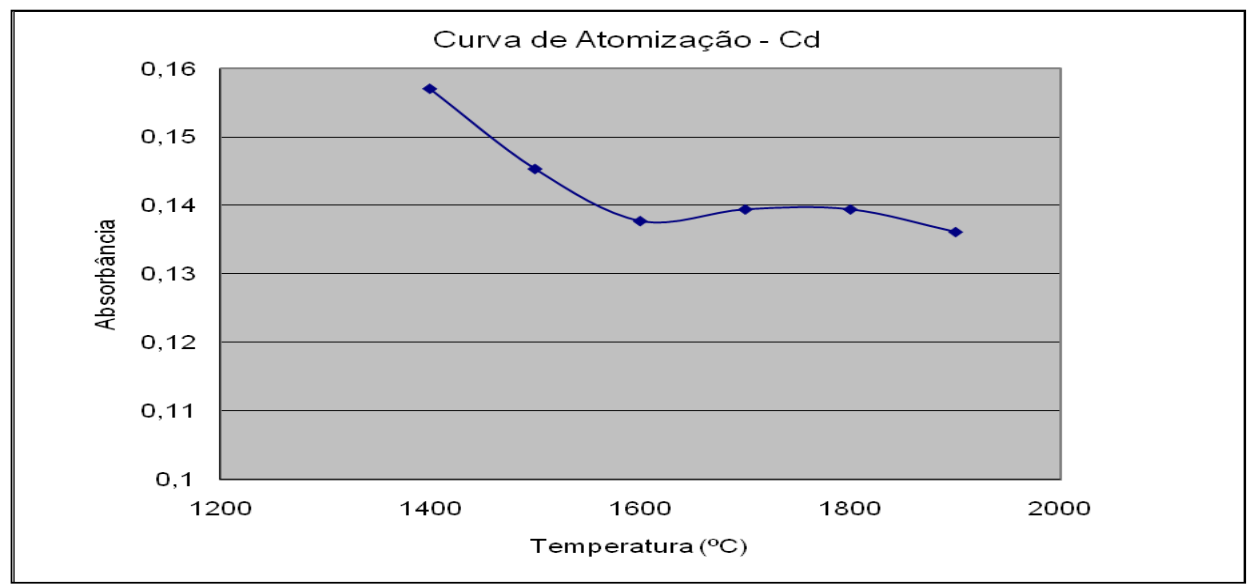

Figura 4. 8 Curva de atomização - Cd

$\mathrm{Na}$ análise da temperatura de atomização, foi observada a formação de picos duplos entre 1400 e $1500^{\circ} \mathrm{C}$, e embora ambos tivessem obtidos maiores valores numéricos de absorbância, optou-se pela utilização da temperatura de atomização de $1600^{\circ} \mathrm{C}$, a qual demonstrou que o analito estava totalmente atomizado.

Após este estudo detalhado das condições otimizadas para as determinações de $\mathrm{Cd}$ e $\mathrm{Pb}$, foi possível estabelecer as etapas de aquecimento do forno de grafite, conforme demonstrado na Tabela 4.8.

Tabela 4.8 - Etapas de aquecimento do forno de grafite para determinação de Cd $\mathrm{e} \mathbf{P b}$

\begin{tabular}{|c|c|c|c|c|c|c|c|c|}
\hline \multirow[t]{2}{*}{ Etapa } & \multicolumn{2}{|c|}{$\begin{array}{l}\text { Teperatura } \\
\left({ }^{\circ} \mathrm{C}\right)\end{array}$} & \multicolumn{2}{|c|}{$\begin{array}{c}\text { Rampa de } \\
\text { Aquecimento } \\
\left({ }^{\circ} \mathrm{C} \mathrm{s}^{-1}\right)\end{array}$} & \multicolumn{2}{|c|}{$\begin{array}{c}\text { Patamar } \\
\text { (s) }\end{array}$} & \multicolumn{2}{|c|}{$\begin{array}{c}\text { Fluxo interno } \\
\text { de argônio } \\
\left(\mathrm{mL} \mathrm{min}^{-1}\right)\end{array}$} \\
\hline & Cd & $\mathrm{Pb}$ & Cd & $\mathbf{P b}$ & Cd & $\mathrm{Pb}$ & Cd & $\mathbf{P b}$ \\
\hline Secagem 1 & 110 & 110 & 1 & 1 & 30 & 30 & 250 & 250 \\
\hline Secagem 2 & 130 & 130 & 15 & 15 & 30 & 30 & 250 & 250 \\
\hline Pirólise & 700 & 850 & 10 & 10 & 20 & 20 & 250 & 250 \\
\hline Atomização & 1600 & 1600 & 0 & 0 & 5 & 5 & 0 & 0 \\
\hline Limpeza & 2450 & 2450 & 1 & 1 & 3 & 3 & 250 & 250 \\
\hline
\end{tabular}




\subsubsection{Calibração do equipamento de GF AAS e leitura das amostras}

Antes da determinação de $\mathrm{Cd}$ e $\mathrm{Pb}$ nas amostras de sedimento foram preparadas soluções de $\mathrm{Cd}$ e $\mathrm{Pb}$ a partir de solução estoque destes mesmos elementos e de solução de $\mathrm{HNO}_{3}$ 0,2\% (v/v) (Merck), usado como diluente, para construção da curva de calibração do equipamento. As soluções da curva de calibração são apresentadas na Tabela 4.9.

Tabela 4.9 Soluções utilizadas na construção da curva de calibração para determinação de $\mathrm{Cd}$ e $\mathrm{Pb}$ pela técnica de GF AAS

\begin{tabular}{ccc}
\hline $\begin{array}{c}\text { Soluções de } \\
\text { calibração }\end{array}$ & \multicolumn{2}{c}{$\begin{array}{c}\text { Concentração } \\
\text { calculada }\left(\boldsymbol{\mu g ~ ~ L ^ { - 1 }}\right)\end{array}$} \\
\cline { 2 - 3 } $\mathbf{~ P b}$ & $\mathbf{C d}$ & 0 \\
\hline Branco & 0 & 7,5 \\
P-1 & 0,739 & 15 \\
P-2 & 1,478 & 30 \\
P-3 & 2,07 & 60 \\
P-4 & 2,956 & 90 \\
P-5 & 4,14 &
\end{tabular}

Utilizou-se o programa Winlab 32 for AAS versão 6.2.0.0079 (Perkin Elmer) para construção da curva analítica e leitura da amostras e o sinal analítico foi determinado a partir da área do pico de absorção e utilizou-se o modo de regressão linear para o ajuste da curva.

Para verificação da precisão e exatidão do método foram analisados os materiais de referência certificados WQB-3 (Lake Ontario Glended Sediment for Trace Elements - Environment Canada) e NIST SRM 2709 (San Joaquim Soil, USA), que possuem valores certificados de concentração (total) para os elementos analisados e com procedimento de abertura 3051A da EPA (US EPA, 2007). 


\subsubsection{Espectrometria de Absorção Atômica com geração de vapor frio (CV AAS)}

A análise das amostras por Espectrometria de Absorção Atômica com Geração de Vapor Frio (CV AAS) teve por objetivo a determinação do mercúrio total presente nas amostras de sedimento. Para tanto, amostras, materiais de referência, um branco e cinco soluções padrão foram submetidos previamente a digestão em meio ácido com aquecimento em bloco digestor, para remoção e solubilização do mercúrio presente nas amostras. $O$ procedimento descrito a seguir foi utilizado para a técnica de CV AAS.

\subsubsection{Preparação e leitura de $\mathrm{Hg}$ total nas amostras}

Para preparação das amostras e determinação da concentração total de $\mathrm{Hg}$ nas amostras de sedimento, foi utilizado procedimento consolidado no laboratório de Absorção Atômica do LAN/IPEN-SP.

Cerca de $500 \mathrm{mg}$ de cada amostra e cerca de $250 \mathrm{mg}$ de cada material de referência foram pesados - Balança Analítica Ohaus AR2140 Adventurer - diretamente nos tubos de digestão de TEFLON® e adicionaramse $4 \mathrm{~mL}$ de $\mathrm{HNO}_{3}$ concentrado P.A. Merck e $2 \mathrm{~mL}$ de $\mathrm{H}_{2} \mathrm{SO}_{4}$ concentrado P.A. Merck. Em seguida, adicionou-se $1 \mathrm{~mL}$ de $\mathrm{H}_{2} \mathrm{O}_{2} 20 \%(\mathrm{v} / \mathrm{v})$, gota a gota, devido à intensidade da reação, que pode causar a perda do analito. Os tubos foram fechados e deixados a temperatura ambiente durante a noite para reação, retomando-se o procedimento na manhã seguinte. Foi então iniciado aquecimento em bloco digestor (TECNAL) a $90^{\circ} \mathrm{C}$, por 3 horas.

Após o resfriamento dos tubos, completou-se o volume diretamente nos tubos, para $50 \mathrm{~mL}$ com água ultrapura Milli-Q. Nessas condições, as amostras, materiais de referência, branco e soluções estavam prontos para leitura no equipamento de Espectrometria de Absorção Atômica com Geração de Vapor Frio do LAN/IPEN- marca Perkin Elmer, modelo FIMS 100 (Flow Injection Mercury System), para quantificação do $\mathrm{Hg}$ total. 


\subsubsection{Calibração do equipamento de CV AAS e leitura das amostras}

Primeiramente, procedeu-se com a verificação dos parâmetros de ajuste do equipamento: ajuste da vazão de $\mathrm{SnCl}_{2} 1,1 \%(\mathrm{~m} / \mathrm{v})$ para 4 a 6 $\mathrm{mL} / \mathrm{min}$; ajuste da vazão de $\mathrm{HCl} 3 \%(\mathrm{v} / \mathrm{v})$ para 9 a $11 \mathrm{~mL} / \mathrm{min}$; leitura da solução teste de $\mathrm{Hg}\left(10,07 \mathrm{ng} \mathrm{mL}^{-1}\right)$ e calibração do equipamento com as soluções padrão da curva de calibração de modo a obter os valores de interceptação da curva, inclinação e coeficiente de correlação ou seja, construção da curva de calibração para posterior leitura das amostras.

As soluções para construção da curva analítica - digeridas juntamente com as amostras - e a solução teste $\left(10,07 \mathrm{ng} \mathrm{mL}^{-1}\right)$ foram preparadas a partir de solução padrão de mercúrio $\left(1157,93 \pm 0,01 \mathrm{ng} \mathrm{mL}^{-1}\right)$ pipetadas com pipetador automático e diluídas em balão volumétrico com água Milli-Q. A Tabela 4.10 apresenta as concentrações das soluções padrão para construção da curva analítica.

A solução de $\mathrm{SnCl}_{2}$ 1,1\% (m/v) é utilizada para promover a redução do mercúrio iônico a mercúrio metálico e a solução de $\mathrm{HCl} 3 \%(\mathrm{v} / \mathrm{v})$, é utilizada como carregador no sistema de injeção em fluxo. Em seguida, procedeu-se à leitura das soluções padrão e do branco para construção da curva analítica, utilizando-se o programa Winlab 32 for AAS versão 6.2.0.0079 (Perkin Elmer) e iniciou-se a leitura das amostras de sedimento e materiais de referência no comprimento de onda de 253,7 nm. O sinal analítico foi determinado a partir da área do pico de absorção e utilizou-se o modo de regressão linear para o ajuste da curva. Os materiais de referência utilizados para verificação da confiabilidade dos resultados foram Marine Sediment (IAEA 433), Lake Sediment (IAEA-SL-1) e MESS-3 Marine Sediment (NRC-CNRC). 
Tabela 4.10 Concentração das soluções utilizadas na construção da curva analítica para determinação por CV AAS

\begin{tabular}{cc}
\hline Solução & $\begin{array}{c}\text { Concentração } \\
\left(\mathrm{ng} \mathrm{mL}^{-1}\right)\end{array}$ \\
\hline P-1 & 0,695 \\
P-2 & 1,158 \\
P-3 & 2,316 \\
P-4 & 4,632 \\
P-5 & 6,948 \\
\hline
\end{tabular}

4.9.3 Espectrometria de emissão atômica com fonte de plasma indutivamente acoplado (ICP OES)

Os metais determinados por ICP OES foram Al, B, Ba, Be, Bi, Cd, Co, Cr, Cu, Fe, Li, Mn, Mo, Ni, Pb, Sn, Sr, Ti, TI, V e Zn. As linhas de emissão utilizadas na determinação de cada elemento estão apresentadas na Tabela 4.11: 
Tabela 4.11 Linhas de emissão para os elementos analisados por ICP OES

\begin{tabular}{|c|c|}
\hline Elemento & $\begin{array}{l}\text { Comprimento de } \\
\text { onda }(\lambda) \text {, em } \mathrm{nm}\end{array}$ \\
\hline$\overline{A l}$ & 308,215 \\
\hline B & 249,677 \\
\hline $\mathbf{B a}$ & 455,403 \\
\hline $\mathrm{Be}$ & 313,042 \\
\hline $\mathbf{B i}$ & 223,061 \\
\hline Cd & 228,802 \\
\hline Co & 228,616 \\
\hline $\mathrm{Cr}$ & 267,716 \\
\hline $\mathrm{Cu}$ & 324,752 \\
\hline $\mathrm{Fe}$ & 259,939 \\
\hline Li & 670,784 \\
\hline Mn & 257,610 \\
\hline Mo & 202,031 \\
\hline $\mathbf{N i}$ & 231,604 \\
\hline $\mathbf{P b}$ & 220,353 \\
\hline Sn & 189,927 \\
\hline $\mathrm{Sr}$ & 407,771 \\
\hline $\mathrm{Ti}$ & 334,940 \\
\hline $\mathrm{TI}$ & 190,801 \\
\hline $\mathbf{V}$ & 292,402 \\
\hline $\mathrm{Zn}$ & 213,857 \\
\hline
\end{tabular}

Soluções analíticas (curva analítica) e de controle (padrões de verificação da curva) foram preparadas a partir da solução multielementar SPECSOL. Para verificação da precisão e exatidão do método foram analisados os materiais de referência certificados WQB-3 e NIST SRM 2709 (San Joaquim Soil), que possuem valores certificados de concentração (total) para quase todos os elementos analisados e com procedimento de abertura 3051A da EPA (US EPA, 2007). 


\subsubsection{Verificação e calibração do equipamento de ICP OES}

As análises foram realizadas utilizando-se um espectrômetro de emissão ótica (ICP OES) modelo Optima ${ }^{T M} 2000$ DV, da PerkinElmer. Este equipamento realiza medições seqüenciais sendo que o plasma possui vista axial e radial. O aparelho é equipado com monocromador composto de dois dispositivos de dispersão, o prisma Litrow e a grade Echelle. Após a dispersão, as radiações são direcionadas para o detector que é do tipo CCD (dispositivo de carga acoplada). O nebulizador utilizado foi do tipo GemCone acoplado a uma camâra de nebulização. O equipamento possui um amostrador automático equipado com bomba peristáltica para inserção da amostra no equipamento. As análises foram realizadas no equipamento do laboratório Analytical Solutions LTDA.

A Tabela 4.12 apresenta as condições utilizadas nas análises de metais pela técnica de ICP OES.

Tabela 4.12 - Parâmetros instrumentais do ICP OES

\begin{tabular}{cc}
\hline Parâmetros Instrumentais & ICP OES \\
\hline Potência de Radiofrequência & $1350 \mathrm{~W}$ \\
Vazão do gás principal & $15 \mathrm{Lin}^{-1}$ \\
Vazão do gás auxiliar & $0,2 \mathrm{~L} \mathrm{~min}^{-1}$ \\
Vazão do gás de nebulização & $0,8 \mathrm{~L} \mathrm{~min} \mathrm{~min}^{-1}$ \\
Nebulizador & GemCone \\
Injetor & Alumina \\
Vazão da amostra & $1,5 \mathrm{~mL} \mathrm{~min}^{-1}$ \\
\hline
\end{tabular}

Argônio comercial com pureza de 99,9\% (Linde Gases) foi utilizado para a geração do plasma, sendo também utilizado como gás de nebulização e auxiliar. Para o shear gás, utilizou-se ar comprimido (para cortar a região fria do plasma). Nitrogênio de grau analítico 99,999\% (Linde Gases) foi utilizado como gás de purga no sistema ótico do espectrômetro.

A verificação do equipamento consistiu no ajuste dos parâmetros de medida e no alinhamento ótico através da leitura de um padrão $1,0 \mathrm{mg} \mathrm{L}^{-1}$ de Mn com comprimento de onda de $257,610 \mathrm{~nm}$ e a checagem dos parâmetros instrumentais, listados na Tabela 4.12 acima. 
Para a calibração do equipamento, foi construída a curva analítica preparada a partir de sete soluções P1, P2, P3, P4, P5, P6 e P7 - estas preparadas a partir de soluções padrão certificadas - e o branco, constituído de uma solução de $\mathrm{HNO}_{3} 5 \%$.

\subsubsection{Linearidade Analítica}

A técnica de ICP OES apresenta uma grande vantagem em relação a outras técnicas óticas, que é a extensa faixa de trabalho, que pode variar de $\mu \mathrm{g} \mathrm{k}^{-1}$ até $\mathrm{g} \mathrm{kg}^{-1}$. Devido a esta característica, foram construídas curvas de calibração que abrangem de $10 \mathrm{mg} \mathrm{L}^{-1}$ até $100 \mathrm{mg} \mathrm{L}^{-1}$, e optou-se em calcular as concentrações das amostras a partir do método de Fator de Calibração (FC), o qual consiste em observar um valor médio entre a divisão de cada intensidade obtida pela concentração do padrão correspondente, e associar este valor médio ao valor de intensidade da amostra, obtendo-se assim o resultado, de acordo com as equações 4.6; 4.7 e 4.8:

$$
\mathrm{FC}=\frac{\text { Intensidade do padrão }}{\text { Concentração do padrão }} \quad \text { (Equação 4.6) }
$$

$$
\text { Média do } F C=\sum_{p} \frac{\Sigma_{p C}}{p} \quad(\text { Equação 4.7) }
$$

onde $\mathrm{p}=$ número de padrões

Concentração da amostra $=$ Intensidade da amostra (Equação 4.8) Média do FC

A linearidade mede o quanto um gráfico da resposta analítica versus a concentração do analito segue uma linha reta. Para a verificação da 
linearidade das curvas de calibração, foram utilizados os métodos do coeficiente de determinação R-quadrado e a incerteza de calibração. Para a aceitação da curva, o $R^{2}$ deve ter valor superior a 0,995, e a incerteza deve ser inferior à $25 \%$.

A incerteza da calibração $\left(I_{c}\right)$ é calculada de acordo com a média do Fator de Calibração e o desvio padrão dos fatores de calibração $\left(\sigma_{F C}\right)$, de acordo com a equação 4.9:

$$
I_{C}=\underline{\sigma}_{F C} \underline{x} 100 \quad \text { Média do FC }
$$

O coeficiente de determinação R-quadrado é obtido através da equação 4.10:

$$
\mathbf{R}^{2}=\frac{\left[\Sigma\left(\mathbf{x}_{\mathrm{i}}-\mathbf{x}\right)\left(\mathbf{y}_{\mathrm{i}}-\mathbf{y}\right)\right]^{2}}{\Sigma\left(\mathbf{x}_{\mathrm{i}}-\mathbf{x}\right)^{2} \Sigma\left(\mathbf{y}_{\mathrm{i}}-\mathbf{y}\right)^{2}} \text { (Equação 4.10) }
$$

Onde $\boldsymbol{x}$ é a média de todos os valores de concentração da curva analítica e $\boldsymbol{y}$ é a média de todos os valores de intensidade dos padrões.

\subsubsection{Analise por Ativação Neutrônica (NAA)}

\subsubsection{Preparação dos padrões sintéticos}

Os padrões sintéticos foram preparados a partir de soluções de sais e óxidos dos elementos de interesse - certificadas pela SPEX CERTIPREP, USA, diluídas a concentrações adequadas para a análise e pipetadas com 
pipetadores automáticos em tiras de papel filtro Whatman ํo 40. Após a secagem das tiras de papel filtro a temperatura ambiente, as mesmas foram dobradas e acondicionadas em invólucros de polietileno, de modo a se obter uma geometria o mais similar possível entre os padrões pipetados e as amostras (envelope plástico de dimensões $1,5 \times 1,5 \mathrm{~cm}^{2}$ ). Antes da preparação dos padrões, os volumes dos pipetadores e balões volumétricos utilizados, foram calibrados gravimetricamente (MOREIRA, 2010).

Podem-se utilizar também padrões sintéticos multielementares, onde as soluções elementares certificadas são diluídas e pipetadas no mesmo papel de filtro, agrupando-se os elementos de interesse de modo que não haja interferência espectral ou química entre si (BOSTELMANN, 2006).

\subsubsection{Irradiação e contagem}

Cerca de $150 \mathrm{mg}$ de amostras de sedimentos (duplicata), materiais de referência e padrões sintéticos foram irradiados por dezesseis horas, sob um fluxo de nêutrons térmicos de $10^{12} \mathrm{n} \mathrm{cm}^{-2} \mathrm{~s}^{-1}$, no Reator de Pesquisa IEAR1 do IPEN/CNEN-SP.

A primeira contagem foi realizada após um tempo de decaimento de 5 a 7 dias, por aproximadamente uma hora para amostras e materiais de referência, e de 15 a 30 minutos para os padrões sintéticos. Os seguintes radioisótopos de $\mathrm{T}_{1 / 2}$ intermediária: ${ }^{76} \mathrm{As},{ }^{82} \mathrm{Br},{ }^{42} \mathrm{~K},{ }^{140} \mathrm{La},{ }^{24} \mathrm{Na},{ }^{147} \mathrm{Nd},{ }^{239} \mathrm{~Np}$, ${ }^{122} \mathrm{Sb},{ }^{153} \mathrm{Sm}$ e ${ }^{175} \mathrm{Yb}$ puderam ser determinados.

A segunda contagem foi realizada após um tempo de decaimento de quinze a vinte dias e um tempo de contagem idêntico ao utilizado na primeira contagem. Os seguintes radioisótopos de $\mathrm{T}_{1 / 2}$ longa: ${ }^{131} \mathrm{Ba},{ }^{141} \mathrm{Ce},{ }^{60} \mathrm{Co},{ }^{57} \mathrm{Cr}$, ${ }^{134} \mathrm{Cs},{ }^{152} \mathrm{Eu},{ }^{59} \mathrm{Fe},{ }^{181} \mathrm{Hf},{ }^{177} \mathrm{Lu},{ }^{233} \mathrm{~Pa},{ }^{86} \mathrm{Rb},{ }^{124} \mathrm{Sb},{ }^{46} \mathrm{Sc},{ }^{75} \mathrm{Se},{ }^{182} \mathrm{Ta},{ }^{160} \mathrm{~Tb},{ }^{169} \mathrm{Yb}$, ${ }^{65} \mathrm{Zn}$ e ${ }^{95} \mathrm{Zr}$ puderam ser determinados. 
Para verificação da precisão e exatidão do método foram analisados os materiais de referência certificados NIST SRM 2704 e 8704 (Buffalo River Sediment), Soil-7 (AIEA) e BEN (Basalt- IWG-GIT), que possuem valores certificados para quase todos os elementos analisados.

\subsubsection{Espectrometria Gama}

A instrumentação utilizada para a medida de radiação gama emitida por amostras radioativas, geralmente consiste de um sistema constituído de um detector, associado a um sistema eletrônico e um computador com analisador multicanal para obtenção dos dados. A maioria dos laboratórios de NAA utilizam um ou mais detectores de germânio hiperpuro (HPGe), montados em criostato a vácuo com nitrogênio líquido (temperatura de 77K).

A contagem das amostras foi realizada em detector de cristal semicondutor de germânio hiperpuro (HPGe) associado a sistema eletrônico de aquisição de dados da CANBERRA, cuja resolução para o pico de 121,97 keV do ${ }^{57} \mathrm{Co}$ é de $1,1 \mathrm{keV}$ e para o pico de $1332,49 \mathrm{keV}$ do ${ }^{60} \mathrm{Co}, 2,0 \mathrm{keV}$. A partir dos espectros gerados, foi possível calcular as concentrações dos elementos de interesse utilizando planilhas de Microsoft Excel®. O mesmo procedimento foi realizado para as amostras das duas campanhas de coleta. A Tabela 4.13 apresenta os radioisótopos utilizados na quantificação dos elementos de interesse pela técnica de NAA, bem como as respectivas energias gama de decaimento e tempos de meia-vida.

Tabela 4.13- Radioisótopos identificados na análise das amostras de sedimento por NAA (IAEA,1990) 


\begin{tabular}{|c|c|c|c|c|c|}
\hline Radioisótopo & $\begin{array}{c}\text { Energia } \\
\text { (kev) }\end{array}$ & $\begin{array}{c}\text { Tempo } \\
\text { de meia-vida }\end{array}$ & Radioisótopo & $\begin{array}{c}\text { Energia } \\
\text { (kev) }\end{array}$ & $\begin{array}{c}\text { Tempo } \\
\text { de meia-vida }\end{array}$ \\
\hline${ }^{76}$ As & 559,1 & 26,32 horas & ${ }^{86} \mathrm{Rb}$ & 1076,6 & 18,66 dias \\
\hline${ }^{131} \mathbf{B a}$ & 496,26 & 11,8 dias & ${ }^{122} \mathrm{Sb}$ & 564,24 & 2,7 dias \\
\hline${ }^{82} \mathrm{Br}$ & $\begin{array}{c}554 \\
776,52\end{array}$ & 35,3 horas & ${ }^{124} \mathrm{Sb}$ & 1690,98 & 60,20 dias \\
\hline${ }^{141} \mathrm{Ce}$ & 145,4 & 32,5 dias & ${ }^{46} \mathrm{Sc}$ & 889,28 & 83,81 dias \\
\hline${ }^{60} \mathrm{Co}$ & $\begin{array}{l}1173,2 \\
1332,5\end{array}$ & 5,27 anos & ${ }^{75} \mathrm{Se}$ & 264,6 & 119,77 dias \\
\hline${ }^{57} \mathrm{Cr}$ & 320,1 & 27,7 dias & ${ }^{153} \mathrm{Sm}$ & 103,18 & 46,27 horas \\
\hline${ }^{134} \mathrm{Cs}$ & 795,85 & 2,06 anos & ${ }^{182} \mathrm{Ta}$ & 1221,41 & 114,5 dias \\
\hline${ }^{152} \mathrm{Eu}$ & 1408 & 13,33 anos & ${ }^{160} \mathrm{~Tb}$ & 879,38 & 72,3 dias \\
\hline${ }^{59} \mathrm{Fe}$ & $\begin{array}{c}1099,25 \\
1291,6\end{array}$ & 44,5 dias & ${ }^{233} \mathbf{P a}$ & 312,01 & 27,0 dias \\
\hline${ }^{181} \mathrm{Hf}$ & 482,18 & 42,39 dias & ${ }^{239} \mathrm{~Np}$ & $\begin{array}{c}228,18 \\
277,6\end{array}$ & 2,36 dias \\
\hline${ }^{140} \mathrm{La}$ & $\begin{array}{c}328,7 \\
1596,21\end{array}$ & 40,27 horas & ${ }^{169} \mathrm{Yb}$ & $\begin{array}{l}177,21 \\
197,96\end{array}$ & 32,2 dias \\
\hline${ }^{177} \mathrm{Lu}$ & 208,36 & 6,71 dias & ${ }^{175} \mathbf{Y b}$ & $\begin{array}{l}282,52 \\
396,33\end{array}$ & 4,19 horas \\
\hline${ }^{24} \mathrm{Na}$ & 1368,6 & 14,96 horas & ${ }^{65} \mathrm{Zn}$ & 1115,5 & 243,9 dias \\
\hline${ }^{147} \mathrm{Nd}$ & $\begin{array}{c}91,10 \\
531,01\end{array}$ & 10,98 dias & & & \\
\hline
\end{tabular}




\subsubsection{Cálculo do Z-score}

Para controle de qualidade dos resultados obtidos pela técnica de NAA, tem sido bastante utilizado o critério de Z-score (Bode, 1996). O cálculo da diferença padronizada ou valor de $Z$ de um resultado analítico é obtido a partir da equação 4.11 abaixo:

$$
Z_{i}=C_{i}-C_{r e f, i} /\left(\sigma_{i}^{2}+\sigma_{r e f, i}^{2}\right)^{1 / 2}
$$

Onde

$$
\begin{aligned}
& \mathbf{C}_{\mathrm{i}=\text { concentração do elemento i na análise do MR, }} \\
& \mathbf{C}_{\text {ref,i }}=\text { valor certificado de concentração ou de consenso para } \\
& \text { o elemento } \mathrm{i}, \\
& \sigma_{\mathrm{i}}=\text { incerteza da concentração do elemento i na análise do MR, } \\
& \sigma_{\text {ref,i }}=\text { incerteza do valor de consenso certificado para o elemento i }
\end{aligned}
$$

No caso da técnica de NAA, o uso do valor de $Z$ para aprovação dos resultados considera que se $\mathbf{Z} /<\mathbf{3}$ tem-se que o resultado individual da amostra controle, no nosso caso o material de referência que está sendo analisado, deve estar dentro de $99 \%$ do intervalo de confiança do valor esperado.

\subsection{Limites de detecção e de quantificação}

\subsubsection{Limites de detecção e de quantificação: AAS e ICP OES}

O limite de deteç̧ão (LD) é a menor quantidade de analito que é significativamente diferente de um branco. Para sua avaliação, foram 
realizadas 7 leituras de brancos analíticos, foram calculadas as médias e os desvios padrões $(\sigma)$ e a partir dos resultados, utilizou-se a equação 4.12 para a determinação do LD nas técnicas de AAS e ICP OES:

$$
\text { L.D. }=x_{\text {branco }}+3 \sigma \quad \text { (Equação 4.12) }
$$

Onde:

LD - Valor do Limite de detecção calculado

$\mathrm{x}_{\text {branco }}=$ média dos valores de brancos analíticos

$(\sigma)$ - Desvios Padrões das leituras dos brancos analíticos

Uma amostra cuja concentração está no limite de detecção pode ser distinguida de um branco, mas o sinal proveniente da amostra é muito ruidoso para ser determinado com exatidão, ou seja, não é possível determinar com certeza se o resultado é devido ao sinal analítico da amostra ou se há interferências devido ao sinal de baixa intensidade, ocasionado pelos ruídos.

Devido a estes fatores, o limite de quantificação (LQ) é normalmente considerado como sendo suficientemente forte para ser medido com mais exatidão. Normalmente considera-se que uma amostra entre os limites de detecção e de quantificação está na região de detecção, mas não na região de quantificação.

O LQ é dado conforme a equação 4.13:

$$
\text { L.Q. }=X_{\text {branco }}+10 \sigma \quad(\text { Equação } 4.13)
$$

A Tabela 4.14 apresenta os LQ e LD obtidos para a técnica de ICP OES: 
Tabela 4.14 - Valores de LD e LQ para a técnica de ICP

\begin{tabular}{|c|c|c|c|}
\hline Parâmetros & Unidade & LD & $\mathbf{L Q}$ \\
\hline$\overline{A l}$ & $\left(\mathrm{mg} \mathrm{kg}^{-1}\right)$ & 0,500 & 1,000 \\
\hline B & $\left(\mathrm{mg} \mathrm{kg}^{-1}\right)$ & 0,500 & 1,000 \\
\hline $\mathrm{Ba}$ & $\left(\mathrm{mg} \mathrm{kg}^{-1}\right)$ & 0,200 & 1,000 \\
\hline $\mathrm{Be}$ & $\left(\mathrm{mg} \mathrm{kg}^{-1}\right)$ & 0,200 & 1,000 \\
\hline$\overline{B i}$ & $\left(\mathrm{mg} \mathrm{kg}^{-1}\right)$ & 1,000 & 5,000 \\
\hline Cd & $\left(\mathrm{mg} \mathrm{kg}^{-1}\right)$ & 0,030 & 0,100 \\
\hline Co & $\left(\mathrm{mg} \mathrm{kg}^{-1}\right)$ & 0,500 & 1,000 \\
\hline $\mathrm{Cr}$ & $\left(\mathrm{mg} \mathrm{kg}^{-1}\right)$ & 0,500 & 1,000 \\
\hline $\mathrm{Cu}$ & $\left(\mathrm{mg} \mathrm{kg}^{-1}\right)$ & 0,100 & 0,500 \\
\hline $\mathrm{Fe}$ & $\left(\mathrm{mg} \mathrm{kg}^{-1}\right)$ & 1,000 & 5,000 \\
\hline Li & $\left(\mathrm{mg} \mathrm{kg}^{-1}\right)$ & 0,500 & 1,000 \\
\hline Mn & $\left(\mathrm{mg} \mathrm{kg}^{-1}\right)$ & 0,500 & 1,000 \\
\hline Mo & $\left(\mathrm{mg} \mathrm{kg}^{-1}\right)$ & 0,200 & 1,000 \\
\hline $\mathbf{N i}$ & $\left(\mathrm{mg} \mathrm{kg}^{-1}\right)$ & 0,500 & 1,000 \\
\hline $\mathbf{P b}$ & $\left(\mathrm{mg} \mathrm{kg}^{-1}\right)$ & 0,200 & 1,000 \\
\hline Sn & $\left(\mathrm{mg} \mathrm{kg}^{-1}\right)$ & 2,000 & 5,000 \\
\hline $\mathrm{Sr}$ & $\left(\mathrm{mg} \mathrm{kg}^{-1}\right)$ & 0,100 & 1,000 \\
\hline $\mathrm{Ti}$ & $\left(\mathrm{mg} \mathrm{kg}^{-1}\right)$ & 0,500 & 1,000 \\
\hline $\mathrm{TI}$ & $\left(\mathrm{mg} \mathrm{kg}^{-1}\right)$ & 0,500 & 1,000 \\
\hline V & $\left(\mathrm{mg} \mathrm{kg}^{-1}\right)$ & 0,200 & 1,000 \\
\hline $\mathrm{Zn}$ & $\left(\mathrm{mg} \mathrm{kg}^{-1}\right)$ & 0,500 & 1,000 \\
\hline
\end{tabular}

A Tabela 4.15 apresenta os resultados dos LD e LQ obtidos para as técnicas de GF AAS e CV AAS.

Tabela 4.15 Valores de LD e LQ para as técnicas GF AAS e CV AAS

\begin{tabular}{c|c|c|c}
\hline & $\begin{array}{c}\mathbf{C d} \\
\left(\mathbf{m g ~ k g}^{-1}\right)\end{array}$ & $\begin{array}{c}\mathbf{P b} \\
\left(\mathbf{m g ~ k g}^{-1}\right)\end{array}$ & $\begin{array}{c}\mathbf{H g} \\
\left(\mu \mathbf{g ~ k g}^{-1}\right)\end{array}$ \\
\hline L.D. & 0,005 & 0,100 & 1 \\
\hline L.Q. & 0,010 & 0,250 & 10 \\
\hline
\end{tabular}




\subsubsection{Limites de detecção e de quantificação: NAA}

Para a determinação dos limites de detecção da técnica NAA, utilizou-se a expressão descrita na equação 4.14 (KEITH, 1983), para cada elemento analisado, nos materiais de referência certificados NIST SRM 2704 e 8704 (Buffalo River Sediment), Soil-7 (AIEA) e BEN (Basalt- IWG-GIT):

(Equação 4.14)

Onde, BG é o valor da contagem do background no fotopico do elemento de interesse (em cps) nos materiais de referência, $\mathbf{T}$ é o tempo vivo (em segundos), $\mathbf{V}$ - Valor certificado, $\mathbf{A}$ é a atividade no fotopico do elemento, e $\mathbf{m}$, a massa da amostra. Após o cálculo com base em cada material de referência, foi calculada a média dos valores obtidos para a obtenção dos valores dos LDs.

Para o cálculo do LQ, foi utilizada a equação 4.15 , conforme descrito abaixo:

$$
L Q=10 * \sqrt{B g} / T
$$

(Equação 4.15)

Os respectivos limites de detecção e quantificação para cada elemento analisado por NAA estão apresentados na Tabela 4.16: 
Tabela 4.16 Limites de Detecção e Quantificação (mg kg-1) para os elementos determinados por NAA

\begin{tabular}{c|c|c}
\hline Elemento & LD & LQ \\
\hline $\mathbf{A s}$ & 0,20 & 0,50 \\
\hline $\mathbf{B a}$ & 25,00 & 75,00 \\
\hline $\mathbf{B r}$ & 0,10 & 0,30 \\
\hline $\mathbf{C a}(\%)$ & 0,10 & 0,30 \\
\hline $\mathbf{C e}$ & 0,30 & 0,80 \\
\hline $\mathbf{C o}$ & 0,05 & 0,15 \\
\hline $\mathbf{C r}$ & 0,50 & 1,50 \\
\hline $\mathbf{C s}$ & 0,05 & 0,15 \\
\hline $\mathbf{E u}$ & 0,01 & 0,03 \\
\hline $\mathbf{F e}(\%)$ & 0,0030 & 0,0100 \\
\hline $\mathbf{H f}$ & 0,05 & 0,15 \\
\hline $\mathbf{K}(\%)$ & 0,08 & 0,25 \\
\hline $\mathbf{L a}$ & 0,05 & 0,20 \\
\hline $\mathbf{L u}$ & 0,004 & 0,010 \\
\hline
\end{tabular}

\begin{tabular}{c|c|c}
\hline Elemento & LD & LQ \\
\hline $\mathbf{N a}$ & 7,00 & 20,00 \\
\hline $\mathbf{N d}$ & 2,00 & 5,50 \\
\hline $\mathbf{R b}$ & 2,00 & 5,00 \\
\hline $\mathbf{S b}$ & 0,03 & 0,09 \\
\hline $\mathbf{S c}$ & 0,005 & 0,020 \\
\hline $\mathbf{S e}$ & - & - \\
\hline $\mathbf{S m}$ & 0,015 & 0,045 \\
\hline $\mathbf{T a}$ & 0,12 & 0,35 \\
\hline $\mathbf{T b}$ & 0,10 & 0,30 \\
\hline $\mathbf{T h} \mathbf{( P a )}$ & 0,05 & 0,15 \\
\hline $\mathbf{U} \mathbf{( N p )}$ & 0,10 & 0,30 \\
\hline $\mathbf{Y b}$ & 0,05 & 0,20 \\
\hline $\mathbf{Z n}$ & 1,00 & 3,00 \\
\hline $\mathbf{Z r}$ & 25,00 & 75,00 \\
\hline
\end{tabular}

\subsection{Interpretação dos resultados}

\subsubsection{Normalização}

Schropp (1988) descreveu uma abordagem para a interpretação de concentrações de metais em sedimentos costeiros. A interpretação dos resultados de metais é dificultada pelo fato de que a concentração absoluta é afetada por uma grande variedade de fatores, incluindo a mineralogia dos sedimentos, granulometria, teor de matéria orgânica e os fatores de enriquecimento antrópico. A ferramenta proposta para a interpretação dos dados é baseada na relação natural, relativamente constante, entre os metais e 
o Al. Foram realizadas as curvas de regressão linear Metal/Al e os limites foram calculados e construídos os diagramas de correlação. Com a avaliação dos dados no diagrama é possível identificar se as concentrações dos metais representam uma concentração natural ou se ocorreu por ação antrópica. No documento são apresentados além das curvas de regressão linear, os limites de confiança e os coeficientes de correlação.

Windom et al (1989), apresentaram as concentrações de metais em níveis traço, provenientes de sedimentos do sudeste dos EUA, em ambientes costeiros, utilizando o Al como normalizador geoquímico para estabelecer a relação entre as concentrações naturais dos elementos dispostos nos sedimentos nas diferentes áreas e as contribuições antrópicas existentes. As amostras foram analisadas pelas técnicas de FAAS e GF AAS, para a análise dos metais em mais de 450 amostras de sedimentos dos estuários e zonas remotas, na costa marinha do sudeste dos EUA, a partir de fontes de contaminantes para alguns metais como $\mathrm{Al}, \mathrm{As}, \mathrm{Cd}, \mathrm{Co}, \mathrm{Cr}, \mathrm{Cu}, \mathrm{Hg}, \mathrm{Fe}, \mathrm{Pb}$, $\mathrm{Mn}, \mathrm{Ni}$, e $\mathrm{Zn}$. Foi sugerido que a covariância dos metais com o Al fornece uma base útil para a identificação e comparação da ação antropogênica nos sedimentos. Pelo uso desta abordagem, sedimentos do rio Savannah, baía de Biscayne e Pensacola foram comparados. Foi verificada uma semelhança entre - Al nas equações de regressão linear, o que sugere uma composição relativamente constante, ou seja, uma proporcionalidade entre os metais, da área de origem das fases naturais dos metais rumo ao sudeste dos EUA.

Aloupi \& Angelidis (2001) determinaram o impacto de contaminantes metálicos provenientes de fontes naturais e antrópicas na zona costeira e no porto da cidade de Mytilene (ilha de Lesvos, Grécia), após a normalização dos dados com o Li utilizando o modelo de correlação linear (no gráfico de scatter plot). Esse método se apresentou mais adequado que o Al como normalizador para descrever, com sucesso, a variação dos metais nos sedimentos da costa. Elementos como $\mathrm{Cd}, \mathrm{Cu}, \mathrm{Pb}$ e $\mathrm{Zn}$ apresentaram contaminação nos sedimentos do porto, enquanto não foi detectada poluição na ampla zona costeira ou nos sedimentos no porto antigo, na parte norte da cidade de Mytilene. A normalização geoquímica dos dados de metais com Li é um método que pode 
detectar o grau de contaminação considerando-se a variabilidade natural nos sedimentos na área de estudo.

Para a realização da normalização com Al, Hortellani et al (2008), destacaram a importância de se obter um nível de recuperação em torno de $100 \%$, sendo definido pelo método de digestão da amostra que propicie a inteira extração dos metais, em especial do Al que foi escolhido como elemento normalizador, utilizando duas técnicas de normalização, que foram a extrapolação da curva de regressão linear e Fator de Enriquecimento. Apresentaram ainda os valores obtidos de "r" (correlações de Pearson), que demonstram as principais correlações entre duas variáveis dos sedimentos aquáticos e observaram que os teores de Al, Fe e Co apresentavam uma significante correlação com os outros metais, e citando Aloupi et al, (2001), Hortellani et al (2008), salientaram que esta condição seria necessária para que um elemento fosse utilizado como elemento normalizador para os elementos anômalos, sugerindo que esses elementos fazem parte da constituição natural dos sedimentos ou resultados de processos climáticos naturais.

Para o presente trabalho, foi utilizado o Sc como elemento normalizador, devido às características de elemento conservativo, pelo método de extrapolação da curva de regressão.

\subsubsection{Cálculo do Fator de Enriquecimento (FE)}

O fator de enriquecimento (FE), definido por Gresens (1967) como a dupla razão normalizada para um elemento de referência $(R E)$, é um índice usado como uma ferramenta para avaliar a extensão da poluição por metais (Audry et. al., 2004). Os metais Fe, Al e Sc são os mais usados para propósitos de normalização (Gomes et. al., 2009) e no presente estudo, utilizou-se o Sc como elemento normalizador. Os valores de referencia utilizados para 
sedimento no presente estudo foram os valores de UCC (Upper Continental Crust) (WEDEPOHL, 1995).

No presente estudo o Fator de Enriquecimento foi calculado utilizando-se a equação 4.16:

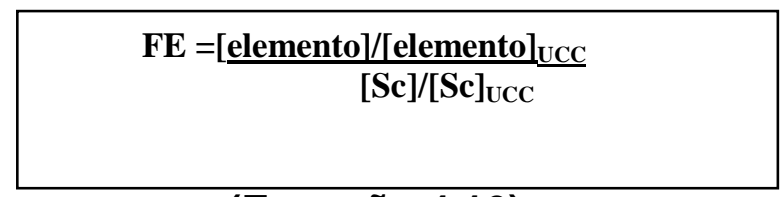

\section{(Equação 4.16)}

Onde:

[elemento] $=$ concentração do elemento no sedimento

[elemento $_{\text {ucc }}=$ concentração do elemento nos valores UCC

$[\mathrm{Sc}]$ = concentração do elemento Sc (elemento normalizador) no sedimento

$[S c]_{\text {ucc }}=$ concentração do elemento Sc descrito na tabela de valores UCC

Por convenção, se o valor de $\mathbf{0 , 5}<\mathrm{FE}<1,5$, considera-se que os metais traço são provenientes totalmente de contribuição crustal (por exemplo, produto de intemperismo) e um valor de FE $>1,5$, é indicativo de que a fonte principal é de contribuição antrópica. Quanto maior o valor de FE, maior o grau de poluição de origem antrópica (ZHANG \& LIU, 2002).

\subsection{3 Índice de Geoacumulação (Igeo)}

O índice de geoacumulação tem sido usado desde a década de 60 e tem sido largamente empregado em estudos de metais traço na Europa (Yaqin et al, 2008). Foi utilizado pela primeira vez para sedimentos de fundo (Müller, 1969) e desde então tem sido aplicado, com sucesso, para medidas de contaminação de solo (Yaqin et al, 2008) e sedimentos (Gomes et al, 2009; Rezaee et al, 2011). 
Para este estudo, foram realizados os cálculos de Índice de Geoacumulação (Igeo) para os resultados de concentração das amostras obtidos pelas técnicas de NAA, ICP OES e AAS, adotando os valores de referência (background) encontrados por Luiz-Silva et al, (2008), para a região do estuário de Santos e São Vicente, nas análises realizadas por ICP OES, GF AAS e CV AAS, bem como os dados descritos por Damato (2010) para os dados obtidos por NAA. Ainda foram utilizados os valores de UCC (Upper Continental Crust), descritos por Wedepohl (1995).

Para o cálculo do Igeo, foi utilizada a Equação 4.17, conforme Müller (1969), Stoffers et al (1986) e Abrahim et al (2005) (apud REZAEE, 2011).

Equação 4.17

$$
\text { IgeO }=\log _{2}\left(\frac{C_{a m}}{1,5 C_{\text {ref }}}\right)
$$

Onde:

$C_{a m}=$ concentração do elemento de interesse na amostra;

$C_{\text {ref }}=$ concentração de referência do elemento de interesse.

Onde $C_{a m}$ é a concentração medida do metal $n$ na fração fina do sedimento (<63 $\mu \mathrm{m})$ e $C_{\text {ref }}$ é o valor geoquímico de "background". O fator 1,5 da equação é usado para compensar possíveis variações dos dados de "background" devido a efeitos litogênicos (Gomes et al, 2009).

No presente estudo não foi analisada a fração fina dos sedimentos $(<63 \mu \mathrm{m})$, apenas a fração total, mas mesmo assim utilizou-se o critério de valores $I_{\text {geo }}$ como critério de comparação dos resultados.

Os valores de $I_{\text {geo }}$ são classificados segundo a Tabela 4.17, quanto ao nível de poluição. 
Tabela 4.17 Classificação do nível de poluição a partir dos valores de IGeo calculados

\begin{tabular}{ll}
\hline$I_{\text {geo }}$ & Nível de poluição \\
\hline$<0$ & Nível basal \\
0 a 1 & Não poluído \\
1 a 2 & Moderadamente poluído \\
2 a 3 & Moderadamente a Poluído \\
3 a 4 & Poluído a Altamente poluído \\
4 a 5 & Muito poluído \\
> 5 & Altamente poluído \\
\hline
\end{tabular}

O índice Igeo estima o grau da poluição dos metais, em uma escala de 7 classes de enriquecimento (Gomes, et al, 2009).

\subsubsection{Gráficos Box Plot}

Tanto a média como o desvio-padrão podem não ser medidas adequadas para representar um conjunto de valores, uma vez que são afetados de forma exagerada, por valores extremos. Além disso, apenas com estas duas medidas não temos idéia da assimetria da distribuição dos valores.

Para solucionar esses problemas, podemos utilizar o box plot. Para construí-lo, desenhamos uma "caixa" com o nível superior dado pelo terceiro quartil (Q3) e o nível inferior pelo primeiro quartil (Q1). A mediana (Q2) é representada por um traço no interior da caixa e segmentos de reta são colocados da caixa até os valores máximo e mínimo, que não sejam observações discrepantes. Em suma, o box plot fornece informações sobre posição, dispersão, assimetria, caudas e valores discrepantes.

A Figura 4.9 demonstra a representação esquemática de um típico gráfico Box Plot: 


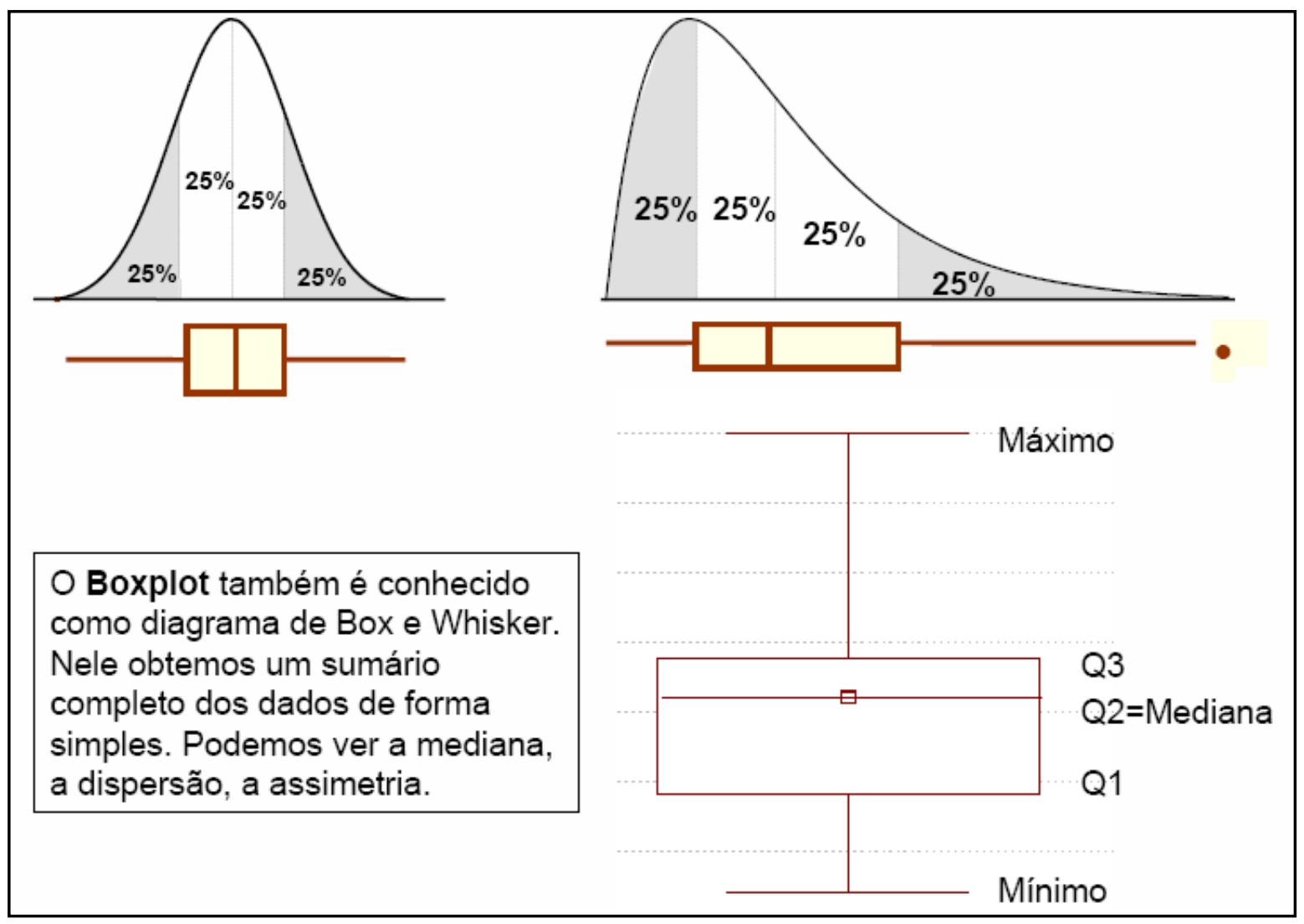

Figura 4.9 Representação esquemática dos gráficos Box-Plot

Os valores que estão distantes do centro da distribuição são referidos como outliers (valores atípicos, discrepantes) e valores extremos, caso preencham as condições especificadas abaixo. Um ponto de dados é considerado um outlier diante das seguintes condições:

O critério para decidir se uma observação é discrepante pode variar; por ora, chamaremos de discrepante os valores maiores do que Q3+1.5*(Q3Q1) ou menores do que Q1-1.5*(Q3-Q1).

Extremos: Um ponto de dados é considerado um valor extremo se as seguintes condições forem atendidas:

$$
\text { dados de valor > ponto UBV }+2 \text { * O.C. (UBV - LBV) }
$$

ou

ponto de dados de valor < LBV - 2 * O.C. (UBV - LBV) 
onde:

UBV (upper value of the box) -É o valor superior da caixa no gráfico de caixa (por exemplo, a média + desvio padrão, ou o percentil $75 \%$ ).

LBV (lower value of the box) - É o menor valor da caixa no gráfico de caixa (por exemplo, a média - desvio padrão, ou o percentil $25 \%$ ).

O.C. (outlier coeficiente) - É o coeficiente especificado para os Outliers. Por padrão, o coeficiente é de 1,5. Assim, os valores extremos são aqueles que estão fora da faixa de comprimento de 3 a caixa de valor superior e inferior da caixa.

\section{Faixa non-outlier}

O intervalo non-outlier é o intervalo de valores que são inferiores ao limite superior outlier (por exemplo, 1,5* altura da caixa) e acima do limite inferior de outlier (por exemplo, $-1,5^{*}$ altura da caixa).

A Figura 4.10 abaixo ilustra os intervalos de outliers e extremos do box "clássico" e o whisker plot onde o valor caixa superior é o percentil 75 (terceiro quartil), o menor valor de caixa é o percentil 25 (primeiro quartil), e o coeficiente de outlier é igual a 1,5. 


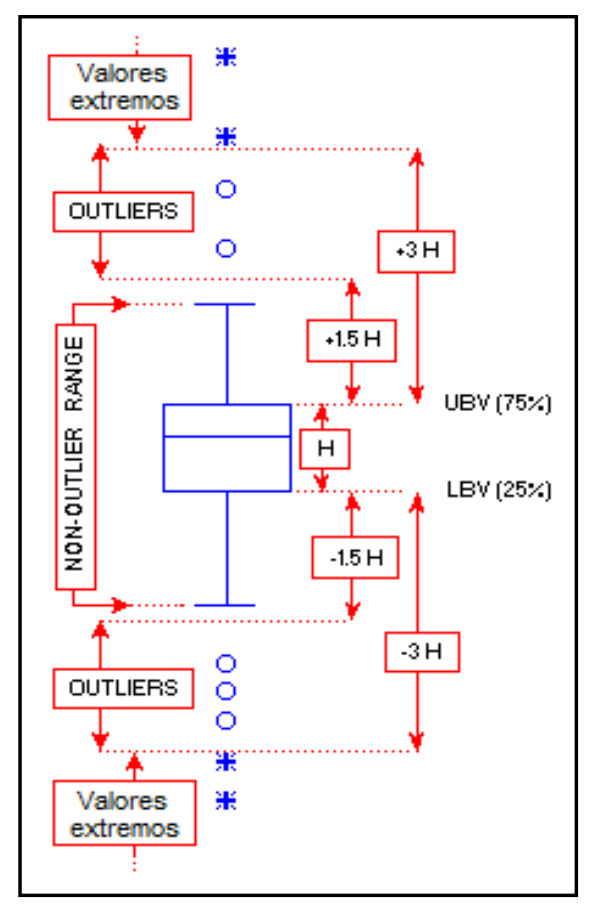

Figura 4. 10 Representação clássica Box Plot com outliers e valores extremos (fonte: SOFTWARE STASOFT STATISTICA 8.0 - Help files)

\subsubsection{Dendrogramas}

Atualmente existe um crescente interesse em métodos de análise de informações para extração de conhecimento de conjuntos de dados. Nesse contexto, o clustering hierárquico pode ser utilizado para analisar dados em diferentes níveis de detalhes (METZ, et al, 2005).

Uma maneira de se obter os agrupamentos é por meio de um algoritmo de clustering hierárquico, o qual representa os clusters em uma estrutura conhecida como dendrograma que consiste de um tipo especial de árvore, na qual os nós pais agrupam os exemplos representados pelos nós filhos. Dessa maneira, um agrupamento hierárquico agrupa os dados de modo que se dois exemplos são agrupados em algum nível, nos níveis mais acima eles continuam fazendo parte do mesmo grupo, construindo uma hierarquia de clusters (agrupamentos). Com a obtenção dessa representação simbólica, a interpretação do conhecimento extraído torna-se mais simples e menos custosa (METZ et al, 2005). 


\section{CAPÍTULO 5}

\section{RESULTADOS E DISCUSSÃO}

No presente estudo, foram empregadas diferentes técnicas analíticas, de modo a obter a concentração dos elementos presentes na fração total das amostras de sedimentos pela técnica de NAA e também a concentração potencialmente disponível dos metais analisados por ICP OES e AAS (GF AAS e CV AAS), após extração com $\mathrm{HNO}_{3}$ (conc). Este capítulo apresenta os resultados obtidos para as amostras e os respectivos materiais de referência utilizados nas análises de metais e os resultados de granulometria, teores de carbonatos, matéria orgânica sedimentar, fósforo inorgânico, fósforo orgânico e total, para as amostras coletadas em 2005.

Serão apresentados primeiramente, os resultados das análises dos materiais de referência para as diferentes técnicas analíticas utilizadas. Em seguida, serão apresentados os resultados obtidos, para cada uma das técnicas, para a região de Santos/ São Vicente e posteriormente, Cananéia.

Os dados obtidos por NAA (concentração total) serão tratados separadamente dos dados obtidos pelas técnicas de ICP OES, GF AAS e CV AAS, para os dois sistemas estuarinos Santos/São Vicente e Complexo estuarino-lagunar de Cananéia. 


\subsection{Resultados das análises dos materiais de referência}

\subsubsection{Resultados das análises dos materiais de referência pela técnica ICP OES}

\subsubsection{Garantia da Qualidade}

Para verificar a eficácia do método, foram analisados os materiais de referência, WQB-3 (Lake Ontario Glended Sediment for Trace Elements Environmental Canada) e San Joaquim Soil - (NIST 2709a). O critério de aceitação dos resultados foi baseado na avaliação do D.P.R (\%) - desvio padrão relativo - o qual deve ser inferior a $20 \%$, e o E.R (\%) - erro relativo percentual- inferior a 30\%, devido ao fato do método de digestão adotado no presente estudo não realizar a digestão total de elementos fortemente ligados à sílica. Dessa forma foram avaliados apenas os elementos potencialmente disponíveis para a coluna d'água (o procedimento de digestão das amostras no presente estudo não utiliza ácido fluorídrico). Entretanto, o material de referência WQB-3 apresenta apenas valores de informação para os elementos estudados (os quais foram utilizados para os cálculos), explicitando em seu certificado de análise que a reprodutibilidade dos resultados é fortemente dependente do processo de digestão, a proporção de ácidos e condições de extração, portanto não foram fornecidos os intervalos de incerteza.

A Tabela 5.1 apresenta os valores de informação dos elementos, média dos valores obtidos nas análises, desvio padrão relativo (D.P.R.\%) e o erro relativo (E.R.\%) associados aos resultados encontrados para o material WQB-3. 
Tabela 5.1 Resultados obtidos nas análises do material de referência WQB-3, por ICP OES

\begin{tabular}{|c|c|c|c|c|}
\hline Parâmetros & $\begin{array}{c}\text { Valor de } \\
\text { informação } \\
\left(\mathrm{mg} \mathrm{kg}^{-1}\right)\end{array}$ & $\begin{array}{c}\text { Média } \\
\left(\mathrm{mg} \mathrm{kg}^{-1}\right), \\
(\mathrm{n}=10)\end{array}$ & $\begin{array}{c}\text { D.P.R. } \\
\text { (\%) }\end{array}$ & $\begin{array}{l}\text { E.R. } \\
\text { (\%) }\end{array}$ \\
\hline $\mathbf{A l}$ & 35645 & 32673 & 17,7 & 8,3 \\
\hline $\mathrm{Ba}$ & 220 & 159 & 2,1 & 27,5 \\
\hline $\mathrm{Be}$ & 1,37 & * & * & $\begin{array}{c}\text { *Valor próximo ao } \\
\text { L.Q. }\end{array}$ \\
\hline $\mathbf{B i}$ & 1,8 & * & * & $\begin{array}{c}\text { *Valor próximo ao } \\
\text { L.Q. }\end{array}$ \\
\hline B & 55,6 & 10,9 & 59,8 & 80,4 \\
\hline Cd & 4,7 & 3,57 & 7,6 & 24,1 \\
\hline $\mathrm{Pb}$ & 242 & 172 & 5,0 & 28,8 \\
\hline Co & 13,4 & 9,98 & 5,5 & 25,5 \\
\hline $\mathrm{Cu}$ & 80,8 & 64,1 & 2,6 & 20,7 \\
\hline $\mathrm{Cr}$ & 105 & 75,2 & 10,5 & 28,4 \\
\hline Sn & 21,1 & 6,97 & 17,7 & 67,0 \\
\hline $\mathrm{Sr}$ & 93,4 & 65,35 & 5,4 & 30,0 \\
\hline $\mathrm{Fe}$ & 58215 & 49062 & 18,2 & 15,7 \\
\hline Li & 32,9 & 40,0 & 15,7 & 21,7 \\
\hline Mn & 1207 & 915,7 & 3,6 & 24,1 \\
\hline Mo & 1,66 & * & * & $\begin{array}{c}\text { *Valor Próximo ao } \\
\text { L.Q. }\end{array}$ \\
\hline $\mathrm{Ni}$ & 53,8 & 39,6 & 4,5 & 26,4 \\
\hline $\mathrm{TI}$ & 1,04 & * & * & $\begin{array}{c}\text { *Valor Próximo ao } \\
\text { L.Q. }\end{array}$ \\
\hline $\mathrm{Ti}$ & 513 & 158,0 & 57,6 & 69,2 \\
\hline V & 76,5 & 37,7 & 27,0 & 50,7 \\
\hline $\mathrm{Zn}$ & 1407 & 1046,5 & 4,7 & 25,6 \\
\hline
\end{tabular}

$\mathrm{n}=\overline{\text { número de determinações }}$

A Tabela 5.2 apresenta os resultados obtidos nas análises do material de referência San Joaquim Soil. 
Tabela 5.2 Resultados obtidos nas análises do material de referência San Joaquim Soil, por ICP OES

\begin{tabular}{|c|c|c|c|c|c|c|c|c|}
\hline \multicolumn{5}{|c|}{ Valores de informação } & \multicolumn{4}{|c|}{ Resultados obtidos } \\
\hline Elemento & & $\begin{array}{l}\text { ai } \\
\text { g }\end{array}$ & $\left.\mathrm{kg}^{-1}\right)$ & $\begin{array}{l}\text { Mediana } \\
\left(\mathrm{mg} \mathrm{kg}^{-1}\right)\end{array}$ & $\begin{array}{l}\text { Média } \\
\left(\mathrm{mg} \mathrm{kg}^{-1}\right)\end{array}$ & $\begin{array}{l}\text { Desvio } \\
\text { Padrão }\end{array}$ & $\begin{array}{l}\text { E.R. } \\
(\%)\end{array}$ & $\begin{array}{l}\text { D.P.R } \\
(\%)\end{array}$ \\
\hline Al & 13000 & - & 17000 & 16000 & 23040 & 1279 & 44 & 6 \\
\hline $\mathrm{Ba}$ & 350 & - & 400 & 380 & 378 & 25 & 1 & 7 \\
\hline $\mathrm{Be}$ & 0,50 & - & 0,72 & 0,61 & $\begin{array}{l}{ }^{*} \text { Valor } \\
\text { Próximo } \\
\text { ao L.Q. }\end{array}$ & $\begin{array}{c}{ }^{*} \text { Valor } \\
\text { Próximo } \\
\text { ao L.Q. }\end{array}$ & $\begin{array}{c}{ }^{*} \text { Valor } \\
\text { Próximo } \\
\text { ao L.Q. }\end{array}$ & $\begin{array}{c}{ }^{*} \text { Valor } \\
\text { Próximo } \\
\text { ao L.Q. }\end{array}$ \\
\hline Cd & 0,33 & - & 0,66 & 0,4 & $\begin{array}{l}\text { *Valor } \\
\text { Próximo } \\
\text { ao L.Q. }\end{array}$ & $\begin{array}{l}\text { *Valor } \\
\text { Próximo } \\
\text { ao L.Q. }\end{array}$ & $\begin{array}{l}{ }^{*} \text { Valor } \\
\text { Próximo } \\
\text { ao L.Q. }\end{array}$ & $\begin{array}{l}\text { *Valor } \\
\text { Próximo } \\
\text { ao L.Q. }\end{array}$ \\
\hline $\mathrm{Cr}$ & 46 & - & 67 & 53 & 63,9 & 5,5 & 20,6 & 9 \\
\hline Co & 8,2 & - & 13 & 10 & 9,7 & 0,8 & 3,5 & 8 \\
\hline $\mathrm{Cu}$ & 24 & - & 28 & 27 & 24,3 & 0,8 & 9,8 & 3 \\
\hline $\mathrm{Fe}$ & 22000 & - & 26000 & 24000 & 28110 & 824 & 17 & 3 \\
\hline $\mathbf{P b}$ & 8.1 & - & 11 & 9,2 & 8,9 & 1,9 & 3,5 & 21 \\
\hline Mn & 380 & - & 450 & 420 & 394,3 & 21,4 & 6,1 & 5 \\
\hline $\mathbf{N i}$ & 59 & - & 71 & 66 & 60,2 & 3,1 & 8,8 & 5 \\
\hline TI & 0,74 & - & 1.6 & 1,2 & $\begin{array}{l}\text { *Valor } \\
\text { Próximo } \\
\text { ao L.Q. }\end{array}$ & $\begin{array}{l}\text { *Valor } \\
\text { Próximo } \\
\text { ao L.Q. }\end{array}$ & $\begin{array}{l}{ }^{*} \text { Valor } \\
\text { Próximo } \\
\text { ao L.Q. }\end{array}$ & $\begin{array}{l}{ }^{*} \text { Valor } \\
\text { Próximo } \\
\text { ao L.Q. }\end{array}$ \\
\hline V & 43 & - & 71 & 48 & 58,9 & 11,7 & $-22,8$ & 20 \\
\hline $\mathrm{Zn}$ & 69 & - & 87 & 79 & 76,7 & 4,4 & 2,9 & 6 \\
\hline
\end{tabular}

$\mathrm{Na}$ avaliação dos resultados obtidos nas análises dos materiais de referência, podemos observar que alguns elementos possuem valores de informação próximos ou inferiores aos Limites de Quantificação do método utilizado, o que elimina a hipótese de se considerar seus resultados adequados, portanto os mesmos não foram utilizados na continuidade do presente estudo. Para o material de referência WQB-3, verificou-se esta situação para os elementos $\mathrm{Be}, \mathrm{Bi}, \mathrm{Mo}$ e $\mathrm{Tl}$, e para o San Joaquim Soil, os elementos $\mathrm{Be}, \mathrm{Cd}$ e TI.

Observou-se ainda que, no material de referência WQB-3, os resultados para os elementos $\mathrm{B}, \mathrm{Sn}$, Ti e $\mathrm{V}$ não se encontravam de acordo com o critério de aceitação estabelecido, portanto também não tiveram continuidade no estudo. No material de referência San Joaquin Soil, verificou-se que os elementos Al e Fe apresentaram valores acima do intervalo de informação fornecido, entretanto como estes elementos foram aprovados no material de referência WQB-3, os mesmos foram considerados no presente estudo. Verificou-se ainda que o Pb apresentou D.P.R (\%) acima do valor estabelecido 
no presente estudo como aceitável, entretanto, está dentro da faixa de aceitação do material de referência San Joaquin Soil. Portanto, optou-se por utilizar-se dos resultados de $\mathrm{Pb}$ obtidos pela técnica GF AAS.

\subsubsection{Resultados das análises dos materiais de referência pela técnica AAS: GF AAS e CV AAS}

\subsubsection{Garantia da Qualidade}

Os metais determinados por GF AAS foram $\mathrm{Cd}$ e $\mathrm{Pb}$ e a técnica de geração de vapor frio (CV AAS), foi utilizada na determinação de $\mathrm{Hg}$.

Para verificar a eficácia do método, foram analisados os materiais de referência, WQB-3 (Lake Ontario Glended Sediment for Trace Elements Environment Canada) e San Joaquim Soil - (NIST 2709a), que possuem valores de informação para os elementos analisados por GF AAS. Para as análises de $\mathrm{Hg}$, foram utilizados os materiais de referência Buffalo River Sediment (NIST SRM 8704) e Marine Sediment (IAEA 433), os quais possuem valores certificados de concentração para $\mathrm{Hg}$.

O critério de aceitação dos resultados de $\mathrm{Cd}$ e $\mathrm{Pb}$ foi baseado na avaliação do desvio-padrão relativo (D.P.R), o qual deve ser inferior a 20\%, e o erro relativo percentual (E.R) inferior a $30 \%$, devido ao fato do método de digestão adotado no presente estudo não realizar a digestão total de elementos fortemente ligados à sílica. Portanto foram avaliados apenas os elementos potencialmente disponíveis, o que caracteriza uma aprovação com base na recuperação de $70-130 \%$ dos analitos em questão. O material de referência WQB-3 apresenta apenas valores de informação para os elementos estudados (os quais foram utilizados para os cálculos), explicitando no certificado de análise que a reprodutibilidade dos resultados é fortemente dependente do processo de digestão, a proporção de ácidos e condições de extração, portanto não foram fornecidos os intervalos de incerteza. 
As Tabelas 5.3 e 5.4 apresentam os resultados obtidos nas análises de $\mathrm{Pb}$ e $\mathrm{Cd}$ dos materiais de referência utilizados.

Tabela 5. 3 Resultados de concentração de $\mathrm{Pb}\left(\mathrm{mg} \mathrm{kg}^{-1}\right)$ por GF AAS, nos materiais de referência

\begin{tabular}{ccccc}
\hline $\begin{array}{c}\text { Material de } \\
\text { Referência } \\
(\mathbf{n}=5)\end{array}$ & $\begin{array}{c}\text { Valor de } \\
\text { Informação } \\
\text { (intervalo) }\end{array}$ & $\begin{array}{c}\text { Valor } \\
\text { encontrado }\end{array}$ & $\begin{array}{c}\text { E.R. } \\
(\%)\end{array}$ & $\begin{array}{c}\text { D.P.R } \\
(\%)\end{array}$ \\
\hline WQB-3 & 231 & $224 \pm 5$ & 3,0 & 2,2 \\
San Joaquim Soil & $\begin{array}{c}9,2 \\
(8,1-11,0)\end{array}$ & $9,53 \pm 0,83$ & 3,6 & 8,7 \\
\hline n= número de determinações & & &
\end{tabular}

n= número de determinaçôes

Tabela 5. 4 Resultados de concentração de Cd (mg kg-1) por GF AAS, nos materiais de referência

\begin{tabular}{ccccc}
\hline $\begin{array}{c}\text { Material de Referência } \\
(\mathbf{n}=\mathbf{5})\end{array}$ & $\begin{array}{c}\text { Valor de } \\
\text { informação } \\
\text { (intervalo) }\end{array}$ & $\begin{array}{c}\text { Valor } \\
\text { encontrado }\end{array}$ & $\begin{array}{c}\text { E.R. } \\
(\%)\end{array}$ & $\begin{array}{c}\text { D.P.R } \\
(\%)\end{array}$ \\
\hline WQB-3 & 3,19 & $3,69 \pm 0,25$ & 15,7 & 6,8 \\
San Joaquim Soil & $\begin{array}{c}0,40 \\
(0,33-0,66)\end{array}$ & $0,29 \pm 0,05$ & 27,5 & 17,2 \\
\hline $\mathrm{n}$ = número de determinações & & &
\end{tabular}

Os resultados para $\mathrm{Cd}$ e $\mathrm{Pb}$ foram considerados adequados na condição de $\mathrm{DPR}<20 \%$ e ER<30\%, devido ao fato do método de digestão adotado no presente estudo não realizar a digestão total de elementos fortemente ligados à sílica, conforme já discutido anteriormente. A análise de $\mathrm{Pb}$ apresentou os resultados mais próximos aos valores de informação, se comparado com o Cd que obteve o E.R. de 15,7 e 27,5\%, respectivamente. O material de referência San Joaquim Soil apresentou um intervalo de concentração para o Cd que variou de 0,33 a 0,66 $\mathrm{mg} \mathrm{kg}^{-1}$ e para o $\mathrm{Pb}$, de 8,1 a $11 \mathrm{mg} \mathrm{kg}^{-1}$, o que indica que os resultados estão dentro do intervalo de concentração do material de referência. 
A Tabela 5.5 apresenta os resultados para $\mathrm{Hg}$ total obtidos nas análises dos materiais de referência. Os resultados apresentaram desvios padrão relativos de 1,3 e 2,3\% e erros relativos de 1,4 e 3,6\%, para os materiais Buffalo River Sediment (NIST SRM 8704) e Marine Sediment (IAEA 433) respectivamente comprovando, portanto, a precisão e exatidão do método.

Tabela 5.5 Resultados de concentração de Mercúrio Total $\left(\mu \mathrm{g} \mathrm{kg}^{-1}\right)$ por CV AAS, nos materiais de referência

\begin{tabular}{ccccc}
\hline $\begin{array}{c}\text { Material de Referência } \\
(\mathbf{n}=\mathbf{3})\end{array}$ & $\begin{array}{c}\text { Valor } \\
\text { Certificado }\end{array}$ & $\begin{array}{c}\text { Valor } \\
\text { encontrado }\end{array}$ & $\begin{array}{c}\text { D.P.R. } \\
(\%)\end{array}$ & $\begin{array}{c}\text { E.R. } \\
(\%)\end{array}$ \\
\hline $\begin{array}{c}\text { Buffalo River Sediment } \\
\text { (NIST SRM 8704) } \\
\begin{array}{c}\text { Marine Sediment } \\
\text { (IAEA 433) }\end{array}\end{array}$ & $1470 \pm 70$ & $1490 \pm 19$ & 1,3 & 1,4 \\
\hline $\mathrm{n}=$ número de determinações & $168 \pm 15$ & $174 \pm 4$ & 2,3 & 3,6 \\
\hline
\end{tabular}

\subsubsection{Resultados das análises dos materiais de referência pela técnica de NAA}

\subsubsection{Garantia da Qualidade}

Para verificação da precisão e exatidão do método foram analisados os materiais de referência certificados NIST SRM 2704 e 8704 (Buffalo River Sediment), Soil-7 (AIEA) e BEN (Basalt-IWG-GIT), que possuem valores certificados para quase todos os elementos analisados.

Para a avaliação da exatidão do procedimento foi calculado o $Z$ score que, de acordo com o INMETRO, é uma das maneiras para se avaliar o desempenho do laboratório utilizando material de referência certificado (INMETRO, 2003).

A Figura 5.1 apresenta os resultados das análises dos materiais de referência analisados por NAA, utilizando-se o critério de Z-score conforme descrito no item 4.9.4.4. 

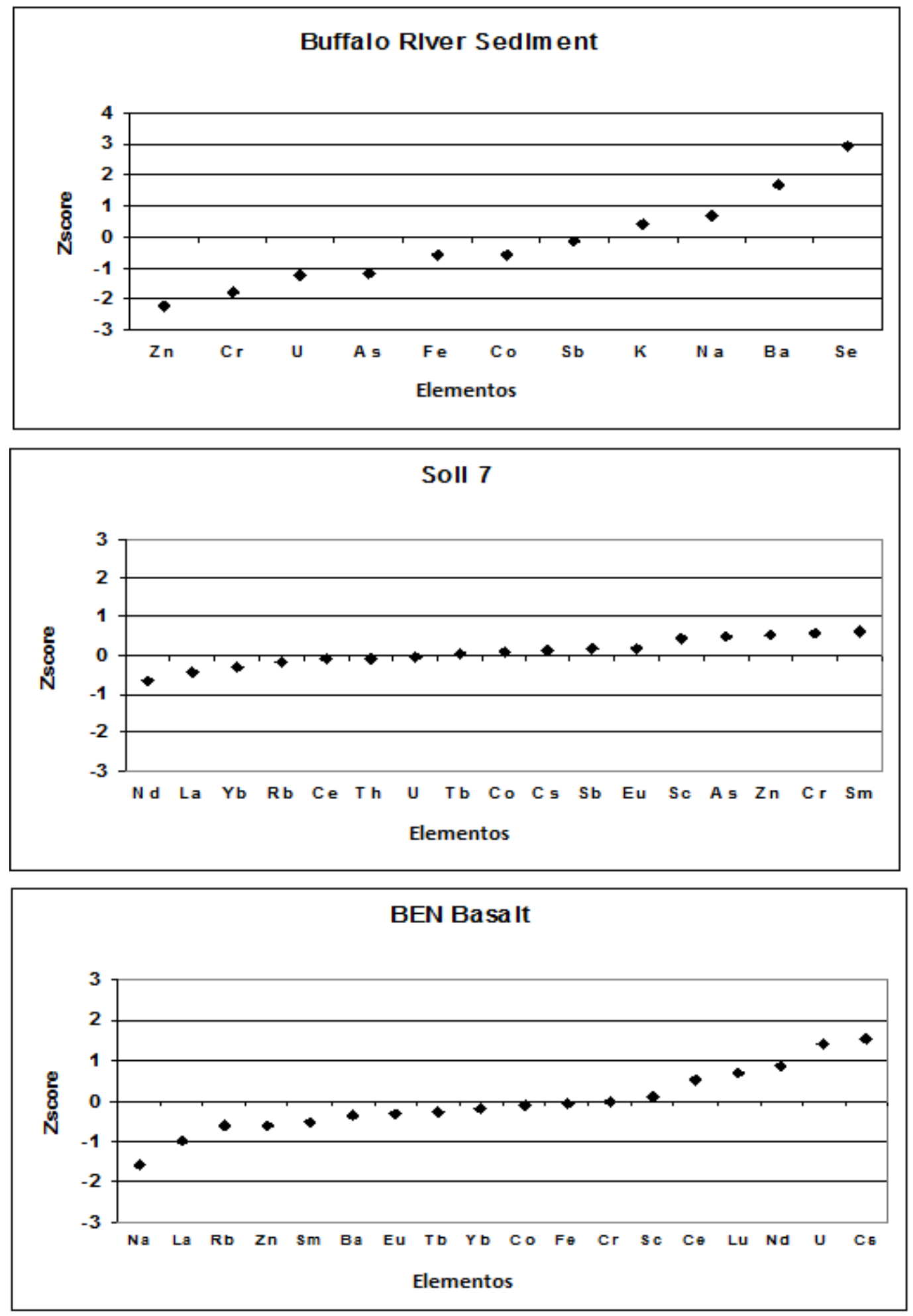

Figura 5. 1 - Gráfico de Z- score para os elementos determinados por NAA nos materiais de referência NIST SRM 2704 (Buffalo River Sediment), SOIL-7 e Basalt-BEN

O critério de Z-score para NAA diz que se os resultados estão dentro do intervalo $/ Z /<3$, considera-se que o resultado individual da amostra 
controle, no nosso caso o material de referência (MR), está dentro de $99 \%$ do intervalo de confiança do valor esperado. Os resultados obtidos para os $3 \mathrm{MR}$ se encontraram dentro do intervalo, comprovando dessa forma a confiabilidade da técnica de NAA e a aceitabilidade dos resultados na determinação de elementos traço em sedimentos.

\subsection{RESULTADOS DAS ANÁLISES DAS AMOSTRAS DE SEDIMENTOS}

\subsubsection{SISTEMA ESTUARINO DE SANTOS E SÃO VICENTE}

Em função da distribuição geográfica dos pontos de amostragem e associado com as características granulométricas definimos 3 áreas principais que mantêm diferenças internas em concentrações de elementos traço e metais considerando particularidades ambientais que combinam condições naturais com contribuições antropogências: Área 1: estações 01 a 06, localizadas no estuário de Santos que se estendem até a porção superior do sistema estuarino, próximo do polo industrial de Cubatão (Figura 4.1); Área 2 (estações 07 a 10, 15, 16), localizadas na baía de Santos onde processos de depuração tendem a ser mais acentuados devido à circulação de compostos químicos e Área 3 (estações 11 a 14), no canal de São Vicente (área ocidental) que se estende da região Casqueiro, com extensiva vegetação de mangue e desenvolvimento urbano com instalações sanitárias precárias. A baía de Santos está sob influência do mar aberto, enquanto os canais apresentam variações hidrológicas associadas aos regimes de maré, variações de profundidade e mais expostos às influências antropogênicas. O canal de São Vicente apresenta profundidades menores do que o Canal de Santos, uma vez que processos de dragagem são requeridos pelo porto, de tempos em tempos. 


\subsubsection{Resultados de $\mathrm{MO}$, silte, argila e areia, $\mathrm{CaCO}_{3}, \mathrm{P}$ inorg, org e total}

Perreti (2006) avaliou os resultados de $\mathrm{MO}$, silte, argila e areia, $\mathrm{CaCO}_{3}$, $\mathrm{P}$ inorg, $\mathrm{P}$ org e $\mathrm{P}$ total das amostras coletadas nos diversos pontos analisados, na região de Santos.

A Tabela 5.6 apresenta os resultados obtidos das amostras coletadas em Santos, inverno e verão de 2005. As amostras coletadas em 2006 não foram analisadas quanto a esses parâmetros.

Com relação às características granulométricas, a variação sazonal normalmente não mostra faixas importantes, mas em sistemas estuarinos, alguma variação pode ocorrer em função dos processos de circulação, influência de maré e entrada de água fresca e material particulado.

A partir dos dados apresentados na Tabela 5.6, observou-se que os pontos interiores da área 1 apresentam importante fração de sedimentos finos (> 50\%) nos 2 períodos, exceto para os pontos 3 e 6 , onde a fração areia é mais importante. A diferença nas características granulométricas sazonais nessa área é evidenciada pelas mudanças em \% observadas nos períodos de verão e inverno, talvez em função dos processos hidrodinâmicos locais e que incluem entradas terrestres e transporte de sedimento ao longo do sistema. Associada a esses aspectos, a presença de $\mathrm{MO}$ alcança um máximo de 18,3\% no ponto mais interno (ponto 1) no inverno. Exceções são os pontos 3 e 6 onde a fração areia é mais alta. Os outros pontos mostraram MO acima de 10\%, revelando uma associação entre sedimentos finos e retenção de MO. A fração carbonática foi mais importante nos pontos 1 (inverno) e 4 (verão) e maior valor de MO também. Uma condição especial foi apresentada no ponto 1 caracterizada pela alta \% de sedimentos ricos em matéria orgânica e $\mathrm{CaCO}_{3}$, na estação inverno. $O$ ponto 4 apresentou semelhante situação na estação verão.

Em geral, os valores médios de $M O$ não apresentaram variação significativa considerando as amostragens feitas nas estações verão e inverno: área 1 (11,1 e 11,3\%), exceto para os pontos 1, 4 e 5; área 3 (7,0 e 6,5\%). No 
caso da área 2, os pontos 7, 8 e 10, apresentaram uma variação significativa em concentrações entre as estações inverno e verão.

Siqueira \& Braga (2001) observaram conteúdo de MO em sedimentos desse estuário variando de 0,16 a 9,94\%, enquanto que os valores para a baía de Santos foram menores do que $1,5 \%$. Aguiar et al (2008) observaram valores de 0,77 a $18,4 \%$ em estudos na mesma região.

Os dados apresentados na Tabela 5.6 também mostraram predominância da fração pelítica (silte+ argila) na área 1, nas amostragens inverno e verão. Entretanto nas áreas 2 e 3, a fração areia mostrou uma grande contribuição nos períodos sazonais. Naturalmente, a capacidade para mobilizar metais e elementos traço difere entre as áreas como resultado de processos de deposição associados a uma hidrodinâmica mais intensa.

\subsubsection{Resultados de concentração para os elementos determinados por ICP OES, GF AAS e CV AAS nos sedimentos}

As Tabelas 5.7 e 5.8 apresentam os resultados obtidos pelas técnicas ICP OES GF AAS e CV AAS, para todas as amostras analisadas nos períodos de inverno e verão, anos 2005 e 2006, separados por áreas, conforme apresentado na Tabela 4.1. Os Anexos de I a VI apresentam as tabelas com os dados de concentração e desvios para todos os pontos amostrados na região de Santos, nos períodos de inverno e verão, 2005 e 2006. 
Tabela 5. 6 - Resultados de matéria orgânica (MO), granulometria (silte, argila e areia), P ( $\mu \mathrm{mol} \mathrm{g}^{-1}$ ) das amostras de sedimentos de Santos inverno e verão de 2005

\begin{tabular}{|c|c|c|c|c|c|c|c|c|c|c|c|c|c|c|c|}
\hline \multirow{2}{*}{ Área } & \multirow{2}{*}{ Ponto } & \multicolumn{2}{|c|}{ MO, ${ }^{*} \%$} & \multicolumn{2}{|c|}{ Silte+argila, (\%) } & \multicolumn{2}{|c|}{ Areia, ${ }^{*}(\%)$} & \multicolumn{2}{|c|}{$\mathrm{CaCO3}^{*}(\%)$} & \multicolumn{2}{|c|}{ P (inorg) } & \multicolumn{2}{|c|}{$P$ (org) } & \multicolumn{2}{|c|}{$\mathbf{P}$ (total) } \\
\hline & & Inverno & Verão & Inverno & Verão & Inverno & Verão & Inverno & Verão & Inverno & Verão & Inverno & Verão & Inverno & Verão \\
\hline 1 & 1 & 18,3 & 12,4 & 91,8 & 55 & 8,2 & 45 & 16,3 & 10,6 & 46,3 & 37,7 & 2,2 & 4,5 & 48,5 & 42,2 \\
\hline 1 & 2 & 15,1 & 15,1 & 82,4 & 64,1 & 17,6 & 35,9 & 11,8 & 7,8 & 38,8 & 36,7 & 2,2 & 4,3 & 41,0 & 41,0 \\
\hline 1 & 3 & 6,1 & 7,8 & 30,8 & 42,1 & 69,2 & 57,9 & 7,4 & 6,8 & 12,6 & 19,4 & 2,1 & 10,3 & 14,7 & 29,7 \\
\hline 1 & 4 & 11,6 & 15,2 & 78,8 & 89,5 & 21,2 & 10,5 & 12,6 & 15,9 & 12,1 & 15,2 & 7,2 & 9,3 & 19,3 & 24,4 \\
\hline 1 & 5 & 10,9 & 13,9 & 65,5 & 62,4 & 34,5 & 37,6 & 10,2 & 9 & 15,3 & 17,6 & 7,2 & 9,4 & 22,5 & 27,0 \\
\hline \multirow[t]{3}{*}{1} & 6 & 4,6 & 3,6 & 20,2 & 8,5 & 79,8 & 91,5 & 5,9 & 3,3 & 6,3 & 4,2 & 2,9 & 2,3 & 9,2 & 6,5 \\
\hline & Min: & 4,6 & 3,6 & 20,2 & 8,5 & 8,2 & 10,5 & 5,9 & 3,3 & 6,3 & 4,2 & 2,1 & 2,3 & 9,2 & 6,5 \\
\hline & Max: & 18,3 & 15,2 & 91,8 & 89,5 & 79,8 & 91,5 & 16,3 & 15,9 & 46,3 & 37,7 & 7,2 & 10,3 & 48,5 & 42,2 \\
\hline 2 & 7 & 1,5 & 6,2 & 1,3 & 24,4 & 98,7 & 75,6 & 4,3 & 18,6 & 4,2 & 5,5 & 0,6 & 5,8 & 4,8 & 11,2 \\
\hline 2 & 8 & 5,0 & 8,5 & 18 & 42,5 & 82 & 57,5 & 7,3 & 7,8 & 9,0 & 9,5 & 3,0 & 7,8 & 12,1 & 17,3 \\
\hline 2 & 9 & 1,0 & 1 & 0,3 & 0,1 & 99,7 & 99,9 & 4,1 & 7,3 & 3,8 & 3,6 & 0,1 & 1,2 & 3,9 & 4,9 \\
\hline 2 & 10 & 1,5 & 6,7 & 2,1 & 19,8 & 97,9 & 80,2 & 4,4 & 16,4 & 4,2 & 9,4 & 0,7 & 3,6 & 5,0 & 13,0 \\
\hline 2 & 15 & & - & & - & & - & & - & 12,1 & - & 6,0 & - & 18,1 & - \\
\hline \multirow[t]{3}{*}{2} & 16 & & - & & - & & - & & - & 3,7 & - & 0,5 & - & 4,2 & - \\
\hline & Min: & 1,0 & 1 & 0,3 & 0,1 & 82 & 57,5 & 4,1 & 7,3 & 3,7 & 3,6 & 0,1 & 1,2 & 3,9 & 4,9 \\
\hline & Max: & 5,0 & 8,5 & 18 & 42,5 & 99,7 & 99,9 & 7,3 & 18,6 & 12,1 & 9,5 & 6,0 & 7,8 & 18,1 & 17,3 \\
\hline 3 & 11 & 0,8 & 0,5 & 0,1 & 0,1 & 99,9 & 99,9 & 0,7 & 0,4 & 1,3 & 0,9 & 1,0 & 0,3 & 1,3 & 1,2 \\
\hline 3 & 12 & 4,9 & 5,1 & 0,4 & 5,9 & 99,6 & 94,1 & 44,5 & 22,1 & 5,0 & 3,2 & 1,7 & 1,6 & 6,8 & 4,8 \\
\hline 3 & 13 & 1,9 & 1,9 & 0,6 & 1,5 & 99,4 & 98,5 & 6,4 & 8,9 & 1,6 & 2,0 & 1,2 & 1,4 & 2,8 & 3,3 \\
\hline \multirow[t]{3}{*}{3} & 14 & 20,2 & 18,5 & 96,9 & 94,1 & 3,1 & 5,9 & 7,8 & 9,6 & 29,1 & 32,5 & 6,2 & 9,0 & 35,4 & 41,5 \\
\hline & Min: & 0,8 & 0,5 & 0,1 & 0,1 & 3,1 & 5,9 & 0,7 & 0,4 & 1,3 & 0,9 & 0,1 & 0,3 & 1,3 & 1,2 \\
\hline & Max: & 20,2 & 18,5 & 96,9 & 94,1 & 99,9 & 99,9 & 44,5 & 22,1 & 29,1 & 32,5 & 6,2 & 9,0 & 35,4 & 41,5 \\
\hline
\end{tabular}


Tabela 5. 7- Valores de concentração de metais $\left(\mathrm{mg} \mathrm{kg}^{-1}\right)$ determinados por ICP OES, Cd e Pb por GF AAS e Hg por CV AAS para as amostras de sedimentos do sistema estuarino Santos/São Vicente (Inverno (I) e Verão (V)/2005), valores de LD e LQ, TEL e PEL

\begin{tabular}{|c|c|c|c|c|c|c|c|c|c|c|c|c|c|c|c|c|c|c|c|c|c|c|c|c|c|c|c|c|}
\hline \multirow[b]{2}{*}{ Área 1} & \multicolumn{2}{|c|}{$\mathbf{C d}^{\mathrm{AAS}}$} & \multicolumn{2}{|c|}{$\mathbf{P b}^{\mathrm{AAS}}$} & \multicolumn{2}{|c|}{$\begin{array}{l}\mathrm{Hg}^{\text {AAS }} \\
\left(\mu \mathrm{kg}^{-1}\right)\end{array}$} & \multicolumn{2}{|c|}{ Al (\%) } & \multicolumn{2}{|c|}{$\mathbf{B a}$} & \multicolumn{2}{|c|}{ Co } & \multicolumn{2}{|c|}{$\mathbf{C u}$} & \multicolumn{2}{|c|}{ Cr total } & \multicolumn{2}{|c|}{$\begin{array}{c}\text { Fe total } \\
(\%)\end{array}$} & \multicolumn{2}{|c|}{$\mathbf{L i}$} & \multicolumn{2}{|c|}{ Mn } & \multicolumn{2}{|c|}{$\mathrm{Ni}$} & \multicolumn{2}{|c|}{$\mathbf{S r}$} & \multicolumn{2}{|c|}{ Zn } \\
\hline & $\overline{\mathbf{V}}$ & I & $\overline{\mathbf{V}}$ & I & $\mathbf{V}$ & I & $\mathbf{V}$ & I & $\mathbf{V}$ & I & $\mathbf{V}$ & I & $\mathbf{V}$ & I & $\mathbf{V}$ & I & $\mathbf{V}$ & I & $\mathbf{V}$ & I & $\mathbf{V}$ & I & $\mathbf{V}$ & I & $\mathbf{V}$ & $\bar{I}$ & $\mathbf{V}$ & I \\
\hline 1 & 0,173 & 0,346 & 11,2 & 24 & 501 & 469 & 3,01 & 6,17 & 123 & 250 & 7 & 9,2 & 15 & 25,7 & 36,2 & 50,7 & 2,56 & 6,15 & 68,1 & 85,8 & 363 & 535 & 14,8 & 20,8 & 82 & 119 & 104 & 156 \\
\hline 2 & 0,17 & 0,214 & 14,6 & 17,9 & 682 & 848 & 5,64 & 6,03 & 108 & 155 & 7,3 & 9,3 & 19,3 & 26,6 & 38 & 45,9 & 4,41 & 5,25 & 74,2 & 81,7 & 285 & 360 & 16,4 & 20,7 & 64 & 80 & 107 & 127 \\
\hline 3 & 0,101 & 0,073 & 8,7 & 16 & 441 & 413 & 3,18 & 3,05 & 55 & 36 & 5,9 & 5,1 & 13,8 & 14,4 & 28,4 & 26,2 & 3,14 & 2,72 & 53,6 & 48,3 & 253 & 235 & 11,4 & 9,6 & 47 & 47 & 83 & 68 \\
\hline 4 & 0,097 & 0,075 & 47 & 28,3 & 367 & 539 & 5,24 & 6,88 & 55 & 84 & 7,1 & 7,2 & 16,2 & 17,7 & 35,8 & 40,3 & 4,17 & 4,39 & 81,2 & 87,5 & 674 & 549 & 14,9 & 17,1 & 315 & 187 & 97 & 96 \\
\hline 5 & 0,114 & 0,063 & 14,6 & 15,1 & 210 & 189 & 5,2 & 5,05 & 55 & 48 & 7 & 5,7 & 18,2 & 14,8 & 35,4 & 30,7 & 3,8 & 3,42 & 70,5 & 59,7 & 675 & 549 & 13,9 & 11,8 & 77 & 67 & 91 & 77 \\
\hline 6 & 0,027 & 0,018 & 3,3 & 11 & 48 & 70 & 1,18 & 1,29 & 18 & 19 & 2,3 & 3,8 & 2,7 & 5,5 & 10,8 & 16,9 & 0,7 & 1,2 & 19,4 & 24 & 132 & 308 & 3,9 & 6,9 & 36 & 52 & 23 & 41 \\
\hline \multicolumn{29}{|l|}{ Área 2} \\
\hline 7 & 0,016 & N.D. & 6,4 & 3,4 & 38 & 10 & 3,14 & 0,68 & 40 & 6 & 4,4 & 2,6 & 1,1 & N.D. & 20,7 & 9,9 & 2,66 & 0,94 & 37,8 & 14,2 & 254 & 169 & 7,2 & 3 & 259 & 26 & 38 & 20 \\
\hline 8 & 0,031 & 0,021 & 10,7 & 10,4 & 58 & 110 & 4,55 & 1,07 & 55 & 14 & 5,9 & 3,6 & 5,4 & 2,9 & 30,9 & 15,4 & 3,43 & 1,2 & 51,8 & 28,7 & 548 & 297 & 12 & 5,6 & 63 & 44 & 60 & 39 \\
\hline 9 & N.D. & N.D. & 2 & 4,5 & 18 & 13 & 0,61 & 0,67 & 7 & 7 & 2,3 & 2,9 & N.D. & N.D. & 9,7 & 11,8 & 0,99 & 1,26 & 12,9 & 11,7 & 122 & 165 & 2,7 & 3,5 & 29 & 27 & 17 & 21 \\
\hline 10 & 0,012 & N.D. & 8 & 9,6 & 55 & 54 & 1,54 & 0,98 & 17 & 16 & 3,4 & 2,8 & 2,9 & 2,2 & 15,4 & 11,6 & 1,01 & 0,88 & 31,1 & 15,1 & 175 & 160 & 6,2 & 3,8 & 77 & 34 & 36 & 23 \\
\hline 15 & - & 0,016 & - & 15,2 & - & 42,1 & - & 2,63 & - & 32 & - & 6,2 & - & 7,7 & - & 30,1 & - & 2,56 & - & 43,4 & - & 667 & - & 13,1 & - & 79 & - & 57 \\
\hline 16 & - & N.D. & - & 4,9 & - & 8,1 & - & 0,72 & - & 10 & - & 2,7 & - & N.D. & - & 12,5 & - & 1,14 & - & 11,5 & - & 140 & - & 3,6 & - & 18 & - & 23 \\
\hline \multicolumn{29}{|l|}{ Área 3} \\
\hline 11 & N.D. & N.D. & 0,3 & 1,5 & 18 & 10 & 0,11 & 0,32 & 2 & 7 & N.D. & N.D. & 0,5 & 1 & 1,1 & 2,8 & 0,05 & 0,15 & 3,5 & 5,6 & 5 & 18 & N.D. & 1,1 & 2 & 5 & 2 & 6 \\
\hline 12 & 0,03 & 0,016 & 2 & 4,6 & 52 & 34 & 1,26 & 1,18 & 15 & 14 & 2,1 & 1,8 & 2,2 & 2,3 & 10,6 & 10,9 & 0,62 & 0,68 & 19,5 & 17,4 & 64 & 84 & 4,2 & 3,6 & 89 & 230 & 19 & 16 \\
\hline 13 & 0,019 & 0,012 & 3,2 & 3,6 & 44 & 46 & 0,58 & 0,53 & 7 & 8 & 1,4 & 1,1 & 1,8 & 1,8 & 7,1 & 5,3 & 0,38 & 0,3 & 13,5 & 7,1 & 41 & 36 & 2,4 & 1,9 & 92 & 59 & 11 & 11 \\
\hline 14 & 0,245 & 0,268 & 11,4 & 28,8 & 804 & 951 & 5,61 & 5,6 & 60 & 83 & 7,1 & 7,5 & 28 & 31,5 & 45,5 & 52,1 & 5,03 & 4,07 & 89,3 & 82,5 & 350 & 350 & 18,2 & 20,6 & 64 & 79 & 144 & 140 \\
\hline L.D. & \multicolumn{2}{|c|}{0,005} & \multicolumn{2}{|c|}{0,100} & & \multicolumn{2}{|c|}{0,5} & \multicolumn{2}{|c|}{0,2} & \multicolumn{2}{|c|}{0,5} & 0, & & 0, & 5 & 0,0 & & & 5 & & & & & & & 0, & \\
\hline L.Q. & 0,0 & 10 & 0,2 & 50 & & & & 0 & & & 1, & 0 & 0 , & & 1 & 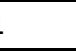 & 0,0 & & & 0 & & & & & & & 1, & \\
\hline TEL & $\mathbf{0}$, & 7 & 30 & 2 & & & & & & & & & 18 &, 7 & 52 & 3 & & & & & & & & 9 & & & 12 & \\
\hline PEL & 41 &, 6 & 11 & 2 & & & & & & & & & 10 & 8 & 10 & 50 & & & & & & & & 8 & & & 27 & \\
\hline
\end{tabular}

N.D. - não determinado 
Tabela 5. 8- Valores de concentração de metais $\left(\mathrm{mg} \mathrm{kg}^{-1}\right)$ determinados por ICP OES, Cd e Pb por GF AAS e Hg por CV AAS para as amostras de sedimentos do sistema estuarino Santos/São Vicente (Inverno (I) e Verão (V)/2006), valores de LD e LQ, TEL e PEL

\begin{tabular}{|c|c|c|c|c|c|c|c|c|c|c|c|c|c|c|c|c|c|c|c|c|c|c|c|c|c|c|c|c|}
\hline \multirow[b]{2}{*}{ Área 1} & \multicolumn{2}{|c|}{$\mathbf{C d}^{\mathrm{AAS}}$} & \multicolumn{2}{|c|}{$\mathbf{P b}^{\mathrm{AAS}}$} & \multicolumn{2}{|c|}{$\begin{array}{l}\mathrm{Hg}^{\mathrm{AAS}} \\
\left(\mu \mathrm{kg}^{-1}\right)\end{array}$} & \multicolumn{2}{|c|}{$\operatorname{Al}(\%)$} & \multicolumn{2}{|c|}{ Ba } & \multicolumn{2}{|c|}{ Co } & \multicolumn{2}{|c|}{$\mathrm{Cu}$} & \multicolumn{2}{|c|}{ Cr total } & \multicolumn{2}{|c|}{ Fe total $(\%)$} & \multicolumn{2}{|c|}{$\mathbf{L i}$} & \multicolumn{2}{|c|}{ Mn } & \multicolumn{2}{|c|}{$\mathbf{N i}$} & \multicolumn{2}{|c|}{$\mathbf{S r}$} & \multicolumn{2}{|c|}{$\mathbf{Z n}$} \\
\hline & $\mathbf{V}$ & I & $\mathbf{V}$ & I & V & I & $\mathbf{V}$ & I & $\mathbf{V}$ & I & $\mathbf{V}$ & I & $\mathbf{V}$ & I & $\mathbf{V}$ & I & $\mathbf{V}$ & I & $\mathbf{V}$ & I & $\mathbf{V}$ & I & $\mathbf{V}$ & I & $\mathbf{V}$ & I & $\mathbf{V}$ & I \\
\hline 1 & 0,344 & 0,284 & 28,9 & 18,8 & 528 & 789 & 3,48 & 5,04 & 143,2 & 226,4 & 9,04 & 8,54 & 29,38 & 27,02 & 46,23 & 51,50 & 4,19 & 4,47 & 92,7 & 76,5 & 500 & 538 & 19,5 & 20,9 & 108,8 & 128,4 & 138,5 & 132,6 \\
\hline 2 & 0,219 & 0,213 & 21 & 16,9 & 472 & 825 & 2,38 & 4,70 & 103,2 & 147,6 & 8,22 & 8,73 & 22,55 & 26,60 & 39,20 & 46,35 & 3,31 & 4,27 & 76,8 & 72,5 & 331 & 407 & 16,4 & 19,5 & 74,5 & 96,6 & 102,4 & 118,0 \\
\hline $2 \mathrm{~A}$ & 0,171 & 0,132 & 24,4 & 17,9 & 396 & 455 & 3,51 & 6,02 & 60,6 & 95,6 & 8,61 & 7,60 & 21,60 & 23,27 & 41,71 & 47,20 & 3,29 & 3,78 & 91,2 & 79,9 & 667 & 852 & 17,0 & 19,0 & 80,3 & 96,2 & 101,9 & 102,7 \\
\hline 3 & 0,105 & 0,089 & 18,1 & 16 & 290,8 & 452,3 & 2,17 & 2,46 & 36,2 & 44,8 & 6,27 & 6,16 & 13,35 & 11,17 & 29,49 & 27,06 & 2,21 & 1,98 & 57,2 & 51,3 & 402 & 240 & 11,2 & 10,8 & 55,0 & 47,0 & 65,7 & 59,3 \\
\hline 4 & 0,102 & 0,087 & 31,4 & 16,5 & 230,3 & 510,5 & 3,92 & 3,15 & 62,9 & 42,0 & 7,98 & 6,65 & 20,46 & 17,23 & 40,32 & 34,58 & 2,91 & 3,07 & 93,9 & 66,4 & 724 & 792 & 15,3 & 13,5 & 316,6 & 345,0 & 85,2 & 84,2 \\
\hline 5 & 0,079 & 0,095 & 17,7 & 17,5 & 166,8 & 342 & 2,02 & 5,47 & 32,1 & 78,6 & 8,27 & 7,41 & 22,51 & 20,33 & 31,39 & 43,96 & 2,11 & 3,49 & 75,4 & 72,1 & 488 & 688 & 10,7 & 17,4 & 87,1 & 101,3 & 68,0 & 93,2 \\
\hline 6 & 0,029 & 0,041 & 8,5 & 12,9 & 60,1 & 75,9 & 0,44 & 2,46 & 8,6 & 36,2 & 2,51 & 4,83 & 2,96 & 8,05 & 9,69 & 24,12 & 0,82 & 2,06 & 16,5 & 36,7 & 206 & 739 & 3,9 & 9,4 & 51,4 & 92,6 & 27,2 & 46,4 \\
\hline \multicolumn{29}{|l|}{ Área 2} \\
\hline 7 & 0,013 & 0,012 & 4,9 & 9,7 & 12,3 & 47,4 & 0,75 & 1,69 & 10,9 & 23,3 & 3,58 & 3,80 & N.D. & 1,54 & 13,08 & 17,49 & 1,46 & 1,79 & 23,3 & 24,5 & 252 & 224 & 4,5 & 6,2 & 132,5 & 98,2 & 33,2 & 31,1 \\
\hline 8 & 0,033 & N.D. & 10 & 5,7 & 71 & 58 & 1,23 & 0,81 & 20,1 & 11,0 & 5,39 & 2,92 & 5,37 & N.D. & 21,32 & 12,02 & 1,82 & 1,12 & 38,5 & 13,2 & 399 & 149 & 8,1 & 3,5 & 56,2 & 21,4 & 45,0 & 24,0 \\
\hline 9 & N.D. & N.D. & 2,5 & 4,1 & 9 & 22,4 & 0,47 & 0,33 & 6,1 & 3,9 & 2,85 & 1,74 & N.D. & N.D. & 10,97 & 7,62 & 1,35 & 0,91 & 12,4 & 7,4 & 205 & 112 & 3,4 & 1,8 & 15,5 & 35,3 & 19,3 & 14,0 \\
\hline 10 & 0,030 & 0,022 & 8,5 & 10,3 & 130,2 & 152 & 1,27 & 2,47 & 19,9 & 37,0 & 4,53 & 4,01 & 4,19 & 4,88 & 17,89 & 21,00 & 1,45 & 1,77 & 34,7 & 32,5 & 230 & 246 & 6,8 & 7,6 & 81,0 & 81,0 & 35,9 & 36,7 \\
\hline 15 & N.D. & N.D. & 2,8 & 5,3 & 8 & 25,3 & 0,34 & 0,58 & 3,5 & 8,3 & 2,64 & 3,35 & N.D. & N.D. & 9,22 & 11,55 & 1,07 & 1,33 & 10,0 & 14,6 & 133 & 139 & 2,7 & 3,8 & 10,0 & 18,2 & 18,3 & 22,2 \\
\hline 16 & 0,018 & 0,015 & 9,8 & 6,8 & 21,2 & 33,4 & 0,99 & 0,51 & 14,3 & 9,3 & 4,68 & 3,31 & 2,72 & 1,85 & 18,59 & 14,27 & 1,69 & 1,43 & 31,9 & 15,8 & 554 & 179 & 6,8 & 4,7 & 48,5 & 31,2 & 40,6 & 27,9 \\
\hline \multicolumn{29}{|l|}{ Área 3} \\
\hline 11 & 0,067 & 0,070 & 3,7 & 8,4 & 47,6 & 159,3 & 1,43 & 2,47 & 23,3 & 36,8 & 3,46 & 3,92 & 3,71 & 9,49 & 15,99 & 23,12 & 1,16 & 1,95 & 34,5 & 37,3 & 117 & 226 & 6,1 & 9,0 & 590,8 & 148,8 & 28,6 & 46,4 \\
\hline 12 & 0,064 & 0,064 & 6,6 & 10,7 & 68 & 199 & 1,43 & 2,99 & 20,8 & 37,9 & 3,78 & 4,12 & 4,55 & 9,54 & 16,93 & 23,49 & 1,27 & 1,82 & 33,4 & 39,0 & 164 & 215 & 7,1 & 9,5 & 48,2 & 104,5 & 33,7 & 49,4 \\
\hline $12 \mathrm{~A}$ & 0,020 & - & 1,4 & - & 23,8 & - & 0,42 & - & 6,5 & - & 1,37 & - & N.D. & - & 5,25 & - & 0,31 & - & 9,1 & - & 32 & - & 2,3 & - & 8,1 & - & 11,2 & - \\
\hline 13 & 0,210 & 0,204 & 19,4 & 23,8 & 310 & 410 & 2,80 & 2,70 & 42,7 & 45,3 & 6,81 & 6,80 & 18,02 & 19,73 & 34,23 & 34,19 & 2,66 & 2,74 & 82,6 & 77,4 & 222 & 227 & 14,1 & 13,8 & 138,4 & 110,1 & 92,7 & 88,1 \\
\hline 14 & 0,300 & 0,291 & 29,1 & 28,2 & 573,2 & 881 & 4,26 & 2,84 & 75,2 & 61,1 & 8,49 & 8,50 & 28,50 & 31,62 & 47,72 & 46,53 & 3,75 & 3,67 & 103,0 & 101,5 & 315 & 446 & 19,3 & 18,1 & 82,1 & 72,6 & 128,9 & 128,8 \\
\hline L.D. & \multicolumn{2}{|c|}{0,005} & \multicolumn{2}{|c|}{0,1} & \multicolumn{2}{|c|}{1} & \multicolumn{2}{|c|}{0,5} & \multicolumn{2}{|c|}{0,2} & 0, & ,5 & $\mathbf{0 ,}$ &, 1 & $\mathbf{0}$ &, 5 & $\mathbf{0 , 0}$ & & 0, & & 0, &, 5 & o, &, 5 & o, &, 1 & &, 5 \\
\hline L.Q. & 0,0 & 01 & 0 , & 25 & & 0 & & 1 & 1 & 1 & 1 & 1 & 0,5 &, 5 & 1 & 1 & $\mathbf{0 , 0}$ & & 1 & & 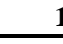 & 1 & 1 & 1 & 1 & 1 & & 1 \\
\hline TEL & $\mathbf{0}$, & ,7 & 30 & ,2 & 1. & 30 & & & & & & & 18 , & 3,7 & 52, & 2,3 & & & & & & & 15 & 5,9 & & & & 24 \\
\hline PEL & 41 & 1,6 & 1 & 12 & 6 & 96 & & & & & & & 10 & 08 & 16 & 60 & & & & & & & & 2,8 & & & & 71 \\
\hline
\end{tabular}


$\mathrm{Na}$ área 1, foram observadas as maiores concentrações para os elementos analisados (Tabelas 5.7 e 5.8): os metais tóxicos ( $\mathrm{Cd}, \mathrm{Hg}$ e $\mathrm{Pb}$ ) e os outros metais ( $\mathrm{Al}, \mathrm{Ba}, \mathrm{Co}, \mathrm{Cr}, \mathrm{Cu}, \mathrm{Fe}, \mathrm{Mn}, \mathrm{Ni}$ e $\mathrm{Zn}$ ), em ambas as estações (2005 e 2006). Essas altas concentrações foram obtidas perto da região de Cubatão, onde ocorre grande impacto das atividades industriais e da influência do porto de Santos.

$\mathrm{Na}$ área 1, as estações 01 a 05 apresentaram também os maiores teores da fração silte + argila (Tabela 5.6), que favorecem a retenção dos metais. Na área 2, os sedimentos apresentaram uma predominância da fração areia em todas as estações assim como na área 3, com exceção da estação 14, com predominância da fração silte e argila e que também apresentou altos teores de metais. Os altos teores de metais também foram seguidos por altos teores de MO.

Segundo o relatório da CETESB de 2001, nos sedimentos da Baixada Santista, as concentrações de Cd oscilaram entre $<0,05 \mathrm{mg} \mathrm{kg}^{-1}$ (na Baía de Santos) a $1,7 \mathrm{mg} \mathrm{kg}^{-1}$ no canal da Cosipa. No canal de Santos, próximo à indústria Dow Química, as concentrações encontradas (entre 1,3 e $1,5 \mathrm{mg} \mathrm{kg}^{-1}$ ) foram equivalentes aos valores observados na região da Cosipa (entre 0,84 e 1,7 $\left.\mathrm{mg} \mathrm{kg}^{-1}\right)$, ultrapassando o valor de TEL $\left(0,676 \mathrm{mg} \mathrm{kg}^{-1}\right)$. Níveis mais elevados de $\mathrm{Cd}$ também foram encontrados, nas desembocaduras dos rios Branco, Mariana e Piaçabuçu, que deságuam no estuário de São Vicente. Os valores foram da ordem de 0,75 a $0,95 \mathrm{mg} \mathrm{kg}^{-1}$, possivelmente relacionados a fontes industriais ou fontes difusas de lixo e esgotos do próprio estuário.

Em relação ao $\mathrm{Pb}$ (CETESB, 2001), no estuário de São Vicente apenas uma amostra proveniente da desembocadura do rio Mariana apresentou valor de $\mathrm{Pb}$ (36 $\left.\mathrm{mg} \mathrm{kg}^{-1}\right)$, o qual está ligeiramente acima do TEL $\left(30,2 \mathrm{mg} \mathrm{kg}^{-1}\right)$, provavelmente devido a algum lançamento pontual.

Com relação à avaliação da concentração de $\mathrm{Cu}$ no sedimento (CETESB, 2001), o relatório da CETESB verificou que o ponto mais crítico encontrava-se na desembocadura do rio Santo Amaro, no estuário de Santos, onde os valores variaram de 85 a $100 \mathrm{mg} \mathrm{kg}^{-1}$, ultrapassando o valor de TEL e 
próximo ao valor de PEL (108 $\mathrm{mg} \mathrm{kg}^{-1}$ ). Estes resultados podem ser atribuídos à origem industrial (Dow Química), ou de áreas a montante no rio Santo Amaro, onde há grande contribuição por esgotos e a influência dos efluentes do aterro sanitário do Guarujá. No ponto de coleta próximo a indústria Cosipa, no estudo da CETESB, 2001, foram observados os segundos maiores valores de Cu para os sedimentos (53 $\mathrm{mg} \mathrm{kg}^{-1}$ ), que devem estar associados aos lançamentos da indústria.

No estuário de São Vicente, a presença de $\mathrm{Cu}$ nos sedimentos variou de 20 a $21 \mathrm{mg} \mathrm{kg}^{-1}$, acima do valor de TEL $\left(18,7 \mathrm{mg} \mathrm{kg}^{-1}\right)$, conforme 0 relatório da CETESB, 2001. No mesmo local, o Cu atingiu na água valores de $30 \mu \mathrm{g} \mathrm{L}^{-1}$, indicando a existência de fonte deste metal na região. Dentre as atividades que ocorrem nesta região é possível destacar a manipulação de resíduos industriais na bacia (indústria Ciel) que podem estar contribuindo para os valores mencionados (CETESB, 2001).

Nos sedimentos, as maiores concentrações de $\mathrm{Cr}$ encontraram-se próximas ao local de lançamento dos efluentes da Cosipa e no rio Piaçaguera, onde os valores variaram entre 23 e $70 \mathrm{mg} \mathrm{kg}^{-1}$, respectivamente. Na região sob influência da Cosipa, em trabalho anterior da CETESB realizado em 1997, (dados não publicados), foram encontradas concentrações de $\mathrm{Cr}$ de até 106 $\mathrm{mg} \mathrm{kg}^{-1}$ (CETESB, 2001).

O relatório da CETESB, 2001, informa que cerca de $40 \%$ das amostras analisadas possuiam valores de $\mathrm{Hg}$ acima de TEL $\left(0,13 \mathrm{mg} \mathrm{kg}^{-1}\right.$ para águas salobras e salinas e $0,17 \mathrm{mg} \mathrm{kg}^{-1}$ para água doce), destas cerca de $8 \%$ das amostras situaram-se acima do valor de PEL $\left(0,696 \mathrm{mg} \mathrm{kg}^{-1}\right.$ para águas salobras e salinas e $0,486 \mathrm{mg} \mathrm{kg}^{-1}$ para águas doces).

Na região do estuário de Santos, segundo o relatório da CETESB, 2001, os valores de $\mathrm{Hg}$ variaram de 0,021 a $0,85 \mathrm{mg} \mathrm{kg}^{-1}$; na região do estuário de São Vicente, o Hg variou de <0,005 à $0,97 \mathrm{mg} \mathrm{kg}^{-1}$ e na Baía de Santos, os valores foram de 0,019 à $0,14 \mathrm{mg} \mathrm{kg}^{-1}$. 
O relatório da CETESB (2001), demonstrou que os sedimentos na área de estudo apresentavam valores de $\mathrm{Ni}$ que variaram de 0,97 a $34 \mathrm{mg} \mathrm{kg}^{-1}$, observando-se valores superiores ao TEL em algumas amostras provenientes do rio Cubatão, de ambos estuários e das proximidades da ilha da Moela. Esse metal é normalmente encontrado em efluentes líquidos industriais, principalmente em refinarias de petróleo, siderúrgicas e fábricas de fertilizantes e de celulose e papel. Na Baixada Santista, as principais fontes do poluente são a Cosipa, a RPBC-PETROBRÁS, a Ultrafértil-Cubatão e a Dow Química, as quais apresentam o metal em seus efluentes, em geral, dentro dos padrões de lançamento (CETESB, 2001).

Nos sedimentos da região em estudo, na avaliação realizada pela CETESB em 2001, foi identificada uma acumulação do Zn, especialmente próximo às fontes industriais. Dentre as fontes existentes, destaca-se a Cosipa, onde os valores de $\mathrm{Zn}$ no sedimento variaram de 260 a $957 \mathrm{mg} \mathrm{kg}^{-1}$ chegando, portanto, a superar o valor PEL. Na região do rio Santo Amaro próximo à Dow Química, os valores de $\mathrm{Zn}$ nos sedimentos também foram elevados, variando de 183 a $221 \mathrm{mg} \mathrm{kg}^{-1}$, superando o valor de TEL. Os sedimentos no ambiente marinho e nos rios em Cubatão apresentaram valores que não ultrapassaram o valor de TEL, podendo ser considerados como decorrentes da constituição da matriz mineral (CETESB, 2001).

Comparando-se os dados de metais em sedimentos apresentados no relatório da CETESB (2001) e os resultados obtidos no presente estudo, com sedimentos coletados em 2005 e 2006, pode-se verificar uma melhora acentuada na qualidade dos sedimentos, com valores de concentração, de maneira geral, inferiores aqueles obtidos pela CETESB, para os mesmos metais analisados.

Siqueira et al (2005), observaram valores de $\mathrm{Hg}$ total em diferentes profundidades no Canal de Santos, Canal de São Vicente e Baía de Santos. Na região do Canal de Santos, observaram que as concentrações de $\mathrm{Hg}$ variaram de 0,119 a $0,814 \mathrm{mg} \mathrm{kg}^{-1}$. A região da COSIPA apresentou o maior valor de $\mathrm{Hg}$ no Canal de Santos. No Canal de São Vicente, os valores de Hg estavam na faixa de 0,050 a $1,0 \mathrm{mg} \mathrm{kg}^{-1}$, sendo que o maior valor foi obtido na região do 
Rio Casqueiro. Na Baía de Santos, a maioria dos pontos estudados apresentaram valores por volta de $0,050 \mathrm{mg} \mathrm{kg}^{-1}$, entretanto na saída do emissário submarino, foi verificada uma concentração de $\mathrm{Hg}$ de $0,504 \mathrm{mg} \mathrm{kg}^{-1}$.

Luiz-Silva et al. (2006), ao estudarem a região de Cubatão, identificaram que os rios Cubatão (com elevadas concentrações de $\mathrm{Hg}-0,65$ à $\left.6,77 \mathrm{mg} \mathrm{kg}^{-1}\right)$ e o rio Morrão, com concentrações de Mn de 3276 à $5699 \mathrm{mg} \mathrm{kg}^{-}$ 1; Cd (0,50-1,6 mg kg-1); Zn (406 a $\left.476 \mathrm{mg} \mathrm{kg}^{-1}\right)$; Pb (92 à $\left.127 \mathrm{mg} \mathrm{kg}^{-1}\right)$; Ba (166 à $\left.196 \mathrm{mg} \mathrm{kg}^{-1}\right) ; \mathrm{Cu}$ (68 à $\left.109 \mathrm{mg} \mathrm{kg}^{-1}\right) ; \mathrm{Cr}\left(117\right.$ à $\left.138 \mathrm{mg} \mathrm{kg}^{-1}\right) ; \mathrm{Fe}(>10 \%)$ e Ni (33 à $39 \mathrm{mg} \mathrm{kg}^{-1}$ ) são de fato as principais vias de entrada de contaminantes metálicos no sistema estuarino.

Quinaglia (2006), avaliou sedimentos na região de Bertioga, e descreveu em suas conclusões a presença de As em concentrações superiores àquelas estabelecidas pelo CONAMA 344/04, nível 1 , onde observou concentração média deste elemento igual a $9,84 \mathrm{mg} \mathrm{kg}^{-1}$. Quinaglia ainda observou os valores basais com valores médios de concentração para metais no Canal de Bertioga, que foram: Al (2,72\%), As $\left(9,84 \mathrm{mg} \mathrm{kg}^{-1}\right)$, Ba $(26,2 \mathrm{mg}$ $\left.\mathrm{kg}^{-1}\right), \mathrm{Cd}\left(<0,02 \mathrm{mg} \mathrm{kg}^{-1}\right)$, Co $\left(6,7 \mathrm{mg} \mathrm{kg}^{-1}\right), \mathrm{Cr}\left(27,8 \mathrm{mg} \mathrm{kg}^{-1}\right), \mathrm{Cu}\left(11 \mathrm{mg} \mathrm{kg}^{-1}\right)$, Fe $(3,2 \%), \mathrm{Hg}\left(<0,02 \mathrm{mg} \mathrm{kg}^{-1}\right), \mathrm{Mn}\left(299 \mathrm{mg} \mathrm{kg}^{-1}\right)$, Mo $\left(<4 \mathrm{mg} \mathrm{kg}^{-1}\right)$, Ni $(11,2 \mathrm{mg}$ $\left.\mathrm{kg}^{-1}\right), \mathrm{Pb}\left(<0,26 \mathrm{mg} \mathrm{kg}^{-1}\right)$ e $\mathrm{Zn}\left(63,8 \mathrm{mg} \mathrm{kg}^{-1}\right)$.

Fukumoto, 2007, analisando por ICP OES testemunhos de sedimentos da região do largo de Santa Rita, Rio Casqueiro e Largo do Canéu, que estão próximos a área 1 do presente estudo, observou que a região do Largo de Santa Rita apresentou valores de concentração de Al (1,4 à 2,1\%), $\mathrm{Cr}\left(22\right.$ à $\left.33 \mathrm{mg} \mathrm{kg}^{-1}\right), \mathrm{Cu}\left(3,1\right.$ à $\left.22 \mathrm{mg} \mathrm{kg}^{-1}\right), \mathrm{Fe}\left(2,8\right.$ à 3,4\%), $\mathrm{Pb}$ (12 à $38 \mathrm{mg} \mathrm{kg}^{-}$ ${ }^{1}$ ) e Zn (45 à $108 \mathrm{mg} \mathrm{kg}^{-1}$ ), nas frações de $152-154 \mathrm{~cm}$ e de $0-2 \mathrm{~cm}$, respectivamente. Na região do Rio Casqueiro, observou-se concentrações de Al (1,4 a 1,3\%), $\operatorname{Cr}\left(17,2\right.$ - $\left.32 \mathrm{mg} \mathrm{kg}^{-1}\right), \mathrm{Cu}\left(2,4\right.$ à $\left.24 \mathrm{mg} \mathrm{kg}^{-1}\right), \mathrm{Fe}(2,1$ a 3,5\%), $\mathrm{Pb}\left(6,7\right.$ a $\left.41 \mathrm{mg} \mathrm{kg}^{-1}\right)$ e Zn (22 à $\left.128 \mathrm{mg} \mathrm{kg}^{-1}\right)$, nas frações de $198-200 \mathrm{~cm}$ e $0-2 \mathrm{~cm}$, respectivamente.

Fukumoto, 2007 ainda avaliou o testemunho coletado no largo do Canéu, onde foi possível identificar que os teores de Al variaram de 0,6 a 1,5\%, 
$\operatorname{Cr}\left(9,1\right.$ a 24,9 mg kg $\left.{ }^{-1}\right), \mathrm{Cu}\left(4,3\right.$ a 10,8 $\left.\mathrm{mg} \mathrm{kg}^{-1}\right) \quad \mathrm{Fe}(0,8$ à 2,2 \%) Pb (7 à $10 \mathrm{mg}$ $\mathrm{kg}^{-1}$ ) e Zn (30 à 51,6 mg kg-1), nas frações dos testemunhos de $0-2 \mathrm{~cm}$ e 177 $\mathrm{cm}$, respectivamente.

Aguiar et al (2008), também observaram valores altos de concentração para Cd (4,4 a 5,2 mg kg $\left.{ }^{-1}\right), \mathrm{Cr}\left(43\right.$ a $\left.67 \mathrm{mg} \mathrm{kg}^{-1}\right), \mathrm{Cu}(15$ a 23 $\left.\mathrm{mg} \mathrm{kg}^{-1}\right), \mathrm{Pb}\left(26\right.$ a $33 \mathrm{mg} \mathrm{kg}^{-1}$ ) e Zn ( 60 a $103 \mathrm{mg} \mathrm{kg}^{-1}$ ), na região do Canal de Santos.

No estudo apresentado no relatório ASA/CEPEA, 2008, foram discutidos os dados de concentração de metais contidos nos sedimentos de superfície de fundo do canal do Porto, nas análises realizadas pela CETESB, 1997. Foi observado que os valores de Cu variaram entre $2,93-100 \mathrm{mg} \mathrm{kg}^{-1}$, o $\mathrm{Cr}$ apresentou uma variação alta de $1,19-100 \mathrm{mg} \mathrm{kg}^{-1}$, bem como o $\mathrm{Pb}$, que variou de 3,75 - $66 \mathrm{mg} \mathrm{kg}^{-1}$. O Zn apresentou valores entre 10 a $221 \mathrm{mg} \mathrm{kg}^{-1}$. Foram observadas variações de $\mathrm{Cd}\left(\leq 0,05\right.$ a $\left.1,5 \mathrm{mg} \mathrm{kg}^{-1}\right)$, Ni (3 a 17) e $\mathrm{Hg}$ ( $\leq$ 0,03 à $\left.0,7 \mathrm{mg} \mathrm{kg}^{-1}\right)$. Os autores do relatório ASA/CEPEA destacaram ainda que este conjunto de dados poderia estar revestido de maior imprecisão devido ao fato que a caracterização sedimentar do material analisado era insuficiente para indicar as concentrações de lama, retentora de metais e de areias inertes. Desta forma, os teores elevados poderiam simplesmente representar pequenas manchas de lama dispostas em meio a predomínio de fundos arenosos, e o inverso em relação aos baixos teores obtidos (YASSUDA et al, 2008).

No presente estudo, os sedimentos da estação 14 (área 3) também apresentaram altas concentrações de metais. Esse ponto também sofre influência do polo de Cubatão e está localizado próximo de uma área de mangue. Essa região pode favorecer a retenção desses metais nos sedimentos devido a suas propriedades físicas e geoquímicas. Um alto teor de $\mathrm{MO}$ e contribuição da fração pelítica nesse ponto foram observadas (Tabela 5.6), devido à vegetação do mangue, contribuição antropogênica e baixa influência de circulação nessas águas pouco profundas. Perto desse ponto existe um aterro sanitário desativado. 
Em geral, as concentrações de metais são muito maiores na parte interna do estuário (área 1) e com valores mais baixos na Baía de Santos (área 2). Esse padrão de distribuição está associado a processos de deposição mais intensos na parte interna do estuário e a um processo de remobilização mais forte na Baía de Santos.

Ao compararmos os resultados obtidos nas análises das amostras coletadas na região de Santos, nos anos de 2005 e 2006, com a legislação CONAMA 344/04 (Tabela 1.2), para os elementos $\mathrm{Cd}, \mathrm{Cr}, \mathrm{Cu}, \mathrm{Hg}, \mathrm{Ni}, \mathrm{Pb}$ e $\mathrm{Zn}$, verificamos que:

- a amostra SV0504 ultrapassou o nível 1 para $\mathrm{Pb}\left(46,7 \mathrm{mg} \mathrm{kg}^{-1}\right)$, no verão

- com exceção da amostra SV0506, todas as demais ultrapassaram o nível 1 para $\mathrm{Hg}\left(0,150 \mathrm{mg} \mathrm{kg}^{-1}\right)$;

- a amostra SI0501(156 mg kg-1) ultrapassou o nível 1 para Zn (150 mg $\mathrm{kg}-1)$;

- para os demais parâmetros analisados, não foram ultrapassados os limites CONAMA ( níveis 1 e 2).

Na comparação com os níveis TEL e PEL, adotados pela CETESB como valores orientadores, as amostras coletadas na região de Santos, nos períodos de inverno e verão dos anos 2005 e 2006, para os elementos analisados por ICP OES Cr, $\mathrm{Cu}, \mathrm{Ni}$ e $\mathrm{Zn}$ e $\mathrm{Cd}$, $\mathrm{Hg}$ e Pb por AAS, observou-se que:

- para o elemento $\mathrm{Cu}$, as amostras SI0501, SI0502, SI0514, SV0502, SV0514, SI0601, SI0602, SI0602A, SI0605, SI0613, SI0614, SV0601, SV0602, SV0602A, SV0604, SV0605 e SV0614 ultrapassaram o limite TEL (18,7 $\left.\mathrm{mg} \mathrm{kg}^{-1}\right)$ para sedimentos de águas salobras;

- para o parâmetro Ni, as amostras SI0501, SI0502, SI0504, SI0514, SV0502, SV0514, SI0601, SI0602, SI0602A, SI0605, SI0614, SV0601, 
SV0602, SV0602A e SV0614 apresentaram níveis acima do limite TEL $\left(15,9 \mathrm{mg} \mathrm{kg}^{-1}\right)$, de sedimentos provenientes de áreas com água salobra;

- o limite TEL ainda foi ultrapassado para o $\mathrm{Zn}\left(124 \mathrm{mg} \mathrm{kg}^{-1}\right)$, nas amostras SI0501, SI0502, SI0514, SV0514, SI0601, SI0614, SV0601, e SV0614;

- em relação ao $\mathrm{Cr}$, nenhuma amostra ultrapassou os limites estabelecidos nos valores orientadores TEL (52,3 $\left.\mathrm{mg} \mathrm{kg}^{-1}\right)$;

- em relação ao $\mathrm{Cd}$, nenhuma amostra dos períodos analisados nos anos de 2005 e 2006 ultrapassou os limites estabelecidos nos valores orientadores TEL $\left(0,7 \mathrm{mg} \mathrm{kg}^{-1}\right)$ e também na legislação CONAMA 344/04;

- Quando comparados os resultados de Hg obtidos, com os limites TEL e $\mathrm{PEL}$, observamos que houve uma contaminação de $\mathrm{Hg}$ nos sedimentos na região de Santos, em ambos os períodos de 2005. Os pontos 01 a 05 e 14 excederam os valores do limite TEL. Os pontos de amostragem 02, 04 e 14 na coleta do inverno de 2005 apresentaram valores acima do limite PEL, assim como os pontos 01, 02 e 14 para a coleta do verão de 2005. Ao comparar os resultados obtidos com a resolução CONAMA 344/04, verificamos que as amostras 01 a 05, no inverno e verão e a amostra 14, no inverno de 2005, apresentaram valores de $\mathrm{Hg}$ acima da legislação vigente para o nível 1 . Em relação às amostras coletadas no verão e inverno de 2006, as amostras SV0601, SV0602, SV0602A, SV0603, SV0604, SV0605, SV0610, SV0613, SV0614, SI0601, SI0602, SI0602 A, SI0603, SI0604, SI0605, SI0610, SI0611, SI0612, SI0613 e SI0614, ultrapassaram o limite TEL para o $\mathrm{Hg}$. As amostras SI0601, SI0602 e SI0614 ultrapassaram o limite PEL para Hg. Quando comparados com a legislação CONAMA 344/04, as amostras coletadas no ano de 2006, observou-se que as amostras SV0601, SV0602, SV0602A, SV0603, SV0604, SV0605, SV0613, SV0614, SI0601, SI0602, SI0602 A, SI0603, SI0604, SI0605, SI0610, SI0611, SI0612, SI0613 e SI0614, ultrapassaram o valor permitido do nível 1 do CONAMA 344/04. 
As amostras SI0601, SI0602 e SI0614 ultrapassaram o nível 2 (0,710 mg $\mathrm{kg}^{1}$ ) descrito na legislação CONAMA 344/04.

- Em relação aos resultados de $\mathrm{Pb}$, apenas o ponto 04 extrapolou o limite TEL (30,2 $\left.\mathrm{mg} \mathrm{kg}^{-1}\right)$, no verão de 2005 e 2006, e também apresentaram valor de $\mathrm{Pb}$ acima da legislação CONAMA 344/04 na coleta realizada no verão de 2005, classificando-se no nível 1. Entretanto, o valor encontrado na amostra (47 mg kg$\left.{ }^{-1}\right)$ é muito próximo ao valor da legislação $(46,7 \mathrm{mg}$ $\left.\mathrm{kg}^{-1}\right)$. As amostras coletadas no inverno e verão de 2006 apresentaram valores inferiores ao nível 1, descrito na legislação CONAMA 344/04.

\subsubsection{Estudo da variação sazonal - Gráficos Box Plot}

Para a verificação da variação sazonal, a partir dos dados obtidos pelas técnicas de ICP OES e AAS, foram confeccionados gráficos de box plot para cada elemento analisado, comparando os períodos Inverno/Verão nos anos de 2005 e 2006, a partir das representações dos quartis e da mediana, além dos limites mínimos e máximos para cada caso.

As denominações utilzadas para os pontos de coleta e períodos foram: SV05 (Santos Verão 2005), SI05 (Santos Inverno 2005), SV06 (Santos Verão 2006), SI06 (Santos Inverno 2006), todas seguidas pelas identificações "A1" (área 1), "A2" (área 2) ou "A3" (área 3).

As Figuras 5.2 à 5.17 apresentam os gráficos Box plot, assim como os testes ANOVA, com o valor do teste $F$, e o valor de $p$ para os elementos Al, $\mathrm{Ba}, \mathrm{Cd}, \mathrm{Co}, \mathrm{Cu}, \mathrm{Cr}, \mathrm{Fe}, \mathrm{Hg}, \mathrm{Li}, \mathrm{Mn}, \mathrm{Ni}, \mathrm{Pb}, \mathrm{Sr}, \mathrm{Ti}, \mathrm{V}$ e Zn. 


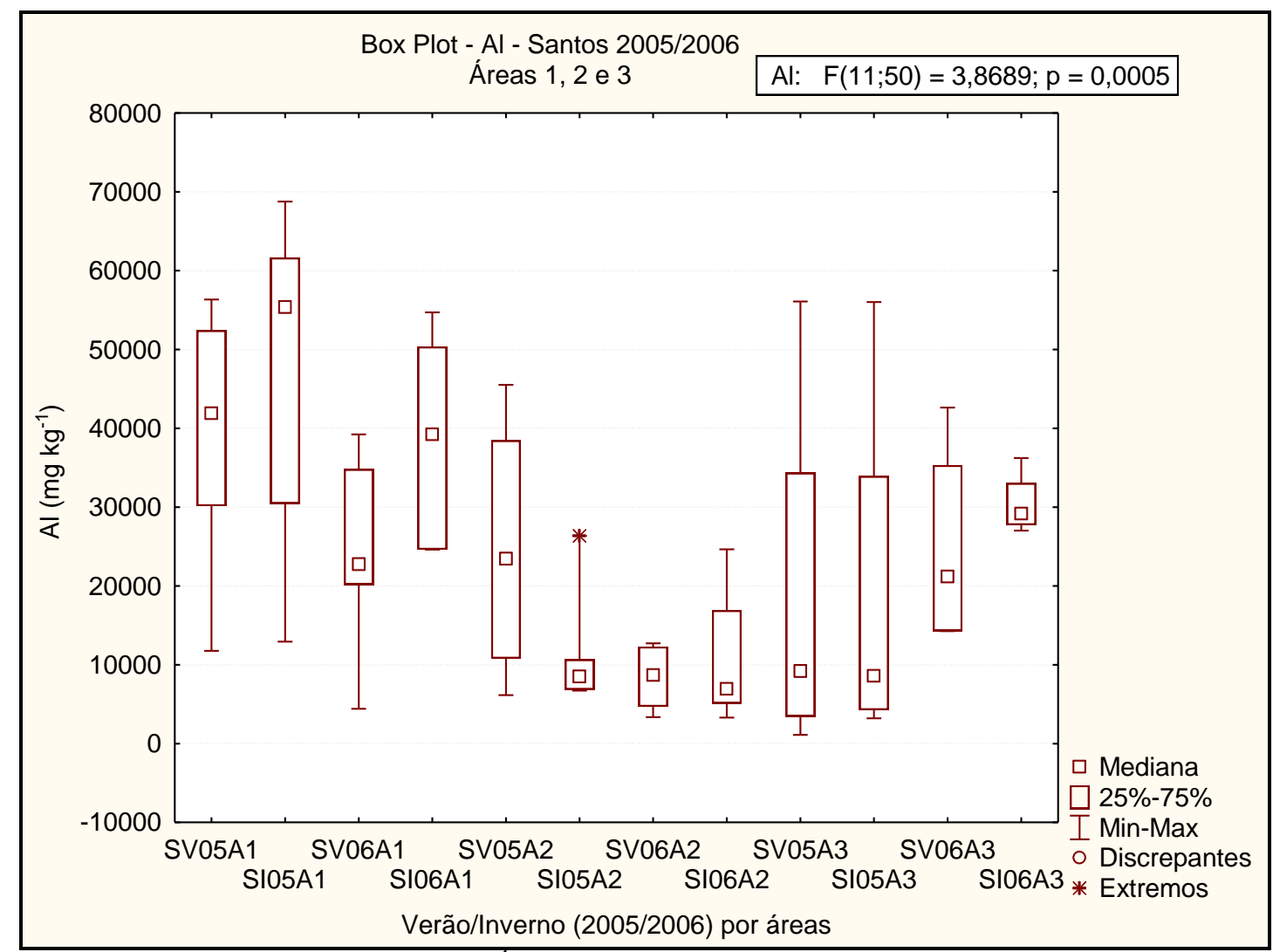

Figura 5.2: Box Plot Al (mg kg $\left.{ }^{-1}\right)$ e teste ANOVA - Santos Inverno/Verão 2005 e 2006

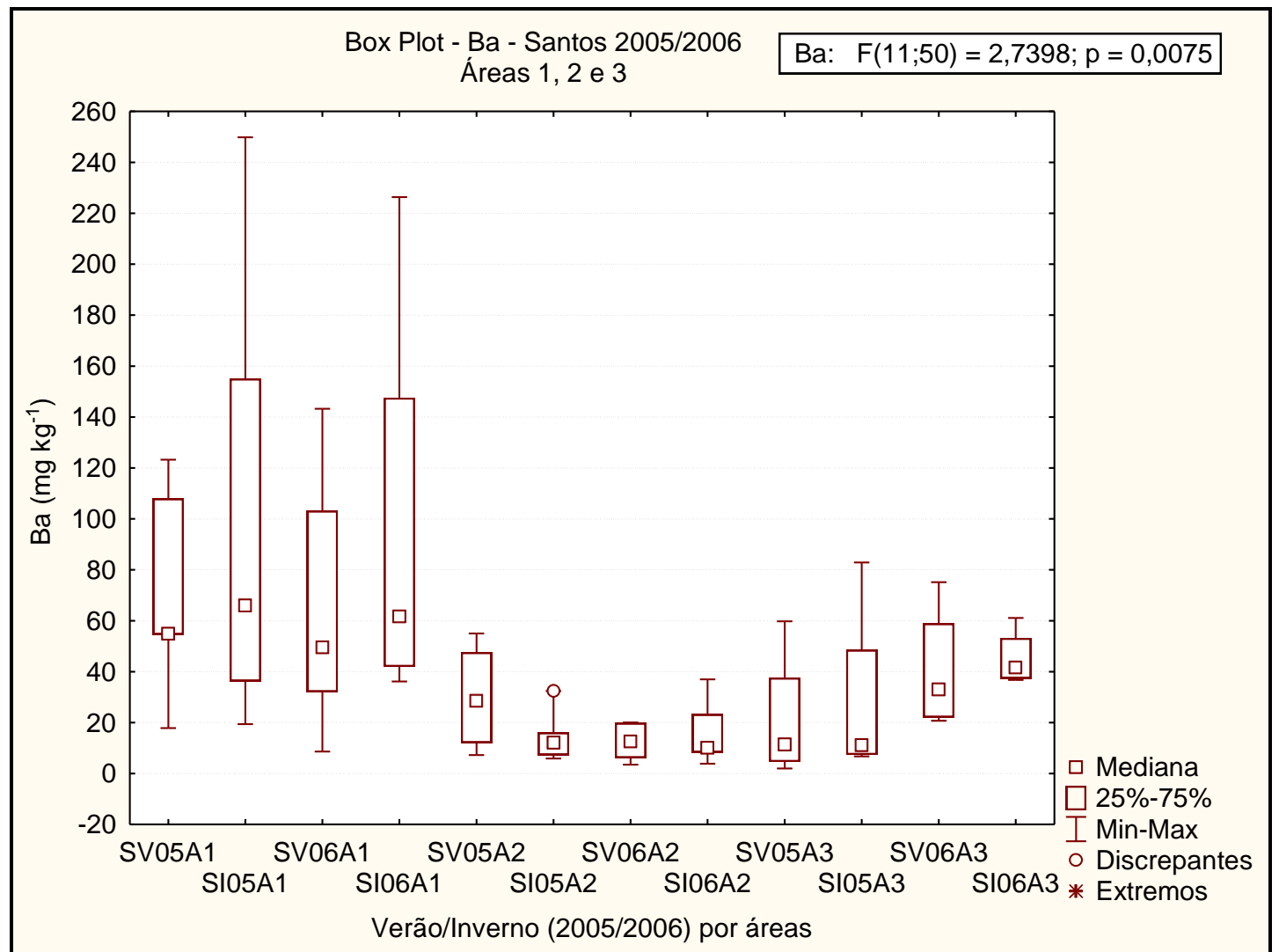

Figura 5.3: Box Plot Ba ( $\left.\mathrm{mg} \mathrm{kg}^{-1}\right)$ e teste ANOVA - Santos Inverno/Verão 2005 e 2006 


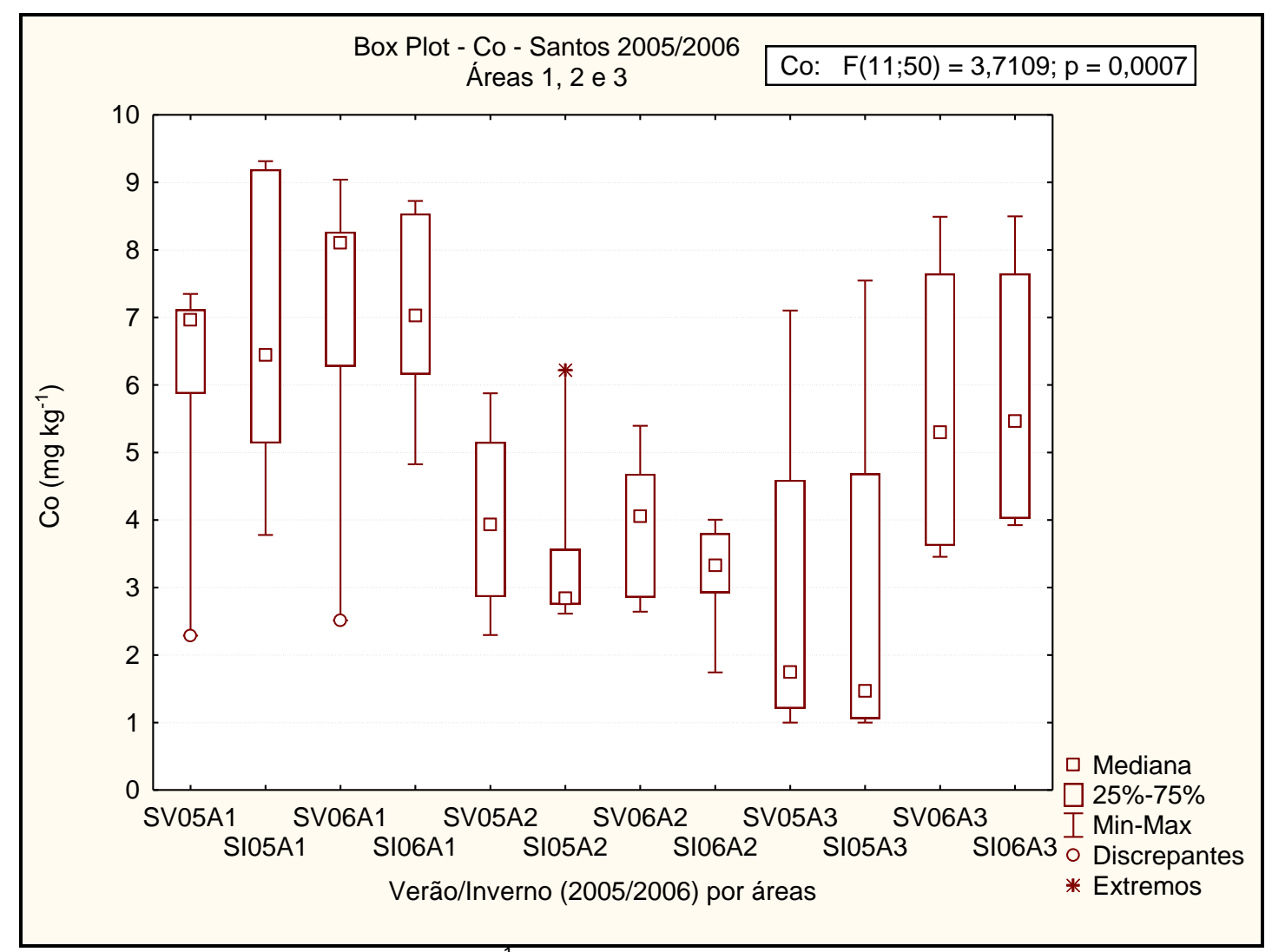

Figura 5.4: Box Plot Co ( $\left.\mathrm{mg} \mathrm{kg}^{-1}\right)$ e teste ANOVA - Santos Inverno/Verão 2005 e 2006

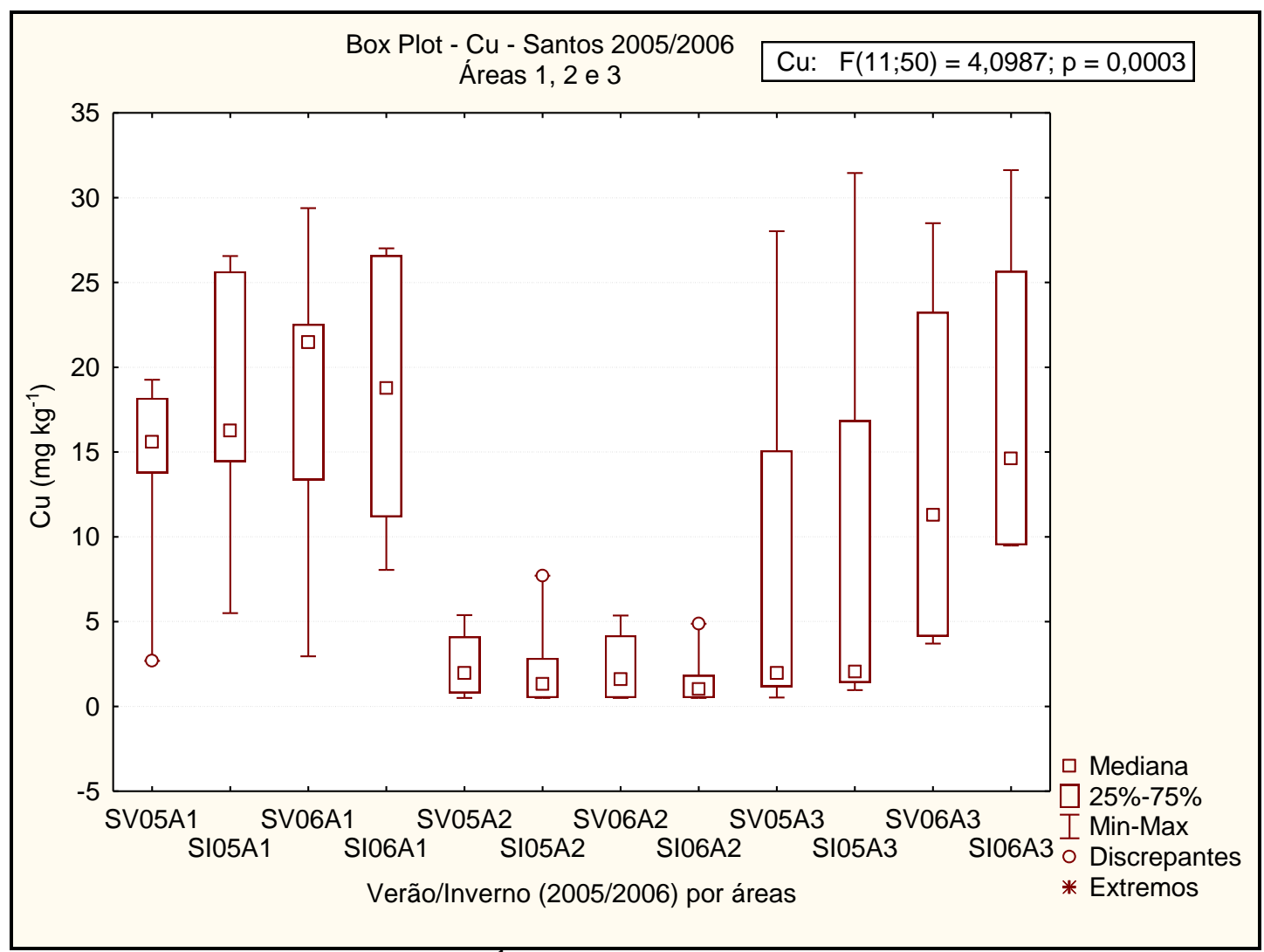

Figura 5.5: Box Plot Cu ( $\left.\mathrm{mg} \mathrm{kg}^{-1}\right)$ e teste ANOVA - Santos Inverno/Verão 2005 e 2006 


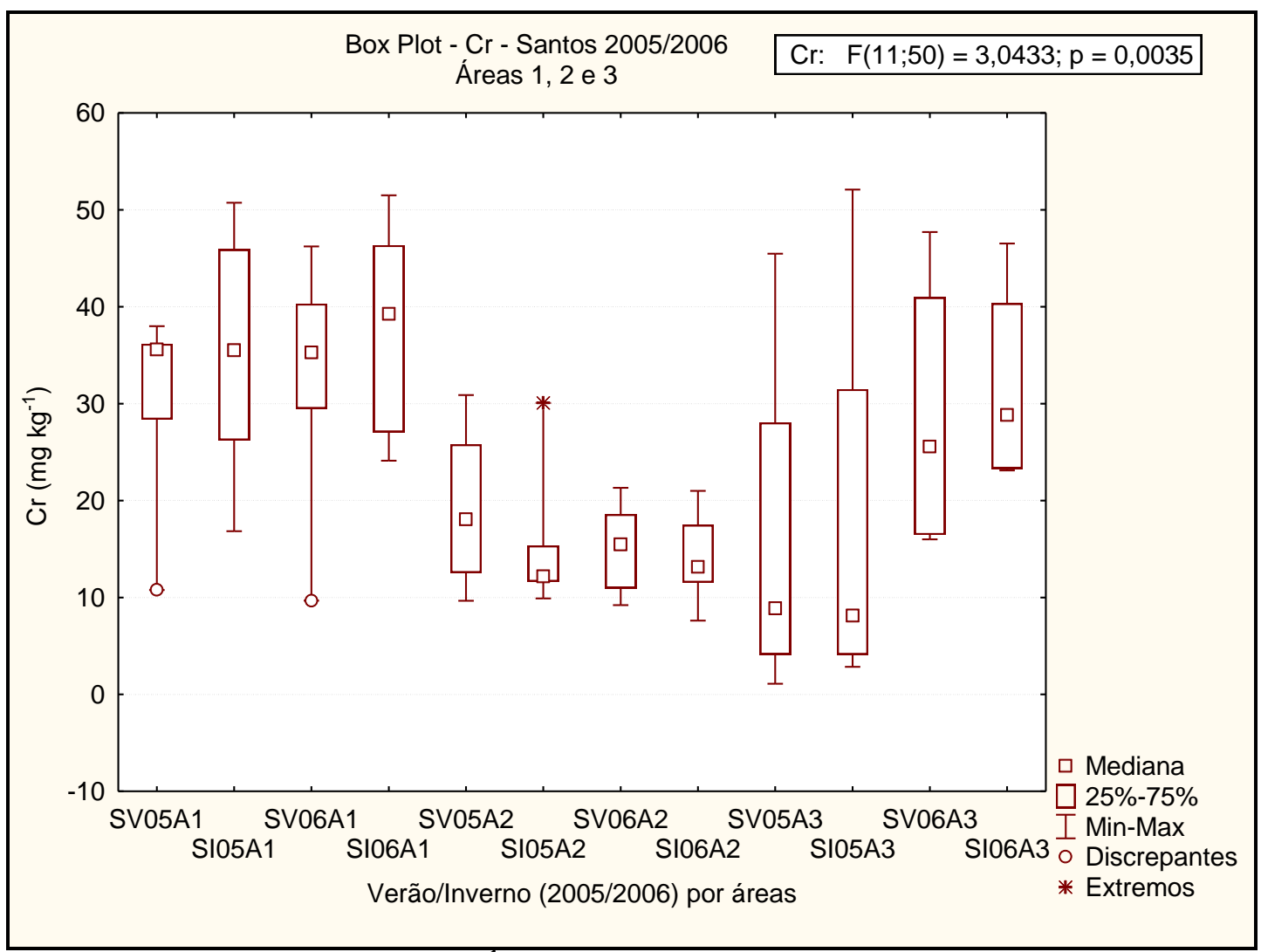

Figura 5.6: Box Plot Cr ( $\left.\mathrm{mg} \mathrm{kg}^{-1}\right)$ e teste ANOVA - Santos Inverno/Verão 2005 e 2006

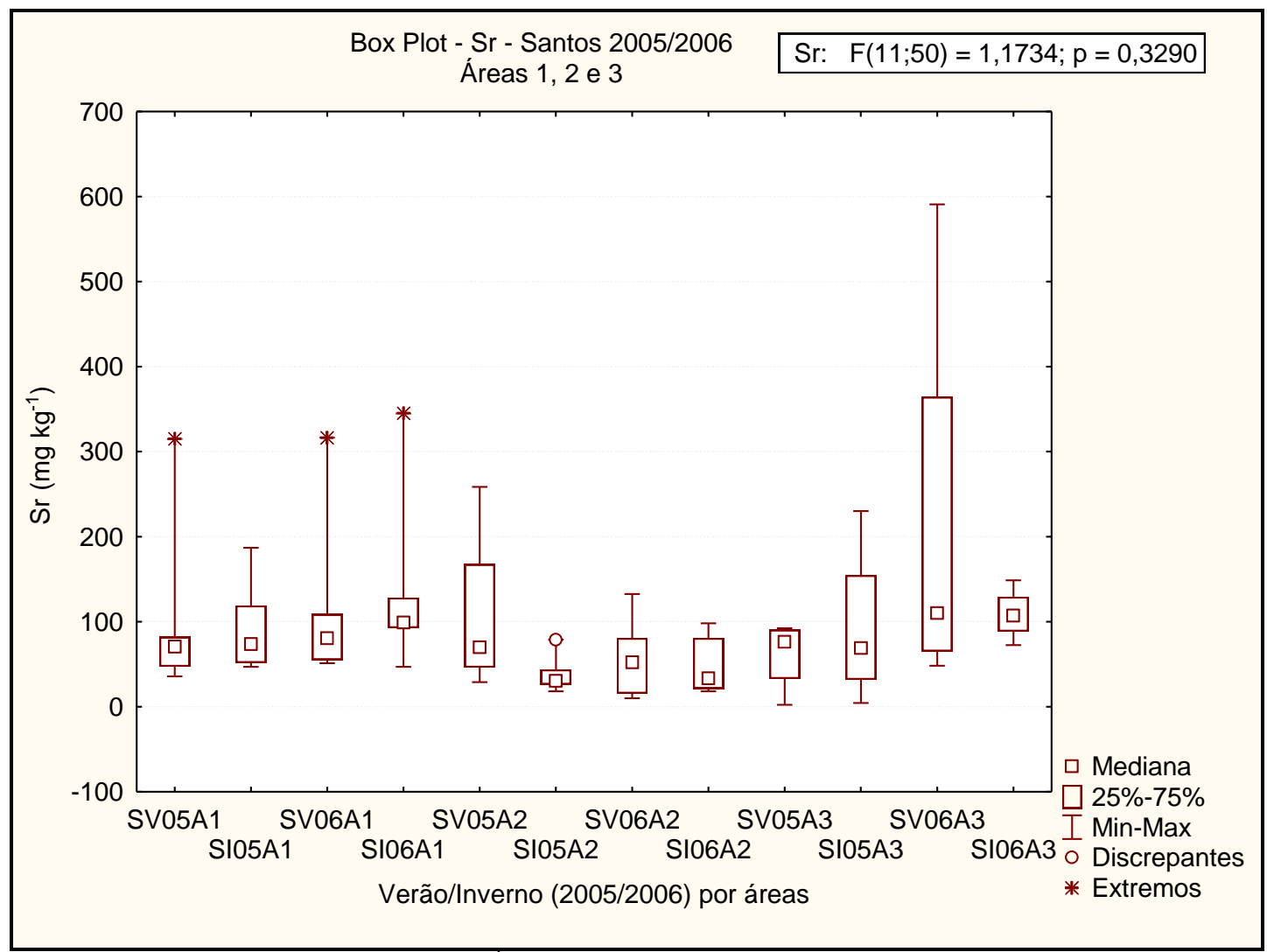

Figura 5.7: Box Plot Sr (mg kg $\left.{ }^{-1}\right)$ e teste ANOVA - Santos Inverno/Verão 2005 e 2006 


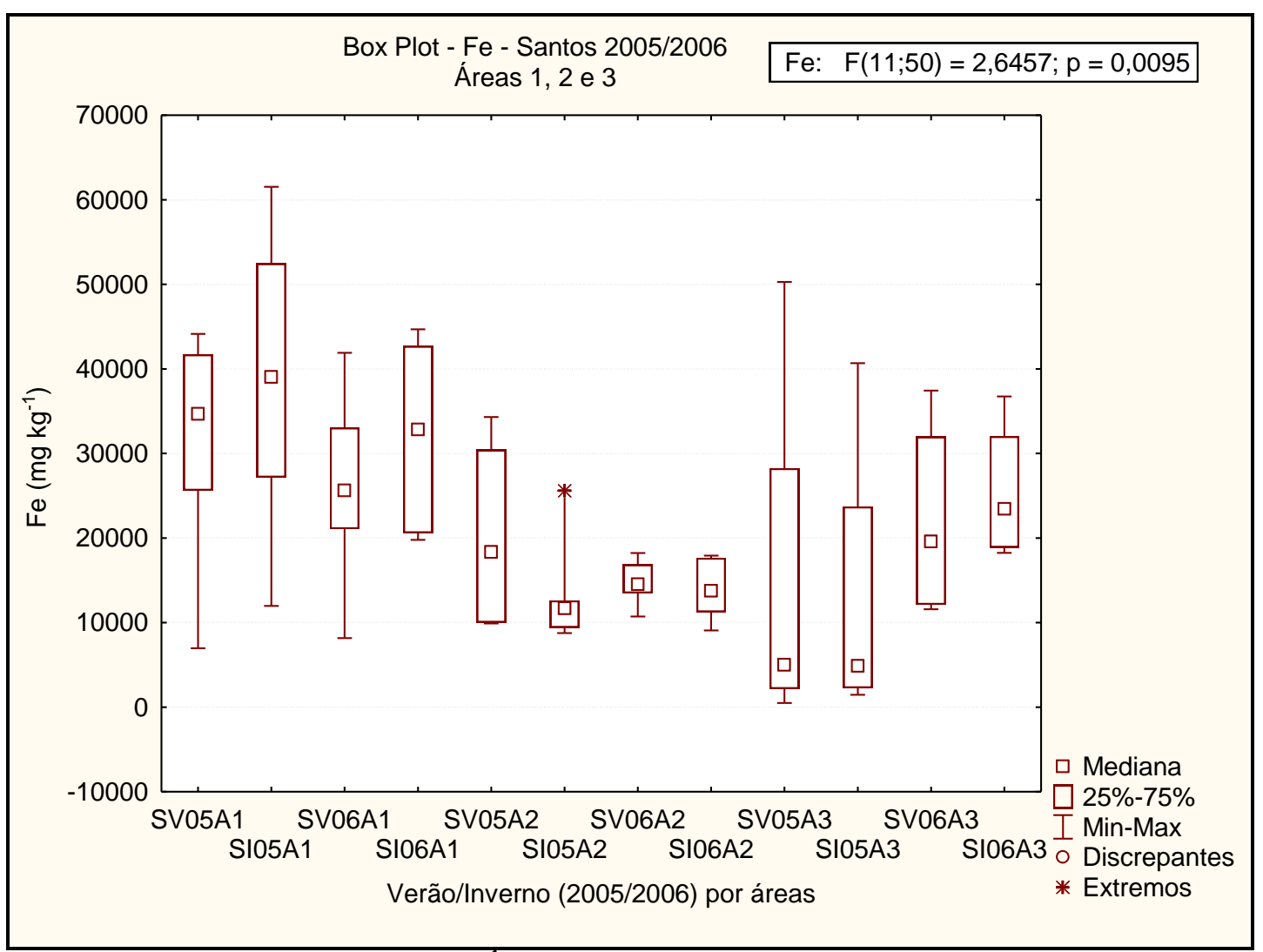

Figura 5.8: Box Plot Fe $\left(\mathrm{mg} \mathrm{kg}^{-1}\right)$ e teste ANOVA - Santos Inverno/Verão 2005 e 2006

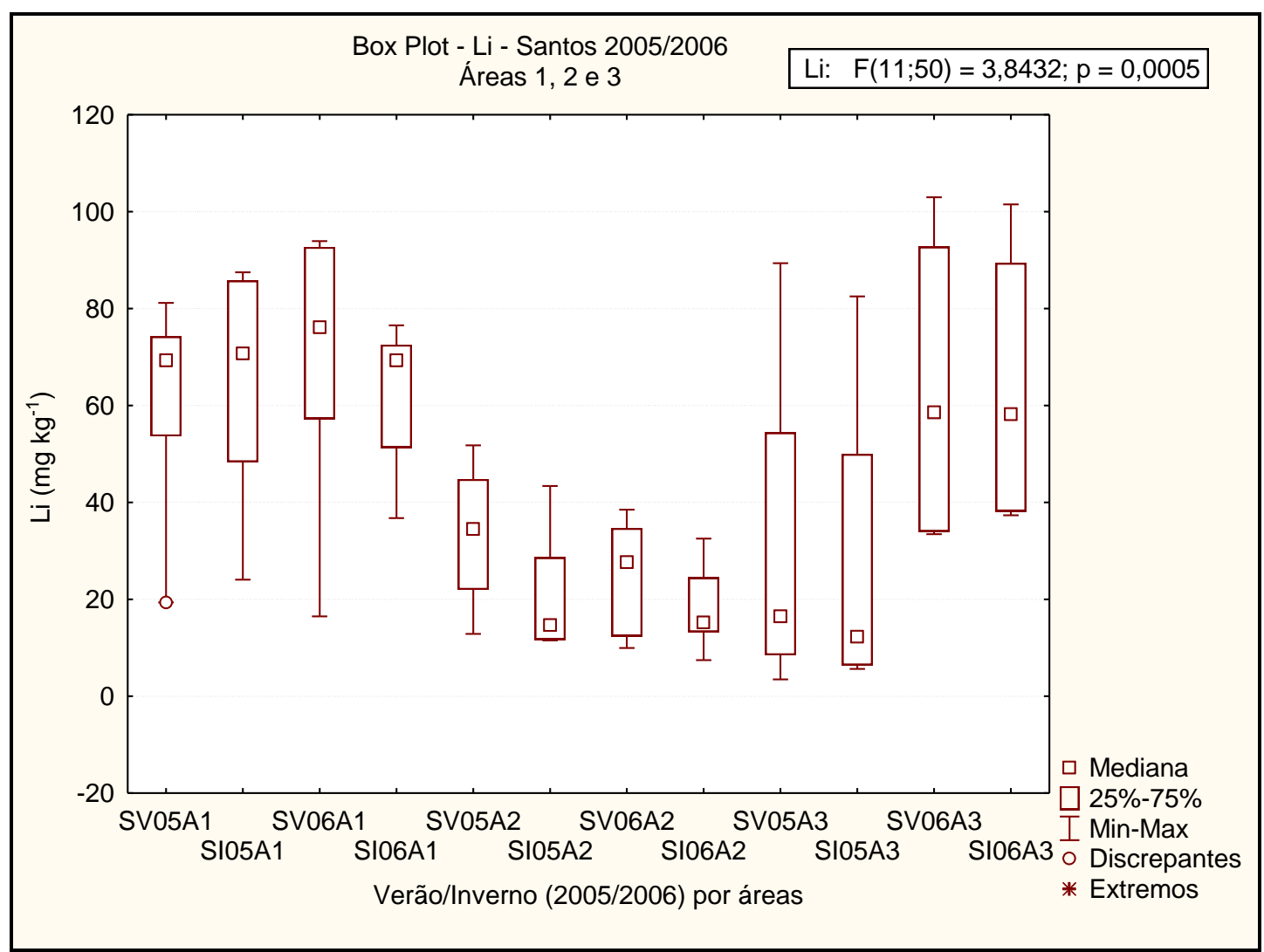

Figura 5.9: Box Plot Li (mg kg $\left.{ }^{-1}\right)$ e teste ANOVA - Santos Inverno/Verão 2005 e 2006 


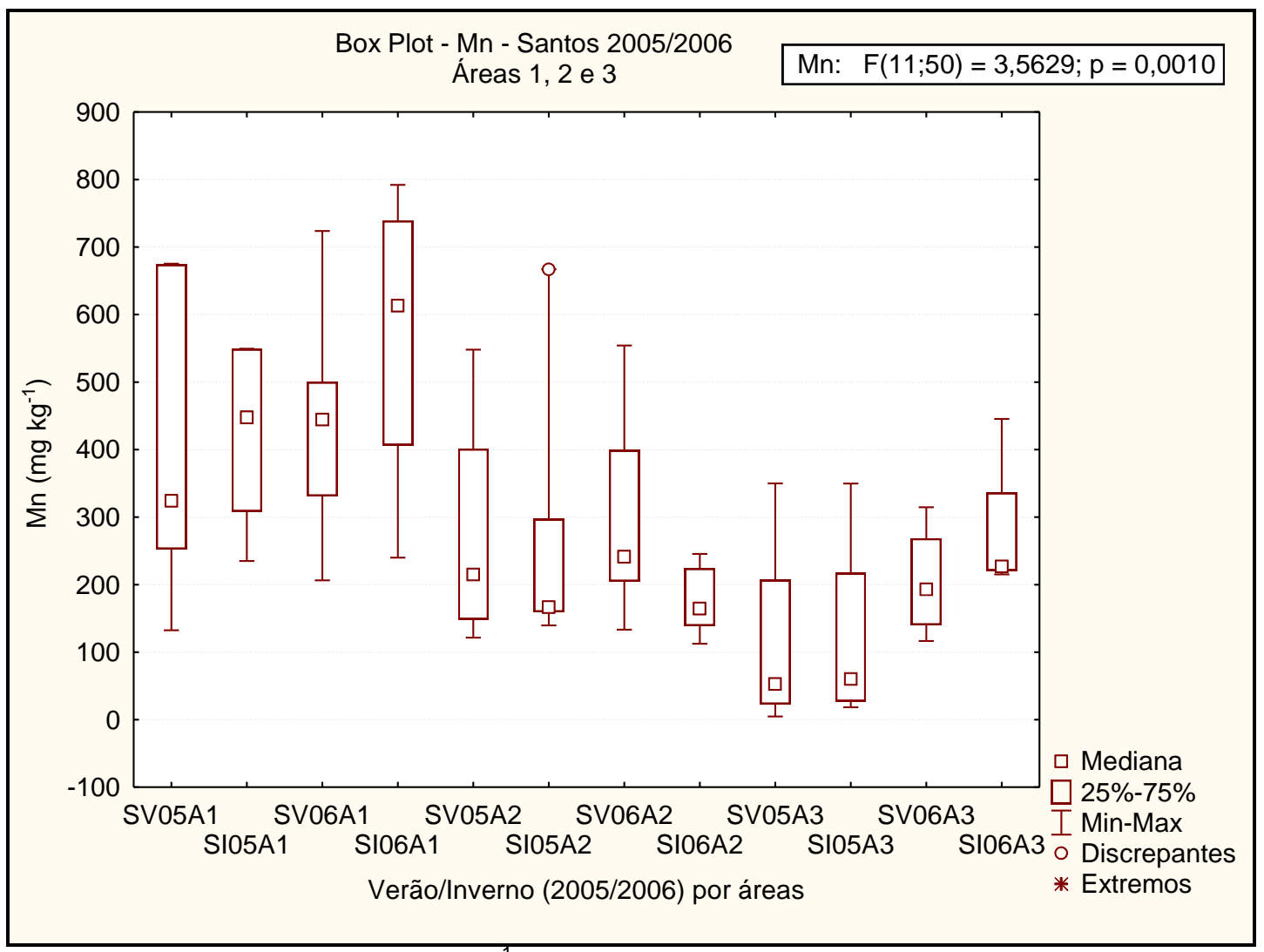

Figura 5.10: Box Plot Mn (mg kg $\left.{ }^{-1}\right)$ e teste ANOVA - Santos Inverno/Verão 2005 e 2006

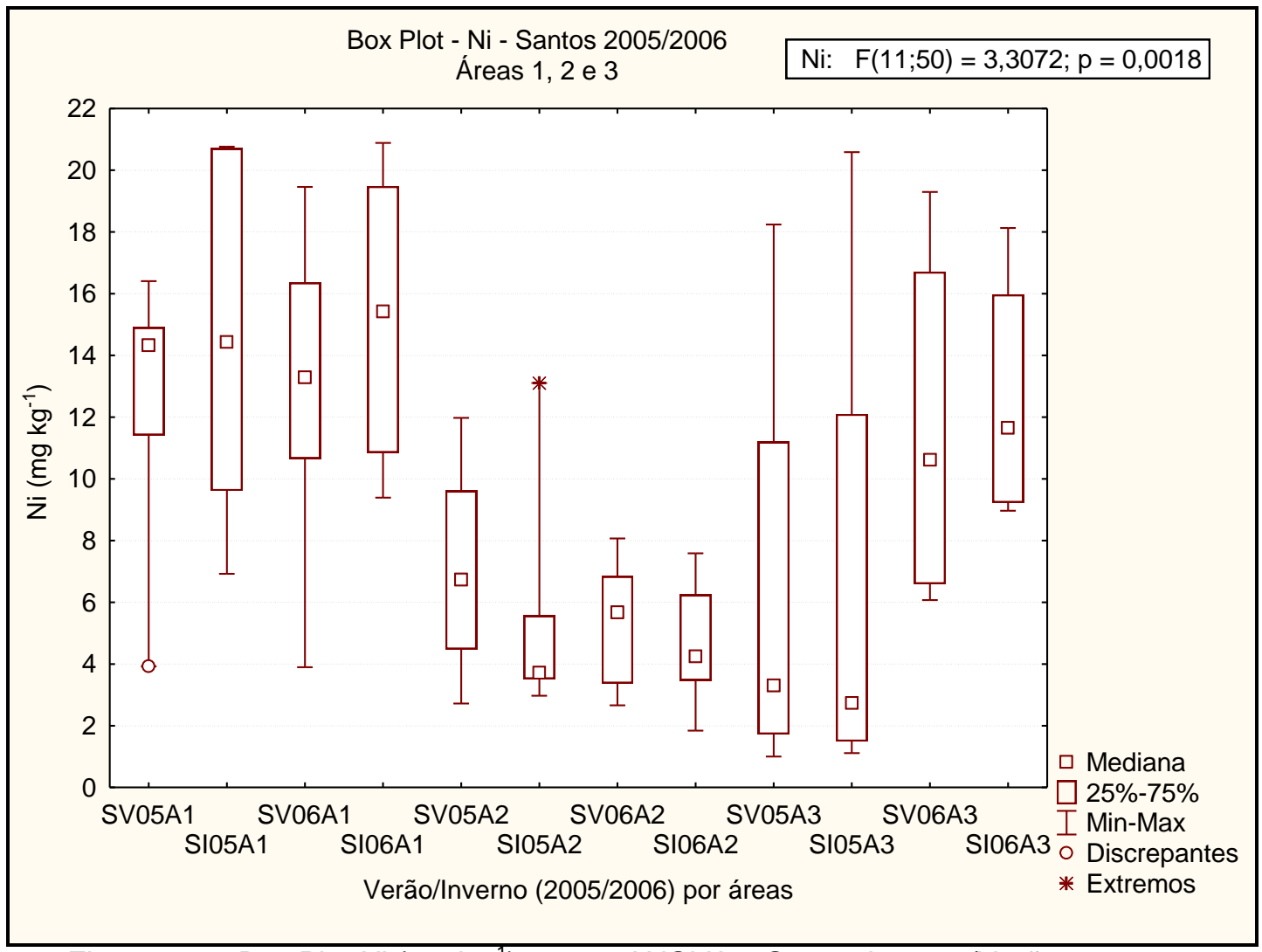

Figura 5.11: Box Plot Ni $\left(\mathrm{mg} \mathrm{kg}^{-1}\right)$ e teste ANOVA - Santos Inverno/Verão 2005 e 2006 


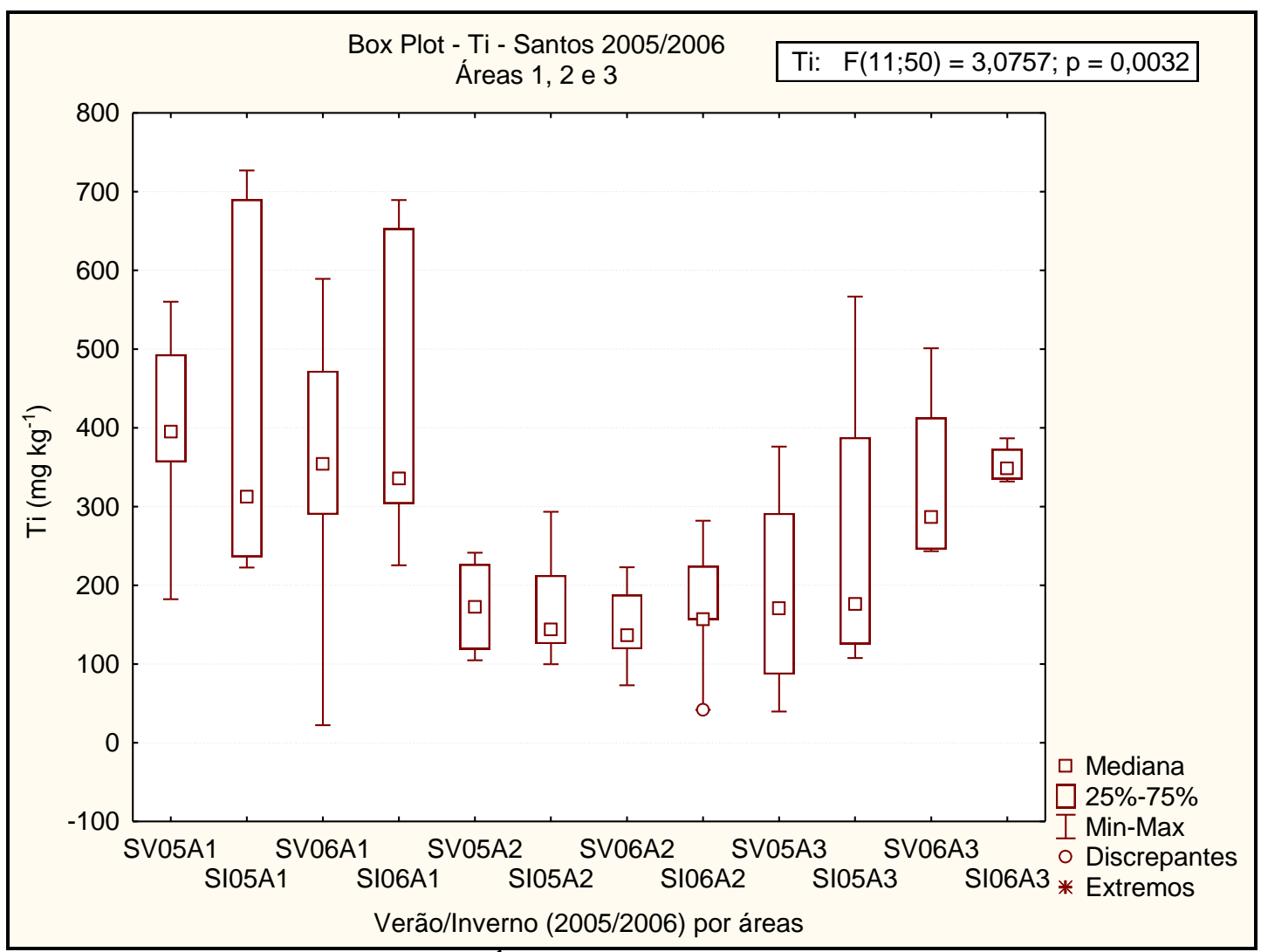

Figura 5.12: Box Plot Ti ( $\left.\mathrm{mg} \mathrm{kg}^{-1}\right)$ e teste ANOVA - Santos Inverno/Verão 2005 e 2006

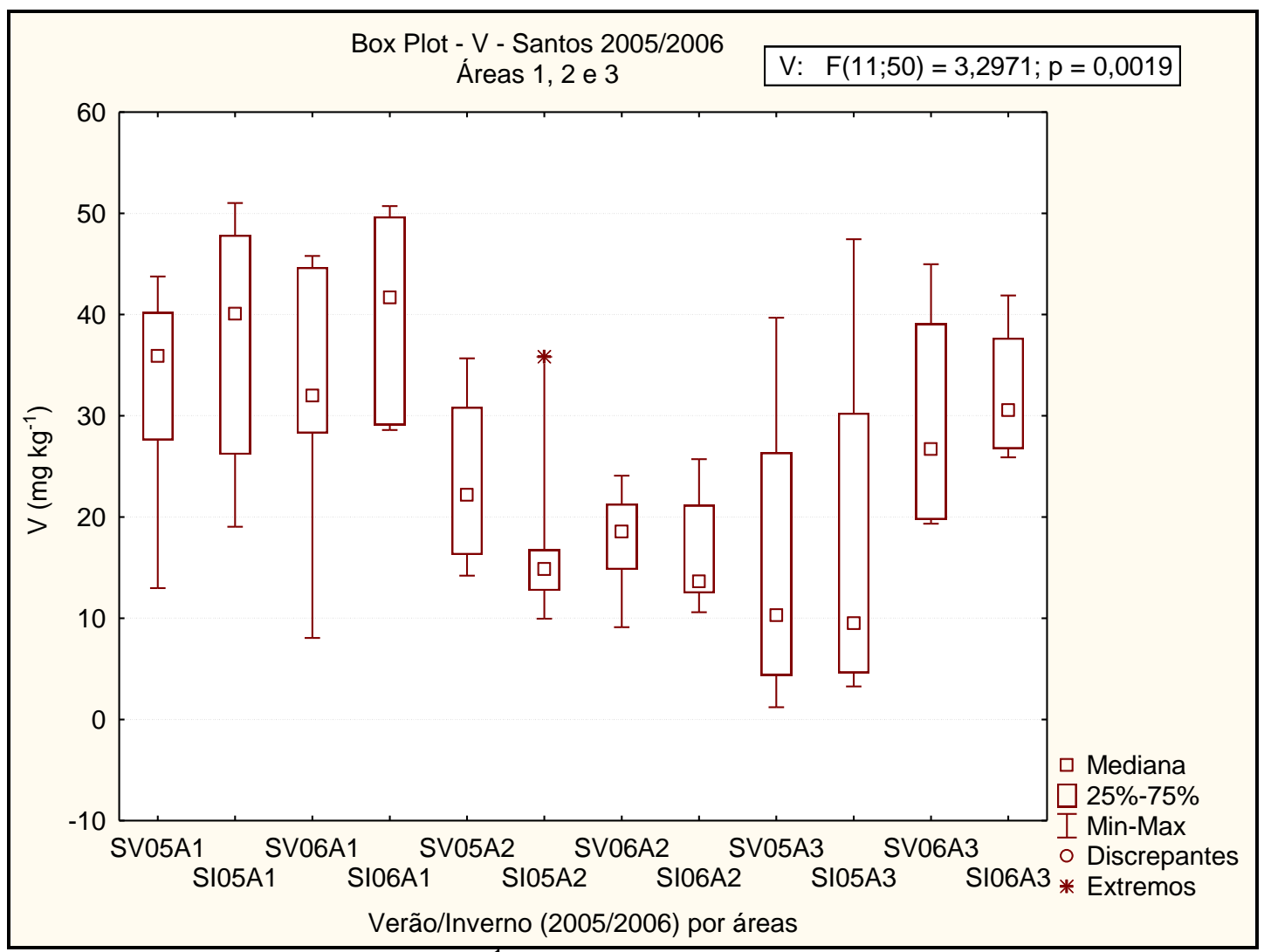

Figura 5.13: Box Plot V (mg kg $\left.{ }^{-1}\right)$ e teste ANOVA - Santos Inverno/Verão 2005 e 2006 


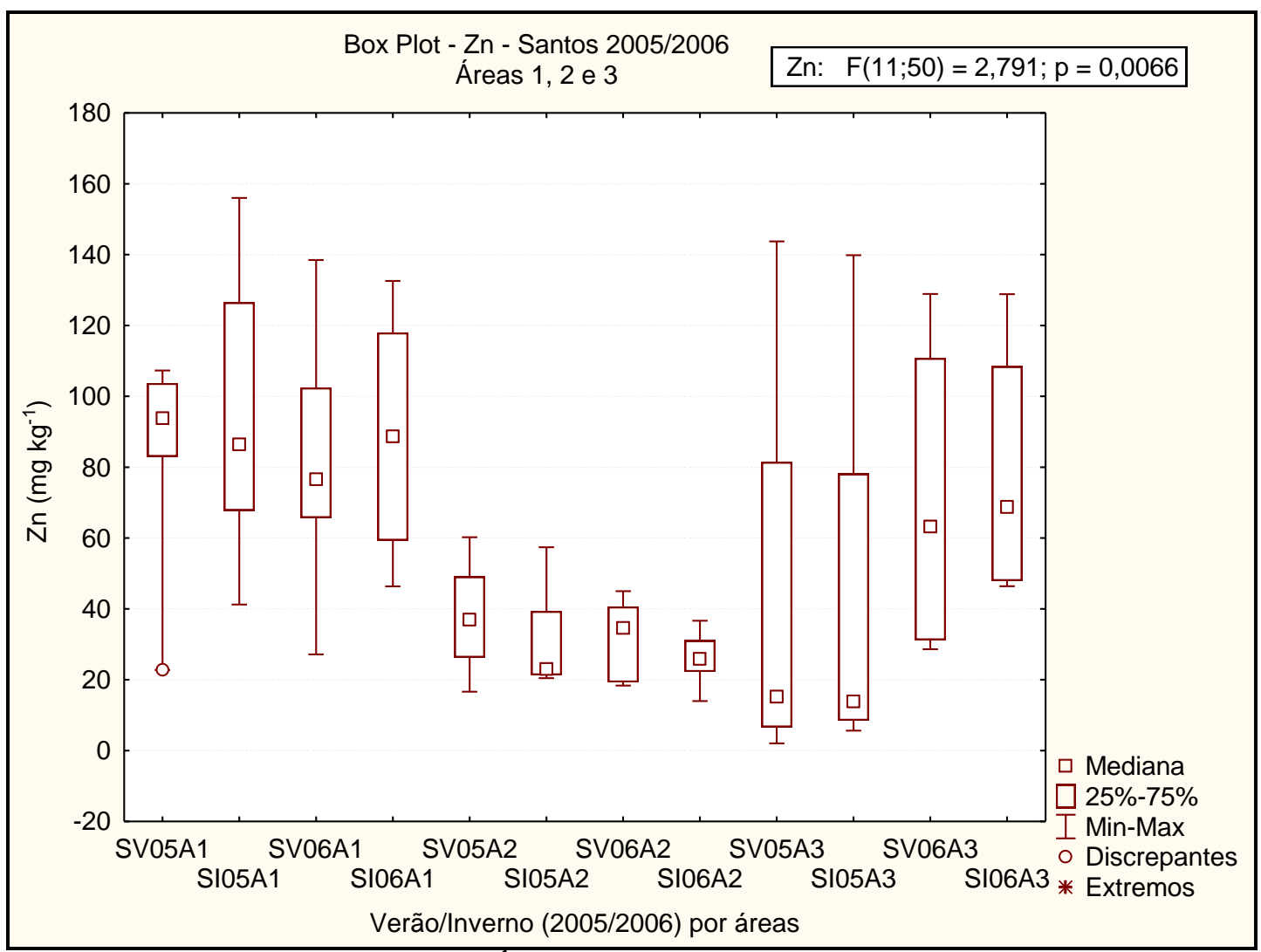

Figura 5.14: Box Plot Zn $\left(\mathrm{mg} \mathrm{kg}^{-1}\right)$ e teste ANOVA - Santos Inverno/Verão 2005 e 2006

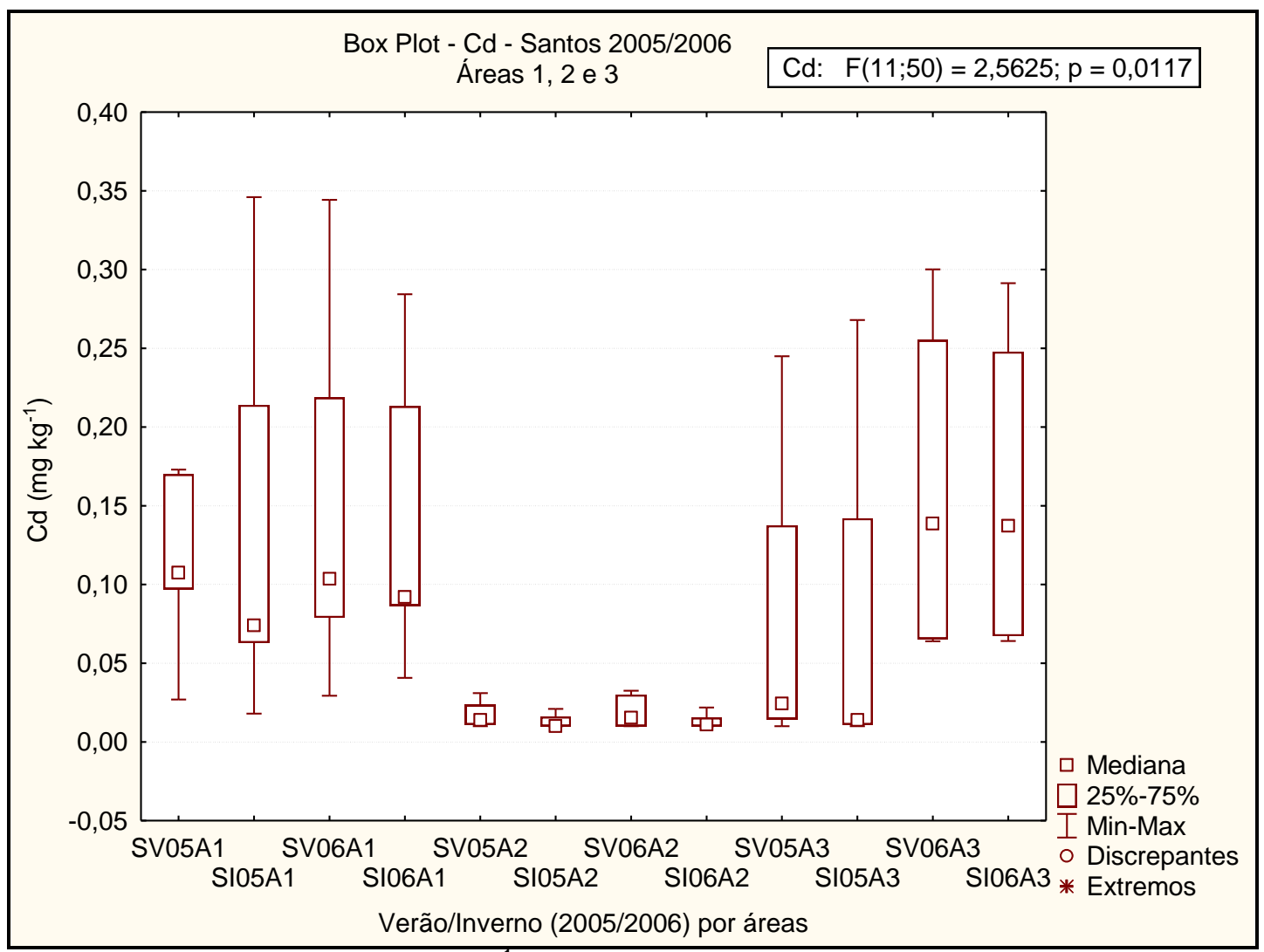

Figura 5.15: Box Plot Cd (mg kg $\left.{ }^{-1}\right)$ e teste ANOVA - Santos Inverno/Verão 2005 e 2006 


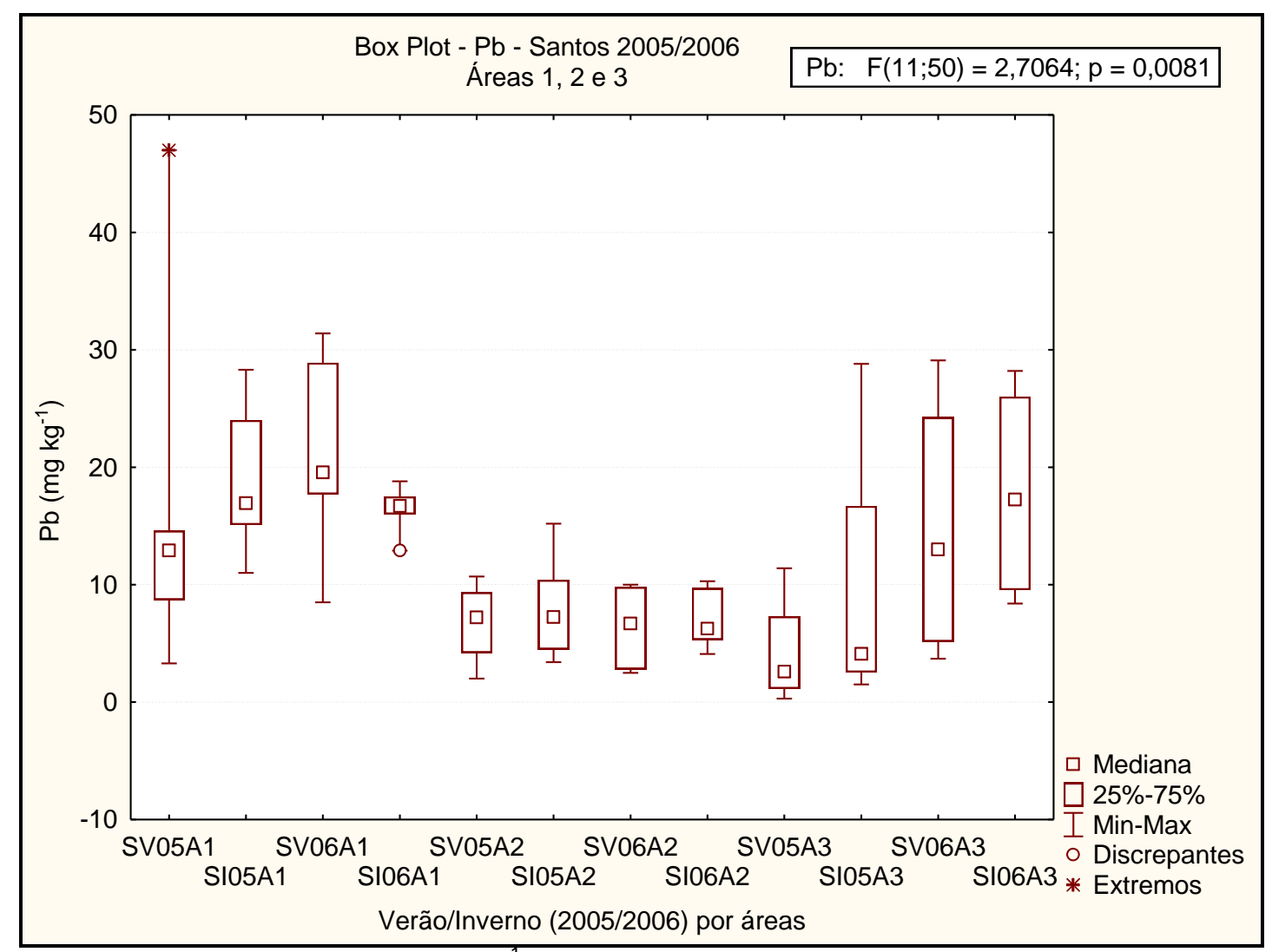

Figura 5.16: Box Plot Pb (mg kg $\left.{ }^{-1}\right)$ e teste ANOVA - Santos Inverno/Verão 2005 e 2006

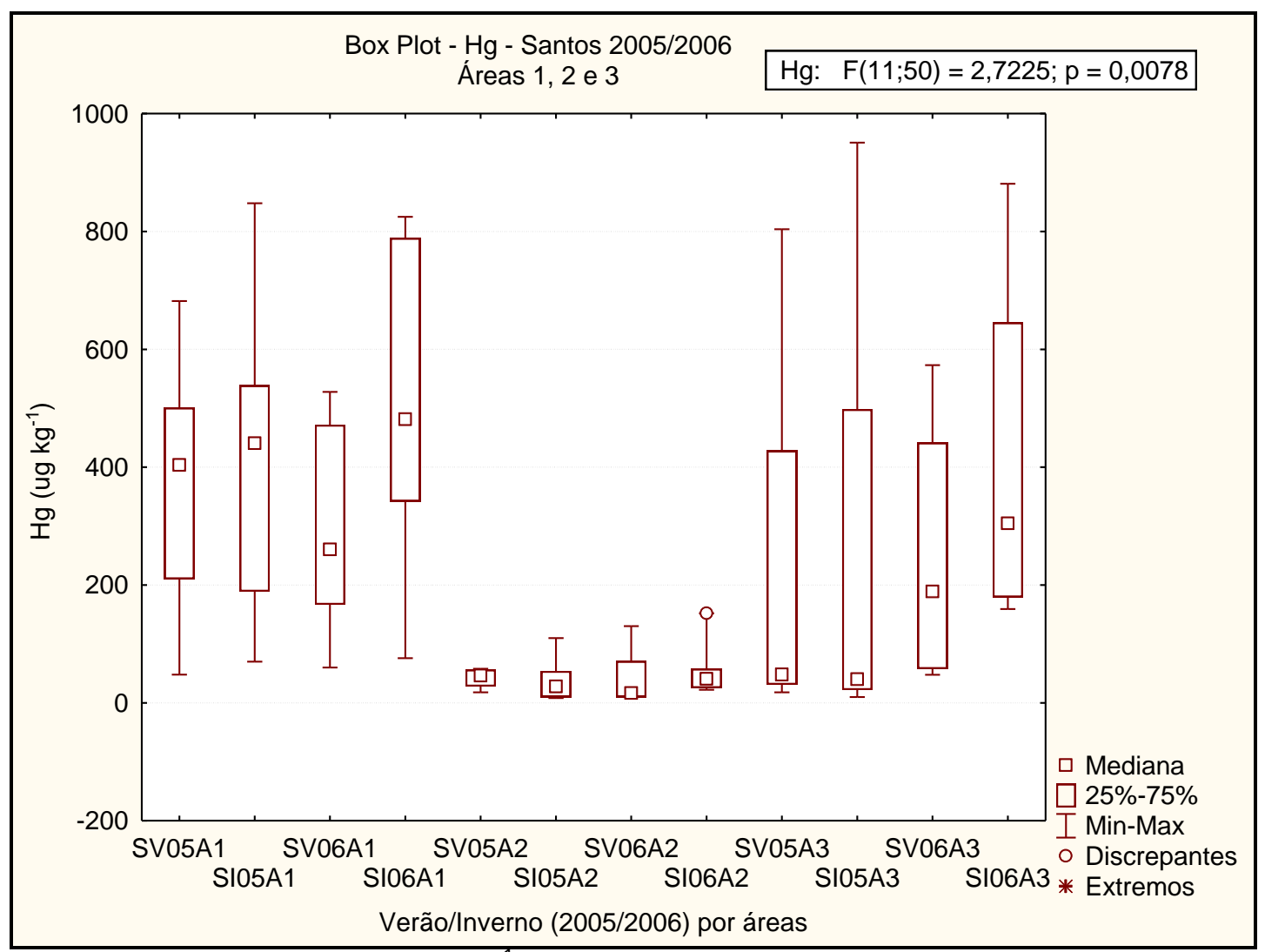

Figura 5.17: Box Plot $\mathrm{Hg}\left(\mathrm{mg} \mathrm{kg}^{-1}\right)$ e teste ANOVA - Santos Inverno/Verão 2005 e 2006 
Após a comparação entre os valores das medianas das concentrações obtidas para os diferentes elementos avaliados, nas 3 áreas demonstradas nos gráficos Box plot representados pelas Figuras 5.2 à 5.17, o teste ANOVA detectou diferenças significativas para os elementos $\mathrm{Al}, \mathrm{Ba}, \mathrm{Co}$, $\mathrm{Cu}, \mathrm{Cr}, \mathrm{Fe}, \mathrm{Li}, \mathrm{Mn}, \mathrm{Ni}, \mathrm{Ti}, \mathrm{V}, \mathrm{Zn}, \mathrm{Cd}, \mathrm{Pb}$ e Hg, pois todos apresentaram valor de $p<0,05$, com exceção apenas do $\operatorname{Sr}(p>0,05)$. Assim sendo, evidenciou-se que as áreas avaliadas diferem-se entre si nas estações de inverno e verão, nos anos de 2005 e 2006.

Foi feita também uma comparação temporal por meio do teste ANOVA, considerando-se os anos de 2005 e 2006, para cada elemento, para cada área estudada, com os valores de concentração obtidos e os resultados estão apresentados na Tabela 5.9.

Tabela 5.9 - Valores obtidos pelo teste ANOVA - Teste F e valor de P

\begin{tabular}{c|ccc|ccc|ccc}
\hline ANOVA & \multicolumn{3}{|c|}{ Área 1 } & \multicolumn{3}{c|}{ Área 2 } & \multicolumn{3}{c}{ Área 3 } \\
\hline Elemento & teste $F$ & valor-P & $F$ crítico & $F$ & valor-P & F crítico & $F$ & valor-P & $F$ crítico \\
\hline Al & 2,07 & 0,14 & 3,10 & 2,65 & 0,08 & 3,16 & 0,33 & 0,81 & 3,49 \\
Ba & 0,43 & 0,73 & 3,10 & 1,74 & 0,19 & 3,16 & 0,71 & 0,57 & 3,49 \\
Cd (GF AAS) & 0,11 & 0,95 & 3,10 & 0,92 & 0,45 & 3,16 & 0,67 & 0,59 & 3,49 \\
Pb (GF AAS) & 0,31 & 0,82 & 3,10 & 0,21 & 0,89 & 3,16 & 1,34 & 0,31 & 3,49 \\
Co & 0,29 & 0,83 & 3,10 & 0,58 & 0,64 & 3,16 & 1,51 & 0,26 & 3,49 \\
Cu & 0,41 & 0,75 & 3,10 & 0,16 & 0,92 & 3,16 & 0,47 & 0,71 & 3,49 \\
Cr & 0,41 & 0,74 & 3,10 & 0,55 & 0,66 & 3,16 & 0,76 & 0,54 & 3,49 \\
$\mathrm{Sr}$ & 0,23 & 0,87 & 3,10 & 1,51 & 0,25 & 3,16 & 0,92 & 0,46 & 3,49 \\
$\mathrm{Fe}$ & 0,85 & 0,48 & 3,10 & 1,09 & 0,38 & 3,16 & 0,48 & 0,70 & 3,49 \\
$\mathrm{Li}$ & 0,12 & 0,95 & 3,10 & 1,40 & 0,28 & 3,16 & 1,21 & 0,35 & 3,49 \\
$\mathrm{Mn}$ & 0,93 & 0,44 & 3,10 & 0,67 & 0,58 & 3,16 & 1,39 & 0,29 & 3,49 \\
$\mathrm{Hg}$ (CV AAS) & 0,77 & 0,53 & 3,10 & 0,19 & 0,90 & 3,16 & 0,21 & 0,89 & 3,49 \\
$\mathrm{Ni}$ & 0,38 & 0,77 & 3,10 & 0,53 & 0,67 & 3,16 & 0,80 & 0,52 & 3,49 \\
$\mathrm{Ti}$ & 0,20 & 0,90 & 3,10 & 0,19 & 0,90 & 3,16 & 1,11 & 0,38 & 3,49 \\
$\mathrm{~V}$ & 0,64 & 0,60 & 3,10 & 0,84 & 0,49 & 3,16 & 1,26 & 0,33 & 3,49 \\
$\mathrm{Zn}$ & 0,15 & 0,93 & 3,10 & 0,68 & 0,57 & 3,16 & 0,42 & 0,74 & 3,49 \\
\hline
\end{tabular}

Ao se analisar as diferenças de mediana para cada área separadamente, o teste ANOVA identificou que não ocorreram diferenças 
significativas quando se compara a concentração dos elementos numa mesma área, nos períodos de inverno e verão, anos de 2005 e 2006, pois as condições de $p>0,05$ e valor de $F<F_{\text {critico, }}$ foram evidenciadas para todos os elementos em cada área avaliada.

\subsubsection{Estudo de Normalização}

Conforme descrito no item 4.11.1, para o presente estudo, foi utilizado o Sc como elemento normalizador, devido às características de elemento conservativo, pelo método de extrapolação da curva de regressão. Os valores de Sc utilizados foram obtidos pela técnica de NAA e estão apresentados no anexo VII.

A Normalização consiste em avaliar as curvas de regressão linear Metal/Sc, assim como seus coeficientes de determinação $\left(r^{2}\right)$, e interpretar os diagramas de curvas de regressão obtidos, para identificar se as concentrações dos metais representam uma concentração natural ou se ocorreram por ação antrópica.

Para a obtenção das curvas de regressão linear scatterplot, foi utilizado o software STATSOFT STATISTICA $8.0{ }^{\circledR}$.

De modo a avaliar os possíveis impactos antrópicos na região em estudo, foram normalizados os resultados obtidos no inverno de 2005. As Figuras 5.18 a 5.31 apresentam os scatter-plot para os elementos $\mathrm{Al}, \mathrm{Ba}, \mathrm{Co}$, $\mathrm{Cu}, \mathrm{Cr}, \mathrm{Sr}, \mathrm{Fe}, \mathrm{Li}, \mathrm{Mn}$, Ni e Zn, respectivamente.

A Figura 5.18 apresenta o scatterplot Al x Sc: 


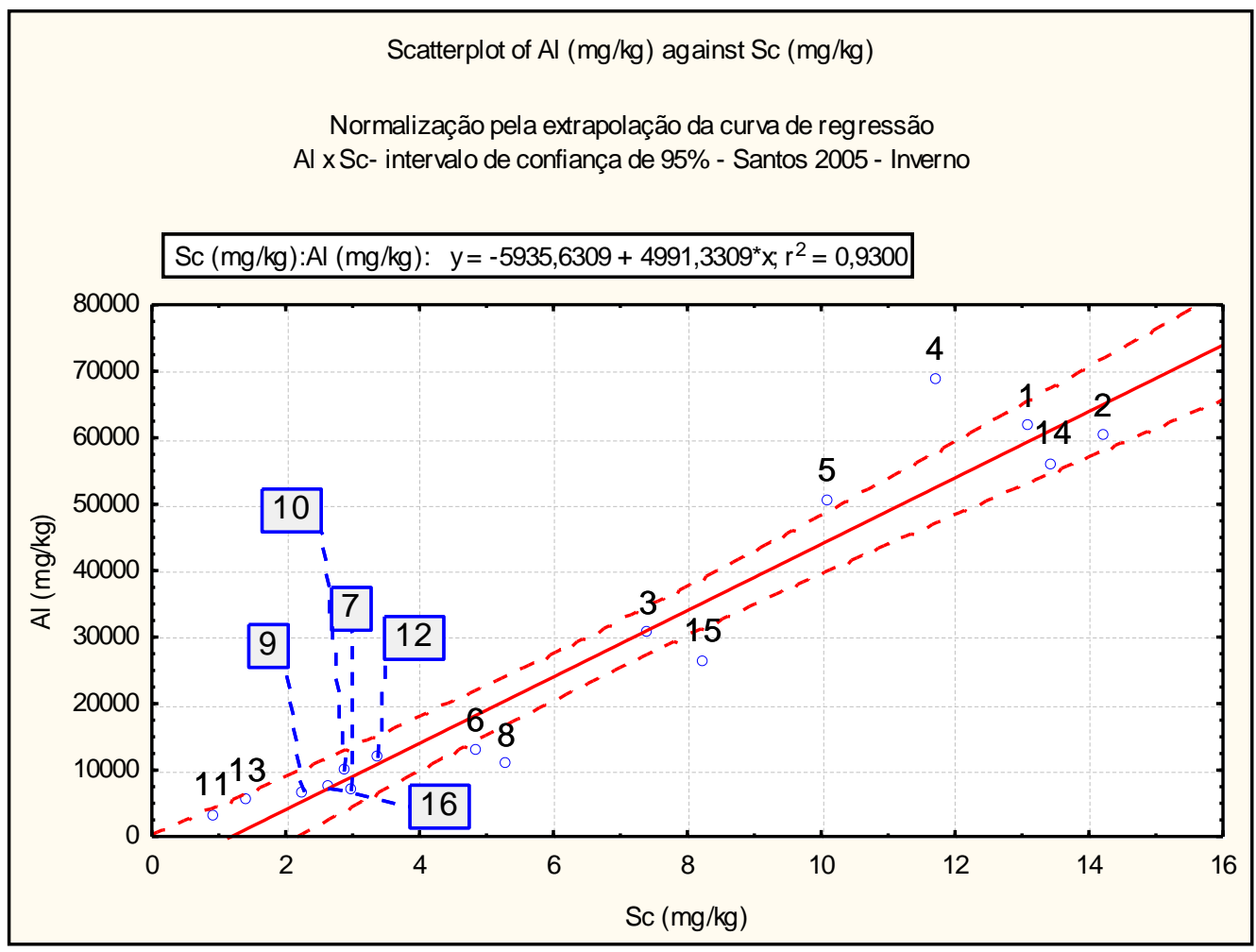

Figura 5.18: Scatterplot Al x Sc- Santos, Inverno de 2005

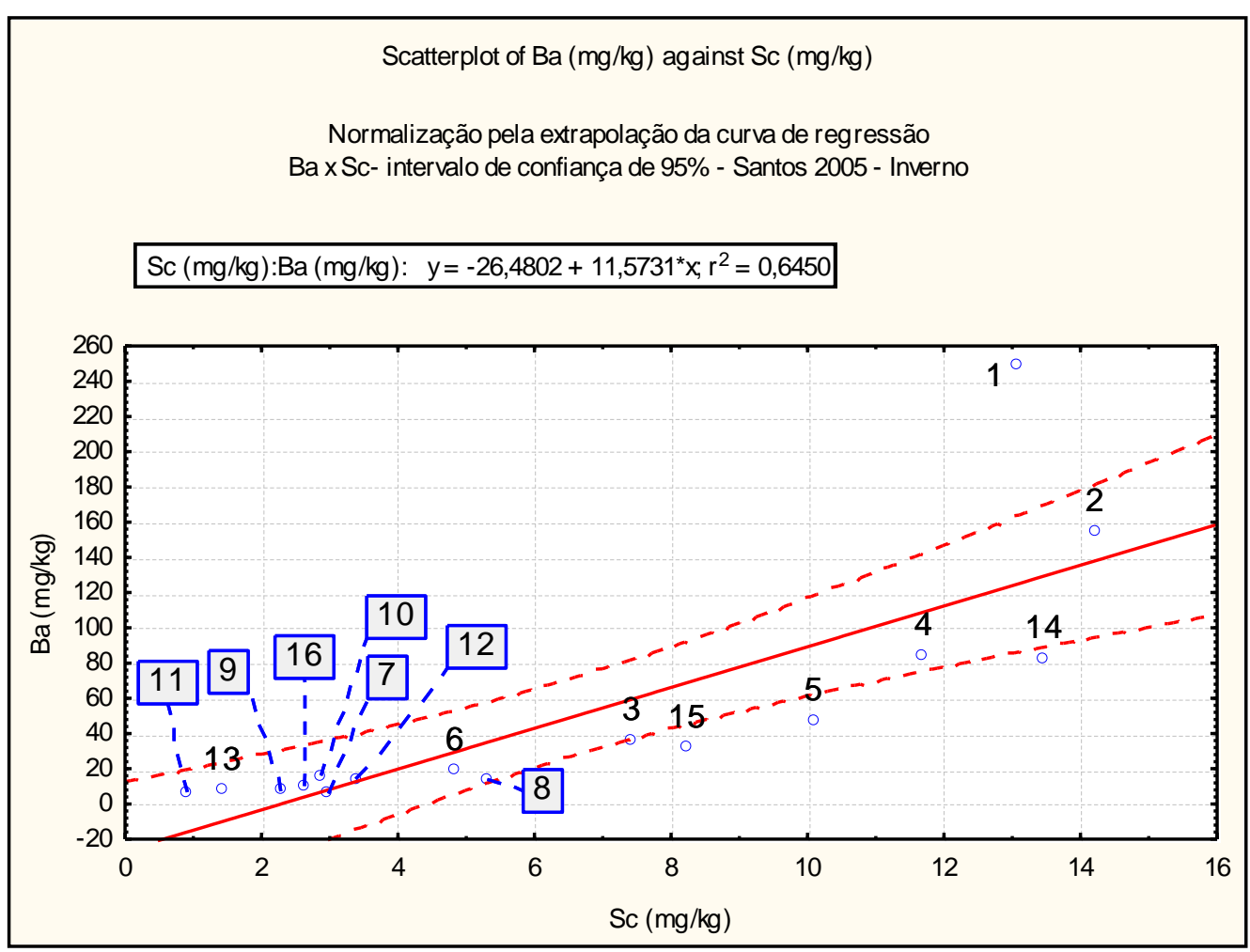

Figura 5.19: Scatterplot Ba x Sc - Santos, Inverno de 2005 


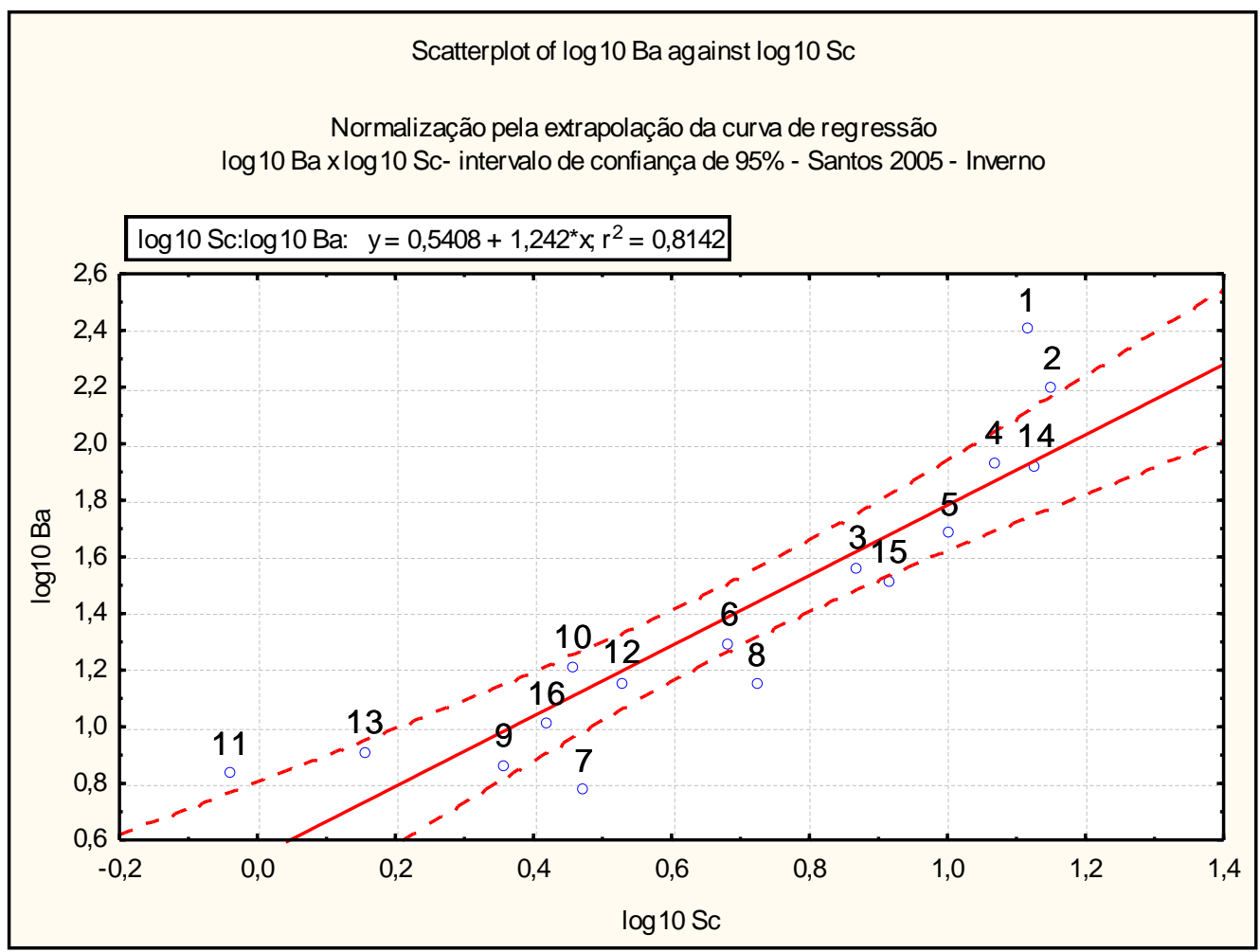

Figura 5.20: Scatterplot $\log _{10} \mathrm{Ba} \times \log _{10} \mathrm{Sc}$ - Santos, Inverno de 2005

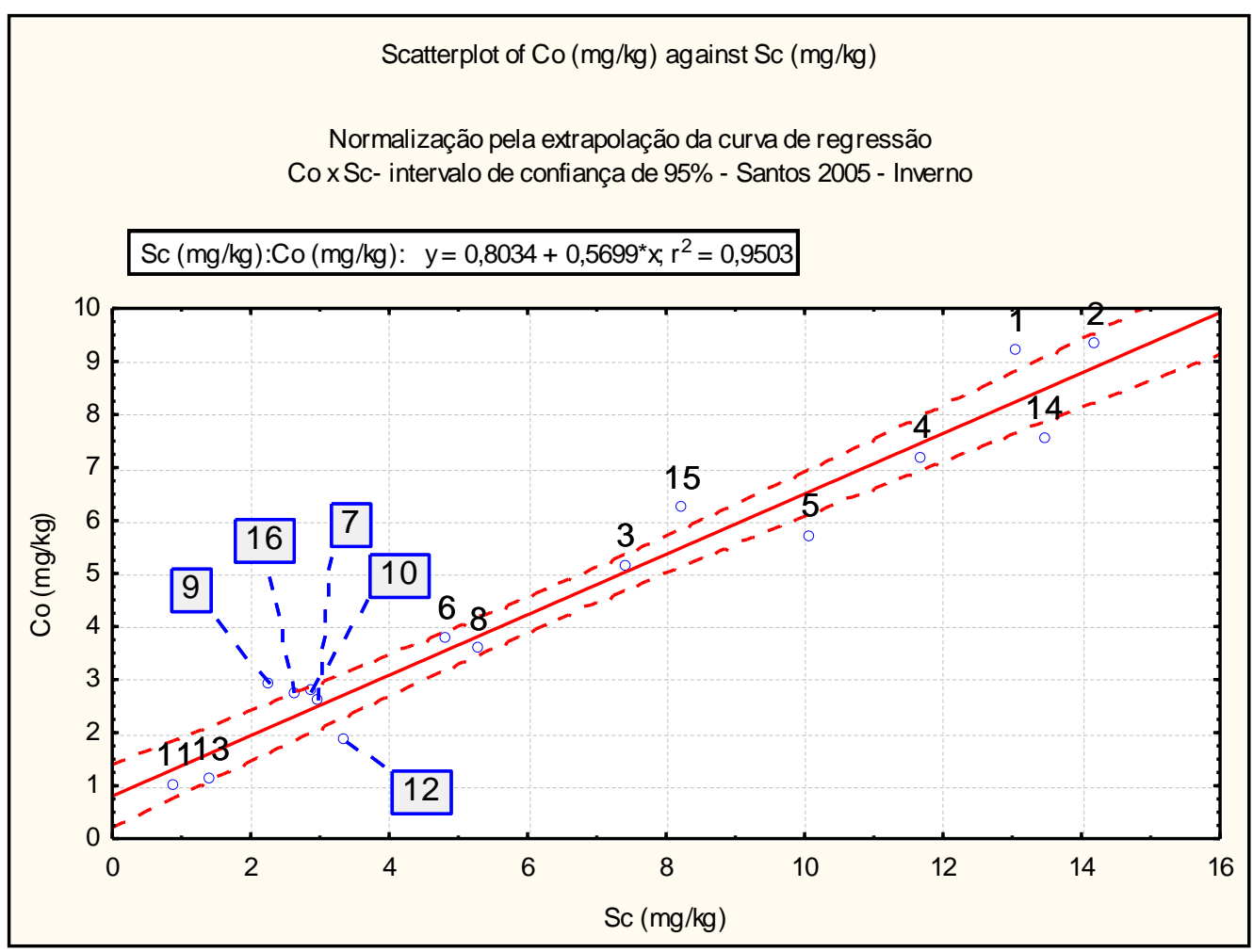

Figura 5.21: Scatterplot Co x Sc - Santos, Inverno de 2005 


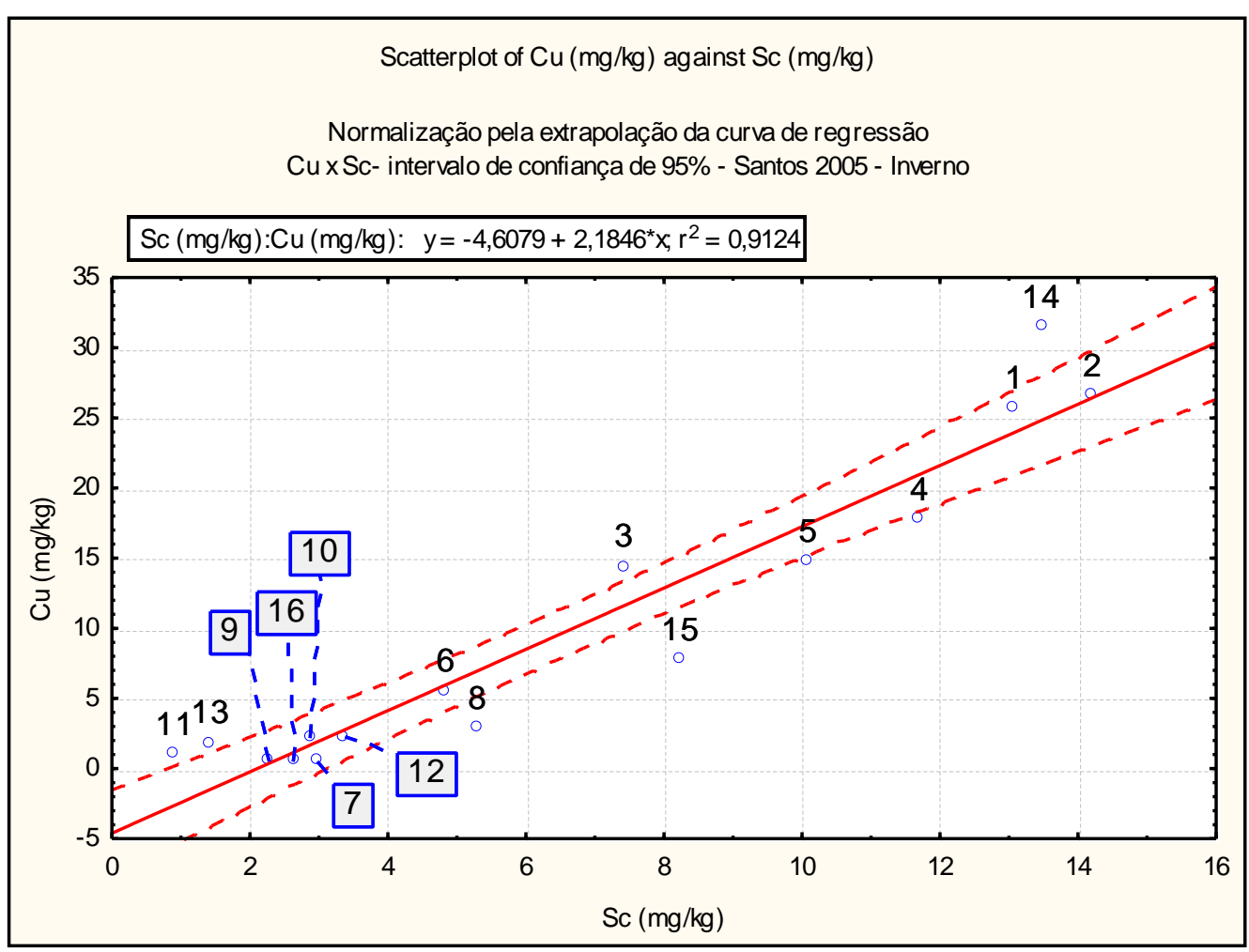

Figura 5.22: Scatterplot Cu x Sc- Santos, Inverno de 2005

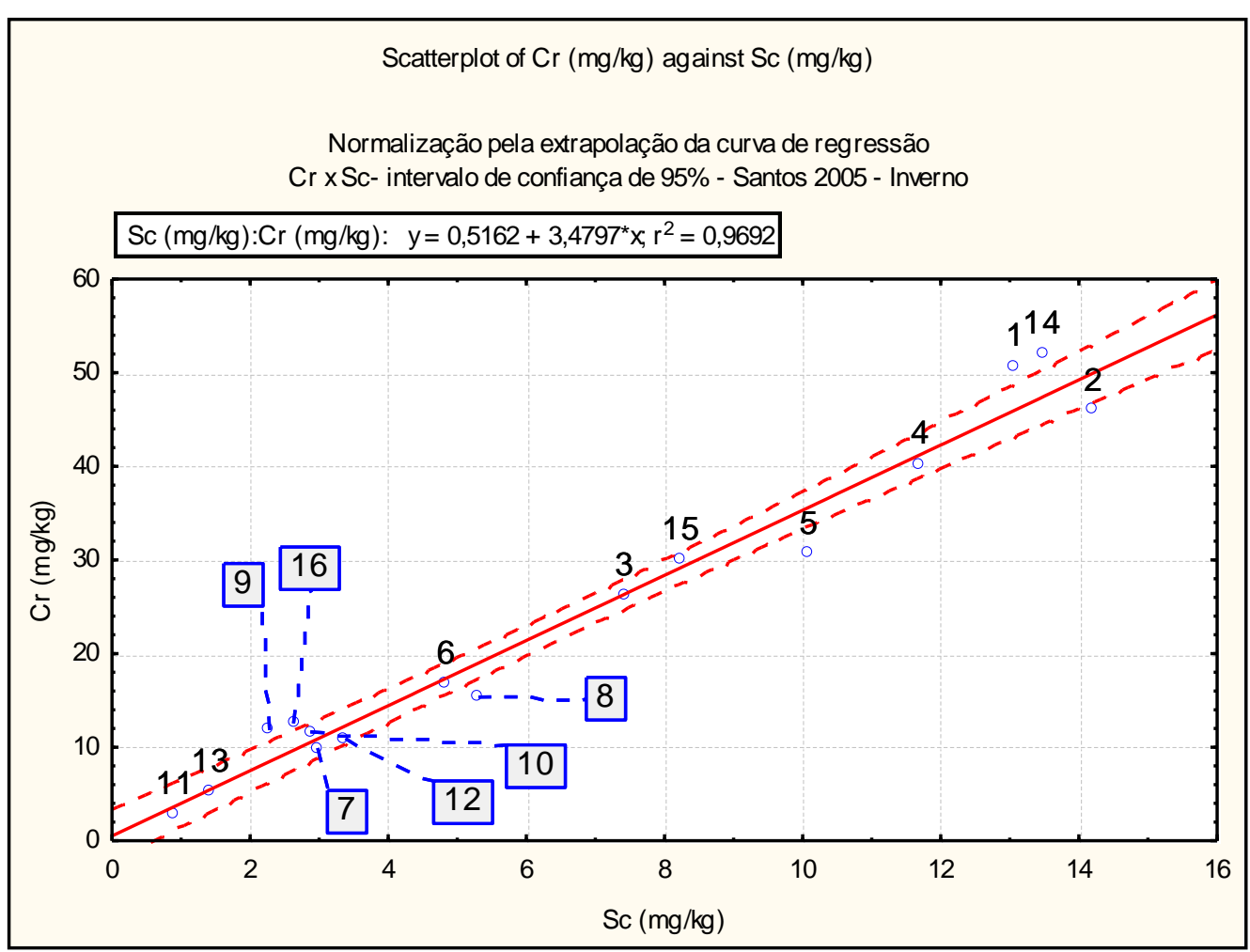

Figura 5.23: Scatterplot Cr x Sc- Santos, Inverno de 2005 


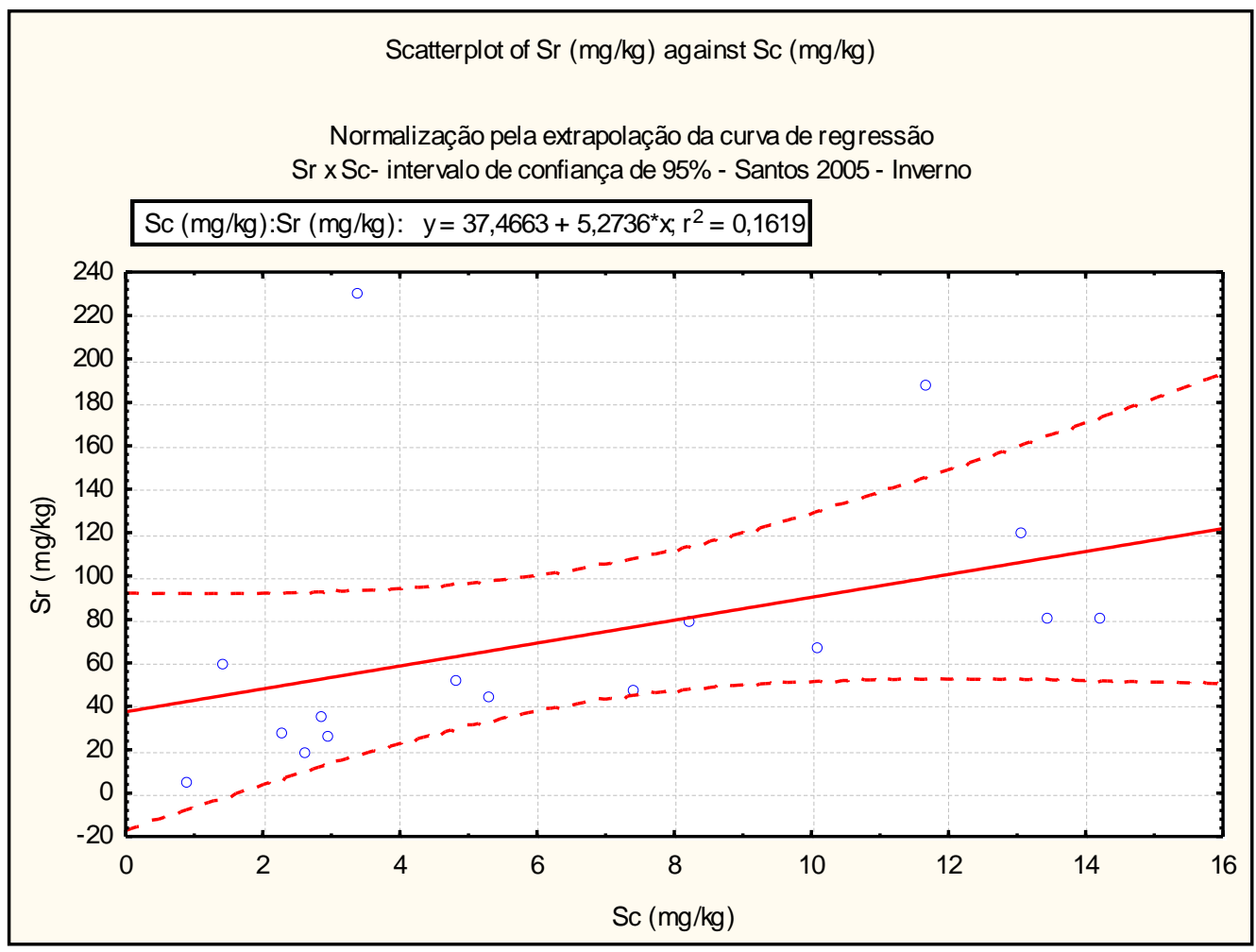

Figura 5.24: Scatterplot Sr x Sc- Santos, Inverno de 2005

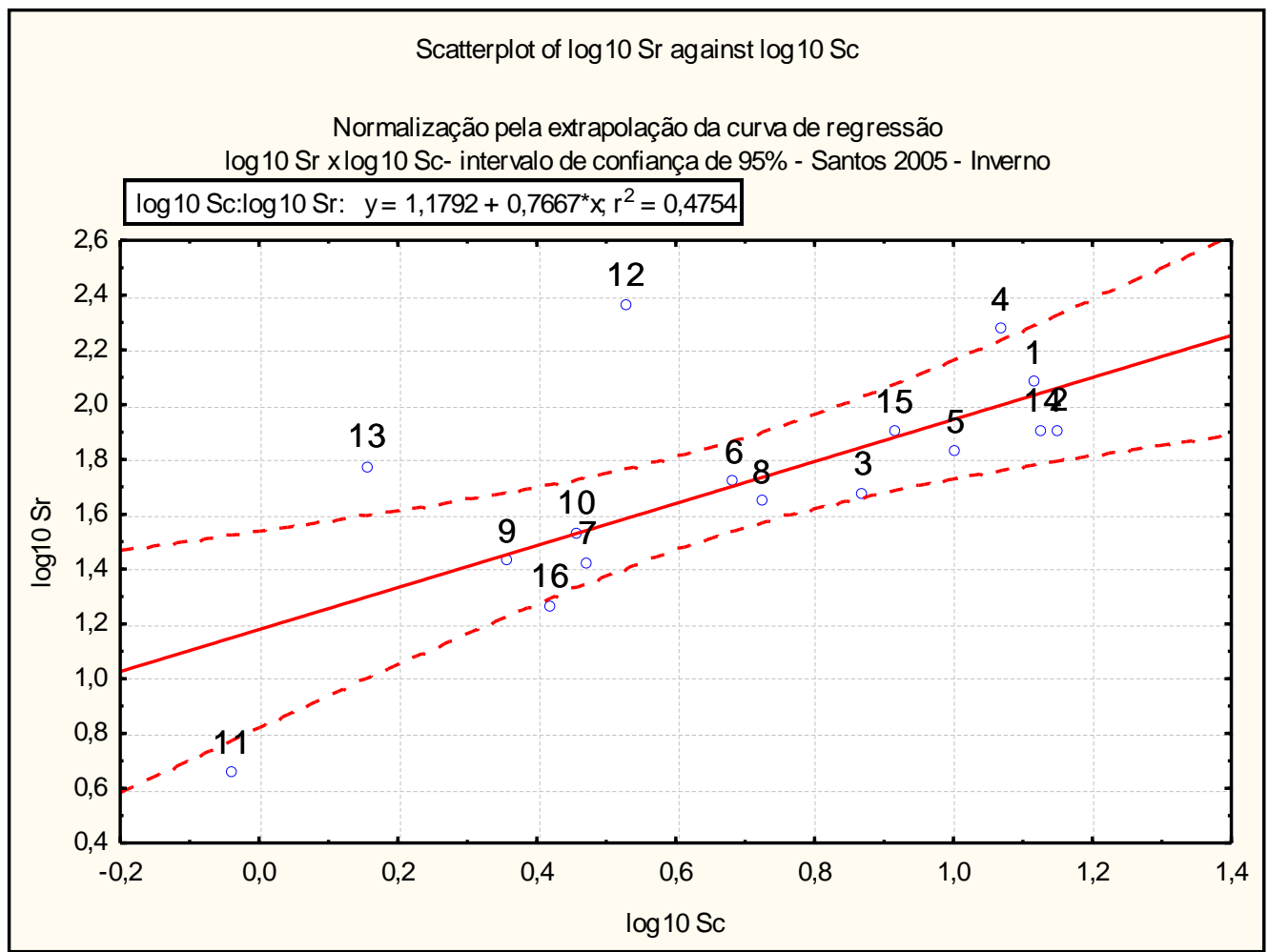

Figura 5.25: Scatterplot $\log _{10} \mathrm{Sr} \times \log _{10} \mathrm{Sc}$ - Santos, Inverno de 2005 


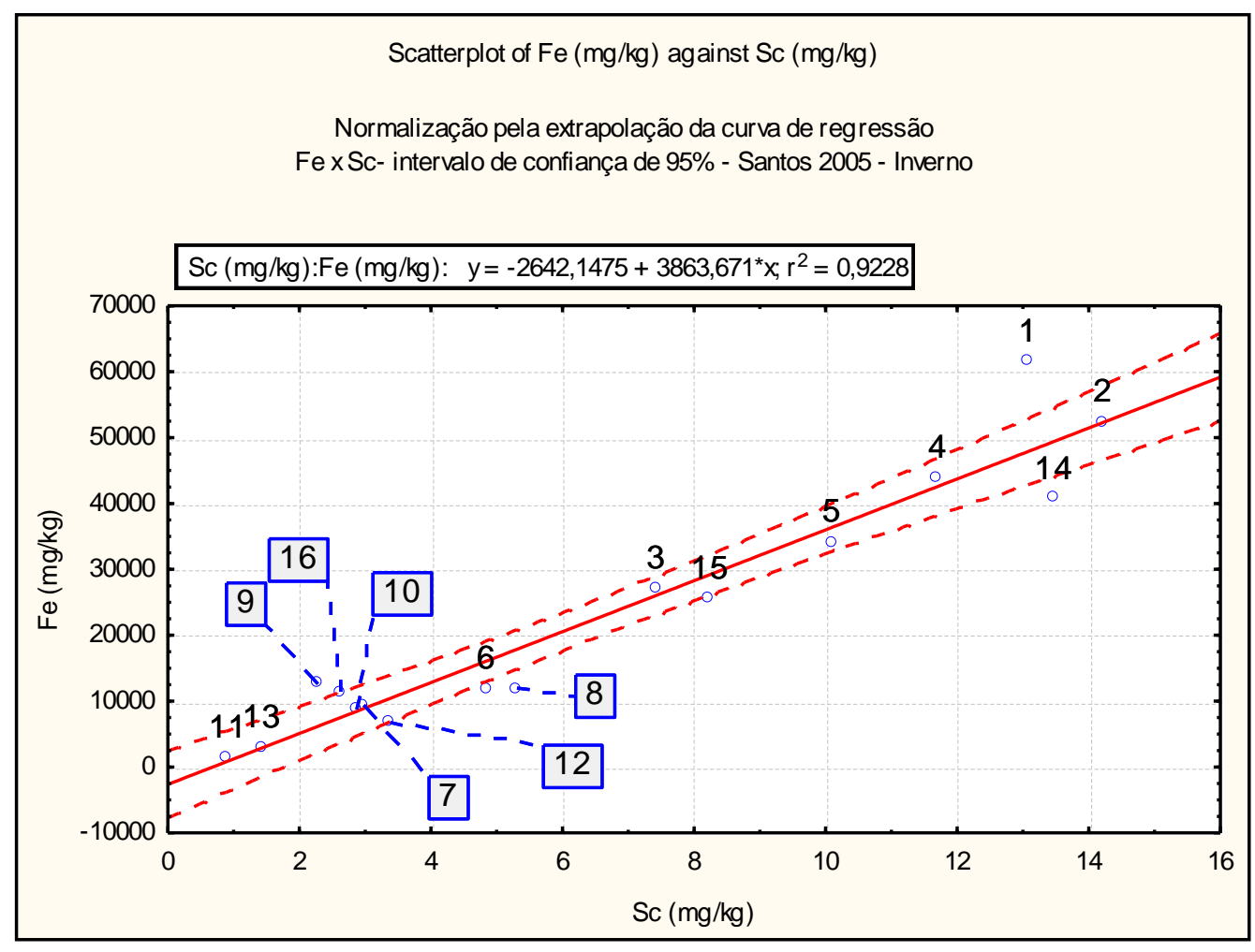

Figura 5.26: Scatterplot Fe x Sc - Santos, Inverno de 2005

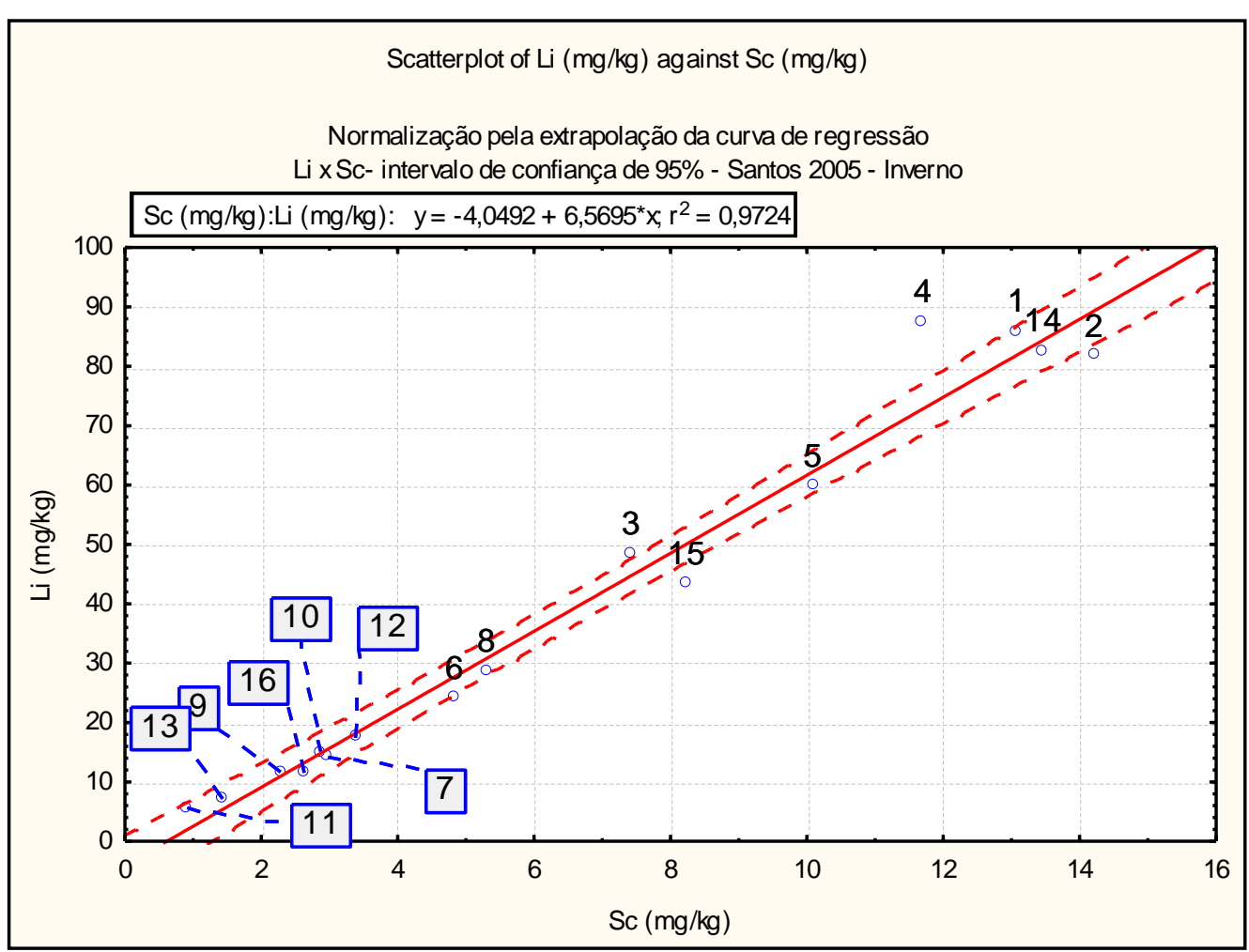

Figura 5.27: Scatterplot Li x Sc - Santos, Inverno de 2005 


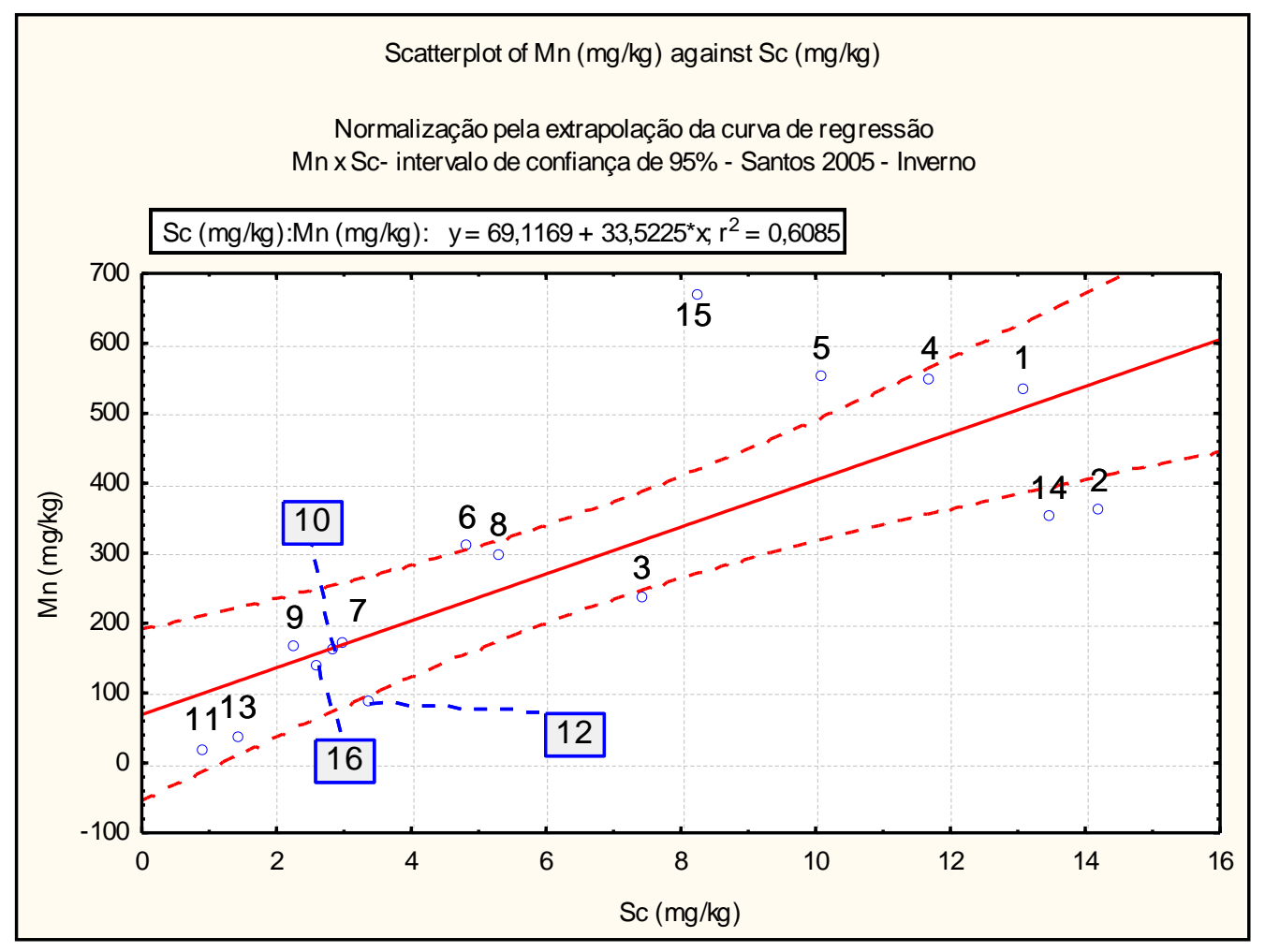

Figura 5.28: Scatterplot Mn x Sc - Santos, Inverno de 2005

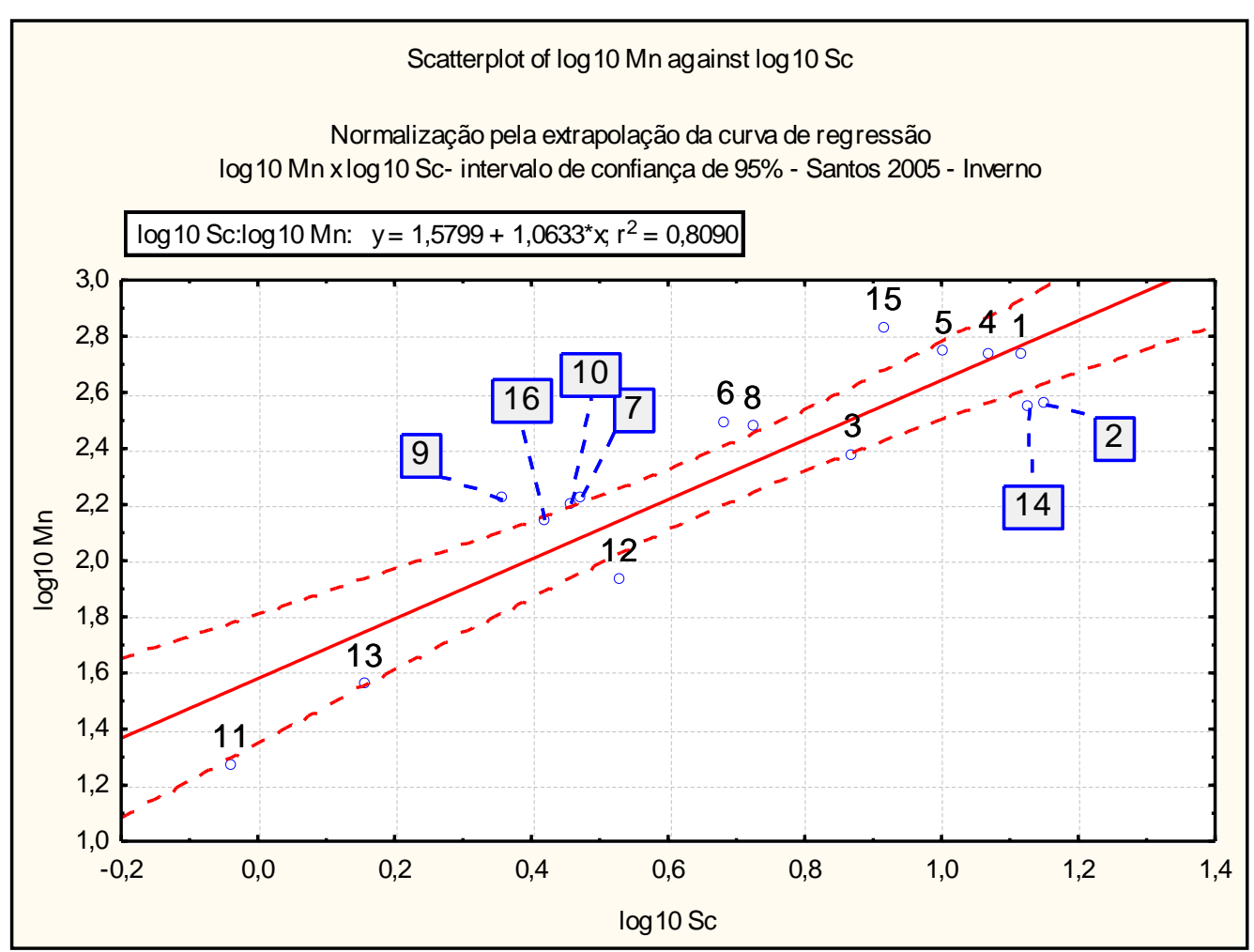

Figura 5.29: Scatterplot $\log _{10} \mathrm{Mn} \times \log _{10} \mathrm{Sc}$ - Santos, Inverno de 2005 


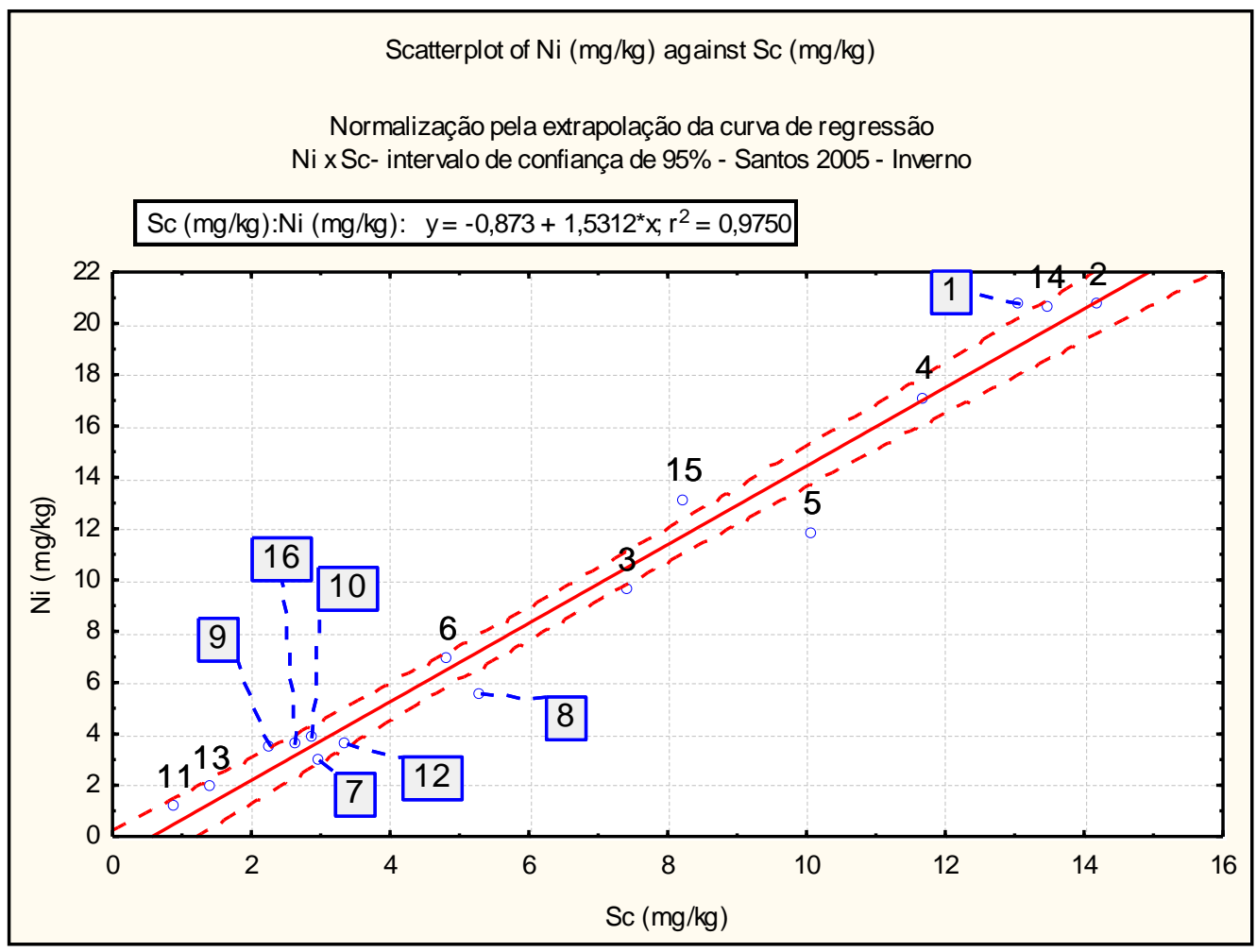

Figura 5.30: Scatterplot Ni x Sc - Santos, Inverno de 2005

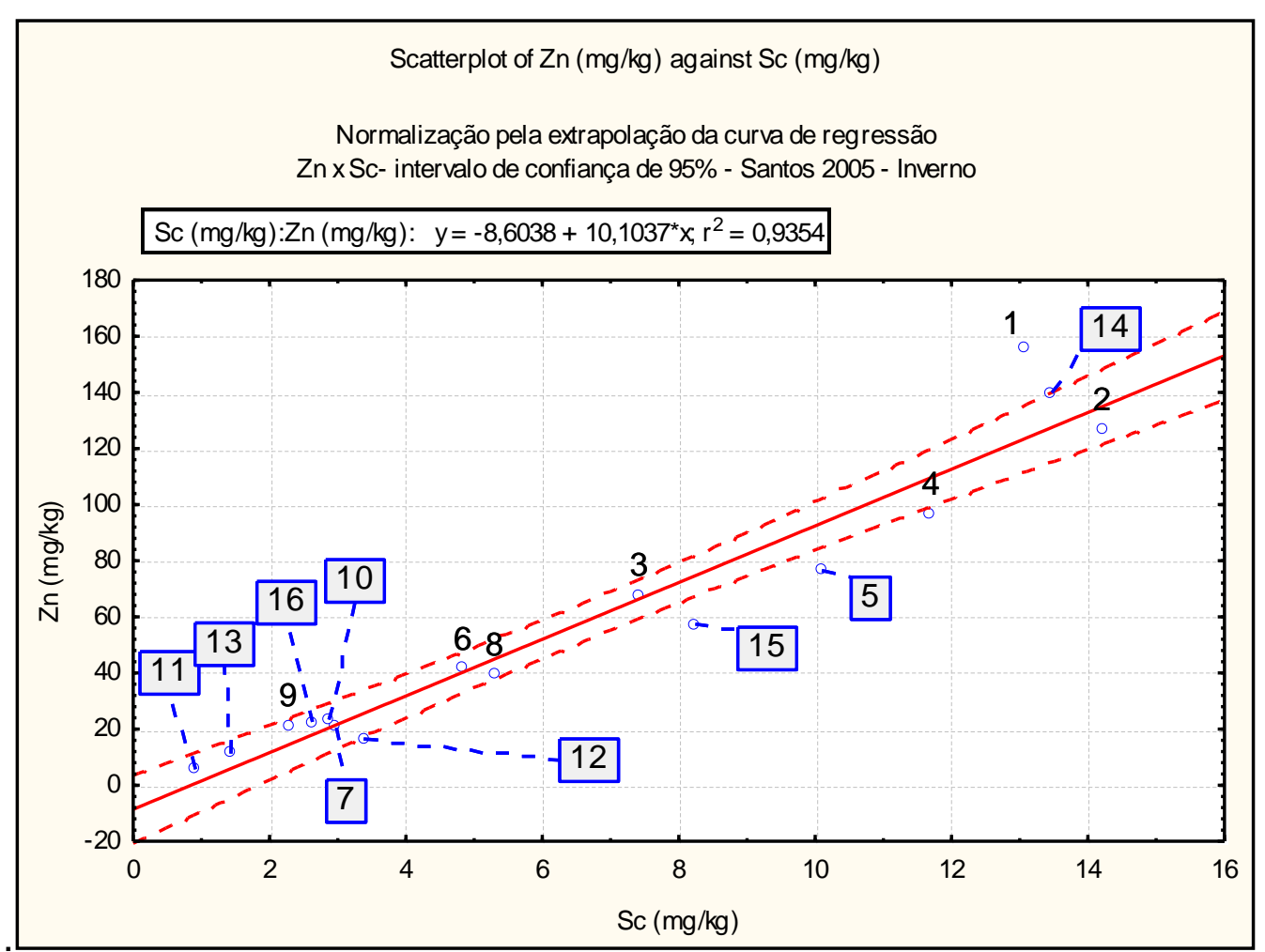

Figura 5.31: Scatterplot Zn x Sc- Santos, Inverno de 2005 
Devido à baixa correlação apresentada de acordo com o coeficiente de determinação, $r^{2}=0,6450(\mathrm{Ba}), r^{2}=0,1619(\mathrm{Sr})$ e $r^{2}=0,6085(\mathrm{Mn})$, optou-se pelo uso da função logarítimica, de modo a facilitar o entendimento dos dados obtidos da região, conforme descrito por Schropp (1988). Foram calculados os logaritmos na base 10 para os resultados de Ba e Sc, Sr e Sc, Mn e Sc, e em seguida foi construído o scatterplot correspondente.

$\mathrm{Na}$ avaliação do scatterplot $\log _{10} \mathrm{Sr} \times \log _{10} \mathrm{Sc}$, verificamos que existe ainda uma baixa correlação entre os elementos $\mathrm{Sr}$ e Sc, pois mesmo após o cálculo na base logarítmica, o coeficiente de determinação encontrado foi $r^{2}=0,4754$. Na análise dos pontos, observa-se que os pontos 4,12 e 13 estão acima do intervalo de confiança de $95 \%$, o que pode indicar uma contribuição de origem antrópica. $\mathrm{O}$ ponto 11 encontra-se levemente abaixo da linha de tendência.

$\mathrm{Na}$ avaliação dos resultados obtidos a partir dos gráficos scatterplots, identificando as estações que apresentaram-se acima da linha de tendência, de uma maneira geral, foi possível concluir que:

- O ponto 1 apresentou um alto índice de elementos com suspeita de contaminação por origem antrópica. Observou-se que os elementos $\mathrm{Ba}, \mathrm{Co}, \mathrm{Cr}$, $\mathrm{Fe}, \mathrm{Ni}$ e $\mathrm{Zn}$ excederam os limites do intervalo de confiança, o que caracteriza um enriquecimento destes elementos no ponto de amostragem.

- Em relação ao ponto 3, verificou-se que os elementos $\mathrm{Cu}$ e $\mathrm{Li}$ extrapolaram os limites de seus respectivos gráficos scatterplots.

- O ponto 4, apresentou enriquecimento de Al, Li e Sr.

- O ponto 9 apresentou nos scatterplots avaliados, que os elementos $\mathrm{Co}, \mathrm{Cr}$, Fe e $\mathrm{Mn}$ apresentaram valores acima dos intervalos de confiança, caracterizando, portanto, uma possível contribuição antrópica.

- O ponto 13 apresentou uma alteração para os elementos Cu e Sr.

- O ponto 14 apresentou valores acima dos intervalos de confiança para os elementos $\mathrm{Cr}$, Cu e $\mathrm{Zn}$. 
- O ponto 15 evidenciou um enriquecimento de Co, Mn e Ni.

A excelente correlação apresentada no scatterplot Li/Sc indica que seria possível a utilização do Li como elemento normalizador da região, já que é um elemento referenciado em outros estudos com a possibilidade de exercer esta característica de normalizador.

Os pontos 2, 5, 6, 7, 8, 10, 11, 12 e 16 apresentaram enriquecimento para um único elemento em cada ponto. $\mathrm{O} B$ a apresentou-se enriquecido nos pontos 2 e 11, o Al no ponto 05 , o $\mathrm{Sr}$ no ponto 12 , o $\mathrm{Cr}$ no ponto 16 e o $\mathrm{Mn}$, apresentou-se enriquecido nos pontos 6, 7, 8 e 10.

\subsubsection{Análise de Agrupamento (Cluster Analysis)}

Para a avaliação da similaridade dos pontos de amostragem em relação à concentração dos metais analisados por ICP OES e AAS (Cd, Hg e $\mathrm{Pb}$ ), nos diferentes períodos sazonais (inverno e verão), foram realizadas análises de agrupamentos, a análise de clusters. Para cada amostra, foram utilizadas as variáveis de concentração dos elementos: $\mathrm{Al}, \mathrm{Ba}, \mathrm{Co}, \mathrm{Cu}, \mathrm{Cr}, \mathrm{Fe}$, $\mathrm{Li}, \mathrm{Mn}, \mathrm{Ni}, \mathrm{Sr}$ e $\mathrm{Zn}$, analisados por ICP OES, e os elementos $\mathrm{Cd}$ e Pb (análise por GF AAS) e Hg (CV AAS). Os dendrogramas foram obtidos a partir do software Statistica 8.0, após normalização dos dados. Para a realização dos cálculos, para as amostras que obtiveram resultados considerados não detectados, utilizou-se o valor de L.Q do método para se obter a correspondência adequada nos cálculos dos dendrogramas.

Visando a verificação da particularidade dos grupos de diferentes amostras, tais como comparações entre os diferentes períodos climáticos (inverno e verão) e temporais (anos de 2005 e 2006), foram obtidos quatro diagramas de clusters, representando cada época específica.

A Figura 5.32 apresenta 0 dendrograma correspondente às amostras de Santos - Inverno de 2005: 


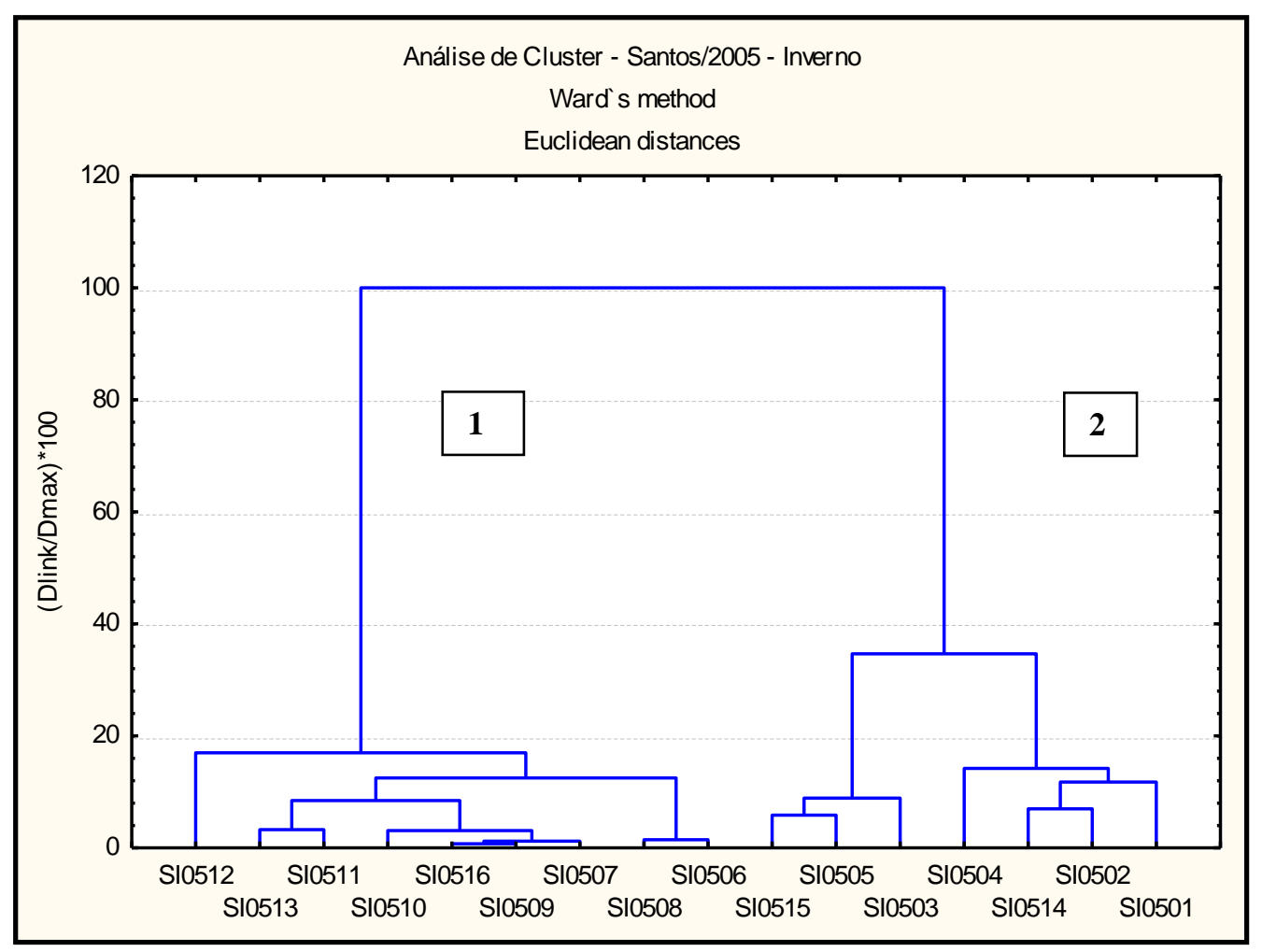

Figura 5.32 - Dendrograma - Amostras de Santos - Inverno de 2005

As amostras de Santos - Inverno de 2005, de acordo com 0 dendrograma apresentado na Figura 5.32, formaram 2 grupos, compostos por amostras de características semelhantes:

- Grupo 1: SI0512, SI0513, SI0511 (subgrupo 1A), SI0510, SI0516, SI0509 e SI0507 (subgrupo 1B); SI0508 e SI0506 (subgrupo 1C)

- Grupo 2: SI0515, SI0505 e SI0503 (sub-grupo 2A) SI0504, SI0514, SI0502 e SI0501 (sub-grupo 2B)

Os grupos formados pelas amostras de Santos - Verão de 2005 são representadas na Figura 5.33: 


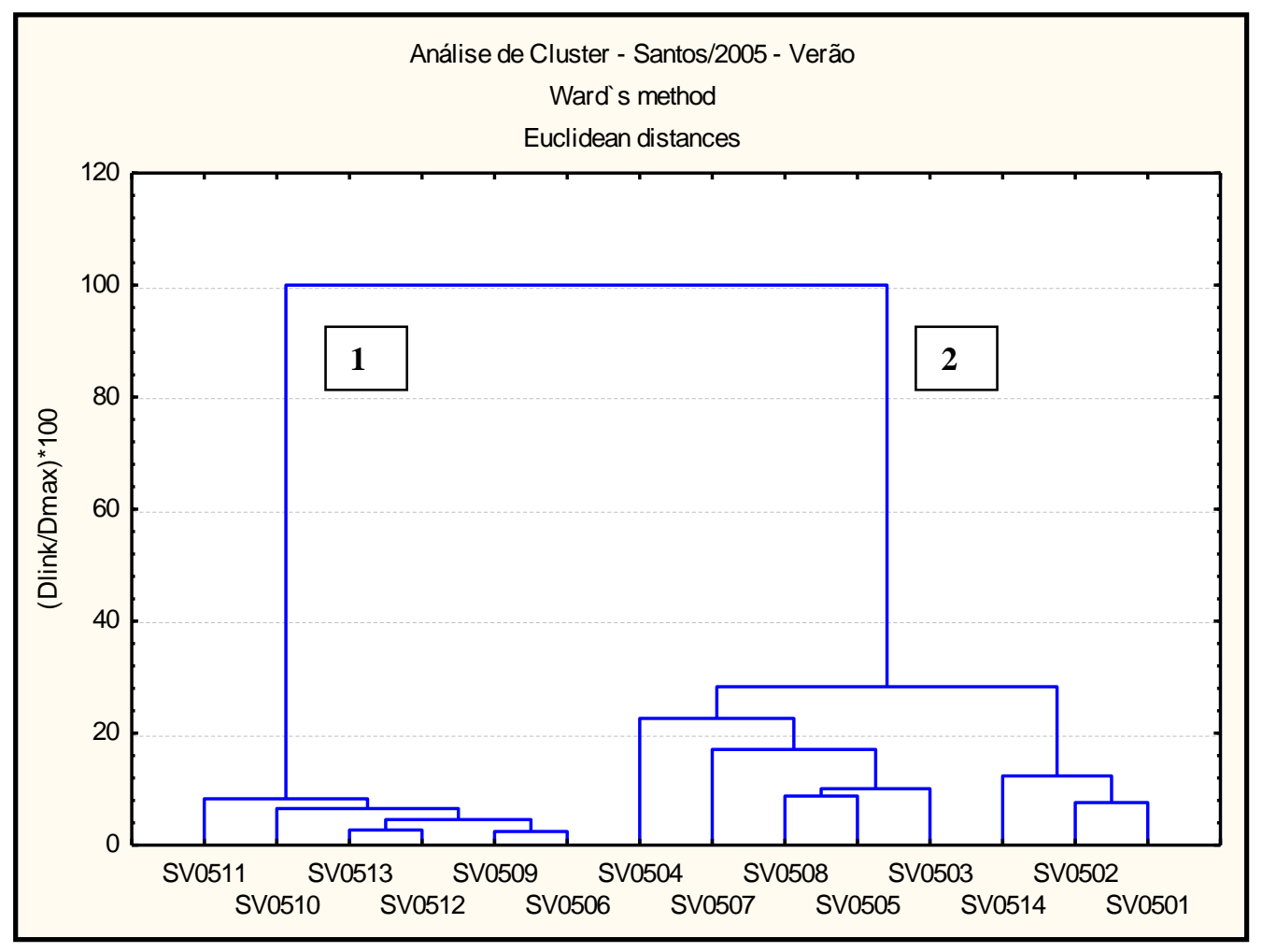

Figura 5.33 - Dendrograma - Amostras de Santos- Verão de 2005

As amostras de Santos - Verão 2005, de acordo com o dendrograma apresentado na Figura 5.33, formaram-se 2 grupos:

- Grupo 1: SV0511 e SV0510, SV0513, SV0512 e SV0509 e SV0506.

- Grupo 2: SV0504 e SV0507, SV0508, SV0505, SV0503 (Sub-grupo 2 A)

SV0514, SV0502 e SV0501 (Sub-grupo 2 B)

A seguir, a Figura 5.34 apresenta o dendrograma obtido a partir dos dados das amostras de Santos - Verão de 2006: 


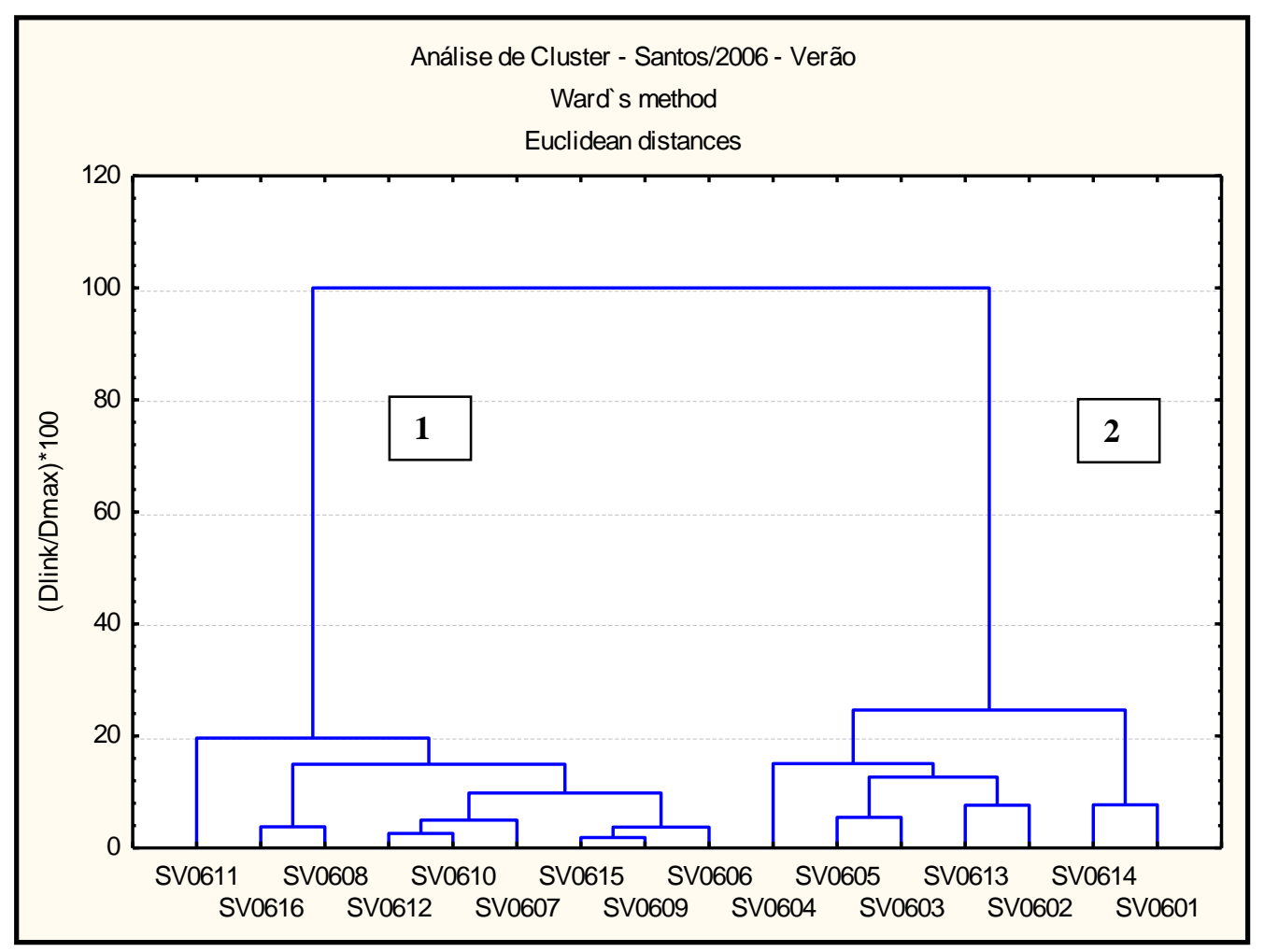

Figura 5.34 - Dendrograma - Amostras de Santos- Verão de 2006

A análise de agrupamento para as amostras de Santos-verão 2006 demonstra a formação de 2 grandes grupos divididos por características semelhantes. As amostras formaram os seguintes grupos:

- Grupo 1: SV0611; SV0616, SV0608 (subgrupo 1A), SV0612, SV0610 e SV0607 (subgrupo 1B), SV0615, SV0609 e SV0606 (subgrupo 1C)

- Grupo 2: SV0604, SV0605 e SV0603 (subgrupo 2A); SV0613 e SV0602 (subgrupo 2B); SV0614 e SV0601(subgrupo 2C) 


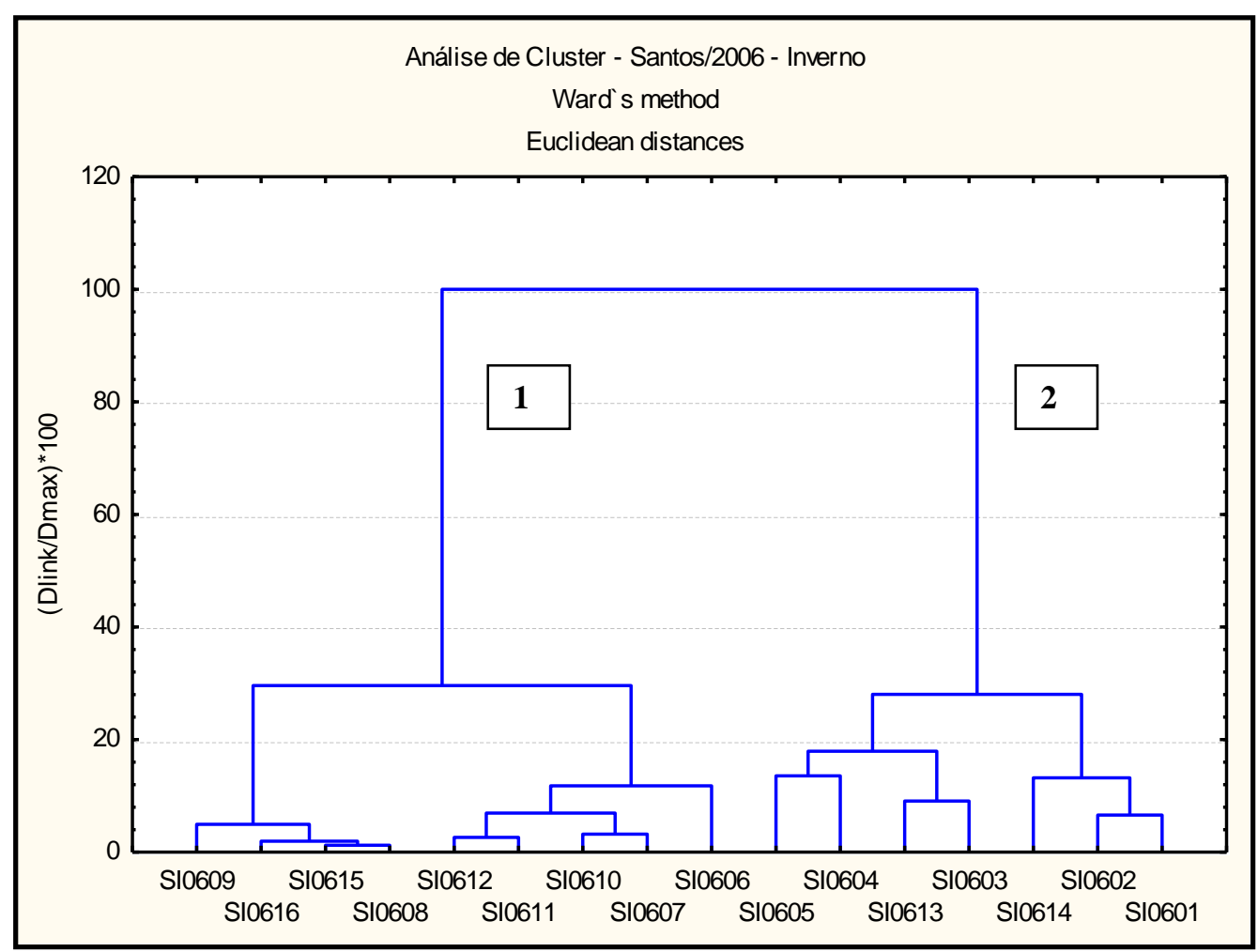

Figura 5.35 - Dendrograma - Amostras Santos - Inverno de 2006

A Figura 5.35 apresenta o dendrograma das amostras de Santos Inverno de 2006, onde são observados dois grandes grupos:

- Grupo 1: SI0609, SI0616, SI0615, SI0608 (subgrupo 1A) SI0612, SI0611, SI0610 e SI0607. A amostra SI0606 pertence ao grupo, entretanto está isolada das demais (subgrupo 1B)

- Grupo 2: SI0605, SI0604, SI0613 e SI0603 (subgrupo 2A); SI0614, SI0602, SI0601 (subgrupo 2B)

O Canal de Santos (área 1 - estações 01 a 05) apresentaram a melhor correlação em todos os períodos inverno e verão, 2005 e 2006, pois estiveram sempre presentes no grupo 2. O grupo 2 formado (estações 01 a 05, 13 e 14) foi o mesmo tanto para o verão quanto para o Inverno/2006. Para as amostras coletadas em 2005, houve uma pequena variação na formação do grupo 2: estações 01 a 05, 07, 08 e 14 (verão) e estações 01 a 05, 14 e 15 (inverno). Vale ressaltar que a amostra correspondente à estação 04 , ficou 
separada das demais no verão de 2005/2006. Essa estação, pela localização, recebe a influência direta do porto de Santos.

A estação 01 está localizada perto do polo industrial da cidade de Cubatão, em zona bastante interna ao estuário recebendo influência direta das fontes poluidoras dessa região.

Devido à baixa energia para dispersão dos efluentes e da ação de deposição de poluentes agregados a materiais particulados em suspensão e ácidos húmicos, os poluentes atingem os sedimentos mais internos ao estuário com maior facilidade. Além disso, as principais fontes antrópicas estão localizadas também na parte mais interna do sistema, como é o caso da área industrial de Cubatão e da zona final do canal do porto (estações 01 e 04, respectivamente) e nas proximidades do aterro sanitário desativado (ponto 14). Os pontos localizados em direção à Baía de Santos estão sujeitos a uma hidrodinâmica maior, o que contribui a uma maior dispersão dos poluentes.

Na Baía de Santos (área 2, estações 07 a 10, 15 e 16), observa-se uma boa correlação entre as amostras coletadas no verão e no inverno/2006, todas elas pertencentes ao grupo 1 dos dendrogramas. O verão de 2005 apresentou as amostras 07 e 08 no grupo 2 e as amostras 09 e 10 no grupo 1, juntamente com as amostras 11, 12 e 13 (área 3). Já as amostras coletadas no inverno/2005, ficaram todas no grupo 1 do dendrograma (estações 06 a 13 áreas 2 e 3). Vale lembrar que não foram coletadas amostras nas estações 15 e 16 em 2005. Ressalta-se aqui também, que a estação 11 ficou isolada no verão de 2005 e 2006, dentro do grupo 1, demonstrando um comportamento diferente das demais estações do grupo. A estação 06, embora situada no canal de Santos, apresentou comportamento semelhante às amostras localizadas na baía de Santos que estão sujeitas a uma hidrodinâmica maior, que contribui para uma maior dispersão dos poluentes.

Comparando com as informações obtidas nos dendrogramas das amostras de Santos, podemos verificar que nos períodos do inverno e verão de 2005, as estações 11, 12 e 13 da área 3 (Canal de São Vicente, estações 11 a 14) estiveram presentes sempre no grupo 1 dos dendrogramas. Nos períodos 
do verão e inverno de 2006, as estações 13 e 14 fizeram parte do grupo 2. A estação 14 esteve sempre presente no grupo 2, juntamente com as amostras do canal de Santos, provavelmente devido à sua composição granulométrica.

De modo a identificar a similaridade entre os elementos analisados nas diversas amostras coletadas em diferentes períodos, foram realizadas as análises de clusters entre os elementos. A Figura 5.36 apresenta o dendrograma referente às amostras coletadas em Santos, inverno de 2005.

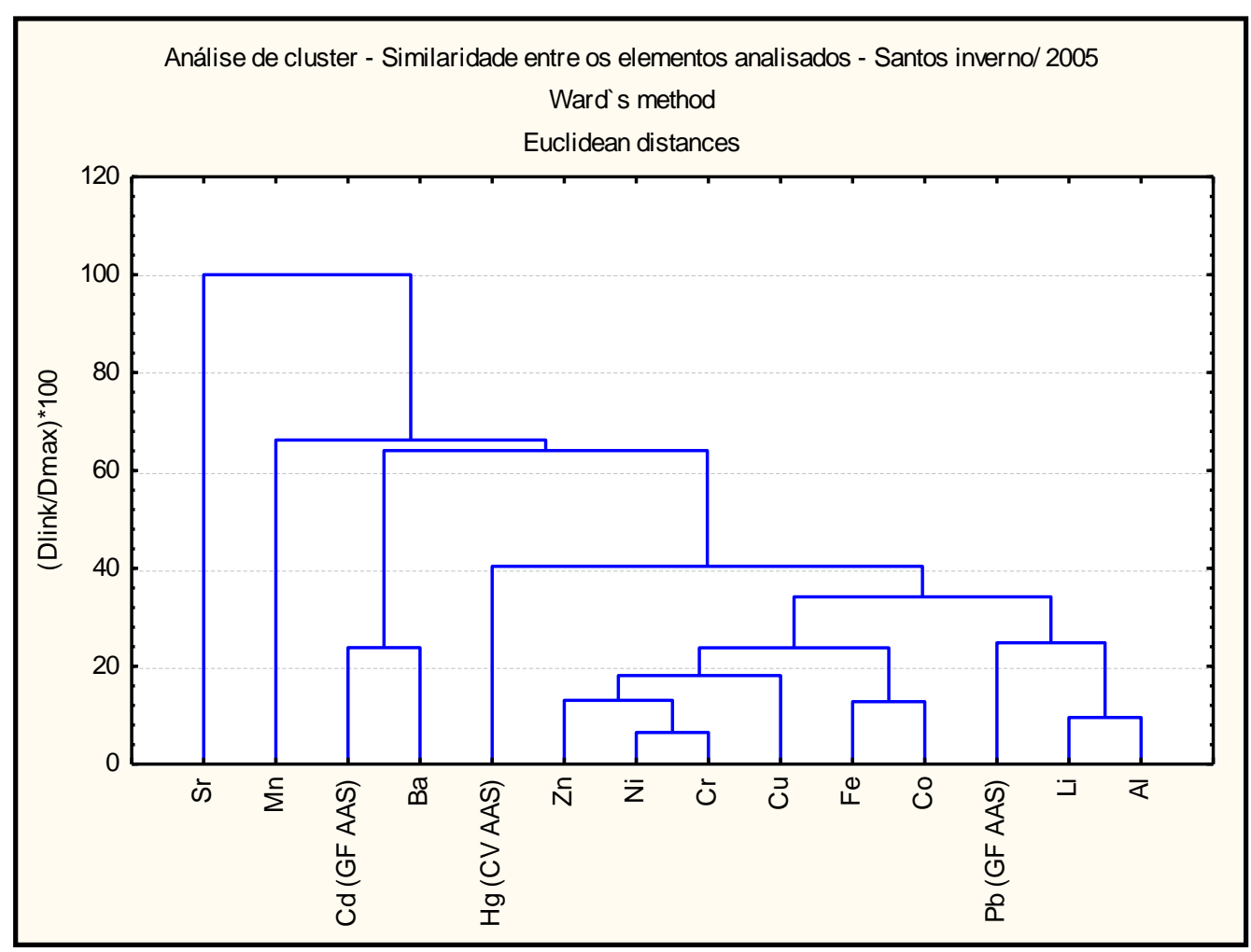

Figura 5.36: Similaridade entre os elementos analisados por ICP OES, GF AAS e CV AAS - Santos, inverno de 2005

A partir da avaliação da similaridade entre os elementos das amostras coletadas em Santos, no inverno de 2005, podemos observar uma correlação entre os elementos $\mathrm{Zn}, \mathrm{Ni}, \mathrm{Cr}, \mathrm{Cu}, \mathrm{Fe}$ e $\mathrm{Co}$. O Pb apresenta boa correlação com os elementos $\mathrm{Al}$ e $\mathrm{Li}$. O Hg aparece isolado dos demais elementos, assim como o $\mathrm{Sr}$ e $\mathrm{Mn}$. O $\mathrm{Cd}$ apresentou-se no mesmo subgrupo do $\mathrm{Ba}$. 
A Figura 5.37 apresenta a análise de cluster das amostras coletadas em Santos, verão de 2005.

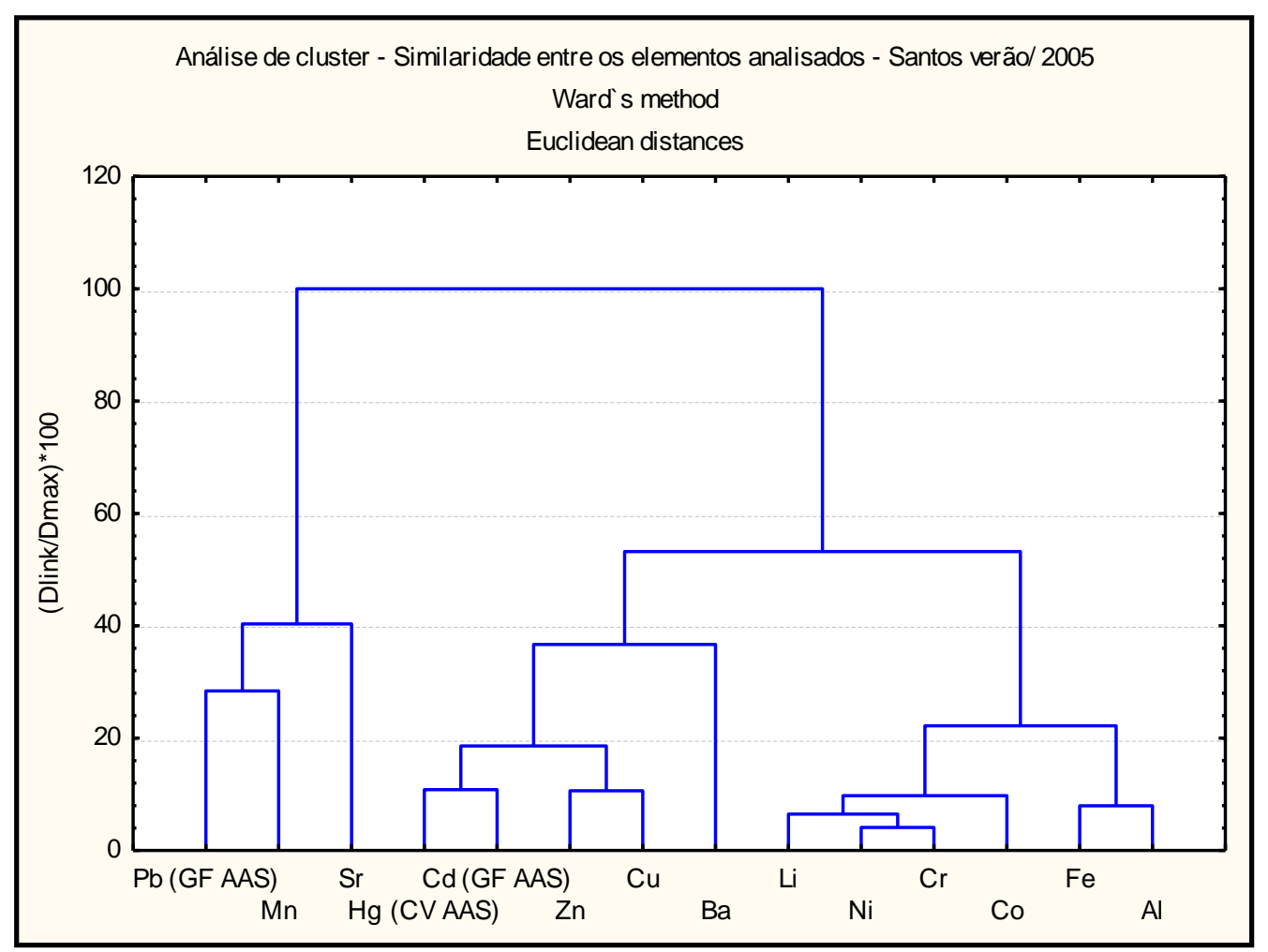

Figura 5.37: Similaridade entre os elementos analisados por ICP OES, GF AAS e CV AAS - Santos, verão de 2005

De acordo com a Figura 5.37, podemos identificar que ocorreu a formação de 2 grupos de elementos:

- Grupo 1: $\mathrm{Pb}, \mathrm{Mn}$ e $\mathrm{Sr}$

- Grupo 2: Hg, Cd, Zn e Cu. O Ba aparece separado dos demais elementos do grupo (sub grupo $2 \mathrm{~A}$ ); $\mathrm{Li}, \mathrm{Ni}, \mathrm{Cr}$ e Co (sub grupo 2B) e Fe e Al (sub grupo 2C)

A Figura 5.38 apresenta a análise de cluster das amostras coletadas em Santos, inverno de 2006. 


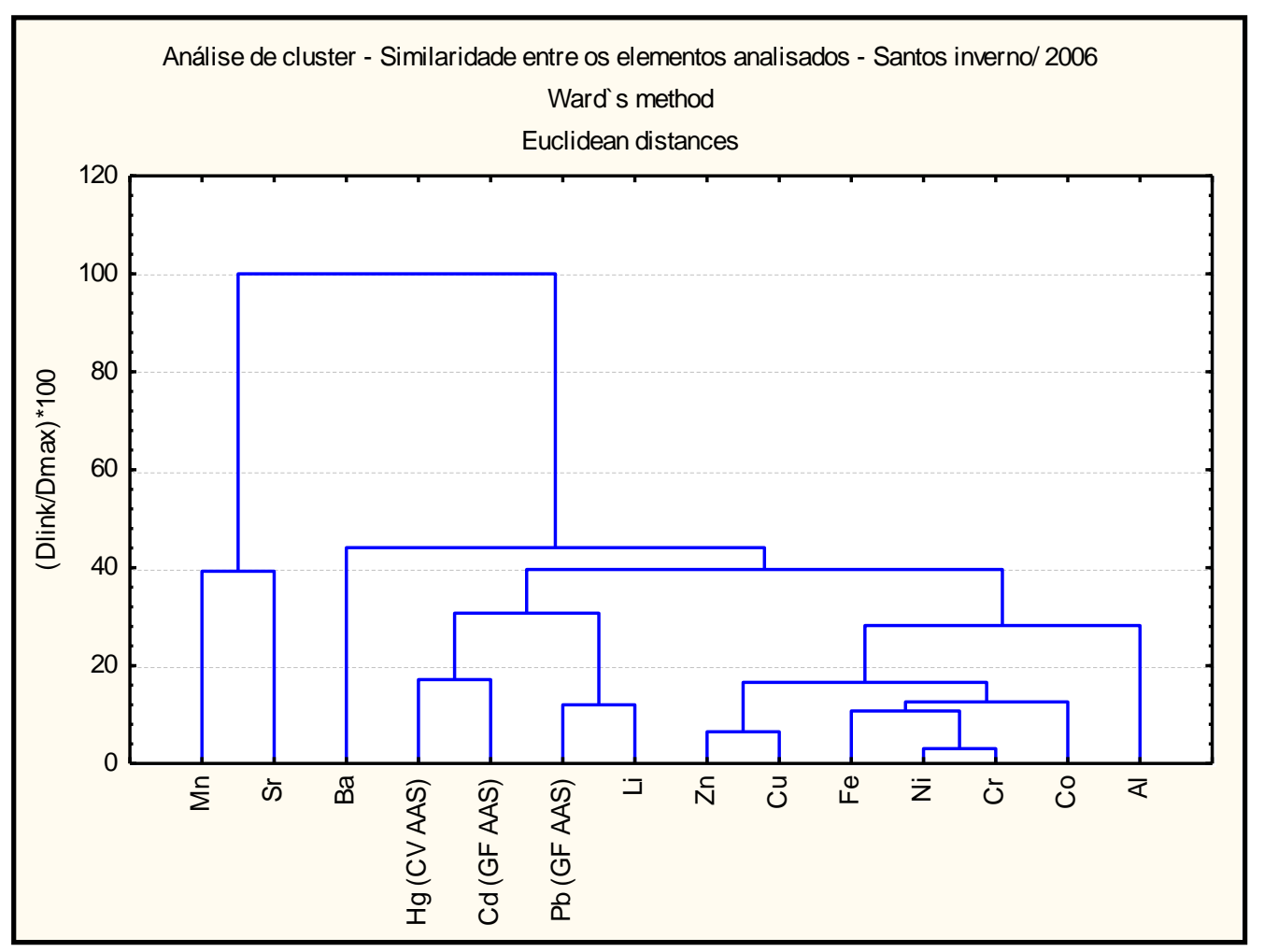

Figura 5.38: Similaridade entre os elementos analisados por ICP OES, GF AAS e CV AAS - Santos, inverno de 2006

A análise de agrupamento apresentou a formação de 2 grupos distintos:

- Grupo 1: Mn e Sr

- Grupo 2: Hg, Cd, Pb e Li (sub grupo 2A); Zn, Cu, Fe, Ni, Cr, Co e Al (sub grupo 2B). O Ba aparece isolado dos outros elementos encontrados no Grupo

A Figura 5.39 apresenta a análise de cluster das amostras coletadas em Santos, verão de 2006. 


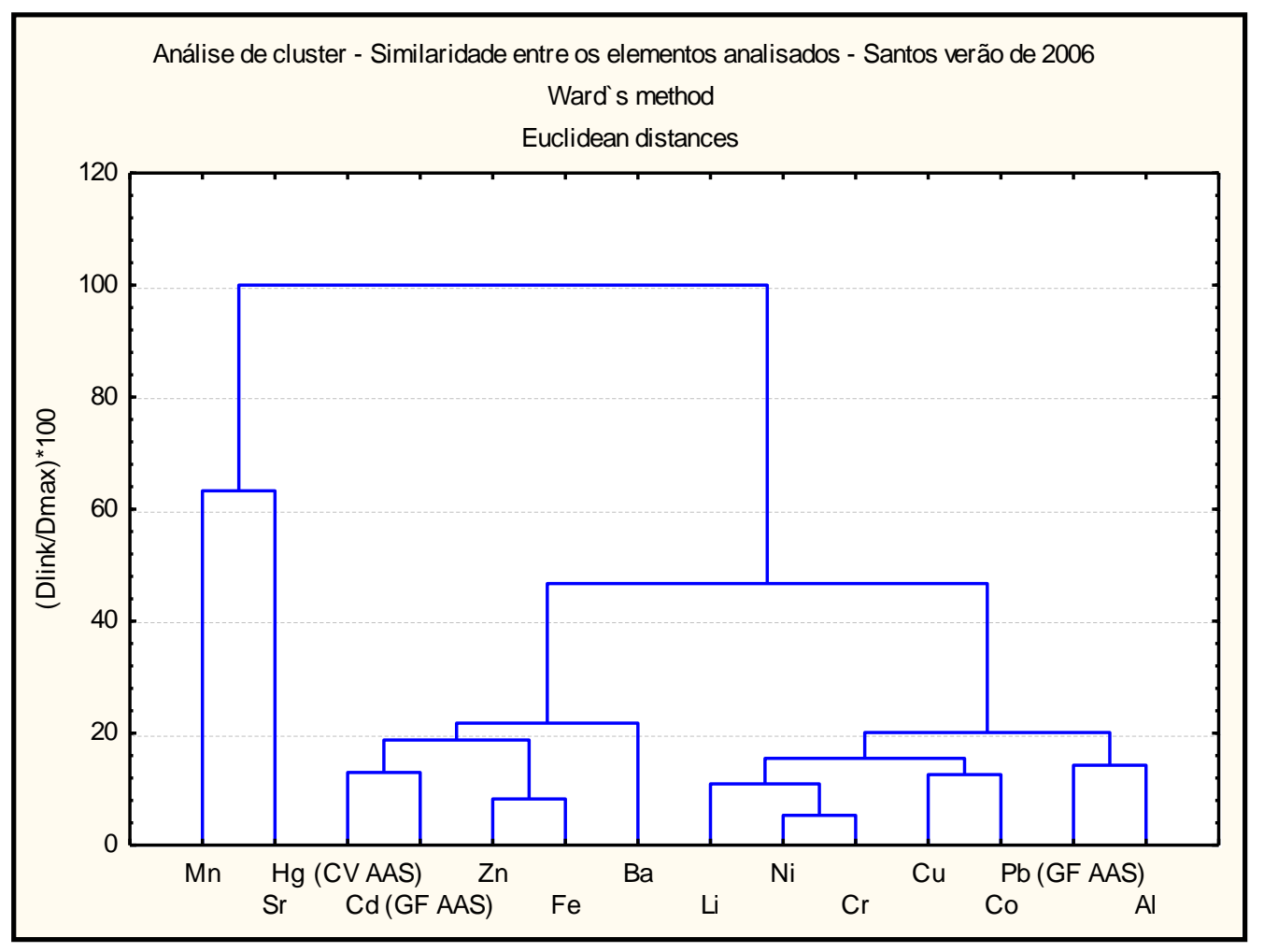

Figura 5.39: Similaridade entre os elementos analisados por ICP OES, GF AAS e CV AAS - Santos, verão de 2006

De acordo com a Figura 5.39, podemos identificar a formação de 2 grupos:

- Grupo 1: Mn e Sr

- Grupo 2: Hg, Cd, Zn, Fe e Ba (subgrupo 2A) $\mathrm{Li}, \mathrm{Ni}, \mathrm{Cr}$, Cu e Co (subgrupo 2B); Pb e Al (subgrupo 2C)

De maneira geral, observou-se que o $\mathrm{Mn}$ e o $\mathrm{Sr}$, $\mathrm{Cr}$ e o Co, assim como o $\mathrm{Cd}$ e $\mathrm{Hg}$ apresentaram-se em grupos semelhantes nos períodos do verão de 2005, inverno e verão de 2006, demonstrando portanto relativa constância em suas proporções encontradas nos diferentes períodos avaliados. Os demais elementos alternaram entre si, em diferentes grupos nos períodos avaliados. 


\subsubsection{Fator de Enriquecimento e Índice de Geoacumulação}

O Fator de Enriquecimento (FE) (Gresens, 1967) e o Índice de Geoacumulação - I geo (Muller, 1979), apresentados nos itens 4.11.2 e 4.11.3, respectivamente, são ferramentas comumente utilizadas para estimar impactos antropogênicos nos sedimentos, e foram utilizados no presente estudo para avaliar o impacto com os elementos analisados por ICP OES e AAS (GF AAS e CV AAS).

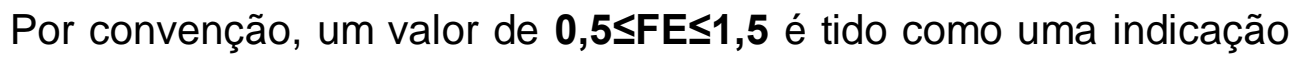
que os elementos traço encontrados são fornecidos a partir da crosta ou por origens naturais de intemperismo e os valores acima de 1,5, indicam contribuições antropogênicas. Quanto maior o valor do FE, maior a contribuição antropogênica. Neste estudo, o FE foi calculado utilizando o Sc como elemento normalizador, e os valores de referência Upper Continental Crust (UCC) (WEDEPOHL, 1995) como valores de referência do "background" da região para os elementos analisados.

A partir dos dados do UCC, foram calculados os FE das amostras analisadas por ICP OES, GF AAS e CV AAS. As Tabelas 5.10 a 5.13 apresentam os resultados dos fatores de enriquecimento calculados para cada elemento, nos diferentes períodos e épocas. A Tabela 5.10 apresenta os valores de UCC para os elementos determinados pelas técnicas de ICP OES e AAS. 
Tabela 5.10: Valores de FE, utilizando Sc como elemento normalizador e os valores UCC, como valores de referência de "background" - Santos 2005, inverno

\begin{tabular}{|c|c|c|c|c|c|c|c|c|c|c|c|c|c|c|c|}
\hline & Estações & Al & $\mathrm{Ba}$ & Co & $\mathrm{Cu}$ & $\mathrm{Cr}$ & $\mathrm{Sr}$ & $\mathrm{Fe}$ & Li & Mn & $\mathrm{Ni}$ & Zn & $\mathrm{Pb}$ (GF AAS) & Cd (GF AAS) & $\mathrm{Hg}$ (CV AAS) \\
\hline \multirow{6}{*}{ 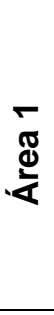 } & SI0501 & 0,43 & 0,20 & 0,42 & 0,96 & 0,78 & 0,20 & 1,07 & 2,09 & 0,54 & 0,60 & 1,61 & 0,76 & 1,82 & 4,48 \\
\hline & SI0502 & 0,38 & 0,11 & 0,40 & 0,91 & 0,65 & 0,13 & 0,84 & 1,83 & 0,34 & 0,55 & 1,20 & 0,52 & 1,03 & 7,46 \\
\hline & SI0503 & 0,37 & 0,05 & 0,42 & 0,95 & 0,71 & 0,14 & 0,83 & 2,07 & 0,42 & 0,49 & 1,23 & 0,89 & 0,68 & 6,94 \\
\hline & SI0504 & 0,53 & 0,08 & 0,37 & 0,74 & 0,69 & 0,35 & 0,85 & 2,38 & 0,62 & 0,55 & 1,11 & 1,00 & 0,44 & 5,75 \\
\hline & SI0505 & 0,45 & 0,05 & 0,34 & 0,72 & 0,61 & 0,15 & 0,77 & 1,88 & 0,72 & 0,44 & 1,02 & 0,62 & 0,43 & 2,34 \\
\hline & SI0506 & 0,24 & 0,04 & 0,47 & 0,56 & 0,70 & 0,24 & 0,56 & 1,58 & 0,85 & 0,54 & 1,15 & 0,93 & 0,25 & 1,79 \\
\hline \multirow{5}{*}{ N } & S10507 & 0,21 & 0,02 & 0,53 & 0,16 & 0,66 & 0,19 & 0,71 & 1,51 & 0,75 & 0,38 & 0,92 & 0,47 & 0,23 & 0,20 \\
\hline & SI0508 & 0,18 & 0,03 & 0,41 & 0,26 & 0,58 & 0,18 & 0,51 & 1,72 & 0,74 & 0,39 & 1,00 & 0,81 & 0,27 & 2,59 \\
\hline & SI0509 & 0,27 & 0,03 & 0,77 & 0,21 & 1,04 & 0,26 & 1,25 & 1,63 & 0,96 & 0,58 & 1,26 & 0,81 & 0,30 & 0,70 \\
\hline & $\begin{array}{l}\text { SI0510 } \\
\text { SI0515 }\end{array}$ & $\begin{array}{l}0,31 \\
0,29\end{array}$ & $\begin{array}{l}0,06 \\
0,04\end{array}$ & $\begin{array}{l}0,58 \\
0,46\end{array}$ & $\begin{array}{l}0,37 \\
0,46\end{array}$ & $\begin{array}{l}0,81 \\
0,73\end{array}$ & $\begin{array}{l}0,26 \\
0,21\end{array}$ & $\begin{array}{l}0,69 \\
0,70\end{array}$ & $\begin{array}{l}1,68 \\
1,68\end{array}$ & $\begin{array}{l}0,74 \\
1,07\end{array}$ & $\begin{array}{l}0,50 \\
0,60\end{array}$ & $\begin{array}{l}1,10 \\
0,94\end{array}$ & $\begin{array}{l}1,38 \\
0,76\end{array}$ & $\begin{array}{l}0,24 \\
0,13\end{array}$ & $\begin{array}{l}2,35 \\
0,64\end{array}$ \\
\hline & SI0516 & 0,25 & 0,04 & 0,63 & 0,19 & 0,95 & 0,15 & 0,99 & 2,09 & 0,70 & 0,51 & 1,16 & 0,77 & 0,26 & 0,38 \\
\hline \multirow{4}{*}{ 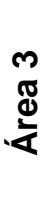 } & SI0511 & 0,32 & 0,08 & 0,66 & 0,52 & 0,62 & 0,11 & 0,36 & 1,96 & 0,27 & 0,46 & 0,83 & 0,68 & 0,75 & 0,67 \\
\hline & SI0512 & 0,32 & 0,04 & 0,33 & 0,33 & 0,65 & 1,51 & 0,45 & 1,64 & 0,33 & 0,40 & 0,65 & 0,56 & 0,32 & 1,27 \\
\hline & SI0513 & 0,34 & 0,06 & 0,47 & 0,63 & 0,74 & 0,91 & 0,48 & 1,59 & 0,33 & 0,49 & 1,06 & 1,03 & 0,56 & 3,98 \\
\hline & SI0514 & 0,38 & 0,06 & 0,34 & 1,14 & 0,77 & 0,13 & 0,68 & 1,95 & 0,34 & 0,58 & 1,40 & 0,88 & 1,36 & 8,82 \\
\hline \multicolumn{2}{|c|}{ UCC (mg kg $\left.{ }^{-1}\right)$} & 77440 & 668 & 11,6 & 14,3 & 35 & 316 & 3,089 & 22 & 527 & 18,6 & 52 & 17 & 0,102 & 0,056 \\
\hline
\end{tabular}

$x$ - valores de FE>1,5 
Tabela 5.11: Valores de FE, utilizando Sc como elemento normalizador e os valores UCC, como valores de referência de "background" - Santos 2005 - verão

\begin{tabular}{|c|c|c|c|c|c|c|c|c|c|c|c|c|c|c|c|}
\hline & Estações & Al & $\mathrm{Ba}$ & Co & $\mathrm{Cu}$ & $\mathrm{Cr}$ & $\mathrm{Sr}$ & $\mathbf{F e}$ & Li & Mn & $\mathbf{N i}$ & Zn & $\mathrm{Pb}$ (GF AAS) & Cd (GF AAS) & $\mathrm{Hg}$ (GF AAS) \\
\hline \multirow{6}{*}{ 通 } & SV0501 & 0,24 & 0,11 & 0,37 & 0,65 & 0,64 & 0,16 & 0,51 & 1,91 & 0,42 & 0,49 & 1,23 & 0,41 & 1,05 & 5,52 \\
\hline & SV0502 & 0,46 & 0,10 & 0,40 & 0,86 & 0,69 & 0,13 & 0,91 & 2,14 & 0,34 & 0,56 & 1,31 & 0,55 & 1,06 & 7,73 \\
\hline & SV0503 & 0,31 & 0,06 & 0,38 & 0,73 & 0,61 & 0,11 & 0,77 & 1,84 & 0,36 & 0,46 & 1,20 & 0,39 & 0,75 & 5,94 \\
\hline & SV0504 & 0,39 & 0,05 & 0,35 & 0,64 & 0,58 & 0,57 & 0,77 & 2,10 & 0,73 & 0,46 & 1,06 & 1,57 & 0,54 & 3,72 \\
\hline & SV0505 & 0,46 & 0,06 & 0,41 & 0,87 & 0,69 & 0,17 & 0,84 & 2,19 & 0,88 & 0,51 & 1,19 & 0,59 & 0,77 & 2,57 \\
\hline & SV0506 & 0,36 & 0,06 & 0,47 & 0,45 & 0,74 & 0,27 & 0,54 & 2,10 & 0,60 & 0,50 & 1,05 & 0,46 & 0,62 & 2,06 \\
\hline \multirow{4}{*}{$\begin{array}{l}\text { N } \\
\text { đ্் } \\
\frac{1}{4}\end{array}$} & SV0507 & 0,47 & 0,07 & 0,45 & 0,09 & 0,69 & 0,95 & 1,00 & 2,00 & 0,56 & 0,45 & 0,85 & 0,44 & 0,18 & 0,80 \\
\hline & SV0508 & 0,50 & 0,07 & 0,43 & 0,32 & 0,75 & 0,17 & 0,94 & 2,00 & 0,88 & 0,55 & 0,98 & 0,53 & 0,25 & 0,88 \\
\hline & SV0509 & 0,27 & 0,04 & 0,68 & 0,24 & 0,95 & 0,32 & 1,10 & 2,01 & 0,79 & 0,50 & 1,10 & 0,41 & 0,34 & 0,66 \\
\hline & SV0510 & 0,25 & 0,03 & 0,37 & 0,25 & 0,55 & 0,31 & 0,41 & 1,78 & 0,42 & 0,42 & 0,87 & 0,59 & 0,15 & 1,24 \\
\hline \multirow{4}{*}{$\begin{array}{l}\text { m } \\
\mathbb{\Phi} \\
\frac{1}{4}\end{array}$} & SV0511 & 0,16 & 0,03 & 0,97 & 0,42 & 0,35 & 0,08 & 0,18 & 1,78 & 0,10 & 0,61 & 0,45 & 0,20 & 1,10 & 1,67 \\
\hline & SV0512 & 0,32 & 0,05 & 0,35 & 0,30 & 0,60 & 0,55 & 0,40 & 1,75 & 0,24 & 0,44 & 0,73 & 0,23 & 0,58 & 1,83 \\
\hline & SV0513 & 0,22 & 0,03 & 0,36 & 0,38 & 0,61 & 0,88 & 0,37 & 1,83 & 0,23 & 0,39 & 0,64 & 0,56 & 0,56 & 2,37 \\
\hline & SV0514 & 0,39 & 0,05 & 0,33 & 1,07 & 0,71 & 0,11 & 0,89 & 2,21 & 0,36 & 0,53 & 1,51 & 0,37 & 1,31 & 7,83 \\
\hline
\end{tabular}

$x$ - valores de FE>1,5 
Tabela 5.12: Valores de FE, utilizando Sc como elemento normalizador e os valores UCC, como valores de referência de "background" - Santos 2006 - inverno

\begin{tabular}{|c|c|c|c|c|c|c|c|c|c|c|c|c|c|c|c|}
\hline & Estações & Al & $\mathrm{Ba}$ & Co & $\mathrm{Cu}$ & $\mathrm{Cr}$ & Sr & $\mathrm{Fe}$ & Li & Mn & $\mathrm{Ni}$ & Zn & $\mathrm{Pb}$ (GF AAS) & Cd (GF AAS) & $\mathrm{Hg}$ (CV AAS) \\
\hline \multirow{6}{*}{$\underset{\mathbb{\Phi}}{\mathbb{2}}$} & SI0601 & 0,34 & 0,18 & 0,39 & 1,00 & 0,78 & 0,22 & 0,77 & 1,84 & 0,54 & 0,59 & 1,35 & 0,59 & 1,48 & 7,46 \\
\hline & SI0602 & 0,35 & 0,13 & 0,43 & 1,07 & 0,76 & 0,18 & 0,79 & 1,89 & 0,44 & 0,60 & 1,30 & 0,57 & 1,20 & 8,45 \\
\hline & SI0603 & 0,30 & 0,06 & 0,50 & 0,73 & 0,72 & 0,14 & 0,60 & 2,18 & 0,43 & 0,54 & 1,07 & 0,88 & 0,82 & 7,55 \\
\hline & S10604 & 0,25 & 0,04 & 0,35 & 0,73 & 0,60 & 0,66 & 0,60 & 1,83 & 0,91 & 0,44 & 0,98 & 0,59 & 0,51 & 5,52 \\
\hline & SI0605 & 0,44 & 0,07 & 0,40 & 0,89 & 0,78 & 0,20 & 0,71 & 2,05 & 0,82 & 0,58 & 1,12 & 0,64 & 0,58 & 3,82 \\
\hline & SI0606 & 0,34 & 0,06 & 0,45 & 0,60 & 0,74 & 0,31 & 0,72 & 1,79 & 1,51 & 0,54 & 0,96 & 0,82 & 0,43 & 1,46 \\
\hline \multirow{6}{*}{ 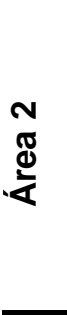 } & S10607 & 0,30 & 0,05 & 0,45 & 0,15 & 0,68 & 0,42 & 0,79 & 1,52 & 0,58 & 0,46 & 0,81 & 0,78 & 0,16 & 1,15 \\
\hline & S10608 & 0,23 & 0,04 & 0,55 & 0,15 & 0,75 & 0,15 & 0,79 & 1,31 & 0,62 & 0,40 & 1,00 & 0,73 & 0,21 & 2,25 \\
\hline & SI0609 & 0,15 & 0,02 & 0,52 & 0,24 & 0,75 & 0,38 & 1,01 & 1,16 & 0,73 & 0,34 & 0,92 & 0,83 & 0,34 & 1,37 \\
\hline & SI0610 & 0,41 & 0,07 & 0,44 & 0,44 & 0,77 & 0,33 & 0,73 & 1,89 & 0,60 & 0,52 & 0,90 & 0,78 & 0,28 & 3,48 \\
\hline & SI0615 & 0,18 & 0,03 & 0,71 & 0,17 & 0,81 & 0,14 & 1,05 & 1,62 & 0,64 & 0,50 & 1,05 & 0,76 & 0,24 & 1,10 \\
\hline & SI0616 & 0,16 & 0,03 & 0,69 & 0,31 & 0,99 & 0,24 & 1,12 & 1,75 & 0,83 & 0,61 & 1,30 & 0,97 & 0,37 & 1,45 \\
\hline \multirow{4}{*}{ 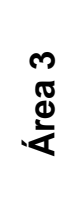 } & SI0611 & 0,42 & 0,06 & 0,37 & 0,72 & 0,71 & 0,51 & 0,68 & 1,84 & 0,46 & 0,52 & 0,97 & 0,53 & 0,75 & 3,08 \\
\hline & SI0612 & 0,36 & 0,06 & 0,37 & 0,69 & 0,70 & 0,34 & 0,61 & 1,84 & 0,42 & 0,53 & 0,99 & 0,65 & 0,65 & 3,70 \\
\hline & SI0613 & 0,25 & 0,05 & 0,40 & 0,94 & 0,67 & 0,24 & 0,61 & 2,41 & 0,29 & 0,51 & 1,16 & 0,96 & 1,37 & 5,01 \\
\hline & SI0614 & 0,25 & 0,05 & 0,40 & 1,19 & 0,72 & 0,12 & 0,64 & 2,49 & 0,46 & 0,53 & 1,34 & 0,90 & 1,54 & 8,50 \\
\hline
\end{tabular}


Tabela 5.13: Valores de FE, utilizando Sc como elemento normalizador e os valores UCC, como valores de referência de "background" - Santos 2006 - verão

\begin{tabular}{|c|c|c|c|c|c|c|c|c|c|c|c|c|c|c|c|}
\hline & Estações & $\mathrm{Al}$ & $\mathrm{Ba}$ & Co & $\mathrm{Cu}$ & $\mathrm{Cr}$ & $\mathrm{Sr}$ & $\mathrm{Fe}$ & $\mathbf{L i}$ & Mn & $\mathrm{Ni}$ & $\mathrm{Zn}$ & $\mathrm{Pb}$ (GF AAS) & Cd (GF AAS) & $\mathrm{Hg}$ (CV AAS) \\
\hline \multirow{6}{*}{$\frac{\sigma}{\mathbb{\Phi}}$} & SV0601 & 0,24 & 0,11 & 0,42 & 1,10 & 0,71 & 0,18 & 0,73 & 2,26 & 0,51 & 0,56 & 1,43 & 0,91 & 1,81 & 5,05 \\
\hline & SV0602 & 0,17 & 0,09 & 0,40 & 0,89 & 0,64 & 0,13 & 0,61 & 1,98 & 0,36 & 0,50 & 1,12 & 0,70 & 1,22 & 4,78 \\
\hline & SV0603 & 0,22 & 0,04 & 0,43 & 0,73 & 0,66 & 0,14 & 0,56 & 2,05 & 0,60 & 0,48 & 0,99 & 0,84 & 0,81 & 4,08 \\
\hline & SV0604 & 0,32 & 0,06 & 0,43 & 0,90 & 0,73 & 0,63 & 0,60 & 2,69 & 0,87 & 0,52 & 1,03 & 1,17 & 0,63 & 2,60 \\
\hline & SV0605 & 0,24 & 0,04 & 0,65 & 1,43 & 0,81 & 0,25 & 0,62 & 3,11 & 0,84 & 0,52 & 1,18 & 0,94 & 0,70 & 2,70 \\
\hline & SV0606 & 0,09 & 0,02 & 0,34 & 0,32 & 0,43 & 0,25 & 0,41 & 1,17 & 0,61 & 0,33 & 0,82 & 0,78 & 0,45 & 1,68 \\
\hline \multirow{6}{*}{ 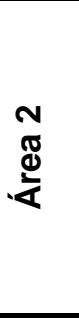 } & SV0607 & 0,16 & 0,03 & 0,51 & 0,11 & 0,61 & 0,69 & 0,77 & 1,73 & 0,78 & 0,40 & 1,04 & 0,47 & 0,21 & 0,36 \\
\hline & SV0608 & 0,18 & 0,03 & 0,51 & 0,41 & 0,67 & 0,20 & 0,65 & 1,93 & 0,83 & 0,48 & 0,95 & 0,65 & 0,35 & 1,40 \\
\hline & SV0609 & 0,19 & 0,03 & 0,79 & 0,22 & 1,00 & 0,16 & 1,40 & 1,80 & 1,24 & 0,58 & 1,19 & 0,47 & 0,31 & 0,51 \\
\hline & SV0610 & 0,24 & 0,04 & 0,57 & 0,42 & 0,74 & 0,37 & 0,68 & 2,28 & 0,63 & 0,53 & 1,00 & 0,72 & 0,42 & 3,37 \\
\hline & SV0615 & 0,11 & 0,01 & 0,60 & 0,18 & 0,69 & 0,08 & 0,91 & 1,18 & 0,66 & 0,37 & 0,92 & 0,43 & 0,26 & 0,37 \\
\hline & SV0616 & 0,18 & 0,03 & 0,56 & 0,26 & 0,73 & 0,21 & 0,75 & 2,00 & 1,45 & 0,51 & 1,08 & 0,79 & 0,24 & 0,52 \\
\hline \multirow{4}{*}{ 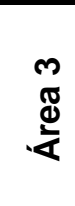 } & SV0611 & 0,27 & 0,05 & 0,43 & 0,38 & 0,66 & 2,72 & 0,55 & 2,28 & 0,32 & 0,47 & 0,80 & 0,32 & 0,96 & 1,24 \\
\hline & SV0612 & 0,23 & 0,04 & 0,41 & 0,40 & 0,61 & 0,19 & 0,51 & 1,90 & 0,39 & 0,48 & 0,81 & 0,49 & 0,79 & 1,52 \\
\hline & SV0613 & 0,23 & 0,04 & 0,38 & 0,82 & 0,63 & 0,28 & 0,56 & 2,43 & 0,27 & 0,49 & 1,15 & 0,74 & 1,33 & 3,58 \\
\hline & SV0614 & 0,31 & 0,06 & 0,42 & 1,13 & 0,78 & 0,15 & 0,69 & 2,66 & 0,34 & 0,59 & 1,41 & 0,97 & 1,67 & 5,83 \\
\hline
\end{tabular}


$\mathrm{Na}$ avaliação do FE das amostras coletadas no período de inverno do ano de 2005 (Tabela 5.10), observa-se que o Hg apresenta valores de FE $>1,5$, nas amostras SI0501, SI0502, SI0503, SI0504, SI0505, SI0506, SI0508, SI0510, SI0513 e SI0514. Estes valores são indicativos de poluição antrópica, e os altos valores encontrados causam preocupação. A amostra SI0501 apresentou valores de FE>1,5 para os elementos $\mathrm{Cd}$ e $\mathrm{Zn}$ e a amostra SI0512, de 1,51 para o Sr. As amostras SI0501 à SI0515 apresentaram valores superiores a 1,5 no cálculo do FE, para o elemento Li.

Em relação aos resultados obtidos para o FE para as amostras coletadas no verão de 2005 (Tabela 5.11), foi possível identificar que as amostras SV0501, SV0502, SV0503, SV0504, SV0505, SV0506, SV0511, SV0512, SV0513 e SV0514 apresentaram valores de FE bastante superiores a 1,5 para $\mathrm{Hg}$, o que indica uma forte contribuição antrópica na região. A amostra SV0514 apresentou valor de FE=1,51 para o elemento $\mathrm{Zn}$ e a amostra SV0504, valor 1,57 para $\circ \mathrm{Pb}$, indicativo de contribuição antrópica para esses 2 elementos. Novamente, as amostras SV0501 à SV0514 apresentaram resultados de $\mathrm{FE}>1,5$ para o Li.

$\mathrm{Na}$ avaliação dos resultados obtidos para FE para as amostras coletadas no inverno de 2006 (Tabela 5.12), verificou-se que as amostras SI0601, SI0602, SI0603, SI0604, SI0605, SI0608, SI0610, SI0611, SI0612, SI0613 e SI0614 apresentaram valores de FE>1,5 para o $\mathrm{Hg}$, bem como a amostra SI0606 para o Mn e a amostra SI0614, para o Cd. As amostras SI0601 à SI0607 e SI0610 a SI0616 apresentaram valores de FE>1,5 para o elemento Li.

Ao avaliar os resultados do FE obtidos para as amostras coletadas no verão de 2006 (Tabela 5.13), observou-se que as amostras SV0601, SV0602, SV0603, SV0604, SV0605, SV0606, SV0610, SV0612, SV0613 e SV0614 tiveram valores de FE $>1,5$ para o $\mathrm{Hg}$, tal como as amostras SV0601 e SV0614 para o Cd, e a amostra SV0611 para o Sr. As amostras SV0601 à SV0605 e SV0607 à SV0616 apresentaram valores de FE>1,5 para o elemento Li. 
De modo a complementar os dados obtidos com o cálculo do fator de enriquecimento, optou-se em realizar o cálculo do $I_{g e o}$, conforme descrito no capítulo 4.11.3.

O Igeo foi calculado considerando os valores descritos por LuizSilva, et al, 2008, como valores de BG para a região, conforme apresentado na Tabela 5.14.

Tabela 5.14: Valores de background da região do Sistema Estuarino Santos-Cubatão (fonte: Luiz-Silva, et al, 2008)

\begin{tabular}{cccc}
\hline Elemento & $\begin{array}{c}\text { Concentrac̃ão } \\
\left(\mathbf{m g ~ k g}^{-1}\right)\end{array}$ & D.P. \\
\hline $\mathbf{A l}(\%)$ & 10,0 & \pm & 0,3 \\
$\mathbf{C d}$ & 0,2 & \pm & 0,1 \\
$\mathbf{C o}$ & 11,8 & \pm & 0,4 \\
$\mathbf{C r}$ & 75 & \pm & 2 \\
$\mathbf{C u}$ & 18,8 & \pm & 0,2 \\
$\mathbf{F e ~ ( \% )}$ & 4,69 & \pm & 0,12 \\
$\mathbf{~ L i}$ & 81,6 & \pm & 3,8 \\
$\mathbf{M n}$ & 645 & \pm & 76 \\
$\mathbf{N i}$ & 27,1 & \pm & 0,6 \\
$\mathbf{P b}$ & 29,5 & \pm & 3,7 \\
$\mathbf{S r}$ & 99 & \pm & 5 \\
$\mathbf{Z n}$ & 92 & \pm & 5 \\
$\mathbf{S c}$ & 16,7 & \pm & 0,7 \\
\hline
\end{tabular}

Para o Hg, utilizou-se como valor de "background", a composição média dos folhelhos $\left(\mathrm{Hg}=0,18 \mathrm{mg} \mathrm{kg}^{-1}\right.$ ) (cit. Luiz-Silva, 2002).

As Tabelas 5.15 a 5.18 apresentam os valores obtidos para o Igeo para todos os pontos de coleta, no verão e inverno de 2005 e 2006, utilizando os valores de Luiz-Silva (2008), como valores de background. 
Tabela 5.15 - Índice de geoacumulação (Igeo) em amostras de sedimentos do estuário de Santos, verão de 2005

\begin{tabular}{|c|c|c|c|c|c|c|c|c|c|c|c|c|c|c|}
\hline & Estações & $\overline{\mathrm{Al}}$ & Co & $\overline{\mathrm{Cu}}$ & $\overline{C r}$ & $\overline{\mathrm{Sr}}$ & $\overline{F e}$ & $\overline{\mathbf{L i}}$ & $\overline{M n}$ & $\overline{\mathrm{Ni}}$ & $\overline{Z n}$ & $\mathrm{~Pb}$ (GF AAS) & Cd (GF AAS) & $\mathrm{Hg}$ (CV AAS) \\
\hline \multirow{5}{*}{$\frac{\overline{\mathbb{d}}}{\stackrel{\bar{\alpha}}{\alpha}}$} & SV0501 & $-2,32$ & $-1,35$ & $-0,90$ & $-1,64$ & $-0,85$ & $-1,46$ & $-0,85$ & $-1,41$ & $-1,46$ & $-0,41$ & $-1,98$ & $-0,79$ & 0,89 \\
\hline & SV0502 & $\begin{array}{l}-1,42 \\
\end{array}$ & $-1,27$ & $-0,55$ & $-1,57$ & $-1,21$ & $-0,67$ & $-0,72$ & $-1,77$ & $-1,31$ & $-0,36$ & $-1,60$ & $-0,82$ & 1,34 \\
\hline & SV0503 & $-2,24$ & $-1,59$ & $-1,03$ & $-1,99$ & $-1,65$ & $-1,17$ & $-1,19$ & $-1,94$ & $-1,83$ & $-0,73$ & $-2,35$ & $-1,57$ & 0,71 \\
\hline & SV0505 & $-1,53$ & $-1,35$ & $-0,63$ & $-1,67$ & $-0,94$ & $-0,89$ & $-0,80$ & $-0,52$ & $-1,55$ & $-0,61$ & $-1,60$ & $-1,39$ & $-0,36$ \\
\hline & SV0506 & $\begin{array}{l}-3,68 \\
\end{array}$ & $-2,95$ & $-3,39$ & $-3,38$ & $-2,05$ & $-3,33$ & $-2,66$ & $-2,87$ & $-3,37$ & $-2,60$ & $-3,75$ & $-3,50$ & $\begin{array}{l}-2,48 \\
\end{array}$ \\
\hline \multirow{3}{*}{ 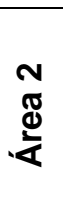 } & SV0507 & $-2,26$ & $-2,00$ & $-4,70$ & $-2,44$ & 0,80 & $-1,41$ & $-1,69$ & $-1,93$ & $-2,49$ & $-1,86$ & $-2,79$ & $-4,24$ & $-2,82$ \\
\hline & SV0509 & $-4,61$ & $-2,95$ & $-4,82$ & $-3,54$ & $-2,36$ & $-2,83$ & $-3,25$ & $-2,99$ & $-3,90$ & $-3,05$ & $-4,47$ & $-4,91$ & $-4,66$ \\
\hline & SV0510 & $-3,28$ & $-2,37$ & $-3,30$ & $-2,87$ & $-0,95$ & $-2,80$ & $-1,98$ & $-2,46$ & $-2,71$ & $-1,94$ & $-2,47$ & $-4,61$ & $-2,30$ \\
\hline \multirow{4}{*}{ 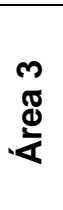 } & SV0511 & $-7,09$ & $-4,15$ & $-5,74$ & $-6,67$ & $\begin{array}{l}-6,02 \\
\end{array}$ & $-7,12$ & $-5,14$ & $\begin{array}{l}-7,68 \\
\end{array}$ & $-5,35$ & $-6,07$ & $-7,21$ & $-4,91$ & $-5,02$ \\
\hline & SV0512 & $-3,57$ & $-3,09$ & $-3,71$ & $-3,40$ & $-0,74$ & $-3,50$ & $-2,65$ & $-3,93$ & $-3,29$ & $-2,84$ & $-4,47$ & $-3,32$ & $-2,38$ \\
\hline & SV0513 & $-4,70$ & $-3,65$ & $-3,97$ & $-3,98$ & $-0,68$ & $-4,20$ & $-3,19$ & $-4,55$ & $-4,05$ & $-3,64$ & $-3,79$ & $-3,97$ & $-2,61$ \\
\hline & SV0514 & $-1,42$ & $\begin{array}{l}-1,32 \\
\end{array}$ & $-0,01$ & $-1,31$ & $-1,22$ & $-0,48$ & $-0,45$ & $-1,47$ & $-1,16$ & 0,06 & $-1,96$ & $-0,29$ & 1,57 \\
\hline
\end{tabular}


Tabela 5.169 - Índice de geoacumulação (Igeo) em amostras de sedimentos do estuário de Santos, inverno de 2005

\begin{tabular}{|c|c|c|c|c|c|c|c|c|c|c|c|c|c|c|}
\hline & & $\overline{A l}$ & Co & $\mathrm{Cu}$ & $\mathrm{Cr}$ & $\mathrm{Sr}$ & $\mathrm{Fe}$ & $\mathrm{Li}$ & Mn & $\mathbf{N i}$ & Zn & $\mathrm{Pb}$ (GF AAS) & Cd (GF AAS) & $\mathrm{Hg}$ (CV AAS) \\
\hline \multirow{4}{*}{$\begin{array}{l}\bar{\Xi} \\
\stackrel{\Xi}{\mathbb{2}}\end{array}$} & SI0501 & $-1,29$ & $-0,95$ & $-0,13$ & $-1,15$ & $-0,32$ & $-0,19$ & $-0,51$ & $\begin{array}{l}-0,85 \\
\end{array}$ & $-0,97$ & 0,18 & $-0,88$ & 0,21 & 0,80 \\
\hline & S10503 & $-2,30$ & $-1,79$ & $-0,97$ & $-2,10$ & $-1,66$ & $-1,37$ & $-1,34$ & $-2,04$ & $-2,08$ & $-1,03$ & $-1,47$ & $-2,04$ & 0,61 \\
\hline & SI0505 & $-1,57$ & $-1,63$ & $-0,93$ & $-1,87$ & $-1,15$ & $-1,04$ & $-1,04$ & $-0,82$ & $-1,79$ & $-0,85$ & $-1,55$ & $-2,26$ & $-0,51$ \\
\hline & SI0506 & $-3,54$ & $-2,23$ & $-2,36$ & $-2,74$ & $-1,52$ & $-2,55$ & $-2,35$ & $-1,65$ & $-2,55$ & $-1,74$ & $-2,01$ & $-4,08$ & $-1,96$ \\
\hline \multirow{4}{*}{ 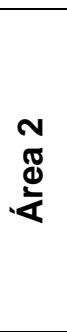 } & SI0507 & $-4,46$ & $-2,76$ & $-4,82$ & $-3,51$ & $-2,51$ & $-2,90$ & $-3,11$ & $-2,52$ & $-3,77$ & $-2,75$ & $-3,70$ & $-4,91$ & $-5,84$ \\
\hline & SI0510 & $-3,94$ & $-2,68$ & $-3,70$ & $-3,27$ & $-2,13$ & $-3,01$ & $-3,02$ & $-2,60$ & $-3,40$ & $-2,56$ & $-2,21$ & $-4,91$ & $-2,32$ \\
\hline & SI0515 & $-2,51$ & $-1,51$ & $-1,87$ & $-1,90$ & $-0,91$ & $-1,46$ & $-1,50$ & $-0,54$ & $-1,63$ & $-1,27$ & $-1,54$ & $-4,23$ & $-2,68$ \\
\hline & SI0516 & $-4,38$ & $-2,69$ & $-4,82$ & $-3,16$ & $-3,02$ & $-2,62$ & $-3,41$ & $-2,79$ & $-3,50$ & $-2,61$ & $-3,18$ & $-4,91$ & $-5,06$ \\
\hline \multirow{2}{*}{ 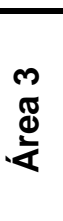 } & SI0511 & $-5,55$ & $-4,15$ & $-4,86$ & $-5,30$ & $-5,04$ & $-5,58$ & $-4,44$ & $-5,72$ & $-5,19$ & $-4,61$ & $-4,88$ & $-4,91$ & $-5,78$ \\
\hline & SI0512 & $-3,67$ & $-3,28$ & $-3,64$ & $-3,37$ & 0,63 & $-3,38$ & $-2,81$ & $-3,52$ & $-3,49$ & $-3,07$ & $-3,27$ & $-4,23$ & $-2,98$ \\
\hline
\end{tabular}


Tabela 5.17 - Índice de geoacumulação (Igeo) em amostras de sedimentos do estuário de Santos, verão de 2006.

\begin{tabular}{|c|c|c|c|c|c|c|c|c|c|c|c|c|c|c|}
\hline & & $\overline{A l}$ & Co & $\overline{\mathrm{Cu}}$ & $\mathrm{Cr}$ & $\mathrm{Sr}$ & $\overline{F e}$ & Li & Mn & $\overline{\mathrm{Ni}}$ & Zn & $\mathrm{Pb}$ (GF AAS) & Cd (GF AAS) & $\mathrm{Hg}$ (CV AAS) \\
\hline \multirow{5}{*}{ 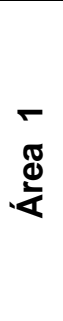 } & SV0601 & $-2,11$ & $-0,97$ & 0,06 & $\overline{-1,28}$ & $-0,45$ & $-0,75$ & $-0,40$ & $-0,95$ & $-1,06$ & 0,01 & $-0,62$ & 0,20 & $\overline{0,97}$ \\
\hline & SV0602 & $-2,66$ & $-1,11$ & $-0,32$ & $-1,52$ & $-0,99$ & $-1,09$ & $-0,67$ & $-1,55$ & $-1,31$ & $-0,43$ & $-1,08$ & $-0,46$ & 0,81 \\
\hline & SV0603 & $-2,79$ & $-1,50$ & $-1,08$ & $-1,93$ & $-1,43$ & $-1,67$ & $-1,10$ & $-1,27$ & $-1,85$ & $-1,07$ & $-1,29$ & $-1,52$ & 0,11 \\
\hline & SV0605 & $-2,90$ & $-1,10$ & $-0,32$ & $-1,84$ & $-0,77$ & $-1,74$ & $-0,70$ & $-0,99$ & $-1,93$ & $\begin{array}{l}-1,02 \\
\end{array}$ & $\begin{array}{l}-1,32 \\
\end{array}$ & $-1,93$ & $-0,69$ \\
\hline & SV0606 & $-5,09$ & $-2,82$ & $-3,25$ & $-3,54$ & $-1,53$ & $-3,11$ & $-2,89$ & $-2,23$ & $-3,38$ & $-2,34$ & $-2,38$ & $-3,35$ & $-2,17$ \\
\hline \multirow{5}{*}{ 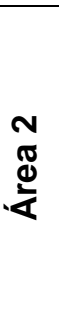 } & SV0607 & $-4,32$ & $-2,31$ & $-4,82$ & $-3,10$ & $-0,16$ & $-2,27$ & $-2,39$ & $\begin{array}{l}-1,94 \\
\end{array}$ & $-3,17$ & $\begin{array}{l}-2,06 \\
\end{array}$ & $-3,18$ & $\begin{array}{l}-4,52 \\
\end{array}$ & $-4,46$ \\
\hline & SV0609 & $-5,00$ & $-2,63$ & $-4,82$ & $-3,36$ & $-3,26$ & $-2,38$ & $-3,31$ & $-2,24$ & $-3,59$ & $-2,84$ & $-4,15$ & $-4,91$ & $-4,91$ \\
\hline & SV0610 & $-3,56$ & $-1,97$ & $-2,75$ & $-2,65$ & $-0,87$ & $-2,28$ & $-1,82$ & $-2,07$ & $-2,58$ & $-1,94$ & $-2,38$ & $-3,33$ & $-1,05$ \\
\hline & SV0615 & $-5,48$ & $-2,74$ & $-4,82$ & $-3,61$ & $-3,89$ & $-2,71$ & $-3,62$ & $-2,86$ & $-3,93$ & $-2,91$ & $-3,98$ & $-4,91$ & $-5,08$ \\
\hline & SV0616 & $-3,93$ & $-1,92$ & $-3,37$ & $-2,60$ & $-1,61$ & $-2,06$ & $-1,94$ & $-0,80$ & $-2,57$ & $-1,76$ & $-2,18$ & $-4,10$ & $-3,67$ \\
\hline \multirow{2}{*}{ 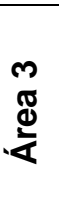 } & SV0611 & $-3,39$ & $-2,36$ & $-2,93$ & $-2,81$ & 1,99 & $-2,60$ & $-1,83$ & $-3,05$ & $-2,74$ & $-2,27$ & $-3,58$ & $-2,16$ & $-2,50$ \\
\hline & SV0612 & $-3,40$ & $-2,23$ & $-2,63$ & $-2,73$ & $-1,62$ & $-2,47$ & $-1,87$ & $-2,56$ & $-2,51$ & $-2,03$ & $-2,75$ & $-2,23$ & $-1,99$ \\
\hline
\end{tabular}


Tabela 5.18 - Índice de geoacumulação (Igeo) em amostras de sedimentos do estuário de Santos, inverno de 2006

\begin{tabular}{|c|c|c|c|c|c|c|c|c|c|c|c|c|c|c|}
\hline & & $\overline{A l}$ & Co & $\mathrm{Cu}$ & $\mathrm{Cr}$ & $\mathrm{Sr}$ & $\mathrm{Fe}$ & $\overline{L i}$ & $M n$ & $\mathbf{N i}$ & $\overline{Z n}$ & $\mathrm{~Pb}$ (GF AAS) & Cd (GF AAS) & $\mathrm{Hg}$ (CV AAS) \\
\hline \multirow{5}{*}{ 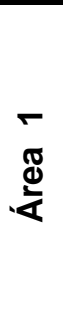 } & SI0601 & $-1,58$ & $-1,05$ & $-0,06$ & $-1,13$ & $-0,21$ & $-0,65$ & $-0,68$ & $-0,85$ & $-0,96$ & $-0,06$ & $-1,24$ & $-0,08$ & 1,55 \\
\hline & S10602 & $-1,68$ & $-1,02$ & $-0,08$ & $-1,28$ & $-0,62$ & $-0,72$ & $-0,75$ & $-1,25$ & $-1,06$ & $-0,23$ & $-1,39$ & $-0,49$ & 1,61 \\
\hline & S10603 & $-2,61$ & $-1,52$ & $-1,33$ & $-2,06$ & $-1,66$ & $-1,83$ & $-1,26$ & $-2,01$ & $-1,91$ & $-1,22$ & $-1,47$ & $-1,75$ & 0,74 \\
\hline & SI0605 & $-1,46$ & $-1,26$ & $-0,47$ & $-1,36$ & $-0,55$ & $-1,01$ & $-0,76$ & $-0,49$ & $-1,23$ & $-0,57$ & $-1,34$ & $-1,66$ & 0,34 \\
\hline & S10606 & $-2,61$ & $-1,87$ & $-1,81$ & $-2,22$ & $-0,68$ & $-1,77$ & $-1,74$ & $-0,39$ & $-2,11$ & $-1,57$ & $-1,78$ & $-2,88$ & $-1,83$ \\
\hline \multirow{5}{*}{ 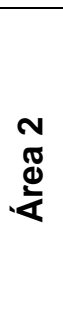 } & S10607 & $-3,15$ & $-2,22$ & $-4,19$ & $-2,68$ & $-0,60$ & $-1,97$ & $-2,32$ & $-2,11$ & $-2,70$ & $-2,15$ & $-2,19$ & $-4,62$ & $-2,51$ \\
\hline & SI0609 & $-5,51$ & $-3,34$ & $-4,82$ & $-3,88$ & $-2,07$ & $-2,95$ & $-4,04$ & $-3,10$ & $-4,46$ & $-3,30$ & $-3,43$ & $-4,91$ & $-3,59$ \\
\hline & SI0610 & $-2,61$ & $-2,14$ & $-2,53$ & $-2,42$ & $-0,88$ & $-1,99$ & $-1,91$ & $-1,98$ & $-2,42$ & $-1,91$ & $-2,10$ & $-3,78$ & $-0,83$ \\
\hline & SI0615 & $-4,71$ & $-2,40$ & $-4,82$ & $-3,28$ & $-3,03$ & $-2,40$ & $-3,07$ & $-2,80$ & $-3,41$ & $-2,63$ & $-3,06$ & $-4,91$ & $-3,42$ \\
\hline & SI0616 & $-4,88$ & $-2,42$ & $-3,93$ & $-2,98$ & $-2,25$ & $-2,30$ & $-2,95$ & $-2,43$ & $-3,13$ & $-2,31$ & $-2,70$ & $-4,28$ & $-3,02$ \\
\hline \multirow{2}{*}{ 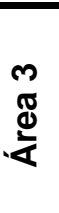 } & SI0611 & $-2,33$ & $-2,17$ & $-1,57$ & $-2,28$ & 0,00 & $-1,85$ & $-1,71$ & $-2,09$ & $-2,18$ & $-1,57$ & $-2,40$ & $-2,09$ & $-0,76$ \\
\hline & SI0612 & $-2,48$ & $-2,10$ & $-1,56$ & $-2,26$ & $-0,51$ & $-1,95$ & $-1,65$ & $-2,17$ & $-2,10$ & $-1,48$ & $-2,05$ & $-2,23$ & $-0,44$ \\
\hline
\end{tabular}


Os índices $I_{\text {geo }}$ obtidos para os elementos analisados nas amostras coletadas no verão de 2005 (Tabela 5.15) demonstram que o Hg das amostras SV0501, SV0503 e SV0504; O Pb da amostra SV0504; o Zn da amostra SV0514 e o Sr da amostra SV0507 estão entre 0 e 1, o que indica que as áreas são consideradas não poluídas para estes elementos. A amostra SV0504 apresentou o $I_{\text {geo }}$ para o $\mathrm{Sr}$ entre 1 e 2, assim como as amostras SV0502 e SV0514, que apresentam valores de $I_{\text {geo }}$ entre 1 e 2 para o $\mathrm{Hg}$, o que pode indicar um nível de poluição moderada. Para os demais elementos e amostras analisadas, foram obtidos índices $\boldsymbol{I}_{\text {geo }}<0$, no período do verão de 2005 .

As amostras coletadas no inverno de 2005 (Tabela 5.16) apresentaram valores de $0<l_{\text {geo }}<1$, para as amostras SI0501 ( $\mathrm{Cd}, \mathrm{Zn} \mathrm{e} \mathrm{Hg}$ ), SI0503 (Hg), SI0504 (Sr e Hg), SI0512 (Sr) e SI0514 (Zn e Cu), indicando que as áreas são consideradas não poluídas. O Hg das amostras SI0502 e SI0514 apresentaram valores $1<l_{\text {geo }}<2$, assim como para as amostras coletadas no verão de 2005. Para os demais elementos e amostras analisadas, foram obtidos índices $\boldsymbol{I}_{g e o<0}$, no período do inverno de 2005.

Ao avaliar os índices $I_{\text {geo }}$ para as amostras coletadas no verão de 2006 (Tabela 5.17), foi possível identificar que as amostras SV0601 (Cu, Zn, Cd e Hg), SV0602, SV0603 e SV0613 (Hg) e SV0614 (Cu e Cd) apresentaram valores $0<l_{\text {geo }}<1$, caracterizando as áreas como não poluídas. As amostras SV0604 e SV0611 (Sr) e SV0614 (Hg) apresentaram valores $1<l_{\text {geo }}<2$, o que caracteriza as áreas como moderadamente poluídas. Vale ressaltar que as amostras SV0601 e SV0602, embora não tenham ultrapassado o valor 1 para o $I_{\text {geo, }}$ apresentaram valores altos para $\circ \mathrm{Hg}\left(0,97\right.$ e $\left.0,81 \mathrm{mg} \mathrm{kg}^{-1}\right)$ respectivamente, assim como nos demais períodos avaliados, o que indica cautela na gestão ambiental deste elemento nas áreas avaliadas. Os demais elementos não apresentaram índices $\boldsymbol{I}_{\text {geo }} \mathbf{0}$, nas diversas áreas avaliadas.

$\mathrm{Na}$ verificação dos dados obtidos com o cálculo do $I_{\text {geo }}$ para as amostras coletadas no período do inverno de 2006 (Tabela 5.18), foi possível identificar que as amostras SI0603, SI0605 e SI0613 (Hg), SI0611 (Sr) e SI0614 $(\mathrm{Cu})$ apresentaram valores $0<\mathrm{lgeo}_{\text {e }}<1$. As amostras SI0601, SI0602 e SI0614 (Hg) e SI0604 (Sr) apresentaram valores 1<lgeo<2, o que indica nível de 
poluição moderada para estes elementos, para as amostras citadas. O Sr pode também ser oriundo dos bioclastos, representados por conchas ou fragmentos de bivalves, de algas calcárias, além de ser um dos elementos dominantes na composição química da areia.

Vale salientar que a comparação entre os resultados obtidos do Igeo e FE com os scatterplots não são diretamente proporcionais, visto que os dados de comparação do Igeo e FE (BG e UCC) são realizados levando-se em consideração os valores de referência e os scatterplots, foram feitos somente considerando-se a fração potencialmente disponível dos elementos após ataque com $\mathrm{HNO}_{3}$ (conc) e um elemento normalizador (Sc), não levando em consideração os dados pretéritos dos elementos avaliados. Entretanto o Igeo, FE e os scatterplots possuem características complementares entre si, que podem retratar de uma forma mais completa as características das regiões.

\subsubsection{Resultados de concentração para os elementos determinados por NAA nos sedimentos}

Para tratamento dos dados foram mantidas as áreas 1, 2 e 3 (Tabela 4.1), conforme já foi feito para os resultados de ICP OES e AAS.

As Tabelas 5.19 e 5.20 apresentam a média, desvio padrão, valores minímos e máximos $\left(\mathrm{mg} \mathrm{kg}^{-1}\right)$ para os elementos analisados por NAA, para as amostras de sedimentos coletadas em Santos, no verão e inverno de 2005 e 2006, respectivamente. Também são apresentados os valores orientadores pelo Canadian Council of Minister of the Environment (CCME): TEL (Threshold Effect Level) e PEL (Probable Effect Level) para sedimentos de águas salobras e NASC (North American Shale Composite). (TAYLOR \& MCLENNAN, 1985)

Os Anexos VII a $\mathrm{X}$ apresentam as tabelas com os dados de concentração e desvios para todos os pontos amostrados no estuário de Santos/São Vicente, nos períodos de inverno e verão, 2005 e 2006, respectivamente, pela técnica de NAA. 
Tabela 5.19- Resultados obtidos para as amostras de Santos - verão(V) e inverno (I) de 2005 - para os elementos analisados por NAA (mg kg-1): média, desvio padrão, mínimo, máximo, valores do NASC, TEL e PEL

\begin{tabular}{|c|c|c|c|c|c|c|c|c|c|c|c|c|c|c|c|c|}
\hline \multirow{2}{*}{\multicolumn{2}{|c|}{ Elementos }} & \multicolumn{4}{|c|}{ Área (1 estações 1 to 6 ) } & \multicolumn{4}{|c|}{ Área 2*(estações 7 a 10, 15, 16) } & \multicolumn{4}{|c|}{ Área 3 (estações 11 to 14) } & \multirow[b]{2}{*}{ NASC } & \multirow{2}{*}{ TEL } & \multirow{2}{*}{ PEL } \\
\hline & & Média & Desv. Pad. & Min. & Max. & média & Desv. Pad. & Min. & Max. & Média & Desv. Pad. & Min. & Max. & & & \\
\hline \multirow[t]{2}{*}{ As } & $\mathbf{V}$ & 10,3 & 5 & 3,8 & 18 & 8,8 & 1,2 & 7,4 & 10,3 & 6 & 5 & 1,4 & 11,3 & & 7,24 & 41,6 \\
\hline & $\mathrm{I}$ & 9,4 & 2,7 & 5,9 & 13,1 & 6 & 1,9 & 3,4 & 7,6 & 5,1 & 4,7 & 0,4 & 11,4 & & & \\
\hline \multirow[t]{2}{*}{$\mathrm{Ba}$} & $\mathbf{V}$ & 388 & 94 & 283 & 524 & 401 & 47 & 338 & 443 & 221 & 161 & 79 & 447 & 636 & & \\
\hline & $\mathrm{I}$ & 537 & 149 & 396 & 771 & 494 & 45 & 450 & 541 & N.D. & N.D. & N.D. & N.D. & & & \\
\hline \multirow[t]{2}{*}{$\mathrm{Br}$} & $\mathbf{V}$ & 76 & 21 & 53 & 103 & 52 & 21 & 22 & 70 & 50 & 56 & 12 & 134 & & & \\
\hline & $I$ & 110 & 31 & 61 & 146 & 38 & 21 & 17 & 61 & 46 & 48 & 11 & 116 & & & \\
\hline \multirow[t]{2}{*}{$\mathrm{Ca}(\%)$} & $\mathbf{V}$ & 1,66 & 1,35 & 0,21 & 4,1 & 1,94 & 1,08 & 0,93 & 3,41 & 1,53 & 1,04 & 0,25 & 2,55 & & & \\
\hline & $\mathrm{I}$ & 1,41 & 0,39 & 0,91 & 2,09 & 0,99 & 0,45 & 0,49 & 1,52 & 2,04 & 2,74 & 0,19 & 6,09 & & & \\
\hline \multirow[t]{2}{*}{$\mathrm{Ce}$} & $\mathbf{V}$ & 95 & 47 & 24 & 167 & 43 & 18 & 20 & 64 & 40 & 43 & 7 & 104 & 73 & & \\
\hline & I & 112 & 84 & 36 & 235 & 31 & 8 & 25 & 42 & 45 & 42 & 21 & 108 & & & \\
\hline \multirow[t]{2}{*}{ Co } & $\mathbf{V}$ & 8,8 & 3 & 3,1 & 11,7 & 5,9 & 2,3 & 3,1 & 8,5 & 4,1 & 4,3 & 0,5 & 10,3 & 26 & & \\
\hline & $\mathrm{I}$ & 8,8 & 3,8 & 3,3 & 12,8 & 4,2 & 1,2 & 3,3 & 5,8 & 3,7 & 4,3 & 0,8 & 10,1 & & & \\
\hline \multirow[t]{2}{*}{$\mathrm{Cr}$} & $\mathbf{V}$ & 59 & 23 & 19 & 89 & 34 & 14 & 14 & 47 & 32 & 30 & 5 & 74 & 125 & 52,3 & 160 \\
\hline & $I$ & 59 & 20 & 29 & 80 & 20 & 8 & 14 & 32 & 31 & 31 & 9 & 76 & & & \\
\hline \multirow[t]{2}{*}{ Cs } & $\mathbf{V}$ & 4,7 & 1,6 & 1,5 & 5,9 & 2,8 & 1,3 & 1,1 & 4,3 & 2,3 & 2,6 & 0,2 & 6,1 & 5,2 & & \\
\hline & $I$ & 5,4 & 1,9 & 2,4 & 7,4 & 1,7 & 0,5 & 1,3 & 2,5 & 2,2 & 2,6 & 0,4 & 6 & & & \\
\hline \multirow[t]{2}{*}{ Eu } & $\mathbf{V}$ & 1,35 & 0,62 & 0,41 & 2,3 & 0,84 & 0,24 & 0,52 & 1,1 & 0,6 & 0,61 & 0,1 & 1,48 & 1,24 & & \\
\hline & $\mathrm{I}$ & 1,65 & 1,19 & 0,54 & 3,39 & 0,56 & 0,16 & 0,42 & 0,76 & 0,59 & 0,73 & 0,1 & 1,66 & & & \\
\hline \multirow[t]{2}{*}{$\mathrm{Fe}(\%)$} & $\mathbf{V}$ & 3,33 & 1,25 & 1,05 & 4,76 & 2,13 & 0,64 & 1,38 & 2,91 & 1,72 & 1,99 & 0,14 & 4,61 & & & \\
\hline & $\mathrm{I}$ & 3,84 & 1,67 & 1,71 & 6,14 & 1,59 & 0,38 & 1,17 & 2,1 & 1,57 & 2,02 & 0,21 & 4,55 & & & \\
\hline \multirow[t]{2}{*}{$\mathrm{Hf}$} & $\mathbf{V}$ & 4,7 & 2,2 & 1,7 & 7,5 & 3,3 & 1,3 & 1,4 & 4,2 & 4,3 & 1,2 & 3,5 & 6,0 & 0,3 & & \\
\hline & $I$ & 4,5 & 1,3 & 2,6 & 6,6 & 2,5 & 0,8 & 1,3 & 3,6 & 4,2 & 1,8 & 2,3 & 6,6 & & & \\
\hline \multirow[t]{2}{*}{ La } & $\mathbf{V}$ & 42 & 21 & 10 & 74 & 18 & 8 & 8 & 27 & 17,5 & 18,6 & 3,1 & 44,8 & 32 & & \\
\hline & I & 49 & 34 & 16 & 96 & 13 & 4 & 9 & 18 & 20,3 & 20,1 & 7,1 & 50,2 & & & \\
\hline
\end{tabular}


Tabela 5.19 Resultados obtidos para as amostras de Santos - verão(V) e inverno (I) de 2005 (continuação)

\begin{tabular}{|c|c|c|c|c|c|c|c|c|c|c|c|c|c|c|c|c|}
\hline \multicolumn{2}{|c|}{ Elementos } & \multirow{2}{*}{$\frac{\text { Média }}{0,25}$} & \multirow{2}{*}{$\begin{array}{c}\text { Desv. Pad. } \\
0,1\end{array}$} & \multirow{2}{*}{$\frac{\text { Min. }}{0,08}$} & \multirow{2}{*}{$\begin{array}{c}\text { Max. } \\
0,38\end{array}$} & \multirow{2}{*}{$\frac{\text { média }}{0,16}$} & \multirow{2}{*}{$\begin{array}{c}\text { Desv. Pad. } \\
0,07\end{array}$} & \multirow{2}{*}{$\begin{array}{c}\text { Min. } \\
0,07\end{array}$} & \multirow{2}{*}{$\frac{\text { Max. }}{0,24}$} & \multirow{2}{*}{$\frac{\text { Média }}{0,16}$} & \multirow{2}{*}{$\begin{array}{c}\text { Desv. Pad. } \\
0,14\end{array}$} & \multirow{2}{*}{$\begin{array}{c}\text { Min. } \\
0,05\end{array}$} & \multirow{2}{*}{$\frac{\text { Max. }}{0,36}$} & \multirow{2}{*}{$\frac{\text { NASC }}{0,48}$} & \multirow[t]{2}{*}{ TEL } & \multirow[t]{2}{*}{ PEL } \\
\hline Lu & V & & & & & & & & & & & & & & & \\
\hline & I & 0,36 & 0,11 & 0,26 & 0,56 & N.D. & N.D. & N.D. & N.D. & N.D. & N.D. & N.D. & N.D. & & & \\
\hline \multirow[t]{2}{*}{$\mathrm{Na}$} & V & 14135 & 3099 & 10565 & 17749 & 12345 & 3087 & 8458 & 15350 & 7384 & 6857 & 2351 & 17466 & & & \\
\hline & I & 15124 & 3727 & 9307 & 19227 & 10456 & 2930 & 8095 & 14647 & 8040 & 10088 & 2016 & 23032 & & & \\
\hline \multirow[t]{2}{*}{ Nd } & $\mathrm{V}$ & 37 & 17 & 9 & 54 & 17 & 3 & 13 & 21 & 17,9 & 16,8 & 4,8 & 42,6 & 33 & & \\
\hline & I & 48 & 30 & 14 & 94 & 13 & 5 & 8 & 19 & 22,7 & 24 & 8 & 58,6 & & & \\
\hline \multirow[t]{2}{*}{$\mathbf{R b}$} & $\mathrm{V}$ & 94 & 39 & 38 & 149 & 59 & 16 & 39 & 73 & 34 & 34 & 5 & 82 & 125 & & \\
\hline & I & 90 & 34 & 53 & 148 & 70 & 27 & 38 & 102 & 35 & 31 & 11 & 79 & & & \\
\hline \multirow[t]{2}{*}{$\mathrm{Sb}$} & $\mathbf{V}$ & 0,57 & 0,27 & 0,21 & 0,87 & 0,31 & 0,07 & 0,21 & 0,37 & 0,4 & 0,36 & 0,08 & 0,92 & & & \\
\hline & I & 0,78 & 0,2 & 0,6 & 0,9 & 0,37 & 0,09 & 0,29 & 0,5 & 0,39 & 0,39 & 0,13 & 0,97 & & & \\
\hline \multirow[t]{2}{*}{$\mathrm{Sc}$} & V & 9,5 & 3,4 & 2,9 & 12,3 & 5,5 & 2,6 & 2 & 8,2 & 4,8 & 5,5 & 0,6 & 12,8 & 15 & & \\
\hline & I & 10,2 & 3,6 & 4,8 & 14,2 & 3,4 & 1,3 & 2,3 & 5,3 & 4,8 & 5,9 & 0,9 & 13,5 & & & \\
\hline \multirow[t]{2}{*}{$\mathrm{Sm}$} & $\mathrm{V}$ & 7 & 3,5 & 1,6 & 12 & 3,2 & 1,4 & 1,5 & 4,8 & 2,8 & 3 & 0,5 & 7,1 & 5,7 & & \\
\hline & I & 5,7 & 2,7 & 1,7 & 8,5 & 2,3 & 0,6 & 1,8 & 3,2 & 3,3 & 3,1 & 1,5 & 7,9 & & & \\
\hline \multirow[t]{2}{*}{$\mathrm{Ta}$} & V & 1,1 & 0,6 & 0,3 & 2,1 & 0,6 & 0,1 & 0,6 & 0,8 & 0,6 & 0,5 & 0,2 & 1,4 & 1,1 & & \\
\hline & I & 1,5 & 1,0 & 0,4 & 2,6 & 0,5 & 0,3 & 0,2 & 1,0 & 1,6 & 2,0 & 0,2 & 4,4 & & & \\
\hline \multirow[t]{2}{*}{$\mathrm{Tb}$} & $\mathbf{V}$ & 0,71 & 0,37 & 0,11 & 1,22 & 0,44 & 0,2 & 0,16 & 0,61 & 0,32 & 0,24 & 0,09 & 0,66 & 0,85 & & \\
\hline & I & 0,69 & 0,39 & 0,21 & 1,12 & 0,26 & 0,11 & 0,16 & 0,4 & 0,22 & 0,15 & 0,12 & 0,44 & & & \\
\hline \multirow[t]{2}{*}{ Th } & V & 11 & 4 & 3 & 16 & 5,6 & 2,2 & 2,6 & 8 & 5,7 & 5,5 & 1,2 & 13,6 & 12 & & \\
\hline & I & 12 & 6 & 5 & 19 & 4,3 & 1,7 & 2,8 & 6,5 & 7,9 & 5,3 & 3,6 & 14,8 & & & \\
\hline \multirow[t]{2}{*}{$\mathbf{U}$} & $\mathrm{V}$ & 3,3 & 1,8 & 1 & 6,2 & 1,6 & 0,9 & 0,5 & 2,5 & 2,3 & 1,5 & 0,6 & 4,2 & 2,7 & & \\
\hline & I & 3,7 & 2,1 & 1,4 & 6,9 & 1 & 0,2 & 0,8 & 1,2 & 2,5 & 1,6 & 1,3 & 4,9 & & & \\
\hline \multirow[t]{2}{*}{$\mathrm{Yb}$} & $\mathrm{V}$ & 1,8 & 0,6 & 0,6 & 2,4 & 1,1 & 0,4 & 0,6 & 1,6 & 1,01 & 0,75 & 0,34 & 2,08 & 3,1 & & \\
\hline & I & 1,9 & 0,7 & 0,9 & 2,9 & 0,8 & 0,3 & 0,6 & 1,2 & 0,92 & 0,83 & 0,36 & 2,15 & & & \\
\hline $\mathrm{Zn}$ & V & 118 & 45 & 31 & 147 & 51 & 24 & 22 & 79 & 62 & 83 & 8 & 186 & & 124 & 271 \\
\hline & I & 124 & 55 & 47 & 194 & 35 & 15 & 22 & 56 & 59 & 90 & 7 & 194 & & & \\
\hline
\end{tabular}

*- Área 2 - as amostras do verão/2005, não foram coletadas nos pontos 15 e 16; ND - não determinado 
Tabela 5.20 - Resultados obtidos das amostras de Santos - verão (V) e inverno (I) de 2006 - para os elementos analisados por NAA ( $\mathrm{mg} \mathrm{kg}^{-1}$ ): média, desvio padrão, mínimo, máximo, valores do NASC, TEL e PEL

\begin{tabular}{|c|c|c|c|c|c|c|c|c|c|c|c|c|c|c|c|c|}
\hline & & \multicolumn{4}{|c|}{ Área 1 (pontos 01 a 06) } & \multicolumn{4}{|c|}{ Área 2 (Pontos 07 a 10, 15, 16) } & \multicolumn{4}{|c|}{ Área 3 (Pontos 11 to 14) } & \multirow[b]{2}{*}{ NASC } & \multirow[b]{2}{*}{ TEL } & \multirow[b]{2}{*}{ PEL } \\
\hline \multicolumn{2}{|c|}{ Elementos } & Média & $\begin{array}{l}\text { Desvio } \\
\text { Padrão }\end{array}$ & $\min$. & max. & Média & $\begin{array}{l}\text { Desvio } \\
\text { Padrão }\end{array}$ & $\min$. & $\max$. & Média & $\begin{array}{l}\text { Desvio } \\
\text { Padrão }\end{array}$ & $\min$. & max. & & & \\
\hline \multirow[t]{2}{*}{ As } & $\mathbf{V}$ & 9,6 & 2,7 & 6,4 & 14 & 8,1 & 3,3 & 2,5 & 12 & 9,7 & 2,8 & 6,9 & 13,1 & & 7,24 & 41,6 \\
\hline & I & 10,3 & 5,6 & 1,6 & 18,5 & 7,4 & 2,2 & 5,2 & 11,4 & 11,6 & 3,9 & 7,2 & 16,7 & & & \\
\hline \multirow[t]{2}{*}{$\mathrm{Ba}$} & V & 153 & 168 & N.D. & 320 & 442,8 & 55,2 & 365,6 & 505,2 & 293 & 38 & 244 & 337 & 636 & & \\
\hline & I & 415 & 196 & 201 & 681 & 482 & 72 & 401 & 601 & 331 & 156 & 212 & 544 & & & \\
\hline \multirow[t]{2}{*}{$\mathrm{Br}$} & V & 131 & 52 & 69 & 212 & 75 & 44,8 & 23 & 135,9 & 148 & 98 & 69 & 285 & & & \\
\hline & I & 155 & 40 & 84 & 199 & 47 & 25 & 22 & 74 & 155 & 54 & 105 & 232 & & & \\
\hline \multirow[t]{2}{*}{$\mathrm{Ca}(\%)$} & V & 1,7 & 0,6 & 1,3 & 2,8 & 1,3 & 0,6 & 0,6 & 2 & 3,4 & 4,5 & 1 & 10,1 & & & \\
\hline & I & 1,7 & 0,7 & 1,2 & 3 & 1 & 0,4 & 0,6 & 1,5 & 2,3 & 0,9 & 1,2 & 3,3 & & & \\
\hline \multirow[t]{2}{*}{$\mathrm{Ce}$} & V & 98,3 & 64,6 & 35,1 & 187,4 & 33,7 & 7,9 & 23 & 45,1 & 68,8 & 30,2 & 38,1 & 101 & 73 & & \\
\hline & I & 118,8 & 82,1 & 46,4 & 257,2 & 32,8 & 8,5 & 19,5 & 44 & 69 & 27,5 & 44,8 & 103,2 & & & \\
\hline \multirow[t]{2}{*}{ Co } & V & 8,7 & 2,6 & 4,7 & 11,5 & 4,9 & 1,3 & 3,4 & 6,9 & 6,6 & 2,5 & 4,2 & 9 & 26 & & \\
\hline & I & 9,3 & 1,8 & 7 & 11,2 & 4,1 & 0,8 & 2,8 & 5,2 & 7,3 & 2,2 & 5,4 & 10,2 & & & \\
\hline \multirow[t]{2}{*}{$\mathrm{Cr}$} & V & 56 & 18 & 25 & 73 & 25 & 7,7 & 13,9 & 36 & 48 & 22 & 28 & 71 & 125 & 52,3 & 160 \\
\hline & I & 59 & 16 & 35 & 77 & 21 & 7 & 13 & 30 & 52 & 15 & 37 & 69 & & & \\
\hline \multirow[t]{2}{*}{ Cs } & V & 5 & 1,7 & 2,2 & 6,8 & 2 & 0,8 & 1 & 3,2 & 4 & 2 & 2 & 5,8 & 5,2 & & \\
\hline & I & 4,7 & 0,9 & 3,7 & 5,8 & 1,8 & 0,6 & 1,1 & 2,7 & 4,5 & 1,6 & 3,2 & 6,6 & & & \\
\hline \multirow[t]{2}{*}{$\mathrm{Eu}$} & V & 1,5 & 0,9 & 0,5 & 2,8 & 0,6 & 0,1 & 0,5 & 0,8 & 0,9 & 0,4 & 0,6 & 1,4 & 1,24 & & \\
\hline & I & 1,7 & 1,2 & 0,7 & 3,7 & 0,6 & 0,1 & 0,4 & 0,8 & 1,1 & 0,4 & 0,7 & 1,6 & & & \\
\hline \multirow[t]{2}{*}{$\mathrm{Fe}(\%)$} & V & 3,5 & 1,4 & 1,6 & 5,5 & 1,9 & 0,4 & 1,5 & 2,4 & 2,8 & 1,3 & 1,6 & 4,2 & & & \\
\hline & I & 3,7 & 1,2 & 2,2 & 5,7 & 1,7 & 0,3 & 1,3 & 2,1 & 3 & 1,1 & 2,1 & 4,5 & & & \\
\hline \multirow[t]{2}{*}{$\mathrm{Hf}$} & V & - & - & - & - & 2,7 & 0,9 & 1,2 & 4 & 3,7 & 1,3 & 2,2 & 5,3 & 6,3 & & \\
\hline & I & 4,1 & 1,2 & 2,9 & 5,5 & 2,4 & 1,2 & 1,1 & 4,5 & 3 & 0,5 & 2,3 & 3,4 & & & \\
\hline La & V & 43 & 26,8 & 15,6 & 81,6 & 15,5 & 4 & 10,2 & 21,3 & 27,7 & 11,7 & 15,1 & 40,6 & 32 & & \\
\hline
\end{tabular}


Tabela 5.20 Resultados obtidos das amostras de Santos - verão (V) e inverno (I) de 2006 - para os elementos analisados por NAA $\left(\mathrm{mg} \mathrm{kg}^{-1}\right)$ : média, desvio padrão, mínimo, máximo, valores do NASC, TEL e PEL (continuação)

\begin{tabular}{|c|c|c|c|c|c|c|c|c|c|c|c|c|c|c|c|c|}
\hline \multicolumn{2}{|c|}{ Elementos } & \multirow{2}{*}{\begin{tabular}{|c|} 
Média \\
46,5 \\
\end{tabular}} & \multirow{2}{*}{$\begin{array}{c}\text { Desvio } \\
\text { Padrão } \\
29,3\end{array}$} & \multirow{2}{*}{$\begin{array}{l}\text { min. } \\
\text { N.D. }\end{array}$} & \multirow{2}{*}{\begin{tabular}{|l|} 
max. \\
93,3 \\
\end{tabular}} & \multirow{2}{*}{\begin{tabular}{|c|} 
Média \\
14,5 \\
\end{tabular}} & \multirow{2}{*}{$\begin{array}{c}\text { Desvio } \\
\text { Padrão } \\
4,7\end{array}$} & \multirow{2}{*}{$\begin{array}{c}\text { min. } \\
8,7\end{array}$} & \multirow{2}{*}{$\begin{array}{c}\max . \\
21,6\end{array}$} & \multirow{2}{*}{$\begin{array}{l}\text { Média } \\
31,4\end{array}$} & \multirow{2}{*}{$\begin{array}{c}\begin{array}{c}\text { Desvio } \\
\text { Padrão }\end{array} \\
12,1\end{array}$} & \multirow{2}{*}{$\begin{array}{l}\text { min. } \\
20,5\end{array}$} & \multirow{2}{*}{$\begin{array}{c}\text { max. } \\
46,2\end{array}$} & \multirow[t]{2}{*}{ NASC } & \multirow[t]{2}{*}{ TEL } & \multirow[t]{2}{*}{ PEL } \\
\hline La & I & & & & & & & & & & & & & & & \\
\hline \multirow[t]{2}{*}{ Lu } & V & 0,1 & 0,1 & N.D. & 0,2 & 0,1 & N.D. & 0,1 & 0,2 & 0,3 & 0,1 & 0,1 & 0,4 & 0,5 & & \\
\hline & I & 0,3 & 0,1 & 0,2 & 0,4 & 0,1 & N.D. & 0,1 & 0,2 & 0,3 & 0,1 & 0,2 & 0,4 & & & \\
\hline \multirow[t]{2}{*}{$\mathrm{Na} \mathrm{( \% )}$} & V & 2,02 & 0,53 & 1,21 & 2,74 & 1,3 & 0,4 & 0,9 & 2 & 1,78 & 1,2 & 0,92 & 3,5 & & & \\
\hline & I & 2,07 & 0,45 & 1,46 & 2,51 & 1,17 & 0,23 & 0,78 & 1,45 & 1,99 & 0,82 & 1,28 & 3,11 & & & \\
\hline \multirow[t]{2}{*}{ Nd } & V & 59,9 & 55,7 & 20,8 & 166,7 & 11,6 & 6,6 & N.D. & 20,4 & 26,3 & 17,7 & 10,9 & 47,7 & 33 & & \\
\hline & I & 45,4 & 23 & 21 & 80,1 & 13,8 & 3,5 & 8,6 & 18,4 & 28,9 & 11,3 & 19,2 & 44,1 & & & \\
\hline \multirow[t]{2}{*}{$\mathbf{R b}$} & V & 82,7 & 26,1 & 56,1 & 124,7 & 67,5 & 12,2 & 48,1 & 80,9 & 59,6 & 28,3 & 33,9 & 91,9 & 125 & & \\
\hline & I & 84,7 & 25,8 & 55,4 & 128,5 & 60,9 & 9,3 & 46,3 & 72,5 & 60,8 & 21,5 & 42,2 & 88,2 & & & \\
\hline \multirow[t]{2}{*}{$\mathrm{Sb}$} & V & 0,6 & 0,2 & 0,3 & 0,9 & 0,2 & 0,2 & N.D. & 0,5 & 0,5 & 0,2 & 0,3 & 0,6 & & & \\
\hline & I & 0,6 & 0,1 & 0,4 & 0,8 & 1,1 & 1,9 & 0,2 & 4,9 & 0,6 & 0,3 & 0,4 & 1,2 & & & \\
\hline \multirow[t]{2}{*}{ Sc } & V & 9,6 & 3,2 & 4,5 & 13,1 & 4,2 & 1,6 & 2,2 & 6,4 & 8,4 & 3,7 & 4,8 & 12,3 & 15 & & \\
\hline & I & 10,4 & 2,7 & 6,5 & 13,2 & 3,6 & 1,4 & 2 & 5,5 & 9,1 & 3,1 & 6,5 & 13 & & & \\
\hline \multirow[t]{2}{*}{ Sm } & $\mathbf{V}$ & 6,6 & 3,8 & 2,4 & 12 & 2,2 & 1,2 & N.D. & 3,3 & 4,5 & 2 & 2,4 & 6,8 & 5,7 & & \\
\hline & I & 8 & 10,7 & N.D. & 29,5 & 2,7 & 0,4 & 2,3 & 3,1 & 1,8 & 2,1 & N.D. & 3,7 & & & \\
\hline \multirow[t]{2}{*}{$\mathrm{Ta}$} & V & - & - & - & - & 0,3 & 0,3 & N.D. & 0,8 & 0,7 & 0,5 & 0,3 & 1,1 & 1,1 & & \\
\hline & I & 0,5 & 0,8 & N.D. & 2,2 & 0,2 & 0,2 & N.D. & 0,4 & 0,8 & 0,3 & 0,5 & 1,1 & & & \\
\hline \multirow[t]{2}{*}{$\mathbf{T b}$} & V & 0,6 & 0,4 & 0,2 & 1,3 & 0,3 & 0,2 & N.D. & 0,5 & 0,6 & 0,4 & 0,2 & 1 & 0,9 & & \\
\hline & I & 1,1 & 1,7 & N.D. & 4,4 & 0,1 & 0,1 & N.D. & 0,2 & 0,7 & 0,1 & 0,6 & 0,9 & & & \\
\hline \multirow[t]{2}{*}{ Th } & $\mathbf{V}$ & 10,5 & 4,6 & 4,2 & 16,6 & 4,3 & 1,1 & 2,8 & 5,9 & 8,8 & 3,7 & 5 & 12,7 & 12 & & \\
\hline & I & 10,8 & 4 & 6,3 & 18 & 4,3 & 1,9 & 2,3 & 7,6 & 9,1 & 3,5 & 6 & 13,6 & & & \\
\hline \multirow[t]{2}{*}{$\mathbf{U}$} & V & 3,2 & 2,2 & 1,1 & 7,1 & 1,2 & 0,2 & 1 & 1,4 & 3,5 & 0,8 & 2,4 & 4,3 & 2,7 & & \\
\hline & I & 3 & 1,4 & 1,9 & 4,8 & 1,1 & 0,5 & 0,6 & 2 & 3,2 & 0,7 & 2,4 & 3,9 & & & \\
\hline $\mathrm{Yb}$ & V & 1,8 & 0,8 & 0,8 & 2,7 & 0,9 & 0,3 & 0,5 & 1,3 & 1,4 & 0,5 & 0,8 & 2 & 3,1 & & \\
\hline & I & 2,1 & 0,9 & 1,1 & 3,7 & 0,8 & 0,2 & 0,6 & 1,2 & 1,4 & 0,4 & 1 & 1,7 & & & \\
\hline $\mathrm{Zn}$ & $\mathbf{V}$ & 113 & 44 & 48 & 173 & 41,4 & 25,1 & N.D. & 66,8 & 109 & 57 & 57 & 176 & & 124 & 271 \\
\hline & I & 107 & 65 & N.D. & 177 & 36 & 14 & 21 & 53 & 108 & 59 & 63 & 190 & & & \\
\hline
\end{tabular}


Em geral, as concentrações de metais e elementos traço foram muito maiores na parte interna do estuário (área 1) e tenderam a apresentar valores menores na baía de Santos (área 2). Este padrão de distribuição está associado ao processo de deposição mais intenso na parte interna do estuário e a um maior processo de remobilização na baía de Santos.

Comparando-se os valores de As, $\mathrm{Cr}$ e $\mathrm{Zn}$ com os valores orientadores TEL e PEL da legislação Canadense e adotados pela CETESB, verificou-se que as amostras da área 1 (estações 01 a 06) excederam levemente os valores TEL para esses elementos (As - 7,24, Cr - 52,30, Zn $124 \mathrm{mg} \mathrm{kg}^{-1}$ ), com exceção da amostra 06 , entre os diferentes períodos avaliados.

Para as amostras da área 2, apenas os valores de concentração de As excederam os valores TEL $\left(7,24 \mathrm{mg} \mathrm{kg}^{-1}\right)$ em todos os pontos de coleta ( 07 a 10, 15 e 16), entre os diferentes períodos avaliados. Nos períodos de inverno dos anos de 2005 e 2006 as amostras 07 e 08 apresentaram valores inferiores ao limite TEL assim como os pontos SV0615 e SI0516. Para os metais $\mathrm{Cr}$ e Zn todos os resultados foram inferiores aos valores TEL. Para a área 3, a maioria dos valores de concentração de As, Cr e Zn estiveram abaixo dos valores TEL, e o ponto 14, em todos os períodos avaliados, excedeu os valores TEL para estes elementos. Os pontos SI0611, SV0611 e SI0613 localizados na área 3, excederam os limites de TEL para o As. O ponto SV0613 ultrapassou o limite TEL de As, Cr e Zn, e o SI0613 ultrapassou o limite TEL também para o Cr. Os valores de concentração obtidos para as amostras coletadas no inverno de 2005 foram, em geral, similares aos valores obtidos no verão, mas apresentaram-se em menores concentrações em alguns pontos.

Como pode ser observado, os valores médios de concentração para as três áreas são significativamente diferentes. Quando os resultados obtidos para as concentrações dos elementos determinados por NAA foram comparados com os valores NASC (North American Shale Composite), observou-se um leve enriquecimento de Elementos Terras Raras ( $\mathrm{La}, \mathrm{Ce}, \mathrm{Nd}$, Sm) e U para a área 1, conforme demonstrado na Figura 5.40. 


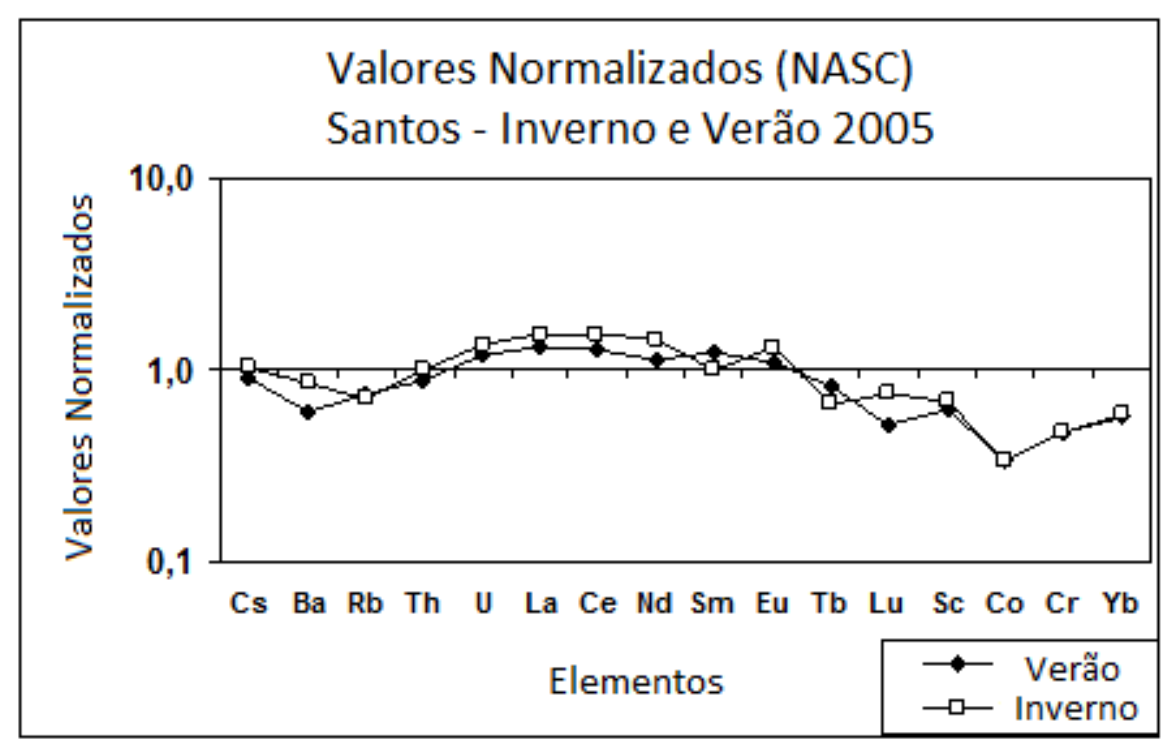

Figura 5.40 - Elementos normalizados pelo NASC para amostras de sedimento - Santos, inverno e verão de 2005 - Área 1

Isto se deve, provavelmente, à influência das fábricas de fertilizantes que foram exploradas ao longo das margens de alguns rios, que produziam um grande volume de fosfogesso, um subproduto da produção de ácido fosfórico, que são depositados em áreas de armazenamento nas proximidades, além de pilhas nas margens dos rios, de acordo com Oliveira et al (2007). Para as áreas 2 e 3, não foi possível observar esta influência.

Oliveira et al (2007), documentou em seu estudo que elementos terras raras (ETR) atuam como traçadores de contaminação de sedimentos por fosfogesso no estuário de Santos. As amostras contaminadas apresentaram uma composição afetada pelo fosfogesso, principalmente pela concentração mais alta dos elementos ETR, $\mathrm{Ba}, \mathrm{Zr}$ e Th e um grau mais forte de fracionamento dos ETR. Os autores também verificaram que o sinal da presença de fosfogesso diminui rapidamente corrente abaixo, apontando para uma área limitada de influência das pilhas.

Silva et al (2011) estudaram a distribuição de metais e elementos traço em testemunhos de sedimentos coletados na Baixada Santista com o objetivo de determinar os níveis basais da região para os elementos $\mathrm{As}, \mathrm{Br}, \mathrm{Cs}$, $\mathrm{Co}, \mathrm{Cr}, \mathrm{Fe}, \mathrm{Hf}, \mathrm{Rb}, \mathrm{Sb}, \mathrm{Sc}, \mathrm{Ta}, \mathrm{Zn}$ e ETR pela técnica de NAA. Foi encontrado 
enriquecimento para os ETR leves ( $\mathrm{La}, \mathrm{Ce}, \mathrm{Nd}, \mathrm{Sm}$ ), Th, $\mathrm{U}, \mathrm{Zn}$ e Hf para os testemunhos coletados na região de Cubatão.

Estas estações de coleta estão localizadas perto da região de Cubatão, uma área sob forte impacto causado pelas atividades industriais. O ponto 4 também recebe a influência do porto de Santos e apresentou maior concentração de As, Cr, Sb, Sc e Zn.

Em 2001, a CETESB apresentou em seu relatório que os valores de As atingiram 9,5 $\mathrm{mg} \mathrm{kg}^{-1}$, em um ponto próximo ao Lixão da Alemoa, e que apenas um único valor de As, na ponta do Itaipú, apresentou valor acima do limite TEL, possivelmente relacionado à disposição de sedimento contaminados dragados do canal de Santos, até 1974. Ainda segundo a CETESB, 2001, o As está presente em sedimentos do sistema estuarino e marinho com uma distribuição difusa, concentrando-se próximo às fontes industriais, locais de deposição de material dragado e do lixão da Alemoa.

\subsection{Fator de enriquecimento (FE) para os elementos determinados por NAA nos sedimentos}

Conforme já dito anteriormente, o Fator de Enriquecimento (FE) apresentado no item 4.11.2 é usualmente empregado para estimar impactos antropogênicos nos sedimentos, e no presente estudo, foi utilizado para avaliar o impacto com os elementos analisados por NAA.

Neste estudo, o FE foi calculado utilizando o Sc como elemento normalizador, e os valores de referência Upper Continental Crust (UCC) (WEDEPOHL, 1995) como valores de referência do "background" da região para os elementos analisados. Também se utilizou como valores de referência da região estudada, os valores de $\mathrm{As}, \mathrm{Ba}, \mathrm{Br}, \mathrm{Ce}, \mathrm{Co}, \mathrm{Cr}, \mathrm{Cs}$, Eu, $\mathrm{Fe}, \mathrm{Hf}, \mathrm{La}$, $\mathrm{Lu}, \mathrm{Nd}, \mathrm{Rb}, \mathrm{Sb}$, , Sm, Ta, Tb, Th, U, Yb, Zn e Sc (elemento normalizador) obtidos por Damatto (2010), nas análises de testemunhos das regiões de 
Cubatão (fatia de $72 \mathrm{~cm}$ de profundidade), São Vicente $(72 \mathrm{~cm}$ de profundidade) e da Baía de Santos (41 cm de profundidade) conforme apresentado na Tabela 5.21:

Tabela 5.21 - Valores obtidos ( $\mathrm{mg} \mathrm{kg}^{-1}$ ) por Damatto (2010), por NAA

\begin{tabular}{|c|c|c|c|}
\hline Elementos & $\begin{array}{c}\text { Perfil RO - } \\
\text { Santos } \\
\text { Cubatão-72 cm }\end{array}$ & $\begin{array}{c}\text { Perfil PO- São } \\
\text { Vicente - } 72 \\
\text { cm }\end{array}$ & $\begin{array}{l}\text { Perfil EM - Baía de } \\
\text { Santos - 41cm }\end{array}$ \\
\hline As & 10,5 & 7 & 9,8 \\
\hline $\mathrm{Ba}$ & 299 & 198 & 288 \\
\hline $\mathrm{Br}$ & 59,5 & 30,1 & 108 \\
\hline $\mathrm{Ce}$ & 107 & 38 & 50 \\
\hline Co & 10,9 & 3 & 6,9 \\
\hline $\mathrm{Cr}$ & 57 & 20 & 46 \\
\hline Cs & 6,7 & 1,9 & 3,17 \\
\hline Eu & 1,3 & 0,55 & 0,98 \\
\hline $\mathrm{Fe}(\%)$ & 4 & 1,29 & 2,37 \\
\hline $\mathrm{Hf}$ & 11,4 & 2,98 & 3,12 \\
\hline La & 44 & 15,6 & 28 \\
\hline Lu & 0,38 & 0,13 & 0,2 \\
\hline Nd & 37 & 14 & 34 \\
\hline $\mathbf{R b}$ & 112 & 37 & 55 \\
\hline Sb & 0,5 & 0,28 & 0,37 \\
\hline Sc & 11,4 & 4,03 & 6,72 \\
\hline Sm & 7,8 & 2,96 & 5,58 \\
\hline $\mathrm{Ta}$ & 2,35 & 0,38 & 0,49 \\
\hline $\mathrm{Tb}$ & 1,01 & 0,27 & 0,47 \\
\hline Th & 19,1 & 4,2 & 5,76 \\
\hline $\mathbf{U}$ & 9,5 & 3,85 & 0,84 \\
\hline $\mathrm{Yb}$ & 1,5 & 0,93 & 1,24 \\
\hline $\mathrm{Zn}$ & 93 & 32 & 55 \\
\hline $\begin{array}{l}\text { Área correspondente } \\
\text { ao presente estudo }\end{array}$ & Área 1 & Área 2 & Área 3 \\
\hline
\end{tabular}

As Tabelas 5.22 a 5.25 apresentam os resultados obtidos no cálculo do FE para as amostras coletadas no inverno e verão, 2005 e 2006, para os elementos determinados por NAA, utilizando-se como valores de referência, os dados de Damatto (2010). 
Tabela 5.2210: Fator de Enriquecimento das amostras coletadas no inverno de 2005, Santos, utilizando os dados obtidos por Damatto (2010), como valores de referência

\begin{tabular}{|c|c|c|c|c|c|c|c|c|c|c|c|c|c|c|c|c|c|c|c|c|c|c|c|}
\hline & & - & 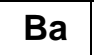 & $\mathrm{Br}$ & e & 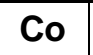 & 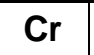 & 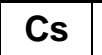 & $\mathbf{u}$ & $e(\%)$ & $\mathrm{Hf}$ & a & - & d & b & b & $\mathbf{m}$ & $a$ & b & $h$ & U & b & !n \\
\hline \multirow{6}{*}{ a 1} & & 90 & 5 & 4 & 1 & 5 & 3 & 8 & 7 & 34 & 0 & 91 & 37 & 22 & 85 & 59 & 94 & 97 & 97 & 87 & 63 & 32 & ,82 \\
\hline & 000 & & 4 & & 9 & & 3 & 9 & 8 & 1,07 & 7 & 59 & 18 & 60 & 06 & 43 & 37 & & 86 & 8 & 48 & 54 & , \\
\hline & & & 2 & & 5 & & 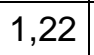 & & ( & & & 34 & 7 & 2 & 2 & 5 & & & & & 39 & 39 & 45 \\
\hline & SI05 & 21 & 34 & 0 & 0,67 & 1 & 1,03 & 9 & 0,9 & 94 & 35 & 0,83 & 0,95 & 0,95 & 0,73 & 1,67 & 33 & 27 & 77 & 59 & 32 & 19 & ,22 \\
\hline & & & 1 & & & & & & & 97 & & 82 & 98 & 67 & 78 &, 56 & & & 8 & 59 & 30 & 36 & 42 \\
\hline & 506 & 32 & 3,11 & 2,43 & 0,79 & 1,08 & 1,20 & 0,84 & 0,98 & 1,00 & 55 & 0,85 & 1,92 & 0,91 & 1,11 & & 0,51 & 0,58 & 48 & 0,58 &, 34 & 1,44 & , 19 \\
\hline \multirow{6}{*}{ Área 2} & & 38 & 3,85 & 0,51 & 1,49 & 0 & 0,92 & 1,07 & 1,43 & 8 & 98 &, 12 & 2,59 & 01 & 2,54 & 77 & 96 & 3 & 78 & 54 & 15 & 1,53 & 23 \\
\hline & & & 3 & & & & & & & 1,1 & 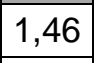 & 0,82 & & & 1,77 & & & & & & 1 & 1,19 & , \\
\hline & SI0509 & 29 & 5,54 & 0,48 & 1,47 & 2 & 0,95 & 1,21 & 1,37 & 1,89 & 24 & 0,99 & & 67 & 5,47 & 2,79 & 0,99 & ,32 & 76 & 41 & 84 & 1,54 & , 18 \\
\hline & SI0510 & 81 & 1,38 & 1,06 & 1,17 & & 0,73 & 1,26 & 1,0 & 0 & ,88 & 0,90 & & 60 & 1,62 & 2,10 & 0,75 & 1,24 & 96 & ,29 & 93 & , 10 & 45 \\
\hline & SI0515 & 4 & & 1,00 & 0,95 & 1,00 & 0,84 & 1,00 & 0,8 & 1,00 &, 74 & 0,73 & & 12 & 1,19 & & 0,57 & 1,71 & 54 & 06 &, 51 & 0,93 & 02 \\
\hline & & 59 & - & 7 & 1,48 & & & 7 & & 1,66 & 79 & 1,04 & - & 81 & 4,04 & - & 1,02 & 36 & 45 & 89 & 28 & 1,59 & 31 \\
\hline \multirow{4}{*}{ Área } & & - & $\begin{array}{l}- \\
\end{array}$ & 1,55 & 2,43 & 1,17 & 1,92 & 0,93 & 0,8 & 0,7 & 6,36 & 2,00 & - & .52 & 1,90 & 2,04 & 2,28 & 2,67 & 3,26 & 10,12 & 2,43 & 1,70 & ,92 \\
\hline & SI0512 & r & - & 1,43 & 0,94 & 1,05 & 1,15 & 1,19 & 1,0 & 0,99 & 0,93 & 1,02 & 2 & 0,90 & 1,10 & 1,23 & 0,89 & 13,93 & 0,57 & 1,03 &, 49 &, 95 & 93 \\
\hline & & & - & 2,12 & 1,70 & 1,00 & 2,64 & 0,89 & 0,7 & 0,9 & 6,19 & 1,92 & -5 & 2,73 & 0,84 & 1,81 & 1,47 & 1,70 & 1,27 & 2,49 & 0,92 & 1,36 & 0,94 \\
\hline & 10514 & 0,48 & - & 1,16 & 0,85 & 1,01 & 1,14 & 0,94 & 0,90 & 1,06 & 0,36 & 0,96 & -1 & 1,25 & 0,64 & 1,04 & 0,79 & 1,11 & 0,49 & 1,05 & 0,38 & 0,69 & 1,81 \\
\hline
\end{tabular}


Tabela 5.23: Fator de Enriquecimento das amostras coletadas no verão de 2005, Santos, utilizando os dados obtidos por Damatto (2010), como valores de referência

\begin{tabular}{|c|c|c|c|c|c|c|c|c|c|c|c|c|c|c|c|c|c|c|c|c|c|c|c|}
\hline Área & nostra & As & $\mathrm{Ba}$ & $\mathrm{Br}$ & $\mathrm{Ce}$ & Co & $\mathrm{Cr}$ & s & $\mathrm{Eu}$ & \%) & $\mathrm{Hf}$ & a & $\mathbf{u}$ & $\mathrm{Nd}$ & $\mathbf{R b}$ & $b$ & Sm & $\mathrm{Ta}$ & $b$ & Th & U & $\mathrm{Yb}$ & $\mathrm{Zn}$ \\
\hline \multirow{5}{*}{ Área 1} & SV0501 & 0,64 & 1,77 & 1,03 & 1,57 & 1,08 & 1,14 & 0,80 & 1,78 & 1,20 & 66 & 1,70 & 0,72 & 1,45 & 1,34 & 1,47 & 1,55 & 0,90 & 1,20 & 0,85 & 0,66 & 1,61 & 1,59 \\
\hline & SV0502 & 1,06 & 1,37 & 1,80 & 1,16 & 0,93 & 1,15 & 0,91 & 1,33 & 0,99 & 0,58 & 1,29 & 0,65 & 1,26 & 1,16 & 1,39 & 1,17 & 0,57 & 0,92 & 0,68 & 0,40 & 1,45 & 1,63 \\
\hline & SV0503 & 1,06 & 1,94 & 1,23 & 1,07 & 0,96 & 1,14 & 0,86 & 1,24 & 0,97 & 0,61 & 1,17 & 1,00 & 1,66 & 0,90 & 1,72 & 1,12 & 0,47 & 0,73 & 0,72 & 0,49 & 1,47 & 1,58 \\
\hline & SV0505 & 1,46 & 1,22 & 1,75 & 0,78 & 0,97 & 1,75 & 0,85 & 0,95 & 0,93 & 0,32 & 0,82 & 0,68 & 0,79 & 0,77 & 0,58 & 0,77 & 0,43 & 0,77 & 0,54 & 0,27 & 1,27 & 1,41 \\
\hline & SV0506 & 1,41 & 3,68 & 3,47 & 0,87 & 1,11 & 1,32 & 0,87 & 1,23 & 1,02 & 0,58 & 0,93 & 0,82 & 0,95 & 1,29 & 1,63 & 0,77 & 0,51 & 0,42 & 0,59 & 0,41 & 1,53 & 1,30 \\
\hline \multirow{2}{*}{ Área 2} & SV0509 & 3,04 & 4,52 & 0,67 & 1,34 & 1,49 & 0,99 & 1,15 & 1,76 & 1,93 & 1,51 & 1,00 & 1,16 & 1,27 & 2,35 & 1,88 & 0,89 & - & 1,13 & 1,49 & 1,97 & 1,52 & 1,32 \\
\hline & SV0510 & 0,91 & 1,41 & 0,66 & 0,96 & 0,99 & 1,02 & 1,02 & 0,98 & 0,97 & 1,41 & 0,72 & 0,84 & 0,60 & 1,16 & 1,07 & 0,60 & 1,44 & 1,10 & 1,13 & 2,14 & 1,06 & 1,00 \\
\hline \multirow{3}{*}{ Área 3} & SV0511 & 0,40 & 2,59 & 2,63 & 1,15 & 1,08 & 1,53 & 0,65 & 1,21 & 0,71 & 7,85 & 1,30 & 2,60 & 2,32 & 0,88 & 1,88 & 1,03 & 3,42 & 2,17 & 1,86 & 1,01 & 2,38 & 1,63 \\
\hline & SV0512 & 0,86 & 1,23 & 1,19 & 0,77 & 1,27 & 1,35 & 1,06 & 0,94 & 1,20 & 1,53 & 0,81 & 0,95 & 0,96 & 0,91 & 1,40 & 0,72 & 1,15 & 1,08 & 1,04 & 0,64 & 1,04 & 1,19 \\
\hline & SV0513 & 0,75 & 1,26 & 1,34 & 1,16 & 1,28 & 2,03 & 0,92 & 1,12 & 1,00 & 3,52 & 1,21 & 1,48 & 1,50 & 0,81 & 1,50 & 1,01 & 1,61 & 1,88 & 1,67 & 1,05 & 1,45 & 1,04 \\
\hline
\end{tabular}


Tabela 5.24: Fator de Enriquecimento das amostras coletadas no inverno de 2006, Santos, utilizando os dados obtidos por Damatto (2010), como valores de referência

\begin{tabular}{|c|c|c|c|c|c|c|c|c|c|c|c|c|c|c|c|c|c|c|c|c|c|c|c|}
\hline A & a & s & a & $\mathrm{Br}$ & $\mathrm{Ce}$ & 0 & C & Cs & Eu & 6) & $\mathrm{Hf}$ & La & Lu & d & $\mathbf{R b}$ & b & $\mathbf{n}$ & a & b & $h$ & U & $b$ & $n$ \\
\hline \multirow{6}{*}{ ea } & & & & -1 & 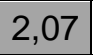 & & & & & & 39 & 33 & 36 & 37 & & & 3,27 & 79 & 75 & 81 & 44 & 12 & 34 \\
\hline & 0602 & 55 & 13 & 5 & 6 & 86 & & 9 & 6 & 95 & 45 & 53 & 33 & 55 & 59 & 10 & & & 41 & 52 & 47 & 48 & - \\
\hline & SI0603 & 17 & 43 & 15 & 91 & 97 & 20 & 84 & 08 & 96 & 64 & 91 &, 76 & 05 & 95 & 2,04 & 81 & & - & 64 & 30 & ,65 & .14 \\
\hline & S & 17 & & 5 & 31 & & & & 0,99 & 95 & 26 & 76 & 78 & 37 & 33 & 30 & & & & 56 & 21 & 10 & 37 \\
\hline & SI0605 & 1,16 & 68 & ,40 & 0,74 & 96 & 1,06 & 0,63 & 0,92 & 0,92 & 0,30 & 0,79 & 0,75 & 0,91 & 0,81 & 1,55 & 0,67 & 0,29 & 0,53 & 0,59 & 0,29 & 1,31 & 1,59 \\
\hline & & 2 & 3 & 0 & 76 & & 8 & 22 & 90 & & 45 & 79 & 01 & 99 & 86 & 54 &, 15 & & 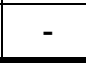 & 57 & 36 & ,33 & 10 \\
\hline \multirow{6}{*}{ Áre } & & 9 & 17 & 87 & 15 & 4 & 34 & 69 & 1,01 & & 90 & 01 & 1,18 & 61 & 65 &, 55 & & & &, 73 & 3,05 & 1,21 & 1,26 \\
\hline & S10608 & 1,17 & 36 &, 55 & 1,35 & ,31 & 0,93 & 1,25 & 1,41 & 43 & 1,56 & 1,06 & 2,19 & 1,13 & 2,75 & 1,58 & 1,04 & 1,53 & 0,93 & 1,35 & 2,09 & 1,48 & 1,27 \\
\hline & S10609 &, 59 & 18 & 67 & I,28 & 36 & ,95 & 1,15 & 1,28 & 81 & 1,17 & 1,02 & 2,64 & 1,09 & 2,77 & 2,05 & 1,52 & 1,01 & & , 32 & 2,24 & 1,51 & 1,25 \\
\hline & SI0610 & 0,88 & 71 & 0,84 & 0,96 & 0,93 & 0,82 & 1,06 & 0,83 & 0,94 & 1,18 & 0,81 & 0,62 & 0,55 & 1,32 & 1,23 & 0,68 & 0,95 & 0,16 & 1,13 & 2,07 & 0,97 & 1,12 \\
\hline & SI0615 & 1,77 & 30 & 0,53 & 1,34 & 1,40 & 0,83 & 1,08 & 1,29 & 1,59 & 1,57 & 1,03 & 1,41 & 0,96 & 2,56 & 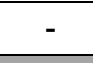 & 0,97 & & & 1,25 & 1,82 & 1,23 & 0,93 \\
\hline & SI0616 & 2,71 & 51 & 32 & 56 & 47 & 0,94 & 1,44 & 1,24 & 1,72 & 1,06 & ,02 & 1,28 & 0,59 & 2,47 & 53 & 0,98 & 1,38 & 60 & 43 & 2,67 & 1,24 & 1,48 \\
\hline \multirow{4}{*}{ Área } & 10 & 1,00 & 10 & 81 & 73 & 18 & 16 & 05 & 0,78 & & 0,48 & 82 & ,25 & 85 & ,71 & 11 & 0,75 & 1,10 & 29 & 90 & 45 &, 67 & 1,31 \\
\hline & SI0612 & 0,62 & 64 & 2,10 & 0,77 & 1,08 & 1,22 & 1,07 & 0,77 & 0,97 & 0,68 & 0,86 & 0,83 & 0,92 & 0,73 & 0,83 & 0,75 & 0,76 & 1,24 & 0,95 & 0,38 & 0,71 & 1,18 \\
\hline & SI0613 & 0,63 & 1,08 & 1,93 & 0,82 & 1,03 & 1,22 & 1,01 & 0,86 & 1,00 & 0,42 & 0,92 & 1,09 & 0,86 & 0,72 & 0,69 & - & 0,80 & 1,24 & 0,96 & 0,38 & 0,74 & 1,38 \\
\hline & SI0614 & 0,74 & 0,34 & 2,39 & \begin{tabular}{|l|}
0,84 \\
\end{tabular} & 1,06 & 1,07 & 1,08 & 0,91 & 1,07 & 0,34 & 0,92 & 0,69 & 0,98 & 0,74 & 1,28 & & 0,90 & 0,73 & 1,00 & 0,3 & 0,58 & 1,85 \\
\hline
\end{tabular}


Tabela 5.25: Fator de Enriquecimento das amostras coletadas no verão de 2006, Santos, utilizando os dados obtidos por Damatto (2010), como valores de referência

\begin{tabular}{|c|c|c|c|c|c|c|c|c|c|c|c|c|c|c|c|c|c|c|c|c|c|c|c|}
\hline Área & Amostra & As & $\mathrm{Ba}$ & $\mathrm{Br}$ & $\mathrm{Ce}$ & Co & $\mathrm{Cr}$ & Cs & Eu & $\mathrm{Fe}(\%)$ & $\mathrm{Hf}$ & La & Lu & Nd & $\mathbf{R b}$ & $\mathrm{Sb}$ & $\mathrm{Sm}$ & $\mathrm{Ta}$ & $\mathrm{Tb}$ & Th & U & $\mathrm{Yb}$ & $\mathrm{Zn}$ \\
\hline \multirow{6}{*}{ Área 1} & SV0601 & 0,95 & - & 3,11 & 1,53 & 0,92 & 1,06 & 0,89 & 1,87 & 1,19 & 0,42 & 1,62 & - & 3,93 & 0,97 & 1,62 & 1,34 & 1,55 & 0,81 & 0,76 & 0,65 & 1,48 & 1,63 \\
\hline & SV0602 & 0,75 & - & 2,06 & 1,49 & 0,94 & 1,18 & 0,90 & 1,77 & 1,06 & 0,54 & 1,49 & - & 1,88 & 0,85 & 1,15 & 1,26 & 0,07 & 1,19 & 0,72 & 0,42 & 1,68 & 1,41 \\
\hline & SV0603 & 0,98 & - & 2,14 & 0,81 & 0,91 & 1,43 & 0,82 & 1,09 & 0,95 & 0,48 & 0,86 & 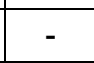 & 0,88 & 0,71 & 1,20 & 0,80 & 0,47 & 0,55 & 0,59 & 0,26 & 1,46 & 1,23 \\
\hline & SV0604 & 1,37 & 0,99 & 2,89 & 0,68 & 0,92 & 1,11 & 0,91 & 0,92 & 0,91 & 0,24 & 0,81 & 0,65 & 1,08 & 0,71 & 1,67 & 0,74 & 0,48 & 0,50 & 0,58 & 0,28 & 1,12 & 1,41 \\
\hline & SV0605 & 1,29 & 1,58 & 2,67 & 0,78 & 0,99 & 1,21 & 0,88 & 0,99 & 0,97 & 0,49 & 0,86 & 0,85 & 1,32 & 0,97 & 1,92 & 0,81 & 0,50 & 0,61 & 0,59 & 0,35 & 1,14 & 1,52 \\
\hline & SV0606 & 1,55 & 2,66 & 2,97 & 0,83 & 1,11 & 1,11 & 0,84 & 1,00 & 1,04 & 0,47 & 0,90 & 1,00 & 1,43 & 1,27 & 1,73 & 0,78 & 0,43 & 0,58 & 0,56 & 0,30 & 1,36 & 1,31 \\
\hline \multirow{6}{*}{ Área 2} & SV0607 & 1,23 & 2,63 & 1,14 & 1,17 & 1,20 & 0,80 & 1,09 & 1,11 & 1,32 & 1,30 & 0,97 & 1,41 & 0,54 & 1,88 & 1,91 & 0,92 & 1,35 & 0,40 & 1,25 & 2,47 & 1,14 & 1,34 \\
\hline & \begin{tabular}{|l|} 
SV0608 \\
\end{tabular} & 1,30 & 1,86 & 1,33 & 0,95 & 1,06 & 0,83 & 1,07 & 0,85 & 1,07 & 1,19 & 0,81 & 1,11 & 0,41 & 1,44 & 1,20 & - & 1,73 & 0,79 & 1,09 & 1,54 & 1,15 & 1,29 \\
\hline & SV0609 & 3,19 & 5,04 & 0,91 & 1,41 & 1,50 & 0,93 & 1,26 & 1,47 & 1,96 & 1,22 & 1,12 & 1,38 & - & 2,68 & - & 1,19 & - & 1,18 & 1,51 & 3,54 & 1,29 & 1,38 \\
\hline & SV0610 & 0,35 & 1,87 & 0,83 & 1,02 & 0,97 & 0,85 & 1,05 & 0,82 & 0,99 & 1,20 & 0,70 & 0,90 & 0,45 & 1,50 & 1,16 & 0,63 & 1,36 & 1,54 & 1,08 & 2,31 & 1,07 & 1,20 \\
\hline & SV0615 & 1,71 & 3,86 & 0,53 & 1,34 & 1,26 & 1,09 & 0,79 & 1,28 & 1,54 & 3,20 & 1,16 & 1,88 & 1,00 & 3,69 & 1,56 & 0,94 & - & & 1,40 & 3,31 & 1,40 & - \\
\hline & SV0616 & 1,26 & 1,68 & 1,42 & 0,88 & 1,05 & 0,82 & 0,88 & 0,82 & 1,18 & 1,02 & 0,83 & 0,79 & 0,79 & 1,82 & - & 0,69 & - & 1,13 & 1,12 & 1,89 & 0,87 & 1,51 \\
\hline \multirow{4}{*}{ Área 3} & SV0611 & 0,96 & 1,43 & 1,93 & 0,84 & 1,18 & 1,16 & 0,88 & 0,85 & 1,02 & 0,63 & 0,81 & 0,71 & 0,65 & 0,86 & 0,84 & 0,68 & 0,62 & 0,65 & 0,99 & 0,53 & 0,73 & 1,73 \\
\hline & SV0612 & 0,71 & 0,89 & 2,05 & 0,92 & 1,13 & 1,14 & 0,95 & 0,83 & 1,01 & 1,28 & 0,97 & 1,28 & 0,65 & 0,66 & 0,93 & 0,83 & 0,49 & 0,83 & 1,09 & 0,81 & 0,77 & 1,29 \\
\hline & SV0613 & 0,57 & 0,54 & 1,90 & 0,86 & 1,05 & 1,18 & 1,14 & 0,78 & 1,02 & 0,46 & 0,81 & 1,00 & 0,90 & 0,75 & 0,86 & 0,67 & 0,97 & 1,19 & 0,99 & 0,36 & 0,68 & 1,62 \\
\hline & SV0614 & 0,61 & 0,50 & 3,10 & 0,87 & 0,98 & 1,16 & 0,95 & 0,83 & 1,06 & 0,37 & 0,85 & 0,81 & 1,12 & 0,81 & 0,71 & 0,75 & 0,96 & 1,19 & 0,99 & 0,31 & 0,69 & 1,80 \\
\hline
\end{tabular}


Após a verificação dos dados obtidos no cálculo do FE, tomando-se por base os valores obtidos por Damatto (2010), foi possível identificar que as amostras da área 1, inverno de 2005, apresentaram FE>1,5 para $\mathrm{Ba}, \mathrm{Br}$ e Sb para a maioria dos pontos de coleta. Verificou-se ainda que na área 1, as amostras SI0501 e SI0502 apresentaram valores de FE > 1,5 para os elementos $\mathrm{Eu}, \mathrm{La}, \mathrm{Nd}$ e Zn e a amostra SI0502, para o Yb.

Nas amostras coletadas no verão de 2005, verificou-se que os elementos $\mathrm{Ba}, \mathrm{Br}, \mathrm{Sb}$ e $\mathrm{Zn}$ apresentaram valores de $\mathrm{FE}>1,5$ para ao menos 3 amostras da área 1 e as demais apresentaram valores próximos de 1,5.

Novamente, para os pontos coletados no inverno de 2006, observouse que na área 1, os elementos $\mathrm{Ba}, \mathrm{Br}, \mathrm{Sb}$ e $\mathrm{Zn}$ apresentaram valores de FE $>1,5$ para a maioria dos pontos. Os elementos $\mathrm{Ce}$, Eu, La e $\mathrm{Nd}$ também apresentaram FE>1,5 para as amostras SI0601 e SI0602.

Na comparação da área 1 com os valores descritos por Damatto ( 2010), observou-se que os elementos $\mathrm{Br}$ e Sb apresentam FE $>1,5$ para a maioria das amostras coletadas no verão de 2006, e que os elementos Eu e $\mathrm{Nd}$ apresentaram FE $>1,5$, para as amostras SV0601 e SV0602. A amostra SV0601 ainda apresentou índices indicativos de contaminação por origem antrópica para os elementos Ce, La, Sb, Ta e Zn.

$\mathrm{Na}$ área 2, as amostras coletadas no inverno de 2005, apresentaram FE $>1,5$ para a maioria das amostras, para os elementos $\mathrm{Rb}, \mathrm{Sb}$ e U. As amostras SI0507 à SI0509 apresentaram valores FE>1,5 para o $\mathrm{Ba}$, enquanto que as amostras SI0509 e SI0516 apresentaram FE>1,5 para o As, Fe, Tb e $\mathrm{Yb}$.

$\mathrm{Na}$ área 2, observou-se que o ponto SV0509 apresentou FE>1,5 para os elementos $\mathrm{As}, \mathrm{Ba}, \mathrm{Eu}, \mathrm{Fe}, \mathrm{Hf}, \mathrm{Rb}, \mathrm{Sb}, \mathrm{U}$ e $\mathrm{Yb}$, sendo este o ponto mais contaminado dessa área. $O$ elemento $U$ apresentou $F E>1,5$ em todas as amostras coletadas no verão e inverno de 2005 e inverno de 2006.

$\mathrm{Na}$ área 2, de uma maneira geral, verificou-se que os elementos As, $\mathrm{Ba}, \mathrm{Fe}, \mathrm{Hf}, \mathrm{Rb}, \mathrm{Sb}$ e U apresentaram FE>1,5. 
As amostras SI0511 e SI0513, situadas na área 3, apresentaram FE $>1,5$ para os elementos $\mathrm{Br}, \mathrm{Ce}, \mathrm{Cr}, \mathrm{Hf}, \mathrm{La}, \mathrm{Nd}, \mathrm{Sb}, \mathrm{Ta}$ e Th, indicando uma possível contaminação de origem antrópica nestas estações, na coleta realizada no inverno de 2005. Os elementos $U$ e Yb apresentaram FE $>1,5$ para a amostra SI0511.

Para as amostras coletadas no verão de 2006, verificou-se que na área 3, os elementos $\mathrm{Br}$ e $\mathrm{Zn}$ apresentaram $\mathrm{FE}>1,5$ para praticamente todas as amostras da área 3 (apenas a amostra SV0612 apresentou FE<1,5 para o Zn).

Foram calculados também os FE utilizando os valores de UCC (Upper Continental Crust) como valores de referência, para os elementos: As, $\mathrm{Ba}, \mathrm{Ca}, \mathrm{Ce}, \mathrm{Co}, \mathrm{Cr}, \mathrm{Cs}$, Eu, Fe, Hf, La, Lu, Na, Nd, Rb, Sb, Sm, Ta, Tb, Th, U, $\mathrm{Yb}$ e Zn. A Tabela 5.26 apresenta os valores de referência descritos por Wedepohl (1995).

Tabela 5.26: Valores do UCC (Upper Continental Crust) em mg kg-1

\begin{tabular}{c|c|c|c|c}
\hline Elemento & UCC & Elemento & UCC \\
\hline $\mathbf{A s}$ & 2 & $\mathbf{N a}$ & 25670 \\
\hline $\mathbf{B a}$ & 668 & $\mathbf{N d}$ & 25,9 \\
\hline $\mathbf{C a}(\%)$ & 2,945 & $\mathbf{R b}$ & 110 \\
\hline $\mathbf{C e}$ & 65,7 & $\mathbf{S b}$ & 0,31 \\
\hline $\mathbf{C o}$ & 11,6 & $\mathbf{S c}$ & 7 \\
\hline $\mathbf{C r}$ & 35 & $\mathbf{S m}$ & 4,7 \\
\hline $\mathbf{C s}$ & 5,8 & $\mathbf{T a}$ & 1,5 \\
\hline $\mathbf{E u}$ & 0,95 & $\mathbf{T b}$ & 0,50 \\
\hline $\mathbf{F e}(\%)$ & 3,089 & $\mathbf{T h}$ & 10,3 \\
\hline $\mathbf{H f}$ & 5,8 & $\mathbf{U}$ & 2,5 \\
\hline $\mathbf{L a}$ & 32,3 & $\mathbf{Y b}$ & 1,5 \\
\hline $\mathbf{L u}$ & 0,27 & $\mathbf{Z n}$ & 52 \\
\hline
\end{tabular}

As Tabelas 5.27 a 5.30 apresentam os resultados obtidos no cálculo do FE para as amostras coletadas no verão e inverno de 2005 e 2006, respectivamente. 
Tabela 5.27: Fator de Enriquecimento, utilizando os dados de UCC como valores de referência, para as amostras Inverno de 2005, Santos.

\begin{tabular}{|c|c|c|c|c|c|c|c|c|c|c|c|c|c|c|c|c|c|c|c|c|c|c|c|c|}
\hline 0 & stações & As & $\mathrm{Ba}$ & $\mathrm{Ca}$ & $\mathrm{Ce}$ & Co & $\overline{\mathrm{Cr}}$ & Cs & $\overline{E u}$ & $\mathrm{Fe}$ & $\mathrm{Hf}$ & La & Lu & $\mathrm{Na}$ & Nd & $\mathbf{R b}$ & $\mathrm{Sb}$ & $\mathrm{Sm}$ & $\mathrm{Ta}$ & $\mathrm{Tb}$ & Th & $\mathbf{U}$ & $\overline{Y b}$ & $\overline{Z n}$ \\
\hline \multirow{5}{*}{ 离 } & SI0501 & 2,9 & 0,5 & 0,3 & 1,9 & 0,5 & 1,2 & 0,6 & 1,9 & 1,1 & 0,5 & 1,6 & 0,8 & 0,4 & 1,9 & 0,5 & 1,6 & 1,0 & 0,9 & 1,2 & 1,0 & 1,5 & 0,8 & 2,0 \\
\hline & SI0502 & 1,9 & 0,4 & 0,2 & 1,5 & 0,5 & 1 & 0,6 & 1,5 & 0,9 & 0,6 & 1,3 & 1,0 & 0,3 & 1,4 & 0,7 & 1,4 & 9 & 0,7 & 1 & 9 & ,1 & ,9 & 1,7 \\
\hline & SI0503 & 3,6 & 0,6 & 0,4 & 0,7 & 0,3 & 1,2 & 0,6 & 0,8 & 0,8 & 0,7 & 0,8 & 1,0 & 0,5 & 1,1 & 0,6 & 1,7 & ,8 & 1,6 & 0,6 & 0,8 & 0,9 & ),9 & 1,6 \\
\hline & S10505 & 3,8 & 0,8 & 0,3 & 0,8 & 0,6 & 1,2 & 0,7 & 0,8 & 0,8 & 0,5 & 0,7 & 0,8 & 0,4 & 0,6 & 0,5 & 1,5 & 0,7 & 0,2 & 0,7 & 0,7 & 0,7 & 0,8 & 1,6 \\
\hline & SI0506 & 4,2 & 0,9 & 0,4 & 0,8 & 0,6 & 1,2 & 0,6 & 0,8 & 0,8 & 0,7 & 0,7 & 1,6 & 0,5 & 0 , & 0,7 & 0,4 & 0,5 & 0,6 & 6 & 7 & 8 &, 9 & 1,3 \\
\hline \multirow{5}{*}{ 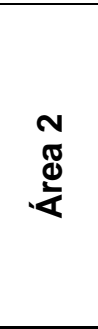 } & S10507 & 7,1 & 1,7 & 0,6 & 1,2 & 0,9 & 1,3 & 0,6 & 1,5 & 1,2 & 1,1 & 1,0 & 2,0 & 0,9 & 1,4 & 1,3 & 2,2 & 1,2 & 0,5 & 0,8 & 1,5 & 0,7 & 1,3 & 1,4 \\
\hline & SI0509 & 11,6 & 2,5 & 0,5 & 1,2 & 0,9 & 1,3 & 0,7 & 1,5 & 1,5 & 0,7 & 0,9 & 0,1 & 1,0 & 0,9 & 2,9 & 3,5 & 1,2 & 0,4 & 1,7 & 0,8 & 1,0 & 1,3 & 1,3 \\
\hline & SI0510 & 4,1 & 0,6 & 1,3 & 0,9 & 0,7 & 1,0 & 0,7 & 1,1 & 0,9 & 1,1 & 0,8 & 0,1 & 0,8 & 0,8 & 0,8 & 2,6 & 0,9 & 0,4 & 9 & 0,8 & 1,0 & 0,9 & 1,6 \\
\hline & SI0515 & 5,3 & 0,1 & 0,4 & 0,7 & 0,6 & 1,1 & 0,6 & 0,9 & 0,8 & 0,4 & 0,7 & 0,0 & 0,6 & 1,5 & 0,6 & 0,2 & 0,7 & 0,6 & 0,5 & 0,6 & 0,5 & 0,8 & 1,1 \\
\hline & SI0516 & 8,1 & 0,3 & 0,5 & 1,2 & 0,9 & 1,2 & 0,8 & 1,5 & 1,3 & 1,0 & 0,9 & 0,1 & 1,0 & 1,1 & 2,1 & 0,8 & 1,3 & 0,9 & 2,4 & 1,1 & 0,8 & 1,4 & 1,4 \\
\hline \multirow{2}{*}{ 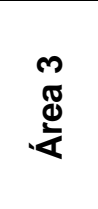 } & 10511 & 1,9 & 0,9 & 0,5 & 2,4 & 0,5 & 1,9 & 0,6 & 0,8 & 0,5 & 5,7 & 1,7 & 0,3 & 0,6 & 7 & 1,1 & 3,1 & 2,5 & 1,2 &, 1 & 7,2 & 6,5 & 1,8 & 1,0 \\
\hline & SI0512 & 5,4 & 0,2 & 4,3 & 0,9 & 0,5 & 1,1 & 0,7 & 1,0 & 0,7 & 0,8 & 0,9 & 0,1 & 0,4 & 0,8 & 0,6 & 1,9 & 1,0 & 6,1 &, 5 & 0,7 & 1,3 & 1,0 & 1,0 \\
\hline
\end{tabular}
$x$-valores com FE $>1,5$ 
Tabela 5.28: Fator de Enriquecimento, utilizando os dados de UCC como valores de referência, para as amostras Verão de 2005, Santos

\begin{tabular}{|c|c|c|c|c|c|c|c|c|c|c|c|c|c|c|c|c|c|c|c|c|c|c|c|c|}
\hline Cea & stações & As & $a$ & $\mathrm{Ca}$ & $\mathbf{e}$ & Co & $\mathrm{Cr}$ & s & $\mathbf{u}$ & e & $\mathrm{Hf}$ & La & Lu & $\mathrm{Ja}$ & $\mathrm{Nd}$ & $\mathbf{R b}$ & $\mathrm{Sb}$ & Sm & $\mathrm{Ta}$ & $\mathrm{Tb}$ & $T h$ & $\mathbf{U}$ & $\mathrm{Yb}$ & $\mathrm{Zn}$ \\
\hline \multirow{5}{*}{ 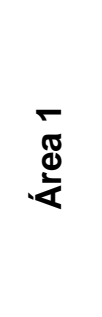 } & V0501 & 2,1 & 0,5 & 0,4 & 6 & 6 & 1 & 6 & 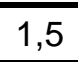 & 1,0 & 0,8 & 1,4 & 0,6 & ,3 & 3 & 0,8 & 1,4 & 1,6 & 0,9 & 1,5 & 1,0 & 5 & 1,0 & 1,7 \\
\hline & SV0502 & 3,4 & 4 & - & 2 & 5 & 1 & 0,6 & 1,1 & 0,8 & 0,7 & 1,1 & 0,6 & 4 & 1 & 0,7 & 1,4 & ,2 & 0,5 & 1,2 & 0,8 & 9 & ,9 & 1,8 \\
\hline & SV0503 & 3,4 & 0,5 & 0,3 & 1 & 0,6 & 4 & 0,6 & 1,0 & 0,8 & 0,7 & 1,0 & 0,9 & 0,4 & 1,5 & 0,6 & 1,7 & ,1 & 0,5 & 1,0 & 0,8 & 1 & 0,9 & 1,7 \\
\hline & SV0505 & 4,7 & 0,3 & 0,4 & 0,8 & 0,6 & 1,7 & 0,6 & 0,8 & 0,7 & 0,4 & 0,7 & 0,6 & 0,5 & 0,7 & 0,5 & 0,6 & 0,8 & 0,4 & 0,9 & 0,6 & 0,6 & 0,8 & 1,5 \\
\hline & SV0506 & 4,6 & 1,0 & 0,6 & 0,9 & 0,6 & 1,3 & 0,6 & 1,0 & 0,8 & 0,7 & 0,8 & 0,7 & 1,0 & 0,9 & 0,8 & 1,7 & 0,8 & 0,5 & 0,5 & 0,7 & 1,0 & 0,9 & 1,4 \\
\hline \multirow{3}{*}{$\begin{array}{l}\text { N } \\
\mathbb{d} \\
\text { 这 }\end{array}$} & V0507 & 4,8 & 0,8 & 1,3 & 0,9 & 0,7 & 1,2 & 0,6 & 1,1 & 0,9 & 0,8 & 0,7 & 0,8 & 0,6 & 0,8 & 0,8 & 1,4 & 0,9 & 0,6 & 1,3 & 0,7 & 1,2 & 1,0 & 1,3 \\
\hline & SV0509 & 15,5 & 2,0 & 1,1 & 1,1 & 0,9 & 1,4 & 0,7 & 1,9 & 1,5 & 0,8 & 0,9 & 0,9 & 1,1 & 1,8 & 1,2 & 2,4 & 1,1 & - & 1,1 & 0,9 & 0,7 & 1,3 & 1,5 \\
\hline & SV0510 & 4,7 & 0,6 & 0,9 & 0,8 & 0,6 & 1,4 & 0,6 & 1,1 & 0,8 & 0,8 & 0,7 & 0,6 & 0,6 & 0,8 & 0,6 & 1,3 & 0,8 & 0,5 & 1,1 & 0,7 & 0,8 & 0,9 & 1,1 \\
\hline \multirow{4}{*}{ 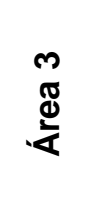 } & SV0511 & 2,4 & 1,3 & 1,0 & 1,1 & 0,5 & 1,5 & 0,4 & 1,2 & 0,5 & 7,0 & 1,1 & 2,2 & 1,0 & 2,1 & 0,5 & 3,0 & 1,1 & 1,5 & 2,0 & 1,3 & 2,8 & 2,5 & 1,7 \\
\hline & SV0512 & 5,3 & 0,6 & 1,5 & 0,8 & 0,6 & 1,4 & 0,6 & 1,0 & 0,9 & 1,4 & 0,7 & 0,8 & 0,4 & 0,9 & 0,5 & 2,2 & 0,8 & 0,5 & 1,0 & 0,8 & 1,8 & 1,1 & 1,3 \\
\hline & SV0513 & 4,5 & 0,6 & 2,6 & 1,1 & 0,6 & 2,0 & 0,5 & 1,1 & 0,7 & 3,1 & 1,0 & 1,2 & 0,5 & 1,4 & 0,5 & 2,3 & 1,1 & 0,7 & 1,7 & 1,2 & 2,7 & 1,5 & 1,1 \\
\hline & SV0514 & 3,1 & 0,4 & 0,2 & 0,9 & 0,5 & 1,2 & 0,6 & 0,9 & 0,8 & - & 0,8 & 0,7 & 0,4 & 0,9 & 0,4 & 1,6 & 0,8 & - & 0,7 & 0,7 & 0,9 & 0,8 & 1,9 \\
\hline
\end{tabular}

$x$ - valores com FE $>1,5$ 
Tabela 5.29: Fator de Enriquecimento, utilizando os dados de UCC como valores de referência, para as amostras Inverno de 2006, Santos

\begin{tabular}{|c|c|c|c|c|c|c|c|c|c|c|c|c|c|c|c|c|c|c|c|c|c|c|c|c|}
\hline Área & stações & As & $\mathrm{Ba}$ & $\mathrm{Ca}$ & $\mathrm{Ce}$ & Co & $\mathrm{Cr}$ & Cs & Eu & $\mathrm{Fe}$ & Hf & $-a$ & Lu & $\mathrm{Na}$ & Nd & $\mathbf{R b}$ & $\mathrm{Sb}$ & $\mathrm{Sm}$ & $\mathrm{Ta}$ & $\mathrm{Tb}$ & Th & $\mathbf{U}$ & $\mathrm{Yb}$ & $\mathrm{Zn}$ \\
\hline \multirow{5}{*}{$\begin{array}{l}\overline{\mathbb{d}} \\
\bar{d}\end{array}$} & SI0601 & 0,4 & 0,5 & 0,2 & 2,1 & 0,5 & 1,2 & 0,5 & 2,1 & 1,0 & 0,5 & 1,5 & 0,7 & 0,5 & 1,6 & 0,6 & 1,0 & 3,3 & 0,8 & 4,7 & 0,9 & 1,0 & 1,3 & 1,8 \\
\hline & S10602 & 5,3 &, 6 &, 2 & 1,6 & 0,5 & 1 & 0,6 & 1,5 & 0,8 & 0,5 & 1,3 & 0,9 &, 5 & ,4 & 4 & 4 & & 0,1 & 1,7 &, 6 & 1 &, 9 & \\
\hline & S10603 & 3,8 & 0,7 & 0,4 & 0,9 & 0,6 & 1,2 & 0,6 & 0,9 & 0,8 & 0,8 & 0,8 & 0,7 & 0,5 & 0,9 & 0,6 & 2,0 & 0,9 & 0,2 & 0,6 & 0,7 & 0,7 & 1,0 & 2,4 \\
\hline & S10605 & 3,8 & 0,2 & 0,4 & 0,7 & 0,6 & 1,1 & 0,4 & 0,8 & 0,7 & 0,4 & 0,7 & 0,6 & 0,6 & 0,8 & 0,5 & 1,5 & 0,7 & 0,3 & 0,7 & 0,7 & 0,7 & 0,8 & 1,7 \\
\hline & S10606 & 4,9 & 0,6 & 0,6 & 0,8 & 0,7 & 1,1 & 0,7 & 0,8 & 0,8 & 0,5 & 0,7 & 0,9 & 0,7 & 0,9 & 0,5 & 1,5 & 0,8 & 0,2 & 0,6 & 0,7 & 0,8 & 0,8 & 1,2 \\
\hline \multirow{5}{*}{$\begin{array}{l}\text { N } \\
\mathbb{\mathbb { J }} \\
\stackrel{\mathbb{d}}{\mathbf{L}}\end{array}$} & 10607 & 3,5 & 1,0 & 0,7 & 0,9 & 0,5 & 1,1 & 0,4 & 1,1 & 0,9 & 1,1 & 0,9 & 0,9 & 0,8 & 0,8 & 0,9 & 1,9 & 0,9 & 0,3 & 0,8 & 1,0 & 1,1 & 1,0 & 1,4 \\
\hline & S10609 & 13,2 & 2,3 & 1,4 & 1,0 & 0,8 & 1,3 & 0,7 & 1,4 & 1,4 & 0,7 & 0,9 & 2,0 & 1,0 & 1,5 & 1,4 & 2,5 & 1,9 & 0,3 & 2,1 & 0,8 & 0,8 & 1,3 & 1,4 \\
\hline & SI0610 & 4,5 & 0,8 & 0,6 & 0,8 & 0,6 & 1,1 & 0,6 & 0,9 & 0,8 & 0,7 & 0,7 & 0,5 & 0,6 & 0,7 & 0,7 & 1,5 & 0,8 & 0,3 & 0,2 & 0,7 & 0,7 & 0,8 & 1,2 \\
\hline & SI0615 & 9,1 & 1,9 & 0,5 & 1,1 & 0,9 & 1,1 & 0,6 & 1,4 & 1,3 & 0,9 & 0,9 & 1,1 & 1,1 & 1,3 & 1,3 & - & 1,2 & 0,6 & 1,5 & 0,7 & 0,6 & 1,1 & 1,0 \\
\hline & SI0616 & 13,9 & 1,6 & 0,6 & 1,2 & 0,9 & 1,3 & 0,8 & 1,3 & 1,4 & 0,6 & 0,9 & 1,0 & 1,1 & 0,8 & 1,3 & 4,3 & 1,2 & 0,5 & 0,6 & 0,8 & 0,9 & 1,1 & 1,6 \\
\hline \multirow{2}{*}{ 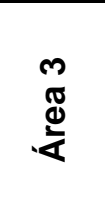 } & SI0611 & 6,1 & 0,6 & 1,2 & 0,7 & 0,5 & 1,1 & 0,6 & 0,8 & 0,7 & 0,4 & 0,7 & 1,0 & 0,6 & 0,8 & 0,4 & 1,7 & 0,8 & 0,5 & 1,2 & 0,6 & 1,2 & 0,7 & $\overline{1,4}$ \\
\hline & SI0612 & 3,7 & 0,3 & 0,8 & 0,8 & 0,5 & 1,2 & 0,6 & 0,8 & 0,7 & 0,6 & 0,7 & 0,7 & 0,5 & 0,9 & 0,4 & 1,3 & 0,8 & 0,3 & 1,2 & 0,7 & 1,0 & 0,8 & 1,3 \\
\hline
\end{tabular}
$x-$ valores com FE $>1,5$ 
Tabela 5.30: Fator de Enriquecimento, utilizando os dados de UCC como valores de referência, para as amostras Verão de 2006, Santos

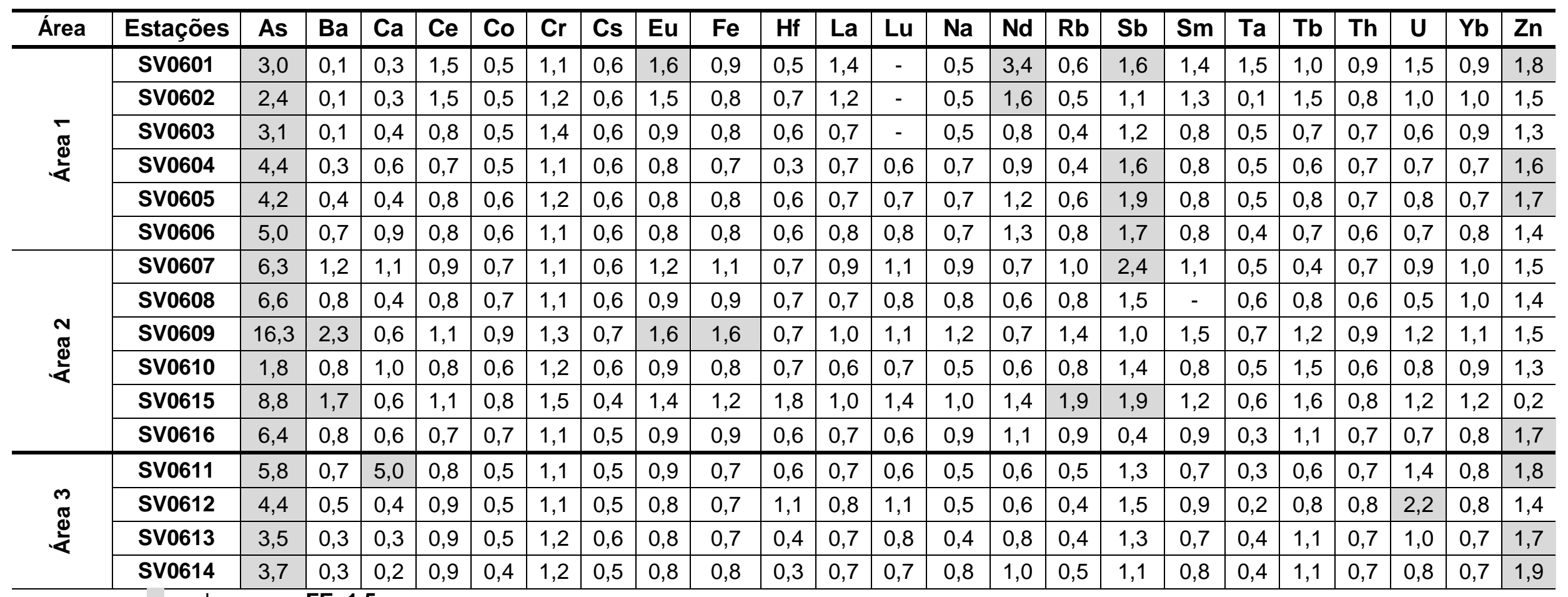
$x$ - valores com FE $>1,5$ 
$\mathrm{Na}$ avaliação dos resultados obtidos para o FE, foi possível identificar que todas as amostras analisadas nos diferentes períodos, com exceção da amostra SI0601, apresentaram valores de FE>1,5 para As, o que indicaria uma contribuição de origem antrópica. Entretanto ao comparar estes dados com os valores de background da região, descritos por Damatto, 2010, podemos verificar que a região já possui naturalmente um teor elevado de As.

Para o Ba, verificou-se FE $>\mathbf{1 , 5}$ para as amostras: SI0507, SI0509, SV0509, SI0608, SI0609, SI0615, SI0616, SV0609 e SV0615. Observou-se ainda que o ponto 09 apresentou $\mathrm{FE}>1,5 \mathrm{em}$ todos os períodos avaliados.

O Ca apresentou valores FE $>1,5$ para as amostras SI0512, SV0513 e SV0611.

O Ce apresentou FE $>1,5$ para as amostras SV0501, SI0501, SI0511, SI0513, SI0601 e SI0602. As amostras SV0601 e SV0602 apresentaram valor de $F E=1,5$, o que reforça a possibilidade dos pontos $01 \mathrm{e}$ 02 terem sofrido impactos de origem antrópica.

Para o Cr, apenas algumas amostras do período de 2005 apresentaram FE>1,5: SI0511, SI0513, SV0505, SV0511 e SV0513.

O Eu apresentou valores de FE $>1,5$ para as amostras SI0501, SI0507, SI0516, SV0509, SI0608, SV0601 e SV0609.

O Fe apresentou uma tendência a valores que sugerem influência no ponto 9, nos quais as amostras SI0509, SV0509, SI0609 apresentaram FE=1,50 e a amostra SV0609, apresentou valor de 1,6.

O Hf sugere que os pontos SI0511, SI0513, SV0511, SV0513 e SV0615 tenham sofrido impacto de origem antrópica (FE>1,5).

O La apresentou valores de FE $>1,5$ para as amostras SI0501, SI0511, SI0513 e SI0601, valores que se confirmaram com os valores de FE calculados com os dados de background descritos por Damatto (2010). 
Para o Lu, verificaram-se valores de FE $>1,5$ para as amostras SI0506, SI0507, SV0511, SI0608 e SI0609.

Para $\circ$ Nd, verificaram-se valores de $\mathrm{FE}>\mathbf{1 , 5}$ para as amostras SI0501, SI0511, SI0513, SI0515, SV0509, SV0511, SI0601, SI0608, SV0601 e SV0602.

Para o Rb, apenas as amostras SI0509, SI0516 e SV0615 apresentaram valores de $\mathrm{FE}>\mathbf{1 , 5}$.

Para os resultados obtidos para o $\mathbf{S b}$, verificou-se que a maioria das amostras apresentaram valores de $F E>1,5$, o que pode sugerir que a região foi afetada com a inclusão deste elemento por fontes antrópicas.

O Sm apresentou valores de FE $>1,5$ para as amostras SI0511, SI0513, SV0501, SI0601 e SI0609.

O Ta apresentou valores de FE $>1,5$ para as amostras SI0503, SI0512 e SV0511.

Em relação ao $\mathbf{T b}$, valores de $\mathbf{F E}>\mathbf{1 , 5}$ foram encontrados para as amostras SI0509, SI0511, SI0516, SV0501, SV0511, SV0513, SI0601, SI0602, SI0609, SV0610 e SV0615.

O Th apresentou valores de $\mathrm{FE}>1,5$ que sugerem alterações de níveis antrópicos nos pontos SI0511 e SI0513.

Para o U, verificaram-se valores de $\mathrm{FE}>\mathbf{1 , 5}$ para as amostras SI0511, SI0513, SV0501, SV0511, SV0512, SV0513, SV0601 e SV0612.

O Yb apresentou valores de FE>1,5 para as amostras SI0511, SV0511 e SV0513.

Nos resultados obtidos para o $\mathbf{Z n}$, observou-se que diversas amostras apresentaram valores de FE $>1,5$, o que sugere alterações antrópicas nas áreas estudadas. 
Ao se comparar os FE obtidos utilizando os valores de referência UCC com os FE calculados com os valores descritos por Damatto, 2010, observou-se que as amostras da área 2, principalmente, apresentaram diferenças em relação ao As. No FE calculado com os dados UCC, todas as amostras (áreas 1, 2 e 3) apresentaram valores de FE $>1,5$ para As. Entretanto, quando comparado com os valores obtidos por Damatto, 2010, principalmente as estações 09, 15 e 16, localizadas na área 2, apresentaram FE>1,5. Esse fato sugere que a região parece apresentar níveis mais elevados de As, provenientes de origem natural.

Em relação aos elementos terras raras, $\mathrm{Ce}, \mathrm{Eu}, \mathrm{La}, \mathrm{Nd}$, em geral, verificou-se que as estações 01, 02 e 11 (2005) apresentaram valores de FE $>1,5$ nos dois casos, com os dados de Damatto (2010) e com os valores de UCC. Conforme discutido anteriormente, provavelmente devido à influencia das pilhas de fosfogesso.

$\mathrm{O} \mathrm{Sb}$ apresentou, de maneira geral, valores de $\mathrm{FE}>1,5$ em todas as áreas em 2005 e áreas 1 e 2, em 2006. Os elementos Rb e U apresentaram valores de $\mathrm{FE}>1,5$ em praticamente todas as estações da área 2 ao se comparar com os dados de FE obtidos por Damatto, 2010. Entretanto, na comparação com os valores UCC, tal fato não foi observado supondo, portanto, que a região possuía níveis inferiores de $\mathrm{Rb}$ na região, e que ocorreu enriquecimento por origem antrópica deste elemento na área 2.

O Zn apresentou nos dois casos, tanto na comparação com os valores de Damatto (2010) quanto aos valores de UCC, níveis que indicam contaminações de origem antrópica nas áreas 1 e 3, principalmente para as amostras coletadas no verão de 2005. 


\subsection{Comparação de valores de concentração obtidos por} meio de diferentes técnicas analíticas

Comparando-se os valores de concentração dos elementos determinados por ICP OES (concentração potencialmente disponível para a coluna d'água - obtida por extração com $\mathrm{HNO}_{3 \text { (conc) }}$ em sistema de microondas) e por NAA (concentração total), é possível estimar a relação $(R)$ entre as concentrações potencialmente disponíveis para a coluna d'agua (obtida com

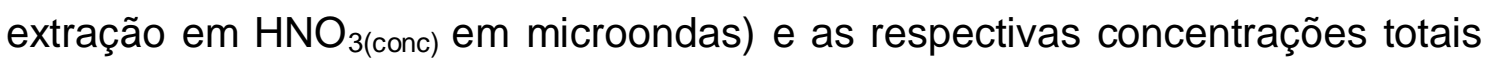
obtidas para cada elemento, conforme a equação 5.1 :

\section{(Equação 5.1)}

Onde:

$R(\%)$ - relação percentual entre as concentrações potencialmente disponíveis para a coluna d'água $x$ concentrações totais

$\mathrm{C}_{\text {pot.disp }}$ - Concentração potencialmente disponível para a coluna d'água (obtida por extração com $\mathrm{HNO}_{3(\mathrm{conc})}$ em microondas, com posterior determinação em ICP OES), em $\mathrm{mg} \mathrm{kg}^{-1}$

$\mathrm{C}_{\text {total }}$ - Concentração total (obtida por NAA), em mg kg ${ }^{-1}$

A Tabela 5.31 apresenta os valores calculados das relações (R) entre a concentração potencialmente disponível e respectiva concentração total dos elementos $\mathrm{Ba}, \mathrm{Co}, \mathrm{Cr}$, $\mathrm{Fe}$ e $\mathrm{Zn}$, das amostras coletadas na região de Santos, Inverno e verão de 2005. 
Tabela 5.31: Relação (\%) entre a concentração potencialmente disponível para a coluna d'água (ICP OES) e concentração total (NAA), Santos, Inverno e Verão de 2005

\begin{tabular}{c|c|c|c|c|c|c|c|c|c|c|c|c}
\hline Inverno/2005 & \multicolumn{3}{|c|}{ Relação (\%) NAA x ICP } & & \multicolumn{4}{|c}{ Verão/2005 } & \multicolumn{4}{|c}{ Relação (\%) NAA x ICP } \\
\hline Amostra & Ba & Co & Cr & Fe & Zn & & Amostra & Ba & Co & Cr & Fe & Zn \\
\hline SI0501 & 39 & 77 & 63 & 100 & 80 & & SV0501 & 24 & 59 & 56 & 54 & 70 \\
\hline SI0502 & 27 & 73 & 57 & 98 & 70 & & SV0502 & 27 & 75 & 60 & 115 & 73 \\
\hline SI0503 & 8 & - & 58 & 106 & 77 & & SV0503 & 12 & 69 & 54 & 98 & 69 \\
\hline SI0504 & 20 & 71 & 67 & 113 & 82 & & SV0504 & 17 & 68 & 54 & 108 & 68 \\
\hline SI0505 & 6 & 61 & 52 & 100 & 65 & & SV0505 & 17 & 74 & 40 & 114 & 77 \\
\hline SI0506 & 5 & 75 & 58 & 70 & 88 & & SV0506 & 6 & 75 & 56 & 66 & 74 \\
\hline SI0507 & 1 & 61 & 53 & 60 & 68 & & SV0507 & 9 & 68 & 59 & 115 & 65 \\
\hline SI0508 & 3 & 61 & 48 & 57 & 71 & & SV0508 & 13 & 69 & 65 & 118 & 77 \\
\hline SI0509 & 1 & 88 & 80 & 83 & 97 & & SV0509 & 2 & 75 & 70 & 72 & 75 \\
\hline SI0510 & 9 & 82 & 82 & 75 & 70 & & SV0510 & 5 & 61 & 39 & 53 & 77 \\
\hline SI0511 & 9 & - & 33 & 69 & 85 & & SV0511 & 3 & - & 23 & 36 & 26 \\
\hline SI0512 & - & 70 & 57 & 63 & 66 & & SV0512 & 7 & 62 & 44 & 45 & 57 \\
\hline SI0513 & - & 77 & 28 & 70 & 105 & & SV0513 & 5 & 63 & 31 & 52 & 58 \\
\hline SI0514 & - & 75 & 68 & 89 & 72 & & SV0514 & 13 & 69 & 61 & 109 & 77 \\
\hline SI0515 & - & 74 & 64 & 88 & 83 & & - & - & - & - & - & - \\
\hline SI0516 & - & 71 & 80 & 74 & 80 & & - & - & - & - & - & - \\
\hline
\end{tabular}

Podemos observar a partir dos dados da Tabela 5.31, que a maioria das amostras apresentou relações acima de $50 \%$ para os elementos $\mathbf{C o}, \mathbf{C r}$, Fe e Zn, o que indica que estes elementos estão presentes, em sua maioria, nas formas potencialmente disponíveis para a coluna d'água. Algumas amostras apresentaram valores um pouco acima de $100 \%$ para o Fe e podem ser considerados adequados até $120 \%$, conforme critério de aceitação dos valores obtidos pela técnica de ICP OES, a qual é susceptível a erros de diluição, entre outros. Estes valores são indicativos de que 100\% do elemento presente está na forma potencialmente disponível.

A Tabela 5.32 apresenta os valores calculados de $\mathrm{R}$ para os elementos $\mathbf{B a}, \mathbf{C o}, \mathbf{C r}, \mathbf{F e}$ e $\mathbf{Z n}$, para as amostras coletadas na região de Santos, Inverno e verão de 2006. 
Tabela 5.32: Relação (\%) entre a concentração potencialmente disponível para a coluna d'água (ICP OES) e concentração total (NAA), Santos, Verão e Inverno de 2006

\begin{tabular}{c|c|c|c|c|c|c|c|c|c|c|c|c}
\hline Inverno/2006 & \multicolumn{3}{|c|}{ Relação (\%) NAA x ICP } & & Verão/2006 & \multicolumn{3}{|c}{ Relação (\%) NAA x ICP } \\
\hline Amostra & Ba & Co & Cr & Fe & Zn & & Amostra & Ba & Co & Cr & Fe & Zn \\
\hline SI0601 & 40 & 76 & 67 & 79 & 75 & & SV0601 & - & 79 & 67 & 77 & 80 \\
\hline SI0602 & 22 & 87 & 68 & 105 & - & & SV0602 & - & 74 & 54 & 72 & 72 \\
\hline SI0602a & 21 & 66 & 57 & 85 & 53 & & SV0602a & - & 80 & 58 & 77 & 74 \\
\hline SI0603 & 9 & 88 & 60 & 79 & 45 & & SV0603 & - & 81 & 46 & 75 & 74 \\
\hline SI0604 & 21 & 65 & 51 & 80 & 65 & & SV0604 & 22 & 81 & 66 & 82 & 67 \\
\hline SI0605 & 39 & 72 & 74 & 96 & 64 & & SV0605 & 10 & 113 & 67 & 80 & 71 \\
\hline SI0606 & 10 & 68 & 69 & 92 & 79 & & SV0606 & 3 & 53 & 39 & 50 & 57 \\
\hline SI0607 & 5 & 97 & 59 & 84 & 59 & & SV0607 & 2 & 68 & 56 & 74 & 71 \\
\hline SI0608 & 2 & 68 & 59 & 70 & 71 & & SV0608 & 4 & 78 & 59 & 76 & 67 \\
\hline SI0609 & 1 & 61 & 58 & 70 & 67 & & SV0609 & 1 & 84 & 79 & 89 & 78 \\
\hline SI0610 & 9 & 77 & 69 & 97 & 73 & & SV0610 & 5 & 94 & 64 & 86 & 76 \\
\hline SI0611 & 11 & 69 & 62 & 94 & 69 & & SV0611 & 7 & 82 & 58 & 74 & 43 \\
\hline SI0612 & 18 & 76 & 58 & 87 & 79 & & SV0612 & 9 & 80 & 54 & 70 & 59 \\
\hline SI0613 & 8 & 87 & 55 & 83 & 79 & & SV0612a & 4 & 87 & 32 & 62 & 88 \\
\hline SI0614 & 28 & 83 & 68 & 83 & 68 & & SV0613 & 15 & 81 & 54 & 75 & 67 \\
\hline SI0615 & 2 & 81 & 71 & 83 & 103 & & SV0614 & 25 & 94 & 67 & 89 & 73 \\
\hline SI0616 & 2 & 76 & 77 & 82 & 80 & & SV0615 & 1 & 76 & 46 & 73 & - \\
\hline- & - & - & - & - & - & & SV0616 & 4 & 85 & 65 & 80 & 65 \\
\hline
\end{tabular}

Assim como para as amostras coletadas em 2005, podemos observar que os elementos $\mathbf{C o}, \mathbf{C r}$, Fe e $\mathbf{Z n}$ apresentaram altos teores de fração potencialmente disponível (ataque com $\mathrm{HNO}_{3}$ em microondas) nas amostras coletadas nos períodos do inverno e verão de 2006. O elemento Ba, de acordo com os resultados obtidos, está presente nas amostras na fração total, que correspondem as frações ligadas à sílica.

\subsection{Análise de Agrupamento - Considerações Finais}

A Figura 5.41 apresenta os dendrogramas considerando-se todos os dados químicos (dados de NAA, ICP OES e AAS), granulometria, (silte+argila, areia) $\mathrm{MO} \mathrm{e} \mathrm{CaCO}_{3}$ referente às amostras coletadas em Santos, verão e inverno de 2005 (35 variáveis, 14 amostras no verão e 16 no inverno). 
As estações 01 a 05 e 14 formaram um grupo separado (a) em ambas as figuras. No inverno, as estações 15 e 16 se uniram a esse grupo e no verão, a estação 08 . O outro grupo (b) formou-se por 2 importantes subgrupos: estações $(07,10$ e 12) e $(06,09,11$ e 13) para as amostras do verão. O grupo (a) em ambos os casos (inverno e verão) foi formado pelas estações que apresentaram uma concentração mais alta principalmente para os metais (Tabela 5.7) e elementos terras raras (ETR), U, Th (Tabela 5.19). O grupo (b) no verão foi formado por 2 sub-grupos constituídos por concentrações intermediárias para os elementos analisados (estações 07, 10 e 12) e concentrações mais baixas para as estações 06, 09, 11 e 13. O grupo (b) para as amostras do inverno foi formado pelas mesmas estações, mas sem uma separação nítida entre os sub-grupos como no caso do verão.

Esses resultados também mostraram que existem ligeiras diferenças na distribuição espacial entre verão e inverno. Isso está provavelmente relacionado a diferenças sazonais de estações chuvosas e secas, incluindo processos hidrodinâmicos locais e biogeoquímicos. Alem disso, no inverno a salinidade aumenta (estação seca) e consequentemente a dessorção de metais pode ocorrer (Wong et al, 2010).

O comportamento dos elementos analisados no inverno foi, em geral, semelhante ao do verão, mas mostraram concentrações mais baixas em algumas estações. 

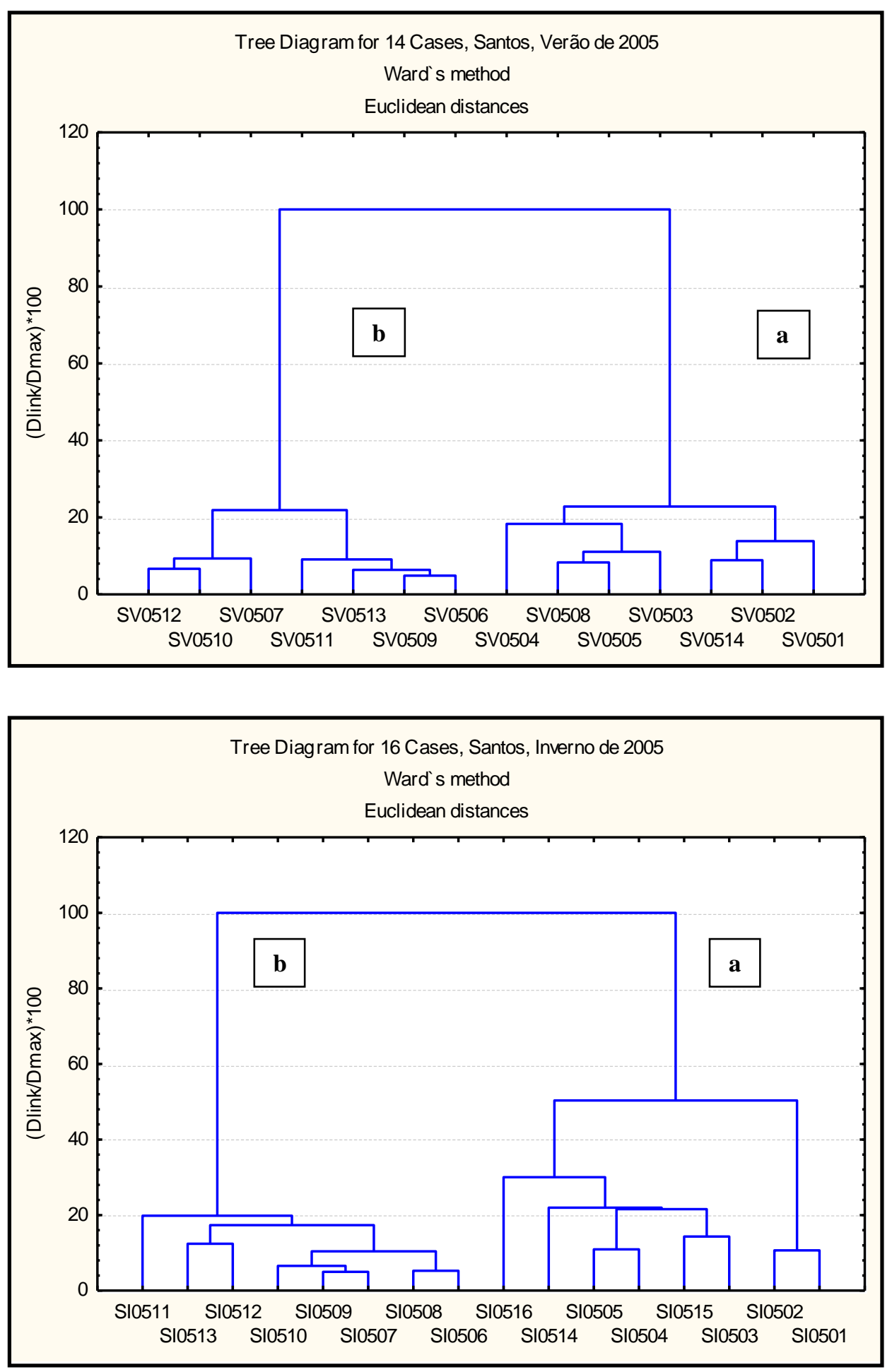

Figura 5.41 - Análise de agrupamento para todos os dados químicos (NAA, ICP OES e AAS), granulometria, $\mathrm{MO}$ e $\mathrm{CaCO}_{3}$ para todas as amostras: verão e inverno (2005) (variáveis: estações) 
A Figura 5.42 apresenta os dendrogramas considerando-se todos os dados químicos (dados de NAA, ICP OES e AAS), granulometria, (silte+argila, areia), $\mathrm{MO}$ e $\mathrm{CaCO}_{3}$ referente às amostras coletadas em Santos, verão e inverno de 2005 (35 variáveis, 14 amostras no verão e 16 no inverno), considerando todos os elementos analisados.

A partir dessas figuras foi possível notar que o conteúdo de MO apresenta uma alta correlação com a fração composta por silte+argila, enquanto a fração areia se correlaciona com a fração carbonática e com o Ta. Em ambas as estações (inverno e verão) verificou-se que os ETR se agruparam com $\mathrm{Ba}$ e $\mathrm{U}$ indicando que esses elementos estão presentes no sedimento na mesma fase mineralógica. Similarmente, os metais $\mathrm{Co}$, Fe e $\mathrm{Zn}$ estão sempre correlacionados com a MO e a fração fina.

Verificou-se ainda que elementos como $\mathrm{Al}, \mathrm{Br}$ e $\mathrm{Pb}$ possuem comportamentos semelhantes nos períodos de verão e inverno. 

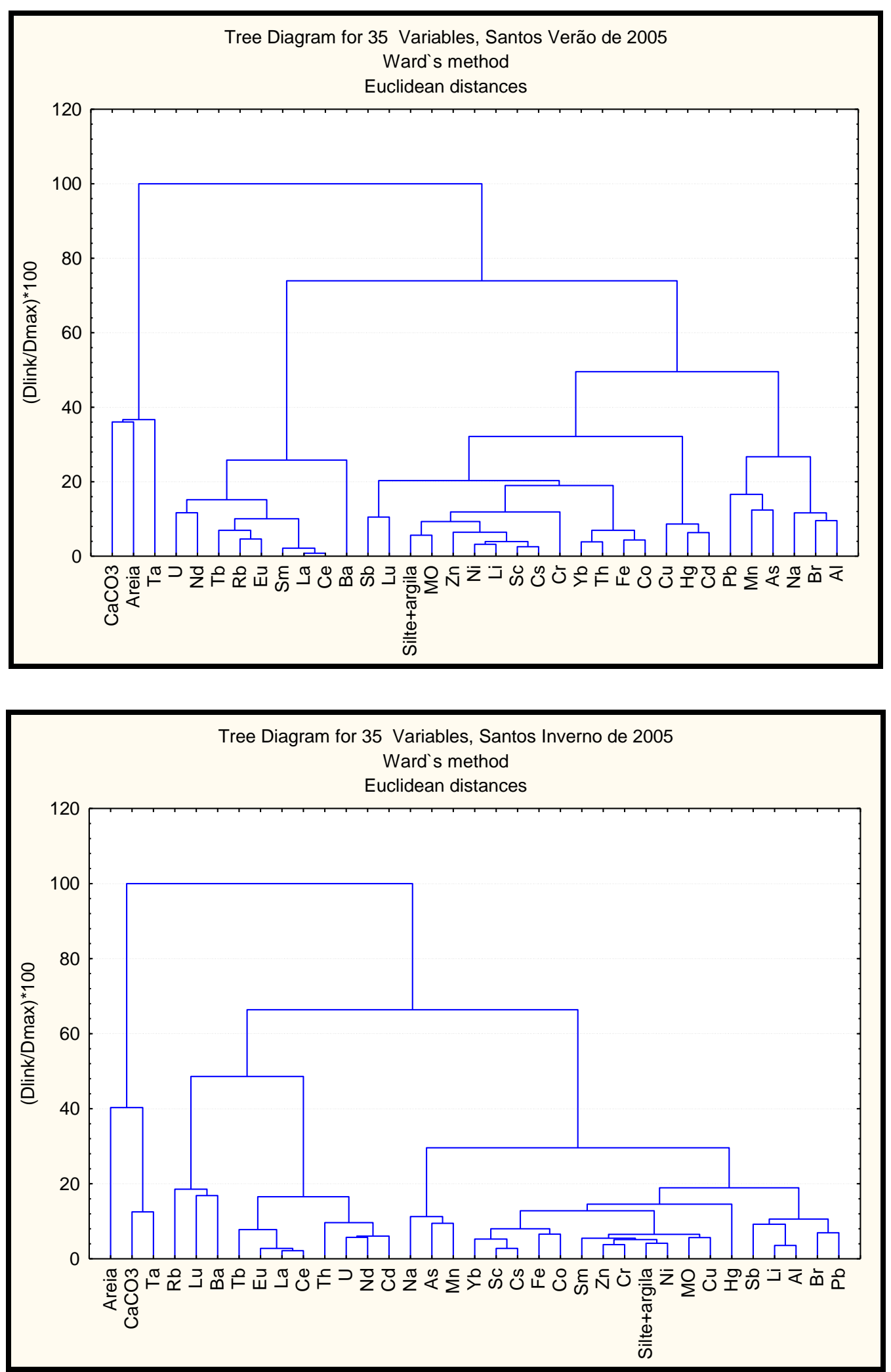

Figura 5.42 - Análise de agrupamento para todos os dados químicos (NAA, ICP OES e AAS), granulometria, $\mathrm{MO}$ e $\mathrm{CaCO}_{3}$ para todas as amostras: verão e inverno (2005) (variáveis: elementos) 


\subsubsection{SISTEMA ESTUARINO LAGUNAR DE CANANÉIA}

Em virtude das características geográficas dos pontos de amostragem da região de Cananéia, conforme já apresentado na Figura 4.4, as amostras foram agrupadas de acordo com suas peculiaridades e divididas em 3 áreas: Área 1: (estações 01 a 06), localizadas no Mar de Cananéia; Área 2 (estações 07 a 09), localizada na baía de Trapandé; Área 3 (estações 10 a 13), no Mar de Cubatão, conforme citado na Tabela 4.2. Estes pontos localizam-se na porção sul do Complexo Estuarino-Lagunar e apresentam hidrodinâmica diferenciada em relação à influência marinha.

\subsubsection{Resultados de $\mathrm{MO}$, silte, argila e areia, $\mathrm{CaCO}_{3}, \mathrm{P}$ inorg e org}

Perreti (2006) avaliou os resultados de MO, silte, argila e areia das amostras coletadas nos diversos pontos analisados, na região de Cananéia, inverno e verão de 2005 e os resultados estão apresentados na Tabela 5.33. Essas determinações foram feitas no LABNUT do IO/USP.

Os sedimentos do estuário de Cananéia são compostos principalmente por frações de areia, mas em alguns pontos a fração pelítica (silte + argila) é representativa. Ao avaliar a matéria orgânica, verificou-se que as estações 4, 9 e 11 apresentaram valores superiores a 10\%, com um conteúdo representativo de teor de $\mathrm{P}$ total e orgânico. Estes pontos apresentaram os valores mais significativos de sedimentos pelíticos e os maiores valores no período do verão. Os metais apresentaram valores positivamente associados ao teor de matéria orgânica e a \% de fração pelítica. As condições climáticas desta região, os processos biogeoquímicos e hidrodinâmicos podem promover diferenças nas concentrações sazonais de elementos em alguns pontos, contribuindo para uma distribuição única.

As estações 4, 9 e 11 apresentaram uma fração pelítica (silte + argila) variando de 20 a 86,7\%, elevado teor de matéria orgânica, bem como a fração de $\mathrm{P}$ org $\left(2,5\right.$ - 9,4 $\left.\mu \mathrm{mol} \mathrm{g}{ }^{-1}\right)$ (Tabela 5.33). A estação 4 apresenta um conteúdo de silte e argila superior a $80 \%$ nos 2 períodos de amostragem, bem como uma 
fração elevada de $P_{\text {inorgânico }}(>20 \%)$. A alta proporção da fração fina e conteúdo M.O. colaboram com a retenção de metais nos sedimentos, corroborando com o alto teor de metais traço.

Um segundo grupo é formado pelas estações 2, 3, 5 e 8, que também mostram um teor de M.O importante, o que facilita a retenção de metais. A estação 2 apresentou variação maior entre o inverno e o verão, diferindo das demais. As estações 1, 6, 7, 10, 12 e 13 apresentaram valores de concentração muito baixos, com valores menores que os valores médios. 
Tabela 5.33 Resultados (\%) de matéria orgânica (MO), granulometria (silte, argila e areia), P ( $\mu$ mol $\mathrm{g}^{-1}$ ) das amostras de sedimentos de Cananéia - inverno e verão em 2005

\begin{tabular}{|c|c|c|c|c|c|c|c|c|c|c|c|c|c|c|}
\hline \multirow[t]{2}{*}{ Estações } & \multicolumn{2}{|c|}{$\begin{array}{l}\text { MO* }^{*} \\
(\%)\end{array}$} & \multicolumn{2}{|c|}{$\begin{array}{c}\text { Silte+argila } \\
(\%)\end{array}$} & \multicolumn{2}{|c|}{$\begin{array}{c}\text { Areia* }^{*} \\
(\%)\end{array}$} & \multicolumn{2}{|c|}{$\begin{array}{c}\mathrm{CaCO}_{3}{ }^{*} \\
(\%)\end{array}$} & \multicolumn{2}{|c|}{ P (inorg) } & \multicolumn{2}{|c|}{ P (org) } & \multicolumn{2}{|c|}{ P (total) } \\
\hline & Inv & Verão & $\ln v$ & Verão & $\operatorname{lnv}$ & Verão & Inv & Verão & $\ln v$ & Verão & Inv & Verão & $\ln v$ & Verão \\
\hline 1 & 3,1 & 1 & 0,7 & 0,4 & 99,3 & 99,6 & 2,1 & 2,7 & 1 & 1,3 & 0 & 0,9 & 1 & 2,2 \\
\hline 2 & 3 & 1,3 & 0,7 & 1,7 & 99,3 & 98,3 & 2 & 1,9 & 2,2 & 1,2 & 2,4 & 0,9 & 4,6 & 2,1 \\
\hline 3 & 2,2 & 8,3 & 4,1 & 3,1 & 95,9 & 96,9 & 3 & 2,9 & 3,7 & 3 & 0,9 & 2,3 & 4,5 & 5,3 \\
\hline 4 & 11,8 & 15,4 & 85,5 & 86,7 & 14,5 & 13,3 & 7,1 & 9,8 & 26,1 & 26,4 & 6,4 & 6,7 & 32,5 & 33,1 \\
\hline 5 & 3,5 & 3,7 & 12,6 & 17,2 & 87,5 & 82,8 & 2,6 & 2,6 & 2,9 & 2,1 & 1,6 & 1,3 & 4,5 & 3,4 \\
\hline 6 & 0,5 & 0,5 & 0 & 0 & 100 & 100 & 0 & 0,4 & 1,3 & 1,3 & 0,2 & 0,2 & 1,5 & 1,5 \\
\hline 7 & 0,7 & 2,2 & 3,5 & 0 & 96,5 & 100 & 4,1 & 1,2 & 1,5 & 2 & 0,6 & 0,8 & 2 & 2,7 \\
\hline 8 & 3,2 & 3,1 & 18,8 & 8,4 & 81,2 & 91,7 & 3,4 & 4,7 & 3,7 & 3,2 & 2,9 & 2,6 & 6,6 & 5,8 \\
\hline 9 & 11,7 & 10,5 & 49,5 & 63,9 & 50,5 & 36,1 & 8,7 & 9,2 & 7,8 & 7,5 & 9,4 & 7,6 & 17,2 & 15 \\
\hline 10 & 2,1 & 2,7 & 0,6 & 0,1 & 99,4 & 99,9 & 1,6 & 1,7 & 1,4 & 1,3 & 1,6 & 1,3 & 3 & 2,6 \\
\hline 11 & 11,2 & 10,1 & 20,4 & 39,6 & 79,6 & 60,2 & 2,9 & 3,8 & 4,2 & 2,8 & 4,1 & 2,5 & 8,3 & 5,3 \\
\hline 12 & 3,1 & 5,8 & 11,5 & 1,3 & 88,5 & 98,7 & 1,9 & 4 & 1,2 & 1,7 & 2,2 & 1,5 & 3,4 & 3,2 \\
\hline 13 & 0,7 & 0,6 & 0,1 & 0,1 & 99,9 & 99,9 & 1 & 0,9 & 2,6 & 1,8 & 1,5 & 0,6 & 4,1 & 2,4 \\
\hline Min: & 0,5 & 0,5 & 0 & 0 & 14,5 & 13,3 & 0 & 0,4 & 1 & 1,2 & 0 & 0,2 & 1 & 1,5 \\
\hline Max: & 11,8 & 15,4 & 85,5 & 86,7 & 100 & 100 & 8,7 & 9,8 & 26,1 & 26,4 & 9,4 & 7,6 & 32,5 & 33,1 \\
\hline
\end{tabular}

* Dados de PERRETTI, 2006 
5.2.2.2 Resultados de concentração para os elementos determinados por ICP OES e AAS (GF AAS e CV AAS) nos sedimentos de Cananéia

As Tabelas 5.34 e 5.35 apresentam os resultados obtidos pelas técnicas ICP OES e AAS, para todas as amostras analisadas nos períodos de inverno e verão, anos 2005 e 2006, separados por áreas, conforme apresentado na Tabela 4.2. Também são apresentados os valores orientadores do Canadian Council of Minister of the Environment (CCME): TEL (Threshold Effect Level) e PEL (Probable Effect Level) (CCME, 1999) para águas salobras. 
Tabela 5.34 - Valores de concentração de metais $\left(\mathrm{mg} \mathrm{kg}^{-1}\right)$ determinados por ICP OES, Cd e Pb por GF AAS e Hg por CV AAS para as amostras de sedimentos do sistema estuarino Lagunar de Cananéia (Inverno (I) e Verão (V)-2005) e valores de LD e LQ, TEL e PEL

\begin{tabular}{|c|c|c|c|c|c|c|c|c|c|c|c|c|c|c|c|c|c|c|c|c|c|c|c|c|c|c|c|c|}
\hline \multirow[b]{2}{*}{$\begin{array}{c}\text { Área } \\
1\end{array}$} & \multicolumn{2}{|c|}{$\mathrm{Cd}^{\mathrm{AAS}}$} & \multicolumn{2}{|c|}{$\mathbf{P b}^{\mathrm{AAS}}$} & \multicolumn{2}{|c|}{\begin{tabular}{|c|}
$\mathbf{H g}^{\mathrm{AAS}}$ \\
$\left(\mu \mathrm{g} \mathrm{kg}^{-1}\right)$ \\
\end{tabular}} & \multicolumn{2}{|c|}{$\mathrm{Al}(\%)$} & \multicolumn{2}{|c|}{$\mathbf{B a}$} & \multicolumn{2}{|c|}{ Co } & \multicolumn{2}{|c|}{$\mathrm{Cu}$} & \multicolumn{2}{|c|}{ Cr total } & \multicolumn{2}{|c|}{$\begin{array}{c}\text { Fe total } \\
(\%)\end{array}$} & \multicolumn{2}{|c|}{$\mathbf{L i}$} & \multicolumn{2}{|c|}{ Mn } & \multicolumn{2}{|c|}{$\mathbf{N i}$} & \multicolumn{2}{|c|}{$\mathrm{Sr}$} & \multicolumn{2}{|c|}{$\mathbf{Z n}$} \\
\hline & V & I & $\mathbf{V}$ & I & $\mathbf{V}$ & I & $\mathbf{V}$ & I & $\mathbf{V}$ & I & $\mathbf{V}$ & I & $\mathbf{v}$ & I & $\mathbf{v}$ & I & V & I & V & I & V & I & $\mathbf{V}$ & I & $\mathbf{V}$ & I & $\mathbf{V}$ & I \\
\hline 1 & 0,012 & N.D. & N.D. & 0,95 & 20,9 & 20,4 & 0,178 & 0,123 & 2,3 & 1,35 & N.D. & N.D. & N.D. & \begin{tabular}{|l|} 
N.D. \\
\end{tabular} & 3,19 & 1,92 & \begin{tabular}{|l|}
0,205 \\
\end{tabular} & 0,104 & 3,91 & 1,96 & \begin{tabular}{|l|}
35,8 \\
\end{tabular} & 24,3 & 1,13 & N.D. & \begin{tabular}{|l|}
9,96 \\
\end{tabular} & 10,22 & 13,1 & 4,3 \\
\hline 2 & 0,174 & N.D. & 0,51 & 5,7 & 21,1 & 18 & 0,362 & 0,834 & 4,41 & 9,83 & N.D. & 2,29 & N.D. & 2,07 & 4,47 & 10,9 & 0,280 & 0,716 & 6,21 & 14,77 & 37,2 & 93,5 & 1,75 & 4 & 29,02 & 18,86 & 9 & 15 \\
\hline 3 & 0,012 & N.D. & 3,90 & 5,31 & 30,6 & 19,8 & 0,608 & 0,864 & 7,78 & 10,68 & 2,18 & 2,26 & \begin{tabular}{|l|}
0,83 \\
\end{tabular} & 1,74 & 9,2 & 10,15 & 0,674 & 0,684 & 11,82 & 13,36 & 123,1 & 110,1 & 3,1 & 3,64 & 14,85 & 19,12 & 14,7 & 14,2 \\
\hline 4 & 0,059 & \begin{tabular}{|l}
0,0631 \\
\end{tabular} & 25,55 & 26,01 & 101 & 81,8 & 3,615 & 4,068 & 50,33 & 52,65 & 7,06 & 7,56 & 11,28 & 12,64 & 36,85 & 39,98 & 3,408 & 3,538 & 48,27 & 53,21 & 449,1 & 526,6 & 14,27 & 15,6 & 46,45 & 51,86 & 57,7 & |60,6 \\
\hline 5 & 0,015 & N.D. & 7,98 & 10,06 & 54,8 & 36,6 & 0,354 & 0,816 & 5,3 & 11,8 & 1,54 & 2,28 & 1,61 & 3,58 & 6,76 & 10,33 & 0,540 & 0,735 & 7,41 & 12,5 & 74,3 & 110,3 & 2,37 & 3,66 & 13,6 & 17,94 & 12,4 & 16,6 \\
\hline 6 & N.D. & N.D. & N.D. & 1,17 & 24,6 & 25,2 & 0,063 & 0,054 & 1,13 & 1,3 & N.D. & N.D. & N.D. & \begin{tabular}{|l|}
0,59 \\
\end{tabular} & 1,19 & 1,13 & \begin{tabular}{|l|}
0,086 \\
\end{tabular} & \begin{tabular}{|l|}
0,069 \\
\end{tabular} & \begin{tabular}{|l|}
1,18 \\
\end{tabular} & N.D. & 9,7 & 20,4 & N.D. & N.D. & 2,69 & 2,07 & 3 & 2,4 \\
\hline \multicolumn{29}{|l|}{\begin{tabular}{c|} 
Área \\
2
\end{tabular}} \\
\hline 7 & 0,0093 & N.D. & 0,1 & \begin{tabular}{|l|}
0,83 \\
\end{tabular} & 27,2 & 23,8 & 0,24 & 0,132 & 2,97 & 1,37 & 1,05 & N.D. & N.D. & \begin{tabular}{|l|} 
N.D. \\
\end{tabular} & 4,24 & 2,6 & \begin{tabular}{|l|}
0,307 \\
\end{tabular} & \begin{tabular}{|l|}
0,170 \\
\end{tabular} & 5,15 & 2,75 & \begin{tabular}{|l|}
63,4 \\
\end{tabular} & 52,3 & 1,17 & N.D. & 22,79 & 12,29 & 7 & 4 \\
\hline 8 & 0,0158 & N.D. & 4,7 & 3,9 & 40 & 17 & 0,74 & 1,208 & 8,52 & 19,71 & 2,66 & 2,77 & \begin{tabular}{|l|} 
N.D. \\
\end{tabular} & \begin{tabular}{|l|}
1,32 \\
\end{tabular} & 11,8 & 13,4 & \begin{tabular}{|l|}
0,836 \\
\end{tabular} & 0,835 & 14,75 & 15,75 & 119,9 & 113,4 & 3,8 & 4,35 & 20,8 & 29,85 & 18 & 18,9 \\
\hline 9 & 0,0534 & 0,04157 & 13,4 & 11,22 & 52,5 & 51,6 & 4,28 & 2,348 & 51,1 & 24,09 & 6,64 & \begin{tabular}{|l|}
5,78 \\
\end{tabular} & 5,35 & \begin{tabular}{|l|}
5,09 \\
\end{tabular} & 37,53 & 29,25 & \begin{tabular}{|l|}
2,758 \\
\end{tabular} & \begin{tabular}{|l|}
2,391 \\
\end{tabular} & \begin{tabular}{|l|}
58,76 \\
\end{tabular} & \begin{tabular}{|l|}
45,91 \\
\end{tabular} & \begin{tabular}{|l|}
312,1 \\
\end{tabular} & 394,5 & 14,75 & 11,01 & 43,52 & 52,37 & 50,6 & 43,3 \\
\hline \multicolumn{29}{|l|}{\begin{tabular}{c|} 
Área \\
3
\end{tabular}} \\
\hline 10 & 0,0091 & N.D. & 2,32 & 1,94 & 26,1 & 15,8 & 0,19 & 0,364 & 2,21 & 5,71 & N.D. & N.D. & \begin{tabular}{|l|} 
N.D. \\
\end{tabular} & 1,16 & 3,52 & 4,71 & \begin{tabular}{|l|}
0,25 \\
\end{tabular} & \begin{tabular}{|l|}
0,282 \\
\end{tabular} & 4,14 & 5,53 & 18,5 & 21,1 & 1,29 & 1,73 & 5,23 & 5,57 & 9 & 9,1 \\
\hline 11 & 0,0322 & 0,0373 & 5,88 & 8,46 & 56,3 & 50,2 & 1,41 & 2,939 & 14,88 & 25,65 & 2,53 & 3,07 & \begin{tabular}{|l|}
1,94 \\
\end{tabular} & \begin{tabular}{|l|}
3,57 \\
\end{tabular} & 14,35 & 18,84 & \begin{tabular}{|l|}
0,87 \\
\end{tabular} & 1,870 & 21,87 & 25,43 & \begin{tabular}{|l|}
70,6 \\
\end{tabular} & 120,1 & 5,14 & 7,11 & 16,95 & 20,96 & 19 & 29 \\
\hline 12 & N.D. & \begin{tabular}{|l|}
0,01146 \\
\end{tabular} & 4,76 & $2,68 \mid$ & 40,7 & 15,3 & 0,40 & \begin{tabular}{|l|}
0,469 \\
\end{tabular} & \begin{tabular}{|l}
5,02 \\
\end{tabular} & 6,71 & 1,13 & 1,13 & 1,92 & \begin{tabular}{|l|}
1,26 \\
\end{tabular} & 6,35 & 5,77 & \begin{tabular}{|l|}
0,40 \\
\end{tabular} & 0,280 & \begin{tabular}{|l|}
6,98 \\
\end{tabular} & 7,92 & \begin{tabular}{|l|}
26,2 \\
\end{tabular} & \begin{tabular}{|l|}
20,3 \\
\end{tabular} & 1,92 & \begin{tabular}{|l|}
2,12 \\
\end{tabular} & \begin{tabular}{|l|}
8,86 \\
\end{tabular} & \begin{tabular}{|l|}
5,24 \\
\end{tabular} & 14,1 & 8,4 \\
\hline 13 & N.D. & N.D. & 2,32 & 1,57 & 32,6 & 21,1 & 0,16 & 0,198 & 2,08 & 3,85 & N.D. & \begin{tabular}{|l|} 
N.D. \\
\end{tabular} & 0,8 & \begin{tabular}{|l|} 
N.D. \\
\end{tabular} & 2,36 & 1,93 & \begin{tabular}{|l|}
0,16 \\
\end{tabular} & 0,124 & \begin{tabular}{|l|}
2,42 \\
\end{tabular} & 3,5 & 20 & 37,5 & N.D. & N.D. & \begin{tabular}{|l|}
8,48 \\
\end{tabular} & 9,03 & 4,7 & 3,2 \\
\hline Min & <L.Q. & $<$ L.Q. & $<\mathrm{L}$.Q. & \begin{tabular}{|l|}
0,83 \\
\end{tabular} & \begin{tabular}{|l}
20,9 \\
\end{tabular} & 15,3 & 0,063 & \begin{tabular}{|l}
0,054 \\
\end{tabular} & 1,13 & 1,3 & $<$ L.Q. & $<\mathrm{L} . \mathrm{Q}$ & <L.Q. & <L.Q. & 1,19 & 1,13 & \begin{tabular}{|l|}
0,086 \\
\end{tabular} & 0,069 & \begin{tabular}{|l|}
1,18 \\
\end{tabular} & $<$ L.Q. & 9,7 & \begin{tabular}{|l|}
20,3 \\
\end{tabular} & <L.Q. & <L.Q. & 2,69 & 2,07 & 3 & 2,4 \\
\hline Max & 0,174 & 0,063 & 25,55 & 26,01 & 101 & 81,8 & 4,28 & 4,068 & 51,1 & 52,65 & 7,06 & 7,56 & 11,28 & 12,64 & 37,53 & 39,98 & 3,408 & 3,538 & 58,76 & 53,21 & 449,1 & 526,6 & 14,75 & 15,6 & 46,45 & 52,37 & 57,7 & 60,6 \\
\hline L.D. & \multicolumn{2}{|c|}{0,005} & \multicolumn{2}{|c|}{0,100} & \multicolumn{2}{|c|}{1} & \multicolumn{2}{|c|}{0,5} & \multicolumn{2}{|c|}{0,2} & \multicolumn{2}{|c|}{0,5} & 0, & 1 & & 0,5 & 0,00 & & & 0,5 & 0, &, 5 & 0, &, 5 & 0 & 1 & 0, & 0,5 \\
\hline L.Q. & & 010 & 0,2 & 250 & & 10 & 1, & 0 & & 0 & 1 & 0 & 0, & 5 & & 1 & $0,0 c$ & & & 1,0 & 1, & 0 & 1, & 0 & 1 & 0 & 1, & 1,0 \\
\hline TEL & & 0,7 & 30 & $\overline{1,2}$ & & 30 & & & & & & & 18 & 3,7 & & 2,3 & & & & & & & 15 & 5,9 & & & & 24 \\
\hline $\begin{array}{l}\text { PEL } \\
\end{array}$ & & 1,6 & 1 & 12 & & 96 & & & & & & & 10 & 08 & & 160 & & & & & & & 42 & 2,8 & & & 27 & 71 \\
\hline
\end{tabular}


Tabela 5.35 - Valores de concentração de metais $\left(\mathrm{mg} \mathrm{kg}^{-1}\right)$ determinados por ICP OES, Cd e Pb por GF AAS e Hg por CV AAS para as amostras de sedimentos do sistema estuarino Lagunar de Cananéia (Inverno (I) e Verão (V)/2006) e valores de LD e LQ, TEL e PEL

\begin{tabular}{|c|c|c|c|c|c|c|c|c|c|c|c|c|c|c|c|c|c|c|c|c|c|c|c|c|c|c|c|c|}
\hline \multirow[b]{2}{*}{$\begin{array}{c}\text { Área } \\
1\end{array}$} & \multicolumn{2}{|c|}{$\mathbf{C d}^{\mathrm{AAS}}$} & \multicolumn{2}{|c|}{$\mathbf{P b}^{\mathrm{AAS}}$} & \multicolumn{2}{|c|}{$\begin{array}{l}\mathrm{Hg}^{\text {AAS }} \\
\left(\mu \mathrm{g} \mathrm{kg}^{-1}\right)\end{array}$} & \multicolumn{2}{|c|}{$\mathrm{Al}(\%)$} & \multicolumn{2}{|c|}{$\mathbf{B a}$} & \multicolumn{2}{|c|}{ Co } & \multicolumn{2}{|c|}{$\mathrm{Cu}$} & \multicolumn{2}{|c|}{ Cr total } & \multicolumn{2}{|c|}{$\begin{array}{c}\text { Fe total } \\
(\%)\end{array}$} & \multicolumn{2}{|c|}{$\mathbf{L i}$} & \multicolumn{2}{|c|}{ Mn } & \multicolumn{2}{|c|}{$\mathbf{N i}$} & \multicolumn{2}{|c|}{$\mathbf{S r}$} & \multicolumn{2}{|c|}{ Zn } \\
\hline & V & I & V & I & V & I & V & I & V & I & $\mathbf{v}$ & I & v & I & V & I & V & I & $\mathbf{v}$ & I & V & I & $\mathbf{v}$ & I & V & I & $\mathbf{V}$ & I \\
\hline 1 & N.D. & N.D. & 1,12 & 0,91 & 31,5 & 7 & 0,15 & 0,09 & 1,8 & 1,88 & N.D. & N.D. & 0,85 & N.D. & 2,47 & 1,7 & 0,15 & 0,10 & 2,8 & 2,2 & 26,4 & 20 & 1,9 & N.D. & 8,1 & 14,3 & 6,5 & 3,5 \\
\hline 2 & N.D. & N.D. & 3 & 4,33 & 28,3 & 28,5 & 0,40 & 0,76 & 6,3 & 9,2 & N.D. & 2,07 & 0,82 & N.D. & 6,91 & 8,56 & 0,41 & 0,68 & 4,8 & 14,7 & 67,3 & 137,1 & 1,31 & 2,92 & 7,7 & 15,1 & 8,3 & 11,4 \\
\hline 3 & 0,016 & N.D. & 10,85 & 6,6 & 75,3 & 26,8 & 2,49 & 0,80 & 37,47 & 11,75 & 4,97 & 2,82 & 6,22 & N.D. & 26,44 & 11,02 & 1,67 & 0,75 & 34,6 & 16,8 & 416,2 & 172 & 10,35 & 3,99 & 51,3 & 20,0 & 35,5 & 16,2 \\
\hline 4 & 0,009 & 0,011 & 4,15 & 5,74 & 47,5 & 27,3 & 0,51 & 0,41 & 7,32 & 8,68 & 1,36 & 1,63 & 1,96 & 1,15 & 6,23 & 5,73 & 0,43 & 0,43 & 10,3 & 9,4 & 136,8 & 54,5 & 2,32 & 2,55 & 18,7 & 11,5 & 9,4 & 9,1 \\
\hline 5 & N.D. & N.D. & 4,92 & 2,61 & 47,3 & 16,2 & 0,85 & 0,32 & 15,12 & 5,9 & 1,47 & N.D. & 1,74 & N.D. & 7,69 & 3,83 & 0,50 & 0,23 & 7,7 & 4,5 & 74,9 & 41,1 & 3,05 & 1,43 & 12,2 & 5,4 & 11,5 & 5,4 \\
\hline 6 & N.D. & N.D. & 1,24 & 1,45 & 34 & 8,4 & 0,13 & 0,11 & 2,53 & 2,63 & N.D. & N.D. & 1,04 & N.D. & 1,95 & 2,18 & 0,10 & 0,09 & 1,8 & 1,6 & 13,8 & 26,8 & N.D. & N.D. & 2,8 & 2,7 & 4,2 & 4 \\
\hline \multicolumn{29}{|l|}{$\begin{array}{c}\text { Área } \\
2\end{array}$} \\
\hline 7 & N.D. & N.D. & 1,04 & 1,77 & 25,5 & 7,9 & 0,16 & 0,15 & 3,29 & 2,6 & N.D. & N.D. & N.D. & N.D. & 2,56 & 3,17 & 0,21 & 0,24 & 3,0 & 3,8 & 75,8 & 58,7 & N.D. & 1,1 & 17,1 & 14,3 & 4,5 & 5,4 \\
\hline 8 & N.D. & N.D. & 6,27 & 3,14 & 47,7 & 19,5 & 1,07 & 0,43 & 14,15 & 6,64 & 2,84 & 2,19 & 1,75 & N.D. & 13,04 & 8,69 & 0,84 & 0,57 & 16,0 & 10,4 & 102 & 99,4 & 4,17 & 2,63 & 20,0 & 26,3 & 18,5 & 13,5 \\
\hline 9 & 0,034 & 0,036 & 10,12 & 10,64 & 85,2 & 47,9 & 3,22 & 2,47 & 34,82 & 29,73 & 5,96 & 6,19 & 5,41 & 3,68 & 30,83 & 28,81 & 2,40 & 1,78 & 48,1 & 55,2 & 311 & 336,5 & 11,69 & 10,85 & 54,5 & 46,4 & 43,2 & 39,5 \\
\hline \multicolumn{29}{|l|}{$\begin{array}{c}\text { Área } \\
3\end{array}$} \\
\hline 10 & N.D. & N.D. & 3,25 & 3,03 & 41,2 & 22,9 & 0,44 & 0,34 & 6,59 & 5,65 & N.D. & 1,2 & 1,21 & N.D. & 5,19 & 5,4 & 0,31 & 0,42 & 5,9 & 8,4 & 28,1 & 36,6 & 1,58 & 2,08 & 7,1 & 65,4 & 8,5 & 11,2 \\
\hline 11 & 0,027 & 0,040 & 8,93 & 12,45 & 78 & 77,1 & 2,56 & 1,14 & 40,74 & 15,91 & 3,4 & 4,18 & 4,49 & 4,36 & 24,15 & 20,11 & 1,58 & 1,66 & 31,1 & 45,8 & 105,9 & 197 & 8,44 & 7,75 & 27,0 & 30,6 & 27,1 & 34,1 \\
\hline 12 & N.D. & 0,011 & 5,5 & 3,61 & 47,9 & 27,1 & 0,87 & 0,37 & 14,75 & 7,04 & 1,24 & 1,29 & 1,22 & N.D. & 9,28 & 5,58 & 0,70 & 0,34 & 8,6 & 6,7 & 32,3 & 54,7 & 2,64 & 1,99 & 9,8 & 9,3 & 10,1 & 9,2 \\
\hline 13 & N.D. & N.D. & 2,99 & 2,6 & 32,7 & 12,9 & 0,13 & 0,14 & 3,95 & 4,2 & N.D. & N.D. & 0,61 & N.D. & 1,83 & 2,24 & 0,15 & 0,15 & 2,3 & 2,6 & 30,9 & 41,5 & N.D. & 2,08 & 6,3 & 10,0 & 3,9 & 13,3 \\
\hline Min. & $<\mathrm{L}$.Q. & <L.Q. & 1,04 & 0,91 & 3,03 & 7 & 0,13 & 0,09 & 0,34 & 1,88 & $<\mathrm{L} . \mathrm{Q}$. & $<$ L.Q. & $<$ L.Q. & $<\mathrm{L}$.Q. & 1,83 & 1,7 & 0,1 & 0,09 & 0,42 & 1,6 & 8,4 & 20 & $<$ L.Q. & $<$ L.Q. & 2,08 & 2,7 & 3,9 & 3,5 \\
\hline Max. & 0,034 & 0,040 & 10,85 & 12,45 & 85,2 & 77,1 & 3,22 & 2,47 & 40,74 & 29,73 & 5,96 & 6,19 & 6,22 & 4,36 & 30,83 & 28,81 & 2,4 & 1,78 & 48,1 & 55,2 & 416,2 & 336,5 & 11,69 & 10,85 & 54,5 & 65,4 & 43,2 & 39,5 \\
\hline L.D. & \multicolumn{2}{|c|}{0,005} & \multicolumn{2}{|c|}{0,1} & \multicolumn{2}{|c|}{1} & \multicolumn{2}{|c|}{0,5} & \multicolumn{2}{|c|}{0,2} & \multicolumn{2}{|c|}{0,5} & $\mathbf{0}$ &, 1 & $\mathbf{0}$, &, 5 & $\mathbf{0 , 0}$ & 001 & & 0,5 & $\mathbf{0}$ &, 5 & $\mathbf{0}$ &, 5 & $\mathbf{0}$ &, 1 & & 0,5 \\
\hline L.Q. & & 01 & & & 1 & 10 & & 1 & & 1 & 1 & 1 & $\mathbf{0}$ &, 5 & 1 & 1 & $\mathbf{0 , 0}$ & 005 & & 1 & 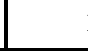 & 1 & 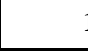 & 1 & 1 & 1 & & 1 \\
\hline TEL & &, 7 & & & 1. & 30 & & & & & & & 18 & 8,7 & 52 & 2,3 & & & & & & & 15 & 5,9 & & & & 124 \\
\hline PEL & & 1,6 & & 12 & 6 & 96 & & & & & & & 1 & 08 & 16 & 60 & & & & & & & 42 & 2,8 & & & & 271 \\
\hline
\end{tabular}


Os Anexos de $\mathrm{XI}$ a XVI apresentam as tabelas com os dados de concentração e desvios obtidos por ICP OES, GF AAS e CV AAS para todos os pontos amostrados no complexo estuarino-lagunar de Cananéia, nos períodos de inverno e verão, 2005 e 2006, respectivamente.

Em relação às amostras coletadas na região de Cananéia, verificamos que as concentrações dos elementos $\mathrm{Cd}, \mathrm{Pb}, \mathrm{Hg}, \mathrm{Cr}$, Cu, Ni e Zn estão abaixo das legislações CONAMA 344/04 e dos Limites TEL e PEL.

Semensatto-Jr et al (2007), identificaram os teores de metais e nãometais em sedimentos de um Manguezal na llha do Cardoso, Cananéia, onde identificaram as concentrações dos sedimentos superficiais coletados entre os anos de 2001 e 2002. Foram observados que os resultados de Al estavam entre $0,11-1,62 \%$, Ba entre 3,2-19,4 $\mathrm{mg} \mathrm{kg}^{-1}, \mathrm{Cd}<\mathrm{L}$.Q a $30,9 \mathrm{mg} \mathrm{kg}^{-1}$, Co: 4 - $47 \mathrm{mg} \mathrm{kg}^{-1}$, Cr <L.Q. a $88 \mathrm{mg} \mathrm{kg}^{-1}$, Cu $<\mathrm{L} . \mathrm{Q}-27 \mathrm{mg} \mathrm{kg}^{-1}$, Fe entre $0,15 \mathrm{a}$ 2,26\%, Mn 11 - $320 \mathrm{mg} \mathrm{kg}^{-1}$, Zn de 5 - $50 \mathrm{mg} \mathrm{kg}^{-1}$.

Aguiar et al (2008), realizaram um estudo na região de Cananéia, avaliando os metais $\mathrm{Pb}, \mathrm{Cd}, \mathrm{Cr}$, Cu e $\mathrm{Zn}$, no qual destacaram que $\mathrm{Pb}, \mathrm{Cd}$ e $\mathrm{Cr}$ parecem sofrer influência antrópica, de origem doméstica, proveniente do escoamento do rio Ribeira de Iguape, o qual escoa em uma área mais urbanizada que Cananéia. Os autores observaram concentrações que variaram de $19-56 \mathrm{mg} \mathrm{kg}^{-1}$ para $\mathrm{Pb} ; 4-6,1 \mathrm{mg} \mathrm{kg}^{-1}$ para $\mathrm{Cd}$, $35-280 \mathrm{mg} \mathrm{kg}^{-1}$ para $\mathrm{Cr}$; $9,5-35 \mathrm{mg} \mathrm{kg}^{-1}$ para Cu e $43-74 \mathrm{mg} \mathrm{kg}^{-1}$ para $\mathrm{Zn}$.

A região de Cananéia-Iguape também possui rochas carbonáticas, que podem contribuir com as concentrações de $\mathrm{Pb}$ nos sedimentos, entretanto a fonte mais significativa deste elemento no sistema é ainda a bacia de drenagem do Vale do Ribeira, o qual no passado, possuía atividades intensas de mineração. A presença dos maiores teores de metais tóxicos na porção interior da área de estudo revelam uma área de baixa energia, tendendo a acumular um maior teor de silte e argila, e consequentemente mais metais tóxicos terão afinidade na fração fina ocorrendo, portanto, um maior acúmulo (Aguiar, et al. 2008). 
Mahiques et al, 2009, estudaram a região próxima ao Valo Grande, a qual foi sujeita à forte exploração de minérios, desde o século XVIII com a mineração de $\mathrm{Au}$ e Ag, e após o ano de 1945, com a indústria Plumbum S/A encerrando suas atividades em 1995. A partir dos resultados obtidos verificaram com a análise de testemunhos de sedimentos, que as concentrações de $\mathrm{Cu}$ variavam de aproximadamente $1 \mathrm{mg} \mathrm{kg}^{-1}$ antes da abertura do Valo Grande à $32 \mathrm{mg} \mathrm{kg}^{-1}$ após o fechamento da empresa Plumbum S/A. Os teores de $\mathrm{Pb}$ variaram de $0,5 \mathrm{mg} \mathrm{kg}^{-1}$ a $42 \mathrm{mg} \mathrm{kg}^{-1}$. O $\mathrm{Cr}$ variou de 6 a $40 \mathrm{mg} \mathrm{kg}^{-1}$, entre a abertura do Valo Grande até o fechamento da empresa Plumbum S/A. O Zn variou de $10 \mathrm{mg} \mathrm{kg}^{-1}$ no período anterior à abertura do Valo Grande para cerca de $80 \mathrm{mg} \mathrm{kg}^{-1}$.

\subsubsection{Estudo da variação sazonal - Gráficos Box Plot}

Para a verificação da variação sazonal, a partir dos dados obtidos pelas técnicas de análise ICP OES e AAS, foram confeccionados gráficos de Box Plot para cada elemento analisado, comparando os períodos e os anos de coleta, sendo identificadas como Cananéia inverno (Cl 2005 e 2006) e verão (CV 2005 e 2006), todas seguidas pelas identificações "A1" (área 1), "A2" (área 2) ou "A3" (área 3), a partir das representações dos quartis e da mediana, além dos limites mínimos e máximos para cada caso.

As Figuras 5.43 à 5.58 apresentam os gráficos Box plot, assim como os testes ANOVA, com o valor do teste $\mathrm{F}$, e o valor-p para os elementos $\mathrm{Al}, \mathrm{Ba}$, $\mathrm{Cd}, \mathrm{Pb}, \mathrm{Co}, \mathrm{Cu}, \mathrm{Cr}, \mathrm{Sr}, \mathrm{Fe}, \mathrm{Li}, \mathrm{Mn}, \mathrm{Hg}, \mathrm{Ni}, \mathrm{Ti}, \mathrm{V}$ e $\mathrm{Zn}$, nas diferentes áreas da região do estuário de Cananéia. 


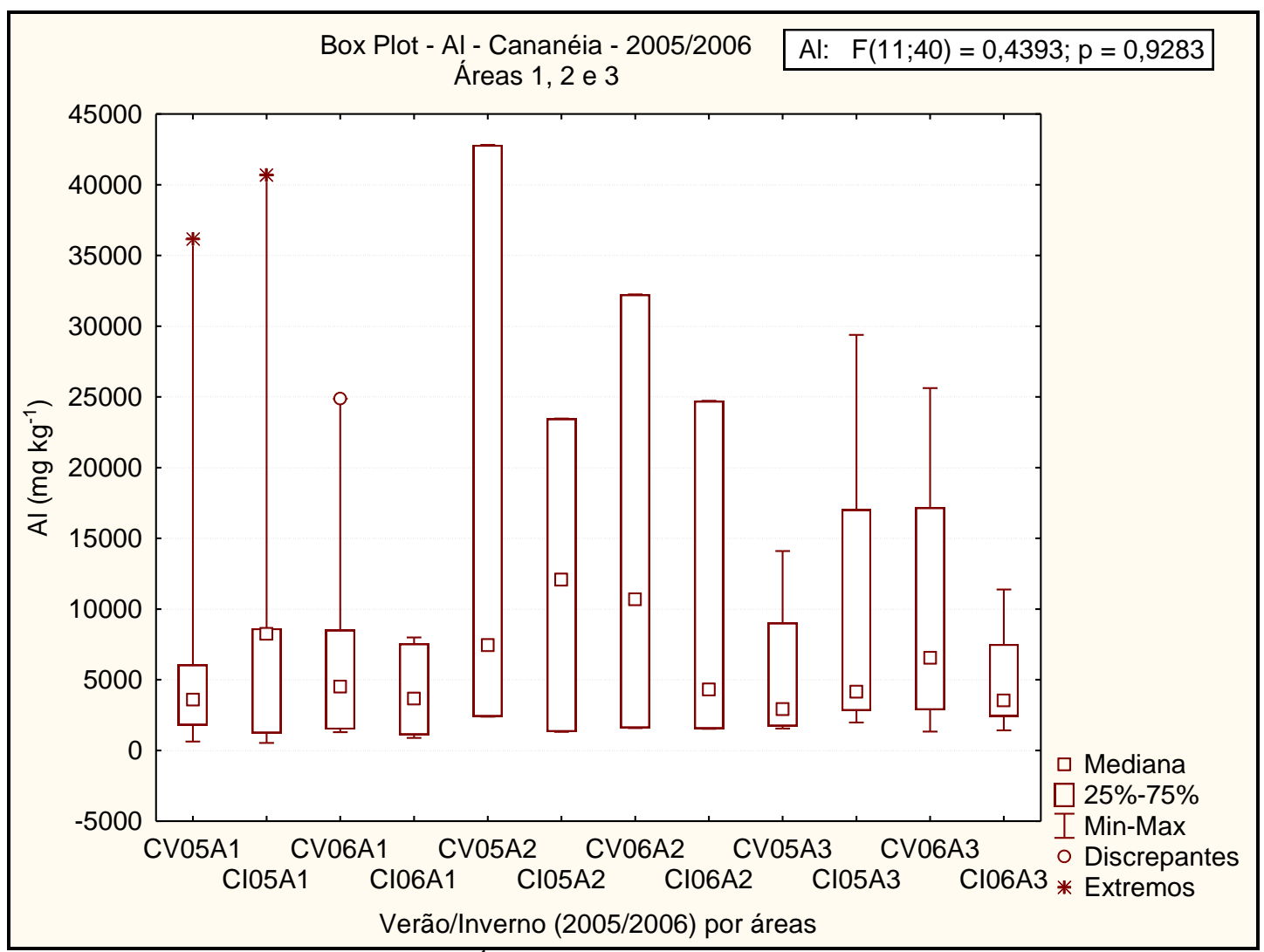

Figura 5.43: Box Plot Al (mg kg $\left.{ }^{-1}\right)$ e teste ANOVA - Cananéia Inverno/Verão 2005 e 2006

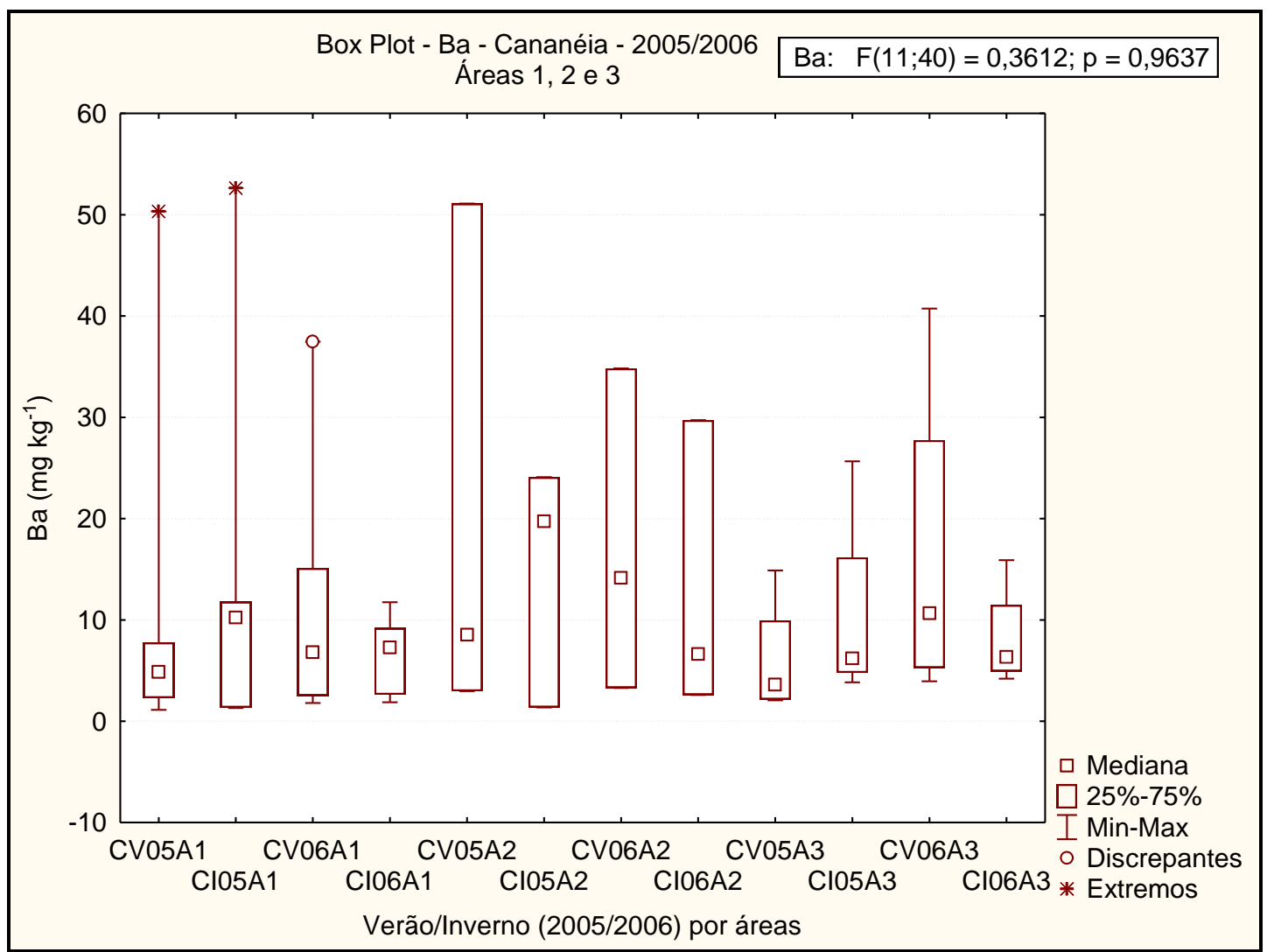

Figura 5.44: Box Plot Ba ( $\left.\mathrm{mg} \mathrm{kg}^{-1}\right)$ e teste ANOVA - Cananéia Inverno/Verão 2005 e 2006 


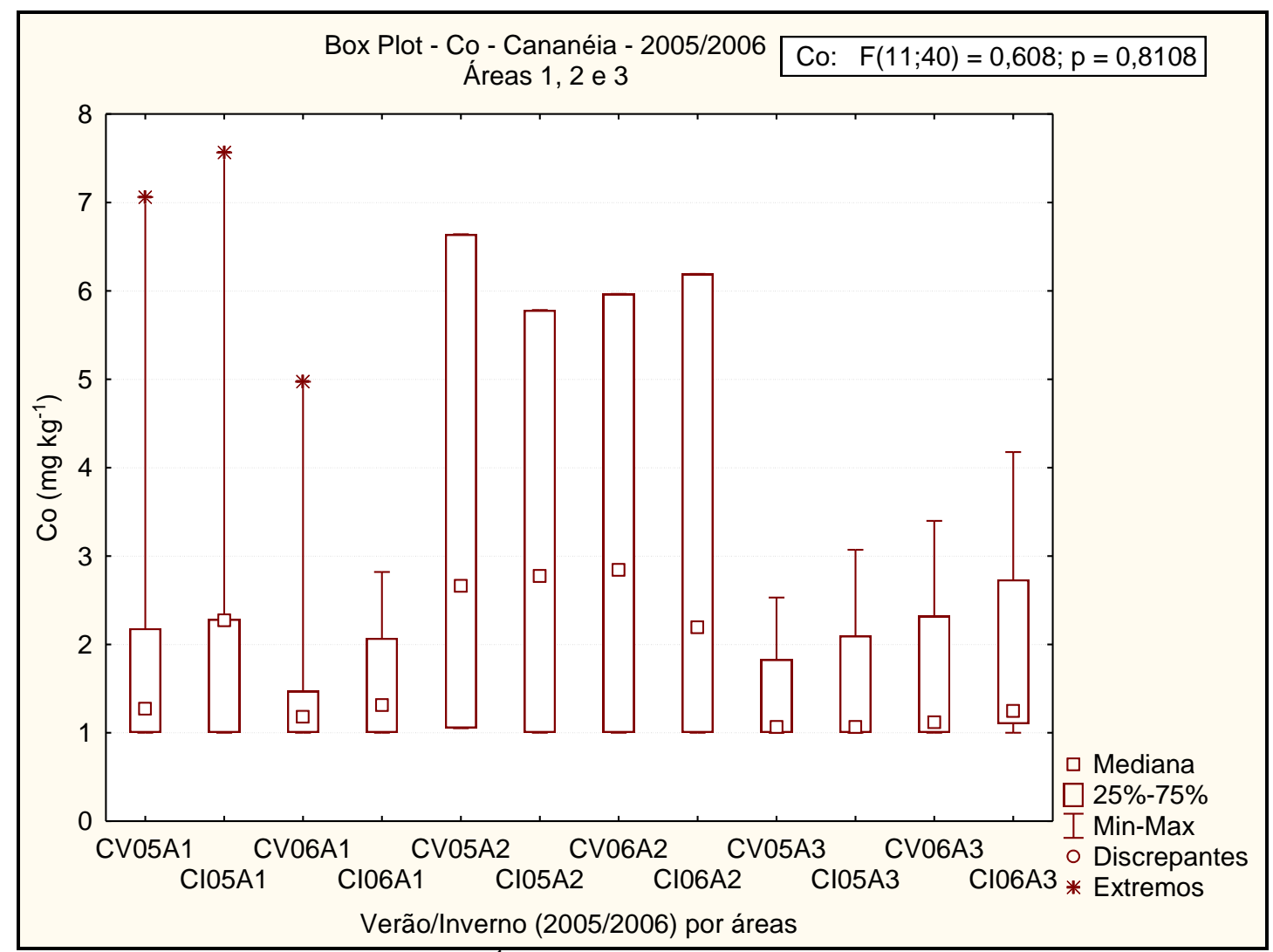

Figura 5.45: Box Plot Co $\left(\mathrm{mg} \mathrm{kg}^{-1}\right)$ e teste ANOVA - Cananéia Inverno/Verão 2005 e 2006

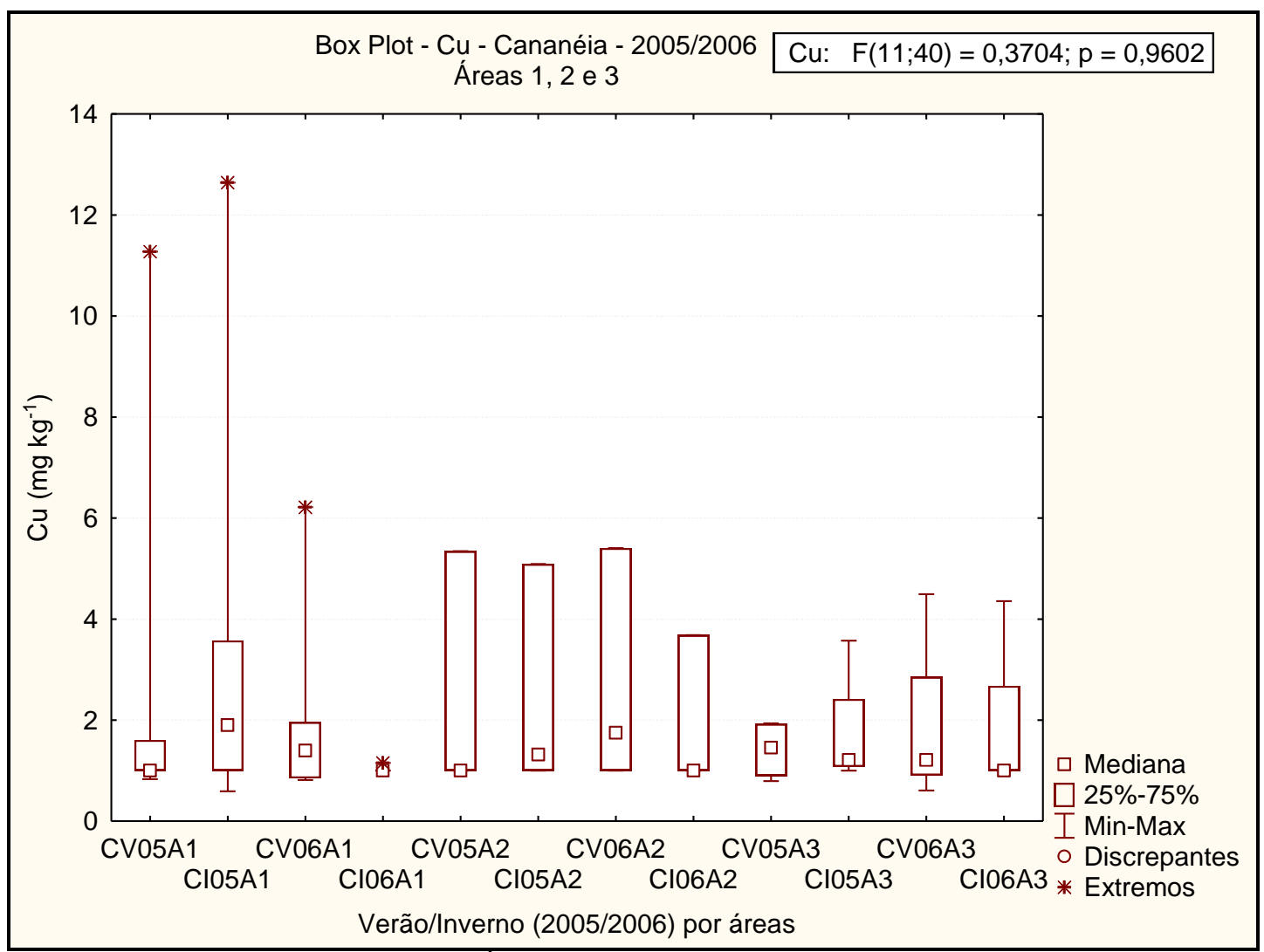

Figura 5.46: Box Plot Cu ( $\left.\mathrm{mg} \mathrm{kg}^{-1}\right)$ e teste ANOVA - Cananéia Inverno/Verão 2005 e 2006 


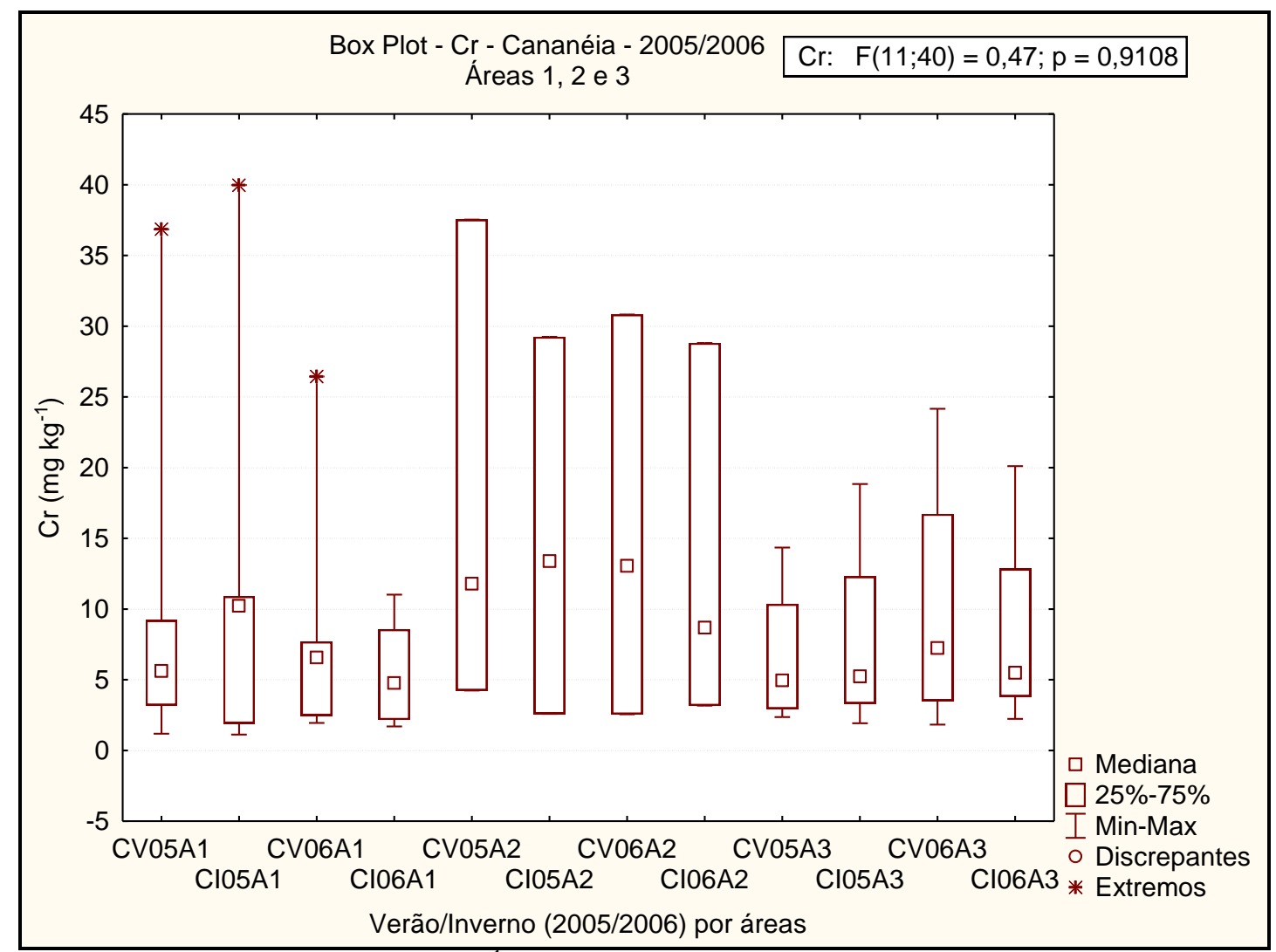

Figura 5.47: Box Plot Cr (mg kg $\left.{ }^{-1}\right)$ e teste ANOVA - Cananéia Inverno/Verão 2005 e 2006

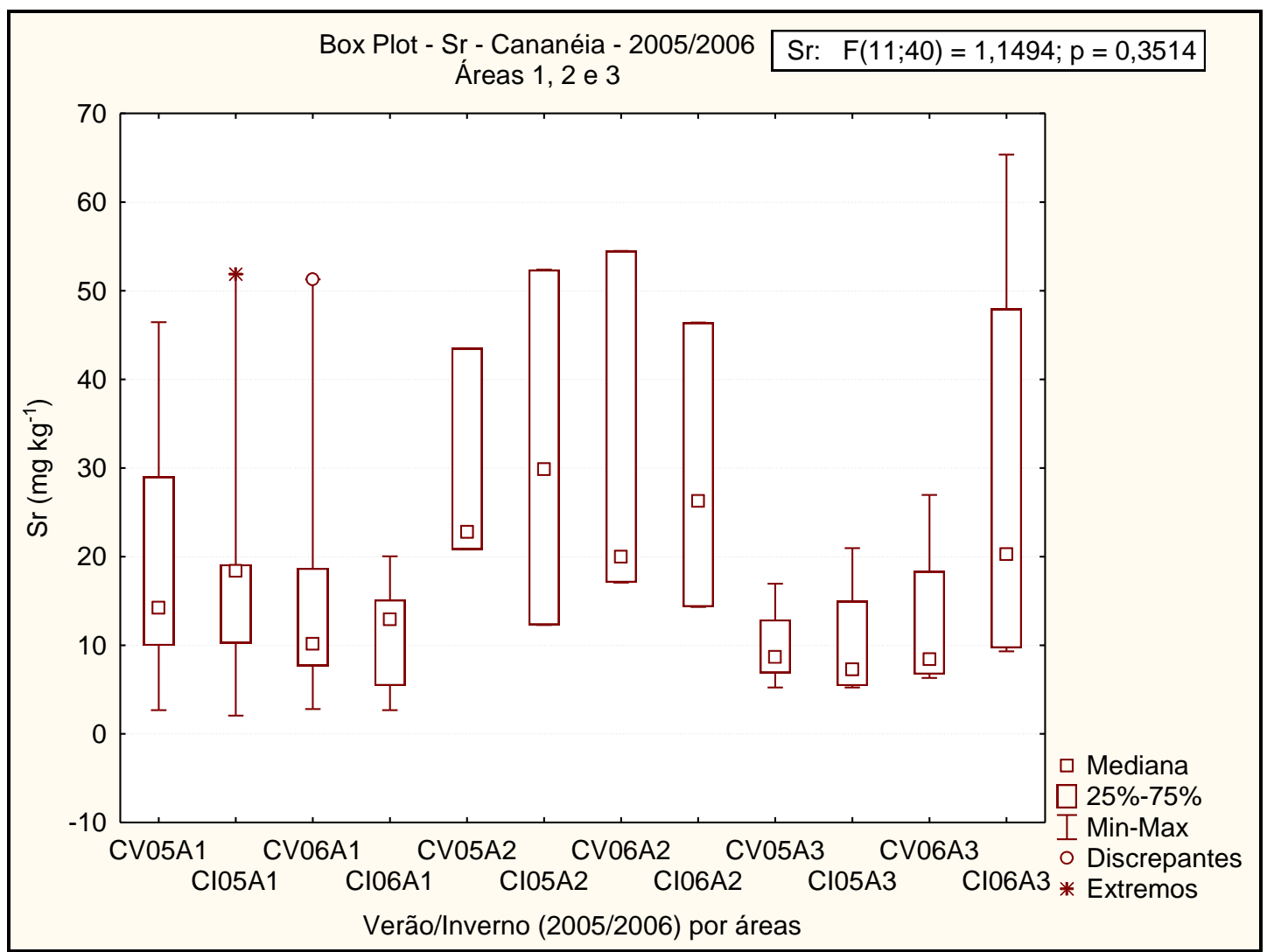

Figura 5.48: Box Plot Sr (mg kg $\left.{ }^{-1}\right)$ e teste ANOVA - Cananéia Inverno/Verão 2005 e 2006 


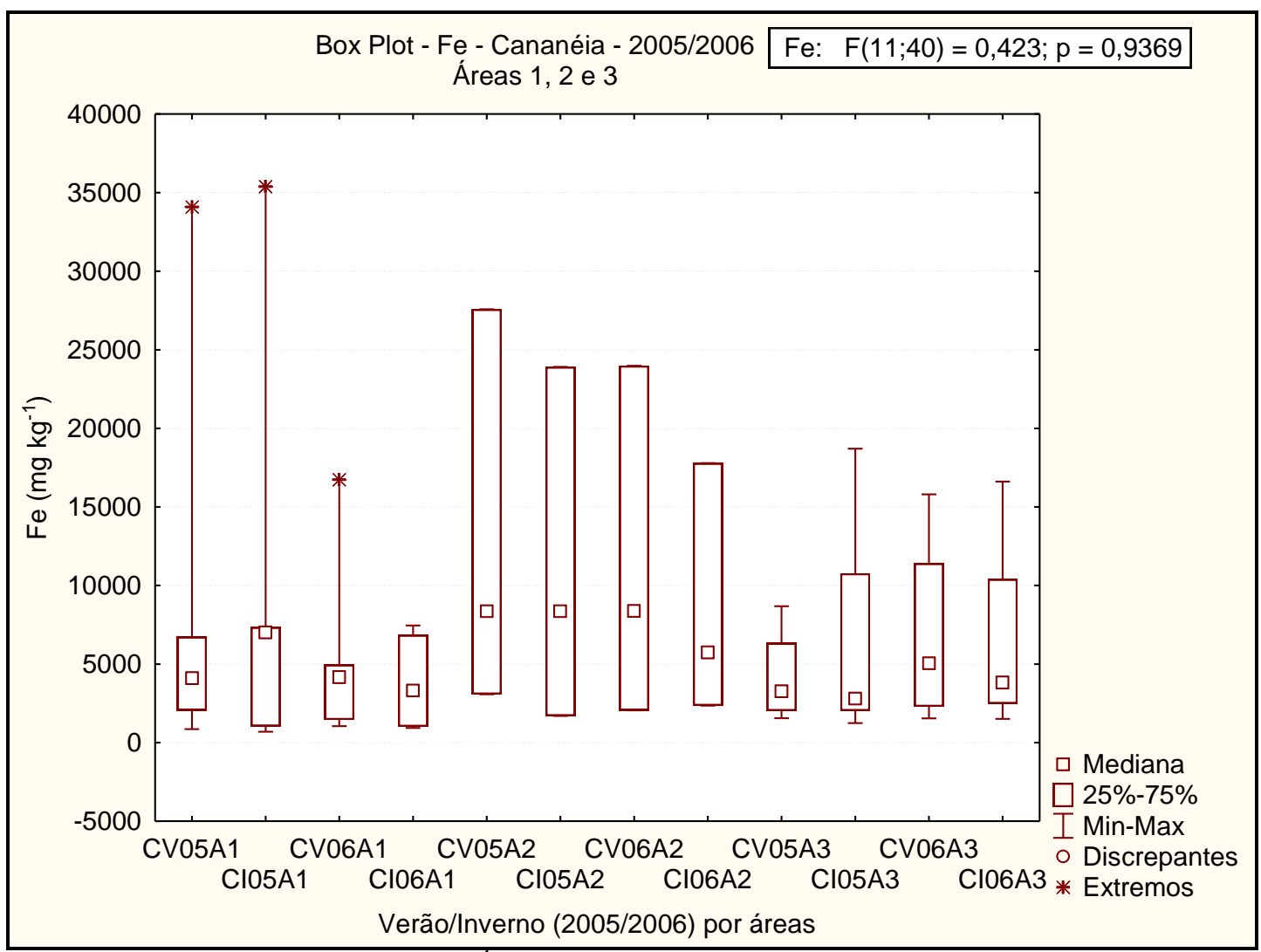

Figura 5.49: Box Plot Fe (mg kg $\left.{ }^{-1}\right)$ e teste ANOVA - Cananéia Inverno/Verão 2005 e 2006

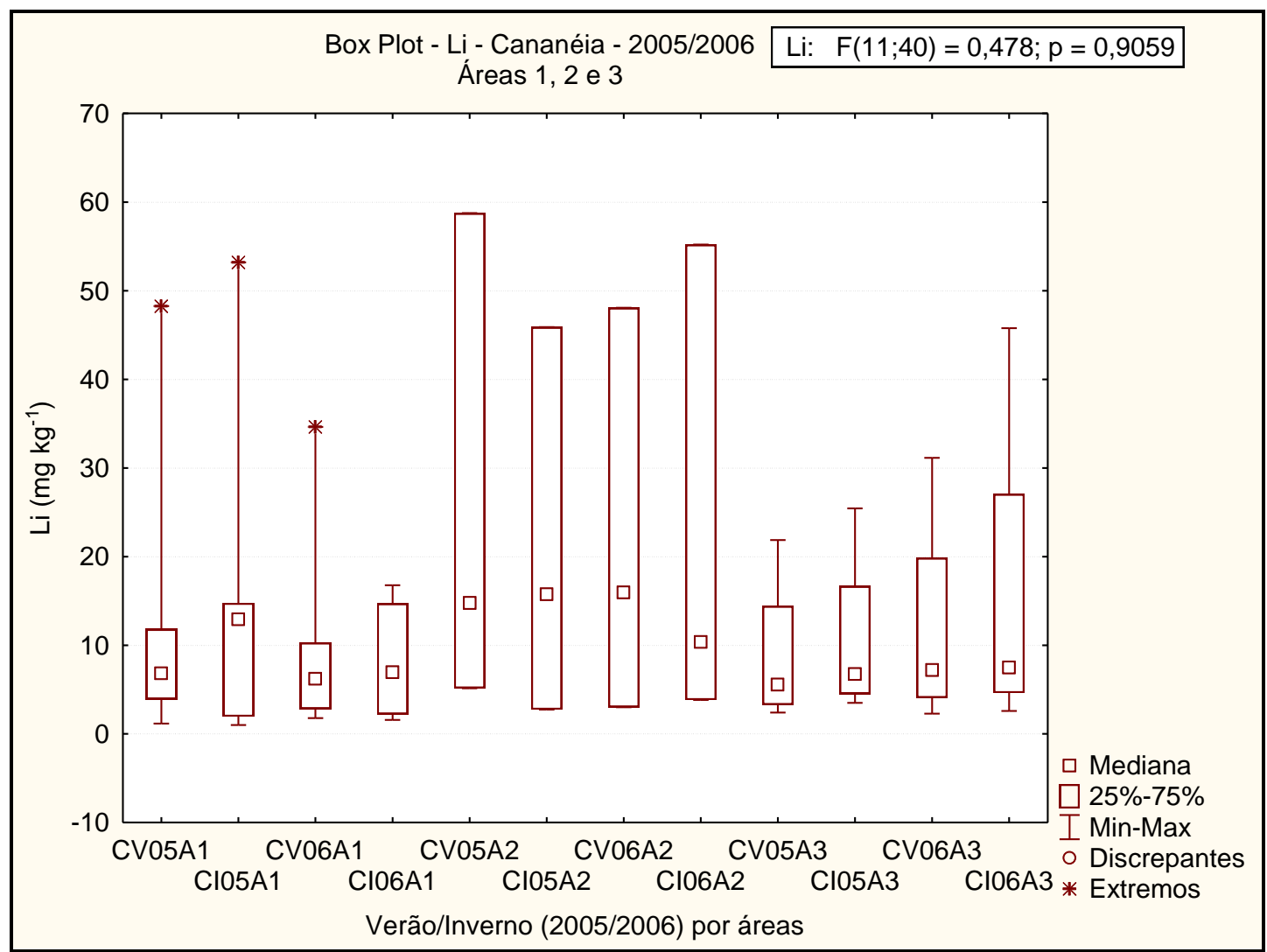

Figura 5.50: Box Plot Li ( $\left.\mathrm{mg} \mathrm{kg}^{-1}\right)$ e teste ANOVA - Cananéia Inverno/Verão 2005 e 2006 


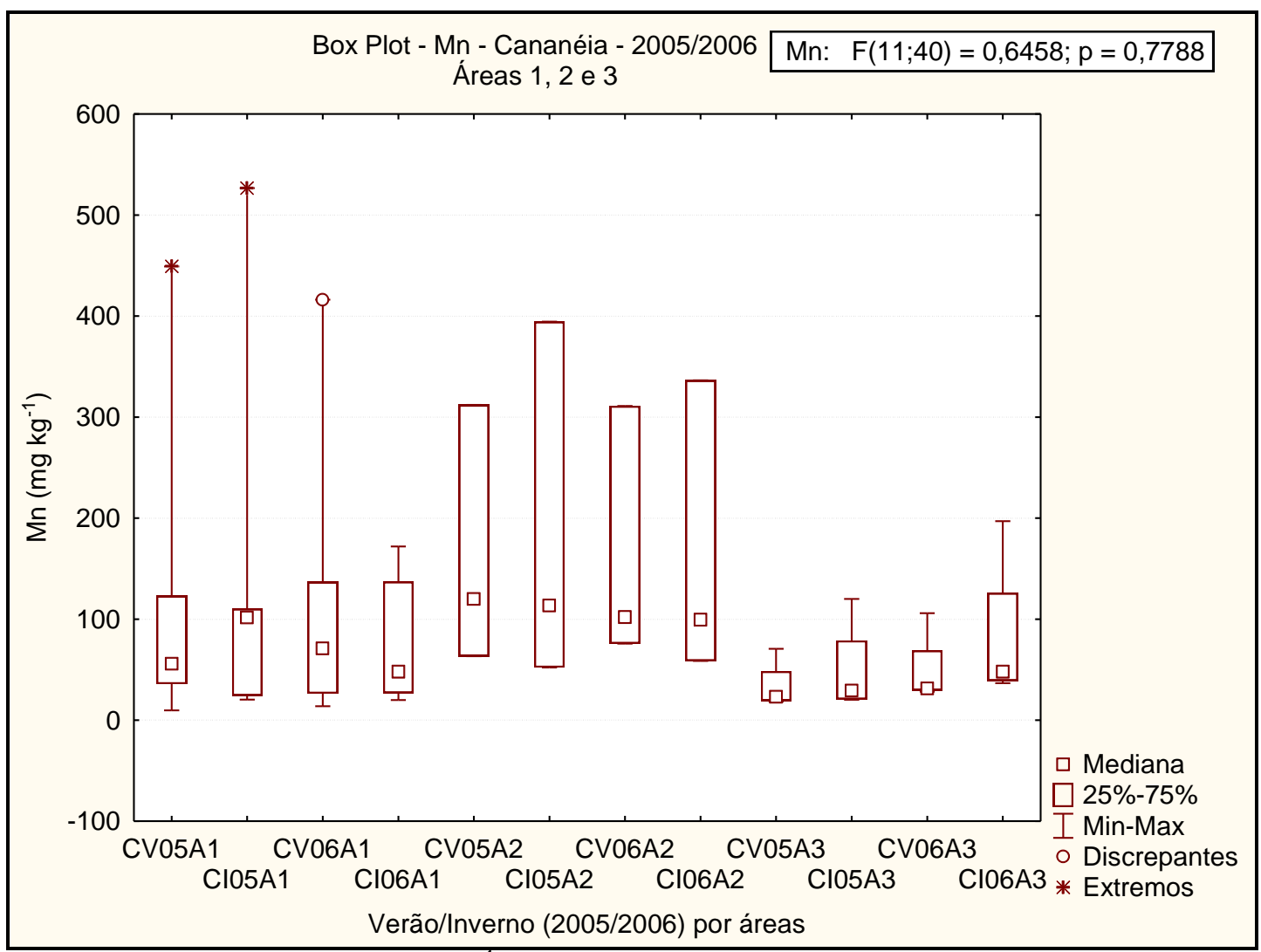

Figura 5.51: Box Plot Mn ( $\left.\mathrm{mg} \mathrm{kg}^{-1}\right)$ e teste ANOVA - Cananéia Inverno/Verão 2005 e 2006

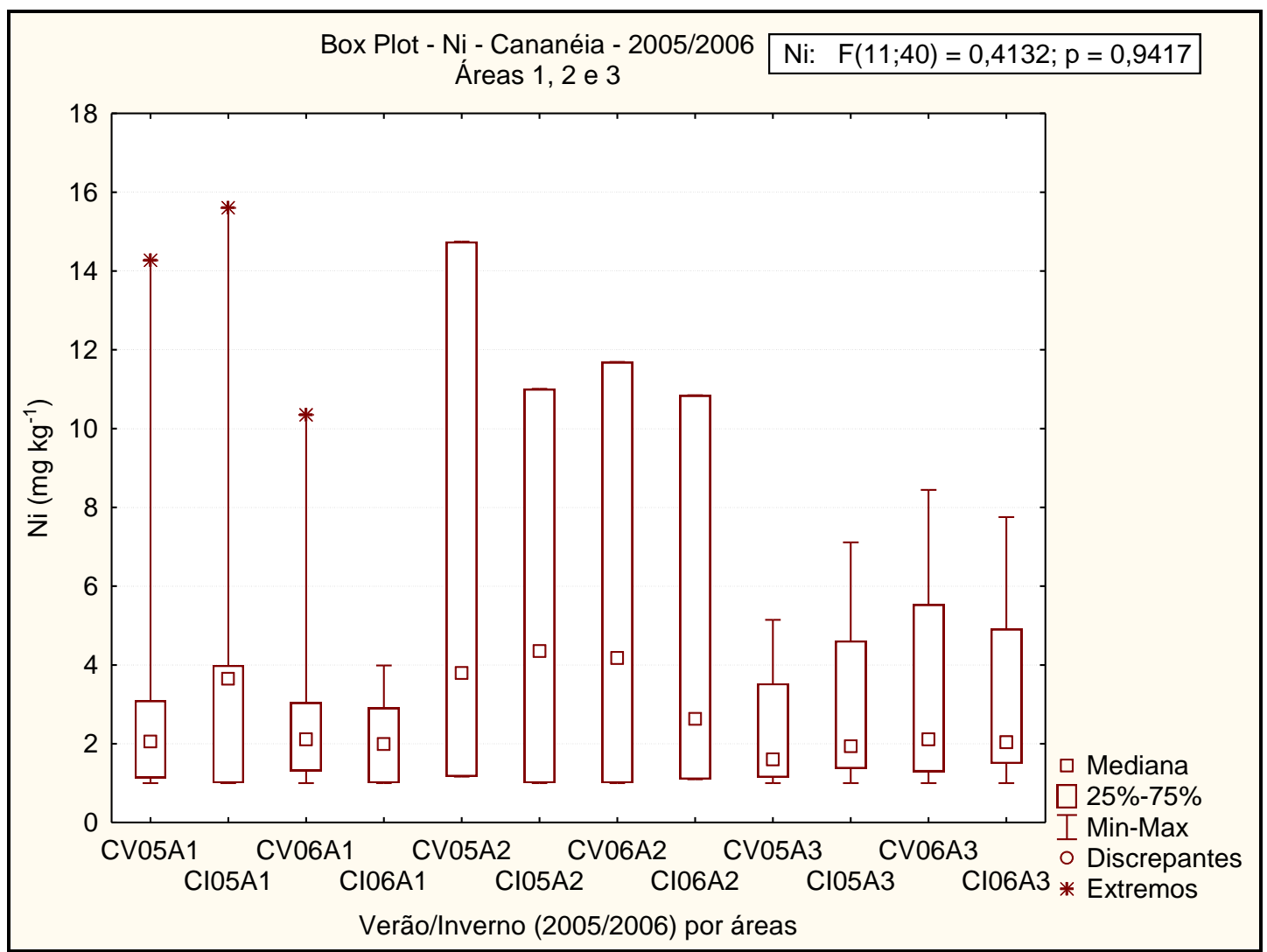

Figura 5.52: Box Plot Ni (mg kg $\left.{ }^{-1}\right)$ e teste ANOVA - Cananéia Inverno/Verão 2005 e 2006 


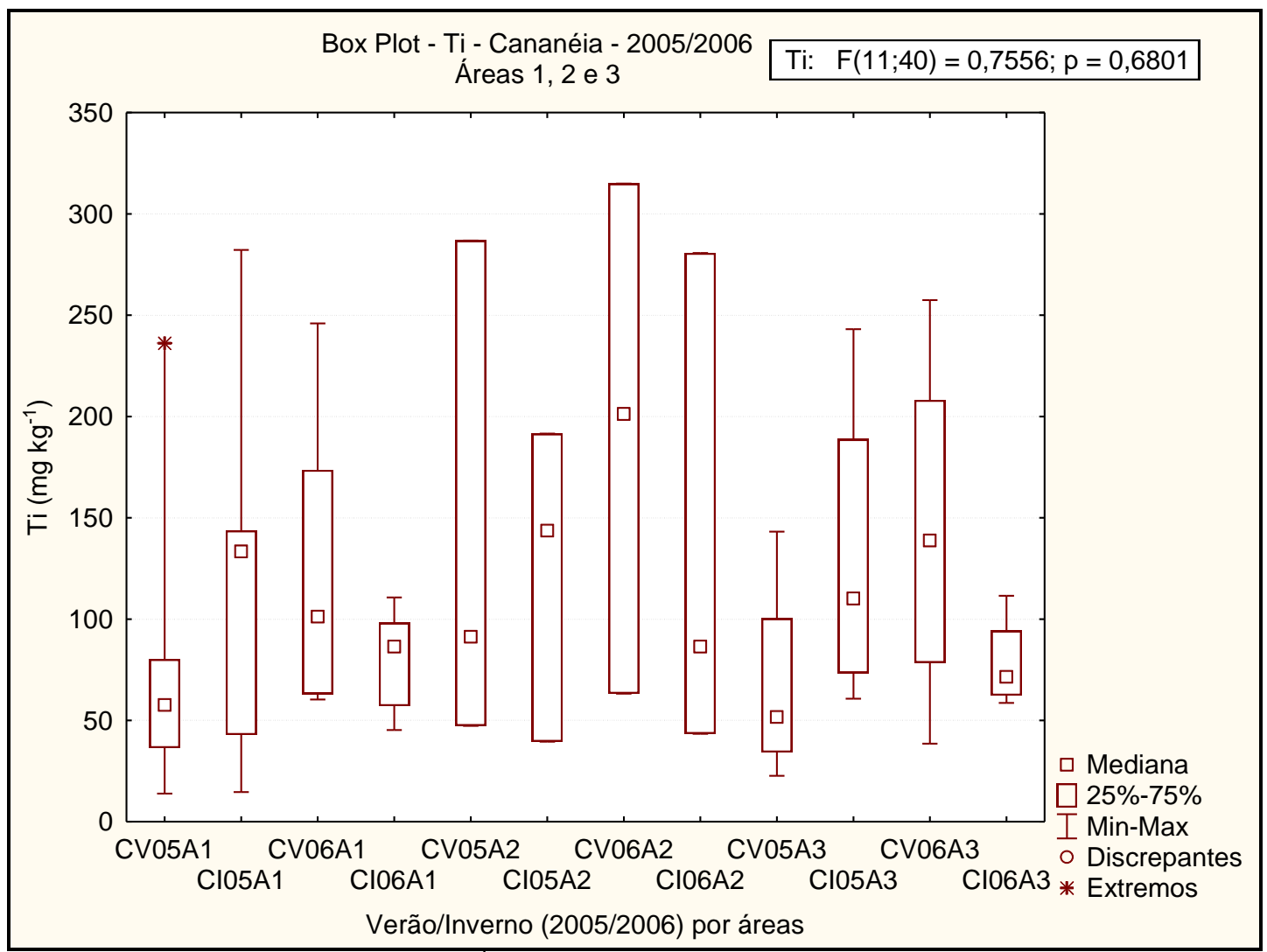

Figura 5.53: Box Plot Ti (mg kg $\left.{ }^{-1}\right)$ e teste ANOVA - Cananéia Inverno/Verão 2005 e 2006

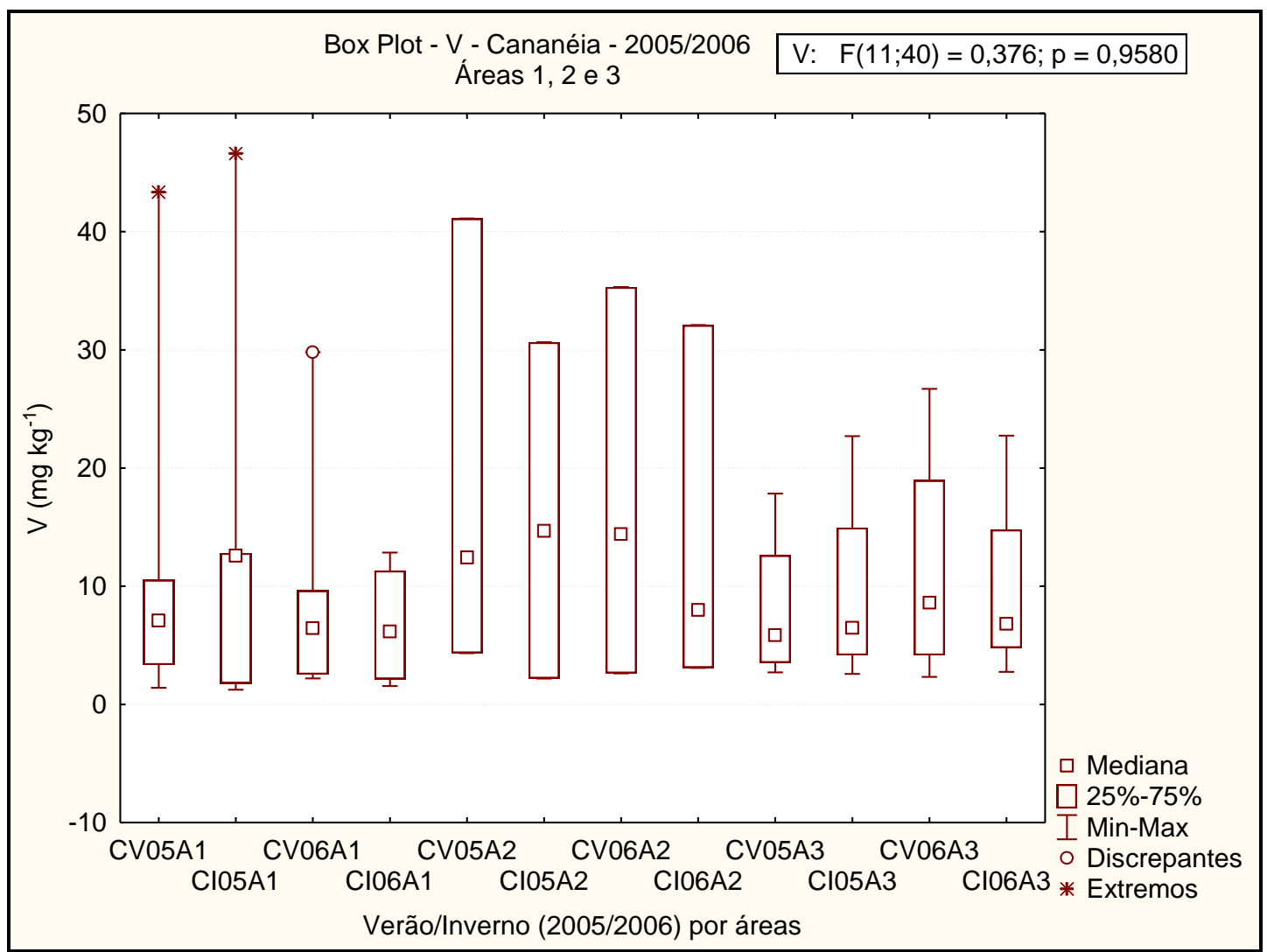

Figura 5.54: Box Plot V $\left(\mathrm{mg} \mathrm{kg}^{-1}\right)$ e teste ANOVA - Cananéia Inverno/Verão 2005 e 2006 


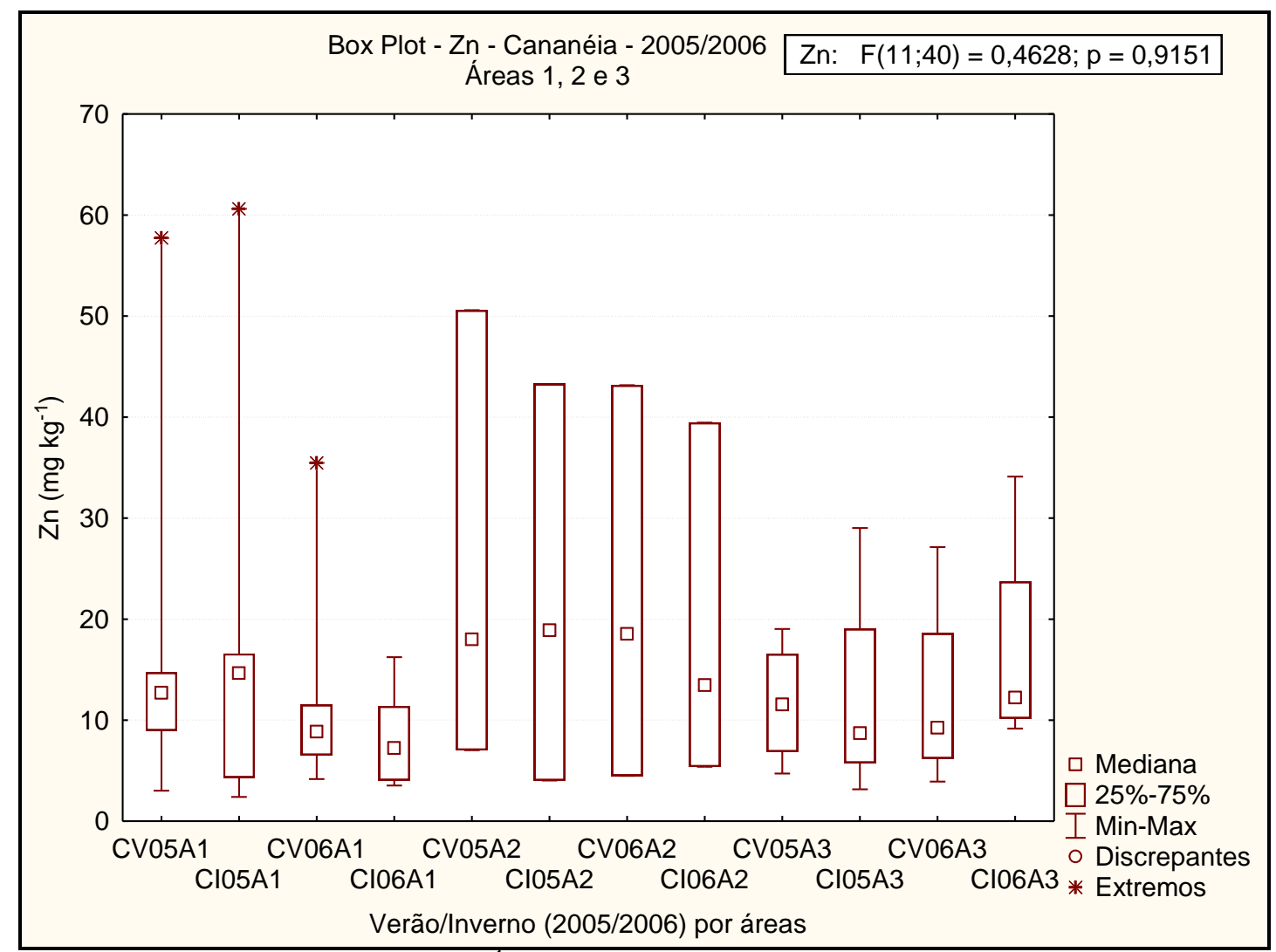

Figura 5.55: Box Plot Zn ( $\left.\mathrm{mg} \mathrm{kg}^{-1}\right)$ e teste ANOVA - Cananéia Inverno/Verão 2005 e 2006

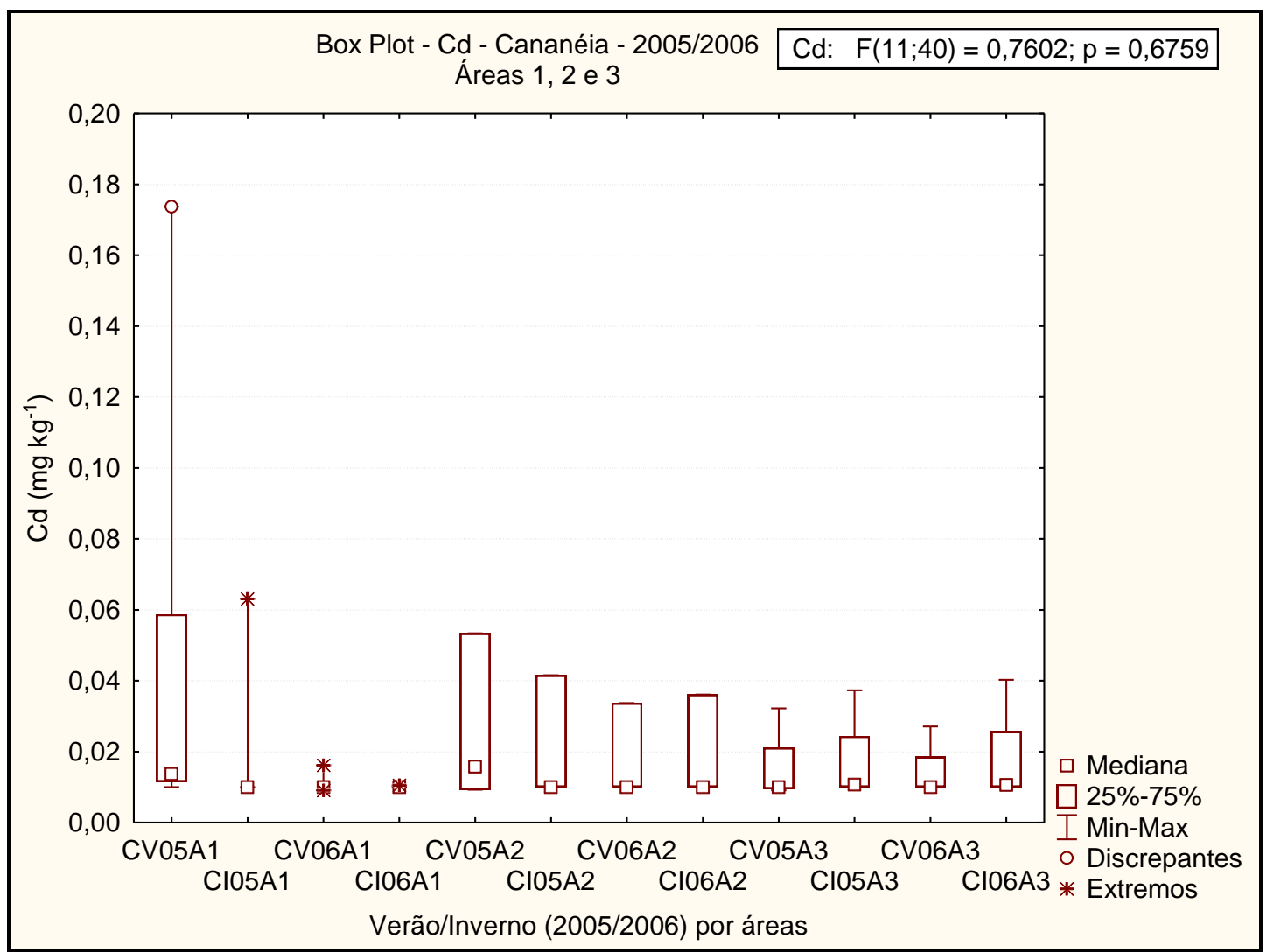

Figura 5.56: Box Plot Cd ( $\left.\mathrm{mg} \mathrm{kg}^{-1}\right)$ e teste ANOVA - Cananéia Inverno/Verão 2005 e 2006 


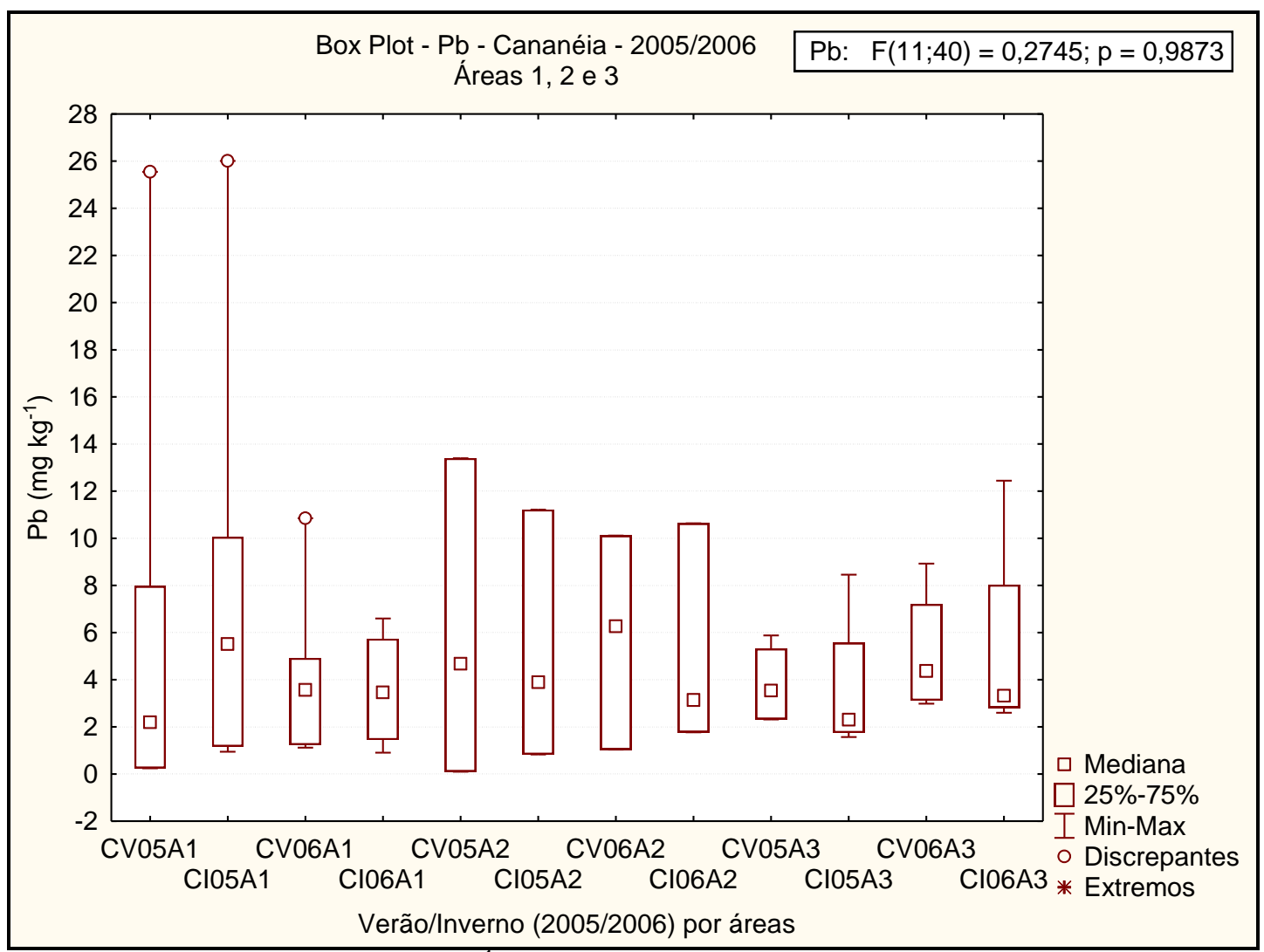

Figura 5.57: Box Plot Pb $\left(\mathrm{mg} \mathrm{kg}^{-1}\right)$ e teste ANOVA - Cananéia Inverno/Verão 2005 e 2006

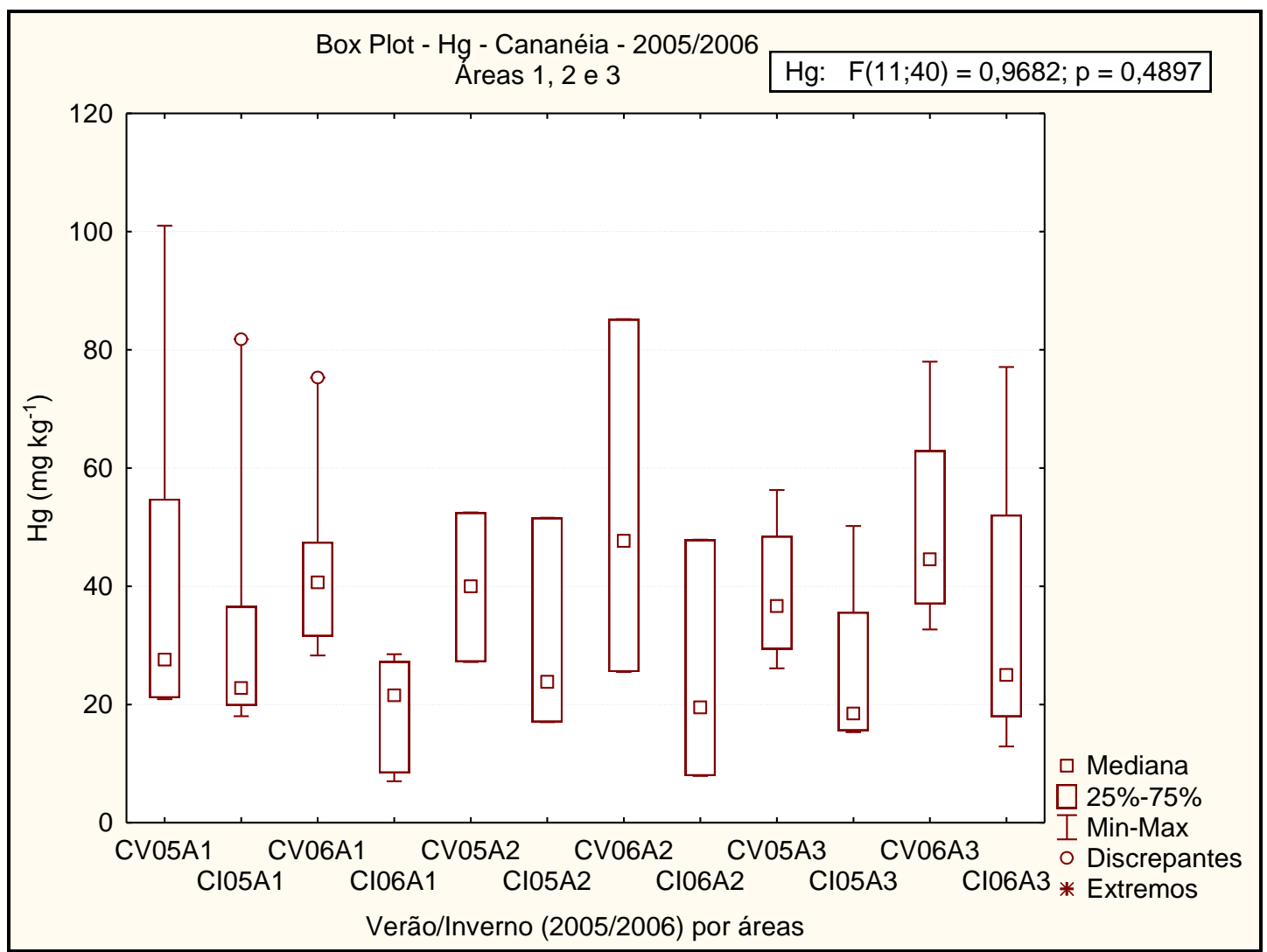

Figura 5.58: Box Plot $\mathrm{Hg}\left(\mathrm{mg} \mathrm{kg}^{-1}\right)$ e teste ANOVA - Cananéia Inverno/Verão 2005 e 2006 
$\mathrm{Na}$ comparação dos valores das medianas das concentrações obtidas para os diferentes elementos avaliados, nas 3 áreas demonstradas pelos gráficos Box plot (Figuras 5.43 à 5.58), o teste ANOVA detectou que não houveram diferenças significativas para todos os elementos avaliados, na comparação entre as áreas, pois todos apresentaram valor-p $>0,05$. Assim sendo, evidenciou-se que as áreas avaliadas se assemelham entre si nas estações de inverno e verão, nos anos de 2005 e 2006.

A Tabela 5.36 apresenta os valores obtidos para o teste ANOVA, para cada uma das 3 áreas avaliadas no estuário de Cananéia, para cada elemento, utilizando-se os dados de verão e inverno de 2005 e 2006.

Tabela 5.36 - Valores obtidos para o teste ANOVA - Teste F e valor-P

\begin{tabular}{c|ccc|ccc|ccc}
\hline ANOVA & \multicolumn{3}{|c|}{ Área 1 - Cananeia } & \multicolumn{3}{c|}{ Área 2 - Cananéia } & \multicolumn{3}{c}{ Área 3 - Cananéia } \\
\hline Elemento & $\boldsymbol{F}$ & valor-P & $\boldsymbol{F}$ crítico & $\boldsymbol{F}$ & valor- $\boldsymbol{P}$ & $\boldsymbol{F}$ crítico & $\boldsymbol{F}$ & valor- $\boldsymbol{P}$ & $\boldsymbol{F}$ crítico \\
\hline Al & 0,42 & 0,74 & 3,10 & 0,12 & 0,95 & 4,07 & 0,36 & 0,78 & 3,49 \\
Ba & 0,28 & 0,84 & 3,10 & 0,10 & 0,96 & 4,07 & 0,72 & 0,56 & 3,49 \\
Cd (GF AAS) & 1,53 & 0,24 & 3,10 & 0,13 & 0,94 & 4,07 & 0,07 & 0,97 & 3,49 \\
Pb (GF AAS) & 0,52 & 0,67 & 3,10 & 0,02 & 1,00 & 4,07 & 0,30 & 0,82 & 3,49 \\
Co & 0,43 & 0,73 & 3,10 & 0,01 & 1,00 & 4,07 & 0,14 & 0,94 & 3,49 \\
Cu & 0,67 & 0,58 & 3,10 & 0,07 & 0,97 & 4,07 & 0,09 & 0,96 & 3,49 \\
Cr & 0,43 & 0,73 & 3,10 & 0,04 & 0,99 & 4,07 & 0,13 & 0,94 & 3,49 \\
Sr & 0,40 & 0,75 & 3,10 & 0,01 & 1,00 & 4,07 & 1,52 & 0,26 & 3,49 \\
Fe & 0,50 & 0,69 & 3,10 & 0,08 & 0,97 & 4,07 & 0,14 & 0,93 & 3,49 \\
Li & 0,33 & 0,80 & 3,10 & 0,02 & 1,00 & 4,07 & 0,19 & 0,90 & 3,49 \\
Mn & 0,24 & 0,87 & 3,10 & 0,02 & 1,00 & 4,07 & 0,66 & 0,59 & 3,49 \\
Hg (CV AAS) & 1,56 & 0,23 & 3,10 & 0,96 & 0,46 & 4,07 & 0,98 & 0,43 & 3,49 \\
Ni & 0,43 & 0,73 & 3,10 & 0,04 & 0,99 & 4,07 & 0,11 & 0,95 & 3,49 \\
Ti & 0,72 & 0,55 & 3,10 & 0,20 & 0,89 & 4,07 & 1,26 & 0,33 & 3,49 \\
V & 0,43 & 0,74 & 3,10 & 0,05 & 0,98 & 4,07 & 0,10 & 0,96 & 3,49 \\
Zn & 0,61 & 0,62 & 3,10 & 0,04 & 0,99 & 4,07 & 0,23 & 0,87 & 3,49 \\
\hline
\end{tabular}

Verificou-se o mesmo comportamento ao avaliarmos cada área individualmente através do teste ANOVA, apresentado na Tabela 5.36, o qual demonstra que em nenhuma das áreas ocorreram casos com valor de $\mathrm{P}<0,05$

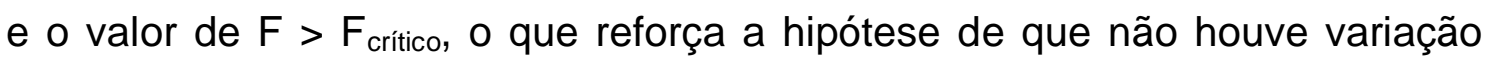
temporal nos diferentes períodos avaliados, para a concentração dos elementos analisados. 
Analisando-se o comportamento das regiões para os diferentes elementos avaliados, observou-se que a região do Mar de Cananéia é a que possui maior número de casos outliers e extremos, o que parece indicar grande influência hidrodinâmica na mobilidade dos metais. O período inverno de 2006 foi o que apresentou uma maior constância nos resultados, não apresentando casos outliers ou valores extremos.

A região do Mar de Cubatão é a região que apresentou a maior proximidade dos valores em relação à mediana, o que pode indicar menor influência hidrodinâmica na mobilidade dos elementos avaliados.

Na Baía de Trapandé, verificou-se um grande numero de casos em que as amostras estiveram fora dos limites do primeiro e terceiro quartis, porém em sua totalidade encontraram-se na região non-outlier.

\subsubsection{Estudo de Normalização}

Conforme descrito no item 4.11.1, para o presente estudo, utilizou-se - Sc como elemento normalizador, devido às características de elemento conservativo, pelo método de extrapolação da curva de regressão. Os valores de Sc utilizados foram obtidos pela técnica de NAA e estão apresentados no anexo XVII.

Foram avaliados os pontos coletados no inverno de 2005, na região de Cananéia e construídos os gráficos scatterplots. As Figuras 5.59 à 5.70 apresentam as curvas de normalização para os diversos elementos determinados nas amostras de Cananéia - Inverno de 2005. 


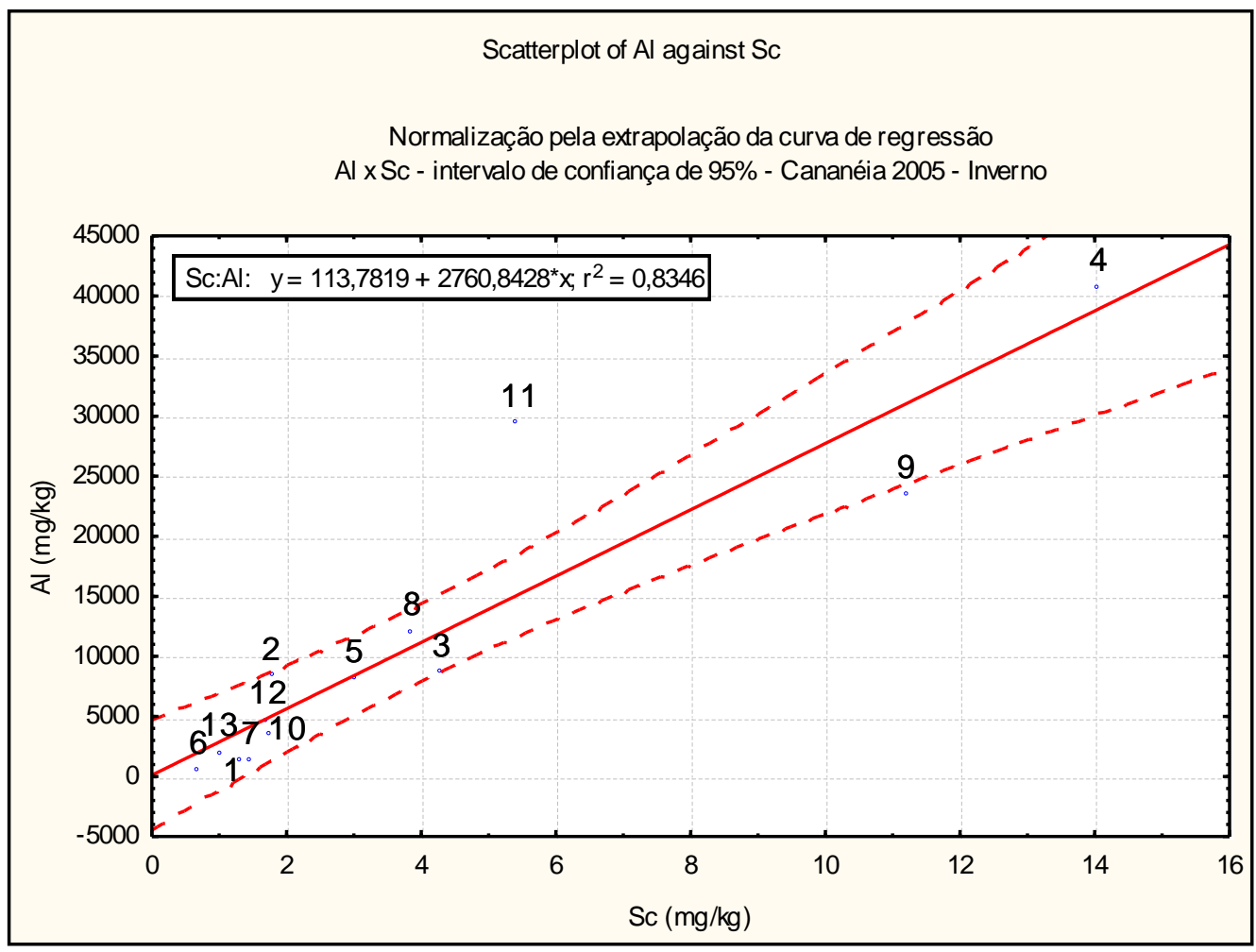

Figura 5.59: Scatterplot - Al x Sc - Cananéia, Inverno de 2005

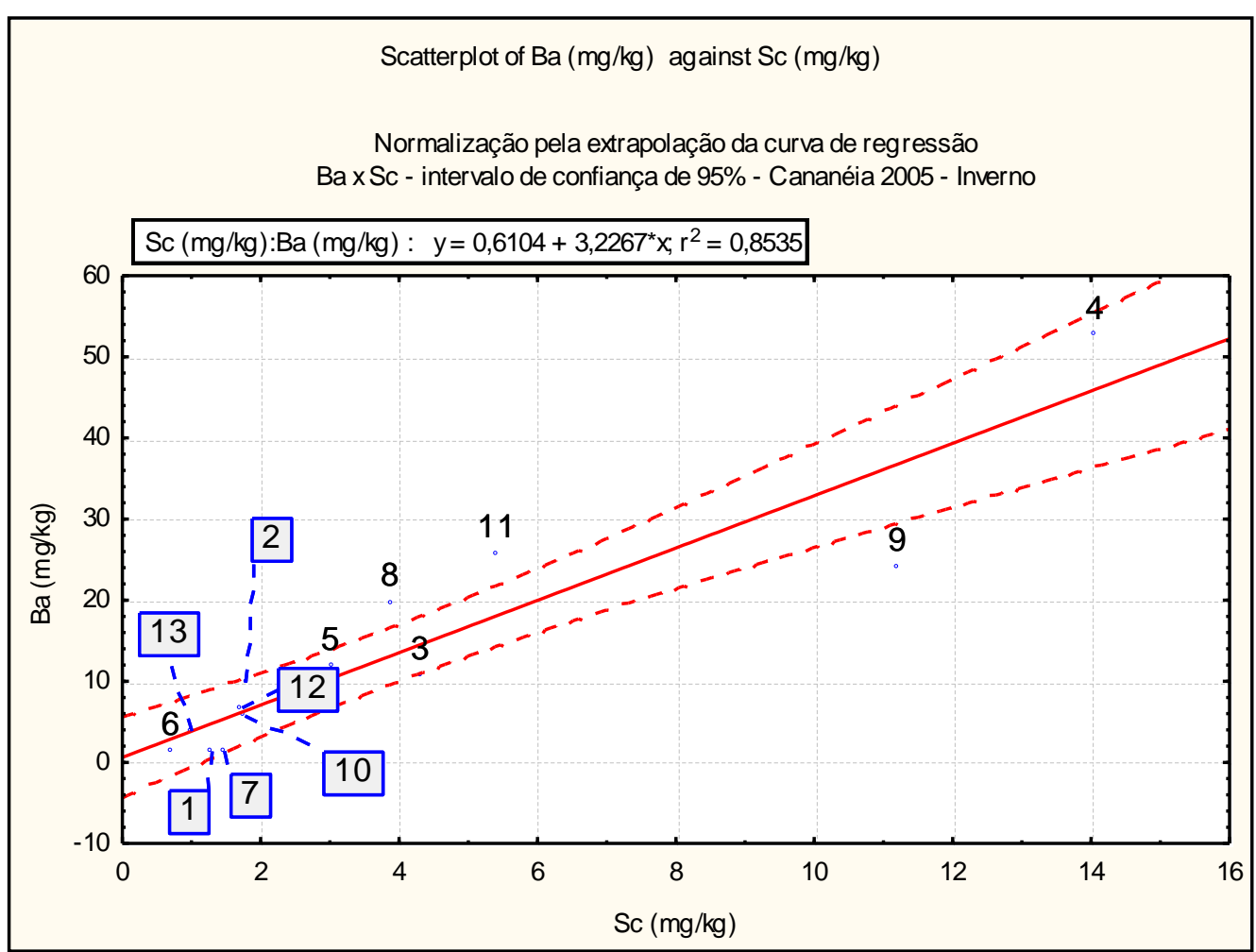

Figura 5.60: Scatterplot Ba x Sc- Cananéia, Inverno de 2005 


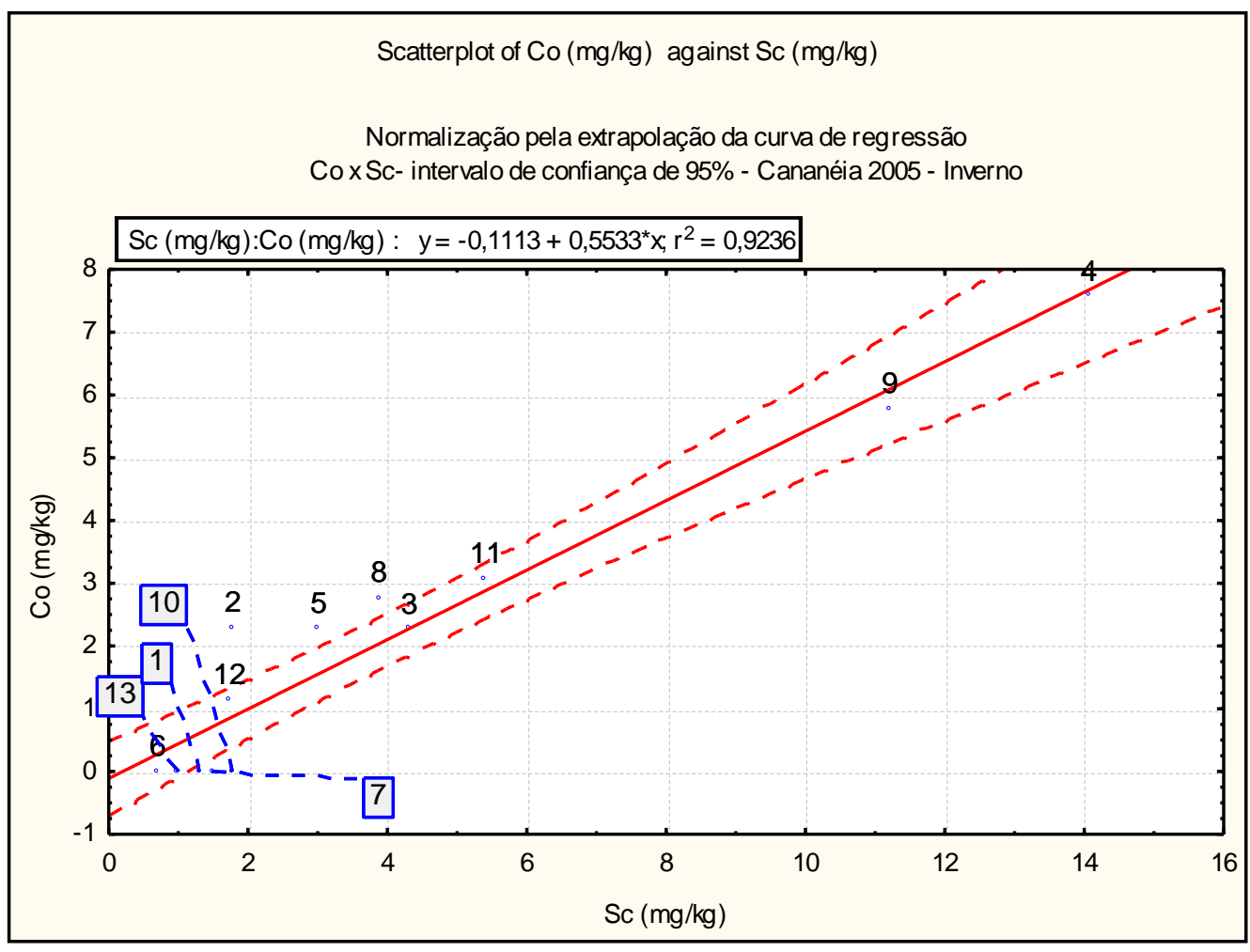

Figura 5.61: Scatterplot Co x Sc- Cananéia, Inverno de 2005

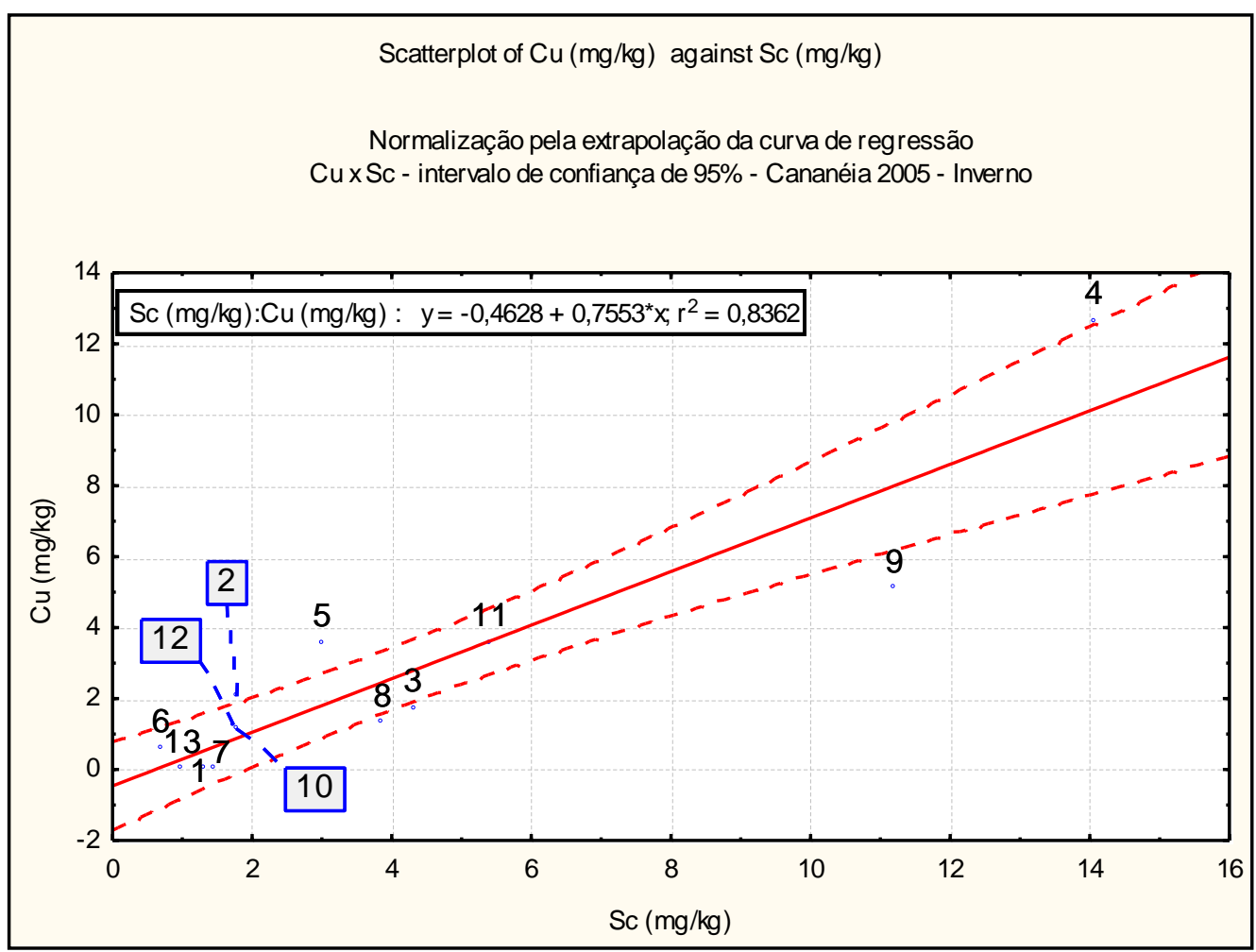

Figura 5.62: Scatterplot Cu x Sc- Cananéia, Inverno de 2005 


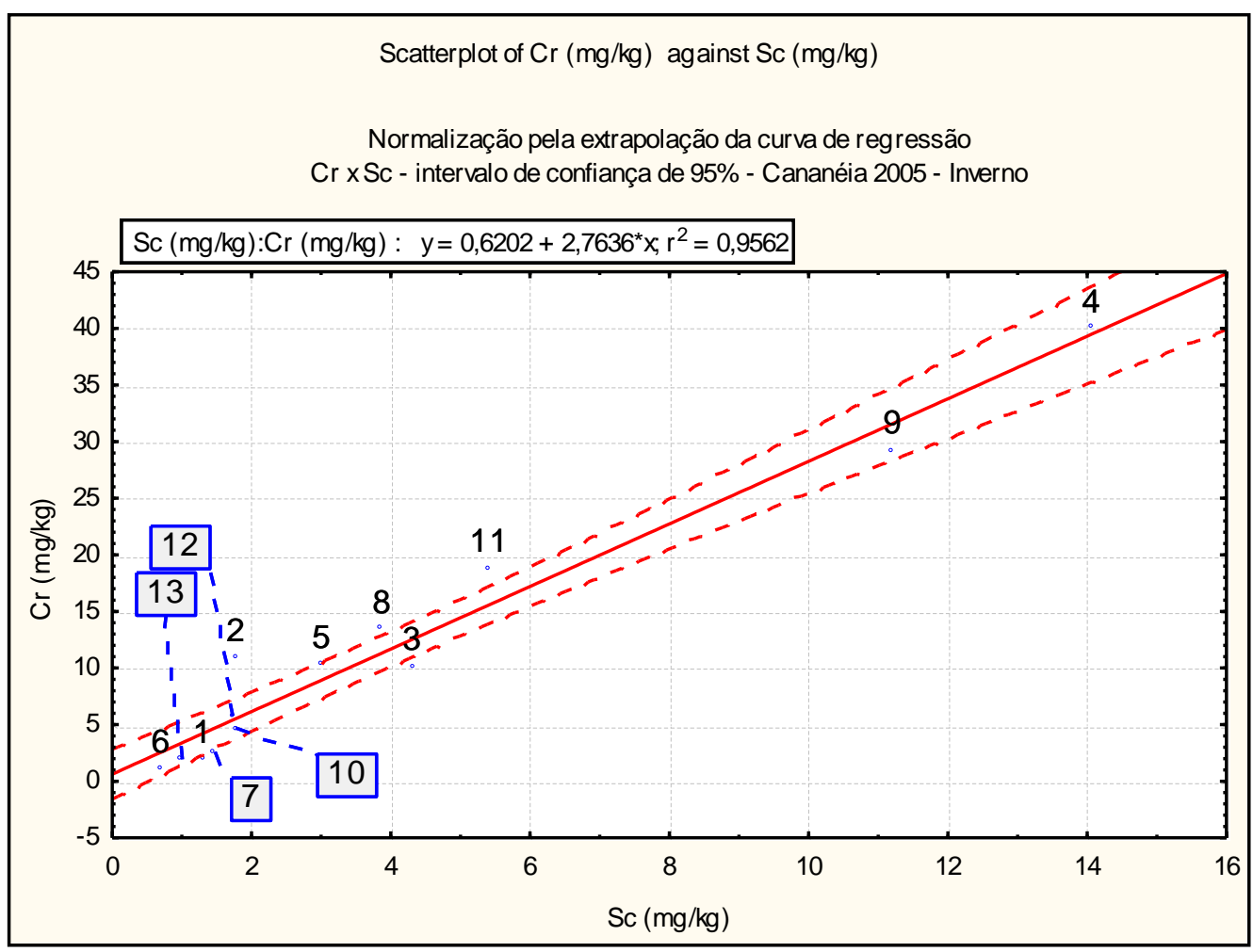

Figura 5.63: Scatterplot Cr x Sc- Cananéia, Inverno de 2005

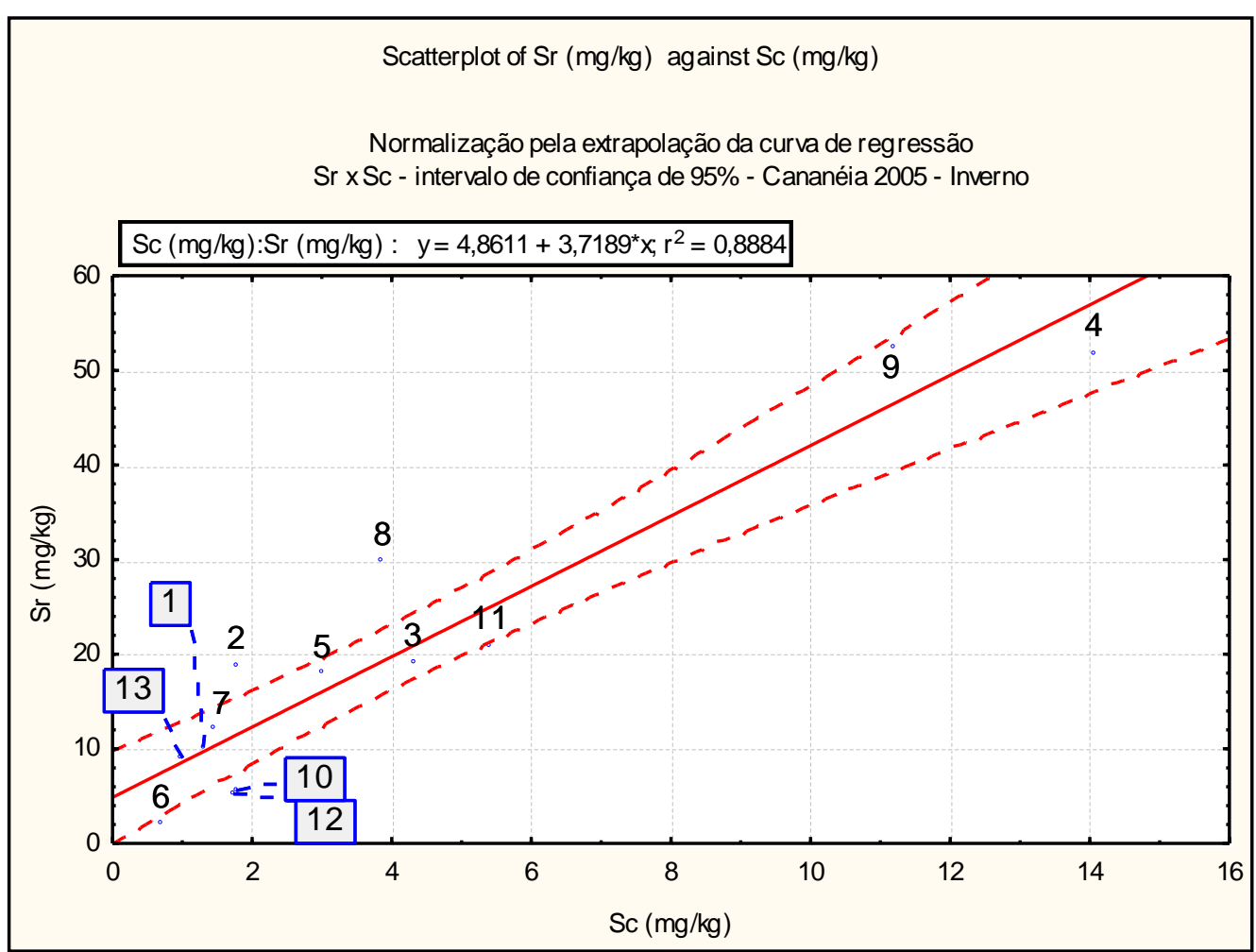

Figura 5.64: Scatterplot Sr x Sc- Cananéia, Inverno de 2005 


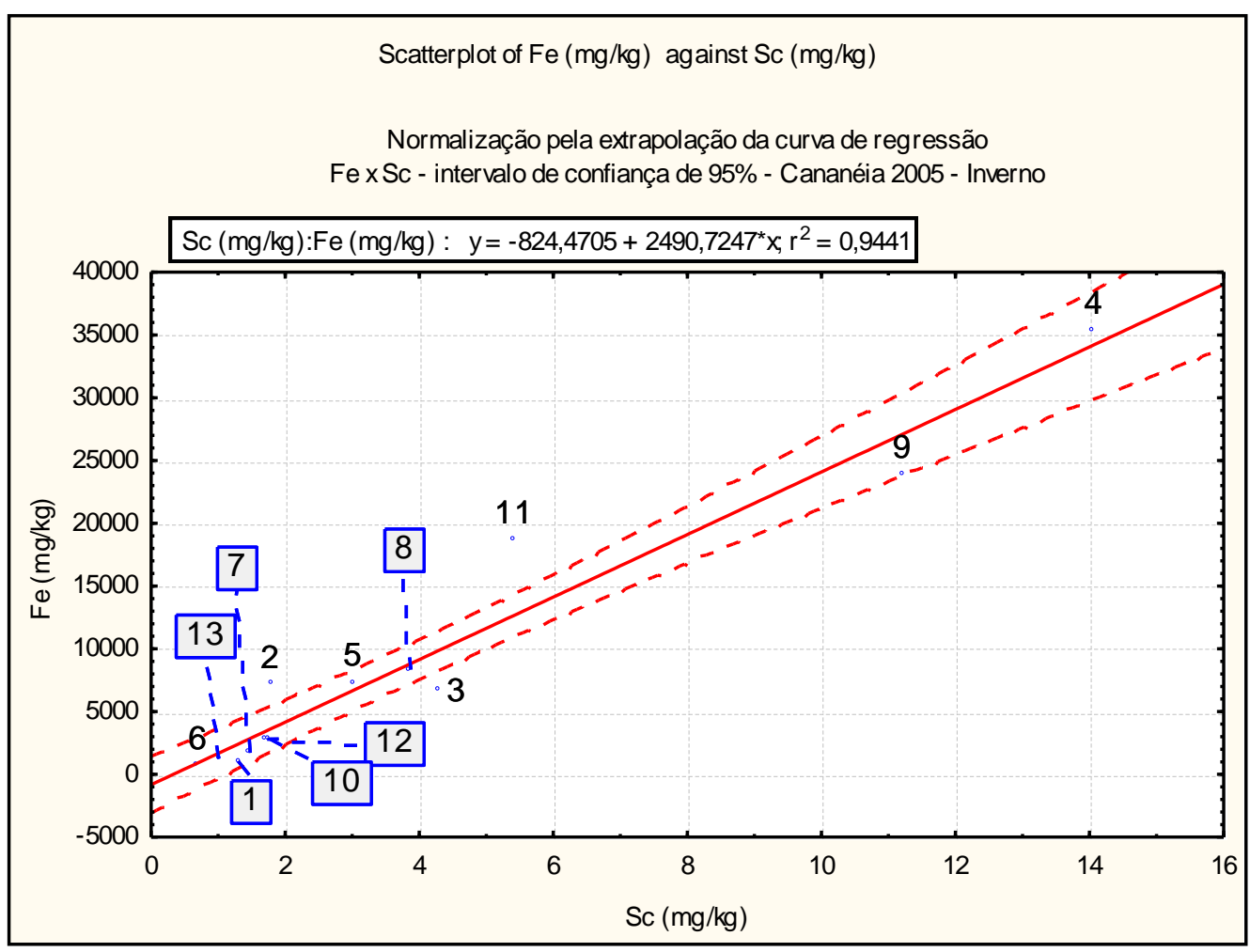

Figura 5.65: Scatterplot Fe x Sc- Cananéia, Inverno de 2005

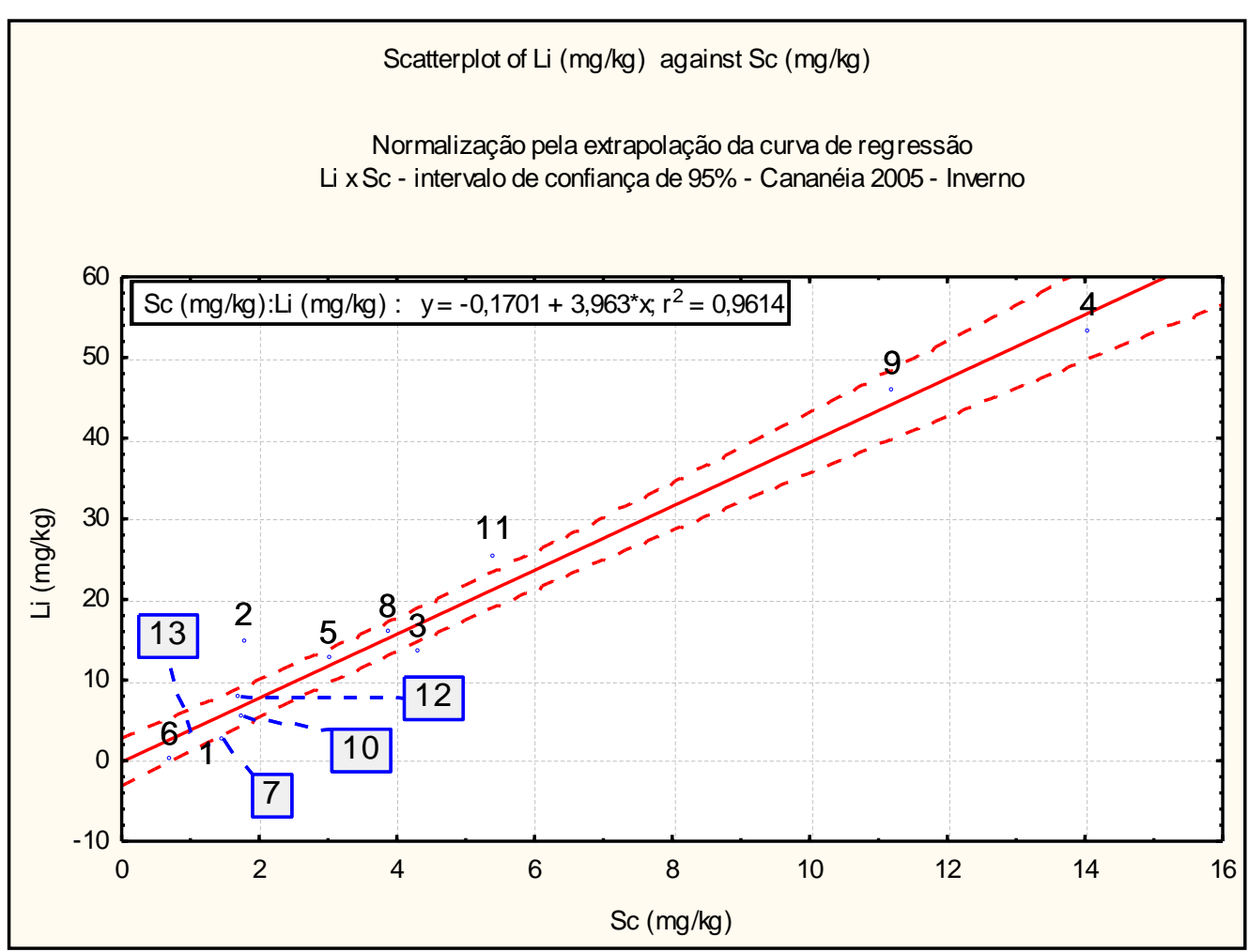

Figura 5.66: Scatterplot Li x Sc- Cananéia, Inverno de 2005 


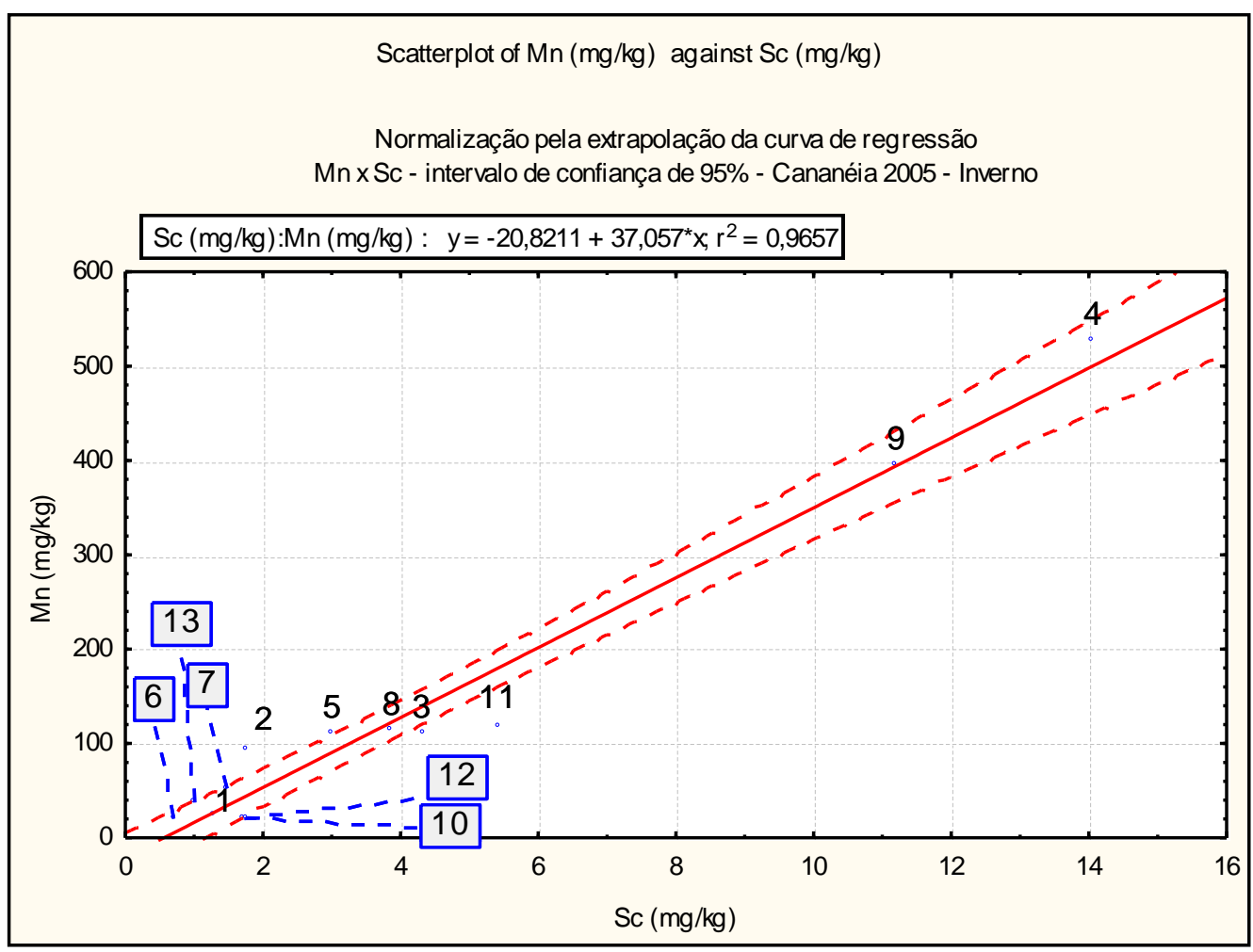

Figura 5.67: Scatterplot Mn x Sc- Cananéia, Inverno de 2005

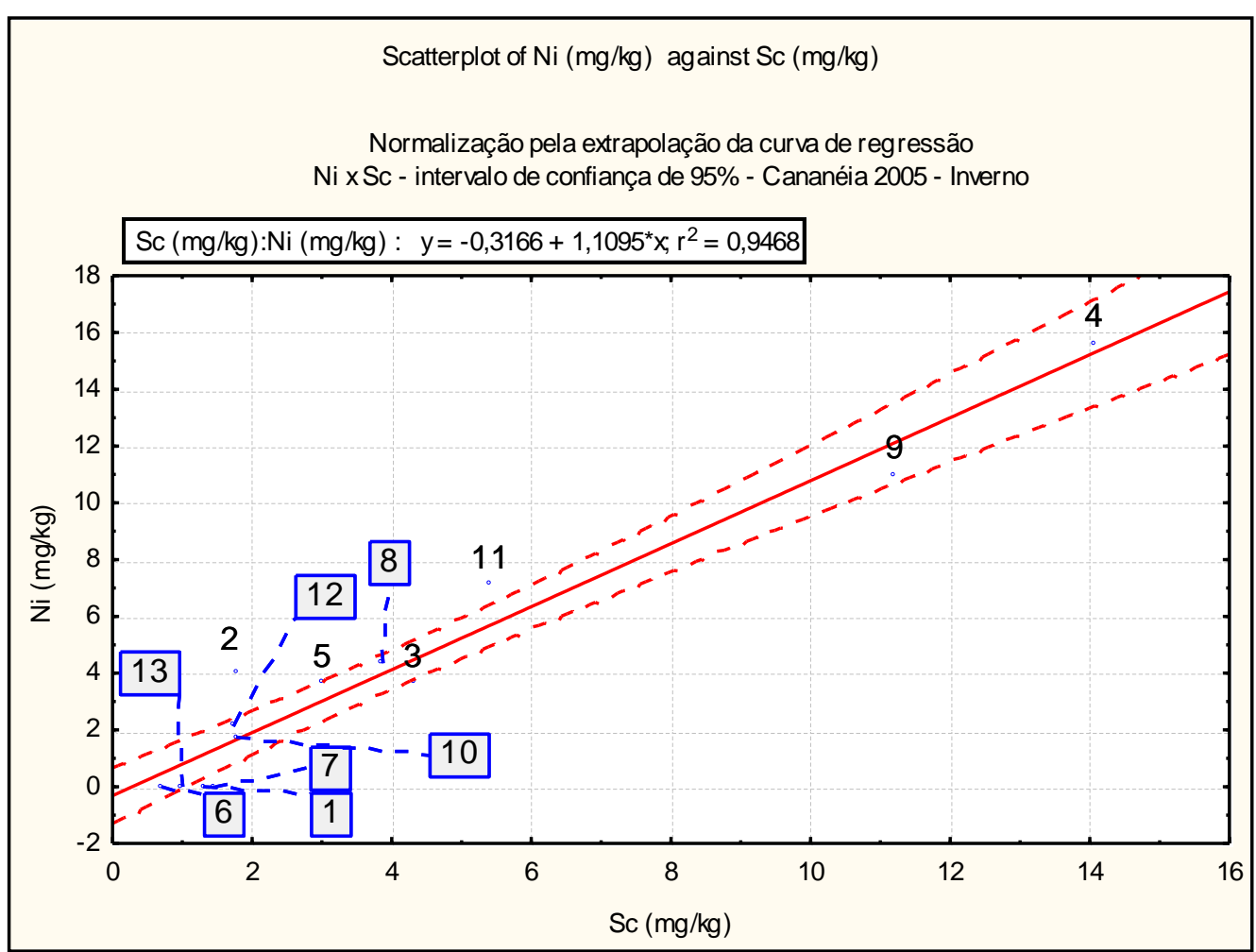

Figura 5.68: Scatterplot Ni x Sc- Cananéia, Inverno de 2005 


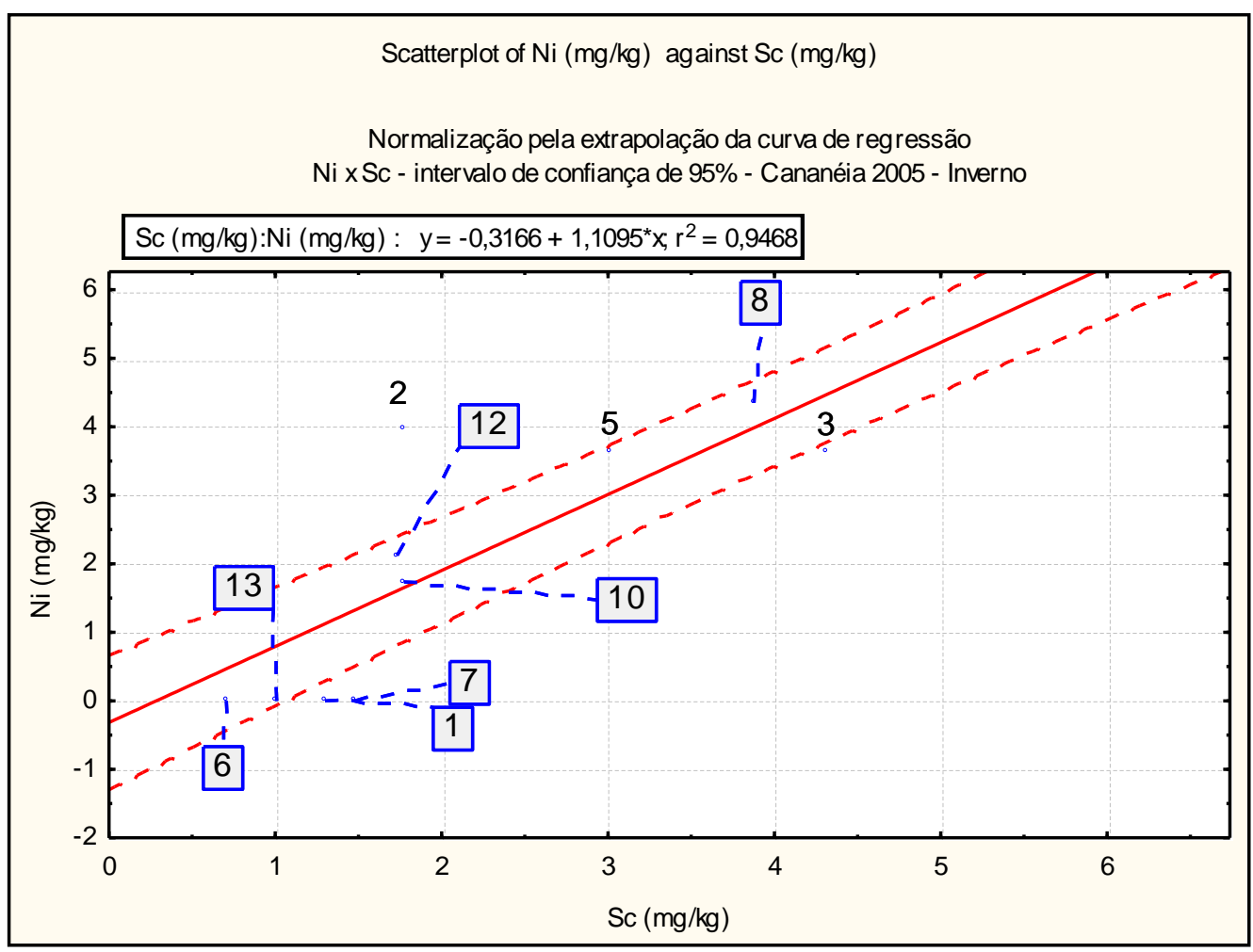

Figura 5.69: Ampliação do Scatterplot Ni x Sc- Cananéia, Inverno de 2005

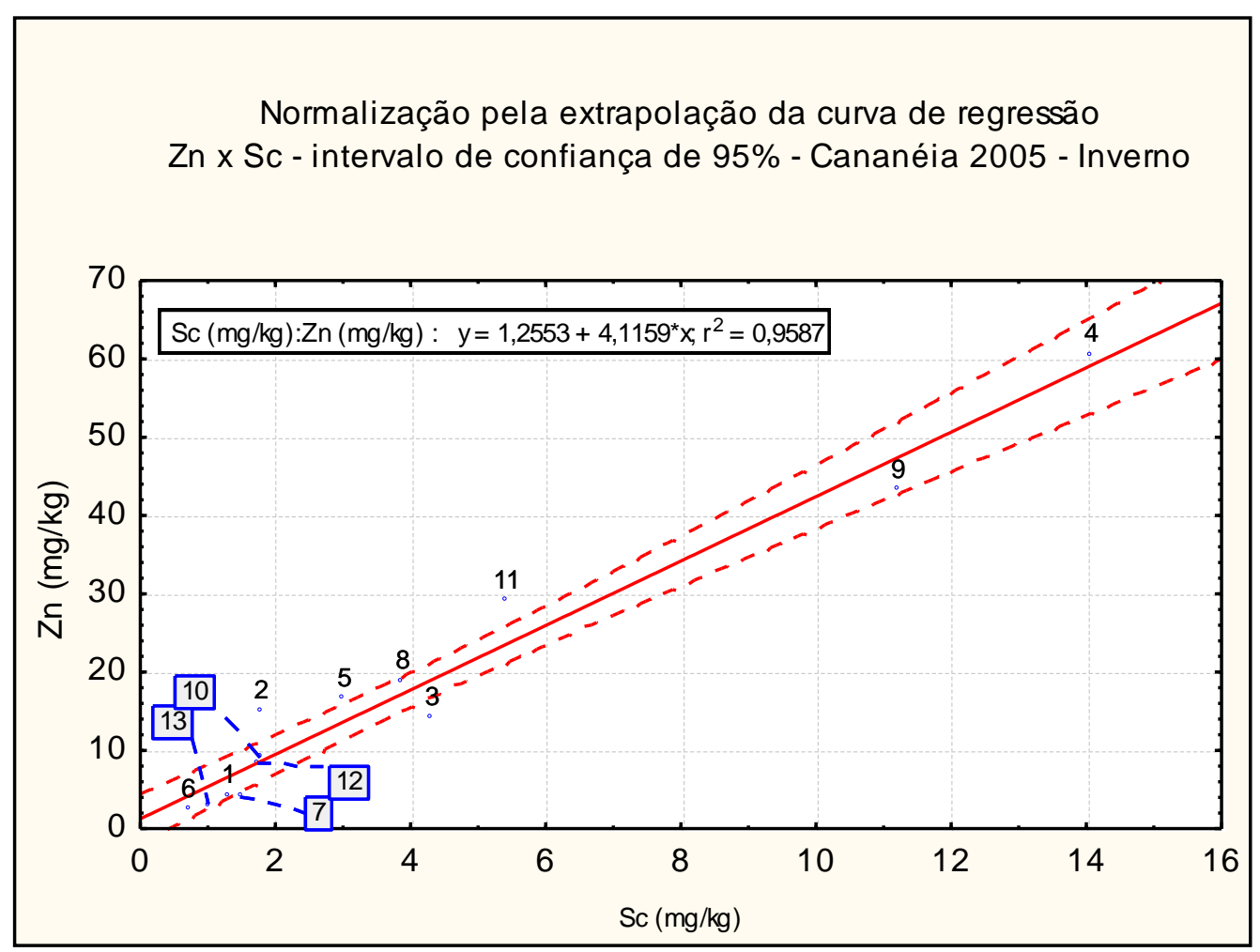

Figura 5.70 - Scatterplot - Zn x Sc- Cananéia, Inverno de 2005 
Após a avaliação dos gráficos scatterplot, observou-se que:

- O ponto 02 apresentou desvios acima do intervalo de confiança para os elementos $\mathrm{Co}, \mathrm{Cr}, \mathrm{Cu}, \mathrm{Fe}, \mathrm{Li}, \mathrm{Mn}, \mathrm{Ni}, \mathrm{Sr}$ e $\mathrm{Zn}$. Tal comportamento pode sugerir fortemente um impacto antrópico neste ponto de amostragem, devido a vários elementos avaliados apresentarem o mesmo comportamento.

- Em relação ao ponto 05 , verificou-se que os elementos $\mathrm{Co}, \mathrm{Cr}, \mathrm{Cu}, \mathrm{Mn}$ e $\mathrm{Zn}$ apresentaram algum desvio em função do Sc, conforme apresentado nos respectivos scatterplots.

- O ponto 11, apresentou desvios para os elementos $\mathrm{Al}, \mathrm{Ba}, \mathrm{Cr}, \mathrm{Fe}, \mathrm{Li}, \mathrm{Ni}$ e Zn.

- Para o ponto 8, foram observados desvios acima do intervalo de confiança para os elementos $\mathrm{Ba}, \mathrm{Co}, \mathrm{Cr}$ e Sr.

Levando-se em conta as considerações acima relatadas, podemos concluir que os pontos $02,05,08$ e 11 apresentaram desvios para vários elementos, portanto apresentam indícios de contaminação por fontes antrópicas.

Em relação aos demais pontos avaliados, não foram observadas alterações significativas nas análises dos gráficos Scatterplots. Como estes pontos também estão em volta da llha de Cananéia, sugere-se uma influência da circulação das ondas de maré que entram pelas desembocaduras de Cananéia (ao Sul) e Icapara (ao norte), também sofrendo influência de águas fluviais e dos ventos (MIYAO et al, 1986). Com esta influência de maré, as possíveis contaminações provenientes do canal do Valo Grande podem ficar dispersas pelo estuário, de acordo com a mobilidade hidrodinâmica. 


\subsubsection{Análise de Clusters}

Para a avaliação da similaridade dos pontos de amostragem em relação à concentração dos metais analisados por ICP OES e AAS $(\mathrm{Cd}, \mathrm{Hg}$ e $\mathrm{Pb}$ ) nos diferentes pontos de amostragem, nos diferentes períodos sazonais (inverno e verão), foram realizadas análises de agrupamentos, a análise de clusters. Para cada amostra, foram utilizadas as variáveis de concentração dos elementos: Al, Ba, Co, Cu, Cr, Fe, Li, Mn, Ni, Sr e Zn. Os dendrogramas foram obtidos a partir do software Statistica $8.0 \AA$. Para a montagem das planilhas de cálculos, para os elementos cujos resultados foram não detectados, utilizou-se o valor de L.Q do método. Posteriormente, foi feita a normalização dos dados, com a utilização do software Statistica 8.0 ®.

Visando a verificação da particularidade dos grupos de diferentes amostras, tais como comparações entre os diferentes períodos climáticos (inverno e verão) e temporais (anos de 2005 e 2006), foram obtidos quatro diagramas de clusters, representando cada época especifica.

A Figura 5.71 apresenta o dendrograma obtido pelo método de Ward, variáveis estações, para as amostras de Cananéia - Verão de 2005.

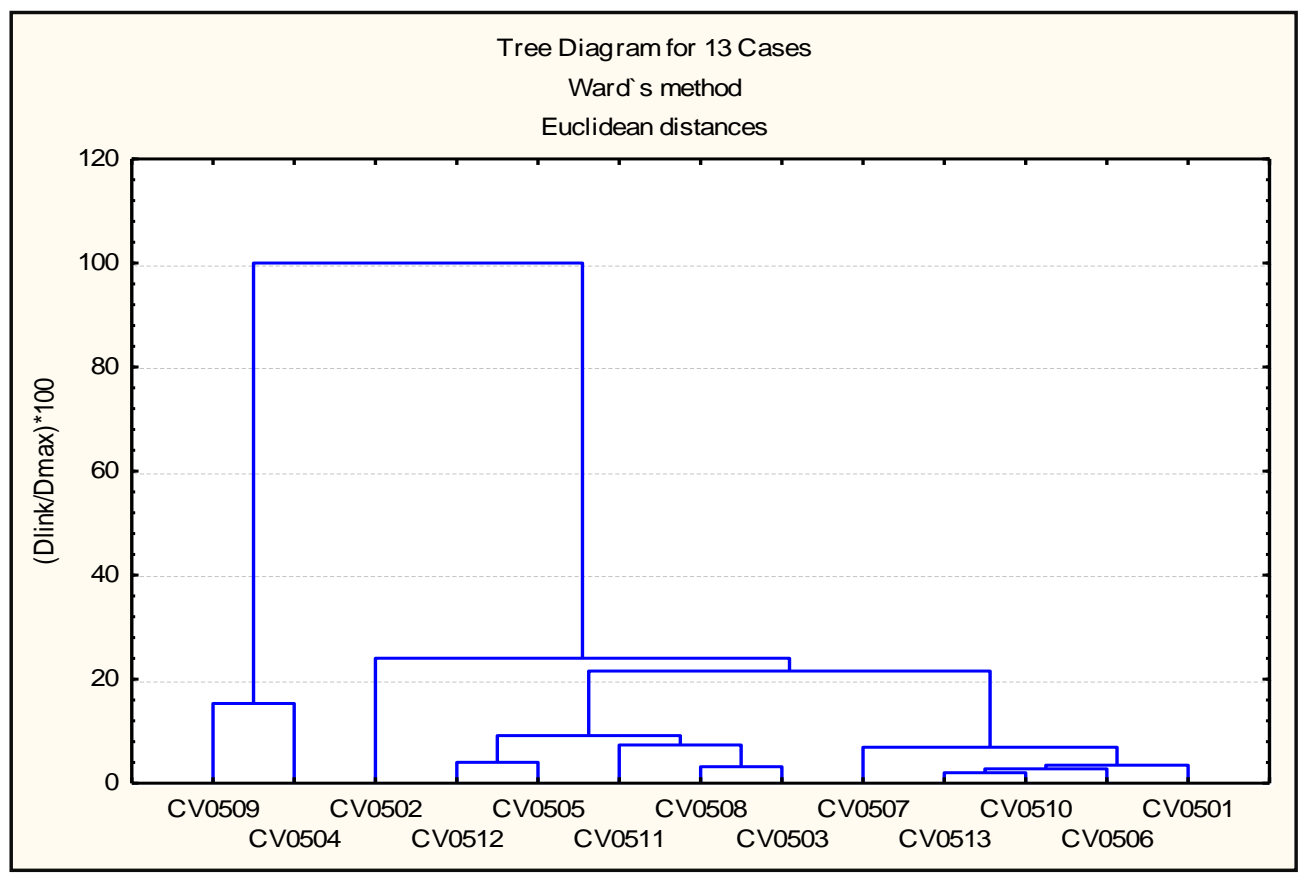

Figura 5.71 -Dendrograma - Cananéia, Verão de 2005 
As amostras de Cananéia - Verão de 2005, formaram dois grandes grupos, compostos pela similaridade das amostras, como demonstrado no dendrograma na Figura 5.71:

- Grupo 1: formado pelas amostras CV0509 e CV0504

- Grupo 2: a amostra CV0502 formou um sub-grupo; as demais amostras formaram vários outros sub-grupos: CV0512, CV0505, CV0511, CV0508, CV0503, CV0507, CV0513, CV0510, CV0506 e CV0501

As amostras de Cananéia têm como principal característica a semelhança entre as amostras dos diferentes pontos, que pode ser evidenciada pela formação de apenas 2 grupos e as pequenas distâncias observadas no dendrograma.

O dendrograma para as amostras do Inverno de 2005 está apresentado na Figura 5.72: 


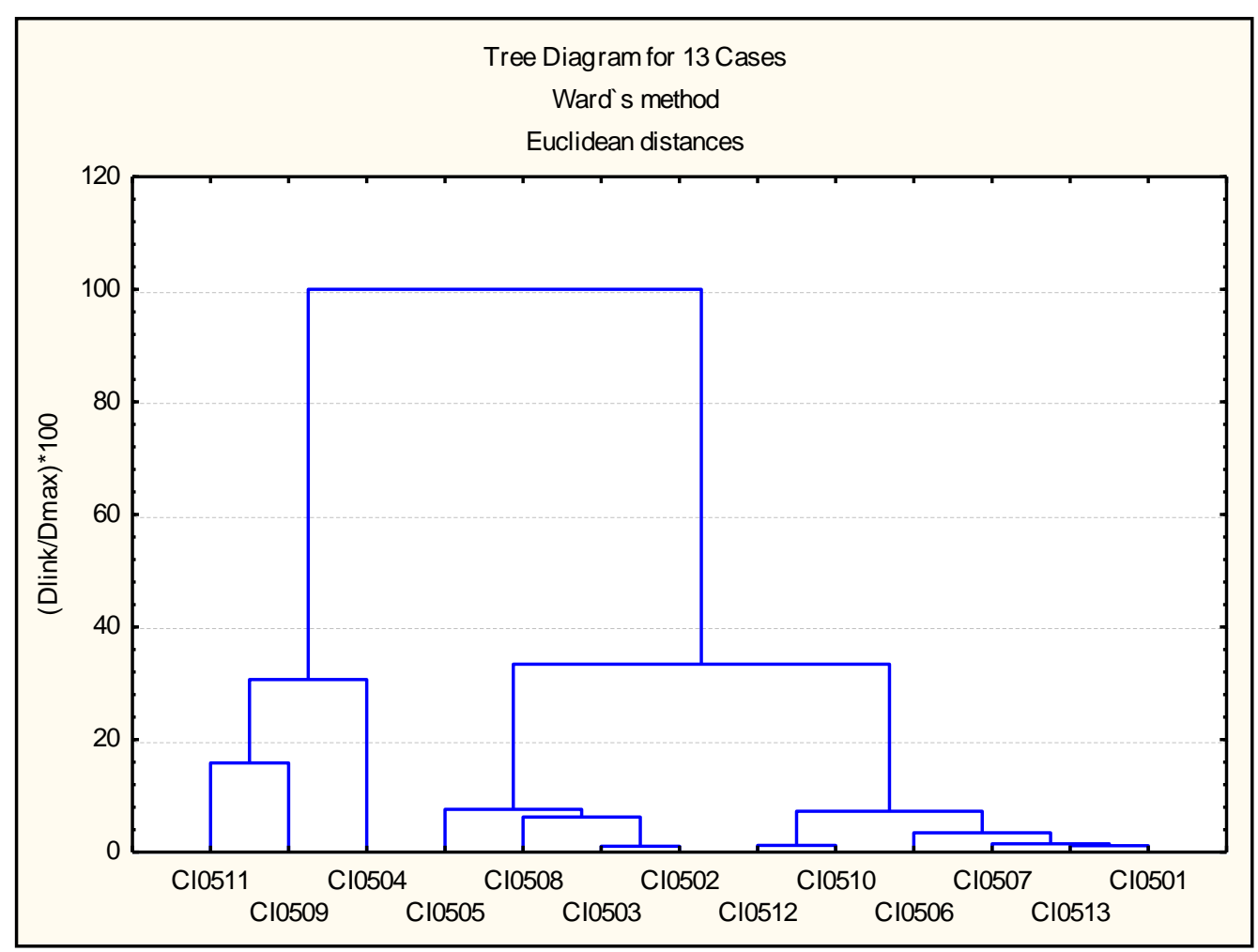

Figura 5.72- Dendrograma - Cananéia- Inverno de 2005

O dendrograma das amostras de Cananéia (Inverno de 2005), também está representado por dois grupos:

- Grupo 1: constituído pelas amostras Cl0511, Cl0504 e Cl0509

- Grupo 2: Cl0505, Cl0508, Cl0503, Cl0502 (subgrupo 2A), Cl0512, Cl0510, Cl0506, Cl0507, Cl0513, Cl0501 (subgrupo 2B)

O grupo 1 foi constituído pelas amostras 04 e 09, e no inverno a amostra 11 também fez parte desse grupo.

Para as amostras coletadas no verão de 2006, o dendrograma formado pelo método de Ward a partir das distancias Euclidianas, está apresentado na Figura 5.73. 


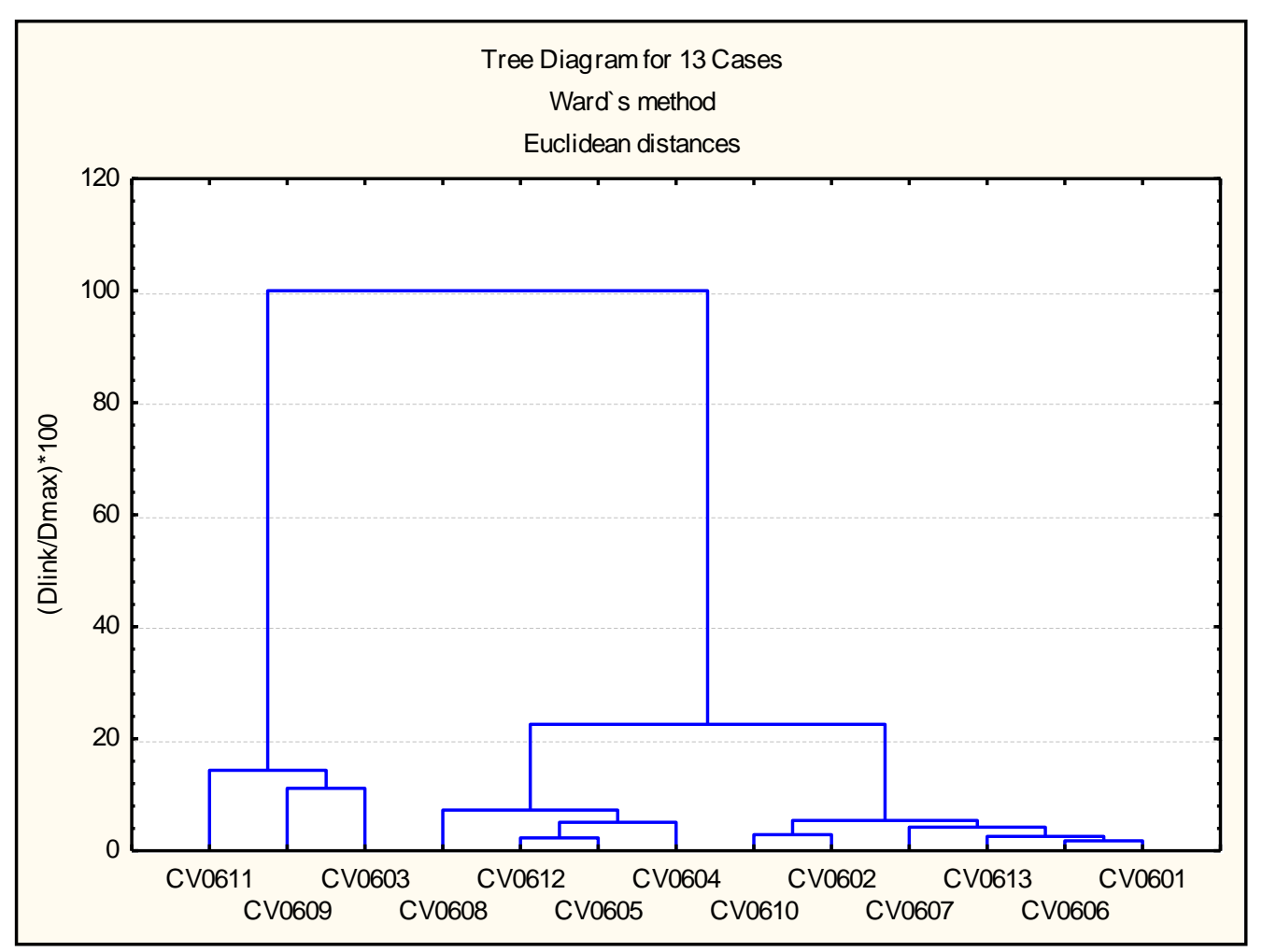

Figura 5.73 - Dendrograma - Cananéia - Verão de 2006

As amostras de Cananéia - Verão de 2006, formaram 2 grandes grupos:

- Grupo 1: formado pelas amostras CV0603, CV0609 e CV0611

- Grupo 2: amostras CV0608, CV0612, CV0605, CV0604 (subgrupo 2A); CV0610, CV0602 (subgrupo 2B), CV0607, CV0606, CV0613 e CV0601 (subgrupo 2C)

A Figura 5.74 apresenta o dendrograma para as amostras de Cananéia - inverno de 2006 


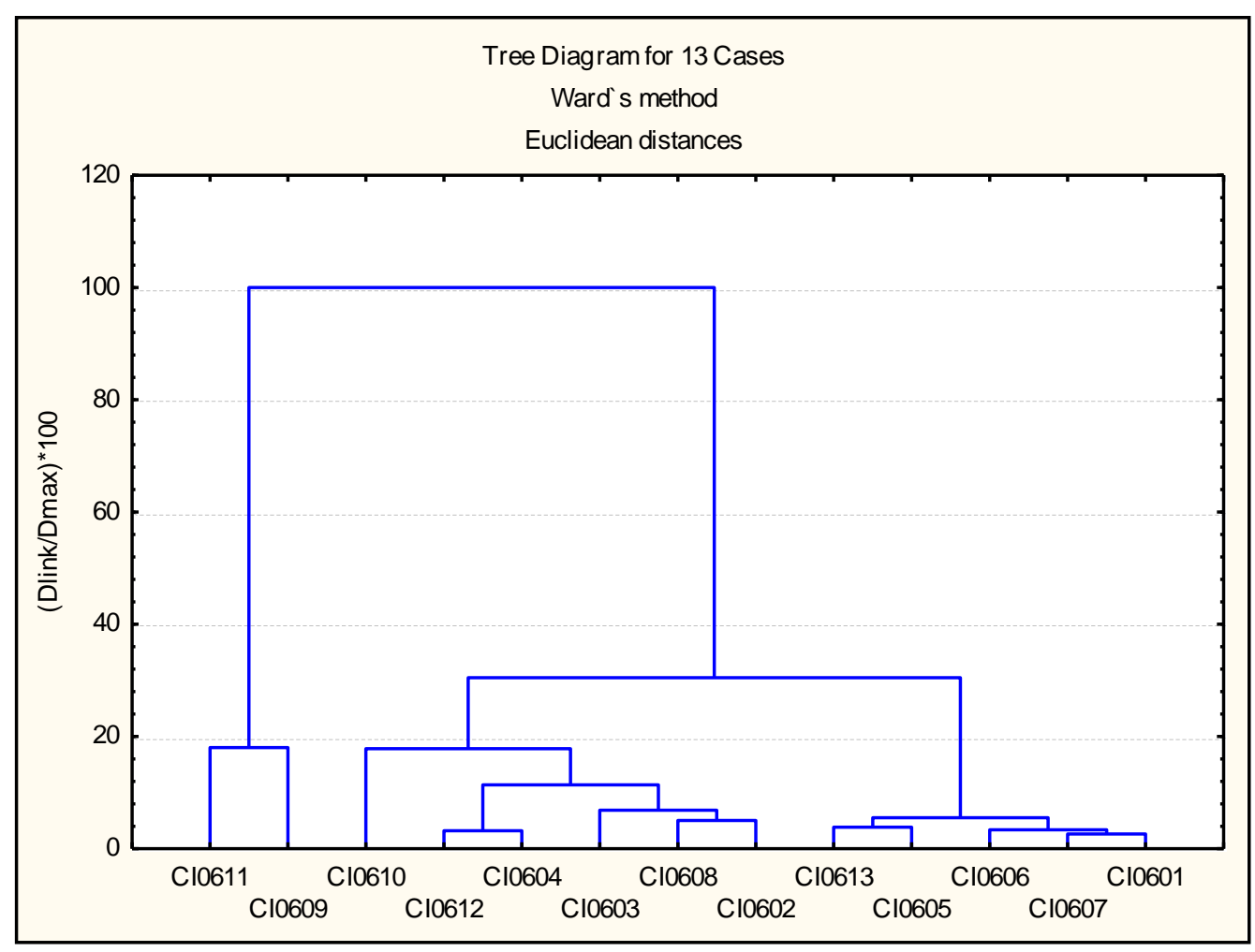

Figura 5.74- Dendrograma - Cananéia - Inverno de 2006

Os pontos de Cananéia - Inverno de 2006 dividiram-se em 2 grupos, sendo que os pontos Cl0609 e Cl0611 ficam isolados dos demais pontos devido à características singulares.

- Grupo 1: amostras Cl0611 e Cl0609

- Grupo 2: amostras Cl0610, Cl0612, Cl0604, Cl0603, Cl0608, Cl0602 (subgrupo 2A); Cl0613, Cl0605 e Cl0606, Cl0607 e Cl0601 (subgrupo 2B)

Analisando os dendrogramas obtidos nos períodos de Inverno e Verão de 2006, podemos observar semelhanças entre as épocas, conforme as distribuições dos grupos nos dois casos.

Assim como para as amostras de 2005, as amostras de Cananéia, Inverno e Verão de 2006, são caracterizadas pela similaridade entre si, como apresentado nos dendrogramas. Este fato pode ser evidenciado devido aos baixos níveis de contaminação encontrados nas áreas. 
Os pontos 09 e 11 apresentaram altos teores de Alumínio e Ferro, se comparado aos demais pontos analisadas, o que justifica a diferenciação encontrada nos dendrogramas, sendo ainda que estes pontos, juntamente ao ponto 04 , apresentam os maiores teores de MO, silte e argila.

\subsubsection{Fator de Enriquecimento e Índice de Geoacumulação}

O Fator de Enriquecimento (FE) e o Índice de Geoacumulação - Igeo (GOMES et al, 2009), apresentados nos itens 4.11 .2 e 4.11.3, respectivamente, são ferramentas habitualmente empregadas para estimar impactos antropogênicos nos sedimentos, e foram utilizados neste estudo para avaliar o impacto com os elementos determinados por ICP OES e AAS (GF AAS e CV AAS).

Neste estudo, o FE foi calculado utilizando o Sc como elemento normalizador, e os valores de referência Upper Continental Crust (UCC) (WEDEPOHL, 1995) como valores de referência do background da região para os elementos analisados.

A partir dos dados do UCC, foram calculados os FE e as Tabelas 5.37 a 5.40 apresentam os resultados dos FE obtidos para cada elemento, nos diferentes períodos e épocas.

Mahiques et al (2009), estudando a influência do Valo Grande no sistema estuarino-lagunar de Cananéia-Iguape, coletaram 4 testemunhos de sedimentos e obtiveram valores de $\mathrm{Cu}, \mathrm{Pb}, \mathrm{Zn}$ e $\mathrm{Cr}$ correspondentes aos períodos antes e após a abertura do canal. Os valores determinados como sendo anteriores à abertura do canal foram considerados como valores de background ( $\mathrm{Cu}-2,6 \mathrm{mg} \mathrm{kg}^{-1} ; \mathrm{Pb}-4,0 \mathrm{mg} \mathrm{kg}^{-1} ; \mathrm{Zn}-16,0 \mathrm{mg} \mathrm{kg}^{-1}$ e Cr- 10,3 $\mathrm{mg} \mathrm{kg}^{-1}$ ) e os valores de FE foram calculados. Para os elementos $\mathrm{Zn} \mathrm{e} \mathrm{Cr}$ os FE apresentaram tendência similar, com um aumento nos níveis inferiores a $130 \mathrm{~cm}$ e um decréscimo após $30 \mathrm{~cm}$ de profundidade, dentro do testemunho. 
Entretanto esses elementos apresentaram FE próximos aos níveis de background. A tendência do FE para o $\mathrm{Cu}$ mostrou um aumento contínuo dos valores em direção ao topo do testemunho, com o maior valor sendo encontrado a $20 \mathrm{~cm}$. Um comportamento semelhante foi observado para o $\mathrm{Pb}$, com um $\mathrm{FE}>5$, a $20 \mathrm{~cm}$. Uma característica distinta entre esses 2 elementos foi o fato de que o FE do $\mathrm{Cu}$ aumentou a partir de $130 \mathrm{~cm}$ em direção ao topo e o $\mathrm{Pb}$, aumentou após $70 \mathrm{~cm}$ de profundidade. 
Tabela 5.37 - Valores de FE, utilizando Sc como elemento normalizador e os valores UCC, como valores de referência de Background - Cananéia 2005 - Verão

\begin{tabular}{|c|c|c|c|c|c|c|c|c|c|c|c|c|c|c|c|}
\hline & Estações & Al & $\mathrm{Ba}$ & Co & $\mathrm{Cu}$ & $\mathrm{Cr}$ & $\mathrm{Sr}$ & $\mathrm{Fe}$ & Li & Mn & $\mathrm{Ni}$ & $\mathrm{Zn}$ & $\begin{array}{c}\mathrm{Pb} \\
\text { (GF AAS) }\end{array}$ & $\begin{array}{c}\text { Cd } \\
\text { (GF AAS) }\end{array}$ & $\begin{array}{c}\mathrm{Hg} \\
\text { (CV AAS) }\end{array}$ \\
\hline \multirow{6}{*}{$\begin{array}{c}\bar{d} \\
\frac{\mathbb{d}}{\alpha}\end{array}$} & CV0501 & 0,12 & 0,02 & 0,46 & 0,19 & 0,49 & 0,17 & 0,36 & 0,96 & 0,37 & 0,33 & 1,36 & 0,08 & 0,63 & 2,01 \\
\hline & CV0502 & 0,18 & 0,03 & 0,34 & 0,14 & 0,50 & 0,36 & 0,36 & 1,11 & 0,28 & 0,37 & 0,68 & 0,12 & 6,69 & 1,48 \\
\hline & CV0503 & 0,13 & 0,02 & 0,30 & 0,09 & 0,43 & 0,08 & 0,35 & 0,87 & 0,38 & 0,27 & 0,46 & 0,37 & 0,18 & 0,89 \\
\hline & CV0504 & 0,23 & 0,04 & 0,30 & 0,39 & 0,52 & 0,07 & 0,55 & 1,09 & 0,42 & 0,38 & 0,55 & 0,75 & 0,29 & 0,90 \\
\hline & CV0505 & 0,11 & 0,02 & 0,31 & 0,26 & 0,45 & 0,10 & 0,41 & 0,78 & 0,33 & 0,30 & 0,55 & 1,09 & 0,35 & 2,27 \\
\hline & CV0506 & 0,08 & 0,02 & 0,86 & 0,35 & 0,34 & 0,08 & 0,28 & 0,53 & 0,18 & 0,53 & 0,57 & 0,15 & 0,97 & 4,36 \\
\hline \multirow{3}{*}{ 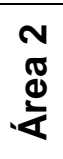 } & CV0507 & 0,15 & 0,02 & 0,43 & 0,17 & 0,57 & 0,34 & 0,47 & 1,11 & 0,57 & 0,30 & 0,64 & 0,03 & 0,43 & 2,30 \\
\hline & CV0508 & 0,17 & 0,02 & 0,41 & 0,06 & 0,61 & 0,12 & 0,49 & 1,21 & 0,41 & 0,37 & 0,62 & 0,50 & 0,28 & 1,29 \\
\hline & CV0509 & 0,35 & 0,05 & 0,36 & 0,23 & 0,67 & 0,09 & 0,56 & 1,67 & 0,37 & 0,50 & 0,61 & 0,49 & 0,33 & 0,59 \\
\hline \multirow{4}{*}{$\begin{array}{l}\text { m } \\
\mathbb{d} \\
\stackrel{\mathbb{d}}{4}\end{array}$} & CV0510 & 0,10 & 0,01 & 0,34 & 0,14 & 0,40 & 0,07 & 0,32 & 0,74 & 0,14 & 0,27 & 0,68 & 0,54 & 0,35 & 1,84 \\
\hline & CV0511 & 0,24 & 0,03 & 0,28 & 0,18 & 0,53 & 0,07 & 0,36 & 1,28 & 0,17 & 0,36 & 0,47 & 0,45 & 0,41 & 1,30 \\
\hline & CV0512 & 0,21 & 0,03 & 0,39 & 0,54 & 0,73 & 0,11 & 0,52 & 1,28 & 0,20 & 0,42 & 1,10 & 1,13 & 0,40 & 2,94 \\
\hline & CV0513 & 0,14 & 0,02 & 0,60 & 0,39 & 0,47 & 0,19 & 0,35 & 0,76 & 0,26 & 0,37 & 0,63 & 0,95 & 0,68 & 4,04 \\
\hline
\end{tabular}


Tabela 5.38: Valores de FE, utilizando Sc como elemento normalizador e os valores UCC, como valores de referência de Background - Cananéia 2005 - Inverno

\begin{tabular}{|c|c|c|c|c|c|c|c|c|c|c|c|c|c|c|c|}
\hline Área & Estações & Al & $\mathrm{Ba}$ & Co & $\mathrm{Cu}$ & $\mathrm{Cr}$ & $\mathrm{Sr}$ & $\mathrm{Fe}$ & Li & Mn & $\mathrm{Ni}$ & $\mathrm{Zn}$ & $\begin{array}{c}\mathrm{Pb} \\
\text { (GF AAS) }\end{array}$ & $\begin{array}{c}\text { Cd } \\
\text { (GF AAS) }\end{array}$ & $\begin{array}{c}\mathrm{Hg} \\
\text { (CV AAS) } \\
\end{array}$ \\
\hline \multirow{4}{*}{ 趂 } & Cl0502 & 0,19 & 0,03 & 0,35 & 0,26 & 0,55 & 0,11 & 0,41 & 1,19 & 0,31 & 0,38 & 0,51 & 0,59 & 0,17 & 0,57 \\
\hline & Cl0504 & 0,25 & 0,04 & 0,31 & 0,42 & 0,54 & 0,08 & 0,54 & 1,14 & 0,47 & 0,40 & 0,55 & 0,72 & 0,29 & 0,69 \\
\hline & Cl0505 & 0,18 & 0,03 & 0,34 & 0,43 & 0,50 & 0,10 & 0,41 & 0,97 & 0,36 & 0,34 & 0,54 & 1,01 & 0,17 & 1,12 \\
\hline & Cl0506 & 0,08 & 0,02 & 0,98 & 0,47 & 0,37 & 0,07 & 0,25 & 0,52 & 0,44 & 0,61 & 0,52 & 0,78 & 1,11 & 5,10 \\
\hline 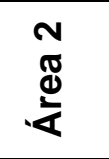 & Cl0509 & 0,22 & 0,03 & 0,36 & 0,26 & 0,60 & 0,12 & 0,56 & 1,50 & 0,54 & 0,43 & 0,60 & 0,47 & 0,29 & 0,66 \\
\hline \multirow{4}{*}{ 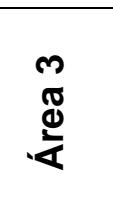 } & Cl0510 & 0,20 & 0,04 & 0,37 & 0,35 & 0,57 & 0,08 & 0,39 & 1,07 & 0,17 & 0,40 & 0,75 & 0,49 & 0,42 & 1,20 \\
\hline & Cl0511 & 0,49 & 0,05 & 0,34 & 0,32 & 0,69 & 0,08 & 0,78 & 1,48 & 0,29 & 0,49 & 0,71 & 0,64 & 0,47 & 1,15 \\
\hline & Cl0512 & 0,15 & 0,03 & 0,25 & 0,22 & 0,42 & 0,04 & 0,23 & 0,91 & 0,10 & 0,29 & 0,41 & 0,40 & 0,29 & 0,69 \\
\hline & $\mathrm{Cl} 0513$ & 0,22 & 0,05 & 0,73 & 0,30 & 0,47 & 0,24 & 0,34 & 1,35 & 0,60 & 0,46 & 0,52 & 0,78 & 0,83 & 3,19 \\
\hline
\end{tabular}


Tabela 5.39: Valores de FE, utilizando Sc como elemento normalizador e os valores UCC, como valores de referência de Background - Cananéia 2006 - Verão

\begin{tabular}{|c|c|c|c|c|c|c|c|c|c|c|c|c|c|c|c|}
\hline Área & Estações & Al & $\mathrm{Ba}$ & Co & $\mathrm{Cu}$ & $\mathrm{Cr}$ & $\mathrm{Sr}$ & $\mathrm{Fe}$ & Li & Mn & $\mathrm{Ni}$ & $\mathrm{Zn}$ & $\begin{array}{c}\mathrm{Pb} \\
\text { (GF AAS) }\end{array}$ & $\begin{array}{c}\mathrm{Cd} \\
\text { (GF AAS) }\end{array}$ & $\begin{array}{c}\mathrm{Hg} \\
\text { (CV AAS) }\end{array}$ \\
\hline \multirow{4}{*}{ ঠ্ঠ } & CV0602 & 0,23 & 0,04 & 0,19 & 0,25 & 0,87 & 0,11 & 0,58 & 0,96 & 0,56 & 0,31 & 0,70 & 0,78 & 0,43 & 2,23 \\
\hline & CV0604 & 0,23 & 0,04 & 0,42 & 0,49 & 0,64 & 0,21 & 0,49 & 1,67 & 0,93 & 0,45 & 0,65 & 0,87 & 0,32 & 3,04 \\
\hline & CV0605 & 0,30 & 0,06 & 0,35 & 0,34 & 0,61 & 0,11 & 0,44 & 0,96 & 0,39 & 0,45 & 0,61 & 0,80 & 0,27 & 2,34 \\
\hline & CV0606 & 0,11 & 0,02 & 0,28 & 0,47 & 0,36 & 0,06 & 0,22 & 0,52 & 0,17 & 0,35 & 0,52 & 0,47 & 0,64 & 3,93 \\
\hline 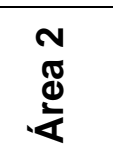 & CV0609 & 0,31 & 0,04 & 0,38 & 0,28 & 0,66 & 0,13 & 0,58 & 1,63 & 0,44 & 0,47 & 0,62 & 0,44 & 0,25 & 1,13 \\
\hline \multirow{4}{*}{ 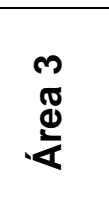 } & CV0610 & 0,24 & 0,04 & 0,18 & 0,36 & 0,62 & 0,09 & 0,42 & 1,12 & 0,22 & 0,36 & 0,69 & 0,80 & 0,41 & 3,09 \\
\hline & CV0611 & 0,39 & 0,07 & 0,34 & 0,37 & 0,81 & 0,10 & 0,60 & 1,66 & 0,24 & 0,53 & 0,61 & 0,62 & 0,31 & 1,64 \\
\hline & CV0612 & 0,25 & 0,05 & 0,24 & 0,19 & 0,59 & 0,07 & 0,51 & 0,87 & 0,14 & 0,32 & 0,43 & 0,72 & 0,22 & 1,91 \\
\hline & CV0613 & 0,15 & 0,05 & 0,38 & 0,37 & 0,46 & 0,17 & 0,44 & 0,91 & 0,51 & 0,47 & 0,66 & 1,54 & 0,86 & 5,12 \\
\hline
\end{tabular}


Tabela 5.40: Valores de FE, utilizando Sc como elemento normalizador e os valores UCC, como valores de referência de Background - Cananéia 2006 - Inverno

\begin{tabular}{c|c|cccccccccccccc}
\hline Área & Estações & Al & Ba & Co & Cu & Cr & Sr & Fe & Li & Mn & Ni & Zn & $\begin{array}{c}\text { Pb } \\
\text { (GF AAS) }\end{array}$ & $\begin{array}{c}\text { Cd } \\
\text { (GF AAS) }\end{array}$ \\
& & Cl0601 & 0,16 & 0,04 & 0,62 & 1,00 & 0,70 & 0,65 & 0,48 & 1,45 & 0,55 & 0,77 & 0,97 & 0,77 & 1,41 \\
(CV AAS)
\end{tabular}


$\mathrm{Na}$ avaliação dos FE calculados para as amostras analisadas por ICP OES, GF AAS e CV AAS, foi possível identificar que o Li presente nas amostras CV0509, Cl0507, Cl0509, CV0603, CV0604, CV0607, CV0609, CV0611, Cl0609 e Cl0611 possuem um indicativo de contaminação por origem antrópica (FE > 1,5).

O Cd apresentou índice de enriquecimento nas amostras CV0502 e Cl0501, ambas da área 1, apenas no período de coleta de 2005. O Mn da amostra CV0607 também apresentou FE>1,5.

Verificou-se ainda que a amostra CV0613 apresentou $F E=1,53$ para o $\mathrm{Pb}$, portanto um pouco acima do valor $\mathrm{FE}>1,5$, o que parece reforçar uma possível contaminação de origem antrópica para este elemento, assim como a amostra CI0613, que apresentou o valor de FE=1,58 para o elemento $\mathrm{Zn}$.

$\mathrm{O} \mathrm{Hg}$ foi o metal que apresentou a maior parte dos casos que sugerem contaminação por origem antrópica, conforme demonstrado pelos valores de FE, entretanto os valores obtidos são relativamente baixos, e a comparação com o valor UCC pode não refletir a realidade da região, fato que foi comprovado pelo cálculo do Igeo, apresentado a seguir.

Os demais elementos analisados por ICP OES, apresentaram valores de $\mathbf{0 , 5}<\mathrm{FE}<\mathbf{1 , 5}$ ou $\mathrm{FE}<\mathbf{0 , 5}$, podendo ser considerados então como de origem natural.

De modo a complementar os dados obtidos com o cálculo do fator de enriquecimento, optou-se em realizar o cálculo do Igeo, conforme descrito no capítulo 4.11.3.

O Igeo foi calculado considerado os valores UCC (Upper Continental Crust), descrito por Wedelpohl, 1995.

As Tabelas 5.41 a 5.44 apresentam os valores obtidos para o Igeo para todos os pontos de coleta no verão e inverno de 2005 e 2006, na região de Cananéia. 
Tabela 5.41 - Índice de geoacumulação (Igeo) em amostras de sedimentos do estuário de Cananéia, verão de 2005

\begin{tabular}{|c|c|c|c|c|c|c|c|c|c|c|c|c|c|c|c|}
\hline Área & Estações & Al & $\mathrm{Ba}$ & Co & $\mathrm{Cu}$ & $\mathrm{Cr}$ & $\mathrm{Sr}$ & $\mathrm{Fe}$ & Li & Mn & $\mathrm{Ni}$ & $\mathrm{Zn}$ & $\begin{array}{c}\mathrm{Pb} \\
\text { (GF AAS) }\end{array}$ & $\begin{array}{c}\text { Cd } \\
\text { (GF } \\
\text { AAS) } \\
\end{array}$ & $\begin{array}{c}\mathrm{Hg} \\
\text { (CV AAS) }\end{array}$ \\
\hline \multirow{6}{*}{ ब্ষ } & CV0501 & $-6,03$ & $-8,77$ & $-4,12$ & $-5,42$ & $-4,04$ & $-5,57$ & $-4,50$ & $-3,08$ & $-4,46$ & $-4,63$ & $-2,57$ & $-6,67$ & $-3,67$ & $-2,01$ \\
\hline & CV0502 & $-5,00$ & $-7,83$ & $-4,12$ & $-5,42$ & $-3,55$ & $-4,03$ & $-4,05$ & $-2,41$ & $-4,41$ & $-3,99$ & $-3,12$ & $-5,65$ & 0,18 & $-1,99$ \\
\hline & CV0503 & $-4,26$ & $-7,01$ & $-3,00$ & $-4,69$ & $-2,51$ & $-5,00$ & $-2,78$ & $-1,48$ & $-2,68$ & $-3,17$ & $-2,41$ & $-2,71$ & $-3,73$ & $-1,46$ \\
\hline & CV0504 & $-1,68$ & $-4,32$ & $-1,30$ & $-0,93$ & $-0,51$ & $-3,35$ & $-0,44$ & 0,55 & $-0,82$ & $-0,97$ & $-0,43$ & 0,00 & $-1,38$ & 0,27 \\
\hline & CV0505 & $-5,04$ & $-7,56$ & $-3,50$ & $-3,74$ & $-2,96$ & $-5,12$ & $-3,10$ & $-2,15$ & $-3,41$ & $-3,56$ & $-2,65$ & $-1,68$ & $-3,32$ & $-0,62$ \\
\hline & CV0506 & $-7,53$ & $-9,79$ & $-4,12$ & $-5,42$ & $-5,46$ & $-7,46$ & $-5,75$ & $-4,81$ & $-6,35$ & $-4,80$ & $-4,70$ & $-6,67$ & $-3,94$ & $-1,77$ \\
\hline \multirow{3}{*}{$\begin{array}{l}\text { N } \\
\mathbb{8} \\
\mathbb{d} \\
\frac{1}{4}\end{array}$} & CV0507 & $-5,60$ & $-8,40$ & $-4,05$ & $-5,42$ & $-3,63$ & $-4,38$ & $-3,91$ & $-2,68$ & $-3,64$ & $-4,58$ & $-3,48$ & $-7,99$ & $-4,04$ & $-1,63$ \\
\hline & CV0508 & $-3,97$ & $-6,88$ & $-2,71$ & $-5,42$ & $-2,15$ & $-4,51$ & $-2,47$ & $-1,16$ & $-2,72$ & $-2,88$ & $-2,12$ & $-2,44$ & $-3,28$ & $-1,07$ \\
\hline & CV0509 & $-1,44$ & $-4,29$ & $-1,39$ & $-2,00$ & $-0,48$ & $-3,45$ & $-0,75$ & 0,83 & $-1,34$ & $-0,92$ & $-0,62$ & $-0,93$ & $-1,52$ & $-0,68$ \\
\hline \multirow{4}{*}{$\begin{array}{l}m \\
\mathbb{d} \\
\frac{d}{4}\end{array}$} & CV0510 & $-5,95$ & $-8,82$ & $-4,12$ & $-5,42$ & $-3,90$ & $-6,50$ & $-4,21$ & $-2,99$ & $-5,42$ & $-4,43$ & $-3,12$ & $-3,46$ & $-4,07$ & $-1,69$ \\
\hline & CV0511 & $-3,04$ & $-6,07$ & $-2,78$ & $-3,47$ & $-1,87$ & $-4,81$ & $-2,42$ & $-0,59$ & $-3,49$ & $-2,44$ & $-2,04$ & $-2,12$ & $-2,25$ & $-0,58$ \\
\hline & CV0512 & $-4,87$ & $-7,64$ & $-3,94$ & $-3,48$ & $-3,05$ & $-5,74$ & $-3,53$ & $-2,24$ & $-4,92$ & $-3,86$ & $-2,47$ & $-2,42$ & $-3,94$ & $-1,05$ \\
\hline & CV0513 & $-6,22$ & $-8,91$ & $-4,12$ & $-4,74$ & $-4,48$ & $-5,80$ & $-4,90$ & $-3,77$ & $-5,30$ & $-4,80$ & $-4,05$ & $-3,46$ & $-3,94$ & $-1,37$ \\
\hline
\end{tabular}


Tabela 5.42 - Índice de geoacumulação (Igeo) em amostras de sedimentos do estuário de Cananéia, inverno de 2005

\begin{tabular}{|c|c|c|c|c|c|c|c|c|c|c|c|c|c|c|c|}
\hline Área & Estações & Al & $\mathrm{Ba}$ & Co & $\mathrm{Cu}$ & $\mathrm{Cr}$ & $\mathrm{Sr}$ & $\mathrm{Fe}$ & $\mathrm{Li}$ & Mn & $\mathrm{Ni}$ & $\mathbf{Z n}$ & $\begin{array}{c}\mathrm{Pb} \\
\text { (GF } \\
\text { AAS) }\end{array}$ & $\begin{array}{c}\text { Cd } \\
\text { (GF } \\
\text { AAS) }\end{array}$ & $\begin{array}{c}\mathrm{Hg} \\
\text { (CV } \\
\text { AAS) }\end{array}$ \\
\hline \multirow{4}{*}{ 趂 } & Cl0501 & $-6,57$ & $-9,54$ & $-4,12$ & $-5,42$ & $-4,77$ & $-5,54$ & $-5,47$ & $-4,07$ & $-5,02$ & $-4,80$ & $-4,18$ & $-4,75$ & $-3,94$ & $-2,04$ \\
\hline & $\mathrm{Cl0503}$ & $-3,75$ & $-6,55$ & $-2,94$ & $-3,62$ & $-2,37$ & $-4,63$ & $-2,76$ & $-1,30$ & $-2,84$ & $-2,94$ & $-2,46$ & $-2,26$ & $-3,94$ & $-2,08$ \\
\hline & Cl0504 & $-1,51$ & $-4,25$ & $-1,20$ & $-0,76$ & $-0,39$ & $-3,19$ & $-0,39$ & 0,69 & $-0,59$ & $-0,84$ & $-0,36$ & 0,03 & $-1,28$ & $-0,04$ \\
\hline & Cl0505 & $-3,83$ & $-6,41$ & $-2,93$ & $-2,58$ & $-2,35$ & $-4,72$ & $-2,66$ & $-1,40$ & $-2,84$ & $-2,93$ & $-2,23$ & $-1,34$ & $-3,94$ & $-1,20$ \\
\hline \multirow{2}{*}{$\begin{array}{l}\mathbf{N} \\
\mathbb{J} \\
\mathbb{1} \\
\end{array}$} & Cl0508 & $-3,27$ & $-5,67$ & $-2,65$ & $-4,02$ & $-1,97$ & $-3,99$ & $-2,47$ & $-1,07$ & $-2,80$ & $-2,68$ & $-2,05$ & $-2,71$ & $-3,94$ & $-2,30$ \\
\hline & Cl0509 & $-2,31$ & $-5,38$ & $-1,59$ & $-2,08$ & $-0,84$ & $-3,18$ & $-0,95$ & 0,48 & $-1,00$ & $-1,34$ & $-0,85$ & $-1,18$ & $-1,88$ & $-0,70$ \\
\hline \multirow{3}{*}{ 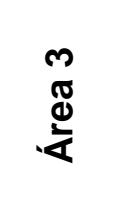 } & $\mathrm{Cl0510}$ & $-5,00$ & $-7,46$ & $-4,12$ & $-4,21$ & $-3,48$ & $-6,41$ & $-4,04$ & $-2,58$ & $-5,23$ & $-4,01$ & $-3,10$ & $-3,72$ & $-3,94$ & $-2,41$ \\
\hline & Cl0511 & $-1,98$ & $-5,29$ & $-2,50$ & $-2,59$ & $-1,48$ & $-4,50$ & $-1,31$ & $-0,38$ & $-2,72$ & $-1,97$ & $-1,43$ & $-1,59$ & $-2,04$ & $-0,74$ \\
\hline & Cl0512 & $-4,63$ & $-7,22$ & $-3,94$ & $-4,09$ & $-3,19$ & $-6,50$ & $-4,05$ & $-2,06$ & $-5,28$ & $-3,72$ & $-3,22$ & $-3,25$ & $-3,74$ & $-2,46$ \\
\hline
\end{tabular}


Tabela 5.43 - Índice de geoacumulação (Igeo) em amostras de sedimentos do estuário de Cananéia, verão de 2006

\begin{tabular}{|c|c|c|c|c|c|c|c|c|c|c|c|c|c|c|c|}
\hline Área & Estações & Al & $\mathrm{Ba}$ & Co & $\mathrm{Cu}$ & $\mathrm{Cr}$ & Sr & $\mathrm{Fe}$ & Li & Mn & $\mathrm{Ni}$ & $\mathbf{Z n}$ & $\begin{array}{c}\mathrm{Pb} \\
\text { (GF } \\
\text { AAS) }\end{array}$ & $\begin{array}{c}\text { Cd } \\
\text { (GF } \\
\text { AAS) }\end{array}$ & $\begin{array}{c}\mathrm{Hg} \\
\text { (CV } \\
\text { AAS) }\end{array}$ \\
\hline \multirow{6}{*}{$\begin{array}{c}\overline{\mathbb{d}} \\
\bar{d} \\
\dot{\frac{1}{\alpha}}\end{array}$} & CV0601 & $-6,28$ & $-9,12$ & $-5,12$ & $-4,66$ & $-4,41$ & $-5,88$ & $-4,99$ & $-3,55$ & $-4,90$ & $-3,88$ & $-3,58$ & $-4,51$ & $-3,94$ & $-1,42$ \\
\hline & CV0602 & $-4,87$ & $-7,31$ & $-5,12$ & $-4,72$ & $-2,93$ & $-5,95$ & $-3,51$ & $-2,78$ & $-3,55$ & $-4,41$ & $-3,23$ & $-3,09$ & $-3,94$ & $-1,57$ \\
\hline & CV0603 & $-2,22$ & $-4,74$ & $-1,81$ & $-1,79$ & $-0,99$ & $-3,21$ & $-1,47$ & 0,07 & $-0,93$ & $-1,43$ & $-1,14$ & $-1,23$ & $-3,24$ & $-0,16$ \\
\hline & CV0604 & $-4,52$ & $-7,10$ & $-3,68$ & $-3,45$ & $-3,08$ & $-4,66$ & $-3,44$ & $-1,68$ & $-2,53$ & $-3,59$ & $-3,05$ & $-2,62$ & $-4,07$ & $-0,82$ \\
\hline & CV0605 & $-3,77$ & $-6,05$ & $-3,57$ & $-3,62$ & $-2,77$ & $-5,28$ & $-3,22$ & $-2,11$ & $-3,40$ & $-3,19$ & $-2,76$ & $-2,37$ & $-3,94$ & $-0,83$ \\
\hline & CV0606 & $-6,49$ & $-8,63$ & $-5,12$ & $-4,36$ & $-4,75$ & $-7,40$ & $-5,47$ & $-4,21$ & $-5,84$ & $-4,80$ & $-4,22$ & $-4,36$ & $-3,94$ & $-1,30$ \\
\hline \multirow{3}{*}{\begin{tabular}{l} 
N \\
$\mathbb{\Xi}$ \\
\multirow{d}{*}{}
\end{tabular}} & CV0607 & $-6,20$ & $-8,25$ & $-5,12$ & $-4,42$ & $-4,36$ & $-4,79$ & $-4,49$ & $-3,45$ & $-3,38$ & $-4,80$ & $-4,12$ & $-4,62$ & $-3,94$ & $-1,72$ \\
\hline & CV0608 & $-3,44$ & $-6,15$ & $-2,62$ & $-3,61$ & $-2,01$ & $-4,57$ & $-2,47$ & $-1,05$ & $-2,95$ & $-2,74$ & $-2,08$ & $-2,02$ & $-3,94$ & $-0,82$ \\
\hline & CV0609 & $-1,85$ & $-4,85$ & $-1,55$ & $-1,99$ & $-0,77$ & $-3,12$ & $-0,95$ & 0,54 & $-1,35$ & $-1,25$ & $-0,85$ & $-1,33$ & $-2,18$ & 0,02 \\
\hline \multirow{4}{*}{ 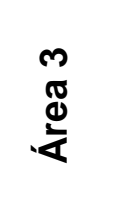 } & CV0610 & $-4,73$ & $-7,25$ & $-5,12$ & $-4,15$ & $-3,34$ & $-6,06$ & $-3,92$ & $-2,50$ & $-4,81$ & $-4,14$ & $-3,20$ & $-2,97$ & $-3,94$ & $-1,03$ \\
\hline & CV0611 & $-2,18$ & $-4,62$ & $-2,36$ & $-2,25$ & $-1,12$ & $-4,14$ & $-1,55$ & $-0,08$ & $-2,90$ & $-1,72$ & $-1,53$ & $-1,51$ & $-2,50$ & $-0,11$ \\
\hline & CV0612 & $-3,73$ & $-6,09$ & $-3,81$ & $-4,14$ & $-2,50$ & $-5,60$ & $-2,72$ & $-1,94$ & $-4,61$ & $-3,40$ & $-2,95$ & $-2,21$ & $-3,94$ & $-0,81$ \\
\hline & CV0613 & $-6,44$ & $-7,99$ & $-5,12$ & $-5,14$ & $-4,84$ & $-6,23$ & $-4,91$ & $-3,85$ & $-4,68$ & $-4,80$ & $-4,32$ & $-3,09$ & $-3,94$ & $-1,36$ \\
\hline
\end{tabular}


Tabela 5.44 - Índice de geoacumulação (Igeo) em amostras de sedimentos do estuário de Cananéia, inverno de 2006

\begin{tabular}{|c|c|c|c|c|c|c|c|c|c|c|c|c|c|c|c|}
\hline Área & Estações & Al & $\mathrm{Ba}$ & Co & $\mathrm{Cu}$ & $\mathrm{Cr}$ & $\mathrm{Sr}$ & $\mathrm{Fe}$ & Li & Mn & $\mathrm{Ni}$ & $\mathrm{Zn}$ & $\begin{array}{c}\mathrm{Pb} \\
\text { (GF } \\
\text { AAS) }\end{array}$ & $\begin{array}{c}\text { Cd } \\
\text { (GF } \\
\text { AAS) }\end{array}$ & $\begin{array}{c}\mathrm{Hg} \\
\text { (CV } \\
\text { AAS) }\end{array}$ \\
\hline \multirow{6}{*}{ ঠ্ } & Cl0601 & $-7,03$ & $-9,06$ & $-5,12$ & $-4,42$ & $-4,95$ & $-5,05$ & $-5,50$ & $-3,89$ & $-5,30$ & $-4,80$ & $-4,48$ & $-4,81$ & $-3,94$ & $-3,58$ \\
\hline & CI0602 & $-3,94$ & $-6,77$ & $-3,07$ & $-4,42$ & $-2,62$ & $-4,97$ & $-2,76$ & $-1,16$ & $-2,53$ & $-3,26$ & $-2,77$ & $-2,56$ & $-3,94$ & $-1,56$ \\
\hline & CI0603 & $-3,86$ & $-6,41$ & $-2,63$ & $-4,42$ & $-2,25$ & $-4,56$ & $-2,64$ & $-0,98$ & $-2,20$ & $-2,81$ & $-2,27$ & $-1,95$ & $-3,94$ & $-1,65$ \\
\hline & CI0604 & $-4,82$ & $-6,85$ & $-3,42$ & $-4,22$ & $-3,20$ & $-5,37$ & $-3,44$ & $-1,82$ & $-3,86$ & $-3,45$ & $-3,10$ & $-2,15$ & $-3,87$ & $-1,62$ \\
\hline & CI0605 & $-5,19$ & $-7,41$ & $-5,12$ & $-4,42$ & $-3,78$ & $-6,45$ & $-4,30$ & $-2,87$ & $-4,27$ & $-4,29$ & $-3,85$ & $-3,29$ & $-3,94$ & $-2,37$ \\
\hline & $\mathrm{Cl0606}$ & $-6,72$ & $-8,57$ & $-5,12$ & $-4,42$ & $-4,59$ & $-7,47$ & $-5,63$ & $-4,38$ & $-4,88$ & $-4,80$ & $-4,29$ & $-4,14$ & $-3,94$ & $-3,32$ \\
\hline \multirow{3}{*}{ 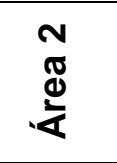 } & CI0607 & $-6,24$ & $-8,59$ & $-5,12$ & $-4,42$ & $-4,05$ & $-5,05$ & $-4,30$ & $-3,10$ & $-3,75$ & $-4,66$ & $-3,85$ & $-3,85$ & $-3,94$ & $-3,41$ \\
\hline & $\mathrm{Cl0608}$ & $-4,75$ & $-7,24$ & $-2,99$ & $-4,42$ & $-2,59$ & $-4,17$ & $-3,02$ & $-1,67$ & $-2,99$ & $-3,41$ & $-2,53$ & $-3,02$ & $-3,94$ & $-2,11$ \\
\hline & CI0609 & $-2,23$ & $-5,07$ & $-1,49$ & $-2,54$ & $-0,87$ & $-3,35$ & $-1,38$ & 0,74 & $-1,23$ & $-1,36$ & $-0,98$ & $-1,26$ & $-2,08$ & $-0,81$ \\
\hline \multirow{4}{*}{$\begin{array}{l}0 \\
\mathbb{J} \\
\stackrel{\mathbb{J}}{<}\end{array}$} & $\mathrm{CI0610}$ & $-5,10$ & $-7,47$ & $-3,86$ & $-4,42$ & $-3,28$ & $-2,86$ & $-3,46$ & $-1,98$ & $-4,43$ & $-3,75$ & $-2,80$ & $-3,07$ & $-3,94$ & $-1,88$ \\
\hline & Cl0611 & $-3,35$ & $-5,98$ & $-2,06$ & $-2,30$ & $-1,38$ & $-3,96$ & $-1,48$ & 0,47 & $-2,00$ & $-1,85$ & $-1,19$ & $-1,03$ & $-1,92$ & $-0,12$ \\
\hline & $\mathrm{Cl0612}$ & $-4,98$ & $-7,15$ & $-3,75$ & $-4,42$ & $-3,23$ & $-5,67$ & $-3,75$ & $-2,31$ & $-3,85$ & $-3,81$ & $-3,08$ & $-2,82$ & $-3,78$ & $-1,63$ \\
\hline & CI0613 & $-6,35$ & $-7,90$ & $-5,12$ & $-4,42$ & $-4,55$ & $-5,56$ & $-4,93$ & $-3,67$ & $-4,25$ & $-4,80$ & $-2,55$ & $-3,29$ & $-3,94$ & $-2,70$ \\
\hline
\end{tabular}


Ao avaliar os resultados obtidos com o cálculo do Igeo, é possível identificar que o $\mathbf{~ i ~ a p r e s e n t o u ~ v a l o r e s ~ d e ~} \mathbf{0}<$ Igeo $<1$ para as amostras CV0504, CV0509, Cl0504, Cl0509, CV0603, CV0609, Cl0609 e Cl0611.

$\mathrm{O} \mathbf{P b}$ apresentou valor 0 para o Igeo na amostra CV0504 e o valor 0,03 para a amostra Cl0504. A amostra CV0502 apresentou valores de $0<$ lgeo $<1$ para o Cd.

Em relação ao $\mathbf{H g}$, observou-se que as amostras CV0504 e CV0609 apresentaram valores $0<$ Igeo $<1$, o que de acordo com o critério descrito na Tabela 4.17, considera as amostras não poluídas, e as demais amostras apresentaram resultados Igeo $<0$, o que demonstra que não ocorreram influências externas ao estuário para este elemento.

Os demais elementos analisados apresentaram Igeo $<0$, o que seria semelhante aos níveis basais.

\subsubsection{Resultados obtidos para os elementos traço e alguns metais por NAA - Cananéia}

A Tabela 5.45 apresenta os resultados obtidos de média, desvio padrão da média, valores mínimos e máximos $\left(\mathrm{mg} \mathrm{kg}^{-1}\right)$ para os elementos analisados por NAA nas amostras de sedimento coletados em Cananéia, inverno e verão de 2005.

Os Anexos XVII a XX apresentam as tabelas com os dados de concentração e desvios para todos os pontos amostrados no estuário de Cananéia, nos períodos de inverno e verão, 2005 e 2006, respectivamente pela técnica de NAA. 
Tabela 5.45 - Resultados obtidos para as amostras de Cananéia 2005 (Verão e Inverno) para os elementos determinados por NAA $\left(\mathrm{mg} \mathrm{kg}^{-1}\right)$, média, desvio padrão, mínimo, máximo e valores TEL e PEL

\begin{tabular}{|c|c|c|c|c|c|c|c|c|c|c|c|c|c|c|c|c|c|c|c|c|c|c|c|c|c|c|c|}
\hline \multirow{2}{*}{\multicolumn{2}{|c|}{ Estação }} & \multicolumn{2}{|c|}{ As } & \multicolumn{2}{|c|}{$\mathrm{Ba}$} & \multicolumn{2}{|c|}{$\mathrm{Br}$} & \multicolumn{2}{|c|}{$\mathrm{Ca}(\%)$} & \multicolumn{2}{|c|}{$\mathrm{Ce}$} & \multicolumn{2}{|c|}{ Co } & \multicolumn{2}{|c|}{$\mathrm{Cr}$} & \multicolumn{2}{|c|}{ Cs } & \multicolumn{2}{|c|}{$\mathrm{Eu}$} & \multicolumn{2}{|c|}{$\mathrm{Fe}(\%)$} & \multicolumn{2}{|c|}{ Hf } & \multicolumn{2}{|c|}{ La } & \multicolumn{2}{|c|}{ Lu } \\
\hline & & I & V & $I$ & V & $I$ & V & $I$ & $\mathbf{V}$ & $I$ & V & $I$ & V & $\mathrm{I}$ & $\mathbf{v}$ & $\mathrm{I}$ & $\mathbf{v}$ & I & $\mathbf{v}$ & $\mathrm{I}$ & $\mathbf{v}$ & $\mathrm{I}$ & $\mathbf{v}$ & $\mathrm{I}$ & $\mathbf{v}$ & $\bar{T}$ & $\mathbf{v}$ \\
\hline \multirow{5}{*}{ অ } & 1 & 1,2 & 3 & 109 & 141 & 14 & 23 & 0,14 & 0,43 & 5 & 12 & 0,5 & 1,3 & 3 & 6 & 0,3 & 0,7 & 0,09 & 0,17 & 0,2 & 0,4 & 2 & 4 & 2,6 & 5,6 & N.D. & 0,1 \\
\hline & 2 & 6,1 & 2,2 & 210 & N.D. & 50 & 22 & 0,64 & 0,41 & 34 & 15 & 3,7 & 1,7 & 24 & 11 & 1,9 & 0,9 & 0,49 & 0,23 & 1,2 & 0,5 & 6 & 2,7 & 16,6 & 7,9 & 0,3 & 0,2 \\
\hline & 4 & 11,3 & 12,1 & 602 & N.D. & 74 & 91 & 1,18 & 0,88 & 95 & 91 & 12,2 & 11,7 & 76 & 71 & 6,3 & 6,3 & 1,37 & 1,4 & 4,7 & 4,5 & 3,7 & 4,5 & 42,8 & 41 & 0,5 & N.D. \\
\hline & 5 & 5,3 & 3,9 & 289 & 164 & 17 & 17 & 0,58 & 0,67 & 32 & 30 & 3,8 & 2,8 & 22 & 16 & 1,8 & 1,5 & 0,44 & 0,35 & 1,3 & 1 & 4,8 & 4,7 & 14,5 & 13,7 & 0,1 & 0,1 \\
\hline & 6 & 1 & 1 & 196 & 162 & 6 & 7 & 0,23 & 0,30 & 7 & 9 & 0,8 & 0,7 & 5 & 5 & 0,3 & 0,4 & 0,1 & 0,13 & 0,2 & 0,2 & 2,2 & 2,9 & 3 & 4,3 & N.D. & 0,1 \\
\hline \multirow{2}{*}{ 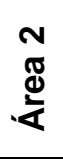 } & 8 & 5,6 & 5,3 & 232 & 339 & 35 & 42 & 0,79 & 0,74 & 31 & 32 & 4,2 & 4,3 & 19 & 24 & 1,5 & 1,7 & 0,53 & 0,46 & 1,2 & 1,3 & 3,4 & 3,5 & 13,5 & 14,1 & 0,1 & 0,1 \\
\hline & 9 & 15,4 & 15,8 & 149 & N.D. & 109 & 74 & 1,08 & 1,02 & 67 & 79 & 8,8 & 10,1 & 57 & 60 & 4,3 & 5,2 & 1,09 & 1,2 & 3 & 3,4 & 5 & 5,4 & 30,7 & 36,3 & N.D. & 0,4 \\
\hline \multirow{4}{*}{ 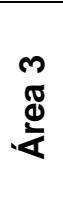 } & 10 & 2,6 & 2,6 & N.D. & 43 & 23 & 22 & 0,44 & 0,38 & 16 & 22 & 1,6 & 1,7 & 15 & 12 & 0,7 & 0,8 & 0,2 & 0,22 & 0,5 & 0,5 & 9,7 & 5,7 & 6,5 & 10,1 & N.D. & 0,3 \\
\hline & 11 & 6,3 & 9,4 & 133 & 95 & 60 & 42 & 0,55 & 0,55 & 40 & 40 & 4,1 & 4,6 & 31 & 41 & 2,7 & 2,6 & 0,58 & 0,62 & 1,6 & 1,5 & 4,7 & 4,6 & 18,1 & 19,6 & 0,2 & 0,2 \\
\hline & 12 & 2 & 2,8 & 171 & 167 & 17 & 26 & 0,99 & 0,73 & 16 & 37 & 2,9 & 2,7 & 21 & 29 & 0,9 & 1,3 & 0,24 & 0,4 & 0,9 & 0,9 & 16,1 & 11,9 & 7,2 & 16,7 & 0,4 & 0,4 \\
\hline & 13 & 1,7 & 1,3 & 188 & 167 & 11 & 14 & 0,55 & 0,38 & 15 & 11 & 1,1 & 1,2 & 4 & 12 & 0,6 & 0,5 & 0,15 & 0,16 & 0,3 & 0,3 & 2,7 & 5,3 & 7,6 & 5 & N.D. & N.D. \\
\hline \multicolumn{2}{|c|}{ TEL } & \multirow{2}{*}{\multicolumn{2}{|c|}{7,24}} & & & & & & & & & & & \multirow{2}{*}{\multicolumn{2}{|c|}{$\begin{array}{l}52,3 \\
160\end{array}$}} & & & & & & & & & & & & \\
\hline & EL & & & & & & & & & & & & & & & & & & & & & & & & & & \\
\hline
\end{tabular}


Tabela 5.45- Resultados obtidos para as amostras de Cananéia 2005 (Verão e Inverno) para os elementos determinados por NAA ( $\mathrm{mg} \mathrm{kg}^{-1}$ ), média, desvio padrão, mínimo, máximo e valores TEL e PEL (continuação)

\begin{tabular}{|c|c|c|c|c|c|c|c|c|c|c|c|c|c|c|c|c|c|c|c|c|c|c|c|c|c|}
\hline \multirow{2}{*}{\multicolumn{2}{|c|}{ Estação }} & \multicolumn{2}{|c|}{$\mathrm{Na}(\%)$} & \multicolumn{2}{|c|}{ Nd } & \multicolumn{2}{|c|}{$\mathbf{R b}$} & \multicolumn{2}{|c|}{$\mathrm{Sb}$} & \multicolumn{2}{|c|}{ Sc } & \multicolumn{2}{|c|}{$\mathrm{Sm}$} & \multicolumn{2}{|c|}{$\mathrm{Ta}$} & \multicolumn{2}{|c|}{$\overline{T b}$} & \multicolumn{2}{|c|}{$\overline{T h}$} & \multicolumn{2}{|c|}{$\bar{U}$} & \multicolumn{2}{|c|}{$\mathrm{Yb}$} & \multicolumn{2}{|c|}{$\mathrm{Zn}$} \\
\hline & & I & V & I & V & 1 & V & I & V & I & V & 1 & V & I & V & I & V & I & V & I & V & I & V & I & V \\
\hline \multirow{6}{*}{$\begin{array}{c}\bar{\Phi} \\
\frac{\Phi}{4}\end{array}$} & 1 & 0,2 & 0,4 & 1 & 5,3 & 16 & 23 & 0,09 & 0,15 & 0,4 & 1,3 & 0,4 & 0,9 & 0,1 & 0,2 & 0,03 & 0,08 & 0,9 & 1,7 & 0,4 & 0,5 & 0,2 & 0,4 & 1 & 12 \\
\hline & 2 & 0,7 & 0,4 & 10,8 & 7,5 & 42 & 22 & 0,24 &, 14 & 4 & 1,8 & 2,6 & 1,3 & 0,5 & 0,3 & 0,3 &, 13 & 3,7 & 2,4 & 2,2 & 0,5 & 1 &, 5 & 25 & 14 \\
\hline & 3 & 0,7 & 0,7 & 17 & 15,6 & 44 & N.D. & 0,24 & 0,3 & 3,7 & 4,3 & 2,4 & 1,9 & 0,5 & 0,5 & 0,23 & 0,25 & 3,9 & 6,3 & 1,8 & 1,2 & 1,2 & 1,2 & 25 & 29 \\
\hline & 4 & 1,8 & 1,1 & 30,7 & 30,8 & 76 & 86 & 0,87 & N.D. & 14,8 & 14,1 & 7,6 & 6,5 & 1 & 0,9 & 1,03 & 1,02 & 13,1 & 12 & 3,7 & 3,3 & 2,1 & 1,8 & 94 & 96 \\
\hline & 5 & 0,6 & 0,4 & 15,1 & 12,8 & 27 & 24 & 0,48 & 0,32 & 4,1 & 3 & 2,5 & 2,2 & 0,4 & 0,4 & 0,32 & 0,16 & 8,1 & 3,9 & 1,6 & 1 & 0,8 & 0,7 & 28 & 29 \\
\hline & 6 & 0,2 & 0,2 & 2,7 & 3,3 & 11 & 14 & 0,07 & 0,1 & 0,6 & 0,7 & 0,5 & 0,7 & 0,2 & 0,2 & 0,09 & 0,08 & 0,9 & 1,3 & 0,5 & 0,5 & 0,3 & 0,3 & 3 & 8 \\
\hline \multirow{3}{*}{$\begin{array}{l}\text { N } \\
\mathbb{\Phi} \\
\stackrel{\frac{1}{4}}{4}\end{array}$} & 7 & 4 & 0,4 & 5 & 7,9 & 21 & 22 & 0,1 & 0,14 & 0,6 & 1,5 & 0,6 & 1,2 & 0,1 & 0,2 & 0,04 & 0,28 & 0,9 & 2 & 0,3 & 0,5 & 0,3 & 0,5 & 7 & 13 \\
\hline & 8 & 0,8 & 0,9 & 16,2 & 17,2 & 40 & 46 & 0,34 & 0,29 & 3,5 & 3,9 & 2 & 2,2 & 0,3 & 0,4 & 0,27 & 0,23 & 3,3 & 3,7 & 1,3 & 1,3 & 0,9 & 0,9 & 33 & 35 \\
\hline & 9 & 1,9 & 1,6 & 35,1 & 24,8 & 75 & 77 & 0,47 & 0,61 & 9,7 & 11,2 & 5 & 6,2 & 0,7 & 0,6 & 0,75 & 0,9 & 8,6 & 10,4 & 3,2 & 2,9 & 1,7 & 2 & 70 & 62 \\
\hline \multirow{4}{*}{$\begin{array}{l}\text { m } \\
\mathbb{\Xi} \\
\stackrel{\mathbb{d}}{\alpha}\end{array}$} & 10 & 0,4 & 0,4 & 6,8 & 8,3 & 13 & 10 & 0,21 & 0,26 & 1,6 & 1,8 & 1,2 & 1,6 & 0,4 & 0,3 & 0,34 & 0,21 & 2,3 & 3,4 & 2 & 1,9 & 1,5 & 1,6 & 19 & 14 \\
\hline & 11 & 1,1 & 0,8 & 20 & 20,1 & 40 & 22 & 0,38 & 0,4 & 5,5 & 5,4 & 3 & 3,2 & 0,5 & 0,4 & 0,26 & 0,78 & 5,3 & 5,5 & 2,1 & 4,8 & 1,1 & 0,9 & 32 & 29 \\
\hline & 12 & 0,3 & 0,5 & 8,3 & 14,4 & 34 & 17 & 0,25 & 0,24 & 2,8 & 1,7 & 1,6 & 3,1 & 0,9 & 0,6 & 0,09 & 0,73 & 5,3 & 6,3 & 2,8 & 2,5 & 2 & 1,8 & 16 & 19 \\
\hline & 13 & 0,3 & 0,3 & 8,3 & 5,6 & 28 & 8 & 0,11 & 0,15 & 0,8 & 1 & 1,2 & 0,6 & 0,2 & 0,4 & 0,1 & 0,16 & 3,2 & 1,5 & 0,6 & 0,8 & 0,4 & 0,5 & 11 & 1 \\
\hline \multicolumn{2}{|c|}{ Média: } & 0,7 & 0,6 & 13,6 & 13,4 & 36 & 31 & 0,3 & 0,24 & 4 & 4 & 2,4 & 2,4 & 0,5 & 0,4 & 0,3 & 0,38 & 4,6 & 4,7 & 1,7 & 1,7 & 1 & 1 & 28 & 28 \\
\hline \multicolumn{2}{|c|}{ Desv. Pad. } & 0,6 & 0,4 & 10,3 & 8,2 & 21 & 25 & 0,22 & 0,16 & 4,1 & 4,1 & 2 & 1,9 & 0,3 & 0,2 & 0,29 & 0,34 & 3,6 & 3,4 & 1,1 & 1,3 & 0,6 & 0,6 & 27 & 26 \\
\hline \multicolumn{2}{|c|}{ Min } & 0,2 & 0,2 & 1 & 3,3 & 11 & 8 & 0,07 & N.D. & 0,4 & 0,7 & 0,4 & 0,6 & 0,1 & 0,2 & 0,03 & 0,08 & 0,9 & 1,3 & 0,3 & 0,5 & 0,2 & 0,3 & 1 & 1 \\
\hline \multicolumn{2}{|c|}{ Max } & 1,9 & 1,6 & 35,1 & 30,8 & 76 & 86 & 0,87 & 0,61 & 14,8 & 14,1 & 7,6 & 6,5 & 1 & 0,9 & 1,03 & 1,02 & 13,1 & 12 & 3,7 & 4,8 & 2,1 & 2 & 94 & 96 \\
\hline \multicolumn{2}{|c|}{ TEL } & & & & & & & & & & & & & & & & & & & & & & & \multicolumn{2}{|c|}{$\begin{array}{l}124 \\
271\end{array}$} \\
\hline
\end{tabular}


Ao avaliar os dados obtidos de média, desvio padrão, valores mínimos e máximos da região de Cananéia, verão e inverno de 2005, é possível verificar que para a maioria dos elementos analisados, os resultados entre o verão e inverno não sofreram alterações significativas (Tabela 5.45).

Quando os resultados obtidos foram comparados aos valores TEL e PEL, verificou-se que as estações 04 e 09, nos períodos do verão e inverno de 2005, apresentaram valores superiores ao TEL para os parâmetros As e $\mathrm{Cr}$. Nenhuma das amostras apresentou valores superiores ao limite PEL.

Ao comparar com a legislação CONAMA 344, verifica-se que a amostra 04 apresenta o resultado de As acima do valor estabelecido pela norma. Os demais parâmetros estão em conformidade com a norma do CONAMA 344 (Tabela 1.2).

A Tabela 5.46 apresenta os resultados obtidos para as amostras coletadas na região de Cananéia, 2006. 
Tabela 5.46 - Resultados obtidos das amostras de Cananéia 2006 (Verão e Inverno) para os elementos determinados por NAA ( $\mathrm{mg} \mathrm{kg}^{-1}$ ), média, desvio padrão, mínimo, máximo e valores TEL e PEL

\begin{tabular}{|c|c|c|c|c|c|c|c|c|c|c|c|c|c|c|c|c|c|c|c|c|c|c|c|c|c|c|c|}
\hline \multirow{2}{*}{\multicolumn{2}{|c|}{ Estação }} & \multicolumn{2}{|c|}{ As } & \multicolumn{2}{|c|}{$\mathrm{Ba}$} & \multicolumn{2}{|c|}{$\mathrm{Br}$} & \multicolumn{2}{|c|}{$\mathrm{Ca}(\%)$} & \multicolumn{2}{|c|}{$\mathrm{Ce}$} & \multicolumn{2}{|c|}{ Co } & \multicolumn{2}{|c|}{$\mathrm{Cr}$} & \multicolumn{2}{|c|}{ Cs } & \multicolumn{2}{|c|}{ Eu } & \multicolumn{2}{|c|}{$\mathrm{Fe}(\%)$} & \multicolumn{2}{|c|}{ Hf } & \multicolumn{2}{|c|}{ La } & \multicolumn{2}{|c|}{ Lu } \\
\hline & & I & V & I & V & I & V & I & V & I & V & I & V & I & V & I & V & I & V & I & V & I & V & I & V & I & V \\
\hline \multirow{6}{*}{ ঠ্ঠু } & 1 & 0,95 & 1,81 & 200 & 87 & 20 & 19 & 0,5 & 0,4 & 6,3 & 10,9 & 0,6 & 0,8 & 7,8 & 5,9 & 0,3 & N.D. & 0,1 & 0,1 & 0,2 & 0,3 & 1,6 & 4,0 & 3,4 & 5,7 & 0,1 & 0,1 \\
\hline & 2 & 6,08 & 1,62 & 143 & 147 & 35 & 19 & 0,6 & 0,6 & 25,6 & 24,3 & 2,9 & 1,3 & 21,7 & 24,1 & 1,4 & 0,5 & 0,4 & 0,2 & 1,1 & 0,5 & 5,1 & 21,3 & 12,1 & 11,3 & 0,2 & 0,2 \\
\hline & 3 & 7,42 & 11,96 & 275 & 300 & 65 & 101 & 0,7 & 1,0 & 31,1 & 51,6 & 3,9 & 6,5 & 25,9 & 40,9 & 1,8 & 3,1 & 0,5 & 0,8 & 1,3 & 2,2 & 4,4 & 5,9 & 14,8 & 23,2 & 0,2 & 0,3 \\
\hline & 4 & 2,93 & 3,28 & 127 & 176 & 29 & 41 & 0,5 & 0,4 & 25,9 & 17,5 & 2,0 & 1,7 & 13,1 & 10,7 & 0,9 & 0,8 & 0,2 & 0,2 & 0,7 & 0,6 & 6,9 & 2,5 & 13,7 & 7,7 & 0,2 & 0,1 \\
\hline & 5 & 1,57 & 2,23 & 145 & 198 & 22 & 29 & 0,4 & 0,5 & 17,2 & 40,3 & 1,1 & 2,1 & 7,6 & 17,0 & 0,7 & 1,1 & 0,2 & 0,3 & 0,3 & 0,8 & 3,5 & 10,7 & 9,6 & 17,3 & 0,1 & 0,2 \\
\hline & 6 & 1,03 & 1,23 & 165 & 145 & 12 & 10 & 0,5 & 0,5 & 11,6 & 16,9 & 0,8 & 1,1 & 10,7 & 17,2 & 0,4 & 0,4 & 0,1 & 0,2 & 0,2 & 0,3 & 6,8 & 13,9 & 6,6 & 7,5 & 0,1 & 0,2 \\
\hline \multirow{3}{*}{ 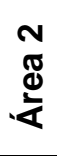 } & 7 & 2,57 & 1,67 & 203 & 258 & 20 & 18 & 0,6 & 0,4 & 12,5 & 7,6 & 1,3 & 1,0 & 5,9 & 10,3 & 0,5 & 0,4 & 0,2 & 0,1 & 0,4 & 0,3 & 1,5 & 2,7 & 6,2 & 3,4 & 0,0 & 0,1 \\
\hline & 8 & 4,69 & 4,46 & 256 & 333 & 43 & 66 & 0,7 & 0,7 & 22,3 & 32,2 & 3,1 & 4,0 & 17,9 & 20,1 & 1,2 & 2 & 0,4 & 0,5 & 0,9 & 1,3 & 4,1 & 4,2 & 10,6 & 13,5 & 0,1 & 0,1 \\
\hline & 9 & 13,98 & 12,66 & 392 & 448 & 121 & 171 & 1,1 & 1,0 & 59,3 & 65,1 & 7,3 & 8,3 & 50,1 & 54,2 & 3,7 & 4,7 & 0,9 & 1,3 & 2,4 & 3,0 & 5,3 & 9,0 & 25,0 & 26,3 & 0,2 & 0,3 \\
\hline \multirow{4}{*}{ 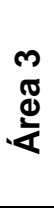 } & 10 & 3,02 & 1,18 & 131 & 96 & 43 & 39 & 0,6 & 0,5 & 22,8 & 16,9 & 2,2 & 1,5 & 19,2 & 10,6 & 1,0 & 0,6 & 0,3 & 0,2 & 0,8 & 0,5 & 12,9 & 9,8 & 10,5 & 6,8 & 0,2 & 0,1 \\
\hline & 11 & 17,68 & 6,17 & 338 & 245 & 120 & 94 & 0,9 & 0,8 & 60,5 & 57,3 & 6,3 & 4,5 & 49,6 & 38,4 & 3,6 & 3,0 & 0,9 & 0,7 & 2,5 & 1,9 & 5,8 & 8,4 & 25,8 & 23,5 & 0,3 & 0,3 \\
\hline & 12 & 3,05 & 2,61 & 248 & 153 & 36 & 35 & 2,0 & 0,9 & 20,3 & 30,2 & 2,5 & 2,6 & 23,5 & 23,6 & 1,1 & 1,1 & 0,3 & 0,3 & 0,9 & 1,2 & 14,3 & 18,4 & 9,2 & 12,9 & 0,3 & 0,3 \\
\hline & 13 & 1,11 & 1,19 & 182 & 215 & 16 & 13 & 0,2 & 0,4 & 14,9 & 11,6 & 1,2 & 0,8 & 12,5 & 11,1 & 0,5 & 0,3 & 0,2 & 0,1 & 0,4 & 0,3 & 7,1 & 3,0 & 6,5 & 5,5 & 0,1 & 0,1 \\
\hline \multicolumn{2}{|c|}{ Média } & 5,08 & 4,00 & 216 & 215 & 45 & 50 & 0,7 & 0,6 & 25,4 & 29,4 & 2,7 & 2,8 & 20,4 & 22,1 & 1,3 & 1,0 & 0,4 & 0,4 & 0,9 & 1,0 & 6,1 & 8,7 & 11,8 & 12,7 & 0,2 & 0,2 \\
\hline \multicolumn{2}{|c|}{$\begin{array}{l}\text { Desv. } \\
\text { Pad. }\end{array}$} & 5,21 & 3,96 & 82 & 102 & 36 & 47 & 0,5 & 0,2 & 16,7 & 18,9 & 2,1 & 2,4 & 14,5 & 14,4 & 1,1 & 1,4 & 0,3 & 0,4 & 0,8 & 0,9 & 3,8 & 6,1 & 6,8 & 7,7 & 0,1 & 0,1 \\
\hline \multicolumn{2}{|c|}{ Min } & 0,95 & 1,18 & 127 & 87 & 12 & 10 & 0,2 & 0,4 & 6,3 & 7,6 & 0,6 & 0,8 & 5,9 & 5,9 & 0,3 & $<$ L.Q. & 0,1 & 0,1 & 0,2 & 0,3 & 1,5 & 2,5 & 3,4 & 3,4 & 0,0 & 0,1 \\
\hline \multicolumn{2}{|c|}{$\operatorname{Max}$} & 17,68 & 12,66 & 392 & 448 & 121 & 171 & 2,0 & 1,0 & 60,5 & 65,1 & 7,3 & 8,3 & 50,1 & 54,2 & 3,7 & 4,7 & 0,9 & 1,3 & 2,5 & 3,0 & 14,3 & 21,3 & 25,8 & 26,3 & 0,3 & 0,3 \\
\hline \multicolumn{2}{|c|}{ TEL } & \multicolumn{2}{|c|}{7,24} & & & & & & & & & & & \multicolumn{2}{|c|}{52,3} & & & & & & & & & & & & \\
\hline \multicolumn{2}{|c|}{ PEL } & & 0 & & & & & & & & & & & & & & & & & & & & & & & & \\
\hline
\end{tabular}


Tabela 5. 46 - Resultados obtidos das amostras de Cananéia 2006 (Verão e Inverno) para os elementos determinados por NAA $\left(\mathrm{mg} \mathrm{kg}^{-1}\right)$, média, desvio padrão, mínimo, máximo e valores TEL e PEL (continuação)

\begin{tabular}{|c|c|c|c|c|c|c|c|c|c|c|c|c|c|c|c|c|c|c|c|c|c|c|c|c|c|}
\hline \multirow{2}{*}{\multicolumn{2}{|c|}{ Estação }} & \multicolumn{2}{|c|}{$\mathrm{Na}$} & \multicolumn{2}{|c|}{ Nd } & \multicolumn{2}{|c|}{$\mathbf{R b}$} & \multicolumn{2}{|c|}{$S b$} & \multicolumn{2}{|c|}{ Sc } & \multicolumn{2}{|c|}{$\mathrm{Sm}$} & \multicolumn{2}{|c|}{$\mathrm{Ta}$} & \multicolumn{2}{|c|}{$\mathrm{Tb}$} & \multicolumn{2}{|c|}{ Th } & \multicolumn{2}{|c|}{$\mathbf{U}$} & \multicolumn{2}{|c|}{$\mathrm{Yb}$} & \multicolumn{2}{|c|}{ Zn } \\
\hline & & I & V & I & V & I & V & I & V & I & V & I & V & I & V & I & V & I & V & I & V & I & V & I & V \\
\hline \multirow{5}{*}{ অ্ঠ } & 1 & 3543 & 3241 & 4,6 & 3,3 & 18,8 & 12,1 & 0,06 & 0,11 & 0,5 & 0,7 & 0,54 & 0,96 & N.D. & N.D. & 0,10 & N.D. & 0,8 & 2,8 & 0,4 & 0,5 & 0,3 & 0,2 & N.D. & N.D. \\
\hline & 3 & 10009 & 16768 & 17,5 & 21,7 & 50,5 & 52,7 & 0,33 & 0,43 & 4,3 & 7,1 & 2,47 & 5,97 & N.D. & N.D. & 0,22 & 0,72 & 4,1 & 7,1 & 1,3 & 1,7 & 0,9 & 1,2 & 23,3 & 54,7 \\
\hline & 4 & 3714 & 5268 & 11,7 & 7,6 & 15,5 & 21,4 & 0,26 & 0,06 & 2,2 & 2,0 & 2,15 & 1,39 & N.D. & N.D. & 0,18 & 0,25 & 4,5 & 2,1 & 2,5 & 0,7 & 1,0 & 0,5 & N.D. & N.D. \\
\hline & 5 & 2827 & 4120 & 4,9 & 13,4 & 15,7 & 21,8 & 0,15 & 0,12 & 1,3 & 2,5 & 1,66 & 2,46 & N.D. & N.D. & 0,09 & 0,25 & 3,1 & 5,5 & 1,0 & 1,6 & 0,4 & 1,1 & 2,9 & 18,0 \\
\hline & 6 & 1978 & 1942 & 5,6 & 5,6 & 14,8 & 14,4 & 0,16 & 0,14 & 0,9 & 1,1 & 1,04 & 1,09 & N.D. & N.D. & 0,04 & 0,18 & 2,3 & 2,5 & 0,9 & 1,3 & 0,6 & 1,4 & 4,5 & 2,7 \\
\hline \multirow{3}{*}{$\begin{array}{l}\text { N } \\
\mathbb{\Phi} \\
\frac{\Phi}{4}\end{array}$} & 7 & 4762 & 3566 & 4,3 & 3,5 & 21,5 & 26,8 & 0,12 & 0,08 & 0,9 & 0,6 & 1,09 & 0,58 & N.D. & N.D. & 0,09 & 0,10 & 1,3 & 0,9 & 0,3 & 0,5 & 0,4 & 0,3 & 6,1 & N.D. \\
\hline & 8 & 8514 & 10436 & 11,7 & 20,0 & 31,5 & 34,2 & 0,21 & 0,26 & 2,6 & 3,7 & 1,82 & 2,42 & N.D. & N.D. & 0,32 & N.D. & 2,7 & 3,8 & 0,9 & 1,1 & 0,7 & 0,8 & 13,2 & N.D. \\
\hline & 9 & 21113 & 23178 & 24,1 & 34,7 & 64,1 & 61,8 & 0,41 & 0,33 & 8,0 & 9,4 & 4,03 & 6,93 & N.D. & N.D. & 0,46 & 0,31 & 7,3 & 9,1 & 1,9 & 2,0 & 1,5 & 1,5 & 63,7 & 73,9 \\
\hline \multirow{3}{*}{ ஹ } & 10 & 5952 & 4990 & 10,8 & 10,0 & 15,1 & 15,4 & 0,19 & 0,16 & 2,4 & 1,7 & 1,73 & 1,22 & N.D. & N.D. & 0,21 & 0,16 & 3,2 & 2,4 & 1,9 & 1,3 & 0,9 & 0,5 & 20,0 & 9,6 \\
\hline & 11 & 18418 & 13457 & 29,4 & 28,6 & 56,4 & 52,1 & 0,43 & 0,32 & 8,5 & 6,0 & 4,43 & 3,98 & N.D. & N.D. & 0,54 & 0,36 & 8,0 & 7,6 & 2,8 & 2,8 & 1,8 & 1,6 & 46,2 & 34,2 \\
\hline & 12 & 5848 & 5619 & 6,6 & 13,4 & 38,3 & 21,8 & 0,14 & 0,19 & 2,7 & 3,1 & 1,66 & 3,71 & 0,58 & N.D. & 0,21 & 0,12 & 4,3 & 4,9 & 2,0 & 2,4 & 1,6 & 1,6 & 15,6 & 15,3 \\
\hline \multicolumn{2}{|c|}{ Média } & 7455 & 7578 & 11,6 & 13,5 & 31,5 & 28,6 & 0,22 & 0,20 & 3,0 & 3,1 & 1,99 & 2,60 & - & - & 0,22 & 0,27 & 3,7 & 4,2 & 1,4 & 1,4 & 0,9 & 0,9 & 20,7 & 26,6 \\
\hline \multicolumn{2}{|c|}{ Desv. Pad. } & 5944 & 6510 & 7,9 & 10,0 & 17,5 & 16,5 & 0,11 & 0,11 & 2,6 & 2,8 & 1,13 & 2,00 & 0,12 & - & 0,15 & 0,18 & 2,1 & 2,5 & 0,8 & 0,7 & 0,5 & 0,5 & 18,8 & 25,7 \\
\hline \multicolumn{2}{|c|}{ Min } & 1978 & 1942 & 4,3 & 3,3 & 14,8 & 12,1 & 0,06 & 0,06 & 0,5 & 0,6 & 0,54 & 0,58 & 0,42 & - & 0,04 & $<$ L.Q. & 0,8 & 0,9 & 0,3 & 0,5 & 0,3 & 0,2 & $<$ L.Q. & $<$ L.Q. \\
\hline \multicolumn{2}{|c|}{ Max } & 21113 & 23178 & 29,4 & 34,7 & 64,1 & 61,8 & 0,43 & 0,43 & 8,5 & 9,4 & 4,43 & 6,93 & 0,58 & - & 0,54 & 0,72 & 8,0 & 9,1 & 2,8 & 2,8 & 1,8 & 1,6 & 63,7 & 73,9 \\
\hline \multicolumn{2}{|c|}{ TEL } & & & & & & & & & & & & & & & & & & & & & & & 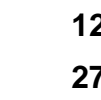 & \\
\hline
\end{tabular}


Ao avaliar os dados obtidos de média, desvio padrão, valores mínimos e máximos da região de Cananéia, verão e inverno de 2006, é possível identificar, assim como nas amostras coletadas em 2005, para a maioria dos elementos analisados, que os resultados obtidos no verão e inverno não sofreram alterações significativas (Tabela 5.46).

Quando os resultados obtidos foram comparados aos valores TEL e PEL, verificou-se que os resultados das estações 03 e 09, períodos do verão e inverno de 2006 e a amostra 11 no período do inverno, apresentaram valores superiores ao TEL para o parâmetro As. A estação 09 apresentou resultado superior a limite TEL para o $\mathrm{Cr}$, para a amostra coletada no verão. Nenhuma das amostras apresentou valores superiores ao limite PEL.

Ao compararmos os resultados com a legislação CONAMA 344, verificou-se que a amostra 03 apresentou valores de As acima do valor estabelecido pela norma, na amostra coletada no verão de 2006, assim como a amostra 09, nos períodos de inverno e verão de 2006 e a amostra 11, no inverno de 2006. Os demais parâmetros estão em conformidade com a norma do CONAMA 344.

\subsubsection{Fator de Enriquecimento (FE) para os elementos determinados por NAA nos sedimentos coletados em Cananéia}

O Fator de Enriquecimento (FE) apresentado no item 4.11.2 foi também utilizado para avaliar o impacto com os elementos analisados por NAA.

Neste estudo, o FE foi calculado utilizando o Sc como elemento normalizador, e os valores de referência Upper Continental Crust (UCC) (WEDEPOHL, 1995) como valores de referência do background da região para os elementos analisados pelas técnica de NAA. 
Com o objetivo de comparar os dados obtidos com outros estudos realizados na região de Cananéia, foram também utilizados como valores de background os valores obtidos por Armelin et al, 2009, nas análises de testemunhos de sedimentos com até $200 \mathrm{~cm}$ de profundidade, realizados na região, pela técnica de NAA.

A Tabela 5.47 apresenta os resultados obtidos por Armelin et al, 2009, para os elementos As, Ba, Cs, Eu, La, Rb, Sb, Sm, Sc, Th e U, na profundidade de $192-194 \mathrm{~cm}$, por NAA

Tabela 5.47: Valores obtidos por Armelin et al, 2009, $\mathrm{mg} \mathrm{kg}^{-1}$, em sedimentos de Cananéia, por NAA

\begin{tabular}{c|c}
\hline Elemento & $\begin{array}{c}\text { Concentração } \\
\left(\mathbf{m g ~ k g}^{-1}\right)\end{array}$ \\
\hline $\mathbf{A s}$ & 4,1 \\
\hline $\mathbf{B a}$ & 277 \\
\hline $\mathbf{C s}$ & 1,4 \\
\hline $\mathbf{E u}$ & 0,36 \\
\hline $\mathbf{L a}$ & 11,2 \\
\hline $\mathbf{R b}$ & 27 \\
\hline $\mathbf{S b}$ & 0,11 \\
\hline $\mathbf{S m}$ & 1,8 \\
\hline $\mathbf{T h}$ & 2,6 \\
\hline $\mathbf{U}$ & 1,5 \\
\hline $\mathbf{S c}$ & 2,4
\end{tabular}

A área 1, Mar de Cananéia, corresponde às estações 01 a 06; a área 2, baía de Trapandé, compreende as estações de 07 a 09 e a área 3, Mar de Cubatão, pelas estações 10 a 13.

As Tabelas 5.48 a 5.51 apresentam os resultados obtidos no cálculo do FE para as amostras coletadas no inverno e verão, nos anos de 2005 e 2006, na região de Cananéia. 
Tabela 5.48: Fator de Enriquecimento (FE) das amostras coletadas no inverno de 2005, Cananéia, utilizando-se como valores de background os dados obtidos por Armelin et al, 2009

\begin{tabular}{|c|c|c|c|c|c|c|c|c|c|c|c|}
\hline Áreas & Amostra & As & $\overline{\mathrm{Ba}}$ & Cs & $\mathrm{Eu}$ & La & $\overline{R b}$ & $\overline{S b}$ & $\overline{S m}$ & Th & $\mathbf{U}$ \\
\hline \multirow{6}{*}{ Área 1} & $\mathrm{Cl} 10501$ & 1,6 & $\overline{2,3}$ & 1,4 & 1,5 & 1,3 & 3,4 & 4,5 & 1,4 & 2,1 & 1,7 \\
\hline & $\mathrm{Cl} 0502$ & 0,9 & 0,5 & 0,8 & 0,8 & 0,9 & 0,9 & 1,3 & 0,9 & 0,9 & 0,9 \\
\hline & Cl0503 & 0,7 & 0,6 & 0,8 & 0,8 & 0,8 & 1,0 & 1,4 & 0,9 & 1,0 & 0,8 \\
\hline & $\mathrm{Cl} 10504$ & 0,4 & 0,4 & 0,7 & 0,6 & 0,6 & 0,5 & 1,3 & 0,7 & 0,8 & 0,4 \\
\hline & $\mathrm{Cl} 0505$ & 0,8 & 0,6 & 0,8 & 0,7 & 0,8 & 0,6 & 2,6 & 0,8 & 1,8 & 0,6 \\
\hline & $\mathrm{Cl} 0506$ & 1,0 & 2,7 & 0,8 & 1,1 & 1,0 & 1,5 & 2,5 & 1,1 & 1,3 & 1,2 \\
\hline \multirow{3}{*}{ Área 2} & Cl0507 & 2,1 & 2,3 & 1,3 & 1,6 & 1,4 & 3,3 & 3,8 & 1,3 & 1,4 & 1,0 \\
\hline & Cl0508 & 0,9 & 0,6 & 0,7 & 1,0 & 0,8 & 1,0 & 2,1 & 0,7 & 0,9 & 0,6 \\
\hline & Cl0509 & 0,9 & 0,1 & 0,8 & 0,7 & 0,7 & 0,7 & 1,1 & 0,7 & 0,8 & 0,5 \\
\hline \multirow{4}{*}{ Área 3} & $\mathrm{Cl} 0510$ & 0,9 & 0,4 & 0,8 & 0,8 & 0,8 & 0,7 & 2,8 & 1,0 & 1,3 & 2,0 \\
\hline & $\mathrm{Cl} 0511$ & 0,7 & 0,2 & 0,8 & 0,7 & 0,7 & 0,7 & 1,5 & 0,7 & 5,2 & 0,6 \\
\hline & Cl0512 & 0,4 & 0,5 & 0,6 & 0,6 & 0,6 & 1,1 & 2,0 & 0,8 & 1,8 & 1,6 \\
\hline & Cl0513 & 1,2 & 2,0 & 1,2 & 1,2 & 2,0 & 3,0 & 2,8 & 2,0 & 3,6 & 1,1 \\
\hline
\end{tabular}

Tabela 5.49: Fator de Enriquecimento (FE) das amostras coletadas no verão de 2005, Cananéia, utilizando-se como valores de background os dados obtidos por Armelin et al, 2009

\begin{tabular}{|c|c|c|c|c|c|c|c|c|c|c|c|}
\hline Área & Amostra & As & $\mathrm{Ba}$ & Cs & $\mathrm{Eu}$ & La & $\mathbf{R b}$ & $\mathbf{S b}$ & $\mathrm{Sm}$ & Th & $\mathrm{U}$ \\
\hline \multirow{6}{*}{ Área 1} & CV0501 & 1,3 & 0,9 & 0,9 & 0,9 & 0,9 & 1,5 & 2,6 & 1,0 & 1,2 & 0,6 \\
\hline & CV0502 & 0,7 & 0,4 & 0,9 & 0,9 & 0,9 & 1,1 & 1,7 & 1,0 & 1,3 & 0,4 \\
\hline & CV0503 & 0,9 & 0,2 & 0,7 & 0,8 & 0,9 & 0,1 & 1,5 & 0,6 & 1,3 & 0,4 \\
\hline & CV0504 & 0,1 & 0,2 & 0,8 & 0,7 & 0,6 & 0,5 & 0,5 & 0,6 & 0,8 & 0,4 \\
\hline & CV0505 & 0,8 & 0,5 & 0,8 & 0,8 & 1,0 & 0,7 & 2,3 & 1,0 & 1,2 & 0,6 \\
\hline & CV0506 & 0,9 & 2,0 & 1,1 & 1,2 & 1,3 & 1,8 & 3,0 & 1,4 & 1,7 & 1,1 \\
\hline \multirow{3}{*}{ Área 2} & CV0507 & 1,0 & 1,3 & 1,1 & 1,3 & 1,1 & 1,4 & 2,1 & 1,1 & 1,2 & 0,6 \\
\hline & CV0508 & 0,8 & 0,8 & 0,7 & 0,8 & 0,8 & 1,0 & 1,7 & 0,8 & 0,9 & 0,5 \\
\hline & CV0509 & 0,8 & 0,1 & 0,8 & 0,7 & 0,7 & 0,6 & 1,2 & 0,7 & 0,9 & 0,4 \\
\hline \multirow{4}{*}{ Área 3} & CV0510 & 0,9 & 0,2 & 0,7 & 0,8 & 1,2 & 0,5 & 3,2 & 1,2 & 1,8 & 1,8 \\
\hline & CV0511 & 1,0 & 0,2 & 0,8 & 0,8 & 0,8 & 0,4 & 1,6 & 0,8 & 0,9 & 1,4 \\
\hline & CV0512 & 1,0 & 0,8 & 1,3 & 1,5 & 2,1 & 0,9 & 3,0 & 2,4 & 3,4 & 2,3 \\
\hline & CV0513 & 0,8 & 1,4 & 0,9 & 1,1 & 1,1 & 0,7 & 3,2 & 0,8 & 1,4 & 1,3 \\
\hline
\end{tabular}


Tabela 5.50: Fator de Enriquecimento das amostras coletadas no inverno de 2006, Cananéia, em comparação com os dados obtidos por Armelin et al, 2009.

\begin{tabular}{|c|c|c|c|c|c|c|c|c|c|c|c|}
\hline Área & Amostra & As & $\mathrm{Ba}$ & Cs & $\mathrm{Eu}$ & La & $\mathbf{R b}$ & $\mathrm{Sb}$ & $\mathrm{Sm}$ & Th & $\mathbf{U}$ \\
\hline \multirow{6}{*}{ Área 1} & Cl0601 & 1,1 & 3,6 & 1,0 & 1,7 & 1,5 & 3,4 & 2,6 & 1,5 & 1,5 & 1,3 \\
\hline & Cl0602 & 1,0 & 0,3 & 0,6 & 0,8 & 0,7 & 1,1 & 1,3 & 0,8 & 1,3 & 0,7 \\
\hline & $\mathrm{Cl0603}$ & 1,0 & 0,6 & 0,7 & 0,8 & 0,7 & 1,0 & 1,7 & 0,8 & 0,9 & 0,5 \\
\hline & Cl0604 & 0,8 & 0,5 & 0,7 & 0,7 & 1,3 & 0,6 & 2,5 & 1,3 & 1,9 & 1,8 \\
\hline & Cl0605 & 0,7 & 1,0 & 0,9 & 0,8 & 1,6 & 1,1 & 2,5 & 1,7 & 2,2 & 1,2 \\
\hline & $\mathrm{Cl} 0606$ & 0,7 & 1,6 & 0,7 & 0,8 & 1,6 & 1,4 & 3,9 & 1,5 & 2,3 & 1,6 \\
\hline \multirow{3}{*}{ Área 2} & Cl0607 & 1,6 & 1,9 & 1,0 & 1,7 & 1,4 & 2,1 & 2,8 & 1,6 & 1,3 & 0,6 \\
\hline & Cl0608 & 1,1 & 0,9 & 0,8 & 1,0 & 0,9 & 1,1 & 1,8 & 0,9 & 1,0 & 0,6 \\
\hline & Cl0609 & 1,0 & 0,4 & 0,8 & 0,7 & 0,7 & 0,7 & 1,1 & 0,7 & 0,8 & 0,4 \\
\hline \multirow{4}{*}{ Área 3} & $\mathrm{Cl0610}$ & 0,7 & 0,5 & 0,7 & 0,7 & 0,9 & 0,6 & 1,8 & 1,0 & 1,2 & 1,2 \\
\hline & Cl0611 & 1,2 & 0,3 & 0,7 & 0,7 & 0,7 & 0,6 & 1,1 & 0,7 & 0,9 & 0,5 \\
\hline & $\mathrm{Cl0612}$ & 0,7 & 0,8 & 0,7 & 0,8 & 0,7 & 1,3 & 1,1 & 0,8 & 1,5 & 1,2 \\
\hline & Cl0613 & 0,6 & 1,4 & 0,7 & 1,1 & 1,2 & 1,8 & 2,7 & 1,3 & 1,4 & 1,2 \\
\hline
\end{tabular}

Tabela 5.51: Fator de Enriquecimento (FE) das amostras coletadas no verão de 2006, Cananéia, utilizando-se como valores de background os dados obtidos por Armelin et al, 2009

\begin{tabular}{|c|c|c|c|c|c|c|c|c|c|c|c|}
\hline Área & Amostra & As & $\mathbf{B a}$ & Cs & Eu & La & $\mathbf{R b}$ & $\mathrm{Sb}$ & $\mathrm{Sm}$ & Th & $\mathbf{U}$ \\
\hline \multirow{6}{*}{ Área 1} & CV0601 & 1,5 & 1,0 & 0,4 & 1,3 & 1,7 & 1,5 & 3,4 & 1,8 & 3,6 & 1,1 \\
\hline & CV0602 & 0,6 & 0,8 & 0,5 & 0,8 & 1,5 & 0,9 & 3,3 & 1,5 & 2,6 & 1,4 \\
\hline & CV0603 & 1,0 & 0,4 & 0,7 & 0,7 & 0,7 & 0,7 & 1,3 & 1,1 & 0,9 & 0,4 \\
\hline & CV0604 & 1,0 & 0,8 & 0,7 & 0,8 & 0,8 & 1,0 & 0,7 & 0,9 & 1,0 & 0,6 \\
\hline & CV0605 & 0,5 & 0,7 & 0,7 & 0,8 & 1,5 & 0,8 & 1,1 & 1,3 & 2,0 & 1,0 \\
\hline & CV0606 & 0,7 & 1,2 & 0,6 & 0,9 & 1,5 & 1,2 & 2,8 & 1,3 & 2,2 & 1,9 \\
\hline \multirow{3}{*}{ Área 2} & CV0607 & 1,6 & 3,8 & 1,0 & 1,6 & 1,2 & 4,0 & 2,9 & 1,3 & 1,5 & 1,3 \\
\hline & CV0608 & 0,7 & 0,8 & 0,9 & 0,9 & 0,8 & 0,8 & 1,5 & 0,9 & 0,9 & 0,5 \\
\hline & CV0609 & 0,8 & 0,4 & 0,9 & 0,9 & 0,6 & 0,6 & 0,8 & 1,0 & 0,9 & 0,3 \\
\hline \multirow{4}{*}{ Área 3} & CV0610 & 0,4 & 0,5 & 0,6 & 0,6 & 0,9 & 0,8 & 2,2 & 1,0 & 1,4 & 1,2 \\
\hline & CV0611 & 0,6 & 0,4 & 0,9 & 0,8 & 0,8 & 0,8 & 1,2 & 0,9 & 1,2 & 0,8 \\
\hline & CV0612 & 0,5 & 0,4 & 0,6 & 0,7 & 0,9 & 0,6 & 1,3 & 1,6 & 1,5 & 1,2 \\
\hline & CV0613 & 0,9 & 2,3 & 0,7 & 0,9 & 1,5 & 2,4 & 3,0 & 2,0 & 1,4 & 1,0 \\
\hline
\end{tabular}

$\mathrm{X}-\mathrm{FE}>\mathbf{1 , 5}$

Analisando-se os valores obtidos no cálculo do FE, com os dados de Armelin et al, 2009, foi possível verificar que as amostras Cl0501, Cl0507, Cl0607 e CV0607 apresentaram índices que indicam impacto antrópico para o 
As. $O$ ponto 07 só não apresentou FE>1,5 para as amostras coletadas no verão de 2005.

Em relação ao Ba, observou-se que as amostras Cl0501, Cl0601, CV0506, Cl0506, Cl0606, Cl0507, Cl0607, CV0607 e CV0613 apresentaram concentrações que provavelmente são provenientes de origem antrópica ou mesmo de influência hidrodinâmica.

O elemento Eu apresentou valores de FE>1,5 nas amostras CI0507, CV0512, Cl0601, Cl0607 e CV0607.

O La encontrado nas amostras Cl0513, CV0512, Cl0605, Cl0606, CV0601 e CV0602 pode ser proveniente de origem antrópica, de acordo com os resultados obtidos no cálculo do FE.

Verificou-se que o Rb das amostras Cl0501, Cl0506, Cl0507, Cl0513, CV0501, CV0506, Cl0601, Cl0607, Cl0613, CV0607 e CV0613 apresentou valores de FE>1,5, demonstrando assim uma possível contaminação de origem antrópica.

No caso do Sb, observou-se que a maioria das amostras apresentaram valores de $\mathbf{F E}>\mathbf{1 , 5}$, podendo estar indicando uma contaminação de origem antrópica.

Em relação ao Sm, as amostras Cl0513, CV0512, Cl0605, Cl0606, Cl0607, CV0601, CV0602, CV0612 e CV0613 apresentaram FE>1,5, demonstrando uma possível contaminação por origem antrópica.

O Th das amostras Cl0501, Cl0505, Cl0511, Cl0512, Cl0513, CV0506, CV0510, CV0512, Cl0604, Cl0605, Cl0606, CV0601, CV0602, CV0605 e CV0606, apresentaram FE>1,5 indicando, dessa forma, que estes pontos possuem possivelmente uma contribuição de origem antrópica.

Foi observado também que o U das amostras Cl0501, Cl0510, Cl0512, CV0510, CV0512, Cl0604, Cl0606 e CV0606 apresentaram FE>1,5. 
Com relação ao Cs, não foram obtidos registros que demonstrem qualquer enriquecimento por este elemento na região.

Foram realizados ainda os cálculos dos FE utilizando os valores UCC (Upper Continental Crust) para os elementos: As, Ba, Ca, Ce, Co, Cr, Cs, $\mathrm{Eu}, \mathrm{Fe}, \mathrm{Hf}, \mathrm{La}, \mathrm{Lu}, \mathrm{Na}, \mathrm{Nd}, \mathrm{Rb}, \mathrm{Sb}, \mathrm{Sm}, \mathrm{Ta}, \mathrm{Tb}, \mathrm{Th}, \mathrm{U}, \mathrm{Yb}$ e Zn e apresentados na Tabela 5.26.

As Tabelas 5.52 a 5.55 apresentam os resultados obtidos no cálculo do FE para as amostras coletadas no verão e inverno de 2005 e 2006, em Cananéia. 
Tabela 5.52: Fator de Enriquecimento, utilizando os dados descritos por Wedepohl, 1995 - Amostras coletadas no Inverno de 2005, Cananéia

\begin{tabular}{|c|c|c|c|c|c|c|c|c|c|c|c|c|c|c|c|c|c|c|c|c|c|c|c|c|}
\hline Área & & As & $\mathrm{Ba}$ & $\mathrm{Ca}$ & $\mathrm{Ce}$ & Co & $\mathrm{Cr}$ & Cs & $\mathrm{Eu}$ & $\mathrm{Fe}$ & $\mathrm{Hf}$ & La & Lu & $\mathrm{Na}$ & $\mathrm{Nd}$ & $\mathbf{R b}$ & $\mathrm{Sb}$ & $\mathrm{Sm}$ & $\mathrm{Ta}$ & Tb & Th & $\mathbf{U}$ & $\mathrm{Yb}$ & $\mathrm{Zn}$ \\
\hline \multirow{5}{*}{ 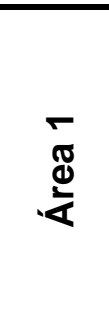 } & Cl0501 & 9,8 & 2,7 & 0,8 & 1,3 & 0,7 & 1,2 & 1,0 & 1,6 & 0,9 & 5,8 & 1,3 & 0,6 & 1,4 & 0,7 & 2,4 & 4,7 & 1,6 & 1,0 & 1,2 & 1,5 & 2,9 & 2,1 & 0,3 \\
\hline & Cl0502 & 5,4 & 0,6 & 0,4 & 0,9 & 0,6 & 1,2 & 0,6 & 0,9 & 0,7 & 1,8 & 0,9 & 1,7 & 0,5 & 0,7 & 0,7 & 1,4 & 1,0 & 0,6 & 1,1 & 0,6 & 1,5 & 1,1 & 0,9 \\
\hline & Cl0503 & 4,1 & 0,7 & 0,4 & 0,8 & 0,5 & 1,0 & 0,6 & 0,8 & 0,8 & 2,1 & 0,8 & 1,8 & 0,5 & 1,2 & 0,7 & 1,4 & 1,0 & 0,7 & 0,9 & 0,7 & 1,4 & 1,5 & 0,9 \\
\hline & Cl0505 & 4,5 & 0,7 & 0,3 & 0,8 & 0,6 & 1,1 & 0,5 & 0,8 & 0,7 & 1,4 & 0,8 & 0,7 & 0,4 & 1,0 & 0,4 & 2,7 & 0,9 & 0,5 & 1,1 & 1,3 & 1,1 & 0,9 & 0,9 \\
\hline & Cl0506 & 5,7 & 3,3 & 0,9 & 1,2 & 0,8 & 1,5 & 0,6 & 1,2 & 0,7 & 4,4 & 1,1 & 0,4 & 0,8 & 1,2 & 1,1 & 2,5 & 1,2 & 1,2 & 2,0 & 1,0 & 2,0 & 1,9 & 0,7 \\
\hline 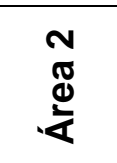 & Cl0509 & 5,5 & 0,2 & 0,3 & 0,7 & 0,5 & 1,2 & 0,5 & 0,8 & 0,7 & 0,6 & 0,7 & 0,0 & 0,5 & 1,0 & 0,5 & 1,1 & 0,8 & 0,3 & 1,1 & 0,6 & 0,9 & 0,8 & 1,0 \\
\hline \multirow{4}{*}{ 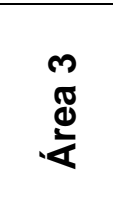 } & Cl0510 & 5,6 & 0,5 & 0,6 & 1,0 & 0,6 & 1,9 & 0,5 & 0,9 & 0,7 & 7,2 & 0,9 & 0,2 & 0,7 & 1,1 & 0,5 & 2,9 & 1,1 & 1,0 & 2,9 & 0,9 & 3,4 & 4,2 & 1,5 \\
\hline & Cl0511 & 4,0 & 0,3 & 0,2 & 0,8 & 0,5 & 1,1 & 0,6 & 0,8 & 0,6 & 1,0 & 0,7 & 1,0 & 0,5 & 1,0 & 0,5 & 1,6 & 0,8 & 0,4 & 0,7 & 3,8 & 1,1 & 0,9 & 0,8 \\
\hline & Cl0512 & 2,5 & 0,7 & 0,8 & 0,6 & 0,6 & 1,6 & 0,4 & 0,6 & 0,7 & 7,0 & 0,6 & 4,0 & 0,3 & 0,8 & 0,8 & 2,0 & 0,8 & 1,5 & 0,5 & 1,3 & 2,8 & 3,4 & 0,8 \\
\hline & Cl0513 & 7,0 & 2,4 & 1,6 & 2,0 & 0,8 & 1,0 & 0,9 & 1,3 & 0,7 & 4,0 & 2,0 & 0,3 & 0,9 & 2,7 & 2,2 & 2,9 & 2,2 & 1,3 & 1,7 & 2,6 & 1,9 & 2,5 & 1,9 \\
\hline
\end{tabular}


Tabela 5.53: Fator de Enriquecimento, utilizando os dados descritos por Wedepohl, 1995 - Amostras coletadas no Verão de 2005,

Cananéia

\begin{tabular}{|c|c|c|c|c|c|c|c|c|c|c|c|c|c|c|c|c|c|c|c|c|c|c|c|c|}
\hline Área & & As & $\mathrm{Ba}$ & $\mathrm{Ca}$ & $\mathrm{Ce}$ & Co & $\mathrm{Cr}$ & Cs & $\mathrm{Eu}$ & $\mathrm{Fe}$ & $\mathrm{Hf}$ & La & Lu & $\mathrm{Na}$ & $\mathrm{Nd}$ & $\mathbf{R b}$ & $\mathrm{Sb}$ & Sm & $\mathrm{Ta}$ & $\mathrm{Tb}$ & Th & $\mathbf{U}$ & $\mathrm{Yb}$ & $\mathrm{Zn}$ \\
\hline \multirow{5}{*}{ 离 } & CV0501 & 8,0 & 1,1 & 0,8 & 1,0 & 0,6 & 1,0 & 0,6 & 1,0 & 0,7 & 3,7 & 0,9 & 1,2 & 0,9 & 1,1 & 1,1 & 2,7 & 1,1 & 0,9 & 0,9 & 0,9 & 1,0 & 1,3 & $\overline{1,3}$ \\
\hline & CV0502 & 4,3 & 0,4 & 0,5 & 0,9 & 0,6 & 1,2 & 0,6 & 1,0 & 0,7 & 1,8 & 1,0 & 2,3 & 0,6 & 1,1 & 0,8 & 1,8 & 1,1 & 0,8 & 1,0 & 0,9 & 0,7 & 1,3 & 1,0 \\
\hline & CV0503 & 5,2 & 0,2 & 0,4 & 1,0 & 0,6 & 1,4 & 0,5 & 0,9 & 0,7 & 1,9 & 0,9 & 0,1 & 0,5 & 1,0 & 0,1 & 1,6 & 0,6 & 0,5 & 0,8 & 1,0 & 0,8 & 1,3 & 0,9 \\
\hline & CV0505 & 4,5 & 0,6 & 0,5 & 1,1 & 0,6 & 1,1 & 0,6 & 0,8 & 0,7 & 1,9 & 1,0 & 1,0 & 0,4 & 1,1 & 0,5 & 2,4 & 1,1 & 0,6 & 0,8 & 0,9 & 1,0 & 1,1 & 1,3 \\
\hline & CV0506 & 5,2 & 2,4 & 1,0 & 1,4 & 0,6 & 1,4 & 0,7 & 1,3 & 0,7 & 4,9 & 1,3 & 2,5 & 0,8 & 1,3 & 1,3 & 3,2 & 1,6 & 1,5 & 1,5 & 1,2 & 2,0 & 2,3 & 1,4 \\
\hline \multirow{2}{*}{$\begin{array}{l}\text { N } \\
\mathbb{d} \\
\stackrel{d}{\alpha}\end{array}$} & CV0507 & 6,0 & 1,5 & 1,1 & 1,2 & 0,8 & 1,2 & 0,8 & 1,5 & 0,8 & 2,1 & 1,1 & 1,2 & 0,8 & 1,4 & 1,0 & 2,2 & 1,2 & 0,8 & 2,7 & 0,9 & 1,0 & 1,5 & 1,2 \\
\hline & CV0509 & 4,9 & 0,1 & 0,2 & 0,8 & 0,5 & 1,1 & 0,6 & 0,8 & 0,7 & 0,6 & 0,7 & 0,8 & 0,4 & 0,6 & 0,4 & 1,2 & 0,8 & 0,3 & 1,1 & 0,6 & 0,7 & 0,8 & 0,7 \\
\hline \multirow{4}{*}{ 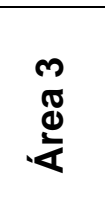 } & CV0510 & 5,1 & 0,3 & 0,5 & 1,3 & 0,6 & 1,3 & 0,5 & 0,9 & 0,7 & 3,9 & 1,2 & 4,6 & 0,6 & 1,3 & 0,4 & 3,3 & 1,4 & 0,8 & 1,7 & 1,3 & 3,1 & 4,1 & 1,0 \\
\hline & CV0511 & 6,1 & 0,2 & 0,2 & 0,8 & 0,5 & 1,5 & 0,6 & 0,8 & 0,6 & 1,0 & 0,8 & 1,2 & 0,4 & 1,0 & 0,3 & 1,7 & 0,9 & 0,4 & 2,0 & 0,7 & 2,5 & 0,8 & 0,7 \\
\hline & CV0512 & 5,7 & 1,0 & 1,0 & 2,3 & 1,0 & 3,4 & 0,9 & 1,7 & 1,2 & 8,3 & 2,1 & 6,3 & 0,8 & 2,2 & 0,6 & 3,2 & 2,7 & 1,7 & 5,9 & 2,5 & 4,1 & 4,8 & 1,5 \\
\hline & CV0513 & 4,6 & 1,7 & 0,9 & 1,2 & 0,7 & 2,3 & 0,6 & 1,2 & 0,8 & 6,3 & 1,1 & 0,3 & 0,8 & 1,5 & 0,5 & 3,3 & 0,9 & 1,7 & 2,2 & 1,0 & 2,4 & 2,2 & 0,2 \\
\hline
\end{tabular}


Tabela 5.54: Fator de Enriquecimento, utilizando os dados descritos por Wedepohl, 1995 - Amostras coletadas no Inverno de 2006, Cananéia

\begin{tabular}{|c|c|c|c|c|c|c|c|c|c|c|c|c|c|c|c|c|c|c|c|c|c|c|c|c|}
\hline Área & & As & $\mathrm{Ba}$ & $\mathrm{Ca}$ & $\mathrm{Ce}$ & Co & $\mathrm{Cr}$ & Cs & $\mathrm{Eu}$ & $\mathrm{Fe}$ & $\mathrm{Hf}$ & La & Lu & $\mathrm{Na}$ & Nd & $\mathbf{R b}$ & $\mathrm{Sb}$ & $\mathrm{Sm}$ & $\mathrm{Ta}$ & $\mathrm{Tb}$ & Th & $\mathbf{U}$ & $\mathrm{Yb}$ & $\mathrm{Zn}$ \\
\hline \multirow{5}{*}{ 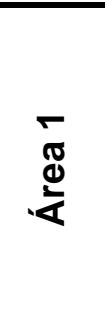 } & $\mathrm{Cl} 0601$ & 6,8 & 4,3 & 2,3 & 1,4 & 0,8 & 3,2 & 0,7 & 1,9 & 0,8 & 4,0 & 1,5 & 3,3 & 2,0 & 2,6 & 2,4 & 2,7 & 1,6 & 3,4 & 2,9 & 1,1 & 2,3 & 2,4 & $\overline{0,8}$ \\
\hline & $\mathrm{Cl} 0602$ & 5,9 & 0,4 & 0,4 & 0,8 & 0,5 & 1,2 & 0,5 & 0,9 & 0,7 & 1,7 & 0,7 & 1,6 & 0,5 & 1,0 & 0,8 & 1,3 & 0,9 & 0,5 & 0,7 & 0,9 & 1,3 & 1,7 & 0,9 \\
\hline & $\mathrm{Cl} 10603$ & 6,0 & 0,7 & 0,4 & 0,8 & 0,5 & 1,2 & 0,5 & 0,8 & 0,7 & 1,2 & 0,7 & 1,1 & 0,6 & 1,1 & 0,7 & 1,7 & 0,9 & 0,4 & 0,7 & 0,6 & 0,8 & 1,0 & 0,7 \\
\hline & Cl0605 & 4,2 & 1,2 & 0,7 & 1,4 & 0,5 & 1,2 & 0,6 & 0,9 & 0,6 & 3,3 & 1,6 & 1,4 & 0,6 & 1,0 & 0,8 & 2,6 & 1,9 & 1,3 & 1,0 & 1,6 & 2,1 & 1,3 & 0,3 \\
\hline & Cl0606 & 4,0 & 1,9 & 1,4 & 1,4 & 0,6 & 2,4 & 0,5 & 0,9 & 0,6 & 9,0 & 1,6 & 2,9 & 0,6 & 1,7 & 1,0 & 4,0 & 1,7 & 1,8 & 0,7 & 1,7 & 2,7 & 3,0 & 0,7 \\
\hline 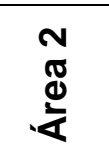 & $\mathrm{Cl} 0609$ & 6,1 & 0,5 & 0,3 & 0,8 & 0,6 & 1,3 & 0,6 & 0,8 & 0,7 & 0,8 & 0,7 & 0,8 & 0,7 & 0,8 & 0,5 & 1,1 & 0,7 & 0,2 & 0,8 & 0,6 & 0,7 & 0,8 & 1,1 \\
\hline \multirow{4}{*}{$\begin{array}{l}m \\
\mathbb{\Xi} \\
\stackrel{\mathbb{d}}{\alpha}\end{array}$} & $\mathrm{Cl} 0610$ & 4,4 & 0,6 & 0,6 & 1,0 & 0,5 & 1,6 & 0,5 & 0,8 & 0,7 & 6,5 & 0,9 & 1,8 & 0,7 & 1,2 & 0,4 & 1,8 & 1,1 & 0,7 & 1,2 & 0,9 & 2,2 & 1,7 & 1,1 \\
\hline & Cl0611 & 7,3 & 0,4 & 0,2 & 0,8 & 0,4 & 1,2 & 0,5 & 0,8 & 0,7 & 0,8 & 0,7 & 0,9 & 0,6 & 0,9 & 0,4 & 1,1 & 0,8 & 0,2 & 0,9 & 0,6 & 0,9 & 1,0 & 0,7 \\
\hline & $\mathrm{Cl} 0612$ & 3,9 & 1,0 & 1,8 & 0,8 & 0,6 & 1,7 & 0,5 & 0,9 & 0,8 & 6,4 & 0,7 & 2,8 & 0,6 & 0,7 & 0,9 & 1,1 & 0,9 & 1,0 & 1,1 & 1,1 & 2,1 & 2,8 & 0,8 \\
\hline & $\mathrm{Cl} 0613$ & 3,4 & 1,7 & 0,5 & 1,4 & 0,7 & 2,2 & 0,5 & 1,2 & 0,7 & 7,6 & 1,2 & 3,3 & 0,8 & 1,5 & 1,3 & 2,8 & 1,5 & 1,7 & 2,2 & 1,1 & 2,1 & 3,5 & 1,0 \\
\hline
\end{tabular}


Tabela 5.55 :Fator de Enriquecimento, utilizando os dados descritos por Wedepohl, 1995 - Amostras coletadas no Verão de 2006, Cananéia

\begin{tabular}{|c|c|c|c|c|c|c|c|c|c|c|c|c|c|c|c|c|c|c|c|c|c|c|c|c|}
\hline Área & Estações & As & $\mathrm{Ba}$ & $\mathrm{Ca}$ & $\mathrm{Ce}$ & Co & $\mathrm{Cr}$ & Cs & $\mathrm{Eu}$ & $\mathrm{Fe}$ & $\mathrm{Hf}$ & La & Lu & $\mathrm{Na}$ & $\mathrm{Nd}$ & $\mathbf{R b}$ & $\mathrm{Sb}$ & $\mathrm{Sm}$ & $\mathrm{Ta}$ & $\mathrm{Tb}$ & Th & $\mathbf{U}$ & $\mathrm{Yb}$ & $\mathrm{Zn}$ \\
\hline \multirow{5}{*}{ 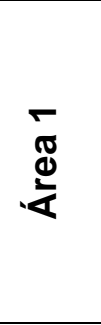 } & CV0601 & 8,7 & 1,2 & 1,2 & 1,6 & 0,6 & 1,6 & 0,2 & 1,4 & 0,8 & 6,6 & 1,7 & 2,4 & 1,2 & 1,2 & 1,1 & 3,5 & 2 & 2,2 & 5,8 & 2,6 & 1,9 & 1,1 & 0,6 \\
\hline & CV0602 & 3,6 & 1 & 0,9 & 1,6 & 0,5 & 3 & 0,4 & 0,9 & 0,7 & 16,2 & 1,5 & 3,6 & 0,6 & 1,5 & 0,6 & 3,4 & 1,7 & 1 & 2 & 1,9 & 2,5 & 2,9 & 0,4 \\
\hline & CV0603 & 5,9 & 0,4 & 0,3 & 0,8 & 0,6 & 1,1 & 0,5 & 0,8 & 0,7 & 1 & 0,7 & 0,9 & 0,6 & 0,8 & 0,5 & 1,4 & 1,2 & 0,2 & 1,4 & 0,7 & 0,7 & 0,8 & 1 \\
\hline & CV0605 & 3,1 & 0,8 & 0,5 & 1,7 & 0,5 & 1,3 & 0,5 & 0,9 & 0,7 & 5,1 & 1,5 & 2,1 & 0,4 & 1,4 & 0,5 & 1,1 & 1,4 & 0,6 & 1,4 & 1,5 & 1,8 & 2,1 & 1 \\
\hline & CV0606 & 4 & 1,4 & 1,1 & 1,7 & 0,6 & 3,2 & 0,4 & 1 & 0,7 & 15,5 & 1,5 & 5,7 & 0,5 & 1,4 & 0,8 & 2,9 & 1,5 & 1,5 & 2,3 & 1,6 & 3,3 & 6,2 & 0,3 \\
\hline \multirow{2}{*}{ 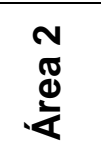 } & CV0607 & 9,8 & 4,6 & 1,5 & 1,4 & 1 & 3,5 & 0,7 & 1,8 & 1,2 & 5,5 & 1,2 & 2,7 & 1,6 & 1,6 & 2,9 & 3 & 1,5 & 2,8 & 2,3 & 1,1 & 2,2 & 2,1 & 0,7 \\
\hline & CV0609 & 4,7 & 0,5 & 0,3 & 0,7 & 0,5 & 1,2 & 0,6 & 1 & 0,7 & 1,2 & 0,6 & 0,8 & 0,7 & 1 & 0,4 & 0,8 & 1,1 & 0,2 & 0,5 & 0,7 & 0,6 & 0,8 & 1,1 \\
\hline \multirow{4}{*}{ 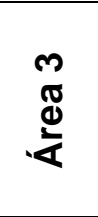 } & CV0610 & 2,5 & 0,6 & 0,8 & 1,1 & 0,6 & 1,3 & 0,4 & 0,7 & 0,7 & 7,1 & 0,9 & 1,8 & 0,8 & 1,6 & 0,6 & 2,2 & 1,1 & 1 & 1,3 & 1 & 2,1 & 1,4 & 0,8 \\
\hline & CV0611 & 3,6 & 0,4 & 0,3 & 1 & 0,5 & 1,3 & 0,6 & 0,9 & 0,7 & 1,7 & 0,9 & 1,2 & 0,6 & 1,3 & 0,6 & 1,2 & 1 & 0,3 & 0,8 & 0,9 & 1,3 & 1,2 & 0,8 \\
\hline & CV0612 & 2,9 & 0,5 & 0,7 & 1 & 0,5 & 1,5 & 0,4 & 0,8 & 0,8 & 7,1 & 0,9 & 2,8 & 0,5 & 1,2 & 0,4 & 1,4 & 1,8 & 0,5 & 0,5 & 1,1 & 2,2 & 2,4 & 0,7 \\
\hline & CV0613 & 5,2 & 2,8 & 1,1 & 1,5 & 0,6 & 2,8 & 0,5 & 1 & 0,8 & 4,5 & 1,5 & 2,1 & 0,8 & 1,6 & 1,7 & 3,1 & 2,3 & 2 & 5,3 & 1 & 1,7 & 1,8 & 0,5 \\
\hline
\end{tabular}


Com relação aos dados obtidos para FE utilizando-se como valores de background os valores de UCC, pudemos verificar que em praticamente todos os pontos avaliados, tanto no verão quanto no inverno dos anos de 2005 e 2006, as amostras demonstraram enriquecimento de As. Entretanto, quando se compara com os dados de FE calculados utilizando-se como valores de background os dados de Armelin et al, 2009, verificou-se que os valores estiveram $\mathbf{0 , 5}<\mathrm{FE}<1,5$ para a maioria das estações, com apenas alguns pontos com $\mathbf{F E}>1,5$, o que parece ser um indício de que a região possui naturalmente um nível mais elevado de As.

Os valores de FE para o $\mathrm{Ba}$, revelaram que as amostras Cl0501, Cl0506, Cl0507, Cl0513, CV0506, CV0507, CV0513, Cl0601, Cl0606, Cl0607, Cl0613, CV0607 e CV0613 apresentaram FE>1,5, indicativo de poluição por origem antrópica.

Em relação ao $\mathrm{Cr}$, as amostras Cl0510, Cl0512, CV0511, CV0512, CV0513, Cl0601, Cl0606, Cl0610, Cl0612, Cl0613, CV0601, CV0602, CV0606, CV0607, CV0612 e CV0613 apresentaram FE>1,5, indicativo contribuição de origem antrópica para este elemento.

Os elementos $\mathrm{Hf}$ e $\mathbf{S b}$ apresentaram valores de $\mathrm{FE}>1,5$ para a maioria das amostras analisadas nos diferentes períodos.

O Rb apresentou para as amostras Cl0501, Cl0507, Cl0513, Cl0601, CV0607 e CV0613 valores de FE>1,5 sugerindo, portanto, impactos de origem antrópica que acrescentaram este elemento nas regiões.

Os elementos terras raras $\mathrm{Ce}, \mathrm{Eu}, \mathrm{La}, \mathrm{Lu}, \mathrm{Nd}, \mathrm{Sm}, \mathrm{Tb}$ e Yb também apresentaram valores de FE $>1,5$ em algumas estações, nos diferentes períodos.

O elemento Ta apresentou valores de FE $>1,5$ para as amostras CV0512, CV0513, Cl0601, Cl0606, Cl0607, Cl0613, CV0601, CV0606, CV0607 e CV0613. 
Em relação ao Th, as amostras Cl0501, Cl0511, Cl0513, CV0512, Cl0605, Cl0606, CV0601, CV0602 e CV0606 apresentaram FE>1,5, indicando portanto uma possível fonte de contaminação por origem antrópica.

O elemento $\mathbf{U}$ apresentou $\mathrm{FE}>\mathbf{1 , 5}$ para as amostras Cl0501, Cl0502, Cl0506, Cl0507, Cl0510, Cl0512, Cl0513, CV0506, CV0510, CV0511, CV0512, CV0513, Cl0601, Cl0604, Cl0605, Cl0606, Cl0610, Cl0612, Cl0613, CV0601, CV0602, CV0605, CV0606, CV0607, CV0610, CV0612 e CV0613, evidenciando, deste modo, uma possível contaminação por origem antrópica na região.

O Zn apresentou vestígios de contaminação de origem antrópica apenas nas amostras Cl0507, Cl0510 e Cl0513.

Os elementos Co, $\mathbf{F e}$ e Cs não apresentaram indícios de contaminação por origem antrópica em nenhuma amostra, de acordo com os valores de FE.

\subsubsection{Comparação de valores de concentração obtidos por meio de diferentes técnicas analíticas}

Comparando-se os valores de concentração dos elementos determinados por ICP OES (concentração móvel ou ambientalmente disponível para a coluna d'água) e por NAA (concentração total), é possível estimar a relação $(R)$ entre as concentrações potencialmente disponíveis para a coluna d'agua (obtida pela extração com $\mathrm{HNO}_{3(\text { conc) }}$ em microondas) e as respectivas concentrações totais obtidas para cada elemento, conforme foi descrito na equação 5.1 .

A Tabela 5.56 apresenta os valores calculados das relações (R) entre a concentração potencialmente disponível para a coluna d'agua e 
respectiva concentração total dos elementos $\mathrm{Ba}, \mathrm{Co}, \mathrm{Cr}$, Fe e Zn, das amostras coletadas na região de Cananéia, Inverno e verão de 2005.

Tabela 5.56: Relação (\%) entre a concentração potencialmente disponível para a coluna d'água (ICP OES) e concentração total (NAA), Cananéia (Verão e Inverno/2005)

\begin{tabular}{c|c|c|c|c|c|c|c|c|c|c|c|c}
\hline & \multicolumn{3}{|c|}{ Relação (\%) NAA vs ICP } & & \multicolumn{4}{|c}{ Relação (\%) NAA vs ICP } \\
\hline Amostra & Ba & Co & Cr & Fe & Zn & & Amostra & Ba & Co & Cr & Fe & Zn \\
\hline Cl0501 & 1 & - & 64 & 52 & - & & CV0501 & 2 & - & 53 & 51 & 109 \\
\hline Cl0502 & 5 & 62 & 45 & 60 & 60 & & CV0502 & - & - & 41 & 56 & 64 \\
\hline Cl0503 & 4 & 67 & 53 & 57 & 57 & & CV0503 & - & 53 & 30 & 52 & 51 \\
\hline CI0504 & 9 & 62 & 53 & 75 & 64 & & CV0504 & - & 60 & 52 & 76 & 60 \\
\hline CI0505 & 4 & 60 & 47 & 57 & 59 & & CV0505 & 3 & 55 & 42 & 54 & 43 \\
\hline CI0506 & 1 & - & 23 & 35 & 80 & & CV0506 & 1 & - & 24 & 43 & 38 \\
\hline CI0507 & 1 & - & 87 & 57 & 58 & & CV0507 & 1 & 58 & 47 & 61 & 54 \\
\hline CI0508 & 8 & 66 & 71 & 70 & 57 & & CV0508 & 3 & 62 & 49 & 64 & 51 \\
\hline CI0509 & 16 & 66 & 51 & 80 & 62 & & CV0509 & - & 66 & 63 & 81 & 82 \\
\hline CI0510 & - & - & 31 & 56 & 48 & & CV0510 & 5 & - & 29 & 50 & 65 \\
\hline CI0511 & 19 & 75 & 61 & 117 & 91 & & CV0511 & 16 & 55 & 35 & 58 & 66 \\
\hline CI0512 & 4 & 39 & 27 & 31 & 52 & & CV0512 & 3 & 42 & 22 & 44 & 74 \\
\hline CI0513 & 2 & - & 48 & 41 & 29 & & CV0513 & 1 & - & 20 & 52 & - \\
\hline
\end{tabular}

Ao avaliar os dados da relação entre os resultados obtidos por ICP OES e NAA, verificou-se que o elemento $B a$ apresentou valores de $\mathbf{R}<\mathbf{5 \%}$, para a maioria das estações, o que indica que este elemento está presente principalmente nas formas insolúveis nos sedimentos. Em relação aos elementos $\mathbf{C o}, \mathbf{F e}$ e $\mathbf{Z n}$, foram observados valores $\mathbf{R}>\mathbf{5 0} \%$ para a maioria das amostras, o que indica que estes elementos, em sua maior parte, estão na forma potencialmente disponível. O elemento $\mathbf{C r}$ apresentou valores que variam entre abaixo e acima de $50 \%$.

As relações que apresentaram valores um pouco acima de $100 \%$ para os elementos $\mathrm{Fe}$ e $\mathrm{Zn}$, podem ser considerados adequados para valores de até $120 \%$, conforme critério de aceitação dos valores obtidos pela técnica de ICP OES, a qual é susceptível a erros de diluição, entre outros. Estes 
valores correspondem a $100 \%$ do elemento presente na forma potencialmente disponível.

Nos casos em que os valores foram inferiores ao Limite de Quantificação dos respectivos elementos, não foi possível realizar o cálculo de relação entre os valores de ICP OES versus NAA.

A Tabela 5.57 apresenta os valores calculados das relações $(R)$ entre a concentração potencialmente disponível para a coluna d'agua e respectiva concentração total dos elementos $\mathrm{Ba}$, Co, $\mathrm{Cr}$, Fe e $\mathrm{Zn}$, para as amostras coletadas na região de Cananéia, Inverno e verão de 2006.

Tabela 5.57: Relação (\%) entre a concentração potencialmente disponível para a coluna d'água (ICP OES) e concentração total (NAA), Cananéia (Verão e Inverno/2006)

\begin{tabular}{c|c|c|c|c|c|c|c|c|c|c|c|c}
\hline & \multicolumn{3}{|c|}{ Relação (\%) NAA x ICP } & & \multicolumn{3}{|c}{ Relação (\%) NAA x ICP } \\
\hline Amostra & Ba & Co & Cr & Fe & Zn & & Amostra & Ba & Co & Cr & Fe & Zn \\
\hline Cl0601 & 1 & - & 22 & 58 & - & & CV0601 & 2 & - & 42 & 54 & - \\
\hline Cl0602 & 6 & 71 & 40 & 61 & 48 & & CV0602 & 4 & - & 29 & 80 & - \\
\hline Cl0603 & 4 & 72 & 43 & 58 & 70 & & CV0603 & 12 & 76 & 65 & 78 & 65 \\
\hline Cl0604 & 7 & 82 & 44 & 65 & - & & CV0604 & 4 & 78 & 58 & 71 & - \\
\hline Cl0605 & 4 & - & 50 & 68 & - & & CV0605 & 8 & 70 & 45 & 61 & 64 \\
\hline Cl0606 & 2 & - & 20 & 39 & 89 & & CV0606 & 2 & - & 11 & 30 & - \\
\hline Cl0607 & 1 & - & 54 & 64 & 88 & & CV0607 & 1 & - & 25 & 67 & - \\
\hline Cl0608 & 3 & 71 & 48 & 64 & 102 & & CV0608 & 4 & 72 & 56 & 63 & - \\
\hline Cl0609 & 8 & 84 & 58 & 73 & 62 & & CV0609 & 8 & 72 & 57 & 81 & 58 \\
\hline Cl0610 & 4 & 55 & 28 & 56 & 56 & & CV0610 & 7 & - & 49 & 57 & 89 \\
\hline Cl0611 & 5 & 67 & 41 & 67 & 74 & & CV0611 & 17 & 75 & 63 & 85 & 79 \\
\hline Cl0612 & 3 & 52 & 24 & 37 & 59 & & CV0612 & 10 & 48 & 39 & 60 & 66 \\
\hline Cl0613 & 2 & - & 18 & 43 & - & & CV0613 & 2 & - & 16 & 57 & - \\
\hline
\end{tabular}

Conforme observado para os dados das amostras coletadas em 2005, verificou-se que o elemento $\mathrm{Ba}$ encontra-se praticamente nas formas insolúveis dos sedimentos e os elementos Co, Fe e $\mathbf{Z n}$, apresentaram valores 
de $R>50 \%$, o que indica que estes elementos estão presentes, em sua maior parte, como potencialmente disponíveis à coluna d'água.

\subsubsection{Análise de Agrupamento}

As Figuras 5.75 e 5.76 apresentam os dendrogramas considerandose todos os dados químicos (dados de NAA, ICP OES e AAS), granulometria, (silte+argila, areia) $\mathrm{MO}$ e $\mathrm{CaCO}_{3}$ referente às amostras coletadas em Cananéia, verão e inverno de 2005 (35 variáveis, 13 amostras no verão e 13 no inverno).

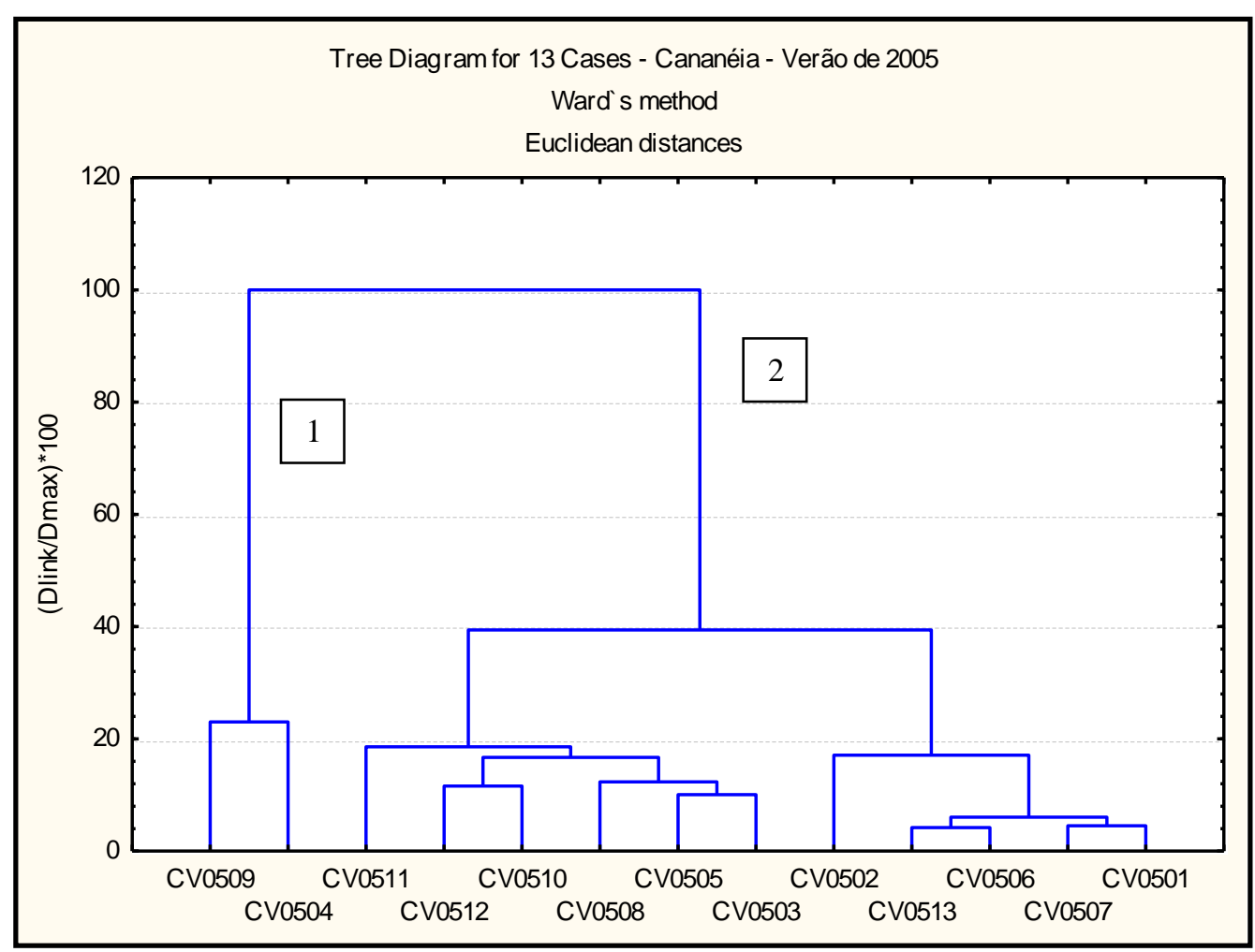

Figura 5.75- Análise de agrupamento para todos os dados químicos (NAA, ICP OES e AAS), granulometria, $\mathrm{MO}$ e $\mathrm{CaCO}_{3}$, Cananéia, verão de 2005 (variáveis: estações) 


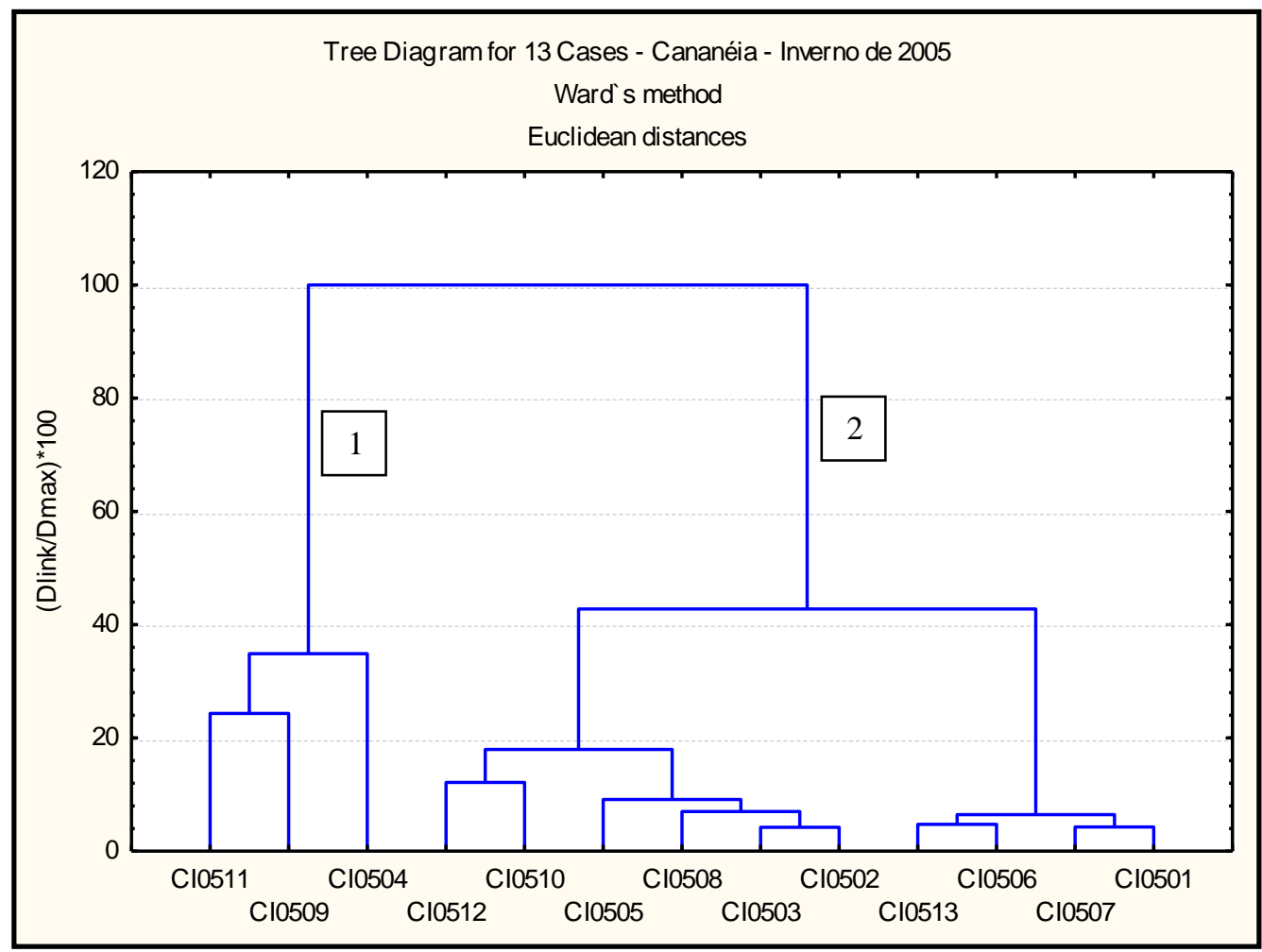

Figura 5.76 - Análise de agrupamento para todos os dados químicos (NAA, ICP OES e AAS), granulometria, $\mathrm{MO}$ e $\mathrm{CaCO}_{3}$, Cananéia, Inverno de 2005 (variáveis: estações)

$\mathrm{Na}$ avaliação dos agrupamentos para todos os dados químicos (NAA, ICP OES e AAS), granulometria, $\mathrm{MO}$ e $\mathrm{CaCO}_{3}$ das amostras coletadas no inverno e verão de 2005 na região de Cananéia, é possível identificar a formação de 3 grupos com características semelhantes, nos quais as estações $(01,06,07$ e 13) e $(03,05,08,10$ e 12) formaram o grupo 2, e as estações 04 e 09 (grupo 1) apresentam-se em situações análogas nos períodos do verão e inverno, pois se apresentam nos mesmos grupos. Apenas as estações 02 e 11 se apresentaram de forma diferente. Talvez a diferença no teor de MO entre verão e inverno para a estação 2 e o teor de MO para a estação 11 em relação as demais estações, possam ter causado essa mudança de grupos nos respectivos dendrogramas.

Verificou-se uma alta correlação entre o teor de $\mathrm{MO}$, fração pelítica e traços de metais neste sistema sob impacto antrópico. O volume de água é mais elevado no verão, e o transporte de partículas aumenta durante este 
período. No inverno, o volume de água é menor e os processos de resuspensão são possíveis em função de tempestades e alterações climáticas associadas aos ventos e a hidrodinâmica.

A posição interna das estações e as diferentes influências da água marinha no entorno do sistema, o período de produção de $\mathrm{MO}$, a movimentação da $\mathrm{MO}$ e processos biogeoquímicos afetam a distribuição final na superfície dos sedimentos deste sistema.

De modo a identificar a similaridade entre os elementos analisados pelas diferentes técnicas analíticas, nas amostras coletadas, foram realizadas as análises de clusters entre os elementos analisados por NAA, CV AAS e GF AAS, assim como os dados de granulometria (silte+argila, areia), $\mathrm{MO}$ e $\mathrm{CaCO}_{3}$. A Figura 5.77 apresenta o dendrograma referente às amostras coletadas em Cananéia, inverno de 2005.

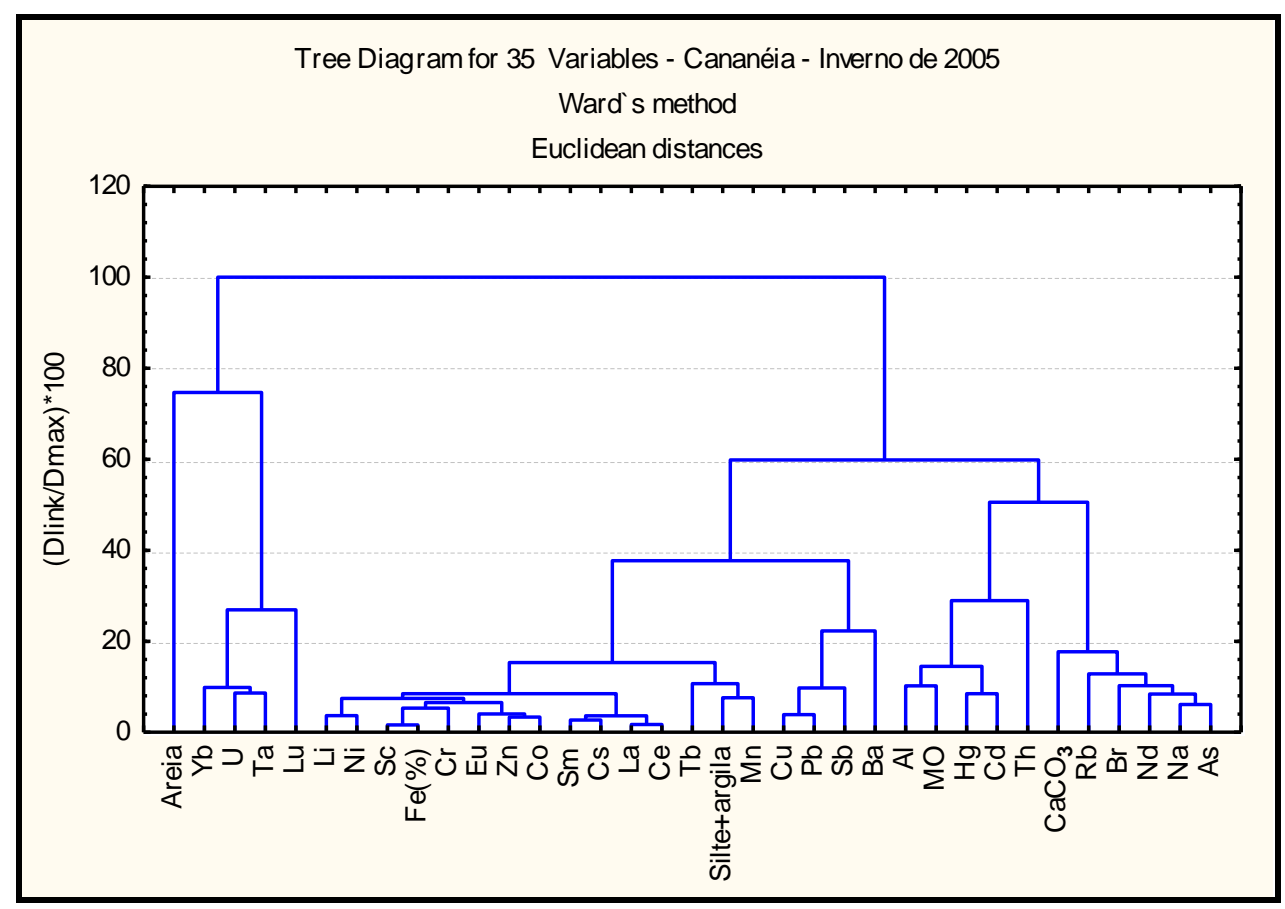

Figura 5.77 - Análise de agrupamento para todos os dados químicos (NAA, ICP OES e AAS), granulometria, $\mathrm{MO}$ e $\mathrm{CaCO}_{3}-$ Cananéia - Inverno de 2005 (variáveis: elementos) 
$\mathrm{Na}$ avaliação da Figura 5.77, foi possível identificar uma correlação entre o conteúdo de $\mathrm{MO}$ com Al, $\mathrm{Hg}$ e $\mathrm{Cd}$, o que indica a forte afinidade destes elementos pela matéria orgânica. Foi possível identificar ainda que o teor de areia e os elementos $\mathrm{Yb}, \mathrm{U}, \mathrm{Ta}$ e Lu possuem características semelhantes nas amostras analisadas, assim como Sm, Cs, La e Ce possuem semelhanças entre si. $\mathrm{O} \mathrm{CaCO}_{3}$ possui proximidade aos elementos $\mathrm{Rb}, \mathrm{Br}, \mathrm{Nd}$, $\mathrm{Na}$ e As.

A fração silte+argila apresenta similaridade ao $\mathrm{Mn}$ e ao $\mathrm{Tb}$, mostrando uma boa correlação entre si.

A Figura 5.78 apresenta o dendrograma referente à comparação entre os elementos analisados por NAA, CV AAS e GF AAS, assim como os dados de granulometria (silte+argila, areia) $\mathrm{MO}$ e $\mathrm{CaCO}_{3}$, das amostras coletadas no verão de 2005:

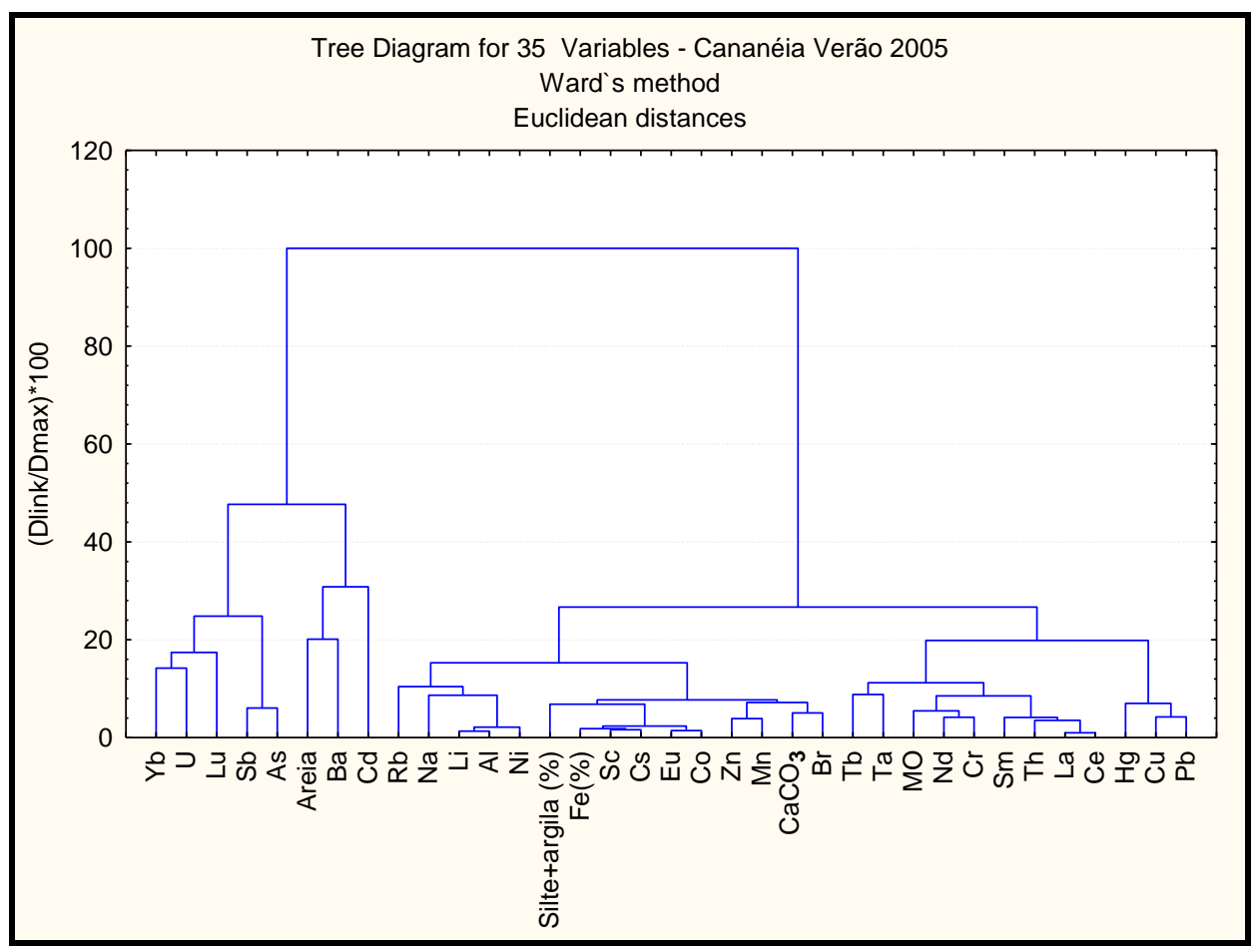

Figura 5.78 - Análise de agrupamento para todos os dados químicos (NAA, ICP OES e AAS), granulometria, $\mathrm{MO}$ e $\mathrm{CaCO}_{3}$ - Cananéia, Verão de 2005 (variáveis: elementos) 
Conforme observado na Figura 5.78, verificou-se as amostras coletadas no verão de 2005, apresentaram resultados de Yb, U, Lu, Sb e As em um mesmo grupo devido as suas características semelhantes. A fração Areia apresentou relação estreita com o $\mathrm{Ba}$, e está em proximidade ao $\mathrm{Cd}$.

O Rb, $\mathrm{Na}, \mathrm{Li}, \mathrm{Al}$ e $\mathrm{Ni}$ estão presentes no mesmo grupo. A fração de Silte+argila está agrupada com o $\mathrm{Fe}, \mathrm{Sc}$, Cs, Eu e Co, e possui proximidade ao grupo que contém $\circ \mathrm{Zn}, \mathrm{Mn}, \mathrm{CaCO}_{3}$ e $\mathrm{Br}$. $\mathrm{O} \mathrm{Tb}$ e $\circ \mathrm{Ta}$ possuem relação estreita entre si, e estão ligados com o teor de MO, Nd, Cr, Sm, Th, La e Ce.

Os elementos $\mathrm{Hg}$, Cu e $\mathrm{Pb}$ estão presentes em um mesmo grupo de acordo com suas características. 


\section{CAPÍTULO 6}

\section{CONCLUSÃO}

\subsection{Conclusões Gerais}

A utilização de diferentes técnicas analíticas para a determinação de metais em sedimentos é de fundamental importância para o detalhamento das concentrações e formas químicas dos elementos presentes nas amostras, os quais podem variar de $\mu \mathrm{g} \mathrm{kg}^{-1}$ até \%, nas formas potencialmente disponíveis para a coluna d'água ou totais. Além destes fatores, cada uma das técnicas analíticas empregadas possui características peculiares, as quais fornecem melhores condições ou até mesmo limitações na determinação das concentrações dos analitos em estudo.

A técnica de NAA demonstrou exatidão e precisão nas análises dos materiais de referência certificados NIST 2704 e 8704 (Buffalo River Sediment), Soil-7 (AIEA) e BEN (Basalt- IWG-GIT), conforme o critério de Z-score, com valores de $\mid Z /<3$, para todos os elementos avaliados no presente estudo. Além da precisão e exatidão conferidas aos resultados obtidos, a técnica de NAA forneceu resultados de concentração total para os elementos analisados nas amostras de sedimentos, nas diferentes áreas estudadas, em uma ampla faixa de concentração apresentando sensibilidade adequada aos diversos elementos estudados.

Dentre as limitações encontradas no trabalho com a técnica de NAA, destaca-se o fato de ser uma técnica bastante demorada quando comparada com as demais técnicas analíticas utilizadas no presente trabalho. Outra 
desvantagem é a geração de resíduo radioativo, o qual deve ser acondicionado corretamente, assim como a exposição dos analistas à radiação.

As técnicas CV AAS e GF AAS possuem excelentes limites de quantificação, que podem chegar a $10 \mu \mathrm{g} \mathrm{kg}^{-1}$, e apresentaram exatidão e precisão adequadas. Os materiais de referência utilizados para a verificação da precisão e exatidão desses métodos possuem valores certificados de concentração total e apenas intervalos de concentração quando se utiliza 0 procedimento de digestão recomendado pela US EPA, adotado no presente trabalho para a determinação da fração potencialmente disponível. Mesmo nessas condições foi possível garantir a qualidade dos dados analíticos obtidos no presente estudo.

Dentre as limitações encontradas no emprego das técnicas CV AAS e GF AAS, podemos destacar a pequena faixa de trabalho, a qual pode submeter as amostras à eventuais diluições e que podem ser fontes de erro aos resultados obtidos. Para essas técnicas torna-se necessário a verificação constante do branco analítico, o qual pode ser susceptível a contaminações oriundas da pureza dos reagentes utilizados, bem como de contaminações cruzadas. Uma grande desvantagem das técnicas CV AAS e GF AAS é a característica de análise monoelementar, embora atualmente estejam surgindo novas tecnologias para superar estes obstáculos. Outra limitação pode ser refletida pelos efeitos de matriz.

O uso da técnica de ICP OES é viável para a determinação multielementar com alta sensibilidade e ampla faixa de trabalho para diversos elementos, além de possuir baixos níveis de radiação de fundo. Se comparada às técnicas de CV AAS e GF AAS, as desvantagens principais do ICP OES são o custo do equipamento e de seus consumíveis, além do equipamento ser menos robusto. A técnica de ICP OES é susceptível a interferências mais pronunciadas do que na técnica CV AAS. Essas interferências se dividem em interferências não espectrais, como transporte de amostra, supressão do sinal e ionização, e as interferências espectrais, como a sobreposição das linhas de 
emissão. O conhecimento destas interferências é de fundamental importância para o desenvolvimento correto das análises.

Assim como as técnicas de CV AAS e GF AAS, os resultados obtidos pela técnica de ICP OES são altamente dependentes dos processos de digestão empregados, e estes estão entre as principais fontes de erros para a obtenção dos resultados analíticos.

Ao realizarmos a comparação dos valores de concentração dos elementos determinados por ICP OES (concentração móvel ou potencialmente disponível para a coluna d'água) e por NAA (concentração total), com os limites TEL e PEL, foi possível identificar situações as quais os elementos apresentaram comportamentos distintos, como por exemplo, os elementos $\mathrm{Cr}$ e Zn, avaliados nas amostras da região de Santos, área 1 (estações 01 a 06).

Nas amostras analisadas por ICP OES, para a identificação dos elementos potencialmente disponíveis, o limite TEL foi ultrapassado para o $\mathrm{Zn}$ (124 $\mathrm{mg} \mathrm{kg}^{-1}$ ), nas amostras SI0501, SI0502, SI0601 e SV0601, situadas na área 1, e nenhuma amostra desta área ultrapassou o limite TEL para $\mathrm{Cr}(52,3$ $\mathrm{mg} \mathrm{kg}^{-1}$ ). Entretanto ao avaliarmos os dados obtidos por NAA, observou-se que tanto o $\mathrm{Zn}$ quanto o $\mathrm{Cr}$ ultrapassaram os limites TEL, nos diferentes períodos avaliados para as estações de 01 a 05, do canal de Santos.

A partir dessa constatação, se fossem considerados apenas os valores de concentração obtidos por NAA (concentração total) para a comparação com os limites TEL e PEL, os mesmos não retratariam a realidade da região, pois seriam ignorados os processos de complexação dos metais, os quais podem manter os metais nas formas insolúveis e os vários níveis de biodisponibilidade dos elementos. Os limites TEL e PEL também não consideram os valores basais locais e a mobilidade dos metais. Por exemplo, verificou-se para o elemento As, valores de concentração elevados, mas que parecem refletir o nível basal para essa região, conforme já discutido em estudos anteriores. Portanto, pode-se concluir que a simples comparação dos valores guia TEL e PEL com a concentração total dos metais, não satisfaz as 
condições para avaliar os efeitos tóxicos desses elementos para o meio ambiente.

No entanto, nas regiões onde não foram observadas concentrações de metais superiores aos valores orientadores TEL e PEL, é possivel afirmar que a possibilidade dos sedimentos exercerem toxicidade na biota é baixa. Todavia, para uma avaliação mais completa da toxicidade dos sedimentos, sugere-se o emprego de linhas de múltipla evidência, as quais deveriam incluir os ensaios toxicológicos, análise da estrutura das comunidades bentônicas, biomonitores e/ou experimentos manipulativos de campo.

\subsection{Conclusões- Sistema Estuarino de Santos e São Vicente}

$\mathrm{Na}$ busca pelo entendimento das variações sazonais no Sistema Estuarino de Santos/São Vicente, na comparação entre os valores das medianas das concentrações obtidas para os diferentes elementos avaliados, nas 3 áreas estudadas, o teste ANOVA detectou diferenças significativas para os elementos $\mathrm{Al}, \mathrm{Ba}, \mathrm{Co}, \mathrm{Cu}, \mathrm{Cr}, \mathrm{Fe}, \mathrm{Li}, \mathrm{Mn}, \mathrm{Ni}, \mathrm{Ti}, \mathrm{V}, \mathrm{Zn}, \mathrm{Cd}, \mathrm{Pb}$ e Hg , pois todos apresentaram valor de $p<0,05$, com exceção apenas do $\operatorname{Sr}(p>0,05)$. Assim sendo, evidenciou-se que as áreas avaliadas diferem-se entre si nas estações de inverno e verão, nos anos de 2005 e 2006.

Ao se analisar as diferenças de mediana para cada área separadamente, o teste ANOVA identificou que não ocorreram diferenças significativas quando se compara a concentração dos elementos numa mesma área, nos períodos de inverno e verão, anos de 2005 e 2006, pois as condições de $p>0,05$ e valor de $F<F_{\text {critico, }}$ foram evidenciadas para todos os elementos em cada área avaliada.

No que diz respeito às características granulométricas, a variação sazonal em sistemas estuarinos pode ocorrer devido aos processos de 
circulação, influência de maré, entrada de água fresca e material particulado. $\mathrm{Na}$ área 1, foram evidenciadas diferenças nas características granulométricas sazonais pela mudança em \% nos períodos de verão e inverno, possivelmente em função dos processos hidrodinâmicos locais que incluem entradas terrestres e transporte de sedimento ao longo do sistema, sendo provavelmente um resultado de poluição difusa da área.

A área 1 apresentou o maior teor de $\mathrm{MO}$ entre as áreas avaliadas, bem como as maiores concentrações dos elementos analisados em ambas as estações (2005 e 2006). Além da contribuição do teor de MO, a área 1 é impactada pelas atividades industriais na região de Cubatão e a influência do Porto de Santos. Essa área apresentou também os maiores teores da fração silte+argila, principalmente nas estações de 01 a 05.

Os sedimentos da estação 14 (área 3) também apresentaram altas concentrações de metais. Esse ponto também sofre influência do polo de Cubatão e está localizado perto de uma área de mangue. Essa região pode favorecer a retenção desses metais nos sedimentos devido a suas propriedades físicas e geoquímicas. Um alto teor de $\mathrm{MO}$ e contribuição da fração pelítica nesse ponto foram observadas, devido à vegetação do mangue, contribuição antropogênica e baixa influência de circulação nessas águas pouco profundas. Perto desse ponto existe um aterro sanitário desativado.

Em geral, as concentrações de metais são muito maiores na parte interna do estuário (área 1) e com valores mais baixos na baía de Santos (área 2). Esse padrão de distribuição está associado a processos de deposição mais intensos na parte interna do estuário e a um processo de remobilização mais forte na Baía de Santos.

Ao compararmos os valores estabelecidos pela legislação CONAMA 344/04 com os resultados obtidos por ICP OES, CV AAS e GF AAS, nas amostras coletadas nos anos de 2005 e 2006, foi observado que a amostra SV0504 ultrapassou o nível 1 para $\mathrm{Pb}\left(46,7 \mathrm{mg} \mathrm{kg}^{-1}\right)$. Para o $\mathrm{Hg}$, com exceção da amostra SV0506, todas as demais ultrapassaram o nível 1 para $\mathrm{Hg}(0,150$ 
$\left.\mathrm{mg} \mathrm{kg}^{-1}\right)$. As amostras SV0501, SV0502 e SV0503 ultrapassaram o nível 2 $\left(0,410 \mathrm{mg} \mathrm{kg}^{-1}\right)$ para esse elemento, tanto no verão quanto no inverno.

A amostra SI0501(156 $\left.\mathrm{mg} \mathrm{kg}^{-1}\right)$ ultrapassou o nível 1 para Zn (150 $\mathrm{mg} \mathrm{kg}^{-1}$ ) e para os demais parâmetros analisados, não foram ultrapassados os limites CONAMA (níveis 1 e 2).

Na comparação com os níveis TEL e PEL, adotados pela CETESB como valores orientadores, as amostras coletadas na região de Santos, nos períodos de inverno e verão dos anos 2005 e 2006, para os elementos analisados por ICP OES $\mathrm{Cr}$, $\mathrm{Cu}, \mathrm{Ni}$ e $\mathrm{Zn}$ e $\mathrm{Cd}$, $\mathrm{Hg}$ e $\mathrm{Pb}$ por AAS, observou-se que as amostras da área 1 apresentaram os maiores valores de concentração e que, em alguns casos, ultrapassaram os limites estabelecidos pela CETESB, assim como o ponto $14 . \mathrm{O} \mathrm{Hg}$ apresentou resultados superiores aos valores guias em todas as áreas estudadas, sendo que na área 2, apenas a estação 10 apresentou valores superiores no período de 2006 para este elemento. O ponto 10 está localizado próximo ao canal de lançamento de águas de drenagem contaminadas por esgoto doméstico. A presença do emissário na Baía de Santos apresenta risco a qualidade da água e do sedimento. Um projeto de extensão de alguns kilometros do emissário está sendo planejado e poderia causar um efeito positivo na qualidade do sedimento da Baía.

Em relação aos dados de metais em sedimentos apresentados no relatório da CETESB (2001) e os resultados obtidos no presente estudo, com sedimentos coletados em 2005 e 2006, pode-se verificar uma melhora acentuada na qualidade dos sedimentos, com valores de concentração, de maneira geral, inferiores aqueles obtidos pela CETESB, para os mesmos metais analisados.

$\mathrm{Na}$ comparação dos resultados obtidos para as amostras coletadas no inverno de 2005, dos gráficos scatterplots com os valores de FE calculados com os valores UCC, observou-se que na maioria dos casos, os elementos que apresentaram valores acima dos intervalos de confiança no gráfico scatterplot, apresentaram valores de $\mathbf{F E}<\mathbf{1 , 5}$. Isso indicaria que as áreas não estariam 
sujeitas a contaminação de origem antrópica pelo critério do FE, enquanto que pelo critério do scatterplot, haveria uma provável contaminação dessa natureza.

Uma situação interessante foi observada em relação ao $\mathrm{Li}$, o qual apresentou valor de FE $>1,5$ para todas as amostras coletadas, o que indicaria que todas as amostras estariam sujeitas a contaminação de origem antrópica. Entretanto a excelente correlação apresentada no scatterplot $\mathrm{Li} \times \mathrm{Sc}$, com o coeficiente de determinação $r^{2}=0,9724$, sugere que as concentrações de Li são de origens naturais, sendo que apenas a estação 4 teria a origem deste elemento por fontes antrópicas. Este fato foi confirmado com o índice $I_{\text {geo }}$ calculado com os valores descritos por Luiz-Silva et al, 2008, o qual apresentou $I_{\text {geo }}<0$ para o Li.

Com as análises de clusters, verificou-se que a área $\mathbf{1}$ apresentou a melhor correlação em todos os períodos avaliados nos anos de 2005 e 2006, e que a estação 06, embora situada no canal de Santos, apresentou comportamento semelhante às amostras localizadas na baía de Santos que estão sujeitas a uma hidrodinâmica maior, que contribui para uma maior dispersão dos poluentes.

$\mathrm{Na}$ avaliação dos dados obtidos por NAA, verificou-se que os valores médios de concentração para as três áreas estudadas foram significativamente diferentes. Quando os resultados obtidos para as concentrações dos elementos determinados por NAA foram comparados com os valores do NASC (North American Shale Composite), observou-se um enriquecimento de Elementos Terras Raras Leves ( $\mathrm{La}, \mathrm{Ce}, \mathrm{Nd}, \mathrm{Sm}$ ) e $\mathrm{U}$ para a área $\mathbf{1}$, conforme demonstrado na Figura 5.40. Tal fato se deve, provavelmente, às fábricas de fertilizantes que produzem toneladas de fosfogesso (sub-produto da produção de ácido fosfórico) e que ficam estocadas a céu aberto.

Os valores de FE obtidos utilizando-se os valores de UCC e os dados descritos por Damatto, 2010, como valores de referência forneceram informações diferentes, indicando que os FE são uma importante ferramenta 
para avaliação da poluição de sedimentos, mas que devem ser utilizados valores basais regionais para tais cálculos e consequentemente, se obter resultados mais verdadeiros da situação local.

\subsection{Conclusões- Sistema Estuarino de Cananéia}

Os sedimentos do estuário de Cananéia são compostos sobretudo por frações de areia, entretanto, em algumas estações a fração pelítica (silte + argila) é representativa. Em relação ao teor de $\mathrm{MO}$, foi observado que as estações 4,9 e 11 possuem valores superiores a 10\%, com um conteúdo expressivo de teor de $P$ total e orgânico. Estas estações apresentaram os valores mais significativos de sedimentos pelíticos e os maiores valores no período do verão. Os metais apresentaram valores positivamente associados ao teor de $\mathrm{MO}$ e a \% de fração pelítica. As condições climáticas desta região, os processos biogeoquímicos e hidrodinâmicos podem promover diferenças nas concentrações sazonais de elementos em alguns pontos, contribuindo para uma distribuição única.

$\mathrm{Na}$ avaliação da variação sazonal e das possíveis influências hidrodinâmicas no sistema estuarino de Cananéia, observou-se que a região do Mar de Cananéia apresentou a maior quantidade de casos de resultados anômalos em relação às medianas da região, o que pode indicar grande influência hidrodinâmica na mobilidade dos metais e/ou variações granulométricas.

$\mathrm{Na}$ comparação dos valores das medianas das concentrações obtidas para os diferentes elementos avaliados, nas 3 áreas estudadas, o teste ANOVA detectou que não houveram diferenças significativas para todos os elementos avaliados, na comparação entre as áreas, pois todos apresentaram valor de $p>0,05$. Assim sendo, evidenciou-se que as áreas avaliadas se 
assemelham entre si nas estações de inverno e verão, nos anos de 2005 e 2006. Na avaliação de cada uma das áreas individualmente, o teste ANOVA detectou que em nenhuma das áreas ocorreram casos com valor de $p<0,05$ e 0 valor de $F>F_{\text {critico, }}$ reforçando a hipótese de que não houve variação temporal nos diferentes períodos avaliados, para a concentração dos elementos analisados.

$\mathrm{Na}$ avaliação dos dados obtidos nas análises de metais e elementos traço por NAA, verificou-se que as estações 04 e 09 apresentaram valores superiores ao limite TEL para os parâmetros As e $\mathbf{C r}$, nos períodos do verão e inverno de 2005, sendo que a amostra 04 ainda superou o limite de As descrito na legislação CONAMA 344. Com relação as amostras coletadas no ano de 2006, verificou-se que os resultados das estações 03 e 09, períodos do verão e inverno de 2006 e a amostra 11 no período do inverno, apresentaram valores superiores ao limite TEL para o parâmetro As. A estação 09 ultrapassou o valor orientador TEL para o $\mathrm{Cr}$, para a amostra coletada no verão. Nenhuma das amostras apresentou valores superiores ao limite PEL.

Após a verificação dos Fatores de Enriquecimento calculados a partir das concentrações totais com os dados pretéritos da região, observou-se valores de FE $>1,5$ para diversos elementos em diferentes áreas, o que reforça a hipótese de entrada de contaminantes no estuário por origens antrópicas.

Ao compararmos os resultados obtidos pelas técnicas ICP OES, CV AAS e GF AAS para as amostras coletadas na região de Cananéia, observouse que as concentrações potencialmente disponíveis dos elementos $\mathbf{C d}, \mathbf{P b}$, $\mathbf{H g}, \mathbf{C r}, \mathbf{C u}, \mathbf{N i}$ e $\mathbf{Z n}$ se encontravam abaixo dos limites estabelecidos pela legislação CONAMA 344/04 e dos limites TEL e PEL, adotados como valores orientadores pela CETESB. Entretanto quando foram avaliados os valores de FE, observou-se que, em alguns casos, ocorreram enriquecimentos de metais nas estações estudadas, em especial para o $\mathbf{H g}$, que apresentou o maior número de casos que sugerem alterações oriundas de fontes antrópicas. Entretanto, ao fazermos a avaliação a partir dos dados obtidos pelo Igeo, 
observamos que o $\mathrm{Hg}$ encontrado na região não é devido a fontes antrópicas, hipótese justificada devido aos baixos níveis encontrados do elemento na região.

Na comparação dos resultados de concentração total com a fração potencialmente disponível, foi observado que os elementos Co, Fe e $\mathbf{Z n}$ estão presentes nos sedimentos principalmente na forma potencialmente disponível, enquanto que $\mathrm{O} \mathbf{B a}$ é encontrado na forma insolúvel. $\mathrm{O} \mathbf{C r}$ possui comportamento diferente, e pode variar sua composição na coluna d'agua.

Com estes dados, sugere-se atenção por parte dos órgãos ambientais, pois embora não tenha sido evidenciado casos de poluição de metais com valores acima dos limites da legislação vigente, a região sofreu alterações com o incremento de metais no ecossistema, necessitando a identificação das fontes de contaminação.

Como ainda existem poucos estudos que contemplem dados específicos da região, é recomendável a realização de outros estudos que restrinjam esta área, de modo a identificar os principais pontos de fornecimento de contaminantes ao estuário, bem como avaliar as condições que são propícias para a liberação destes contaminantes para o meio ambiente, a partir das análises de água, sedimentos e organismos que estão presentes na região, e também a constante avaliação do entorno do estuário de Cananéia, como forma de monitoramento ambiental para identificar se as concentrações de metais observadas continuam em um mesmo patamar ou se ocorrem decréscimos com o passar dos anos, uma vez que as atividades de mineração e refino no rio Ribeira do Iguape, que poderiam ser uma das fontes de contaminação, já cessaram desde 1996.

Finalizando, podemos afirmar que os dados obtidos no presente estudo podem também contribuir para os esforços ao desenvolvimento, a restauração e a proteção do ambiente natural desses importantes ecossistemas. O volume de dados gerados com o presente estudo contribuiu, de forma significativa, para o entendimento da variação sazonal, hidrodinâmica 
e de processos biogeoquímicos que ocorrem em ambos os estuários em estudo. Nenhum estudo anterior contemplou todos os parâmetros estudados no presente trabalho. 


\section{REFERÊNCIAS}

ABESSA, D.M.S.; CARR, R. S.; RACHID, B.R.F.; SOUSA, E.C.P.M.; HORTELANI, M.A.; SARKIS, J.E. Influence of a Brazilian sewage outfall on the toxicity and contamination of adjacent sediments. Marine Pollution Bulettin., v. 50 , p. $875-885,2005$.

ADAMS, W.J.; KIMERLE, R.A.; BARNETT, J.W. Sediment quality and aquatic life assessment. American Chemical Society Environ. Sci. Technol., v 26, n.10, p. $1865-1875,1992$

AGUIAR, V. M. C.; BRAGA, E. S. \& BAPTISTA NETO, J. A., Heavy metal assessment in two subtropical estuarine systems in the state of São Paulo, Brazil. Marine Pollution: new Research. 1 ed., Tobias N. Hofer. (Org.), New York: Nova Publishers, v. 1, p. 379-397, 2008.

AGUIAR, V.M.C. Variação Espacial e Temporal das Características Biogeoquímicas do Fósforo e do Chumbo e Transporte de Propriedades no Sistema Estuarino de Santos/São Vicente e na Porção Sul do Complexo estuarino-lagunar de Cananéia-Iguape (São Paulo). 2005. Tese (Doutorado), Instituto Oceanográfico da Universidade de São Paulo, São Paulo, $243 p$.

AL-JUNDI, J.; RANDLE, K. Instrumental neutron activation analysis (NAA) of estuarine sediments. J. Radioanal. Nucl. Chem, v. 249, n. 2, p. 361-367, 2001.

ALOUPI, M. ANGELIDIS, M.O. Geochemistry of natural and anthropogenic metals in the coastal sediments of the island of Lesvos, Aegean Sea, Environmental Pollution, n. 113, p. 211 - 219, 2001. 
AMORIM, E. P., FAVARO, D. I. T., BERBEL, G. B. B., BRAGA, E. S. Assessment of metal and trace element concentrations in the Cananéia estuary, Brazil, by neutron activation and atomic absorption techniques. J. Radioanal. Nucl. Chem., v. 278, n.2, p. 485-489, 2008.

AMORIM, E. P., FAVARO, D. I. T., BERBEL, G. B. B., BRAGA, E. S. Metal and trace element assessment of estuary sediments from Santos, Brazil, by neutron activation and atomic absorption techniques. Proceeding of International Nuclear Atlantic Conference, Santos, September 30 to October 5, v.1, p. 01 09, 2007.

AMORIM, E. P., FAVARO, D. I. T., BERBEL, G. B. B., BRAGA, E. S. Santos estuarine sediments, Brazil - metal and trace element assessment by neutron activation analysis. Proceeding of International Nuclear Atlantic Conference, Rio de Janeiro,RJ, Brazil, September 27 to October 2,v.1, p.111, 2009.

ANJOS, V.E. Especiação de cobre e arsênio no complexo estuarino da baía de Paranaguá. 2006. Dissertação (Mestrado), Universidade Federal do Paraná, Curitiba, Paraná.

ARMELIN, M.J.A; SAIKI, M. NAA applied to the multielemental characterization of a sedimentary column: a contribution to oceanographic studies, J. Radioanal. Nucl. Chem., n.282, p. 91-94, 2009.

AUDRY, S., SCHAEFER, J., BLANC, G., JOUSNNEAU, J-M. Fifty-year sedimentary record of heavy-metal pollution $(\mathrm{Cd}, \mathrm{Zn}, \mathrm{Cu}, \mathrm{Pb})$ in Lot River reservoirs (France). Environ. Pollut., v.132, p.413-426, 2004.

AZEVEDO, F.A., CHASIN, A.A.M - Metais - Gerenciamento da Toxicidade, Ed. Atheneu, 2003. 
BACCAN, N. - Introdução à Espectrometria de Absorção Atômica UNICAMP - Campinas, 1994.

BAIRD, C. Química Ambiental, Ed. Bookman, p.555-557, 2002.

BARCELLOS, R.L.; BERBEL, G.B.B.; BRAGA, E.S.; FURTADO, V.V. Distribuição e características do fósforo sedimentar no sistema estuarino lagunar de Cananéia-Iguape, Estado de São Paulo, Brasil. Geochim. Brasil., v. 19, n. 1, p. 22-36, 2005.

BARTRAM, J.; BALLANCE, R. Water Quality Monitoring - A Practical Guide to the Design and Implementation of Freshwater Quality Studies and Monitoring Programmes. Published of behalf of United Nations Environment Programme (UNEP) and World Health Organization (WHO), 1996. ISBN 0419 223207.

BECEGATO, J.L. Impacto Ambiental Antrópico na APA (Área de Proteção Ambiental) da llha comprida (SP), da pré-história à atualidade. 2007. Dissertação (Mestrado). Universidade de Guarulhos, São Paulo. 95p.

BERBEL, G.B.B. Estudo do fósforo sedimentar e de suas especiações químicas em dois sistemas costeiros e Plataforma Continental Sudeste (Brasil) e Baía do Almirantado (região Antártica) considerando suas relações biogeoquímicas. 2008. Tese (Doutorado) - Instituto Oceanográfico, Universidade de São Paulo, São Paulo.305 p.

BERNARDES, M.E.C. Circulação estacionária e Extratificação de Sal em Canais Estuarinos parcialmente misturados: simulação com modelos analíticos. 2001.Dissertação (Mestrado). Instituto Oceanográfico, Universidade de São Paulo, São Paulo, 214p. 
BODE, P. Instrumental and organizational aspects of a neutron activation analysis laboratory. Delft, Netherlands: Interfaculty Reactor Institute, p. 147, 1996.

BORDON, I.C.A.C., SARKIS, J.E.S., GOBBATO, G.M., HORTELLANI, M.A., PEIXOTO, C.M. Metal concentration in sediments from the Santos Estuarine system: a recent assessment. J. Braz. Chem. Soc. v.22, p.10, 1858-1865, 2011.

BOSS, C. B.; FREDEEN, K.J. Concepts, Instrumentation and Techniques in Inductively Coupled Plama Optical Emission Spectrometry, 2.ed. Perkin Elmer Corporation, 1997.

BOSTELMANN, E. Avaliação da concentração de metais em amostras de sedimento do Reservatório Billings, Braço Rio Grande, São Paulo, Brasil. 2006. Dissertação (Mestrado) - Instituto de Pesquisas Energéticas Nucleares, São Paulo. 116p.

BRAGA, E.S., BONETTI, C.V.D.H., BURONE, L., BONETTI FILHO, J. Eutrophization and bacterial pollution caused by industrial and domestic waste at Baixada Santista Estuarine System. Marine Pollution Bulletin, v.2, n. 40, p.165-173, 2000.

BURTON Jr, A. Assessing Contaminated Aquatic Sediments, American Chemical Society Environ. Sci. Techonol., v.26, n.10, p. 1862 - 1863, 1992.

BYERS, C.; E.L. MILLS \& STUART, P. L. A comparation of methods of determining organic carbon in marine sediments, with suggestions for a standard methods, Hydrobiologia. V.58, n.1, p. $43-47,1978$.

CAMERON, W.M. \& PRITCHARD, D.W. Estuaries. In: Hill, M.N. (ed.). The Sea. New York, Wiley Interscience, p. 306-332, 1963. 
CARRASCO, M., RAMIREZ, L.; BENAVENTE, J.A. Assessment of urban and industrial contamination levels in the bay of Cadiz, SW Spain. Marine Pollution Bulletin, v. 46, n. 3, p. $335-345,2003$.

CCME - Canadian Council of Ministers of the Environment, Canadian Environmental Quality Guidelines for the Protection of Aquatic Life, 1999.

CESAR, A.; PEREIRA, C.D.S.; SANTOS, A.R.; ABESSA, D.M.S.; FERNÁNDEZ, N.; CHOUERI, R.B.; DELVALLS, T.A. Ecotoxicological assessment of sediments from the Santos and São Vicente Estuarine System - Brazil. Brazilian Journal of Oceanography, v. 54, n. 1, p. 55-63, 2006.

CETESB. Companhia de Tecnologia de Saneamento Ambiental. Poluição das Águas no Estuário e Baía de Santos. Relatório Técnico. v.1, 1979. 71p.

CETESB. Companhia de Tecnologia de Saneamento Ambiental. Metais pesados na Baía de Santos e Estuários de Santos e São Vicente. Relatório Técnico. 1981. 231p.

CETESB. Companhia de Tecnologia de Saneamento Ambiental. Contaminantes na Bacia do rio Cubatão e seus reflexos na biota aquática. Relatório Técnico. 1990. 81p. mais anexos.

CETESB. Companhia de Tecnologia de Saneamento Ambiental. Sistema Estuarino de Santos São Vicente, Relatório Técnico, 2001. 178p.

CONAMA - Conselho Nacional do Meio Ambiente, Ministério do Meio Ambiente. Resolução CONAMA no 344, de 25 de março de 2004. Publicada no Diário Oficial da União: República Federativa do Brasil, Poder Executivo, Brasília, DF, n.87, 07 jan. 2004. 
CONAMA - Conselho Nacional do Meio Ambiente, Ministério do Meio Ambiente. Resolução CONAMA no 454, de 1 de novembro de 2012. Publicada no Diário Oficial da União: República Federativa do Brasil, Poder Executivo, Brasília, DF, n.216, 08 nov. 2012, p. 66.

CORREIA, P.R.M.; NOMURA, C.S.; OLIVEIRA, P.V. Espectrometria de Absorção Atômica multielementar: Desafios e perspectivas. Revista Analytica, n.5, junho/julho, p.52-59, 2003.

CRISTACHE, C., GMÉLING, K., CULICOV, O., FRONTASYEVA, M.V., TOMA, M., DULIU, O.G. An ENAA and PGAA comparative study of anoxic Black Sea sediments. J. Radioanal. Nucl. Chem., v.279, n.1, p. 7-12, 2009.

CUNHA, F.G. Contaminação humana e ambiental por chumbo no Vale do Ribeira nos Estados de São Paulo e Paraná. (2003). Tese (Doutorado), Departamento de Geologia e recursos Naturais, Universidade de Campinas, Campinas, São Paulo.

DAMATTO, S.R. Radionuclídeos Naturais das séries do ${ }^{238} \mathrm{U}$ e ${ }^{232} \mathrm{Th}$, elementos traço e maiores determinados em perfis de sedimento da Baixada Santista para avaliação de áreas impactadas. 2010. Tese (Doutorado) - Instituto de Pesquisas Energéticas e Nucleares, São Paulo. $253 p$.

DAY JR, J.W., HALL, C.A.S., KEMP, W.M., YANES-ARANCIBA. Estuarine Ecology, Wiley, 558p., 1989

DEAN, J.R. Pratical Inductively Coupled Plasma Spectroscopy, ed. John Wiley \& Sons Ltda, 2005.

DINESCU, I. C.; DULIU, O. G.; BADEA, M.; MIHÃILESCU, N. G.; VANGHELIE, I. Investigation of the vertical distribution of major and trace elements in Matita 
Lake (Danube Delta) sediments by activation analysis. J. Radioanal. Nucl. Chem, v. 238, n. 1-2, p. 75-81, 1998.

DURÃO JUNIOR, W.A. Especiação, Quantificação, Distribuição e Transporte de Mercúrio em Solos Contaminados do Município de Descoberto, Minas Gerais. 2010. Tese de Doutorado, Instituto de Ciências Exatas da Universidade Federal de Minas Gerais, Belo Horizonte, Minas Gerais.

DUTRA, R.L.; CANTOS, G.A.; PEROZIN, A.R.;Silva, C.S.M.; WALTRICK, C.D.A.;BALEM, M.G.; HERMES, E.M.; MELO, E.S. Determinação de Zinco em Soro Sanguíneo pelo método de FAAS e sua correlação com o estado de estresse. Rev. Saúde, Piracicaba, v.6, n.14, p.31-37, 2004.

EC- Environment Canada. Canada Water Quality Guidelines for the Protection of Aquatic Life. Summary Tables.1999.

ELLIOTT, M. \& McLUSKY, D. S. The need for definitions in understanding estuaries. Estuarine, Coastal and Shelf Science, v. 55, n.6, p. 815-827, 2002.

EYSINK, G.G.J., LAMPARELLI, M.C., VARGAS-BOLDRINI, C., MARTINS, M.C. Contaminants in the Cubatão River basin and its Estuary (SP,Brazil), relating to the Aquatic Biota. Part I. Heavy Metals, Arsenic and Cyanide. 11th Biennial International Estuarine Research Conference, San Francisco, USA. Session: Inputs and Cycling of Natural and Contaminant Materials in Estuaries, November 1991.

FABRINO, H.J.F. Emprego de Otimização Multivariada no desenvolvimento de métodos para determinação de metais de interesse em soro e sangue humanos por espectrometria de absorção atômica em forno de grafite. 2008. Dissertação (Mestrado), Instituto de Ciências Exatas da Universidade Federal de Minas Gerais, área de Química Analítica, Belo Horizonte, Minas Gerais. 
FALCÃO, M.G. A ictiofauna em planícies de maré nas baías de Laranjeiras e de Paranaguá, Paraná, Dissertação (Mestrado), Universidade Federal do Paraná, Curitiba, 2005.

FAVARO, D.I.T., MOREIRA, S.R.D., CAMPOS, V. A., MAZZILLI, B., CAMPAGNOLI, F. Determinação Multielementar por Ativação Neutrônica de Sedimento do Reservatório Billings, Braço Rio Grande, São Paulo. In: ENCONTRO NACIONAL DE APLICAÇÕES NUCLEARES, 5. 2000, Rio de Janeiro, Anais. Rio de Janeiro: ABEN, 2001, CD-ROM.

FÁVARO, D.I.T.; DAMATTO, S.R.; SILVA, P.S.C.; RIGA, AA; SAKAMOTO, A.Y.; MAZZILLI, B.P. Chemical Characterization and ${ }^{210} \mathrm{~Pb}$ dating in wetland sediments from the Nhecolândia Pantanal Pond, Brazil. J. Radioanal. Nucl. Chem, v. 269, n.3, p. 719-726, 2006.

FÁVARO, D.I.T.; DAMATTO, S.R.; MOREIRA, E.G.; MAZZILLI, B.P.; CAMPAGNOLI, F. Chemical characterization and recent sedimentation rates in sediment cores from Rio Grande Reservoir, SP, Brazil. J. Radioanal. Nucl. Chem, v. 273, n.2, p. 451-463, 2007.

FERREIRA, D. I. C. Desenvolvimento de métodos analíticos para determinação de níquel e vanádio em petróleo por espectrometria de absorção atômica em forno de grafite. 2005. Dissertação (Mestrado), Universidade Federal do Rio Grande do Sul, Rio Grande do Sul.

FIGUEIRA, R.C.L.; TRAMONTE, K.M.; BATISTA, M.F.; RIBEIRO, A.P.; SALAROLI, A.B.; MAHIQUES, M.M. Estudo da disponibilidade de metais em sedimentos do Sistema Estuarino-Lagunar de Cananéia-Iguape, Oceanografia e Políticas Públicas, Santos, SP, Brasil. V Simpósio Brasileiro de Oceanografia, 2011. 
FigueIREDO, A. M. G., ENZWEILER, J., CAMARGo, S.P., SíGOLO, J. B., GUMIERO, F. C., PAVESE, A. C., MILIAN, F. M.. Metal contamination in urban park soils of São Paulo. J. Radioanal. Nucl. Chem., v.280, n.2, p. 423-429, 2009.

FOLK, R. L \& WARD, W. C. Brazos River Bar: Study of the significance of grain size parametres. Journal of Sedimentary Petrology, v.27, p. 3-27, 1957.

FORSTNER, U. Inorganic chemistry and elemental spectrum. In sediments: Chemistry and toxicity of enplane pollutants. Lewis Publishers. 1990.

FRANKLIN, R.L., FERREIRA, F.J., BEVILACQUA, J.E., FAVARO, D.I.T. Assessment of Metals and Trace Elements in Sediments from Rio Grande Reservoir, Brazil, by Neutron Activation Analysis. . J. Radioanal. Nucl. Chem., v.291, p. 147-153, 2012.

FUKUMOTO, M.M. Determinação da história deposicional recente do Alto Estuário Santista, com base nos teores de metais e na suscetibilidade magnética dos sedimentos. 2007. Tese (Doutorado), Instituto Oceanográfico da Universidade de São Paulo, São Paulo.

FULFARO, V.J. \& PONÇANO, W.L. Sedimentação atual do estuário e baía de Santos: Um modelo geológico aplicado a projetos de expansão da zona portuária. Anais do Congresso da Associação Brasileira de Geologia de Engenharia, ABES, Rio de Janeiro, p. 67-90, 1976.

FULFARO, V.J., REQUEJO, C.S., LANDIM, F.M.B., FULFARO, R. Distribuição de elementos metálicos nos sedimentos da baía de Santos, Sp. Atas do 40 Simpósio Regional de Geologia, SBG, São Paulo, p. 275-289, 1983.

GLASCOCK, M.D. - An Overview of Neutron Activation Analysis, 2003 Disponível em: http://www.missouri.edul glascoklnaa_over.htm, acesso em fevereiro de 2011 
GOMES, F.C., GODOY, J.M., GODOY, M.L.D.P., CARVALHO, Z.L., LOPES, R.T., SANCHEZ-CABEZA, J.A., LACERDA, L.D., WASSERMAN, J.C. Metal concentration, fluxes, inventories and chronologies in sediments from Sepetiba and Ribeira Bays: A comparative study. Marine Pollution Bulletin, v.59, p.123133, 2009.

GONÇALVES, W.F.L. Sazonalidade Geoquímica em águas intersticiais, superficiais e sedimentos estuarinos de Cubatão (SP), impactados por atividades industriais. 2009. Dissertação (Mestrado), Instituto de Geociências da Universidade Estadual de Campinas, Campinas.

GREENBERG, R.R; BODE, P.; FERnANDES, E. A. N.; Neutron Activation Analysis: A primary method of measurement. Spetrochimia Acta, Parte B, 66, p. 193-241,2011.

GRESENS, R. L. Composition-volume relationships of metasomatism. Chemical Geology, v. 2, p. 47-55, 1967.

GUILHEN, S.N.; PIRES, M.A.F.; DANTAS, E.S.K.; XAVIER, F.V. Validação de metodologia analítica para determinação de mercúrio total em amostras de urina por espectrometria de absorção atômica com geração de vapor frio (CV AAS). Estudo de Caso. Quim. Nova, v. 33, n.6, p.1285-1290, 2010.

GUIMARÃES G.M., ZAHN, G.S., FRANKLIN, R.L., SILVA, P.C.S., FÁVARO, D.I.T. 2012 Neutron Activation Analysis applied in sediment samples from the Guarapiranga Reservoir for metals and trace elements assessment. J. Radioanal. Nucl. Chem., v.291, p. 155-161, 2012.

HALLS, D.J.; FELL, G.S.; DUNBAR, P.M. Determination of Copper in urine by graphite furnace atomic absorption spectrometry. Clinica Chimica Acta, v.114, n.1, p.21-27, 1981. 
HARPER, K.; OLIVEIRA, A.P. Determinação de elementos-traço em solos e lodos de esgoto por ICP OES. Revista Analytica, n. 23, p. 53-59, 2006.

HORNG, C.J.; LIN, S.R. Determination of urinary Zinc, Chromium and Copper in steel production workers. Biological Trace Element Research, v. 55, n.3, p.307-314, 1996.

HORTELLANI, M. A.; SARKIS, J. E. S.; BONETTI, J; BONETTI, C. Evaluation of Mercury Contamination in Sediments from Santos- São Vicente Estuarine System, São Paulo State, Brazil. J. Braz. Chem. Soc., v.16, n. 6A, p. 11401149, 2005.

HORTELLANI, M.A.; SARKIS, J.E.S.; ABESSA,. D.M.S.; SOUSA, E.C.P.M. Avaliação da contaminação por elementos metálicos dos sedimentos do estuário Santos-São Vicente, Quim. Nova, v. 31, n.1, p. 10-19, 2008.

HYPOLITO, R.; FERRER, L. M.; NASCIMENTO, S. C. Comportamento de Espécies de Mercúrio no Sistema Sedimento-Água do Mangue no Município de Cubatão, São Paulo. Águas Subterrâneas, v. 19, n. 1, p. 15-24, 2005.

IAEA - INTERNATIONAL ATOMIC ENERGY AGENCY. Pratical aspects of operating a neutron analysis laboratory, Vienna, 1990. (IAEA- TECDOC 564).

IAEA - INTERNATIONAL ATOMIC ENERGY AGENCY. Use of research reactors for neutron activation analysis. 2001. (IAEA- TECDOC 1215).

IAEA - INTERNATIONAL ATOMIC ENERGY AGENCY. Collection and preparation of bottom sediment samples for analysis of radionuclides and trace elements, 2003. (IAEA - TECDOC 1360). 
INMETRO - Instituto Nacional de Metrologia, Normalização e Qualidade Industrial. Orientações sobre Validação de Métodos de Ensaios Químicos, DOQCGCRE-008, 2003.

IUPAC - Technical Report - The determination of Mercury species in environmental and biological Samples. Pure \& Appl. Chem., v. 70, n.8, p. 1585 - 1615, Great Britain, 1998.

KALANTARI, M.R. \& EBADI, A.G. Geochemical Assessment of some heavy metal levels in Neka River Sediments - Neka City, Iran. Journal of Applied Sciences, v. 6, n. 5, p. 1017-1019, 2006.

KEITH, L.H.; CRUMMET, W.; DEEGAN, J.R.; LIBBY, R.A.;TAYLOR, J.K.;WENTLER, G. Principles of environmental analysis. Anal. Chem., v.55, p. 2210-2218, 1983.

LARIZZATTI, F. E. ; FAVARO, D. I. T. ; MOREIRA, S. R. D. ; MAZZILLI, B. P. ; PIOVANO, E. L. Multielemental Determination by Instrumental Neutron Activation Analysis and Recent Sedimentation Rates Using ${ }^{210} \mathrm{~Pb}$ Dating Method at Laguna del Plata, Cordoba, Argentina. J. Radioanal. Nucl. Chem, v. 249 n.1, p.263-268, 2001.

LLOYD, A., PARRY, S.J., LYNN, N.M., GILES, I.S. Development of an Elemental tracer using nêutron activation analysis for application in an estuarine environment. . J. Radioanal. Nucl. Chem., v.264, n.1, p. 83-90, 2005.

LONG, E.R.; MACDONALD, D.D.; SMITH, S.L.; CALDER F.D. Incidence of adverse biological effects within ranges of chemical concentrations in marine and estuarine sediments. Environmental Management n.19, v.1, p. 81-97, 1995. 
LUIZ-SILVA, W. L.; MATOS, R.H.R.; KRISTOSCH, G.C. Geoquímica e índice de geoacumulação de mercúrio em sedimentos de superfície do estuário de Santos - Cubatão (SP). Quím. Nova, v. 25, n.5, p. 753-756, 2002.

LUIZ-SILVA, W.L; MATOS, R.H.R.; KRISTOSCH, G.C, MACHADO, W. Variabilidade Espacial e Sazonal da concentração de elementos-traço em Sedimentos do sistema estuarino de Santos-Cubatão (SP). Quim. Nova, v. 29, n. 2, p. 256-263, 2006.

LUIZ-SILVA, W.L; MACHADO, W.; MATOS, R.H.R. Multi-elemental Contamination and Historic Record in Sediments from the Santos-Cubatão Estuarine System, Brazil. J. Braz. Chem. Soc., v.19, n.8, p.1490-1500, 2008.

MACHADO, W.; LUIZ-SILVA, W.; SANDERS, C.J.; PATCHINEELAM, S.R. Coupled anthropogenic anomalies of radionuclides and major elements in estuarine sediments. J. Environ. Rad., n. 99, p. 1329-1334, 2008.

MAHIQUES, M.M.; BURONE, L.; FIGUEIRA, R.C.L.; OLIVEIRA, A.A.; WANDERLEY, L.; CAPELLARI, B.; ROGACHESKI, C.E.; BARROSO, C.P.; ANTOS, L.A.S.; CORDERO, L.M.; CUSSIOLI, M.C. Anthropogenic Influences in a Lagoonal Environment: A Multiproxy approach at the Valo Grande Mouth Cananéia-Iguape System (SE-Brazil), Brazilian Journal of Oceanography, v. 57, n. 4, p. 325-337, 2009.

MALUF, J.C.C. Estudo dos metais Traço (Zinco, Cádmio e Chumbo) em duas regiões do complexo estuarino-lagunar de Cananéia-lguape(SP) sob diferentes pressões antrópicas. 2009. Dissertação (Mestrado), Instituto Oceanográfico da Universidade de São Paulo, área de Oceanografia Química e Geológica, São Paulo.

MANAHAN, S.E. Environmental Chemistry, $7^{\text {th }}$ ed.: Lewis Publishers, 1999. 
MANNING, T.J.; GROW, W.R. Inductively Coupled Plasma-Atomic Emission Spectrometry. V.2, n.1. Springer-V Erla G, New York, 1997.

MARTINS, C.C.; MAHIQUES, M.M.; BÍCEGO, M.C.; FUKUMOTO, M.M.; MONTONE, R.C. Comparison between anthropogenic hydrocarbons and magnetic susceptibility in sediment cores from the Santos Estuary, Brazil. Marine Pollution Bulettin, v. 54, p. 226-246, 2007.

METZ, J., MONARD, M.C., Clustering hierárquico: uma metodologia para auxiliar na interpretação dos clusters, XXV CONGRESSO DA SOCIEDADE BRASILEIRA DE COMPUTAÇÃO, V ENIA, 2005, p. 1170 - 1173.

MIYAO, S. Y.; NISHIHARA, L; SARTI, C. C. Características Físicas e Químicas do Sistema Estuarino-Lagunar de Cananéia-Iguape. Bolm. Inst. Oceanogr., São Paulo, v. 34, p. 23-36, 1986

MOREIRA, E. G. Preparo e caracterização de um material de referência de mexilhão perna perna (Linnaeus, 1975). 2010. Tese (Doutorado) - Instituto de Pesquisas Energéticas e Nucleares, São Paulo.

MOREIRA, F.R.; MOREIRA, J.C.; COUTADA, F.P.L. Influência da geometria da plataforma na determinação de Chumbo em Zidovudina (AZT) por ET AAS. Quím. Nova, v.25,n.3, p. 379-383, 2002. 283p.

MOZETO, A.A.; JARDIM, W.F. A Química Ambiental no Brasil. Quim. Nova, v. 25, Supl. 1, p. 7-11, 2002.

MULLER, G. Schwermetalle in den sedimenten des Rheins - Veränderungen seit. Unmschau v.79, p.778-783. 1979.

NEPO - Núcleo de Estudos Populacionais, UNICAMP. http://www.nepo.unicamp.br/textos/publicacoes/livros/vulnerabilidade/arquuivos/ arquuivos/vulnerab cap 11 pgs 305 336.pdf, acesso em 03/12/12. 
NIZOLI, E.C.; SILVA, W.L. O papel dos sulfetos volatilizados por acidificação no controle do potencial de biodisponibilidade de metais em sedimentos contaminados de um estuário tropical no sudeste do Brasil, Quim, Nova, v. 32, n. 2, p. $365-372,2009$.

NORDBERG, G.F.; FOWLER, B.A.; NORDBERG, M.; FRIBERG, L. Handbook on the Toxicology of Metals, 3 ed., editora AP, 2005.

OLIVEIRA, E.; SANTOS, J. S.; SANTOS, M.L.P. Estudo da mobilização de metais e elementos traços em ambientes aquáticos do semiárido brasileiro aplicando análises de componentes principais. Quim. Nova, v. 31, n. 5, p. 1107-1111, 2008.

OLIVEIRA, S.M.B., SILVA, P.S.C., MAZZILLI, B.P., FAVARO, D.I.T., SAUIEA, C.H. Rare earth elements as tracers of sediment contamination by phosphogypsum in the Santos estuary, southern Brazil. Applied Geochemistry v.22, p.837-850, 2007.

PERKIN ELMER - Analytical Methods - Atomic Absorption Spectroscopy USA, 1996.

PERKIN ELMER, Guide to Atomic Spectroscopy Techniques and Applications, AA, GFAA, ICP, ICP-MS, 2000.

PERRETI, A.R. Estudo biogeoquímico das águas de fundo e da matéria orgânica sedimentar com ênfase às proteínas e carboidratos totais em dois sistemas estuarinos do Estado de São Paulo. 2006. Dissertação (Mestrado), Instituto Oceanográfico da Universidade de São Paulo, IOUSP, São Paulo.

PINTO, A.G.N.; HORBE, A.M.C.; SILVA, M.S.R.; MIRANDA, S.A.F.; PASCOALOTO, D.; SANTOS, H.M.C. Efeitos da ação antrópica sobre a 
hidrogeoquímica do rio Negro na orla de Manaus/AM. Acta Amazonica, v.39, n.3, p. $627-638,2009$.

QUINÁGLIA, G. A. Caracterização dos Níveis Basais de Concentração de Metais nos Sedimentos do Sistema Estuarino da Baixada Santista. 2006. Tese (Doutorado), Instituto de Química da Universidade de São Paulo, IQ USP. São Paulo. 239p.

QUINAIA, S.P.; NOBREGA, J.A. Determinação direta de cromo em açúcar e leite por espectrometria de absorção atômica com atomização eletrotérmica em forno de grafite. Quím. Nova, v.23, n.2, p.185-190, 2000.

REZAEE, Kh, ABDI, M.R., SAION, E.B., NAGHAVI, K., SHAFAEI, M.A. Distribution of trace elements in the marine sediments along the South China Sea, Malaysia. J. Radioanal. Nucl. Chem., v.287, n.3, 773-740(8), DOI 10.1007/s10967-010-0950-5, 8 p., 2011.

ROSE, N.; YANG, H. Trace element pollution records in some UK lake sediments, their history, influence factors and regional differences, Environmental International v.31, p. $63-75,2005$.

SAITO, R.T.; FIGUEIRA, R.C.L.; TESSLER, M.G.; CUNHA, I.I.L. Níveis de Chumbo, Cobre e Zinco em amostras de sedimentos do sistema costeiro Cananéia-lguape (São Paulo, Brasil). In: VIII CONGRESSO BRASILEIRO DE GEOQUÍMICA, I SIMPÓSIO DE GEOQUÍMICA DOS PAÍSES DO MERCOSUL, 21 a 26 outubro, 2001, Curitiba, Paraná, Brasil, 2001.CR ROM.

SCHIFER, T. S.; JÚNIOR, S.B.; MONTANO, M.A.E. Aspectos toxicológicos do chumbo. Infarma, v. 17, n. 5/6, 2005.

SCHROPP, S.J. A Guide to the interpretation of Metal Concentrations in estuarine sediments, Florida Department of Environmental RegulationSkidaway Institute of Oceanography, Savannah, Georgia, 1988. 
SEMENSATTO-JR, D.L.; ARAÚJO, G.C.L.; FUNO, H.F.; SANTA-CRUZ, J.; DIASBRITO, D. Metais e não metais em sedimentos de um manguezal não-poluído, Ilha do Cardoso, Cananéia (SP). Rev. Pesquisa em Geociências, v. 34 n. 2, p. 25-31, 2007.

SILVA , P.S.C. Caracterização Química e Radiológica dos sedimentos do estuário de Santos, São Vicente e Baía de Santos. 2004. Tese (Doutorado) - Instituto de Pesquisas Energéticas e Nucleares, São Paulo. 268p.

SILVA, P.S.C.; DAMATTO, S.R.; MALDONADO, C.; FAVARO, D.I.T.; MAZILLI, B.P. Metal distribution in Sediment Cores from São Paulo State Coast, Brazil, Marine Pollution Bulletin, v. 65, n. 5, p. 1130-1139, 2011.

SIQUEIRA, G.W. \& BRAGA, E.S. Estudo dos teores de $\mathrm{Hg}$ na fração fina do sedimento: uma visão ambiental com aplicação de normalizantes geoquímicos para as regiões estuarinas de Santos/São Vicente e Baía de Santos. Anais do VIII Congresso Brasileiro de Geoquímica e I Simpósio de Geoquímica dos Países do Mercosul, p.7, 2001.

SIQUEIRA, G.W., LIMA, W.N., MENDES, A.S., APRILE, F.M., BRAGA, E.S., MAHIQUES, M.M. Evolução do impacto ambiental causado por matéria orgânica, mercúrio e arsênio nos sedimentos de fundo do sistema estuarino de Santos. Geochim. Brasil., v.18, n.1, p. 54-63, 2004.

SIQUEIRA, G.W., BRAGA, E.S., PEREIRA, S.F.P., SILVA, E. Distribuição do mercúrio em sedimentos de fundo no Estuário de Santos - SP/Brasil. Revista Esc. Minas, Ouro Preto, v.58 n.8, p. 309-316, 2005.

SIQUEIRA, G.W., BRAGA, E.S.,MAHIQUES, M.M. Aprile, F.M. Determinação da Matéria Orgânica e razões $\mathrm{C} / \mathrm{N}$ e C/S em sedimentos de fundo do Estuário de Santos - SP/Brasil. Arq. Ciên. Mar, Fortaleza, v.39, p.18-27, 2006. 
SIQUEIRA, G.W., Estudo dos teores de metais pesados e outros elementos em sedimentos superficiais do sistema estuarino de Santos (Baixada santista - São Paulo) e da plataforma continental do Amazonas (Margem continental norte). 2003. Tese (Doutorado), Instituto Oceanográfico da Universidade de São Paulo. São Paulo, 350p.

SOUSA, E.C.P.M.; ABESSA, D.M.S.; RACHID, B.R.F.; GASPARRO, M.R.; ZARONI, L.P. Ecotoxicological assessment of sediments from the port of Santos and the disposal sites of dredged material, Brazilian Journal of Oceanography, v. 55, n. 2, p. 75-81, 2007.

SPAZIANI, M.; OLIVEIRA, P.V.; CADORE, S.; OLIVEIRA, E. Determinação de alguns constituintes inorgânicos em amostras de vinhos por espectrometria atômica: ICP OES e ET AAS. Revista Analytica, n. 20, p. 48-54 , 2006.

SUGUIO, K. Introdução à sedimentologia. Editora Edgard Blücher (Universidade de São Paulo), 317p, 1973.

TAYLOR, S.R. \& MCLENNAN, S.M. The Continental Crust: Its Composition and Evolution. Oxford, London: Blackwell Scientific, ISBN 063201148 3, 1985.

TOMMASI, L.R. Consideração ecológica sobre o Sistema Estuarino de Santos, estado de São Paulo, Tese de Livre -Docência, Instituto Oceanográfico, USP, São Paulo, 2 vols, 489p, 1979.

TOMMASI, L.R. Poluição marinha no Brasil: Síntese do conhecimento, Publ. Esp. Instituto Oceanográfico, São Paulo, 5, p. 1-30, 1983.

TOWNSEND, A.T; O'SULLIVAN, J; FEATHERSTONE, A.M.; BUTLER, E.C.V.; MACKEY, D.J. The application of ICP-SMS, GF-AAS and HG-AFS to the analysis of water and sediment samples from a temperate stratified estuary. $\boldsymbol{J}$. Environmental Monitoring, n.3, p.113 -120, Royal Society of Chemistry, 2001. 
U.S. DEPARTMENT OF HEALTH AND HUMAN SERVICES, Toxicological Profile for Copper. Public Health Service Agency for Toxic Substances and Disease, 2004.

U.S.EPA - Method 6010C - Inductively Coupled Plasma-Atomic Emission Spectrometry. 2007. Disponível em $<$ http://www.epa.gov/osw/hazard/testmethods/sw846/pdfs/6010c.pdf>. Acesso em 16 de outubro de 2011.

U.S.EPA - United States Environmental Protection Agency, Method SW-846 3051A: Microwave assisted acid digestion of sediments, sludges, soils, and oils, Revision 1, U.S.: U.S.EPA., Feb, 2007

U.S.EPA - United States Environmental Protection Agency, Method SW-846 7473: Mercury in solids and solutions by thermal decomposition, almagamation, and atomic absorption spectrophotometry Revision 1, U.S.: U.S.EPA., Feb, 2007.

VALLIUS, H.; LEIVUORI, M.. The distribution of heavy metals and arsenic in recent sediments in the Gulf of Finland, BOREAL ENVIRONMENT RESEARCH, v. 4, p. 19-29, Helsinki, Finland, 18 March 1999.

VARGAS-BOLDRINI, C.; EYSINK, G.G.J.; LAMPARELLI, M.C.; MARTINS, M.C. Contaminants in the Cubatão River basin and its Estuary (SP,Brazil), relating to the Aquatic Biota. Part 2. Organic Compounds. 11th Biennal International Estuarine Research Conference, San Francisco, USA. Session: Inputs and Cycling of Natural and Contaminant Materials in Estuaries., November 1991.

WARD CENTER STAFF - Neutron activation analysis, 2000 - Disponível em: http://www.lbl.govlabclwallchartlchapters $\backslash 13 \backslash 5 . h t m l$, acesso em fevereiro de 2012. 
WEDEPOHL, K.H. The composition of the continental crust. Geochim. Cosmochim. Acta, v.59, p.1217-1232, 1995.

WILLIAMS, P. L.; JAMES, R.C.; ROBERTS, S.M. Principles of Toxicology: Environmental and Industrial Applications, 2 ed. John Wiley \& Sons, Inc., 2000. ISBN 0-471-29321-0.

WINDOM, H.L.; SCHROPP, S.J.; CALDER, F.D.; RYAN, J.D.; SMITH, R.G.; BURNEY, L.C.; LEWIS, F.G.; RAWLLNSONT, C.H. Natural trace metal concentrations in estuarine and coastal marine sediments of the Southeastern United States, Environ. Sci. Techonol, v. 23, p. 314-320, 1989.

WONG, V.N.L., JOHNSTON, S.G., BURTON, E.D., BUSH, R.T., SULLIVAN, L.A., SLAVICH, P.G. Seawater causes rapid trace metal mobilization in coastal lowland acid sulfate soils: Implications of sea level rise for water quality. Geoderma, 160, p.252-263, 2010.

YAQIN, J. I.; FENG, Y.; WU, J.; ZHU, T.; BAI, Z., DUAN, C., Using geoaccumulation índex to study source profiles of soil dust in China. $J$. Environmental Sciences. v. 20, issue 5, p. 571-578, 2008.

YASSUDA, E.A; SIERRA, B.M.; PINCINATO, F.L.; CLAYZET, G.; GUIMARÃES, M.R.F.; CORRÊA, M.A.; TESSLER, M.G. Metais contidos nos sedimentos do Estuário e Baía de Santos e na plataforma Continental rasa contígua ao estuário, Relatório técnico ASA/CEPEA, 2008.

ZHANG, J. \& LIU, C. L., Riverine composition and Estuarine Geochemistry of Particulate Metals in China - Weathering Features, Anthropogenic Impact and Chemical Fluxes. Estuarine, Coastal and Shelf Science Lett., v.54, p. 10511070, 2002. 


\section{ANEXOS}


ANEXO I- Valores de concentração $\left(\mathrm{mg} \mathrm{kg}^{-1}\right)$ determinados por ICP OES para as amostras de sedimentos do sistema estuarino Santos/São Vicente (Inverno/2005) e valores de LD e LQ

\begin{tabular}{|c|c|c|c|c|c|c|c|c|c|c|c|c|c|c|c|c|c|c|}
\hline Parâmetros & Unidade & L.D. & L.Q. & SI0501 & & $\begin{array}{l}\text { Desvio } \\
\text { Padrão }\end{array}$ & S10502 & & $\begin{array}{l}\text { Desvio } \\
\text { Padrão }\end{array}$ & S10503 & & $\begin{array}{l}\text { Desvio } \\
\text { Padrão } \\
\end{array}$ & SI0504 & & $\begin{array}{l}\text { Desvio } \\
\text { Padrão } \\
\end{array}$ & S10505 & & $\begin{array}{l}\text { Desvio } \\
\text { Padrão } \\
\end{array}$ \\
\hline Al & $\left(\mathrm{mg} \mathrm{kg}^{-1}\right)$ & 0,5 & 1,0 & 61652 & \pm & 12069 & 60278 & \pm & 11800 & 30447 & \pm & 5960 & 68779 & \pm & 13464 & 50484 & \pm & 9882 \\
\hline $\mathrm{Ba}$ & $\left(\mathrm{mg} \mathrm{kg}^{-1}\right)$ & 0,2 & 1,0 & 249,8 & \pm & 13,5 & 155,0 & \pm & 8,4 & 36,2 & \pm & 2,0 & 84,5 & \pm & 4,6 & 47,6 & \pm & 2,6 \\
\hline Co & $\left(\mathrm{mg} \mathrm{kg}^{-1}\right)$ & 0,5 & 1,0 & 9,19 & \pm & 0,37 & 9,32 & \pm & 0,38 & 5,14 & \pm & 0,21 & 7,18 & \pm & 0,29 & 5,71 & \pm & 0,23 \\
\hline $\mathrm{Cu}$ & $\left(\mathrm{mg} \mathrm{kg}^{-1}\right)$ & 0,1 & 0,5 & 25,7 & \pm & 5,2 & 26,6 & \pm & 5,4 & 14,4 & \pm & 2,9 & 17,7 & \pm & 3,6 & 14,8 & \pm & 3,0 \\
\hline $\mathrm{Cr}$ & $\left(\mathrm{mg} \mathrm{kg}^{-1}\right)$ & 0,5 & 1,0 & 50,7 & \pm & 2,0 & 45,9 & \pm & 1,8 & 26,2 & \pm & 1,0 & 40,3 & \pm & 1,6 & 30,7 & \pm & 1,2 \\
\hline Sr & $\left(\mathrm{mg} \mathrm{kg}^{-1}\right)$ & 0,1 & 1,0 & 119,1 & \pm & 5,8 & 80,4 & \pm & 3,9 & 47,0 & \pm & 2,3 & 186,9 & \pm & 9,0 & 66,8 & \pm & 3,2 \\
\hline $\mathrm{Fe}$ & $\left(\mathrm{mg} \mathrm{kg}^{-1}\right)$ & 1,0 & 5,0 & 61529 & \pm & 8321 & 52480 & \pm & 7098 & 27163 & \pm & 3674 & 43903 & \pm & 5937 & 34226 & \pm & 4629 \\
\hline $\mathbf{L i}$ & $\left(\mathrm{mg} \mathrm{kg}^{-1}\right)$ & 0,5 & 1,0 & 85,8 & \pm & 4,6 & 81,7 & \pm & 4,4 & 48,3 & \pm & 2,6 & 87,5 & \pm & 4,7 & 59,7 & \pm & 3,2 \\
\hline$M n$ & $\left(\mathrm{mg} \mathrm{kg}^{-1}\right)$ & 0,5 & 1,0 & 535 & \pm & 25 & 360 & \pm & 17 & 235 & \pm & 11 & 549 & \pm & 26 & 549 & \pm & 26 \\
\hline $\mathrm{Ni}$ & $\left(\mathrm{mg} \mathrm{kg}^{-1}\right)$ & 0,5 & 1,0 & 20,76 & \pm & 0,85 & 20,71 & \pm & 0,85 & 9,61 & \pm & 0,39 & 17,08 & \pm & 0,70 & 11,80 & \pm & 0,48 \\
\hline $\mathrm{Zn}$ & $\left(\mathrm{mg} \mathrm{kg}^{-1}\right)$ & 0,5 & 1,0 & 156,0 & \pm & 18,1 & 126,5 & \pm & 14,7 & 67,7 & \pm & 7,9 & 96,4 & \pm & 11,2 & 76,5 & \pm & 8,9 \\
\hline Parâmetros & Unidade & L.D. & L.Q. & S10506 & & $\begin{array}{l}\text { Desvio } \\
\text { Padrão }\end{array}$ & S10507 & & $\begin{array}{l}\text { Desvio } \\
\text { Padrão }\end{array}$ & S10508 & & $\begin{array}{l}\text { Desvio } \\
\text { Padrão }\end{array}$ & S10509 & & $\begin{array}{l}\text { Desvio } \\
\text { Padrão }\end{array}$ & SI0510 & & $\begin{array}{l}\text { Desvio } \\
\text { Padrão }\end{array}$ \\
\hline Al & $\left(\mathrm{mg} \mathrm{kg}^{-1}\right)$ & 0,5 & 1,0 & 12930 & \pm & 2027 & 6846 & \pm & 1340 & 10693 & \pm & 2093 & 6715 & \pm & 1053 & 9803 & \pm & 1537 \\
\hline $\mathrm{Ba}$ & $\left(\mathrm{mg} \mathrm{kg}^{-1}\right)$ & 0,2 & 1,0 & 19,4 & \pm & 1,7 & 5,9 & \pm & 0,3 & 13,9 & \pm & 0,8 & 7,3 & \pm & 0,6 & 16,1 & \pm & 1,4 \\
\hline Co & $\left(\mathrm{mg} \mathrm{kg}^{-1}\right)$ & 0,5 & 1,0 & 3,78 & \pm & 0,23 & 2,61 & \pm & 0,11 & 3,57 & \pm & 0,14 & 2,92 & \pm & 0,18 & 2,76 & \pm & 0,17 \\
\hline $\mathrm{Cu}$ & $\left(\mathrm{mg} \mathrm{kg}^{-1}\right)$ & 0,1 & 0,5 & 5,5 & \pm & 0,3 & N.D. & \pm & - & 2,9 & \pm & 0,6 & N.D. & \pm & - & 2,2 & \pm & 0,1 \\
\hline $\mathrm{Cr}$ & $\left(\mathrm{mg} \mathrm{kg}^{-1}\right)$ & 0,5 & 1,0 & 16,9 & \pm & 1,0 & 9,9 & \pm & 0,4 & 15,4 & \pm & 0,6 & 11,8 & \pm & 0,7 & 11,6 & \pm & 0,7 \\
\hline $\mathrm{Sr}$ & $\left(\mathrm{mg} \mathrm{kg}^{-1}\right)$ & 0,1 & 1,0 & 51,7 & \pm & 1,8 & 26,1 & \pm & 1,3 & 43,7 & \pm & 2,1 & 26,5 & \pm & 0,9 & 33,9 & \pm & 1,2 \\
\hline $\mathrm{Fe}$ & $\left(\mathrm{mg} \mathrm{kg}^{-1}\right)$ & 1,0 & 5,0 & 11973 & \pm & 745 & 9399 & \pm & 1271 & 11984 & \pm & 1621 & 12626 & \pm & 786 & 8750 & \pm & 545 \\
\hline $\mathbf{L i}$ & $\left(\mathrm{mg} \mathrm{kg}^{-1}\right)$ & 0,5 & 1,0 & 24,0 & \pm & 1,7 & 14,2 & \pm & 0,8 & 28,7 & \pm & 1,5 & 11,7 & \pm & 0,8 & 15,1 & \pm & 1,1 \\
\hline$M n$ & $\left(\mathrm{mg} \mathrm{kg}^{-1}\right)$ & 0,5 & 1,0 & 308 & \pm & 14 & 169 & \pm & 8 & 297 & \pm & 14 & 165 & \pm & 7 & 160 & \pm & 7 \\
\hline $\mathbf{N i}$ & $\left(\mathrm{mg} \mathrm{kg}^{-1}\right)$ & 0,5 & 1,0 & 6,92 & \pm & 0,58 & 2,97 & \pm & 0,12 & 5,56 & \pm & 0,23 & 3,51 & \pm & 0,30 & 3,84 & \pm & 0,32 \\
\hline $\mathrm{Zn}$ & $\left(\mathrm{mg} \mathrm{kg}^{-1}\right)$ & 0,5 & 1,0 & 41,2 & \pm & 6,4 & 20,4 & \pm & 2,4 & 39,4 & \pm & 4,6 & 21,3 & \pm & 3,3 & 23,4 & \pm & 3,6 \\
\hline
\end{tabular}


ANEXO I- Valores de concentração ( $\left.\mathrm{mg} \mathrm{kg}^{-1}\right)$ determinados por ICP OES para as amostras de sedimentos do sistema estuarino Santos/São Vicente (Inverno/2005) e valores de LD e LQ (continuação)

\begin{tabular}{|c|c|c|c|c|c|c|c|c|c|c|c|c|c|c|c|c|c|c|}
\hline Parâmetros & SI0511 & & $\begin{array}{l}\text { Desvio } \\
\text { Padrão }\end{array}$ & SI0512 & & $\begin{array}{l}\text { Desvio } \\
\text { Padrão }\end{array}$ & SI0513 & & $\begin{array}{l}\text { Desvio } \\
\text { Padrão }\end{array}$ & SI0514 & & $\begin{array}{l}\text { Desvio } \\
\text { Padrão }\end{array}$ & SI0515 & & $\begin{array}{l}\text { Desvio } \\
\text { Padrão }\end{array}$ & SI0516 & & $\begin{array}{l}\text { Desvio } \\
\text { Padrão }\end{array}$ \\
\hline Al & 3208 & \pm & 503 & 11845 & \pm & 1856 & 5327 & \pm & 835 & 56023 & \pm & 8781 & 26348 & \pm & 4130 & 7236 & \pm & 1134 \\
\hline $\mathrm{Ba}$ & 6,8 & \pm & 0,6 & 14,2 & \pm & 1,3 & 8,1 & \pm & 0,7 & 82,9 & \pm & 7,3 & 32,4 & \pm & 2,9 & 10,2 & \pm & 0,9 \\
\hline Co & N.D. & \pm & - & 1,83 & \pm & 0,11 & 1,11 & \pm & 0,07 & 7,55 & \pm & 0,45 & 6,22 & \pm & 0,37 & 2,75 & \pm & 0,17 \\
\hline $\mathrm{Cu}$ & 1,0 & \pm & 0,1 & 2,3 & \pm & 0,1 & 1,8 & \pm & 0,1 & 31,5 & \pm & 1,8 & 7,7 & \pm & 0,4 & N.D. & \pm & - \\
\hline $\mathrm{Cr}$ & 2,8 & \pm & 0,2 & 10,9 & \pm & 0,7 & 5,3 & \pm & 0,3 & 52,1 & \pm & 3,2 & 30,1 & \pm & 1,9 & 12,5 & \pm & 0,8 \\
\hline $\mathrm{Sr}$ & 4,5 & \pm & 0,2 & 230,3 & \pm & 7,8 & 59,0 & \pm & 2,0 & 79,4 & \pm & 2,7 & 79,0 & \pm & 2,7 & 18,3 & \pm & 0,6 \\
\hline $\mathrm{Fe}$ & 1474 & \pm & 92 & 6767 & \pm & 421 & 3034 & \pm & 189 & 40676 & \pm & 2532 & 25592 & \pm & 1593 & 11445 & \pm & 712 \\
\hline Li & 5,6 & \pm & 0,4 & 17,4 & \pm & 1,2 & 7,1 & \pm & 0,5 & 82,5 & \pm & 5,7 & 43,4 & \pm & 3,0 & 11,5 & \pm & 0,8 \\
\hline$M n$ & 18 & \pm & 1 & 84 & \pm & 4 & 36 & \pm & 2 & 350 & \pm & 16 & 667 & \pm & 30 & 140 & \pm & 6 \\
\hline $\mathrm{Ni}$ & 1,12 & \pm & 0,09 & 3,61 & \pm & 0,30 & 1,87 & \pm & 0,16 & 20,59 & \pm & 1,74 & 13,11 & \pm & 1,11 & 3,58 & \pm & 0,30 \\
\hline $\mathrm{Zn}$ & 5,7 & \pm & 0,9 & 16,4 & \pm & 2,6 & 11,3 & \pm & 1,8 & 139,9 & \pm & 21,8 & 57,4 & \pm & 8,9 & 22,6 & \pm & 3,5 \\
\hline
\end{tabular}


Anexo II- Valores de concentração ( $\mathrm{mg} \mathrm{kg}^{-1}$ ) determinados por ICP OES para as amostras de sedimentos do sistema estuarino Santos/São Vicente (Verão/2005) e valores de LD e LQ

\begin{tabular}{|c|c|c|c|c|c|c|c|c|c|c|c|c|c|c|c|c|c|}
\hline Parâmetros & Unidade & L.D. & L.Q. & SV0501 & \multicolumn{2}{|c|}{$\begin{array}{l}\text { Desvio } \\
\text { Padrão }\end{array}$} & SV0502 & & $\begin{array}{l}\text { Desvio } \\
\text { Padrão }\end{array}$ & SV0503 & & $\begin{array}{l}\text { Desvio } \\
\text { Padrão }\end{array}$ & SV0504 & $\begin{array}{l}\text { Desvio } \\
\text { Padrão }\end{array}$ & \multicolumn{2}{|l|}{ SV0505 } & $\begin{array}{l}\text { Desvio } \\
\text { Padrão } \\
\end{array}$ \\
\hline $\mathrm{Al}$ & $\left(\mathrm{mg} \mathrm{kg}^{-1}\right)$ & 0,5 & 1,0 & $30138 \pm$ & & 00 & $56352 \pm$ & \pm & 11031 & 31808 & \pm & 6227 & $52444 \pm$ & 10266 & 51983 & \pm & 10176 \\
\hline $\mathrm{Ba}$ & $\left(\mathrm{mg} \mathrm{kg}^{-1}\right)$ & 0,2 & 1,0 & $123,3 \pm$ & & ,7 & $108,0 \pm$ & \pm & 5,8 & 54,9 & \pm & 3,0 & 54,9 & 3,0 & 54,6 & \pm & 2,9 \\
\hline Co & $\left(\mathrm{mg} \mathrm{kg}^{-1}\right)$ & 0,5 & 1,0 & 6,96 & & 28 & 7,35 & \pm & 0,30 & 5,87 & \pm & 0,24 & 7,12 & 0,29 & 6,96 & \pm & 0,28 \\
\hline $\mathrm{Cu}$ & $\left(\mathrm{mg} \mathrm{kg}^{-1}\right)$ & 0,1 & 0,5 & 15,0 & & 1 & 19,3 & \pm & 3,9 & 13,8 & \pm & 2,8 & 16,2 & 3,3 & 18,2 & \pm & 3,7 \\
\hline $\mathrm{Cr}$ & $\left(\mathrm{mg} \mathrm{kg}^{-1}\right)$ & 0,5 & 1,0 & 36,2 & & 4 & 38,0 & \pm & 1,5 & 28,4 & \pm & 1,1 & 35,8 & 1,4 & 35,4 & \pm & 1,4 \\
\hline $\mathrm{Sr}$ & $\left(\mathrm{mg} \mathrm{kg}^{-1}\right)$ & 0,1 & 1,0 & 82,2 & & 0 & 64,2 & \pm & 3,1 & 47,2 & \pm & 2,3 & $314,9 \pm$ & 15,2 & 77,2 & \pm & 3,7 \\
\hline $\mathrm{Fe}$ & $\left(\mathrm{mg} \mathrm{kg}^{-1}\right)$ & 1,0 & 5,0 & $25614 \pm$ & & 164 & $44146 \pm$ & \pm & 5970 & 31356 & \pm & 4241 & $41710 \pm$ & 5641 & 37976 & \pm & 5136 \\
\hline $\mathrm{Li}$ & $\left(\mathrm{mg} \mathrm{kg}^{-1}\right)$ & 0,5 & 1,0 & 68,1 & & 7 & 74,2 & \pm & 4,0 & 53,6 & \pm & 2,9 & 81,2 & 4,4 & 70,5 & \pm & 3,8 \\
\hline $\mathrm{Mn}$ & $\left(\mathrm{mg} \mathrm{kg}^{-1}\right)$ & 0,5 & 1,0 & 363 & & 17 & 285 & \pm & 13 & 253 & \pm & 12 & 674 & 32 & 675 & \pm & 32 \\
\hline $\mathrm{Ni}$ & $\left(\mathrm{mg} \mathrm{kg}^{-1}\right)$ & 0,5 & 1,0 & 14,79 & & 61 & 16,41 & \pm & 0,67 & 11,41 & \pm & 0,47 & $14,91 \pm$ & 0,61 & 13,86 & \pm & 0,57 \\
\hline $\mathrm{Zn}$ & $\left(\mathrm{mg} \mathrm{kg}^{-1}\right)$ & 0,5 & 1,0 & $103,7 \pm$ & & 2,0 & 107,3 & \pm & 12,5 & 82,9 & \pm & 9,6 & 97,0 & 11,3 & 90,6 & \pm & 10,5 \\
\hline Parâmetros & Unidade & L.D. & L.Q. & SV0506 & & $\begin{array}{l}\text { Desvio } \\
\text { Padrão }\end{array}$ & SV0507 & & $\begin{array}{l}\text { Desvio } \\
\text { Padrão }\end{array}$ & SV0508 & & $\begin{array}{l}\text { Desvio } \\
\text { Padrão }\end{array}$ & SV0509 & $\begin{array}{l}\text { Desvio } \\
\text { Padrão }\end{array}$ & SV0510 & & $\begin{array}{l}\text { Desvio } \\
\text { Padrão }\end{array}$ \\
\hline $\mathrm{Al}$ & $\left(\mathrm{mg} \mathrm{kg}^{-1}\right)$ & 0,5 & 1,0 & 11760 & $I$ & 2302 & 31432 & \pm & 6153 & 45521 & \pm & 8911 & 6138 & \pm 1202 & 15432 & \pm & 3021 \\
\hline $\mathrm{Ba}$ & $\left(\mathrm{mg} \mathrm{kg}^{-1}\right)$ & 0,2 & 1,0 & 17,9 & \pm & 1,0 & 40,2 & \pm & 2,2 & 55,0 & \pm & 3,0 & 7,3 & 0,4 & 16,9 & \pm & 0,9 \\
\hline Co & $\left(\mathrm{mg} \mathrm{kg}^{-1}\right)$ & 0,5 & 1,0 & 2,29 & \pm & 0,09 & 4,44 & \pm & 0,18 & 5,88 & \pm & 0,24 & 2,30 & 0,09 & 3,43 & \pm & 0,14 \\
\hline $\mathrm{Cu}$ & $\left(\mathrm{mg} \mathrm{kg}^{-1}\right)$ & 0,1 & 0,5 & 2,7 & \pm & 0,5 & 1,1 & \pm & 0,2 & 5,4 & \pm & 1,1 & N.D. & \pm & 2,9 & \pm & 0,6 \\
\hline $\mathrm{Cr}$ & $\left(\mathrm{mg} \mathrm{kg}^{-1}\right)$ & 0,5 & 1,0 & 10,8 & \pm & 0,4 & 20,7 & \pm & 0,8 & 30,9 & \pm & 1,2 & 9,7 & 0,4 & 15,4 & \pm & 0,6 \\
\hline $\mathrm{Sr}$ & $\left(\mathrm{mg} \mathrm{kg}^{-1}\right)$ & 0,1 & 1,0 & 35,8 & \pm & 1,7 & 258,5 & \pm & 12,5 & 63,2 & \pm & 3,1 & 29,0 & 1,4 & 76,6 & \pm & 3,7 \\
\hline $\mathrm{Fe}$ & $\left(\mathrm{mg} \mathrm{kg}^{-1}\right)$ & 1,0 & 5,0 & 6978 & \pm & 944 & 26564 & \pm & 3593 & 34310 & \pm & 4640 & 9896 & 1338 & 10108 & \pm & 1367 \\
\hline $\mathrm{Li}$ & $\left(\mathrm{mg} \mathrm{kg}^{-1}\right)$ & 0,5 & 1,0 & 19,4 & \pm & 1,0 & 37,8 & \pm & 2,0 & 51,8 & \pm & 2,8 & 12,9 & 0,7 & 31,1 & \pm & 1,7 \\
\hline $\mathrm{Mn}$ & $\left(\mathrm{mg} \mathrm{kg}^{-1}\right)$ & 0,5 & 1,0 & 132 & \pm & 6 & 254 & \pm & 12 & 548 & \pm & 26 & 122 & 6 & 175 & \pm & 8 \\
\hline $\mathrm{Ni}$ & $\left(\mathrm{mg} \mathrm{kg}^{-1}\right)$ & 0,5 & 1,0 & 3,92 & \pm & 0,16 & 7,25 & \pm & 0,30 & 11,98 & \pm & 0,49 & 2,72 & 0,11 & 6,23 & \pm & 0,26 \\
\hline $\mathrm{Zn}$ & $\left(\mathrm{mg} \mathrm{kg}^{-1}\right)$ & 0,5 & 1,0 & 22,8 & \pm & 2,6 & 38,0 & \pm & 4,4 & 60,3 & \pm & 7,0 & 16,6 & 1,9 & 35,9 & \pm & 4,2 \\
\hline
\end{tabular}


Anexo II- Valores de concentração $\left(\mathrm{mg} \mathrm{kg}^{-1}\right)$ determinados por ICP OES para as amostras de sedimentos do sistema estuarino Santos/São Vicente (Verão/2005) e valores de LD e LQ (continuação)

\begin{tabular}{|c|c|c|c|c|c|c|c|c|c|c|c|c|c|c|c|}
\hline Parâmetros & Unidade & L.D. & L.Q. & SV0511 & & $\begin{array}{l}\text { Desvio } \\
\text { Padrão } \\
\end{array}$ & SV0512 & & $\begin{array}{l}\text { Desvio } \\
\text { Padrão } \\
\end{array}$ & SV0513 & & $\begin{array}{l}\text { Desvio } \\
\text { Padrão } \\
\end{array}$ & SV0514 & & $\begin{array}{l}\text { Desvio } \\
\text { Padrão } \\
\end{array}$ \\
\hline $\mathrm{Al}$ & $\left(\mathrm{mg} \mathrm{kg}^{-1}\right)$ & 0,5 & 1,0 & 1106 & \pm & 216 & 12614 & \pm & 2469 & 5772 & \pm & 1130 & 56102 & \pm & 10982 \\
\hline $\mathrm{Ba}$ & $\left(\mathrm{mg} \mathrm{kg}^{-1}\right)$ & 0,2 & 1,0 & 2,0 & \pm & 0,1 & 15,4 & \pm & 0,8 & 7,2 & \pm & 0,4 & 59,8 & \pm & 3,2 \\
\hline Co & $\left(\mathrm{mg} \mathrm{kg}^{-1}\right)$ & 0,5 & 1,0 & N.D. & \pm & - & 2,08 & \pm & 0,08 & 1,41 & \pm & 0,06 & 7,10 & \pm & 0,29 \\
\hline $\mathrm{Cu}$ & $\left(\mathrm{mg} \mathrm{kg}^{-1}\right)$ & 0,1 & 0,5 & 0,5 & \pm & 0,1 & 2,2 & \pm & 0,4 & 1,8 & \pm & 0,4 & 28,0 & \pm & 5,7 \\
\hline $\mathrm{Cr}$ & $\left(\mathrm{mg} \mathrm{kg}^{-1}\right)$ & 0,5 & 1,0 & 1,1 & \pm & 0,0 & 10,6 & \pm & 0,4 & 7,1 & \pm & 0,3 & 45,5 & \pm & 1,8 \\
\hline $\mathrm{Sr}$ & $\left(\mathrm{mg} \mathrm{kg}^{-1}\right)$ & 0,1 & 1,0 & 2,3 & \pm & 0,1 & 88,7 & \pm & 4,3 & 92,5 & \pm & 4,5 & 63,6 & \pm & 3,1 \\
\hline $\mathrm{Fe}$ & $\left(\mathrm{mg} \mathrm{kg}^{-1}\right)$ & 1,0 & 5,0 & 506 & \pm & 68 & 6210 & \pm & 840 & 3832 & \pm & 518 & 50293 & \pm & 6802 \\
\hline $\mathrm{Li}$ & $\left(\mathrm{mg} \mathrm{kg}^{-1}\right)$ & 0,5 & 1,0 & 3,5 & \pm & 0,2 & 19,5 & \pm & 1,0 & 13,5 & \pm & 0,7 & 89,3 & \pm & 4,8 \\
\hline $\mathrm{Mn}$ & $\left(\mathrm{mg} \mathrm{kg}^{-1}\right)$ & 0,5 & 1,0 & 4,7 & \pm & 0,2 & 64 & \pm & 3 & 41 & \pm & 2 & 350 & \pm & 17 \\
\hline $\mathrm{Ni}$ & $\left(\mathrm{mg} \mathrm{kg}^{-1}\right)$ & 0,5 & 1,0 & N.D. & \pm & - & 4,15 & \pm & 0,17 & 2,45 & \pm & 0,10 & 18,24 & \pm & 0,75 \\
\hline $\mathrm{Zn}$ & $\left(\mathrm{mg} \mathrm{kg}^{-1}\right)$ & 0,5 & 1,0 & 2,1 & \pm & 0,2 & 19,3 & \pm & 2,2 & 11,1 & \pm & 1,3 & 143,7 & \pm & 16,7 \\
\hline
\end{tabular}


Anexo III - Valores de concentração $\left(\mathrm{mg} \mathrm{kg}^{-1}\right)$ determinados por ICP OES para as amostras de sedimentos do sistema estuarino Santos/São Vicente (Inverno/2006) e valores de LD e LQ

\begin{tabular}{|c|c|c|c|c|c|c|c|c|c|c|c|c|c|c|c|c|c|c|}
\hline Parâmetros & Unidade & L.D. & L.Q. & SI0601 & & $\begin{array}{l}\text { Desvio } \\
\text { Padrão }\end{array}$ & SI0602 & & $\begin{array}{l}\text { Desvio } \\
\text { Padrão }\end{array}$ & $\begin{array}{c}\text { SI0602 } \\
\text { A }\end{array}$ & & $\begin{array}{l}\text { Desvio } \\
\text { Padrão }\end{array}$ & SI0603 & & $\begin{array}{l}\text { Desvio } \\
\text { Padrão }\end{array}$ & SI0604 & & $\begin{array}{l}\text { Desvio } \\
\text { Padrão }\end{array}$ \\
\hline $\mathrm{Al}$ & $\left(\mathrm{mg} \mathrm{kg}^{-1}\right)$ & 0,5 & 1,0 & 50363 & \pm & 7894 & 46958 & \pm & 7360 & 60160 & \pm & 9429 & 24604 & \pm & 1230 & 31516 & \pm & 4940 \\
\hline $\mathrm{Ba}$ & $\left(\mathrm{mg} \mathrm{kg}^{-1}\right)$ & 0,2 & 1,0 & 226,4 & \pm & 19,9 & 147,6 & \pm & 13,0 & 95,6 & \pm & 8,4 & 44,8 & \pm & 2,0 & 42,0 & \pm & 3,7 \\
\hline Co & $\left(\mathrm{mg} \mathrm{kg}^{-1}\right)$ & 0,5 & 1,0 & 8,54 & \pm & 0,51 & 8,73 & \pm & 0,53 & 7,60 & \pm & 0,46 & 6,16 & \pm & 0,16 & 6,65 & \pm & 0,40 \\
\hline $\mathrm{Cu}$ & $\left(\mathrm{mg} \mathrm{kg}^{-1}\right)$ & 0,1 & 0,5 & 27,02 & \pm & 1,54 & 26,60 & \pm & 1,51 & 23,27 & \pm & 1,33 & 11,17 & \pm & 1,61 & 17,23 & \pm & 0,98 \\
\hline $\mathrm{Cr}$ & $\left(\mathrm{mg} \mathrm{kg}^{-1}\right)$ & 0,5 & 1,0 & 51,50 & \pm & 3,19 & 46,35 & \pm & 2,87 & 47,20 & \pm & 2,92 & 27,06 & \pm & 0,63 & 34,58 & \pm & 2,14 \\
\hline $\mathrm{Sr}$ & $\left(\mathrm{mg} \mathrm{kg}^{-1}\right)$ & 0,1 & 1,0 & 128,4 & \pm & 4,4 & 96,6 & \pm & 3,3 & 96,2 & \pm & 3,3 & 47,0 & \pm & 1,9 & 345,0 & \pm & 11,7 \\
\hline $\mathrm{Fe}$ & $\left(\mathrm{mg} \mathrm{kg}^{-1}\right)$ & 1,0 & 5,0 & 44686 & \pm & 2782 & 42712 & \pm & 2659 & 37799 & \pm & 2353 & 19785 & \pm & 784 & 30739 & \pm & 1913 \\
\hline $\mathrm{Li}$ & $\left(\mathrm{mg} \mathrm{kg}^{-1}\right)$ & 0,5 & 1,0 & 76,5 & \pm & 5,3 & 72,5 & \pm & 5,0 & 79,9 & \pm & 5,6 & 51,3 & \pm & 2,4 & 66,4 & \pm & 4,6 \\
\hline $\mathrm{Mn}$ & $\left(\mathrm{mg} \mathrm{kg}^{-1}\right)$ & 0,5 & 1,0 & 538 & \pm & 24 & 407 & \pm & 18 & 852 & \pm & 39 & 240 & \pm & 7 & 792 & \pm & 36 \\
\hline $\mathrm{Ni}$ & $\left(\mathrm{mg} \mathrm{kg}^{-1}\right)$ & 0,5 & 1,0 & 20,9 & \pm & 1,8 & 19,5 & \pm & 1,6 & 19,0 & \pm & 1,6 & 10,8 & \pm & 0,2 & 13,5 & \pm & 1,1 \\
\hline $\mathrm{Zn}$ & $\left(\mathrm{mg} \mathrm{kg}^{-1}\right)$ & 0,5 & 1,0 & 132,6 & \pm & 20,7 & 118,0 & \pm & 18,4 & 102,7 & \pm & 16,0 & 59,3 & \pm & 5,3 & 84,2 & \pm & 13,1 \\
\hline Parâmetros & Unidade & L.D. & L.Q. & SI0605 & & $\begin{array}{l}\text { Desvio } \\
\text { Padrão }\end{array}$ & SI0606 & & $\begin{array}{l}\text { Desvio } \\
\text { Padrão }\end{array}$ & SI0607 & & $\begin{array}{l}\text { Desvio } \\
\text { Padrão }\end{array}$ & SI0608 & & $\begin{array}{l}\text { Desvio } \\
\text { Padrão }\end{array}$ & SI0609 & & $\begin{array}{l}\text { Desvio } \\
\text { Padrão }\end{array}$ \\
\hline $\mathrm{Al}$ & $\left(\mathrm{mg} \mathrm{kg}^{-1}\right)$ & 0,5 & 1,0 & 54722 & \pm & 8577 & 24605 & \pm & 3856 & 16921 & \pm & 2652 & 8124 & \pm & 1273 & 3300 & \pm & 517 \\
\hline $\mathrm{Ba}$ & $\left(\mathrm{mg} \mathrm{kg}^{-1}\right)$ & 0,2 & 1,0 & 78,6 & \pm & 6,9 & 36,2 & \pm & 3,2 & 23,3 & \pm & 2,1 & 11,0 & \pm & 1,0 & 3,9 & \pm & 0,3 \\
\hline Co & $\left(\mathrm{mg} \mathrm{kg}^{-1}\right)$ & 0,5 & 1,0 & 7,41 & \pm & 0,45 & 4,83 & \pm & 0,29 & 3,80 & \pm & 0,23 & 2,92 & \pm & 0,18 & 1,74 & \pm & 0,10 \\
\hline $\mathrm{Cu}$ & $\left(\mathrm{mg} \mathrm{kg}^{-1}\right)$ & 0,1 & 0,5 & 20,33 & \pm & 1,2 & 8,05 & \pm & 0,46 & 1,54 & \pm & 0,09 & N.D. & \pm & - & N.D. & \pm & - \\
\hline $\mathrm{Cr}$ & $\left(\mathrm{mg} \mathrm{kg}^{-1}\right)$ & 0,5 & 1,0 & 43,96 & \pm & 2,7 & 24,12 & \pm & 1,49 & 17,49 & \pm & 1,08 & 12,02 & \pm & 0,74 & 7,62 & \pm & 0,47 \\
\hline $\mathrm{Sr}$ & $\left(\mathrm{mg} \mathrm{kg}^{-1}\right)$ & 0,1 & 1,0 & 101,3 & \pm & 3,4 & 92,6 & \pm & 3,1 & 98,2 & \pm & 3,3 & 21,4 & \pm & 0,7 & 35,3 & \pm & 1,2 \\
\hline $\mathrm{Fe}$ & $\left(\mathrm{mg} \mathrm{kg}^{-1}\right)$ & 1,0 & 5,0 & 34913 & \pm & 2173 & 20590 & \pm & 1282 & 17932 & \pm & 1116 & 11249 & \pm & 700 & 9081 & \pm & 565 \\
\hline $\mathrm{Li}$ & $\left(\mathrm{mg} \mathrm{kg}^{-1}\right)$ & 0,5 & 1,0 & 72,1 & \pm & 5,0 & 36,7 & \pm & 2,6 & 24,5 & \pm & 1,7 & 13,2 & \pm & 0,9 & 7,4 & \pm & 0,5 \\
\hline $\mathrm{Mn}$ & $\left(\mathrm{mg} \mathrm{kg}^{-1}\right)$ & 0,5 & 1,0 & 688 & \pm & 31 & 739 & \pm & 34 & 224 & \pm & 10 & 149 & \pm & 7 & 112 & \pm & 5 \\
\hline $\mathrm{Ni}$ & $\left(\mathrm{mg} \mathrm{kg}^{-1}\right)$ & 0,5 & 1,0 & 17,4 & \pm & 1,5 & 9,4 & \pm & 0,8 & 6,2 & \pm & 0,5 & 3,5 & \pm & 0,3 & 1,8 & \pm & 0,2 \\
\hline $\mathrm{Zn}$ & $\left(\mathrm{mg} \mathrm{kg}^{-1}\right)$ & 0,5 & 1,0 & 93,2 & \pm & 14,5 & 46,4 & \pm & 7,2 & 31,1 & \pm & 4,8 & 24,0 & \pm & 3,7 & 14,0 & \pm & 2,2 \\
\hline
\end{tabular}


Anexo III - Valores de concentração ( $\mathrm{mg} \mathrm{kg}^{-1}$ ) determinados por ICP OES para as amostras de sedimentos do sistema estuarino Santos/São Vicente (Inverno/2006) e valores de LD e LQ (continuação)

\begin{tabular}{|c|c|c|c|c|c|c|c|c|c|}
\hline Parâmetros & Unidade & L.D. & L.Q. & SI0610 & & $\begin{array}{l}\text { Desvio } \\
\text { Padrão }\end{array}$ & SI0611 & & $\begin{array}{l}\text { Desvio } \\
\text { Padrão }\end{array}$ \\
\hline $\mathrm{Al}$ & $\left(\mathrm{mg} \mathrm{kg}^{-1}\right)$ & 0,5 & 1,0 & 24652 & \pm & 3864 & 29875 & \pm & 4683 \\
\hline $\mathrm{Ba}$ & $\left(\mathrm{mg} \mathrm{kg}^{-1}\right)$ & 0,2 & 1,0 & 37,0 & \pm & 3,3 & 36,8 & \pm & 3,2 \\
\hline Co & $\left(\mathrm{mg} \mathrm{kg}^{-1}\right)$ & 0,5 & 1,0 & 4,01 & \pm & 0,24 & 3,92 & \pm & 0,24 \\
\hline $\mathrm{Cu}$ & $\left(\mathrm{mg} \mathrm{kg}^{-1}\right)$ & 0,1 & 0,5 & 4,88 & \pm & 0,28 & 9,49 & \pm & 0,54 \\
\hline $\mathrm{Cr}$ & $\left(\mathrm{mg} \mathrm{kg}^{-1}\right)$ & 0,5 & 1,0 & 21,00 & \pm & 1,30 & 23,12 & \pm & 1,43 \\
\hline $\mathrm{Sr}$ & $\left(\mathrm{mg} \mathrm{kg}^{-1}\right)$ & 0,1 & 1,0 & 81,0 & \pm & 2,8 & 148,8 & \pm & 5,1 \\
\hline $\mathrm{Fe}$ & $\left(\mathrm{mg} \mathrm{kg}^{-1}\right)$ & 1,0 & 5,0 & 17665 & \pm & 1100 & 19515 & \pm & 1215 \\
\hline $\mathrm{Li}$ & $\left(\mathrm{mg} \mathrm{kg}^{-1}\right)$ & 0,5 & 1,0 & 32,5 & \pm & 2,3 & 37,3 & \pm & 2,6 \\
\hline $\mathrm{Mn}$ & $\left(\mathrm{mg} \mathrm{kg}^{-1}\right)$ & 0,5 & 1,0 & 246 & \pm & 11 & 226 & \pm & 10 \\
\hline $\mathrm{Ni}$ & $\left(\mathrm{mg} \mathrm{kg}^{-1}\right)$ & 0,5 & 1,0 & 7,6 & \pm & 0,6 & 9,0 & \pm & 0,8 \\
\hline $\mathrm{Zn}$ & $\left(\mathrm{mg} \mathrm{kg}^{-1}\right)$ & 0,5 & 1,0 & 36,7 & \pm & 5,7 & 46,4 & \pm & 7,2 \\
\hline Parâmetros & Unidade & L.D. & L.Q. & SI0615 & & $\begin{array}{l}\text { Desvio } \\
\text { Padrão }\end{array}$ & SI0616 & & $\begin{array}{l}\text { Desvio } \\
\text { Padrão }\end{array}$ \\
\hline $\mathrm{Al}$ & $\left(\mathrm{mg} \mathrm{kg}^{-1}\right)$ & 0,5 & 1,0 & 5755 & \pm & 288 & 5091 & \pm & 254 \\
\hline $\mathrm{Ba}$ & $\left(\mathrm{mg} \mathrm{kg}^{-1}\right)$ & 0,2 & 1,0 & 8,3 & \pm & 0,4 & 9,3 & \pm & 0,4 \\
\hline Co & $\left(\mathrm{mg} \mathrm{kg}^{-1}\right)$ & 0,5 & 1,0 & 3,35 & \pm & 0,08 & 3,31 & \pm & 0,08 \\
\hline $\mathrm{Cu}$ & $\left(\mathrm{mg} \mathrm{kg}^{-1}\right)$ & 0,1 & 0,5 & N.D. & \pm & - & 1,85 & \pm & 0,27 \\
\hline $\mathrm{Cr}$ & $\left(\mathrm{mg} \mathrm{kg}^{-1}\right)$ & 0,5 & 1,0 & 11,55 & \pm & 0,27 & 14,27 & \pm & 0,33 \\
\hline $\mathrm{Sr}$ & $\left(\mathrm{mg} \mathrm{kg}^{-1}\right)$ & 0,1 & 1,0 & 18,2 & \pm & 0,7 & 31,2 & \pm & 1,3 \\
\hline $\mathrm{Fe}$ & $\left(\mathrm{mg} \mathrm{kg}^{-1}\right)$ & 1,0 & 5,0 & 13285 & \pm & 526 & 14263 & \pm & 565 \\
\hline $\mathrm{Li}$ & $\left(\mathrm{mg} \mathrm{kg}^{-1}\right)$ & 0,5 & 1,0 & 14,6 & \pm & 0,7 & 15,8 & \pm & 0,7 \\
\hline $\mathrm{Mn}$ & $\left(\mathrm{mg} \mathrm{kg}^{-1}\right)$ & 0,5 & 1,0 & 139 & \pm & 4 & 179 & \pm & 5 \\
\hline $\mathrm{Ni}$ & $\left(\mathrm{mg} \mathrm{kg}^{-1}\right)$ & 0,5 & 1,0 & 3,8 & \pm & 0,1 & 4,7 & \pm & 0,1 \\
\hline $\mathrm{Zn}$ & $\left(\mathrm{mg} \mathrm{kg}^{-1}\right)$ & 0,5 & 1,0 & 22,2 & \pm & 2,0 & 27,9 & \pm & 2,5 \\
\hline
\end{tabular}


Anexo IV . Valores de concentração $\left(\mathrm{mg} \mathrm{kg}^{-1}\right)$ determinados por ICP OES para as amostras de sedimentos do sistema estuarino Santos/São Vicente (Verão/2006) e valores de LD e LQ

\begin{tabular}{|c|c|c|c|c|c|c|c|c|c|c|c|c|c|c|c|c|c|c|}
\hline Parâmetros & Unidade & L.D. & L.Q. & SV0601 & & $\begin{array}{l}\text { Desvio } \\
\text { Padrão } \\
\end{array}$ & SV0602 & & $\begin{array}{l}\text { Desvio } \\
\text { Padrão } \\
\end{array}$ & $\begin{array}{c}\text { SV0602 } \\
\text { A }\end{array}$ & & $\begin{array}{l}\text { Desvio } \\
\text { Padrão } \\
\end{array}$ & SV0603 & & $\begin{array}{l}\text { Desvio } \\
\text { Padrão } \\
\end{array}$ & SV0604 & & $\begin{array}{l}\text { Desvio } \\
\text { Padrão }\end{array}$ \\
\hline $\mathrm{Al}$ & $\left(\mathrm{mg} \mathrm{kg}^{-1}\right)$ & 0,5 & 1,0 & 34832 & \pm & 1741 & 23835 & \pm & 1191 & 35150 & \pm & 1757 & 21670 & \pm & 1083 & 39237 & \pm & 1961 \\
\hline $\mathrm{Ba}$ & $\left(\mathrm{mg} \mathrm{kg}^{-1}\right)$ & 0,2 & 1,0 & 143,2 & \pm & 6,5 & 103,2 & \pm & 4,6 & 60,6 & \pm & 2,7 & 36,2 & \pm & 1,6 & 62,9 & \pm & 2,8 \\
\hline Co & $\left(\mathrm{mg} \mathrm{kg}^{-1}\right)$ & 0,5 & 1,0 & 9,04 & \pm & 0,23 & 8,22 & \pm & 0,21 & 8,61 & \pm & 0,22 & 6,27 & \pm & 0,16 & 7,98 & \pm & 0,20 \\
\hline $\mathrm{Cu}$ & $\left(\mathrm{mg} \mathrm{kg}^{-1}\right)$ & 0,1 & 0,5 & 29,38 & \pm & 4,25 & 22,55 & \pm & 3,26 & 21,60 & \pm & 3,12 & 13,35 & \pm & 1,93 & 20,46 & \pm & 2,96 \\
\hline $\mathrm{Cr}$ & $\left(\mathrm{mg} \mathrm{kg}^{-1}\right)$ & 0,5 & 1,0 & 46,23 & \pm & 1,08 & 39,20 & \pm & 0,92 & 41,71 & \pm & 0,97 & 29,49 & \pm & 0,69 & 40,32 & \pm & 0,94 \\
\hline $\mathrm{Sr}$ & $\left(\mathrm{mg} \mathrm{kg}^{-1}\right)$ & 0,1 & 1,0 & 108,8 & \pm & 4,4 & 74,5 & \pm & 3,0 & 80,3 & \pm & 3,3 & 55,0 & \pm & 2,2 & 316,6 & \pm & 12,9 \\
\hline $\mathrm{Fe}$ & $\left(\mathrm{mg} \mathrm{kg}^{-1}\right)$ & 1,0 & 5,0 & 41904 & \pm & 1660 & 33066 & \pm & 1310 & 32943 & \pm & 1305 & 22119 & \pm & 876 & 29137 & \pm & 1154 \\
\hline $\mathrm{Li}$ & $\left(\mathrm{mg} \mathrm{kg}^{-1}\right)$ & 0,5 & 1,0 & 92,7 & \pm & 4,3 & 76,8 & \pm & 3,5 & 91,2 & \pm & 4,2 & 57,2 & \pm & 2,6 & 93,9 & \pm & 4,3 \\
\hline $\mathrm{Mn}$ & $\left(\mathrm{mg} \mathrm{kg}^{-1}\right)$ & 0,5 & 1,0 & 500 & \pm & 14 & 331 & \pm & 9 & 667 & \pm & 19 & 402 & \pm & 11 & 724 & \pm & 20 \\
\hline $\mathrm{Ni}$ & $\left(\mathrm{mg} \mathrm{kg}^{-1}\right)$ & 0,5 & 1,0 & 19,5 & \pm & 0,4 & 16,4 & \pm & 0,3 & 17,0 & \pm & 0,3 & 11,2 & \pm & 0,2 & 15,3 & \pm & 0,3 \\
\hline $\mathrm{Zn}$ & $\left(\mathrm{mg} \mathrm{kg}^{-1}\right)$ & 0,5 & 1,0 & 138,5 & \pm & 12,4 & 102,4 & \pm & 9,2 & 101,9 & \pm & 9,1 & 65,7 & \pm & 5,9 & 85,2 & \pm & 7,6 \\
\hline
\end{tabular}

\begin{tabular}{|c|c|c|c|c|c|c|c|c|c|c|c|c|c|c|c|c|c|c|}
\hline Parâmetros & Unidade & L.D. & L.Q. & SV0605 & & $\begin{array}{l}\text { Desvio } \\
\text { Padrão }\end{array}$ & SV0606 & & $\begin{array}{l}\text { Desvio } \\
\text { Padrão }\end{array}$ & SV0607 & & $\begin{array}{l}\text { Desvio } \\
\text { Padrão }\end{array}$ & SV0608 & & $\begin{array}{l}\text { Desvio } \\
\text { Padrão }\end{array}$ & SV0609 & & $\begin{array}{l}\text { Desvio } \\
\text { Padrão }\end{array}$ \\
\hline $\mathrm{Al}$ & $\left(\mathrm{mg} \mathrm{kg}^{-1}\right)$ & 0,5 & 1,0 & 20164 & \pm & 1008 & 4422 & \pm & 221 & 7526 & \pm & 376 & 12303 & \pm & 615 & 4695 & \pm & 235 \\
\hline $\mathrm{Ba}$ & $\left(\mathrm{mg} \mathrm{kg}^{-1}\right)$ & 0,2 & 1,0 & 32,1 & \pm & 1,4 & 8,6 & \pm & 0,4 & 10,9 & \pm & 0,5 & 20,1 & \pm & 0,9 & 6,1 & \pm & 0,3 \\
\hline Co & $\left(\mathrm{mg} \mathrm{kg}^{-1}\right)$ & 0,5 & 1,0 & 8,27 & \pm & 0,21 & 2,51 & \pm & 0,06 & 3,58 & \pm & 0,09 & 5,39 & \pm & 0,14 & 2,85 & \pm & 0,07 \\
\hline $\mathrm{Cu}$ & $\left(\mathrm{mg} \mathrm{kg}^{-1}\right)$ & 0,1 & 0,5 & 22,51 & \pm & 3,25 & 2,96 & \pm & 0,43 & N.D. & \pm & - & 5,37 & \pm & 0,78 & N.D. & \pm & - \\
\hline $\mathrm{Cr}$ & $\left(\mathrm{mg} \mathrm{kg}^{-1}\right)$ & 0,5 & 1,0 & 31,39 & \pm & 0,73 & 9,69 & \pm & 0,23 & 13,08 & \pm & 0,31 & 21,32 & \pm & 0,50 & 10,97 & \pm & 0,26 \\
\hline $\mathrm{Sr}$ & $\left(\mathrm{mg} \mathrm{kg}^{-1}\right)$ & 0,1 & 1,0 & 87,1 & \pm & 3,5 & 51,4 & \pm & 2,1 & 132,5 & \pm & 5,4 & 56,2 & \pm & 2,3 & 15,5 & \pm & 0,6 \\
\hline $\mathrm{Fe}$ & $\left(\mathrm{mg} \mathrm{kg}^{-1}\right)$ & 1,0 & 5,0 & 21070 & \pm & 835 & 8171 & \pm & 324 & 14611 & \pm & 579 & 18229 & \pm & 722 & 13480 & \pm & 534 \\
\hline $\mathrm{Li}$ & $\left(\mathrm{mg} \mathrm{kg}^{-1}\right)$ & 0,5 & 1,0 & 75,4 & \pm & 3,5 & 16,5 & \pm & 0,8 & 23,3 & \pm & 1,1 & 38,5 & \pm & 1,8 & 12,4 & \pm & 0,6 \\
\hline $\mathrm{Mn}$ & $\left(\mathrm{mg} \mathrm{kg}^{-1}\right)$ & 0,5 & 1,0 & 488 & \pm & 14 & 206 & \pm & 6 & 252 & \pm & 7 & 399 & \pm & 11 & 205 & \pm & 6 \\
\hline $\mathrm{Ni}$ & $\left(\mathrm{mg} \mathrm{kg}^{-1}\right)$ & 0,5 & 1,0 & 10,7 & \pm & 0,2 & 3,9 & \pm & 0,1 & 4,5 & \pm & 0,1 & 8,1 & \pm & 0,2 & 3,4 & \pm & 0,1 \\
\hline $\mathrm{Zn}$ & $\left(\mathrm{mg} \mathrm{kg}^{-1}\right)$ & 0,5 & 1,0 & 68,0 & \pm & 6,1 & 27,2 & \pm & 2,4 & 33,2 & \pm & 3,0 & 45,0 & \pm & 4,0 & 19,3 & \pm & 1,7 \\
\hline
\end{tabular}


Anexo IV . Valores de concentração $\left(\mathrm{mg} \mathrm{kg}^{-1}\right)$ determinados por ICP OES para as amostras de sedimentos do sistema estuarino Santos/São Vicente (Verão/2006) e valores de LD e LQ (continuação)

\begin{tabular}{|c|c|c|c|c|c|c|c|c|c|c|c|c|c|c|c|c|c|c|}
\hline Parâmetros & Unidade & L.D. & L.Q. & SV0610 & & $\begin{array}{l}\text { Desvio } \\
\text { Padrão }\end{array}$ & SV0611 & & $\begin{array}{l}\text { Desvio } \\
\text { Padrão }\end{array}$ & SV0612 & & $\begin{array}{l}\text { Desvio } \\
\text { Padrão }\end{array}$ & $\begin{array}{c}\text { SV0612 } \\
\text { A }\end{array}$ & & $\begin{array}{l}\text { Desvio } \\
\text { Padrão }\end{array}$ & SV0613 & & $\begin{array}{l}\text { Desvio } \\
\text { Padrão }\end{array}$ \\
\hline Al & $\left(\mathrm{mg} \mathrm{kg}^{-1}\right)$ & 0,5 & 1,0 & 12729 & \pm & 636 & 14311 & \pm & 715 & 14257 & \pm & 713 & 4167 & \pm & 208 & 28017 & \pm & 1401 \\
\hline $\mathrm{Ba}$ & $\left(\mathrm{mg} \mathrm{kg}^{-1}\right)$ & 0,2 & 1,0 & 19,9 & \pm & 0,9 & 23,3 & \pm & 1,1 & 20,8 & \pm & 0,9 & 6,5 & \pm & 0,3 & 42,7 & \pm & 1,9 \\
\hline Co & $\left(\mathrm{mg} \mathrm{kg}^{-1}\right)$ & 0,5 & 1,0 & 4,53 & \pm & 0,11 & 3,46 & \pm & 0,09 & 3,78 & \pm & 0,10 & 1,37 & \pm & 0,03 & 6,81 & \pm & 0,17 \\
\hline $\mathrm{Cu}$ & $\left(\mathrm{mg} \mathrm{kg}^{-1}\right)$ & 0,1 & 0,5 & 4,19 & \pm & 0,61 & 3,71 & \pm & 0,54 & 4,55 & \pm & 0,66 & N.D. & \pm & - & 18,02 & \pm & 2,60 \\
\hline $\mathrm{Cr}$ & $\left(\mathrm{mg} \mathrm{kg}^{-1}\right)$ & 0,5 & 1,0 & 17,89 & \pm & 0,42 & 15,99 & \pm & 0,37 & 16,93 & \pm & 0,40 & 5,25 & \pm & 0,12 & 34,23 & \pm & 0,80 \\
\hline $\mathrm{Sr}$ & $\left(\mathrm{mg} \mathrm{kg}^{-1}\right)$ & 0,1 & 1,0 & 81,0 & \pm & 3,3 & 590,8 & \pm & 24,1 & 48,2 & \pm & 2,0 & 8,1 & \pm & 0,3 & 138,4 & \pm & 5,6 \\
\hline $\mathrm{Fe}$ & $\left(\mathrm{mg} \mathrm{kg}^{-1}\right)$ & 1,0 & 5,0 & 14492 & \pm & 574 & 11586 & \pm & 459 & 12660 & \pm & 501 & 3089 & \pm & 122 & 26551 & \pm & 1052 \\
\hline $\mathrm{Li}$ & $\left(\mathrm{mg} \mathrm{kg}^{-1}\right)$ & 0,5 & 1,0 & 34,7 & \pm & 1,6 & 34,5 & \pm & 1,6 & 33,4 & \pm & 1,5 & 9,1 & \pm & 0,4 & 82,6 & \pm & 3,8 \\
\hline $\mathrm{Mn}$ & $\left(\mathrm{mg} \mathrm{kg}^{-1}\right)$ & 0,5 & 1,0 & 230 & \pm & 6 & 117 & \pm & 3 & 164 & \pm & 5 & 32 & \pm & 1 & 222 & \pm & 6 \\
\hline $\mathrm{Ni}$ & $\left(\mathrm{mg} \mathrm{kg}^{-1}\right)$ & 0,5 & 1,0 & 6,8 & \pm & 0,1 & 6,1 & \pm & 0,1 & 7,1 & \pm & 0,1 & 2,26 & \pm & 0,05 & 14,1 & \pm & 0,3 \\
\hline $\mathrm{Zn}$ & $\left(\mathrm{mg} \mathrm{kg}^{-1}\right)$ & 0,5 & 1,0 & 35,9 & \pm & 3,2 & 28,6 & \pm & 2,6 & 33,7 & \pm & 3,0 & 11,2 & \pm & 1,0 & 92,7 & \pm & 8,3 \\
\hline
\end{tabular}

\begin{tabular}{|c|c|c|c|c|c|c|c|c|c|c|c|c|}
\hline Parâmetros & Unidade & L.D. & L.Q. & SV0614 & & $\begin{array}{l}\text { Desvio } \\
\text { Padrão }\end{array}$ & SV0615 & & $\begin{array}{l}\text { Desvio } \\
\text { Padrão }\end{array}$ & SV0616 & & $\begin{array}{l}\text { Desvio } \\
\text { Padrão }\end{array}$ \\
\hline $\mathrm{Al}$ & $\left(\mathrm{mg} \mathrm{kg}^{-1}\right)$ & 0,5 & 1,0 & 42632 & \pm & 2131 & 3357 & \pm & 168 & 9871 & \pm & 493 \\
\hline $\mathrm{Ba}$ & $\left(\mathrm{mg} \mathrm{kg}^{-1}\right)$ & 0,2 & 1,0 & 75,2 & \pm & 3,4 & 3,5 & \pm & 0,2 & 14,3 & \pm & 0,6 \\
\hline Co & $\left(\mathrm{mg} \mathrm{kg}^{-1}\right)$ & 0,5 & 1,0 & 8,49 & \pm & 0,21 & 2,64 & \pm & 0,07 & 4,68 & \pm & 0,12 \\
\hline $\mathrm{Cu}$ & $\left(\mathrm{mg} \mathrm{kg}^{-1}\right)$ & 0,1 & 0,5 & 28,50 & \pm & 4,12 & N.D. & \pm & - & 2,72 & \pm & 0,39 \\
\hline $\mathrm{Cr}$ & $\left(\mathrm{mg} \mathrm{kg}^{-1}\right)$ & 0,5 & 1,0 & 47,72 & \pm & 1,11 & 9,22 & \pm & 0,22 & 18,59 & \pm & 0,43 \\
\hline $\mathrm{Sr}$ & $\left(m g k g^{-1}\right)$ & 0,1 & 1,0 & 82,1 & \pm & 3,3 & 10,0 & \pm & 0,4 & 48,5 & \pm & 2,0 \\
\hline $\mathrm{Fe}$ & $\left(\mathrm{mg} \mathrm{kg}^{-1}\right)$ & 1,0 & 5,0 & 37451 & \pm & 1483 & 10718 & \pm & 425 & 16878 & \pm & 669 \\
\hline $\mathrm{Li}$ & $\left(\mathrm{mg} \mathrm{kg}^{-1}\right)$ & 0,5 & 1,0 & 103,0 & \pm & 4,8 & 10,0 & \pm & 0,5 & 31,9 & \pm & 1,5 \\
\hline $\mathrm{Mn}$ & $\left(\mathrm{mg} \mathrm{kg}^{-1}\right)$ & 0,5 & 1,0 & 315 & \pm & 9 & 133 & \pm & 4 & 554 & \pm & 15 \\
\hline $\mathrm{Ni}$ & $\left(\mathrm{mg} \mathrm{kg}^{-1}\right)$ & 0,5 & 1,0 & 19,3 & \pm & 0,4 & 2,7 & \pm & 0,1 & 6,8 & \pm & 0,1 \\
\hline $\mathrm{Zn}$ & $\left(\mathrm{mg} \mathrm{kg}^{-1}\right)$ & 0,5 & 1,0 & 128,9 & \pm & 11,5 & 18,3 & \pm & 1,6 & 40,6 & \pm & 3,6 \\
\hline
\end{tabular}


Anexo V - Resultados de Cd, Pb e Hg em Sedimentos coletados em Santos - Inverno e Verão de 2005

\begin{tabular}{|c|c|c|c|c|c|c|c|c|c|c|c|c|c|}
\hline Amostras & $\begin{array}{c}\mathrm{Pb} \\
\left(\mathrm{mg} \mathrm{kg}^{-1}\right)\end{array}$ & $\begin{array}{l}\text { Desvio } \\
\text { Padrão }\end{array}$ & $\begin{array}{c}\text { Cd } \\
\left(\mathrm{mg} \mathrm{kg}^{-1}\right)\end{array}$ & $\begin{array}{l}\text { Desvio } \\
\text { Padrão }\end{array}$ & $\begin{array}{c}\mathrm{Hg} \\
\text { (ng g-1) }\end{array}$ & $\begin{array}{l}\text { Desvio } \\
\text { Padrão }\end{array}$ & Amostras & $\begin{array}{c}\mathrm{Pb} \\
\left(\mathrm{mg} \mathrm{kg}^{-1}\right)\end{array}$ & $\begin{array}{l}\text { Desvio } \\
\text { Padrão }\end{array}$ & $\begin{array}{c}\text { Cd } \\
\left(\mathrm{mg} \mathrm{kg}^{-1}\right)\end{array}$ & $\begin{array}{l}\text { Desvio } \\
\text { Padrão }\end{array}$ & $\begin{array}{c}\mathrm{Hg} \\
\left(\mathrm{ng} \mathrm{g}^{-1}\right)\end{array}$ & $\begin{array}{l}\text { Desvio } \\
\text { Padrão }\end{array}$ \\
\hline SV0501 & 11,2 & 0,8 & 0,1731 & 0,0022 & 500,7 & 1,6 & SI0501 & 24,0 & 1,8 & 0,3460 & 0,0045 & 468,8 & 11,97 \\
\hline SV0502 & 14,6 & 1,1 & 0,1698 & 0,0022 & 681,5 & 2,1 & SI0502 & 17,9 & 1,6 & 0,2137 & 0,0028 & 848 & 2 \\
\hline SV0503 & 8,7 & 0,6 & 0,1012 & 0,0013 & 441,3 & 1 & SI0503 & 16,0 & 1,5 & 0,0732 & 0,0009 & 412,5 & 4,4 \\
\hline SV0504 & 47,0 & 3,5 & 0,0970 & 0,0013 & 366,8 & 8,3 & SI0504 & 28,3 & 2,6 & 0,0753 & 0,0010 & 538,9 & 0,9 \\
\hline SV0505 & 14,6 & 1,1 & 0,1142 & 0,0015 & 210,2 & 0,4 & SI0505 & 15,1 & 1,4 & 0,0628 & 0,0032 & 189,2 & 4,6 \\
\hline SV0506 & 3,3 & 0,2 & 0,0266 & 0,0003 & 48,4 & 0,2 & SI0506 & 11,0 & 1,0 & 0,0177 & 0,0009 & 69,5 & 1,6 \\
\hline SV0507 & 6,4 & 0,5 & 0,0159 & 0,0002 & 38,3 & 0,2 & SI0507 & 3,4 & 0,3 & N.D. & - & N.D. & - \\
\hline SV0508 & 10,7 & 0,8 & 0,0305 & 0,0004 & 57,7 & 1 & SI0508 & 10,4 & 0,9 & 0,0207 & 0,0010 & 110,1 & 0,7 \\
\hline SV0509 & 2,0 & 0,1 & N.D. & - & 10,7 & 0,9 & SI0509 & 4,5 & 0,4 & N.D. & - & 12,8 & 2,9 \\
\hline SV0510 & 8,0 & 0,7 & 0,0123 & 0,0006 & 55 & 1,1 & SI0510 & 9,6 & 0,9 & N.D. & - & 53,97 & 1,2 \\
\hline SV0511 & 0,3 & 0,0 & N.D. & - & N.D. & - & SI0511 & 1,5 & 0,1 & N.D. & - & N.D. & - \\
\hline SV0512 & 2,0 & 0,2 & 0,0300 & 0,0004 & 51,9 & 1 & SI0512 & 4,6 & 0,4 & 0,0160 & 0,0008 & 34,3 & 1 \\
\hline SV0513 & 3,2 & 0,2 & 0,0192 & 0,0002 & 44,3 & 0,5 & SI0513 & 3,6 & 0,3 & 0,0117 & 0,0006 & 45,7 & 1,7 \\
\hline \multirow[t]{3}{*}{ SV0514 } & 11,4 & 0,8 & 0,2447 & 0,0032 & 804,4 & 0,5 & SI0514 & 28,8 & 2,6 & 0,2676 & 0,0135 & 950,8 & 11 \\
\hline & & & & & & & SI0515 & 15,2 & 1,4 & 0,0160 & 0,0008 & 42,1 & 1,1 \\
\hline & & & & & & & SI0516 & 4,9 & 0,5 & N.D. & - & N.D. & - \\
\hline
\end{tabular}

N.D. - Não Detectado (menor que o Limite de Quantificação) 
Anexo VI - Resultados de Cd, Pb e Hg em Sedimentos coletados em Santos - Inverno e Verão de 2006

\begin{tabular}{|c|c|c|c|c|c|c|c|c|c|c|c|c|c|}
\hline Amostras & $\begin{array}{c}\mathrm{Pb} \\
\left(\mathrm{mg} \mathrm{kg}^{-1}\right)\end{array}$ & $\begin{array}{l}\text { Desvio } \\
\text { Padrão }\end{array}$ & $\begin{array}{c}\mathrm{Cd} \\
\left(\mathrm{mg} \mathrm{kg}^{-1}\right)\end{array}$ & $\begin{array}{l}\text { Desvio } \\
\text { Padrão }\end{array}$ & $\begin{array}{c}\mathrm{Hg}_{(\mathbf{g ~ g}} \\
(\mathbf{n g})\end{array}$ & $\begin{array}{l}\text { Desvio } \\
\text { Padrão }\end{array}$ & Amostras & $\begin{array}{c}\mathrm{Pb} \\
\left(\mathrm{mg} \mathrm{kg}^{-1}\right)\end{array}$ & $\begin{array}{l}\text { Desvio } \\
\text { Padrão }\end{array}$ & $\begin{array}{c}\mathrm{Cd} \\
\left(\mathrm{mg} \mathrm{kg}^{-1}\right)\end{array}$ & $\begin{array}{l}\text { Desvio } \\
\text { Padrão }\end{array}$ & $\begin{array}{c}\mathrm{Hg}_{(\mathbf{g ~ g}} \\
(\mathbf{n g})\end{array}$ & $\begin{array}{l}\text { Desvio } \\
\text { Padrão }\end{array}$ \\
\hline SV0602 & 21,0 & 2,6 & 0,2187 & 0,0167 & 472 & 3 & SI0602 & 16,9 & 1,5 & 0,2132 & 0,0108 & 825 & 2,5 \\
\hline SV0602 A & 24,4 & 3,1 & 0,1706 & 0,0130 & 396 & 8 & SI0602 A & 17,9 & 1,6 & 0,1316 & 0,0067 & 455 & 43 \\
\hline SV0604 & 31,4 & 3,9 & 0,1022 & 0,0078 & 230,3 & 1,1 & SI0604 & 16,5 & 1,5 & 0,0865 & 0,0044 & 510,5 & 1,9 \\
\hline SV0605 & 17,7 & 2,2 & 0,0789 & 0,0060 & 166,8 & 0,7 & SI0605 & 17,5 & 1,6 & 0,0949 & 0,0048 & 342 & 4 \\
\hline SV0606 & 8,5 & 1,1 & 0,0294 & 0,0022 & 60,1 & 0,3 & SI0606 & 12,9 & 1,2 & 0,0407 & 0,0021 & 75,9 & 6,5 \\
\hline SV0609 & 2,5 & 0,3 & N.D. & - & N.D. & - & SI0609 & 4,1 & 0,4 & N.D. & - & 22,4 & 2,6 \\
\hline SV0610 & 8,5 & 1,1 & 0,0299 & 0,0023 & 130,2 & 0,7 & SI0610 & 10,3 & 0,9 & 0,0219 & 0,0011 & 152 & 3 \\
\hline SV0611 & 3,7 & 0,5 & 0,0670 & 0,0051 & 47,6 & 0,2 & SI0611 & 8,4 & 0,8 & 0,0704 & 0,0036 & 159,3 & 0,2 \\
\hline SV0612 & 6,6 & 0,8 & 0,0639 & 0,0049 & 68 & 0,1 & SI0612 & 10,7 & 1,0 & 0,0641 & 0,0032 & 199 & 18 \\
\hline SV0612 A & 1,4 & 0,2 & 0,0200 & 0,0015 & 23,8 & 0,1 & SI0613 & 23,8 & 3,0 & 0,2042 & 0,0156 & 410 & 4 \\
\hline SV0613 & 19,4 & 2,4 & 0,2102 & 0,0161 & 310 & 4 & SI0614 & 28,2 & 3,5 & 0,2914 & 0,0223 & 881 & 3 \\
\hline
\end{tabular}


Anexo VII: Resultados obtidos por NAA, Santos, Inverno de 2005. Resultados expressos mg kg-1 e com Desvio Padrão (D.P.)

\begin{tabular}{c|c|c|c|c|c|c|c|c|c|c|c|c|c|c|c|c|c|c}
\hline Amostra & As & D.P. & Ba & D.P. & Br & D.P. & Ca & D.P. & Ce & D.P. & Co & D.P. & Cr & D.P. & Cs & D.P. & Eu & D.P. \\
\hline SI0501 & 10,8 & 0,4 & 635 & 39 & 139,4 & 4,6 & 1,42 & 0,04 & 235 & 1,5 & 11,88 & 0,07 & 80,4 & 0,7 & 6,8 & 0,37 & 3,39 & 0,02 \\
\hline SI0502 & 7,8 & 0,4 & 573 & 38 & 106,5 & 3,6 & 1,32 & 0,05 & 199 & 1,3 & 12,81 & 0,07 & 80,1 & 0,7 & 7,4 & 0,13 & 2,88 & 0,02 \\
\hline SI0503 & 7,7 & 0,2 & 432 & 202 & 91,6 & 1,7 & 1,26 & 0,04 & 52 & 0,6 & 3,32 & 0,03 & 45,4 & 0,5 & 3,8 & 0,09 & 0,82 & 0,01 \\
\hline SI0504 & 13,1 & 0,3 & 413 & 30 & 146,4 & 2,7 & 2,09 & 0,06 & 74 & 0,8 & 10,14 & 0,06 & 60,3 & 0,7 & 6,1 & 0,12 & 1,22 & 0,01 \\
\hline SI0505 & 11,0 & 0,3 & 771 & 90 & 113,4 & 1,7 & 1,45 & 0,05 & 76 & 0,6 & 9,40 & 0,06 & 58,6 & 0,9 & 5,6 & 0,12 & 1,11 & 0,01 \\
\hline SI0506 & 5,9 & 0,1 & 396 & 28 & 61,5 & 0,9 & 0,91 & 0,02 & 36 & 0,4 & 5,01 & 0,03 & 29,2 & 0,4 & 2,4 & 0,14 & 0,54 & 0,01 \\
\hline SI0507 & 6,0 & 0,1 & 492 & 34 & 24,5 & 0,3 & 0,72 & 0,05 & 33 & 0,4 & 4,27 & 0,03 & 18,8 & 0,4 & 1,5 & 0,04 & 0,62 & 0,01 \\
\hline SI0508 & 7,0 & 0,2 & 450 & 35 & 61,3 & 0,7 & 1,39 & 0,03 & 42 & 0,4 & 5,85 & 0,04 & 31,7 & 0,5 & 2,5 & 0,05 & 0,76 & 0,01 \\
\hline SI0509 & 7,6 & 0,2 & 541 & 135 & 17,5 & 0,2 & 0,49 & 0,03 & 25 & 0,4 & 3,33 & 0,02 & 14,8 & 0,3 & 1,3 & 0,07 & 0,456 & 0,004 \\
\hline SI0510 & 3,4 & 0,1 & 170 & 83 & 48,8 & 1,0 & 1,52 & 0,07 & 25 & 0,4 & 3,36 & 0,02 & 14,3 & 0,3 & 1,7 & 0,03 & 0,417 & 0,003 \\
\hline SI0511 & N.D. & - & N.D. & - & 10,6 & 0,1 & 0,19 & 0,01 & 21 & 0,5 & 0,80 & 0,01 & 8,7 & 0,2 & 0,4 & 0,02 & 0,103 & 0,002 \\
\hline SI0512 & 5,2 & 0,1 & N.D. & - & 36,2 & 0,5 & 6,09 & 0,10 & 30 & 0,3 & 2,63 & 0,02 & 19,3 & 0,4 & 1,9 & 0,17 & 0,468 & 0,004 \\
\hline SI0513 & 1,4 & 0,1 & N.D. & - & 22,7 & 0,3 & 0,58 & 0,01 & 23 & 0,2 & 1,45 & 0,01 & 18,8 & 0,3 & 0,6 & 0,03 & 0,147 & 0,003 \\
\hline SI0514 & 11,3 & 0,3 & N.D. & - & 116,4 & 2,2 & 1,31 & 0,04 & 108 & 0,9 & 10,12 & 0,06 & 76,3 & 1,3 & 6,0 & 0,99 & 1,66 & 0,01 \\
\hline SI0515 & 12,5 & 0,2 & N.D. & - & 132,5 & 1,7 & 1,27 & 0,04 & 58 & 0,60 & 8,44 & 0,03 & 47,3 & 0,7 & 3,9 & 0,12 & 0,97 & 0,01 \\
\hline SI0516 & 6,1 & 0,1 & N.D. & - & 24,2 & 0,33 & 0,57 & 0,02 & 29 & 0,31 & 3,85 & 0,02 & 15,7 & 0,3 & 1,7 & 0,05 & 0,541 & 0,004 \\
\hline
\end{tabular}


Anexo VII: Resultados obtidos por NAA, Santos, Inverno de 2005. Resultados expressos $\mathrm{mg} \mathrm{kg}^{-1} \mathrm{e}$ com Desvio Padrão (D.P.) (continuação)

\begin{tabular}{c|c|c|c|c|c|c|c|c|c|c|c|c|c|c|c|c|c|c}
\hline Amostra & $\mathbf{F e}(\%)$ & D.P. & Hf & D.P. & La & D.P. & Lu & D.P. & Na & D.P. & Nd & D.P. & Rb & D.P. & Sb & D.P. & Sc & D.P. \\
\hline SI0501 & 6,14 & 0,04 & 5,23 & 0,09 & 96,2 & 0,4 & 0,38 & 0,02 & 19227 & 156 & 94,1 & 3,8 & 109 & 4 & 0,91 & 0,04 & 13,08 & 0,02 \\
\hline SI0502 & 5,34 & 0,04 & 6,62 & 0,12 & 87,0 & 0,4 & 0,56 & 0,03 & 16314 & 135 & 73,9 & 5,1 & 148 & 5 & 0,89 & 0,05 & 14,22 & 0,02 \\
\hline SI0503 & 2,55 & 0,02 & 4,20 & 0,07 & 27,0 & 0,1 & 0,29 & 0,01 & 12499 & 51 & 29,3 & 1,4 & 67 & 4 & 0,57 & 0,04 & 7,43 & 0,01 \\
\hline SI0504 & 3,87 & 0,02 & 4,12 & 0,07 & 37,7 & 0,1 & 0,37 & 0,02 & 18361 & 73 & 36,2 & 3,7 & 84 & 3 & 0,86 & 0,08 & 11,71 & 0,02 \\
\hline SI0505 & 3,42 & 0,02 & 3,93 & 0,07 & 31,9 & 0,1 & 0,33 & 0,07 & 15035 & 60 & 22,0 & 2,5 & 77 & 3 & 0,69 & 0,05 & 10,10 & 0,02 \\
\hline SI0506 & 1,71 & 0,01 & 2,65 & 0,05 & 15,9 & 0,1 & 0,31 & 0,05 & 9307 & 34 & 14,3 & 0,7 & 53 & 3 & N.D. & - & 4,85 & 0,01 \\
\hline SI0507 & 1,56 & 0,01 & 2,74 & 0,05 & 13,88 & 0,05 & 0,23 & 0,05 & 10232 & 37 & 15,3 & 0,6 & 62 & 4 & 0,29 & 0,01 & 2,98 & 0,01 \\
\hline SI0508 & 2,10 & 0,01 & 3,61 & 0,07 & 18,1 & 0,1 & N.D. & - & 14647 & 53 & 19,2 & 1,0 & 77 & 4 & 0,50 & 0,02 & 5,31 & 0,01 \\
\hline SI0509 & 1,52 & 0,01 & 1,31 & 0,03 & 9,37 & 0,04 & N.D. & - & 8095 & 31 & 7,7 & 0,6 & 102 & 16 & 0,35 & 0,02 & 2,28 & 0,00 \\
\hline SI0510 & 1,17 & 0,003 & 2,50 & 0,04 & 10,71 & 0,04 & N.D. & - & 8851 & 34 & 8,7 & 0,5 & 38 & 6 & 0,34 & 0,02 & 2,87 & 0,01 \\
\hline SI0511 & 0,21 & 0,001 & 4,30 & 0,07 & 7,10 & 0,03 & N.D. & - & 2016 & 14 & 8,0 & 0,6 & 16 & 4 & 0,13 & 0,01 & 0,915 & 0,004 \\
\hline SI0512 & 1,07 & 0,01 & 2,32 & 0,04 & 13,3 & 0,1 & N.D. & - & 4985 & 23 & 10,6 & 0,8 & 34 & 3 & 0,29 & 0,03 & 3,38 & 0,01 \\
\hline SI0513 & 0,436 & 0,003 & 6,56 & 0,11 & 10,66 & 0,04 & N.D. & - & 2128 & 9 & 13,6 & 0,5 & 11 & 2 & 0,18 & 0,02 & 1,434 & 0,004 \\
\hline SI0514 & 4,55 & 0,02 & 3,61 & 0,07 & 50,2 & 0,2 & N.D. & - & 23032 & 84 & 58,6 & 3,1 & 79 & 6 & 0,97 & 0,10 & 13,47 & 0,02 \\
\hline SI0515 & 2,90 & 0,01 & 2,84 & 0,05 & 24,95 & 0,07 & N.D. & - & 19212 & 54 & 46,6 & 2,0 & 80 & 12 & N.D. & - & 8,24 & 0,01 \\
\hline SI0516 & 1,54 & 0,01 & 2,19 & 0,04 & 11,4 & 0,03 & N.D. & - & 9475 & 27 & 10,8 & 0,8 & 87 & 8 & N.D. & - & 2,630 & 0,005 \\
\hline
\end{tabular}


Anexo VII: Resultados obtidos por NAA, Santos, Inverno de 2005. Resultados expressos $\mathrm{mg} \mathrm{kg}^{-1}$ e com Desvio Padrão (D.P.) (continuação)

\begin{tabular}{|c|c|c|c|c|c|c|c|c|c|c|c|c|c|c|c|c|}
\hline Amostra & $\mathrm{Se}$ & D.P. & $\mathrm{Sm}$ & D.P. & $\mathrm{Ta}$ & D.P. & $\mathrm{Tb}$ & D.P. & Th & D.P. & $\mathbf{U}$ & D.P. & $\mathbf{Y b}$ & D.P. & $\mathrm{Zn}$ & D.P. \\
\hline SI0501 & 3,83 & 0,58 & 8,37 & 0,03 & 2,61 & 0,25 & 1,12 & 0,07 & 19,07 & 0,13 & 6,86 & 0,36 & 2,28 & 0,05 & 194 & 3 \\
\hline SI0502 & 2,33 & 0,59 & 8,48 & 0,03 & 2,14 & 0,21 & 1,08 & 0,01 & 18,57 & 0,13 & 5,69 & 0,33 & 2,89 & 0,07 & 180 & 3 \\
\hline SI0503 & N.D. & - & 3,96 & 0,01 & 2,50 & 0,35 & N.D. & - & 8,40 & 0,07 & 2,41 & 0,11 & 1,36 & 0,03 & 88 & 3 \\
\hline SI0505 & I.D. & - & 4,89 & 0,01 & 0,45 & 0,10 & 0,520 & 0,003 & 9,90 & 0,09 & 2,53 & 0,12 & 1,81 & 0,05 & 117 & 2 \\
\hline SI0506 & N.D. & - & 1,685 & 0,004 & 0,58 & 0,06 & 0,207 & 0,001 & 4,69 & 0,05 & 1,38 & 0,05 & 0,92 & 0,02 & 47 & 2 \\
\hline SI0507 & N.D. & - & 2,370 & 0,008 & 0,29 & 0,03 & 0,163 & 01 & 6,48 & 0,08 & 0,80 & 0,06 & 0,84 & 0,02 & 30 & 1 \\
\hline SI0510 & N.D. & - & 1,790 & 0,004 & 0,26 & 0,02 & 0,192 & 0,006 & 3,18 & 0,05 & 1,05 & 0,08 & 0,58 & 0,03 & 34 & 1 \\
\hline SI0511 & N.D. & - & 1,533 & 0,004 & 0,23 & 0,03 & 0,200 & 0,024 & 9,65 & 0,11 & 2,12 & 0,11 & 0,36 & 0,02 & 6,7 & 0,3 \\
\hline SI0512 & N.D. & - & 2,213 & 0,005 & 4,44 & 0,74 & 0,129 & 0,005 & 3,63 & 0,04 & 1,57 & 0,06 & 0,74 & 0,03 & 25 & 1 \\
\hline SI0513 & 0,44 & 0,08 & 1,553 & 0,004 & 0,23 & 0,03 & 0,122 & 0,010 & 3,72 & 0,04 & 1,26 & 0,05 & 0,45 & 0,02 & 10,7 & 0,4 \\
\hline SI0514 & 0,94 & 0,18 & 7,850 & 0,013 & 1,41 & 0,10 & 0,441 & 0,004 & 14,76 & 0,14 & 4,86 & 0,19 & 2,15 & 0,06 & 194 & 3 \\
\hline
\end{tabular}


Anexo VIII: Resultados obtidos por NAA, Santos, Verão de 2005. Resultados expressos mg kg ${ }^{-1}$ e com Desvio Padrão (D.P.)

\begin{tabular}{|c|c|c|c|c|c|c|c|c|c|c|c|c|c|c|c|c|c|c|}
\hline Amostra & As & D.P. & $\mathrm{Ba}$ & D.P. & $\mathrm{Br}$ & D.P. & $\mathrm{Ca}$ & D.P. & $\mathrm{Ce}$ & D.P. & Co & D.P. & $\mathrm{Cr}$ & D.P. & Cs & D.P. & Eu & D.P. \\
\hline SV0501 & 6,7 & 1,0 & 524 & 58 & 60,9 & 2,7 & 1,71 & 0,04 & 166,6 & 4,7 & 11,7 & 0,2 & 64,4 & 1,3 & 5,3 & 0,3 & 2,30 & 0,08 \\
\hline SV0503 & 9,1 & 0,3 & 73 & 43 & 59,8 & 1,9 & 1,2 & 0,03 & 93,6 & 2,7 & 8,5 & 0,2 & 3,0 & 1,9 & 4,7 &, 2 & 32 &, 05 \\
\hline SV0505 & 13,7 & 0,6 & 326 & 21 & 93 & 3 & 1,94 & 0,11 & 74,7 & 2,0 & 9,5 & 0,2 & 89,4 & 1,8 & 5,1 & 0,3 & 11 &, 03 \\
\hline SV & 3,8 & 0,2 & 283 & 18 & 53 & 2 & 77 & 0,02 &, 9 & 0,7 & 1 & 0,1 & 19,4 & 0,4 & 1,5 & 1 & 41 &, 02 \\
\hline SV0507 & 8,3 & 0,4 & 443 & 28 & 56 & 2 & 3,41 & 0,09 & 48,9 & 1,3 & 6,5 & 0,1 & 34,9 & 0,7 & 3,0 & 0,2 & 0,93 & 0,03 \\
\hline SV0510 & 7,4 & 0,3 & 338 & 23 & 59 & 2 & 2,05 & 0,05 & 40,0 & 1,7 & 5,7 & 0,1 & 39,2 & 0,8 & 2,7 & 0,1 & 80 & 0,03 \\
\hline SV0511 & 0,43 & 0,05 & 79 & 5 & 12,2 & 0,4 & 0,25 & 0,01 & 6,7 & 0,3 & 0,5 & 0,0 & 4,7 & 0,2 & 0,19 & 0,01 & 0,102 & 0,004 \\
\hline SV0512 & 5,4 & 0,2 & 218 & 15 & 32 & 1 & 2,19 & 0,05 & 26,2 & 1,1 & 3,4 & 0,1 & 24,1 & 0,5 & 1,8 & 0,1 & 0,46 & 0,02 \\
\hline SV0513 & 3,0 & 0,1 & 142 & 10 & 23 & 1 & 2,55 & 0,05 & 25,1 & 1,1 & 2,2 & 0,0 & 23,2 & 0,5 & 1,0 & 0,1 & 0,35 & 0,01 \\
\hline SV0514 & 11,4 & 0,5 & 447 & 28 & 134 & 5 & 1,16 & 0,04 & 103,5 & 0,7 & 10,3 & 0,1 & 74,2 & 0,6 & 6,1 & 0,1 & 1,48 & 0,01 \\
\hline
\end{tabular}




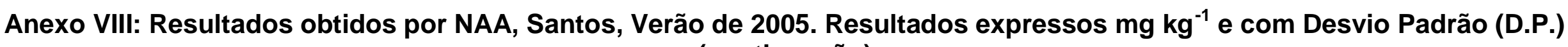
(continuação)

\begin{tabular}{|c|c|c|c|c|c|c|c|c|c|c|c|c|c|c|c|c|c|c|}
\hline Amostra & $\mathrm{Fe}(\%)$ & D.P. & $\mathrm{Hf}$ & D.P. & La & D.P. & Lu & D.P. & $\mathrm{Na}$ & D.P. & Nd & D.P. & $\mathbf{R b}$ & D.P. & $\mathrm{Sb}$ & D.P. & Sc & D.P. \\
\hline SV0501 & 4,76 & 0,03 & 7,5 & 0,2 & 74,1 & 0,3 & 0,27 & 0,02 & 10565 & 109 & 53 & 6 & 149 & 15 & 0,73 & 0,04 & 11,3 & 0,2 \\
\hline SV0503 & 18 & 0,02 & 5,7 & 0,1 & 42,1 & 0,2 & 0,31 & 0,02 & 13805 & 138 & 50 & 5 & 82 & 4 & 0,70 &, 03 & 9,3 & 0,2 \\
\hline SV0505 & 33 & 0,02 & 3,28 &, 07 & 32,3 & 0,3 & 0,23 & 0,01 & 17124 & 262 & 26 & 3 & 77 & 3 & 26 &, 03 & 0,2 & 0,2 \\
\hline SV0506 & 1,05 & 0,01 & 1,70 & 0,03 & 10,5 & 0,1 & 0,08 & 0,00 & 10600 & 163 & 9 & 0 & 37 & 2 & 0,21 & 0,02 & 2,93 & 0,05 \\
\hline SV0507 & 2,32 & 0,01 & 4,21 & 0,09 & 20,6 & 0,2 & 0,19 & 0,01 & 14210 & 218 & 19 & 2 & 71 & 3 & 0,37 & 0,03 & 6,0 & 0,1 \\
\hline SV0510 & 1,92 & 0,01 & 3,67 & 0,08 & 16,8 & 0,1 & 0,14 & 0,01 & 11361 & 137 & 17 & 3 & 53 & 4 & 0,33 & 0,02 & 5,6 & 0,1 \\
\hline SV0511 & 0,14 & 0,01 & 3,60 & 0,09 & 3,12 & 0,02 & 0,052 & 0,003 & 2351 & 29 & 5 & 1 & 5 & 0 & 0,081 & 0,005 & 0,62 & 0,01 \\
\hline SV0512 & 1,38 & 0,01 & 4,08 & 0,09 & 11,3 & 0,1 & 0,11 & 0,01 & 5678 & 68 & 12 & 2 & 30 & 2 & 0,35 & 0,02 & 3,6 & 0,1 \\
\hline SV0513 & 0,734 & 0,004 & 5,99 & 0,12 & 10,8 & 0,1 & 0,11 & 0,01 & 4040 & 49 & 12 & 2 & 17 & 1 & 0,24 & 0,01 & 2,3 & 0,1 \\
\hline SV0514 & 4,61 & 0,03 & N.D. & 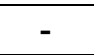 & 44,8 & 0,2 & 0,36 & 0,01 & 17466 & 144 & 43 & 2 & 82 & 3 & 0,92 & 0,04 & 12,84 & 0,02 \\
\hline
\end{tabular}


Anexo VIII: Resultados obtidos por NAA, Santos, Verão de 2005. Resultados expressos mg kg-1 e com Desvio Padrão (D.P.) (continuação)

\begin{tabular}{|c|c|c|c|c|c|c|c|c|c|c|c|c|c|c|c|c|}
\hline Amostra & Se & D.P. & Sm & D.P. & $\mathrm{Ta}$ & D.P. & $\mathrm{Tb}$ & D.P. & Th & D.P. & $\mathbf{U}$ & D.P. & $\mathbf{Y b}$ & D.P. & $\mathrm{Zn}$ & D.P. \\
\hline SV0501 & N.D. & - & 12,0 & 0,3 & 2,1 & 0,2 & 1,2 & 0,2 & 16,0 & 0,6 & 6,2 & 0,5 & 2,4 & 0,1 & 147 & 4 \\
\hline SV0503 & 0,8 & 0,1 & 7,1 & 0,1 & 0,9 & 0,1 & 0,6 & 0,1 & 11,2 & 0,4 & 3,8 & 0,3 & 1,8 & 0,1 & 120 & 3 \\
\hline SV0505 & 1,3 & 0,1 & 5,4 & 0,1 & 0,91 & 0,08 & 0,7 & 0,1 & 9,3 & 0,3 & 2,3 & 0,3 & 1,7 & 0,1 & 117 & 3 \\
\hline SV0506 & N.D. & - & 1,55 & 0,03 & 0,31 & 0,04 & 0,11 & 0,02 & 2,9 & 0,1 & 1,0 & 0,2 & 0,59 & 0,03 & 31 & 1 \\
\hline SV0507 & N.D. & - & 3,7 & 0,1 & 0,78 & 0,07 & 0,6 & 0,1 & 6,2 & 0,2 & 2,5 & 0,3 & 1,3 & 0,1 & 58 & 2 \\
\hline SV0510 & N.D. & - & 2,8 & 0,1 & 0,59 & 0,06 & 0,43 & 0,05 & 5,4 & 0,2 & 1,5 & 0,1 & 1,1 & 0,1 & 46 & 2 \\
\hline SV0511 & N.D. & - & 0,47 & 0,01 & 0,20 & 0,03 & 0,09 & 0,01 & 1,2 & 0,0 & 0,6 & 0,1 & 0,34 & 0,02 & 8 & 0,5 \\
\hline SV0512 & N.D. & - & 1,91 & 0,05 & 0,39 & 0,04 & 0,26 & 0,03 & 3,9 & 0,2 & 2,2 & 0,2 & 0,86 & 0,04 & 34 & 1 \\
\hline SV0513 & N.D. & - & 1,71 & 0,04 & 0,35 & 0,03 & 0,29 & 0,05 & 4,0 & 0,2 & 2,3 & 0,2 & 0,77 & 0,04 & 19 & 1 \\
\hline SV0514 & 3,5 & 0,8 & 7,13 & 0,03 & N.D. & 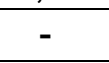 & 0,7 & 0,1 & 13,6 & 0,1 & 4,2 & 0,2 & 2,1 & 0,1 & 186 & 3 \\
\hline
\end{tabular}


Anexo IX: Resultados obtidos por NAA, Santos, Inverno de 2006. Resultados expressos $\mathrm{mg} \mathrm{kg}^{-1}$ e com Desvio Padrão (D.P.)

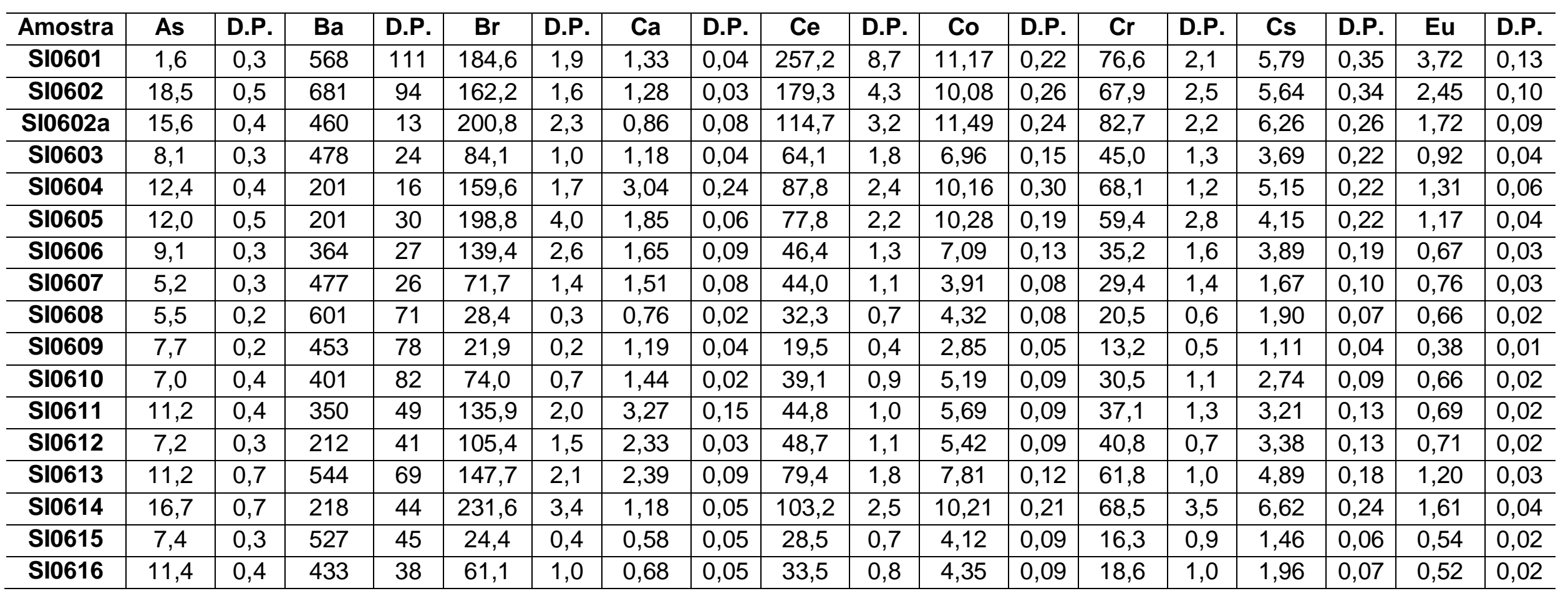


Anexo IX: Resultados obtidos por NAA, Santos, Inverno de 2006. Resultados expressos $\mathrm{mg} \mathrm{kg}^{-1}$ e com Desvio Padrão (D.P.) (continuação)

\begin{tabular}{|c|c|c|c|c|c|c|c|c|c|c|c|c|c|c|c|c|c|c|}
\hline Amostra & (\%) & & $\pi$ & D.P. & a & & Lu & $\mathbf{D}$ & a & 1. & Nd & D.P. & $\mathbf{R b}$ & P. & b & D.P. & Sc & D.P. \\
\hline SI0601 & 65 & 4 & 21 &, 11 & 107 & 34 & 028 & מח רחת & 3862 & 143 & 80,1 & 51 & & 12,6 & 0,58 & 0,04 & 13,22 &, 17 \\
\hline & & & & & & & & & & & & & & & & & & \\
\hline & & & 13 & &, 95 & 22 & & & & 45 & & & & & & & & 17 \\
\hline & 52 & 1 & 31 & 09 & 17 & 14 & & 01 & & 0 & & & & & 67 & & & 14 \\
\hline & & & & & & & & & & 148 & & & & & & & 55 & 15 \\
\hline & & & & & & & & & & 21 & & & & & & & & \\
\hline & & 2 & 93 & 8 & & & & 0,02 & & 41 & 1,0 & & & & 44 & & & 08 \\
\hline & & & & 12 & & & & & & 131 & & & & & 44 & & & 06 \\
\hline & & & & 04 & 14, & & & & & & & & & & 8 & &, 22 & 04 \\
\hline & & & 11 & & & 5 & & & & 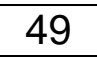 & $1, c$ & 1, & & 2, & 3 & & 4 &, 03 \\
\hline & & & & & & & & & & & & & & & & & & 07 \\
\hline & & & & & & & & & & 1 & 9,6 & & & & 0 & & 47 & 08 \\
\hline & & 01 & 37 & 07 & 22,46 & 0,10 & & 0,02 & & 85 & 21,6 & 2 & & 2, & 39 & & 6,73 & 0,09 \\
\hline & & & & & & 0 & & & & 137 & 30,7 & 3 & & & r & & 23 & 13 \\
\hline & & & & & & & & & & 23 & & & & & & & & \\
\hline & 1,60 & 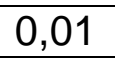 & & 04 & 12 & 0,06 & & 0 , & & 86 & 13,9 & $1, \mathrm{c}$ & & <, & & & 2,86 & 03 \\
\hline 0616 & 1,75 & 01 & 42 & 03 & 12,18 & 0,07 & 11 & 0,01 & 11482 & 90 & 8,6 & 1,4 & 08 & 2,7 &, 56 & 09 & 2,88 &, 03 \\
\hline
\end{tabular}


Anexo IX: Resultados obtidos por NAA, Santos, Inverno de 2006. Resultados expressos $\mathrm{mg} \mathrm{kg}^{-1} \mathrm{e}$ com Desvio Padrão (D.P.) (continuação)

\begin{tabular}{|c|c|c|c|c|c|c|c|c|c|c|c|c|c|c|c|c|}
\hline Amostra & Se & D.P. & Sm & D.P. & $\mathrm{Ta}$ & D.P. & Tb & D.P. & Th & D.P. & $\mathbf{U}$ & D.P. & $\mathrm{Yb}$ & D.P. & $\mathrm{Zn}$ & D.P. \\
\hline SI0601 & N.D. & - & 29,54 & 0,87 & 2,15 & 0,20 & 4,39 & 2,07 & 18,02 & 0,52 & 4,84 & 0,23 & 3,68 & 0,56 & 177,1 & 7,5 \\
\hline SI0602 & N.D. & - & N.D. & - & N.D. & 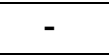 & 1,53 & 0,76 & 10,67 & 0,33 & 4,74 & 0,18 & 2,37 & 0,21 & N.D. & - \\
\hline SI0602a & N.D. & - & 6,70 & 0,10 & N.D. & - & N.D. & - & 13,58 & 0,38 & 2,49 & 0,17 & 1,86 & 0,10 & 193,9 & 11,5 \\
\hline SI0603 & N.D. & - & 4,48 & 0,10 & N.D. & - & N.D. & - & 8,06 & 0,22 & 1,87 & 0,13 & 1,63 & 0,15 & 130,9 & 10,1 \\
\hline SI0604 & N.D. & - & 5,63 & 0,08 & N.D. & - & N.D. & - & 10,93 & 0,30 & 2,00 & 0,15 & 1,67 & 0,10 & 129,1 & 9,2 \\
\hline SI0605 & N.D. & - & 5,17 & 0,13 & 0,66 & 0,08 & 0,53 & 0,13 & 11,14 & 0,38 & 2,70 & 0,18 & 1,93 & 0,14 & 145,4 & 6,1 \\
\hline SI0606 & N.D. & - & 3,35 & 0,07 & 0,23 & 0,06 & N.D. & - & 6,27 & 0,22 & 1,95 & 0,15 & 1,14 & 0,10 & 58,4 & 3,5 \\
\hline S10607 & N.D. & - & 3,10 & 0,09 & N.D. & N.D. & N.D. & - & 7,63 & 0,26 & 1,96 & 0,15 & 1,15 & 0,07 & 52,9 & 3,6 \\
\hline S10608 & N.D. & - & 2,79 & 0,03 & 0,36 & 0,04 & 0,21 & 0,08 & 3,73 & 0,10 & 0,84 & 0,06 & 0,88 & 0,04 & 33,6 & 1,1 \\
\hline S10609 & N.D. & - & 2,58 & 0,09 & 0,15 & 0,03 & N.D. & - & 2,31 & 0,06 & 0,57 & 0,03 & 0,57 & 0,02 & 20,9 & 0,6 \\
\hline SI0610 & N.D. & - & 3,08 & 0,03 & 0,38 & 0,03 & 0,06 & 0,02 & 5,28 & 0,15 & 1,41 & 0,07 & 0,98 & 0,04 & 50,0 & 1,3 \\
\hline SI0611 & N.D. & - & 3,56 & 0,08 & 0,67 & 0,06 & 0,56 & 0,10 & 6,04 & 0,23 & 2,76 & 0,13 & 1,00 & 0,04 & 67,1 & 2,4 \\
\hline SI0612 & N.D. & - & 3,71 & 0,08 & 0,48 & 0,07 & 0,56 & 0,09 & 6,65 & 0,25 & 2,43 & 0,12 & 1,10 & 0,05 & 62,9 & 2,5 \\
\hline SI0613 & 2,09 & 0,57 & N.D. & N.D. & 0,77 & 0,09 & 0,85 & 0,18 & 10,21 & 0,38 & 3,69 & 0,18 & 1,75 & 0,07 & 111,9 & 4,2 \\
\hline SI0614 & N.D. & - & N.D. & N.D. & 1,10 & 0,13 & 0,63 & 0,07 & 13,57 & 0,47 & 3,86 & 0,21 & 1,74 & 0,09 & 190,4 & 6,6 \\
\hline SI0615 & N.D. & - & 2,30 & 0,05 & N.D. & 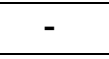 & N.D. & - & 3,06 & 0,11 & 0,65 & 0,07 & 0,65 & 0,03 & 21,7 & 1,0 \\
\hline SI0616 & N.D. & - & 2,34 & 0,05 & 0,29 & 0,05 & 0,12 & 0,02 & 3,52 & 0,14 & 0,96 & 0,08 & 0,66 & 0,03 & 34,8 & 1,3 \\
\hline
\end{tabular}


Anexo X: Resultados obtidos por NAA, Santos, Verão de 2006. Resultados expressos mg kg-1 e com Desvio Padrão (D.P.)

\begin{tabular}{|c|c|c|c|c|c|c|c|c|c|c|c|c|c|c|c|c|c|c|}
\hline Amostra & As & D.P. & $\mathrm{Ba}$ & D.P. & $\mathrm{Br}$ & D.P. & $\mathrm{Ca}$ & D.P. & $\mathrm{Ce}$ & D.P. & Co & D.P. & $\mathrm{Cr}$ & D.P. & Cs & D.P. & Eu & D.P. \\
\hline SV0601 & 11,4 & 0,2 & N.D. & - & 212,3 & 2,9 & 1,56 & 0,04 & 187,4 & 2,2 & 11,49 & 0,04 & 69,1 & 1,1 & 6,8 & 0,2 & 2,79 & 0,01 \\
\hline SV0602 & 8,5 & 0,3 & N.D. & - & 132,7 & 2,3 & 1,31 & 0,04 & 172,3 & 6,7 & 11,11 & 0,07 & 72,8 & 4,3 & 6,5 & 0,5 & 2,49 & 0,16 \\
\hline SV0602a & 13,9 & 0,5 & N.D. & - & 183,2 & 3,0 & 1,54 & 0,05 & 106,3 & 3,5 & 10,74 & 0,06 & 71,8 & 4,3 & 5,6 & 0,1 & 1,73 & 0,18 \\
\hline SV0603 & 8,0 & 0,3 & N.D. & - & 99,4 & 1,6 & 1,43 & 0,05 & 67,8 & 2,6 & 7,71 & 0,05 & 63,5 & 0,9 & 4,3 & 0,4 & 1,11 & 0,09 \\
\hline SV0604 & 14,0 & 0,3 & 288 & 16 & 167,3 & 2,2 & 2,76 & 0,05 & 70,7 & 0,6 & 9,80 & 0,08 & 61,5 & 0,7 & 5,9 & 0,1 & 1,16 & 0,01 \\
\hline SV0605 & 9,2 & 0,2 & 320 & 17 & 107,4 & 1,4 & 1,29 & 0,03 & 56,5 & 0,5 & 7,31 & 0,05 & 46,8 & 0,5 & 4,0 & 0,1 & 0,87 & 0,01 \\
\hline SV0606 & 6,4 & 0,1 & 312 & 16 & 69,5 & 0,8 & 1,65 & 0,03 & 35,1 & 0,3 & 4,74 & 0,04 & 24,9 & 0,3 & 2,2 & 0,1 & 0,51 & 0,01 \\
\hline SV0607 & 7,7 & 0,2 & 482 & 23 & 78,5 & 0,9 & 1,95 & 0,05 & 37,4 & 0,9 & 5,26 & 0,08 & 23,4 & 0,9 & 2,2 & 0,1 & 0,69 & 0,02 \\
\hline SV0608 & 12,0 & 1,9 & 505 & 19 & 135,9 & 1,5 & 1,10 & 0,10 & 45,1 & 1,0 & 6,92 & 0,11 & 36,0 & 1,6 & 3,2 & 0,1 & 0,79 & 0,02 \\
\hline SV0609 & 10,2 & 0,2 & 473 & 15 & 31,9 & 0,3 & 0,59 & 0,03 & 23,0 & 0,5 & 3,38 & 0,05 & 13,9 & 0,5 & 1,3 & 0,1 & 0,47 & 0,01 \\
\hline SV0610 & 2,5 & 0,1 & 388 & 27 & 64,9 & 0,7 & 2,05 & 0,12 & 36,7 & 0,8 & 4,83 & 0,08 & 28,1 & 1,0 & 2,4 & 0,1 & 0,58 & 0,02 \\
\hline SV0611 & 8,0 & 0,2 & 337 & 38 & 69,5 & 0,7 & 10,09 & 0,61 & 38,1 & 0,9 & 4,22 & 0,07 & 27,7 & 0,7 & 2,0 & 0,1 & 0,56 & 0,02 \\
\hline SV0612 & 6,9 & 0,2 & 244 & 31 & 85,7 & 0,9 & 0,99 & 0,02 & 48,5 & 1,2 & 4,72 & 0,09 & 31,5 & 0,9 & 2,5 & 0,1 & 0,63 & 0,02 \\
\hline SV0612a & 1,8 & 0,1 & 168 & 10 & 28,4 & 0,4 & 0,56 & 0,02 & 19,3 & 0,4 & 1,56 & 0,03 & 16,2 & 0,5 & 0,9 & 0,0 & 0,20 & 0,01 \\
\hline SV0613 & 10,8 & 0,3 & 289 & 20 & 153,5 & 2,0 & 1,31 & 0,03 & 87,6 & 2,3 & 8,43 & 0,14 & 63,6 & 1,7 & 5,8 & 0,3 & 1,15 & 0,04 \\
\hline SV0614 & 13,1 & 0,6 & 302 & 30 & 284,7 & 3,6 & 1,08 & 0,04 & 101,0 & 2,3 & 8,99 & 0,15 & 70,9 & 2,6 & 5,5 & 0,2 & 1,40 & 0,05 \\
\hline SV0615 & 6,7 & 0,2 & 443 & 25 & 23,0 & 0,3 & 0,68 & 0,02 & 26,8 & 0,7 & 3,47 & 0,08 & 20,0 & 0,8 & 1,0 & 0,1 & 0,50 & 0,01 \\
\hline SV0616 & 9,3 & 0,3 & 366 & 28 & 116,0 & 1,8 & 1,20 & 0,03 & 33,4 & 1,0 & 5,49 & 0,10 & 28,5 & 1,1 & 2,1 & 0,1 & 0,61 & 0,02 \\
\hline
\end{tabular}




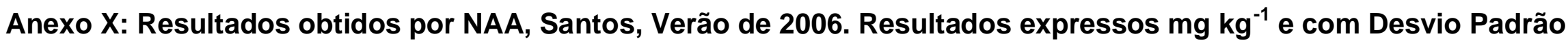
(D.P.) (continuação)

\begin{tabular}{|c|c|c|c|c|c|c|c|c|c|c|c|c|c|c|c|c|c|c|}
\hline Amostra & $\mathrm{Fe}(\%)$ & D.P. & $\mathrm{Hf}$ & D.P. & La & D.P. & Lu & D.P. & $\mathrm{Na}$ & D.P. & Nd & D.P. & $\mathbf{R b}$ & D.P. & Sb & D.P. & Sc & D.P. \\
\hline SV0601 & 5,45 & 0,02 & 5,48 & 0,09 & 81,64 & 0,27 & N.D. & - & 23366 & 67 & 166,7 & 5,7 & 124,7 & 12,6 & 0,93 & 0,05 & 13,07 & 0,02 \\
\hline SV0602 & 4,59 & 0,04 & 6,65 & 0,14 & 70,90 & 0,32 & N.D. & - & 22323 & 118 & 75,1 & 6,1 & 102,6 & 12,2 & 0,62 & 0,03 & 12,34 & 0,10 \\
\hline SV0602a & 4,27 & 0,03 & 4,39 & 0,09 & 44,28 & 0,21 & N.D. & - & 29341 & 156 & 52,4 & 2,6 & 81,0 & 14,1 & 0,52 & 0,03 & 12,91 & 0,11 \\
\hline SV0603 & 2,96 & 0,02 & 4,23 & 0,09 & 29,53 & 0,15 & N.D. & - & 17761 & 99 & 25,4 & 1,4 & 62,2 & 10,8 & 0,47 & 0,03 & 8,90 & 0,08 \\
\hline SV0604 & 3,55 & 0,02 & 2,66 & 0,05 & 34,61 & 0,10 & 0,24 & 0,01 & 27455 & 100 & 38,7 & 1,3 & 77,2 & 2,6 & 0,81 & 06 & 11,09 & 0,02 \\
\hline SV0605 & 2,64 & 0,02 & 3,82 & 0,07 & 25,51 & 0,08 & 0,22 & 0,01 & 18461 & 69 & 33,1 & 0,6 & 73,5 & 2,4 & 0,65 & 0,04 & 7,72 & 0,02 \\
\hline SV0606 & 1,64 & 0,01 & 2,10 & 0,04 & 15,56 & 0,04 & 0,15 & 0,005 & 12159 & 45 & 20,8 & 0,6 & 56,1 & 1,9 & 0,34 & 0,02 & 4,48 & 0,01 \\
\hline SV0607 & 1,99 & 0,01 & 2,59 & 0,04 & 17,28 & 0,07 & 0,18 & 0,01 & 14380 & 82 & 11,8 & 3,0 & 65,8 & 2,9 & 0,45 & 0,03 & 28 & 0,05 \\
\hline SV0608 & 2,39 & 0,02 & 3,50 & 0,06 & 21,33 & 0,09 & 0,21 & 0,01 & 19727 & 128 & 13,1 & 2,3 & 74,9 & 3,6 & 0,42 & 0,03 & 35 & 0,08 \\
\hline SV0609 & 1,51 & 0,01 & 1,24 & 0,02 & 10,21 & 0,05 & 0,09 & 0,01 & 9300 & 54 & N.D. & - & 48,1 & 2,1 & N.D. & - & 19 & 0,03 \\
\hline SV0610 & 1,69 & 0,01 & 2,69 & 0,05 & 14,02 & 0,06 & 0,13 & 0,01 & 9375 & 68 & 10,9 & 2,9 & 59,6 & 4,0 & 0,31 & 0,02 & 4 & 0,06 \\
\hline SV0611 & 1,57 & 0,01 & 2,23 & 0,05 & 15,08 & 0,07 & 0,11 & 0,01 & 9232 & 68 & 10,9 & 3,0 & 37,8 & 2,7 & 0,28 & 0,02 & 81 & 0,06 \\
\hline SV0612 & 1,81 & 0,01 & 5,30 & 0,10 & 21,09 & 0,09 & 0,23 & 0,01 & 9677 & 66 & 12,7 & 3,0 & 33,9 & 2,4 & 0,36 & 0,02 & 5,59 & 0,07 \\
\hline SV0612a & 0,50 & 0,00 & 5,69 & 0,12 & & 0,04 & 0,14 & 0,01 & 3961 & 25 & 10,1 & 1,3 & 16,6 & 0,9 & 0,19 & 0,01 & 1,78 & 0,02 \\
\hline SV0613 & 3,53 & 0,04 & 3,72 & 0,07 & 33,95 & 0,15 & 0,35 & 0,02 & 17304 & 118 & 33,8 & 3,7 & 74,6 & 3,9 & 0,65 & 0,04 & 10,82 & 0,13 \\
\hline SV0614 & 4,19 & 0,03 & 3,38 & 0,06 & 40,61 & 0,19 & 0,32 & 0,01 & 34968 & 218 & 47,7 & 5,3 & 91,9 & 4,2 & 0,61 & 0,05 & 12,30 & 0,15 \\
\hline SV0615 & 1,46 & 0,01 & 3,98 & 0,11 & 12,92 & 0,07 & 0,15 & 0,01 & 9459 & 68 & 13,5 & 2,0 & 80,9 & 7,4 & 0,23 & 0,02 & 2,68 & 0,03 \\
\hline SV0616 & 2,12 & 0,02 & 2,40 & 0,07 & 17,53 & 0,10 & 0,12 & 0,01 & 16795 & 122 & 20,4 & 3,3 & 75,8 & 7,6 & N.D. & & 5,08 & 0,06 \\
\hline
\end{tabular}


Anexo X: Resultados obtidos por NAA, Santos, Verão de 2006. Resultados expressos mg kg-1 e com Desvio Padrão (D.P.) (continuação)

\begin{tabular}{|c|c|c|c|c|c|c|c|c|c|c|c|c|c|c|c|c|}
\hline Amostra & $\mathrm{Se}$ & D.P. & Sm & D.P. & $\mathrm{Ta}$ & D.P. & Tb & D.P. & Th & D.P. & $\mathbf{U}$ & D.P. & $\mathbf{Y b}$ & D.P. & $\mathrm{Zn}$ & D.P. \\
\hline SV0601 & 1,11 & 0,13 & 12,02 & 0,02 & 4,18 & 1,01 & 0,94 & 0,03 & 16,65 & 0,14 & 7,08 & 0,30 & 2,54 & 0,08 & 173,5 & 2,4 \\
\hline SV0602 & 1,36 & 0,21 & 10,60 & 0,05 & 0,17 & 0,06 & 1,30 & 0,17 & 14,92 & 0,18 & 4,30 & 0,23 & 2,72 & 0,33 & 141,8 & 2,3 \\
\hline SV0602a & N.D. & - & 7,17 & 0,02 & 0,17 & 0,06 & 1,11 & 0,07 & 13,28 & 0,16 & 4,27 & 0,30 & 2,38 & 0,29 & 137,9 & 2,3 \\
\hline SV0603 & 0,66 & 0,13 & 4,89 & 0,01 & 0,87 & 0,10 & 0,43 & 0,04 & 8,80 & 0,12 & 1,91 & 0,15 & 1,71 & 0,19 & 89,2 & 1,6 \\
\hline SV0604 & N.D. & - & 5,60 & 0,01 & 1,09 & 0,13 & 0,49 & 0,02 & 10,76 & 0,08 & 2,59 & 0,07 & 1,64 & 0,05 & 127,8 & 4,3 \\
\hline SV0605 & 0,60 & 0,14 & 4,27 & 0,01 & 0,80 & 0,07 & 0,42 & 0,01 & 7,67 & 0,06 & 2,22 & 0,07 & 1,16 & 0,04 & 95,5 & 3,0 \\
\hline SV0606 & N.D. & - & 2,38 & 0,004 & 0,40 & 0,05 & 0,23 & 0,01 & 4,20 & 0,04 & 1,13 & 0,03 & 0,80 & 0,03 & 48,0 & 1,2 \\
\hline SV0607 & N.D. & - & 3,28 & 0,10 & 0,42 & 0,05 & 0,12 & 0,01 & 4,57 & 0,13 & 1,32 & 0,08 & 0,90 & 0,04 & 47,0 & 2,0 \\
\hline SV0608 & N.D. & - & N.D. & - & 0,80 & 0,11 & 0,35 & 0,05 & 5,93 & 0,17 & 1,22 & 0,07 & 1,35 & 0,06 & 66,8 & 2,0 \\
\hline SV0609 & N.D. & - & 2,16 & 0,05 & N.D. & - & 0,18 & 0,02 & 2,84 & 0,08 & 0,97 & 0,07 & 0,52 & 0,03 & 24,7 & 0,9 \\
\hline SV0610 & N.D. & - & 2,53 & 0,05 & 0,48 & 0,08 & 0,52 & 0,17 & 4,49 & 0,13 & 1,40 & 0,08 & 0,96 & 0,05 & 47,4 & 1,7 \\
\hline SV0611 & N.D. & - & 2,40 & 0,05 & 0,28 & 0,05 & 0,21 & 0,04 & 4,95 & 0,14 & 2,42 & 0,17 & 0,81 & 0,04 & 66,0 & 3,3 \\
\hline SV0612 & N.D. & - & 3,42 & 0,09 & 0,26 & 0,04 & 0,31 & 0,04 & 6,33 & 0,18 & 4,32 & 0,22 & 0,99 & 0,05 & 57,4 & 2,1 \\
\hline SV0612a & N.D. & - & N.D. & - & 0,31 & 0,04 & 0,23 & 0,03 & 3,26 & 0,09 & 1,44 & 0,08 & 0,96 & 0,06 & 12,8 & 0,9 \\
\hline SV0613 & N.D. & - & 5,32 & 0,06 & 0,99 & 0,08 & 0,86 & 0,10 & 11,11 & 0,31 & 3,70 & 0,19 & 1,69 & 0,06 & 138,8 & 5,2 \\
\hline SV0614 & N.D. & - & 6,77 & 0,08 & 1,11 & 0,08 & 0,98 & 0,13 & 12,67 & 0,35 & 3,60 & 0,22 & 1,96 & 0,09 & 175,8 & 6,6 \\
\hline SV0615 & N.D. & - & 2,09 & 0,07 & N.D. & - & N.D. & - & 3,22 & 0,10 & 1,11 & 0,07 & 0,69 & 0,05 & N.D. & 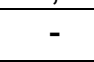 \\
\hline SV0616 & N.D. & - & 2,92 & 0,13 & N.D. & - & 0,40 & 0,13 & 4,89 & 0,15 & 1,20 & 0,11 & 0,82 & 0,06 & 62,8 & 3,8 \\
\hline
\end{tabular}


ANEXO XI- Valores de concentração $\left(\mathrm{mg} \mathrm{kg}^{-1}\right)$ determinados por ICP OES para as amostras de sedimentos do sistema estuarino de Cananéia (Verão/2005) e valores de LD e LQ.

\begin{tabular}{|c|c|c|c|c|c|c|c|c|c|c|c|c|c|c|c|c|c|c|}
\hline Parâmetros & Unidade & L.D. & L.Q. & CV0501 & & $\begin{array}{l}\text { Desvio } \\
\text { Padrão }\end{array}$ & CV0502 & & $\begin{array}{l}\text { Desvio } \\
\text { Padrão }\end{array}$ & CV0503 & & $\begin{array}{l}\text { Desvio } \\
\text { Padrão }\end{array}$ & CV0504 & & $\begin{array}{l}\text { Desvio } \\
\text { Padrão }\end{array}$ & CV0505 & & $\begin{array}{l}\text { Desvio } \\
\text { Padrão }\end{array}$ \\
\hline $\mathrm{Ba}$ & $\left(\mathrm{mg} \mathrm{kg}^{-1}\right)$ & 0,2 & 1,0 & 2,30 & \pm & 0,20 & 4,41 & \pm & 0,39 & 7,78 & \pm & 0,69 & 50,33 & \pm & 4,43 & 5,30 & \pm & 0,47 \\
\hline $\mathrm{Cu}$ & $\left(\mathrm{mg} \mathrm{kg}^{-1}\right)$ & 0,1 & 0,5 & N.D. & \pm & - & N.D. & \pm & - & 0,83 & \pm & 0,05 & 11,28 & \pm & 0,64 & 1,61 & \pm & 0,09 \\
\hline $\mathrm{Cr}$ & $\left(\mathrm{mg} \mathrm{kg}^{-1}\right)$ & 0,5 & 1,0 & 3,19 & \pm & 0,20 & 4,47 & \pm & 0,28 & 9,20 & \pm & 0,57 & 36,85 & \pm & 2,28 & 6,76 & \pm & 0,42 \\
\hline $\mathrm{Sr}$ & $\left(\mathrm{mg} \mathrm{kg}^{-1}\right)$ & 0,1 & 1,0 & 9,96 & \pm & 0,34 & 29,02 & \pm & 0,99 & 14,85 & \pm & 0,50 & 46,45 & \pm & 1,58 & 13,60 & \pm & 0,46 \\
\hline Mn & $\left(\mathrm{mg} \mathrm{kg}^{-1}\right)$ & 0,5 & 1,0 & 35,8 & \pm & 1,6 & 37,2 & \pm & 1,7 & 123,1 & \pm & 5,6 & 449,1 & \pm & 20,4 & 74,3 & \pm & 3,4 \\
\hline $\mathrm{Ni}$ & $\left(\mathrm{mg} \mathrm{kg}^{-1}\right)$ & 0,5 & 1,0 & 1,13 & \pm & 0,10 & 1,75 & \pm & 0,15 & 3,10 & \pm & 0,26 & 14,27 & \pm & 1,20 & 2,37 & \pm & 0,20 \\
\hline $\mathrm{Zn}$ & $\left(\mathrm{mg} \mathrm{kg}^{-1}\right)$ & 0,5 & 1,0 & 13,1 & \pm & 2,0 & 9,0 & \pm & 1,4 & 14,7 & \pm & 2,3 & 57,7 & \pm & 9,0 & 12,4 & \pm & 1,9 \\
\hline Parâmetros & Unidade & L.D. & L.Q. & CV0506 & & $\begin{array}{l}\text { Desvio } \\
\text { Padrão }\end{array}$ & CV0507 & & $\begin{array}{l}\text { Desvio } \\
\text { Padrão }\end{array}$ & CV0508 & & $\begin{array}{l}\text { Desvio } \\
\text { Padrão } \\
\end{array}$ & CV0509 & & $\begin{array}{l}\text { Desvio } \\
\text { Padrão }\end{array}$ & CV0510 & & $\begin{array}{l}\text { Desvio } \\
\text { Padrão }\end{array}$ \\
\hline Al & $\left(\mathrm{mg} \mathrm{kg}^{-1}\right)$ & 0,5 & 1,0 & 628 & \pm & 98 & 2395 & \pm & 375 & 7437 & \pm & 1166 & 42818 & \pm & 6711 & 1877 & \pm & 294 \\
\hline $\mathrm{Cr}$ & $\left(\mathrm{mg} \mathrm{kg}^{-1}\right)$ & 0,5 & 1,0 & 1,19 & \pm & 0,07 & 4,24 & \pm & 0,26 & 11,80 & \pm & 0,73 & 37,53 & \pm & 2,32 & 3,52 & \pm & 0,22 \\
\hline $\mathrm{Sr}$ & $\left(\mathrm{mg} \mathrm{kg}^{-1}\right)$ & 0,1 & 1,0 & 2,69 & \pm & 0,09 & 22,79 & \pm & 0,77 & 20,80 & \pm & 0,71 & 43,52 & \pm & 1,48 & 5,23 & \pm & 0,18 \\
\hline $\mathrm{Fe}$ & $\left(\mathrm{mg} \mathrm{kg}^{-1}\right)$ & 1,0 & 5,0 & 859 & \pm & 53 & 3074 & \pm & 191 & 8359 & \pm & 520 & 27584 & \pm & 1717 & 2503 & \pm & 156 \\
\hline Li & $\left(\mathrm{mg} \mathrm{kg}^{-1}\right)$ & 0,5 & 1,0 & 1,18 & \pm & 0,08 & 5,15 & \pm & 0,36 & 14,75 & \pm & 1,03 & 58,76 & \pm & 4,09 & 4,14 & \pm & 0,29 \\
\hline$M n$ & $\left(\mathrm{mg} \mathrm{kg}^{-1}\right)$ & 0,5 & 1,0 & 9,7 & \pm & 0,4 & 63,4 & \pm & 2,9 & 119,9 & \pm & 5,4 & 312,1 & \pm & 14,2 & 18,5 & \pm & 0,8 \\
\hline $\mathrm{Ni}$ & $\left(\mathrm{mg} \mathrm{kg}^{-1}\right)$ & 0,5 & 1,0 & N.D. & \pm & - & 1,17 & \pm & 0,10 & 3,80 & \pm & 0,32 & 14,75 & \pm & 1,24 & 1,29 & \pm & 0,11 \\
\hline $\mathrm{Zn}$ & $\left(\mathrm{mg} \mathrm{kg}^{-1}\right)$ & 0,5 & 1,0 & 3,0 & \pm & 0,5 & 7,0 & \pm & 1,1 & 18,0 & \pm & 2,8 & 50,6 & \pm & 7,9 & 9,0 & \pm & 1,4 \\
\hline
\end{tabular}


ANEXO XI- Valores de concentração $\left(\mathrm{mg} \mathrm{kg}^{-1}\right)$ determinados por ICP OES para as amostras de sedimentos do sistema estuarino de Cananéia (Verão/2005) e valores de LD e LQ.(continuação)

\begin{tabular}{|c|c|c|c|c|c|c|c|c|c|c|c|c|}
\hline Parâmetros & Unidade & L.D. & L.Q. & CV0511 & & $\begin{array}{l}\text { Desvio } \\
\text { Padrão }\end{array}$ & CV0512 & & $\begin{array}{l}\text { Desvio } \\
\text { Padrão }\end{array}$ & CV0513 & & $\begin{array}{l}\text { Desvio } \\
\text { Padrão }\end{array}$ \\
\hline Al & $\left(\mathrm{mg} \mathrm{kg}^{-1}\right)$ & 0,5 & 1,0 & 14109 & \pm & 2211 & 3962 & \pm & 621 & 1553 & \pm & 243 \\
\hline $\mathrm{Ba}$ & $\left(\mathrm{mg} \mathrm{kg}^{-1}\right)$ & 0,2 & 1,0 & 14,88 & \pm & 1,31 & 5,02 & \pm & 0,44 & 2,08 & \pm & 0,18 \\
\hline Co & $\left(\mathrm{mg} \mathrm{kg}^{-1}\right)$ & 0,5 & 1,0 & 2,53 & \pm & 0,15 & 1,13 & \pm & 0,07 & N.D. & \pm & - \\
\hline $\mathrm{Cu}$ & $\left(\mathrm{mg} \mathrm{kg}^{-1}\right)$ & 0,1 & 0,5 & 1,94 & \pm & 0,11 & 1,92 & \pm & 0,11 & 0,80 & \pm & 0,05 \\
\hline $\mathrm{Cr}$ & $\left(\mathrm{mg} \mathrm{kg}^{-1}\right)$ & 0,5 & 1,0 & 14,35 & \pm & 0,89 & 6,35 & \pm & 0,39 & 2,36 & \pm & 0,15 \\
\hline $\mathrm{Sr}$ & $\left(\mathrm{mg} \mathrm{kg}^{-1}\right)$ & 0,1 & 1,0 & 16,95 & \pm & 0,58 & 8,86 & \pm & 0,30 & 8,48 & \pm & 0,29 \\
\hline $\mathrm{Fe}$ & $\left(\mathrm{mg} \mathrm{kg}^{-1}\right)$ & 1,0 & 5,0 & 8680 & \pm & 540 & 4004 & \pm & 249 & 1554 & \pm & 97 \\
\hline Li & $\left(\mathrm{mg} \mathrm{kg}^{-1}\right)$ & 0,5 & 1,0 & 21,87 & \pm & 1,52 & 6,98 & \pm & 0,49 & 2,42 & \pm & 0,17 \\
\hline$M n$ & $\left(\mathrm{mg} \mathrm{kg}^{-1}\right)$ & 0,5 & 1,0 & 70,6 & \pm & 3,2 & 26,2 & \pm & 1,2 & 20,0 & \pm & 0,9 \\
\hline $\mathbf{N i}$ & $\left(\mathrm{mg} \mathrm{kg}^{-1}\right)$ & 0,5 & 1,0 & 5,14 & \pm & 0,43 & 1,92 & \pm & 0,16 & N.D. & \pm & - \\
\hline $\mathrm{Zn}$ & $\left(\mathrm{mg} \mathrm{kg}^{-1}\right)$ & 0,5 & 1,0 & 19,0 & \pm & 3,0 & 14,1 & \pm & 2,2 & 4,7 & \pm & 0,7 \\
\hline
\end{tabular}


ANEXO XII- Valores de concentração $\left(\mathrm{mg} \mathrm{kg}^{-1}\right)$ determinados por ICP OES para as amostras de sedimentos do sistema estuarino de Cananéia (Inverno/2005) e valores de LD e LQ.

\begin{tabular}{|c|c|c|c|c|c|c|c|c|c|c|c|c|c|c|c|c|c|c|}
\hline Parâmetros & Unidade & L.D. & L.Q. & Cl0501 & & $\begin{array}{l}\text { Desvio } \\
\text { Padrão }\end{array}$ & Cl0502 & & $\begin{array}{l}\text { Desvio } \\
\text { Padrão }\end{array}$ & Cl0503 & & $\begin{array}{l}\text { Desvio } \\
\text { Padrão }\end{array}$ & Cl0504 & & $\begin{array}{l}\text { Desvio } \\
\text { Padrão }\end{array}$ & Cl0505 & & $\begin{array}{l}\text { Desvio } \\
\text { Padrão }\end{array}$ \\
\hline Al & $\left(\mathrm{mg} \mathrm{kg}^{-1}\right)$ & 0,5 & 1,0 & 1226 & \pm & 192 & 8341 & \pm & 1307 & 8636 & \pm & 1354 & 40683 & \pm & 6376 & 8161 & \pm & 1279 \\
\hline $\mathrm{Ba}$ & $\left(\mathrm{mg} \mathrm{kg}^{-1}\right)$ & 0,2 & 1,0 & 1,35 & \pm & 0,12 & 9,83 & \pm & 0,87 & 10,68 & \pm & 0,94 & 52,65 & \pm & 4,64 & 11,80 & \pm & 1,04 \\
\hline Co & $\left(\mathrm{mg} \mathrm{kg}^{-1}\right)$ & 0,5 & 1,0 & N.D. & \pm & - & 2,29 & \pm & 0,14 & 2,26 & \pm & 0,14 & 7,56 & \pm & 0,46 & 2,28 & \pm & 0,14 \\
\hline $\mathrm{Cu}$ & $\left(\mathrm{mg} \mathrm{kg}^{-1}\right)$ & 0,1 & 0,5 & N.D. & \pm & - & 2,07 & \pm & 0,12 & 1,74 & \pm & 0,10 & 12,64 & \pm & 0,72 & 3,58 & \pm & 0,20 \\
\hline $\mathrm{Cr}$ & $\left(\mathrm{mg} \mathrm{kg}^{-1}\right)$ & 0,5 & 1,0 & 1,92 & \pm & 0,12 & 10,90 & \pm & 0,67 & 10,15 & \pm & 0,63 & 39,98 & \pm & 2,47 & 10,33 & \pm & 0,64 \\
\hline Sr & $\left(\mathrm{mg} \mathrm{kg}^{-1}\right)$ & 0,1 & 1,0 & 10,22 & \pm & 0,35 & 18,86 & \pm & 0,64 & 19,12 & \pm & 0,65 & 51,86 & \pm & 1,76 & 17,94 & \pm & 0,61 \\
\hline$M n$ & $\left(\mathrm{mg} \mathrm{kg}^{-1}\right)$ & 0,5 & 1,0 & 24,3 & \pm & 1,1 & 93,5 & \pm & 4,2 & 110,1 & \pm & 5,0 & 526,6 & \pm & 23,9 & 110,3 & \pm & 5,0 \\
\hline $\mathrm{Ni}$ & $\left(\mathrm{mg} \mathrm{kg}^{-1}\right)$ & 0,5 & 1,0 & N.D. & \pm & - & 4,00 & \pm & 0,34 & 3,64 & \pm & 0,31 & 15,60 & \pm & 1,32 & 3,66 & \pm & 0,31 \\
\hline $\mathrm{Zn}$ & $\left(\mathrm{mg} \mathrm{kg}^{-1}\right)$ & 0,5 & 1,0 & 4,3 & \pm & 0,7 & 15,0 & \pm & 2,3 & 14,2 & \pm & 2,2 & 60,6 & \pm & 9,4 & 16,6 & \pm & 2,6 \\
\hline Parâmetros & Unidade & L.D. & L.Q. & Cl0506 & & $\begin{array}{l}\text { Desvio } \\
\text { Padrão }\end{array}$ & Cl0507 & & $\begin{array}{l}\text { Desvio } \\
\text { Padrão }\end{array}$ & $\mathrm{Cl} 0508$ & & $\begin{array}{l}\text { Desvio } \\
\text { Padrão }\end{array}$ & Cl0509 & & $\begin{array}{l}\text { Desvio } \\
\text { Padrão }\end{array}$ & $\mathrm{Cl} 0510$ & & $\begin{array}{l}\text { Desvio } \\
\text { Padrão }\end{array}$ \\
\hline $\mathrm{Cr}$ & $\left(\mathrm{mg} \mathrm{kg}^{-1}\right)$ & 0,5 & 1,0 & 1,13 & \pm & 0,07 & 2,60 & \pm & 0,16 & 13,40 & \pm & 0,83 & 29,25 & \pm & 1,81 & 4,71 & \pm & 0,29 \\
\hline $\mathrm{Sr}$ & $\left(\mathrm{mg} \mathrm{kg}^{-1}\right)$ & 0,1 & 1,0 & 2,07 & \pm & 0,07 & 12,29 & \pm & 0,42 & 29,85 & \pm & 1,01 & 52,37 & \pm & 1,78 & 5,57 & \pm & 0,19 \\
\hline $\mathrm{Fe}$ & $\left(\mathrm{mg} \mathrm{kg}^{-1}\right)$ & 1,0 & 5,0 & 694 & \pm & 43 & 1704 & \pm & 106 & 8347 & \pm & 520 & 23913 & \pm & 1489 & 2822 & \pm & 176 \\
\hline Li & $\left(\mathrm{mg} \mathrm{kg}^{-1}\right)$ & 0,5 & 1,0 & N.D. & \pm & - & 2,75 & \pm & 0,19 & 15,75 & \pm & 1,10 & 45,91 & \pm & 3,19 & 5,53 & \pm & 0,38 \\
\hline Mn & $\left(\mathrm{mg} \mathrm{kg}^{-1}\right)$ & 0,5 & 1,0 & 20,4 & \pm & 0,9 & 52,3 & \pm & 2,4 & 113,4 & \pm & 5,1 & 394,5 & \pm & 17,9 & 21,1 & \pm & 1,0 \\
\hline $\mathrm{Ni}$ & $\left(\mathrm{mg} \mathrm{kg}^{-1}\right)$ & 0,5 & 1,0 & N.D. & \pm & - & N.D. & \pm & - & 4,35 & \pm & 0,37 & 11,01 & \pm & 0,93 & 1,73 & \pm & 0,15 \\
\hline $\mathrm{Zn}$ & $\left(\mathrm{mg} \mathrm{kg}^{-1}\right)$ & 0,5 & 1,0 & 2,4 & \pm & 0,4 & 4,0 & \pm & 0,6 & 18,9 & \pm & 2,9 & 43,3 & \pm & 6,7 & 9,1 & \pm & 1,4 \\
\hline
\end{tabular}


ANEXO XII- Valores de concentração ( $\left.\mathrm{mg} \mathrm{kg}^{-1}\right)$ determinados por ICP OES para as amostras de sedimentos do sistema estuarino de Cananéia (Inverno/2005) e valores de LD e LQ.(continuação)

\begin{tabular}{|c|c|c|c|c|c|c|c|c|c|c|c|c|}
\hline Parâmetros & Unidade & L.D. & L.Q. & Cl0511 & & $\begin{array}{l}\text { desvio } \\
\text { padrão }\end{array}$ & $\mathrm{Cl} 0512$ & & $\begin{array}{l}\text { desvio } \\
\text { padrão }\end{array}$ & Cl0513 & & $\begin{array}{l}\text { desvio } \\
\text { padrão }\end{array}$ \\
\hline Al & $\left(\mathrm{mg} \mathrm{kg}^{-1}\right)$ & 0,5 & 1,0 & 29394 & \pm & 5754 & 4689 & \pm & 918 & 1981 & \pm & 388 \\
\hline $\mathrm{Ba}$ & $\left(\mathrm{mg} \mathrm{kg}^{-1}\right)$ & 0,2 & 1,0 & 25,65 & \pm & 1,39 & 6,71 & \pm & 0,36 & 3,85 & \pm & 0,21 \\
\hline Co & $\left(\mathrm{mg} \mathrm{kg}^{-1}\right)$ & 0,5 & 1,0 & 3,07 & \pm & 0,12 & 1,13 & \pm & 0,05 & N.D. & \pm & - \\
\hline $\mathrm{Cu}$ & $\left(\mathrm{mg} \mathrm{kg}^{-1}\right)$ & 0,1 & 0,5 & 3,57 & \pm & 0,73 & 1,26 & \pm & 0,26 & N.D. & \pm & - \\
\hline $\mathrm{Cr}$ & $\left(\mathrm{mg} \mathrm{kg}^{-1}\right)$ & 0,5 & 1,0 & 18,84 & \pm & 0,74 & 5,77 & \pm & 0,23 & 1,93 & \pm & 0,08 \\
\hline $\mathrm{Sr}$ & $\left(\mathrm{mg} \mathrm{kg}^{-1}\right)$ & 0,1 & 1,0 & 20,96 & \pm & 1,01 & 5,24 & \pm & 0,25 & 9,03 & \pm & 0,44 \\
\hline $\mathrm{Fe}$ & $\left(\mathrm{mg} \mathrm{kg}^{-1}\right)$ & 1,0 & 5,0 & 18703 & \pm & 2529 & 2803 & \pm & 379 & 1242 & \pm & 168 \\
\hline Li & $\left(\mathrm{mg} \mathrm{kg}^{-1}\right)$ & 0,5 & 1,0 & 25,43 & \pm & 1,37 & 7,92 & \pm & 0,43 & 3,50 & \pm & 0,19 \\
\hline$M n$ & $\left(\mathrm{mg} \mathrm{kg}^{-1}\right)$ & 0,5 & 1,0 & 120,1 & \pm & 5,7 & 20,3 & \pm & 1,0 & 37,5 & \pm & 1,8 \\
\hline $\mathbf{N i}$ & $\left(\mathrm{mg} \mathrm{kg}^{-1}\right)$ & 0,5 & 1,0 & 7,11 & \pm & 0,29 & 2,12 & \pm & 0,09 & N.D. & \pm & - \\
\hline $\mathrm{Zn}$ & $\left(\mathrm{mg} \mathrm{kg}^{-1}\right)$ & 0,5 & 1,0 & 29,0 & \pm & 3,4 & 8,4 & \pm & 1,0 & 3,2 & \pm & 0,4 \\
\hline
\end{tabular}


ANEXO XIII- Valores de concentração $\left(\mathrm{mg} \mathrm{kg}^{-1}\right)$ determinados por ICP OES para as amostras de sedimentos do sistema estuarino de Cananéia (Verão/2006) e valores de LD e LQ.

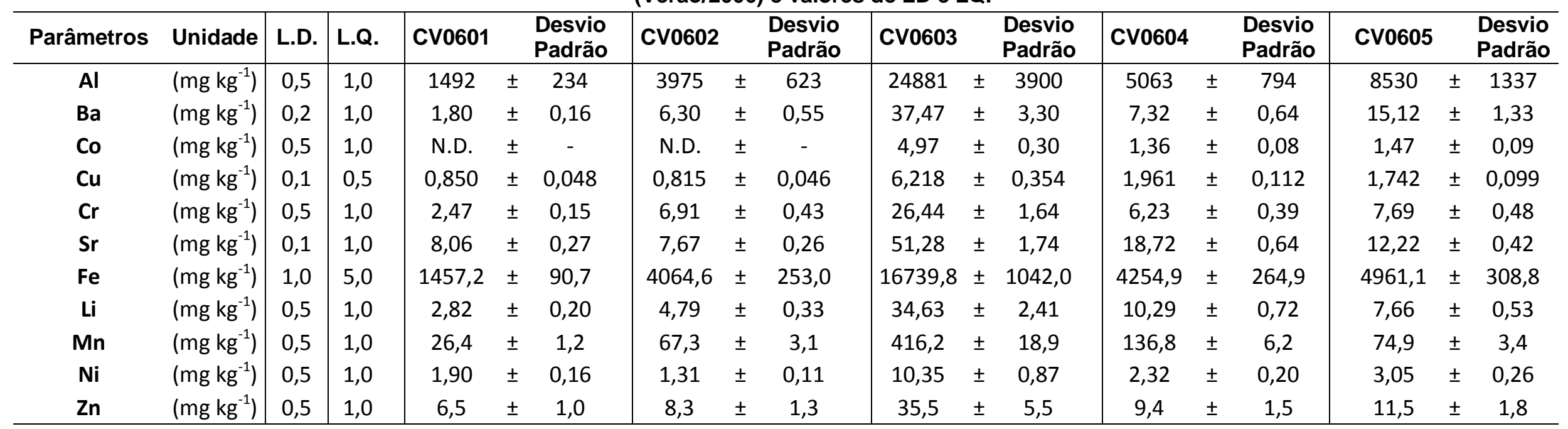

\begin{tabular}{|c|c|c|c|c|c|c|c|c|c|c|c|c|c|c|c|c|c|c|}
\hline Parâmetros & Unidade & L.D. & L.Q. & CV0606 & & $\begin{array}{l}\text { Desvio } \\
\text { Padrão }\end{array}$ & CV0607 & & $\begin{array}{l}\text { Desvio } \\
\text { Padrão }\end{array}$ & CV0608 & & $\begin{array}{l}\text { Desvio } \\
\text { Padrão }\end{array}$ & CV0609 & & $\begin{array}{l}\text { Desvio } \\
\text { Padrão }\end{array}$ & CV0610 & & $\begin{array}{l}\text { Desvio } \\
\text { Padrão }\end{array}$ \\
\hline Al & $\left(\mathrm{mg} \mathrm{kg}^{-1}\right)$ & 0,5 & 1,0 & 1292 & \pm & 203 & 1583 & \pm & 248 & 10673 & \pm & 1673 & 32248 & \pm & 5054 & 4385 & \pm & 687 \\
\hline $\mathrm{Ba}$ & $\left(\mathrm{mg} \mathrm{kg}^{-1}\right)$ & 0,2 & 1,0 & 2,53 & \pm & 0,22 & 3,29 & \pm & 0,29 & 14,15 & \pm & 1,25 & 34,82 & \pm & 3,07 & 6,59 & \pm & 0,58 \\
\hline $\mathrm{Cu}$ & $\left(\mathrm{mg} \mathrm{kg}^{-1}\right)$ & 0,1 & 0,5 & 1,043 & \pm & 0,059 & N.D. & \pm & - & 1,751 & \pm & 0,100 & 5,405 & \pm & 0,308 & 1,211 & \pm & 0,069 \\
\hline $\mathrm{Cr}$ & $\left(\mathrm{mg} \mathrm{kg}^{-1}\right)$ & 0,5 & 1,0 & 1,95 & \pm & 0,12 & 2,56 & \pm & 0,16 & 13,04 & \pm & 0,81 & 30,83 & \pm & 1,91 & 5,19 & \pm & 0,32 \\
\hline $\mathrm{Sr}$ & $\left(\mathrm{mg} \mathrm{kg}^{-1}\right)$ & 0,1 & 1,0 & 2,81 & \pm & 0,10 & 17,08 & \pm & 0,58 & 20,00 & \pm & 0,68 & 54,49 & \pm & 1,85 & 7,12 & \pm & 0,24 \\
\hline Mn & $\left(\mathrm{mg} \mathrm{kg}^{-1}\right)$ & 0,5 & 1,0 & 13,8 & \pm & 0,6 & 75,8 & \pm & 3,4 & 102,0 & \pm & 4,6 & 311,0 & \pm & 14,1 & 28,1 & \pm & 1,3 \\
\hline $\mathbf{N i}$ & $\left(\mathrm{mg} \mathrm{kg}^{-1}\right)$ & 0,5 & 1,0 & N.D. & \pm & - & N.D. & \pm & - & 4,17 & \pm & 0,35 & 11,69 & \pm & 0,99 & 1,58 & \pm & 0,13 \\
\hline $\mathrm{Zn}$ & $\left(\mathrm{mg} \mathrm{kg}^{-1}\right)$ & 0,5 & 1,0 & 4,2 & \pm & 0,7 & 4,5 & \pm & 0,7 & 18,5 & \pm & 2,9 & 43,2 & \pm & 6,7 & 8,5 & \pm & 1,3 \\
\hline
\end{tabular}


ANEXO XIII- Valores de concentração $\left(\mathrm{mg} \mathrm{kg}^{-1}\right)$ determinados por ICP OES para as amostras de sedimentos do sistema estuarino de Cananéia (Verão/2006) e valores de LD e LQ.(continuação

\begin{tabular}{|c|c|c|c|c|c|c|c|c|c|c|c|c|}
\hline Parâmetros & Unidade & L.D. & L.Q. & CV0611 & & $\begin{array}{l}\text { Desvio } \\
\text { Padrão }\end{array}$ & CV0612 & & $\begin{array}{l}\text { Desvio } \\
\text { Padrão }\end{array}$ & CV0613 & & $\begin{array}{l}\text { Desvio } \\
\text { Padrão }\end{array}$ \\
\hline $\mathrm{Al}$ & $\left(\mathrm{mg} \mathrm{kg}^{-1}\right)$ & 0,5 & 1,0 & 25632 & \pm & 4017 & 8744 & \pm & 1370 & 1342 & \pm & 210 \\
\hline $\mathrm{Ba}$ & $\left(\mathrm{mg} \mathrm{kg}^{-1}\right)$ & 0,2 & 1,0 & 40,74 & \pm & 3,59 & 14,75 & \pm & 1,30 & 3,95 & \pm & 0,35 \\
\hline Co & $\left(\mathrm{mg} \mathrm{kg}^{-1}\right)$ & 0,5 & 1,0 & 3,40 & \pm & 0,20 & 1,24 & \pm & 0,07 & N.D. & \pm & - \\
\hline $\mathrm{Cu}$ & $\left(\mathrm{mg} \mathrm{kg}^{-1}\right)$ & 0,1 & 0,5 & 4,494 & \pm & 0,256 & 1,215 & \pm & 0,069 & 0,607 & \pm & 0,035 \\
\hline $\mathrm{Cr}$ & $\left(\mathrm{mg} \mathrm{kg}^{-1}\right)$ & 0,5 & 1,0 & 24,15 & \pm & 1,49 & 9,28 & \pm & 0,57 & 1,83 & \pm & 0,11 \\
\hline $\mathrm{Sr}$ & $\left(\mathrm{mg} \mathrm{kg}^{-1}\right)$ & 0,1 & 1,0 & 26,97 & \pm & 0,92 & 9,75 & \pm & 0,33 & 6,31 & \pm & 0,21 \\
\hline $\mathrm{Fe}$ & $\left(\mathrm{mg} \mathrm{kg}^{-1}\right)$ & 1,0 & 5,0 & 15803,7 & \pm & 983,7 & 7014,1 & \pm & 436,6 & 1544,0 & \pm & 96,1 \\
\hline Li & $\left(\mathrm{mg} \mathrm{kg}^{-1}\right)$ & 0,5 & 1,0 & 31,14 & \pm & 2,17 & 8,58 & \pm & 0,60 & 2,29 & \pm & 0,16 \\
\hline Mn & $\left(\mathrm{mg} \mathrm{kg}^{-1}\right)$ & 0,5 & 1,0 & 105,9 & \pm & 4,8 & 32,3 & \pm & 1,5 & 30,9 & \pm & 1,4 \\
\hline $\mathbf{N i}$ & $\left(\mathrm{mg} \mathrm{kg}^{-1}\right)$ & 0,5 & 1,0 & 8,44 & \pm & 0,71 & 2,64 & \pm & 0,22 & N.D. & \pm & - \\
\hline $\mathrm{Zn}$ & $\left(\mathrm{mg} \mathrm{kg}^{-1}\right)$ & 0,5 & 1,0 & 27,1 & \pm & 4,2 & 10,1 & \pm & 1,6 & 3,9 & \pm & 0,6 \\
\hline
\end{tabular}


ANEXO XIV- Valores de concentração $\left(\mathrm{mg} \mathrm{kg}^{-1}\right)$ determinados por ICP OES para as amostras de sedimentos do sistema estuarino de Cananéia (Inverno/2006) e valores de LD e LQ.

\begin{tabular}{|c|c|c|c|c|c|c|c|c|c|c|c|c|c|c|c|c|c|c|}
\hline Parâmetros & Unidade & L.D. & L.Q. & Cl0601 & & $\begin{array}{l}\text { Desvio } \\
\text { Padrão }\end{array}$ & Cl0602 & & $\begin{array}{l}\text { Desvio } \\
\text { Padrão }\end{array}$ & Cl0603 & & $\begin{array}{l}\text { Desvio } \\
\text { Padrão }\end{array}$ & $\mathrm{Cl0604}$ & & $\begin{array}{l}\text { Desvio } \\
\text { Padrão }\end{array}$ & Cl0605 & & $\begin{array}{l}\text { Desvio } \\
\text { Padrão }\end{array}$ \\
\hline Al & $\left(\mathrm{mg} \mathrm{kg}^{-1}\right)$ & 0,5 & 1,0 & 888 & \pm & 44 & 7563 & \pm & 378 & 7996 & \pm & 400 & 4113 & \pm & 206 & 3191 & \pm & 160 \\
\hline $\mathrm{Ba}$ & $\left(\mathrm{mg} \mathrm{kg}^{-1}\right)$ & 0,2 & 1,0 & 1,88 & \pm & 0,08 & 9,20 & \pm & 0,41 & 11,75 & \pm & 0,53 & 8,68 & \pm & 0,39 & 5,90 & \pm & 0,27 \\
\hline $\mathrm{Cu}$ & $\left(\mathrm{mg} \mathrm{kg}^{-1}\right)$ & 0,1 & 0,5 & N.D. & \pm & - & N.D. & \pm & - & N.D. & \pm & - & 1,154 & \pm & 0,167 & N.D. & \pm & - \\
\hline $\mathrm{Cr}$ & $\left(\mathrm{mg} \mathrm{kg}^{-1}\right)$ & 0,5 & 1,0 & 1,70 & \pm & 0,04 & 8,56 & \pm & 0,20 & 11,02 & \pm & 0,26 & 5,73 & \pm & 0,13 & 3,83 & \pm & 0,09 \\
\hline $\mathrm{Sr}$ & $\left(\mathrm{mg} \mathrm{kg}^{-1}\right)$ & 0,1 & 1,0 & 14,34 & \pm & 0,58 & 15,14 & \pm & 0,62 & 20,04 & \pm & 0,82 & 11,48 & \pm & 0,47 & 5,42 & \pm & 0,22 \\
\hline$M n$ & $\left(\mathrm{mg} \mathrm{kg}^{-1}\right)$ & 0,5 & 1,0 & 20,0 & \pm & 0,6 & 137,1 & \pm & 3,8 & 172,0 & \pm & 4,8 & 54,5 & \pm & 1,5 & 41,1 & \pm & 1,1 \\
\hline $\mathrm{Ni}$ & $\left(\mathrm{mg} \mathrm{kg}^{-1}\right)$ & 0,5 & 1,0 & N.D. & \pm & - & 2,92 & \pm & 0,06 & 3,99 & \pm & 0,08 & 2,55 & \pm & 0,05 & 1,43 & \pm & 0,03 \\
\hline$Z n$ & $\left(\mathrm{mg} \mathrm{kg}^{-1}\right)$ & 0,5 & 1,0 & 3,5 & \pm & 0,3 & 11,4 & \pm & 1,0 & 16,2 & \pm & 1,5 & 9,1 & \pm & 0,8 & 5,4 & \pm & 0,5 \\
\hline Parâmetros & Unidade & L.D. & L.Q. & Cl0606 & & $\begin{array}{l}\text { Desvio } \\
\text { Padrão } \\
\end{array}$ & Cl0607 & & $\begin{array}{l}\text { Desvio } \\
\text { Padrão } \\
\end{array}$ & Cl0608 & & $\begin{array}{l}\text { Desvio } \\
\text { Padrão } \\
\end{array}$ & Cl0609 & & $\begin{array}{l}\text { Desvio } \\
\text { Padrão } \\
\end{array}$ & Cl0610 & & $\begin{array}{l}\text { Desvio } \\
\text { Padrão } \\
\end{array}$ \\
\hline $\mathrm{Cr}$ & $\left(\mathrm{mg} \mathrm{kg}^{-1}\right)$ & 0,5 & 1,0 & 2,18 & \pm & 0,05 & 3,17 & \pm & 0,07 & 8,69 & \pm & 0,20 & 28,81 & \pm & 0,67 & 5,40 & \pm & 0,13 \\
\hline $\mathrm{Sr}$ & $\left(\mathrm{mg} \mathrm{kg}^{-1}\right)$ & 0,1 & 1,0 & 2,68 & \pm & 0,11 & 14,32 & \pm & 0,58 & 26,29 & \pm & 1,07 & 46,42 & \pm & 1,89 & 65,36 & \pm & 2,66 \\
\hline $\mathrm{Fe}$ & $\left(\mathrm{mg} \mathrm{kg}^{-1}\right)$ & 1,0 & 5,0 & 935,5 & \pm & 37,1 & 2352,1 & \pm & 93,2 & 5730,9 & \pm & 227,0 & 17784,8 & \pm & 704,5 & 4210,7 & \pm & 166,8 \\
\hline Li & $\left(\mathrm{mg} \mathrm{kg}^{-1}\right)$ & 0,5 & 1,0 & 1,58 & \pm & 0,07 & 3,84 & \pm & 0,18 & 10,37 & \pm & 0,48 & 55,21 & \pm & 2,55 & 8,36 & \pm & 0,39 \\
\hline $\mathrm{Mn}$ & $\left(\mathrm{mg} \mathrm{kg}^{-1}\right)$ & 0,5 & 1,0 & 26,8 & \pm & 0,7 & 58,7 & \pm & 1,6 & 99,4 & \pm & 2,8 & 336,5 & \pm & 9,4 & 36,6 & \pm & 1,0 \\
\hline $\mathrm{Ni}$ & $\left(\mathrm{mg} \mathrm{kg}^{-1}\right)$ & 0,5 & 1,0 & N.D. & \pm & - & 1,10 & \pm & 0,02 & 2,63 & \pm & 0,05 & 10,85 & \pm & 0,22 & 2,08 & \pm & 0,04 \\
\hline Zn & $\left(\mathrm{mg} \mathrm{kg}^{-1}\right)$ & 0,5 & 1,0 & 4,0 & \pm & 0,4 & 5,4 & \pm & 0,5 & 13,5 & \pm & 1,2 & 39,5 & \pm & 3,5 & 11,2 & \pm & 1,0 \\
\hline
\end{tabular}


ANEXO XIV- Valores de concentração $\left(\mathrm{mg} \mathrm{kg}^{-1}\right)$ determinados por ICP OES para as amostras de sedimentos do sistema estuarino de Cananéia (Inverno/2006) e valores de LD e LQ.(continuação)

\begin{tabular}{|c|c|c|c|c|c|c|c|c|c|c|c|c|}
\hline Parâmetros & Unidade & L.D. & L.Q. & Cl0611 & & $\begin{array}{l}\text { Desvio } \\
\text { Padrão } \\
\end{array}$ & $\mathrm{Cl} 0612$ & & $\begin{array}{l}\text { Desvio } \\
\text { Padrão } \\
\end{array}$ & Cl0613 & & $\begin{array}{l}\text { Desvio } \\
\text { Padrão } \\
\end{array}$ \\
\hline Al & $\left(\mathrm{mg} \mathrm{kg}^{-1}\right)$ & 0,5 & 1,0 & 11380 & \pm & 569 & 3668 & \pm & 183 & 1425 & \pm & 71 \\
\hline $\mathrm{Ba}$ & $\left(\mathrm{mg} \mathrm{kg}^{-1}\right)$ & 0,2 & 1,0 & 15,91 & \pm & 0,72 & 7,04 & \pm & 0,32 & 4,20 & \pm & 0,19 \\
\hline Co & $\left(\mathrm{mg} \mathrm{kg}^{-1}\right)$ & 0,5 & 1,0 & 4,18 & \pm & 0,11 & 1,29 & \pm & 0,03 & N.D. & \pm & - \\
\hline $\mathrm{Cu}$ & $\left(\mathrm{mg} \mathrm{kg}^{-1}\right)$ & 0,1 & 0,5 & 4,356 & \pm & 0,629 & N.D. & \pm & - & N.D. & \pm & - \\
\hline $\mathrm{Cr}$ & $\left(\mathrm{mg} \mathrm{kg}^{-1}\right)$ & 0,5 & 1,0 & 20,11 & \pm & 0,47 & 5,58 & \pm & 0,13 & 2,24 & \pm & 0,05 \\
\hline $\mathrm{Sr}$ & $\left(\mathrm{mg} \mathrm{kg}^{-1}\right)$ & 0,1 & 1,0 & 30,56 & \pm & 1,24 & 9,33 & \pm & 0,38 & 10,03 & \pm & 0,41 \\
\hline $\mathrm{Fe}$ & $\left(\mathrm{mg} \mathrm{kg}^{-1}\right)$ & 1,0 & 5,0 & 16609,4 & \pm & 657,9 & 3439,1 & \pm & 136,2 & 1517,5 & \pm & 60,1 \\
\hline Li & $\left(\mathrm{mg} \mathrm{kg}^{-1}\right)$ & 0,5 & 1,0 & 45,78 & \pm & 2,11 & 6,65 & \pm & 0,31 & 2,60 & \pm & 0,12 \\
\hline $\mathrm{Mn}$ & $\left(\mathrm{mg} \mathrm{kg}^{-1}\right)$ & 0,5 & 1,0 & 197,0 & \pm & 5,5 & 54,7 & \pm & 1,5 & 41,5 & \pm & 1,2 \\
\hline $\mathbf{N i}$ & $\left(\mathrm{mg} \mathrm{kg}^{-1}\right)$ & 0,5 & 1,0 & 7,75 & \pm & 0,16 & 1,99 & \pm & 0,04 & N.D. & \pm & - \\
\hline $\mathrm{Zn}$ & $\left(\mathrm{mg} \mathrm{kg}^{-1}\right)$ & 0,5 & 1,0 & 34,1 & \pm & 3,0 & 9,2 & \pm & 0,8 & 13,3 & \pm & 1,2 \\
\hline
\end{tabular}


Anexo XV - Resultados de Cd, Pb e Hg em Sedimentos coletados em Cananéia - Inverno e Verão de 2005

\begin{tabular}{|c|c|c|c|c|c|c|c|c|c|c|c|c|c|}
\hline Amostras & $\begin{array}{c}\mathrm{Pb} \\
\left(\mathrm{mg} \mathrm{kg}^{-1}\right)\end{array}$ & $\begin{array}{l}\text { Desvio } \\
\text { Padrão }\end{array}$ & $\begin{array}{c}\text { Cd } \\
\left(\mathrm{mg} \mathrm{kg}^{-1}\right)\end{array}$ & $\begin{array}{l}\text { Desvio } \\
\text { Padrão }\end{array}$ & $\begin{array}{c}\mathrm{Hg} \\
(\mathrm{ng} \mathrm{g}-1)\end{array}$ & $\begin{array}{l}\text { Desvio } \\
\text { Padrão }\end{array}$ & Amostras & $\begin{array}{c}\mathrm{Pb} \\
\left(\mathrm{mg} \mathrm{kg}^{-1}\right)\end{array}$ & $\begin{array}{l}\text { Desvio } \\
\text { Padrão }\end{array}$ & $\begin{array}{c}\text { Cd } \\
\left(\mathrm{mg} \mathrm{kg}^{-1}\right)\end{array}$ & $\begin{array}{l}\text { Desvio } \\
\text { Padrão }\end{array}$ & $\begin{array}{c}\mathrm{Hg} \\
\left(\mathrm{ng} \mathrm{g}^{-1}\right)\end{array}$ & $\begin{array}{l}\text { Desvio } \\
\text { Padrão }\end{array}$ \\
\hline Cl0501 & 0,9 & 0,1 & N.D. & - & 20,4 & 4,2 & CV0501 & N.D. & - & 0,012 & 0,001 & 20,9 & 2,3 \\
\hline Cl0502 & 5,7 & 0,4 & N.D. & - & 18,0 & 1,0 & CV0502 & 0,5 & 0,0 & 0,174 & 0,014 & 21,1 & 0,3 \\
\hline Cl0503 & 5,3 & 0,4 & N.D. & - & 19,8 & 1,5 & CV0503 & 3,9 & 0,3 & 0,011 & 0,001 & 30,6 & 0,6 \\
\hline Cl0504 & 26,0 & 1,9 & 0,063 & 0,004 & 81,8 & 3,6 & CV0504 & 25,5 & 1,9 & 0,059 & 0,008 & 101,0 & 1,0 \\
\hline Cl0505 & 10,1 & 0,7 & N.D. & - & 36,6 & 5,9 & CV0505 & 8,0 & 0,6 & 0,015 & 0,001 & 54,8 & 3,9 \\
\hline Cl0506 & 1,2 & 0,1 & N.D. & - & 25,2 & 8,7 & CV0506 & N.D. & - & N.D. & - & 24,6 & 1,1 \\
\hline Cl0507 & 0,8 & 0,1 & N.D. & - & 23,8 & 6,4 & CV0507 & 0,1 & 0,0 & 0,009 & 0,002 & 27,2 & 0,6 \\
\hline Cl0508 & 3,9 & 0,3 & N.D. & - & 17,0 & 3,0 & CV0508 & 4,7 & 0,3 & 0,016 & 0,001 & 40,0 & 2,8 \\
\hline Cl0509 & 11,2 & 0,8 & 0,042 & 0,003 & 51,6 & 2,5 & CV0509 & 13,4 & 1,0 & 0,053 & 0,006 & 52,5 & 0,4 \\
\hline Cl0510 & 1,9 & 0,1 & N.D. & - & 15,8 & 5,7 & CV0510 & 2,3 & 0,2 & 0,009 & 0,001 & 26,1 & 1,3 \\
\hline Cl0511 & 8,5 & 0,6 & 0,037 & 0,003 & 50,2 & 2,1 & CV0511 & 5,9 & 0,4 & 0,032 & 0,004 & 56,3 & 3,1 \\
\hline Cl0512 & 2,7 & 0,2 & 0,011 & 0,001 & 15,3 & 4,8 & CV0512 & 4,8 & 0,4 & N.D. & - & 40,7 & 2,6 \\
\hline Cl0513 & 1,6 & 0,1 & N.D. & - & 21,1 & 3,0 & CV0513 & 2,3 & 0,2 & N.D. & - & 32,6 & 1,0 \\
\hline
\end{tabular}


Anexo XVI - Resultados de Cd, Pb e Hg em Sedimentos coletados em Cananéia - Inverno e Verão de 2006

\begin{tabular}{|c|c|c|c|c|c|c|c|c|c|c|c|c|c|}
\hline Amostras & $\begin{array}{c}\mathrm{Pb} \\
\left(\mathrm{mg} \mathrm{kg}^{-1}\right)\end{array}$ & $\begin{array}{l}\text { Desvio } \\
\text { Padrão }\end{array}$ & $\frac{\mathrm{Cd}}{\left(\mathrm{mg} \mathrm{kg}^{-1}\right)}$ & $\begin{array}{l}\text { Desvio } \\
\text { Padrão }\end{array}$ & $\underset{\left(\mathrm{ng} \mathrm{g}^{-1}\right)}{\mathrm{Hg}}$ & $\begin{array}{l}\text { Desvio } \\
\text { Padrão }\end{array}$ & Amostras & $\begin{array}{c}\mathrm{Pb} \\
\left(\mathrm{mg} \mathrm{kg}^{-1}\right)\end{array}$ & $\begin{array}{l}\text { Desvio } \\
\text { Padrão }\end{array}$ & $\begin{array}{c}\mathrm{Cd} \\
\left(\mathrm{mg} \mathrm{kg}^{-1}\right)\end{array}$ & $\begin{array}{l}\text { Desvio } \\
\text { Padrão }\end{array}$ & $\begin{array}{c}\mathrm{Hg} \\
\left(\mathrm{ng} \mathrm{g}^{-1}\right)\end{array}$ & $\begin{array}{l}\text { Desvio } \\
\text { Padrão }\end{array}$ \\
\hline $\mathrm{Cl0601}$ & 0,9 & 0,1 & N.D. & - & 7,0 & 1,8 & CV0601 & 1,1 & 0,1 & N.D. & - & 31,45 & 0,1 \\
\hline $\mathrm{Cl0602}$ & 4,3 & 0,5 & N.D. & - & 28,5 & 1,9 & CV0602 & 3,0 & 0,3 & N.D. & - & 28,3 & 0,2 \\
\hline $\mathrm{Cl0603}$ & 6,6 & 0,8 & N.D. & - & 26,8 & 2,5 & CV0603 & 10,8 & 1,0 & 0,016 & 0,002 & 75,3 & 0,3 \\
\hline Cl0605 & 2,6 & 0,3 & N.D. & - & 16,2 & 0,5 & CV0605 & 4,9 & 0,4 & N.D. & - & 47,3 & 1,5 \\
\hline $\mathrm{Cl0606}$ & 1,5 & 0,2 & N.D. & - & 8,4 & 2,3 & CV0606 & 1,2 & 0,1 & N.D. & - & 33,95 & 3,2 \\
\hline $\mathrm{Cl0607}$ & 1,8 & 0,2 & N.D. & - & 7,9 & 2,9 & CV0607 & 1,0 & 0,1 & N.D. & - & 25,5 & 0,4 \\
\hline $\mathrm{Cl0610}$ & 3,0 & 0,4 & N.D. & - & 22,9 & 3,8 & CV0610 & 3,3 & 0,3 & N.D. & - & 41,2 & 0,4 \\
\hline Cl0611 & 12,4 & 1,6 & 0,040 & 0,003 & 77,1 & 4,1 & CV0611 & 8,9 & 0,8 & 0,027 & 0,001 & 78 & 0,8 \\
\hline Cl0612 & 3,6 & 0,5 & 0,011 & 0,001 & 79,5 & 2,8 & CV0612 & 5,5 & 0,5 & N.D. & - & 116,2 & 0,14 \\
\hline Cl0613 & 2,6 & 0,3 & N.D. & - & 27,1 & 3,3 & CV0613 & 3,0 & 0,3 & N.D. & - & 47,9 & 0,2 \\
\hline
\end{tabular}

N.D. - Não Detectado (menor que o Limite de Quantificação) 
Anexo XVII: Resultados obtidos por NAA, Cananéia, Inverno de 2005. Resultados expressos $\mathrm{mg} \mathrm{kg}^{-1}$ e com Desvio Padrão (D.P.)

\begin{tabular}{c|c|c|c|c|c|c|c|c|c|c|c|c|c|c|c|c|c|c}
\hline Amostra & As & D.P. & Ba & D.P. & Br & D.P. & Ca(\%) & D.P. & Ce & D.P. & Co & D.P. & Cr & D.P. & Cs & D.P. & Eu & D.P. \\
\hline Cl0501 & 1,17 & 0,04 & 109 & 17 & 13,9 & 0,4 & 0,14 & 0,01 & 5,1 & 0,2 & 0,47 & 0,01 & 2,6 & 0,2 & 0,34 & 0,03 & 0,09 & 0,00 \\
\hline Cl0502 & 6,10 & 0,18 & 210 & 24 & 50,1 & 1,4 & 0,64 & 0,01 & 34,1 & 1,0 & 3,66 & 0,07 & 24,0 & 1,2 & 1,93 & 0,09 & 0,49 & 0,02 \\
\hline Cl0503 & 4,34 & 0,18 & 262 & 29 & 36,8 & 1,1 & 0,70 & 0,02 & 26,8 & 1,1 & 3,40 & 0,07 & 19,2 & 1,5 & 1,84 & 0,09 & 0,43 & 0,02 \\
\hline Cl0504 & 11,28 & 0,59 & 602 & 90 & 73,6 & 1,7 & 1,18 & 0,03 & 95,3 & 2,7 & 12,22 & 0,24 & 75,8 & 4,9 & 6,33 & 0,32 & 1,37 & 0,07 \\
\hline Cl0505 & 5,30 & 0,27 & 289 & 31 & 17,4 & 0,4 & 0,58 & 0,02 & 32,0 & 0,9 & 3,82 & 0,08 & 22,0 & 1,7 & 1,81 & 0,09 & 0,44 & 0,02 \\
\hline Cl0506 & 1,01 & 0,04 & 196 & 21 & 5,6 & 0,1 & 0,23 & 0,01 & 6,7 & 0,2 & 0,77 & 0,02 & 4,5 & 0,4 & 0,31 & 0,02 & 0,10 & 0,00 \\
\hline Cl0507 & 2,06 & 0,08 & 152 & 13 & 12,0 & 0,4 & 0,90 & 0,02 & 7,3 & 0,3 & 0,96 & 0,02 & 3,3 & 0,3 & 0,44 & 0,02 & 0,13 & 0,00 \\
\hline Cl0508 & 5,59 & 0,27 & 232 & 20 & 34,9 & 1,2 & 0,79 & 0,02 & 30,5 & 0,8 & 4,21 & 0,08 & 18,8 & 1,4 & 1,52 & 0,10 & 0,53 & 0,02 \\
\hline Cl0509 & 15,36 & 0,47 & 149 & 59 & 108,7 & 3,6 & 1,08 & 0,02 & 66,7 & 2,4 & 8,79 & 0,17 & 56,9 & 2,8 & 4,29 & 0,21 & 1,09 & 0,05 \\
\hline Cl0510 & 2,61 & 0,04 & $n . d$. & - & 23,1 & 0,8 & 0,44 & 0,01 & 15,9 & 0,5 & 1,61 & 0,03 & 15,4 & 0,8 & 0,73 & 0,04 & 0,20 & 0,01 \\
\hline Cl0511 & 6,31 & 0,22 & 133 & 25 & 59,9 & 2,1 & 0,55 & 0,01 & 40,0 & 1,1 & 4,08 & 0,08 & 31,1 & 1,5 & 2,69 & 0,13 & 0,58 & 0,02 \\
\hline Cl0512 & 1,98 & 0,09 & 171 & 32 & 16,5 & 0,6 & 0,99 & 0,02 & 16,4 & 0,5 & 2,94 & 0,06 & 21,4 & 1,8 & 0,91 & 0,05 & 0,24 & 0,01 \\
\hline Cl0513 & 1,65 & 0,07 & 188 & 34 & 11,2 & 0,4 & 0,55 & 0,02 & 15,3 & 0,4 & 1,10 & 0,02 & 4,2 & 0,3 & 0,60 & 0,03 & 0,15 & 0,01 \\
\hline
\end{tabular}

N.D. - Não detectado 
Anexo XVII: Resultados obtidos por NAA, Cananéia, Inverno de 2005. Resultados expressos mg kg ${ }^{-1}$ e com Desvio Padrão (D.P.) (continuação)

\begin{tabular}{|c|c|c|c|c|c|c|c|c|c|c|c|c|c|c|c|c|c|c|}
\hline Amostra & $\mathrm{Fe}(\%)$ & D.P. & Hf & D.P. & La & D.P. & Lu & D.P. & $\mathrm{Na}$ & D.P. & Nd & D.P. & $\mathbf{R b}$ & D.P. & Sb & D.P. & Sc & D.P. \\
\hline Cl0501 & 0,157 & 0,001 & 2,00 & 0,04 & 2,60 & 0,02 & N.D. & - & 2090 & 27 & 1,0 & 0,1 & 16 & 1 & 0,09 & 0,01 & 0,42 & 0,01 \\
\hline Cl0502 & 1,207 & 0,007 & 6,03 & 0,10 & 16,62 & 0,12 & 0,27 & 0,05 & 7166 & 93 & 10,8 & 1,3 & 42 & 5 & 0,24 & 0,01 & 3,96 & 0,06 \\
\hline Cl0503 & 1,247 & 0,006 & 6,59 & 0,11 & 13,97 & 0,15 & 0,26 & 0,01 & 6759 & 123 & 17,0 & 3,0 & 44 & 4 & 0,24 & 0,02 & 3,74 & 0,06 \\
\hline Cl0504 & 4,667 & 0,024 & 3,65 & 0,06 & 42,76 & 0,32 & 0,50 & 0,13 & 17692 & 228 & 30,7 & 3,5 & 76 & 5 & 0,87 & 0,10 & 14,85 & 0,24 \\
\hline Cl0505 & 1,343 & 0,007 & 4,82 & 0,08 & 14,49 & 0,11 & 0,11 & 0,03 & 5538 & 73 & 15,1 & 1,1 & 27 & 2 & 0,48 & 0,02 & 4,10 & 0,07 \\
\hline Cl0506 & 0,178 & 0,001 & 2,24 & 0,04 & 3,02 & 0,02 & N.D. & - & 1884 & 25 & 2,7 & 0,0 & 11 & 1 & 0,07 & 0,01 & 0,62 & 0,01 \\
\hline Cl0507 & 0,260 & 0,001 & 1,19 & 0,02 & 3,73 & 0,02 & 0,040 & 0,001 & 3663 & 39 & 5,0 & 0,6 & 21 & 1 & 0,10 & 0,01 & 0,57 & 0,01 \\
\hline Cl0508 & 1,241 & 0,004 & 3,42 & 0,05 & 13,47 & 0,06 & 0,15 & 0,01 & 7965 & 83 & 16,2 & 2,4 & 40 & 2 & 0,34 & 0,01 & 3,50 & 0,07 \\
\hline Cl0509 & 2,955 & 0,016 & 4,98 & 0,10 & 30,65 & 0,14 & N.D. & - & 19372 & 167 & 35,1 & 5,0 & 75 & 8 & 0,47 & 0,03 & 9,73 & 0,16 \\
\hline Cl0510 & 0,520 & 0,003 & 9,74 & 0,17 & 6,50 & 0,03 & N.D. & - & 4040 & 35 & 6,8 & 1,7 & 13 & 2 & 0,21 & 0,02 & 1,64 & 0,03 \\
\hline Cl0511 & 1,560 & 0,008 & 4,71 & 0,08 & 18,05 & 0,08 & 0,21 & 0,01 & 10753 & 103 & 20,0 & 2,6 & 40 & 4 & 0,38 & 0,02 & 5,46 & 0,09 \\
\hline Cl0512 & 0,855 & 0,005 & 16,10 & 0,29 & 7,17 & 0,03 & 0,43 & 0,05 & 3429 & 33 & 8,3 & 1,2 & 34 & 3 & 0,25 & 0,01 & 2,76 & 0,04 \\
\hline Cl0513 & 0,273 & 0,002 & 2,75 & 0,05 & 7,61 & 0,04 & N.D. & - & 2866 & 28 & 8,3 & 1,1 & 28 & 3 & 0,11 & 0,01 & 0,83 & 0,01 \\
\hline
\end{tabular}


Anexo XVII: Resultados obtidos por NAA, Santos, Inverno de 2005. Resultados expressos $\mathrm{mg} \mathrm{kg}^{-1}$ e com Desvio Padrão (D.P.) (continuação)

\begin{tabular}{|c|c|c|c|c|c|c|c|c|c|c|c|c|c|c|c|c|}
\hline Amostra & $\mathrm{Se}$ & D.P. & $\mathrm{Sm}$ & D.P. & $\mathrm{Ta}$ & D.P. & $\mathrm{Tb}$ & D.P. & Th & D.P. & $\mathbf{U}$ & D.P. & Yb & D.P. & $\mathrm{Zn}$ & D.P. \\
\hline Cl0501 & N.D. & - & 0,44 & 0,01 & 0,09 & 0,01 & 0,03 & 0,01 & 0,9 & 0,0 & 0,44 & 0,05 & 0,19 & 0,02 & 0,9 & 0,3 \\
\hline Cl0502 & 0,28 & 0,09 & 2,57 & 0,05 & 0,54 & 0,06 & 0,30 & 0,05 & 3,7 & 0,1 & 2,2 & 0,1 & 0,95 & 0,05 & 25,5 & 1,3 \\
\hline Cl0503 & 0,39 & 0,15 & 2,40 & 0,06 & 0,54 & 0,05 & 0,23 & 0,04 & 3,9 & 0,1 & 1,8 & 0,2 & 1,16 & 0,07 & 24,8 & 1,2 \\
\hline Cl0504 & 0,81 & 0,16 & 7,61 & 0,16 & 1,01 & 0,08 & 1,03 & 0,14 & 13,1 & 0,5 & 3,7 & 0,3 & 2,11 & 0,09 & 94,0 & 4,2 \\
\hline Cl0505 & 0,94 & 0,30 & 2,51 & 0,05 & 0,44 & 0,03 & 0,32 & 0,05 & 8,1 & 0,4 & 1,6 & 0,1 & 0,83 & 0,04 & 27,8 & 1,3 \\
\hline Cl0506 & 0,11 & 0,02 & 0,51 & 0,02 & 0,16 & 0,02 & 0,09 & 0,02 & 0,9 & 0,0 & 0,45 & 0,05 & 0,26 & 0,02 & 3,3 & 0,2 \\
\hline Cl0507 & 0,20 & 0,07 & 0,57 & 0,02 & 0,14 & 0,02 & 0,04 & 0,01 & 0,9 & 0,0 & 0,34 & 0,04 & 0,26 & 0,01 & 6,9 & 0,2 \\
\hline Cl0508 & 0,55 & 0,18 & 1,95 & 0,06 & 0,34 & 0,03 & 0,27 & 0,04 & 3,3 & 0,2 & 1,25 & 0,09 & 0,87 & 0,04 & 32,5 & 0,8 \\
\hline Cl0509 & 0,74 & 0,14 & 5,01 & 0,08 & 0,72 & 0,06 & 0,75 & 0,10 & 8,6 & 0,3 & 3,2 & 0,3 & 1,65 & 0,09 & 70,2 & 2,0 \\
\hline Cl0510 & 0,50 & 0,19 & 1,17 & 0,02 & 0,36 & 0,03 & 0,34 & 0,07 & 2,3 & 0,1 & 2,0 & 0,2 & 1,49 & 0,13 & 18,7 & 0,7 \\
\hline Cl0511 & 0,34 & 0,10 & 3,04 & 0,06 & 0,47 & 0,05 & 0,26 & 0,04 & 30,5 & 8,4 & 2,1 & 0,2 & 1,05 & 0,05 & 32,1 & 1,0 \\
\hline Cl0512 & 0,39 & 0,11 & 1,57 & 0,03 & 0,88 & 0,06 & 0,09 & 0,02 & 5,3 & 0,2 & 2,8 & 0,2 & 1,99 & 0,11 & 16,5 & 0,7 \\
\hline Cl0513 & 0,11 & 0,08 & 1,24 & 0,02 & 0,23 & 0,02 & 0,10 & 0,01 & 3,2 & 0,2 & 0,57 & 0,05 & 0,44 & 0,02 & 11,4 & 0,5 \\
\hline
\end{tabular}


Anexo XVIII: Resultados obtidos por NAA, Cananéia, Verão de 2005. Resultados expressos mg kg-1 e com Desvio Padrão (D.P.)

\begin{tabular}{c|c|c|c|c|c|c|c|c|c|c|c|c|c|c|c|c|c|c}
\hline Amostra & As & D.P. & Ba & D.P. & Br & D.P. & Ca(\%) & D.P. & Ce & D.P. & Co & D.P. & Cr & D.P. & Cs & D.P. & Eu & D.P. \\
\hline CV0501 & 3,0 & 0,2 & 141 & 90 & 22,9 & 1,3 & 0,43 & 0,01 & 11,8 & 0,3 & 1,33 & 0,03 & 6,4 & 0,5 & 0,69 & 0,03 & 0,17 & 0,01 \\
\hline CV0502 & 2,2 & 0,1 & N.D. & - & 22,4 & 1,3 & 0,41 & 0,01 & 14,8 & 0,6 & 1,66 & 0,03 & 11,1 & 0,8 & 0,91 & 0,05 & 0,23 & 0,01 \\
\hline CV0503 & 6,4 & 0,3 & N.D. & - & 42,0 & 1,1 & 0,71 & 0,01 & 38,7 & 1,1 & 4,06 & 0,08 & 30,9 & 1,6 & 1,83 & 0,09 & 0,53 & 0,02 \\
\hline CV0504 & 2,1 & 0,2 & N.D. & - & 91,1 & 3,2 & 0,88 & 0,01 & 91,1 & 2,6 & 11,70 & 0,23 & 70,6 & 3,7 & 6,28 & 0,32 & 1,40 & 0,05 \\
\hline CV0505 & 3,9 & 0,2 & 164 & 9 & 17,0 & 0,6 & 0,67 & 0,01 & 30,0 & 0,8 & 2,81 & 0,05 & 16,4 & 0,8 & 1,45 & 0,07 & 0,35 & 0,02 \\
\hline CV0506 & 1,0 & 0,1 & 162 & 9 & 6,6 & 0,2 & 0,30 & 0,01 & 9,1 & 0,2 & 0,74 & 0,01 & 5,0 & 0,2 & 0,44 & 0,02 & 0,13 & 0,01 \\
\hline CV0507 & 2,5 & 0,1 & 216 & 25 & 20,6 & 0,8 & 0,67 & 0,02 & 16,5 & 0,5 & 1,84 & 0,04 & 8,8 & 0,4 & 0,94 & 0,15 & 0,29 & 0,01 \\
\hline CV0508 & 5,3 & 0,2 & 339 & 38 & 42,1 & 1,5 & 0,74 & 0,02 & 32,4 & 0,9 & 4,26 & 0,09 & 23,9 & 1,2 & 1,66 & 0,14 & 0,46 & 0,01 \\
\hline CV0509 & 15,8 & 0,5 & N.D. & - & 73,6 & 2,4 & 1,02 & 0,02 & 79,4 & 3,1 & 10,14 & 0,28 & 60,3 & 4,2 & 5,17 & 0,36 & 1,20 & 0,06 \\
\hline CV0510 & 2,6 & 0,1 & 43 & 8 & 22,4 & 0,8 & 0,38 & 0,01 & 21,8 & 0,6 & 1,67 & 0,03 & 11,8 & 0,6 & 0,76 & 0,04 & 0,22 & 0,01 \\
\hline CV0511 & 9,4 & 0,3 & 95 & 27 & 42,0 & 1,3 & 0,55 & 0,01 & 39,5 & 1,1 & 4,63 & 0,09 & 40,9 & 1,4 & 2,63 & 0,14 & 0,62 & 0,02 \\
\hline CV0512 & 2,8 & 0,1 & 167 & 47 & 26,4 & 0,8 & 0,73 & 0,01 & 37,5 & 1,1 & 2,75 & 0,06 & 29,2 & 1,4 & 1,32 & 0,07 & 0,40 & 0,01 \\
\hline CV0513 & 1,3 & 0,1 & 167 & 47 & 13,8 & 0,4 & 0,38 & 0,01 & 10,9 & 0,3 & 1,21 & 0,03 & 11,8 & 0,6 & 0,52 & 0,05 & 0,16 & 0,01 \\
\hline
\end{tabular}


Anexo XVIII: Resultados obtidos por NAA, Cananéia, Verão de 2005. Resultados expressos $\mathrm{mg} \mathrm{kg}^{-1}$ e com Desvio Padrão (D.P.) (continuação)

\begin{tabular}{|c|c|c|c|c|c|c|c|c|c|c|c|c|c|c|c|c|c|c|}
\hline Amostra & $\mathrm{Fe}(\%)$ & D.P. & Hf & D.P. & La & D.P. & Lu & D.P. & $\mathrm{Na}$ & D.P. & Nd & D.P. & $\mathbf{R b}$ & D.P. & $\mathrm{Sb}$ & D.P. & Sc & D.P. \\
\hline CV0501 & 0,429 & 0,002 & 3,974 & 0,063 & 5,576 & 0,027 & 0,06 & 0,01 & 4196 & 45 & 5,3 & 0,5 & 22,5 & 2,2 & 0,15 & 0,01 & 1,30 & 0,02 \\
\hline CV0502 & 0,531 & 0,003 & 2,715 & 0,046 & 7,896 & 0,037 & 0,16 & 0,02 & 3637 & 39 & 7,5 & 1,5 & 22,0 & 2,2 & 0,14 & 0,01 & 1,78 & 0,03 \\
\hline CV0503 & 1,324 & 0,007 & 6,694 & 0,119 & 17,176 & 0,091 & N.D. & - & 7304 & 57 & 15,6 & 1,2 & N.D. & - & 0,30 & 0,02 & 4,31 & 0,07 \\
\hline CV0504 & 4,470 & 0,024 & 4,548 & 0,081 & 40,996 & 0,148 & N.D. & - & 11153 & 87 & 30,8 & 2,1 & 86,0 & 32,0 & N.D. & - & 14,07 & 0,23 \\
\hline CV0505 & 0,983 & 0,005 & 4,673 & 0,089 & 13,659 & 0,054 & 0,11 & 0,01 & 4072 & 28 & 12,8 & 1,1 & 23,9 & 1,1 & 0,32 & 0,01 & 3,02 & 0,05 \\
\hline CV0506 & 0,214 & 0,001 & 2,886 & 0,054 & 4,257 & 0,017 & 0,07 & 0,01 & 1960 & 14 & 3,3 & 0,3 & 14,3 & 0,6 & 0,10 & 0,01 & 0,71 & 0,01 \\
\hline CV0507 & 0,539 & 0,003 & 2,592 & 0,049 & 7,771 & 0,037 & 0,07 & 0,01 & 4216 & 33 & 7,9 & 1,5 & 22,5 & 1,1 & 0,14 & 0,01 & 1,48 & 0,02 \\
\hline CV0508 & 1,325 & 0,007 & 3,523 & 0,058 & 14,063 & 0,064 & 0,14 & 0,01 & 8800 & 69 & 17,2 & 3,1 & 45,8 & 2,3 & 0,29 & 0,02 & 3,88 & 0,06 \\
\hline CV0509 & 3,383 & 0,034 & 5,425 & 0,130 & 36,334 & 0,151 & 0,36 & 0,05 & 15644 & 125 & 24,8 & 0,0 & 76,8 & 6,3 & 0,61 & 0,06 & 11,21 & 0,26 \\
\hline CV0510 & 0,538 & 0,004 & 5,735 & 0,089 & 10,076 & 0,044 & 0,31 & 0,03 & 3883 & 32 & 8,3 & 1,1 & 10,4 & 0,8 & 0,26 & 0,03 & 1,77 & 0,03 \\
\hline CV0511 & 1,523 & 0,008 & 4,604 & 0,083 & 19,631 & 0,085 & 0,25 & 0,06 & 7554 & 56 & 20,1 & 1,8 & 21,7 & 1,5 & 0,40 & 0,02 & 5,42 & 0,09 \\
\hline CV0512 & 0,931 & 0,005 & 11,907 & 0,209 & 16,674 & 0,074 & 0,42 & 0,13 & 5174 & 38 & 14,4 & 2,0 & 17,5 & 1,2 & 0,24 & 0,01 & 1,73 & 0,04 \\
\hline CV0513 & 0,337 & 0,002 & 5,297 & 0,094 & 5,025 & 0,024 & N.D. & - & 3059 & 23 & 5,6 & 0,0 & 8,3 & 0,8 & 0,15 & 0,01 & 1,01 & 0,02 \\
\hline
\end{tabular}


Anexo XVIII: Resultados obtidos por NAA, Cananéia, Inverno de 2005. Resultados expressos $\mathrm{mg} \mathrm{kg}^{-1}$ e com Desvio Padrão (D.P.) (continuação)

\begin{tabular}{c|c|c|c|c|c|c|c|c|c|c|c|c|c|c|c|c}
\hline Am0stra & Se & D.P. & Sm & D.P. & Ta & D.P. & Tb & D.P. & Th & D.P. & U & D.P. & Yb & D.P. & Zn & D.P. \\
\hline CV0501 & N.D. & - & 0,94 & 0,02 & 0,24 & 0,02 & 0,08 & 0,01 & 1,70 & 0,06 & 0,48 & 0,05 & 0,36 & 0,02 & 12,4 & 0,5 \\
\hline CV0502 & 0,16 & 0,03 & 1,29 & 0,02 & 0,31 & 0,02 & 0,13 & 0,02 & 2,42 & 0,09 & 0,47 & 0,05 & 0,48 & 0,02 & 13,6 & 0,4 \\
\hline CV0503 & N.D. & - & 1,86 & 0,04 & 0,47 & 0,03 & 0,25 & 0,04 & 6,27 & 0,25 & 1,17 & 0,07 & 1,18 & 0,11 & 29,4 & 1,0 \\
\hline CV0504 & 1,02 & 0,20 & 6,54 & 0,16 & 0,92 & 0,06 & 1,02 & 0,13 & 12,00 & 0,46 & 3,27 & 0,23 & 1,76 & 0,14 & 96,1 & 3,1 \\
\hline CV0505 & 0,25 & 0,04 & 2,22 & 0,04 & 0,37 & 0,03 & 0,16 & 0,02 & 3,91 & 0,14 & 1,04 & 0,06 & 0,72 & 0,03 & 29,1 & 1,0 \\
\hline CV0506 & N.D. & - & 0,74 & 0,01 & 0,22 & 0,02 & 0,08 & 0,01 & 1,27 & 0,05 & 0,50 & 0,03 & 0,35 & 0,02 & 7,5 & 0,3 \\
\hline CV0507 & N.D. & - & 1,22 & 0,02 & 0,24 & 0,03 & 0,28 & 0,07 & 1,97 & 0,08 & 0,52 & 0,04 & 0,49 & 0,03 & 12,8 & 0,6 \\
\hline CV0508 & N.D. & - & 2,19 & 0,04 & 0,36 & 0,04 & 0,23 & 0,06 & 3,68 & 0,14 & 1,27 & 0,09 & 0,93 & 0,05 & 35,0 & 1,2 \\
\hline CV0509 & N.D. & - & 6,16 & 0,15 & 0,62 & 0,06 & 0,90 & 0,18 & 10,44 & 0,54 & 2,94 & 0,25 & 1,99 & 0,13 & 61,6 & 3,9 \\
\hline CV0510 & N.D. & - & 1,63 & 0,04 & 0,31 & 0,03 & 0,21 & 0,03 & 3,44 & 0,13 & 1,94 & 0,19 & 1,55 & 0,08 & 13,6 & 0,7 \\
\hline CV0511 & N.D. & - & 3,21 & 0,03 & 0,44 & 0,07 & 0,78 & 0,15 & 5,54 & 0,21 & 4,75 & 0,31 & 0,95 & 0,06 & 28,9 & 1,5 \\
\hline CV0512 & N.D. & - & 3,13 & 0,03 & 0,62 & 0,07 & 0,73 & 0,15 & 6,35 & 0,25 & 2,53 & 0,21 & 1,77 & 0,11 & 19,0 & 0,9 \\
\hline CV0513 & N.D. & - & 0,60 & 0,01 & 0,37 & 0,05 & 0,16 & 0,05 & 1,50 & 0,06 & 0,85 & 0,06 & 0,46 & 0,03 & 1,4 & 0,5 \\
\hline
\end{tabular}




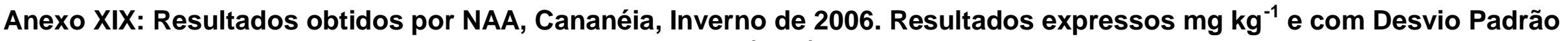
(D.P.)

\begin{tabular}{c|c|c|c|c|c|c|c|c|c|c|c|c|c|c|c|c|c|c}
\hline Amostra & As & D.P. & Ba & D.P. & Br & D.P. & Ca(\%) & D.P. & Ce & D.P. & Co & D.P. & Cr & D.P. & Cs & D.P. & Eu & D.P. \\
\hline Cl0601 & 0,95 & 0,05 & 200 & 9 & 20,20 & 0,28 & 0,46 & 0,02 & 6,3 & 0,2 & 0,61 & 0,01 & 7,8 & 0,2 & 0,29 & 0,02 & 0,123 & 0,004 \\
\hline Cl0602 & 6,08 & 0,17 & 143 & 15 & 35,04 & 0,50 & 0,61 & 0,02 & 25,6 & 0,6 & 2,91 & 0,05 & 21,7 & 0,8 & 1,35 & 0,08 & 0,420 & 0,014 \\
\hline Cl0603 & 7,42 & 0,20 & 275 & 17 & 65,03 & 0,94 & 0,74 & 0,02 & 31,1 & 0,7 & 3,92 & 0,06 & 25,9 & 1,0 & 1,79 & 0,07 & 0,493 & 0,014 \\
\hline Cl0604 & 2,93 & 0,07 & 127 & 10 & 29,11 & 0,25 & 0,45 & 0,01 & 25,9 & 0,6 & 1,99 & 0,03 & 13,1 & 0,5 & 0,94 & 0,04 & 0,241 & 0,007 \\
\hline Cl0605 & 1,57 & 0,06 & 145 & 10 & 21,67 & 0,20 & 0,40 & 0,01 & 17,2 & 0,4 & 1,06 & 0,02 & 7,6 & 0,2 & 0,69 & 0,03 & 0,154 & 0,006 \\
\hline Cl0606 & 1,03 & 0,04 & 165 & 8 & 12,26 & 0,12 & 0,53 & 0,01 & 11,6 & 0,3 & 0,83 & 0,02 & 10,7 & 0,4 & 0,37 & 0,03 & 0,109 & 0,004 \\
\hline Cl0607 & 2,57 & 0,09 & 203 & 9 & 20,46 & 0,22 & 0,56 & 0,02 & 12,5 & 0,3 & 1,25 & 0,03 & 5,9 & 0,2 & 0,52 & 0,03 & 0,238 & 0,007 \\
\hline Cl0608 & 4,69 & 0,16 & 256 & 17 & 42,98 & 0,56 & 0,72 & 0,02 & 22,3 & 0,5 & 3,08 & 0,06 & 17,9 & 0,6 & 1,24 & 0,06 & 0,385 & 0,010 \\
\hline Cl0609 & 13,98 & 0,56 & 392 & 22 & 120,99 & 1,68 & 1,10 & 0,03 & 59,3 & 1,4 & 7,33 & 0,15 & 50,1 & 0,8 & 3,73 & 0,14 & 0,882 & 0,023 \\
\hline Cl0610 & 3,02 & 0,10 & 131 & 5 & 43,44 & 0,55 & 0,56 & 0,01 & 22,8 & 0,5 & 2,19 & 0,03 & 19,2 & 0,7 & 0,96 & 0,04 & 0,264 & 0,007 \\
\hline Cl0611 & 17,68 & 0,40 & 338 & 14 & 119,97 & 1,52 & 0,89 & 0,02 & 60,5 & 1,3 & 6,28 & 0,09 & 49,6 & 1,2 & 3,64 & 0,12 & 0,880 & 0,022 \\
\hline Cl0612 & 3,05 & 0,15 & 248 & 8 & 35,74 & 0,72 & 2,04 & 0,22 & 20,3 & 0,4 & 2,50 & 0,04 & 23,5 & 0,9 & 1,09 & 0,08 & 0,335 & 0,012 \\
\hline Cl0613 & 1,11 & 0,09 & 182 & 5 & 16,22 & 0,32 & 0,24 & 0,03 & 14,9 & 0,3 & 1,24 & 0,02 & 12,5 & 0,5 & 0,46 & 0,03 & 0,189 & 0,006 \\
\hline
\end{tabular}

N.D. - Não detectado 
Anexo XIX: Resultados obtidos por NAA, Cananéia, Inverno de 2006. Resultados expressos $\mathrm{mg} \mathrm{kg}^{-1}$ e com Desvio Padrão (D.P.) (continuação)

\begin{tabular}{|c|c|c|c|c|c|c|c|c|c|c|c|c|c|c|c|c|c|c|}
\hline Amostra & $\mathrm{Fe}(\%)$ & D.P. & $\mathrm{Hf}$ & D.P. & La & D.P. & Lu & D.P. & $\mathrm{Na}$ & D.P. & Nd & D.P. & $\mathbf{R b}$ & D.P. & Sb & D.P. & Sc & D.P. \\
\hline Cl0601 & 0,178 & 0,001 & 1,611 & 0,029 & 3,39 & 0,02 & 0,061 & 0,004 & 3543,2 & 24,9 & 4,6 & 0,3 & 18,8 & 0,9 & 0,058 & 0,006 & 0,487 & 0,009 \\
\hline Cl0602 & 1,130 & 0,009 & 5,071 & 0,094 & 12,05 & 0,05 & 0,217 & 0,014 & 6817,9 & 48,1 & 12,9 & 1,5 & 45,2 & 4,0 & 0,209 & 0,014 & 3,581 & 0,064 \\
\hline $\mathrm{Cl} 0603$ & 1,280 & 0,008 & 4,422 & 0,076 & 14,82 & 0,07 & 0,176 & 0,012 & 10009,0 & 69,9 & 17,5 & 2,1 & 50,5 & 3,1 & 0,327 & 0,019 & 4,318 & 0,054 \\
\hline CI0604 & 0,660 & 0,004 & 6,938 & 0,117 & 13,73 & 0,06 & 0,207 & 0,010 & 3713,5 & 22,9 & 11,7 & 1,4 & 15,5 & 0,8 & 0,260 & 0,013 & 2,242 & 0,026 \\
\hline Cl0605 & 0,346 & 0,002 & 3,488 & 0,067 & 9,57 & 0,04 & 0,071 & 0,004 & 2827,0 & 17,4 & 4,9 & 0,9 & 15,7 & 0,8 & 0,151 & 0,009 & 1,294 & 0,015 \\
\hline Cl0606 & 0,239 & 0,002 & 6,789 & 0,112 & 6,61 & 0,02 & 0,102 & 0,005 & 1978,1 & 12,3 & 5,6 & 0,8 & 14,8 & 0,7 & 0,162 & 0,009 & 0,911 & 0,011 \\
\hline CI0607 & 0,367 & 0,003 & 1,507 & 0,034 & 6,16 & 0,03 & 0,047 & 0,003 & 4762,4 & 32,8 & 4,3 & 0,8 & 21,5 & 0,9 & 0,119 & 0,009 & 0,928 & 0,012 \\
\hline CI0608 & 0,901 & 0,006 & 4,078 & 0,070 & 10,63 & 0,05 & 0,131 & 0,005 & 8513,7 & 58,9 & 11,7 & 1,4 & 31,5 & 1,5 & 0,208 & 0,014 & 2,584 & 0,033 \\
\hline CI0609 & 2,426 & 0,015 & 5,306 & 0,092 & 25,01 & 0,11 & 0,239 & 0,012 & 21113,3 & 142,9 & 24,1 & 2,8 & 64,1 & 2,9 & 0,406 & 0,041 & 8,008 & 0,100 \\
\hline $\mathrm{Cl0610}$ & 0,753 & 0,004 & 12,943 & 0,191 & 10,54 & 0,05 & 0,171 & 0,006 & 5951,9 & 38,5 & 10,8 & 1,8 & 15,1 & 0,6 & 0,194 & 0,012 & 2,406 & 0,032 \\
\hline Cl0611 & 2,493 & 0,013 & 5,752 & 0,086 & 25,82 & 0,11 & 0,294 & 0,010 & 18418,0 & 119,1 & 29,4 & 3,0 & 56,4 & 1,9 & 0,428 & 0,024 & 8,476 & 0,113 \\
\hline Cl0612 & 0,929 & 0,005 & 14,339 & 0,243 & 9,15 & 0,05 & 0,288 & 0,009 & 5847,6 & 48,8 & 6,6 & 1,0 & 38,3 & 1,4 & 0,138 & 0,016 & 2,712 & 0,034 \\
\hline Cl0613 & 0,350 & 0,003 & 7,095 & 0,110 & 6,50 & 0,04 & 0,144 & 0,005 & 3416,7 & 30,0 & 6,4 & 1,0 & 22,6 & 0,9 & 0,141 & 0,012 & 1,130 & 0,014 \\
\hline
\end{tabular}


Anexo XIX: Resultados obtidos por NAA, Cananéia, Inverno de 2006. Resultados expressos $\mathrm{mg} \mathrm{kg}^{-1}$ e com Desvio Padrão (D.P.) (continuação)

\begin{tabular}{c|c|c|c|c|c|c|c|c|c|c|c|c|c|c|c|c}
\hline Amostra & Se & D.P. & Sm & D.P. & Ta & D.P. & Tb & D.P. & Th & D.P. & U & D.P. & Yb & D.P. & Zn & D.P. \\
\hline Cl0601 & N.D. & - & 0,54 & 0,01 & N.D. & - & 0,10 & 0,02 & 0,77 & 0,02 & 0,40 & 0,03 & 0,25 & 0,02 & N.D. & - \\
\hline Cl0602 & N.D. & - & 2,15 & 0,06 & N.D. & - & 0,17 & 0,04 & 4,86 & 0,18 & 1,63 & 0,08 & 1,34 & 0,06 & 24,0 & 1,20 \\
\hline Cl0603 & 0,561 & 0,187 & 2,47 & 0,07 & N.D. & - & 0,22 & 0,04 & 4,11 & 0,12 & 1,26 & 0,07 & 0,89 & 0,04 & 23,3 & 1,31 \\
\hline Cl0604 & N.D. & - & 2,15 & 0,04 & N.D. & - & 0,18 & 0,03 & 4,51 & 0,12 & 2,53 & 0,07 & 1,04 & 0,04 & N.D. & - \\
\hline Cl0605 & N.D. & - & 1,66 & 0,03 & N.D. & - & 0,09 & 0,01 & 3,10 & 0,09 & 0,95 & 0,05 & 0,37 & 0,02 & 2,9 & 0,48 \\
\hline Cl0606 & N.D. & - & 1,04 & 0,02 & N.D. & - & 0,04 & 0,01 & 2,29 & 0,06 & 0,89 & 0,05 & 0,59 & 0,03 & 4,5 & 0,32 \\
\hline Cl0607 & N.D. & - & 1,09 & 0,03 & N.D. & - & 0,09 & 0,01 & 1,31 & 0,04 & 0,35 & 0,03 & 0,42 & 0,02 & 6,1 & 0,62 \\
\hline Cl0608 & N.D. & - & 1,82 & 0,04 & N.D. & - & 0,32 & 0,05 & 2,69 & 0,05 & 0,90 & 0,06 & 0,69 & 0,05 & 13,2 & 0,68 \\
\hline Cl0609 & N.D. & - & 4,03 & 0,10 & N.D. & - & 0,46 & 0,05 & 7,28 & 0,18 & 1,91 & 0,13 & 1,46 & 0,06 & 63,7 & 1,91 \\
\hline Cl0610 & 0,208 & 0,055 & 1,73 & 0,03 & N.D. & - & 0,21 & 0,03 & 3,19 & 0,09 & 1,87 & 0,08 & 0,89 & 0,03 & 20,0 & 0,69 \\
\hline CI0611 & 0,451 & 0,147 & 4,43 & 0,08 & N.D. & - & 0,54 & 0,07 & 7,97 & 0,22 & 2,81 & 0,11 & 1,75 & 0,06 & 46,2 & 1,38 \\
\hline Cl0612 & N.D. & - & 1,66 & 0,03 & 0,581 & 0,050 & 0,21 & 0,03 & 4,27 & 0,15 & 1,99 & 0,13 & 1,63 & 0,06 & 15,6 & 0,90 \\
\hline Cl0613 & N.D. & - & 1,14 & 0,02 & 0,415 & 0,036 & 0,18 & 0,03 & 1,77 & 0,09 & 0,84 & 0,06 & 0,84 & 0,03 & 8,3 & 0,54 \\
\hline
\end{tabular}


Anexo XX: Resultados obtidos por NAA, Cananéia, Verão de 2006. Resultados expressos $\mathrm{mg} \mathrm{kg}^{-1}$ e com Desvio Padrão (D.P.)

\begin{tabular}{l|c|c|c|c|c|c|c|c|c|c|c|c|c|c|c|c|c|c}
\hline & As & D.P. & Ba & D.P. & Br & D.P. & Ca(\%) & D.P. & Ce & D.P. & Co & D.P. & Cr & D.P. & Cs & D.P. & Eu & D.P. \\
\hline CV0601 & 1,81 & 0,09 & 87 & 11 & 18,72 & 0,29 & 0,36 & 0,01 & 10,9 & 0,4 & 0,76 & 0,03 & 5,9 & 0,4 & N.D. & - & 0,14 & 0,01 \\
\hline CV0602 & 1,62 & 0,12 & 147 & 7 & 19,28 & 0,69 & 0,61 & 0,01 & 24,3 & 0,6 & 1,33 & 0,02 & 24,1 & 0,6 & 0,50 & 0,03 & 0,20 & 0,01 \\
\hline CV0603 & 11,96 & 0,50 & 300 & 17 & 100,68 & 1,62 & 1,04 & 0,03 & 51,6 & 1,2 & 6,50 & 0,11 & 40,9 & 1,5 & 3,07 & 0,12 & 0,76 & 0,02 \\
\hline CV0604 & 3,28 & 0,22 & 176 & 8 & 41,35 & 1,92 & 0,39 & 0,01 & 17,5 & 0,4 & 1,74 & 0,03 & 10,7 & 0,4 & 0,79 & 0,04 & 0,22 & 0,01 \\
\hline CV0605 & 2,23 & 0,18 & 198 & 20 & 28,82 & 0,50 & 0,53 & 0,01 & 40,3 & 1,0 & 2,11 & 0,03 & 17,0 & 0,4 & 1,06 & 0,04 & 0,30 & 0,01 \\
\hline CV0606 & 1,23 & 0,10 & 145 & 9 & 9,74 & 0,18 & 0,49 & 0,01 & 16,9 & 0,4 & 1,09 & 0,02 & 17,2 & 0,3 & 0,39 & 0,02 & 0,154 & 0,004 \\
\hline CV0607 & 1,67 & 0,12 & 258 & 13 & 17,87 & 0,32 & 0,38 & 0,01 & 7,6 & 0,2 & 0,97 & 0,02 & 10,3 & 0,4 & 0,35 & 0,02 & 0,141 & 0,004 \\
\hline CV0608 & 4,46 & 0,14 & 333 & 14 & 65,65 & 0,82 & 0,70 & 0,02 & 32,2 & 1,0 & 3,97 & 0,07 & 23,1 & 0,9 & 1,95 & 0,09 & 0,478 & 0,015 \\
\hline CV0609 & 12,66 & 0,35 & 448 & 33 & 170,56 & 2,12 & 1,04 & 0,03 & 65,1 & 2,8 & 8,29 & 0,14 & 54,2 & 2,1 & 4,73 & 0,20 & 1,326 & 0,042 \\
\hline CV0610 & 1,18 & 0,06 & 96 & 7 & 38,80 & 0,48 & 0,53 & 0,01 & 16,9 & 0,5 & 1,53 & 0,03 & 10,6 & 0,4 & 0,57 & 0,03 & 0,153 & 0,007 \\
\hline CV0611 & 6,17 & 0,22 & 245 & 14 & 94,39 & 1,30 & 0,78 & 0,02 & 57,3 & 1,7 & 4,50 & 0,07 & 38,4 & 1,1 & 3,00 & 0,12 & 0,725 & 0,024 \\
\hline CV0612 & 2,61 & 0,10 & 153 & 9 & 35,32 & 0,44 & 0,90 & 0,01 & 30,2 & 0,9 & 2,58 & 0,04 & 23,6 & 0,9 & 1,14 & 0,05 & 0,339 & 0,012 \\
\hline CV0613 & 1,19 & 0,08 & 215 & 19 & 12,92 & 0,14 & 0,36 & 0,01 & 11,6 & 0,3 & 0,82 & 0,02 & 11,1 & 0,4 & 0,34 & 0,04 & 0,114 & 0,004 \\
\hline
\end{tabular}

N.D. - Não detectado 
Anexo XX: Resultados obtidos por NAA, Cananéia, Verão de 2006. Resultados expressos $\mathrm{mg} \mathrm{kg}^{-1} \mathrm{e}$ com Desvio Padrão (D.P.) (continuação)

\begin{tabular}{|c|c|c|c|c|c|c|c|c|c|c|c|c|c|c|c|c|c|c|}
\hline Amostra & $\mathrm{Fe}(\%)$ & D.P. & $\mathrm{Hf}$ & D.P. & La & D.P. & Lu & D.P. & $\mathrm{Na}$ & D.P. & Nd & D.P. & $\mathbf{R b}$ & D.P. & $\mathrm{Sb}$ & D.P. & Sc & D.P. \\
\hline CV0601 & 0,270 & 0,003 & 3,97 & 0,08 & 5,68 & 0,04 & 0,068 & 0,004 & 3241 & 25 & 3,3 & 0,9 & 12,1 & 1,7 & 0,114 & 0,013 & 0,727 & 0,010 \\
\hline CV0602 & 0,509 & 0,003 & 21,28 & 0,43 & 11,28 & 0,05 & 0,221 & 0,009 & 3610 & 37 & 9,0 & 0,9 & 16,1 & 0,7 & 0,239 & 0,029 & 1,588 & 0,020 \\
\hline CV0603 & 2,156 & 0,013 & 5,93 & 0,12 & 23,19 & 0,10 & 0,253 & 0,012 & 16768 & 157 & 21,7 & 1,7 & 52,7 & 2,1 & 0,434 & 0,075 & 7,131 & 0,090 \\
\hline CV0604 & 0,596 & 0,004 & 2,49 & 0,05 & 7,75 & 0,05 & 0,102 & 0,005 & 5268 & 54 & 7,6 & 1,2 & 21,4 & 0,9 & 0,062 & 0,016 & 1,955 & 0,025 \\
\hline CV0605 & 0,813 & 0,004 & 10,65 & 0,17 & 17,27 & 0,08 & 0,208 & 0,007 & 4120 & 43 & 13,4 & 1,5 & 21,8 & 1,1 & 0,125 & 0,026 & 2,529 & 0,011 \\
\hline CV0606 & 0,344 & 0,002 & 13,92 & 0,22 & 7,48 & 0,04 & 0,238 & 0,008 & 1942 & 22 & 5,6 & 0,7 & 14,4 & 0,6 & 0,138 & 0,016 & 1,081 & 0,005 \\
\hline CV0607 & 0,308 & 0,002 & 2,72 & 0,05 & 3,39 & 0,02 & 0,061 & 0,003 & 3566 & 38 & 3,5 & 0,2 & 26,8 & 1,1 & 0,077 & 0,012 & 0,592 & 0,004 \\
\hline CV0608 & 1,331 & 0,008 & 4,19 & 0,09 & 13,49 & 0,05 & 0,143 & 0,007 & 10436 & 64 & 20,0 & 1,6 & 34,2 & 1,5 & 0,259 & 0,017 & 3,713 & 0,047 \\
\hline CV0609 & 2,975 & 0,018 & 9,00 & 0,31 & 26,31 & 0,10 & 0,286 & 0,010 & 23178 & 143 & 34,7 & 2,3 & 61,8 & 2,8 & 0,329 & 0,034 & 9,389 & 0,118 \\
\hline CV0610 & 0,539 & 0,004 & 9,80 & 0,21 & 6,85 & 0,03 & 0,116 & 0,005 & 4990 & 30 & 10,0 & 0,8 & 15,4 & 0,7 & 0,165 & 0,012 & 1,665 & 0,021 \\
\hline CV0611 & 1,852 & 0,012 & 8,38 & 0,17 & 23,51 & 0,08 & 0,266 & 0,011 & 13457 & 90 & 28,6 & 1,8 & 52,1 & 2,7 & 0,316 & 0,020 & 5,956 & 0,138 \\
\hline CV0612 & 1,167 & 0,008 & 18,45 & 0,42 & 12,90 & 0,05 & 0,337 & 0,012 & 5619 & 38 & 13,4 & 0,7 & 21,8 & 1,3 & 0,194 & 0,012 & 3,134 & 0,051 \\
\hline CV0613 & 0,269 & 0,002 & 2,96 & 0,05 & 5,49 & 0,02 & 0,064 & 0,004 & 2313 & 14 & 4,6 & 0,3 & 21,2 & 1,1 & 0,109 & 0,007 & 0,799 & 0,010 \\
\hline
\end{tabular}


Anexo XX: Resultados obtidos por NAA, Cananéia, Verão de 2006. Resultados expressos $\mathrm{mg} \mathrm{kg}^{-1}$ e com Desvio Padrão (D.P.) (continuação)

\begin{tabular}{c|c|c|c|c|c|c|c|c|c|c|c|c|c|c|c|c}
\hline Amostra & Se & D.P. & Sm & D.P. & Ta & D.P. & Tb & D.P. & Th & D.P. & U & D.P. & Yb & D.P. & Zn & D.P. \\
\hline CV0601 & N.D. & - & 0,96 & 0,03 & N.D. & - & N.D. & - & 2,82 & 0,12 & 0,49 & 0,05 & 0,17 & 0,02 & N.D. & - \\
\hline CV0602 & N.D. & - & 1,83 & 0,03 & N.D. & - & 0,23 & 0,06 & 4,48 & 0,17 & 1,40 & 0,08 & 0,99 & 0,05 & 4,7 & 0,41 \\
\hline CV0603 & N.D. & - & 5,97 & 0,11 & N.D. & - & 0,72 & 0,19 & 7,06 & 0,26 & 1,71 & 0,11 & 1,22 & 0,06 & 54,7 & 1,97 \\
\hline CV0604 & N.D. & - & 1,39 & 0,03 & N.D. & - & 0,25 & 0,09 & 2,10 & 0,08 & 0,69 & 0,05 & 0,47 & 0,02 & N.D. & - \\
\hline CV0605 & N.D. & - & 2,46 & 0,09 & N.D. & - & 0,25 & 0,04 & 5,46 & 0,16 & 1,63 & 0,16 & 1,13 & 0,05 & 18,0 & 1,05 \\
\hline CV0606 & N.D. & - & 1,09 & 0,03 & N.D. & - & 0,18 & 0,04 & 2,52 & 0,07 & 1,27 & 0,09 & 1,43 & 0,07 & 2,7 & 0,39 \\
\hline CV0607 & N.D. & - & 0,58 & 0,02 & N.D. & - & 0,10 & 0,02 & 0,93 & 0,03 & 0,47 & 0,04 & 0,27 & 0,02 & N.D. & - \\
\hline CV0608 & N.D. & - & 2,42 & 0,05 & N.D. & - & N.D. & - & 3,77 & 0,11 & 1,10 & 0,08 & 0,77 & 0,04 & N.D. & - \\
\hline CV0609 & N.D. & - & 6,93 & 0,13 & N.D. & - & 0,31 & 0,05 & 9,07 & 0,26 & 1,98 & 0,15 & 1,54 & 0,07 & 73,9 & 2,24 \\
\hline CV0610 & N.D. & - & 1,22 & 0,03 & N.D. & - & 0,16 & 0,03 & 2,44 & 0,07 & 1,25 & 0,09 & 0,51 & 0,02 & 9,6 & 0,77 \\
\hline CV0611 & N.D. & - & 3,98 & 0,11 & N.D. & - & 0,36 & 0,05 & 7,56 & 0,22 & 2,81 & 0,12 & 1,58 & 0,06 & 34,2 & 1,27 \\
\hline CV0612 & N.D. & - & 3,71 & 0,10 & N.D. & - & 0,12 & 0,03 & 4,95 & 0,14 & 2,44 & 0,11 & 1,59 & 0,07 & 15,3 & 0,70 \\
\hline CV0613 & N.D. & - & 1,23 & 0,04 & N.D. & - & N.D. & - & 1,23 & 0,04 & 0,50 & 0,03 & 0,32 & 0,03 & N.D. & - \\
\hline
\end{tabular}


